Análise bidirecional da língua na simplificação sintática em textos do português voltada à acessibilidade digital 



\title{
Análise bidirecional da língua na simplificação sintática em textos do português voltada à acessibilidade digital
}

\author{
Arnaldo Candido Junior
}

Orientadora: Profa. Dra. Sandra Maria Aluísio

Tese apresentada ao Instituto de Ciências Matemáticas e de Computação - ICMC-USP, como parte dos requisitos para obtenção do título de Doutor em Ciências - Ciências de Computação e Matemática Computacional. VERSÃO REVISADA

USP - São Carlos

Maio de 2013 
Ficha catalográfica elaborada pela Biblioteca Prof. Achille Bassi e Seção Técnica de Informática, ICMC/USP,

com os dados fornecidos pelo(a) autor(a)

Candido Junior, Arnaldo
Análise bidirecional da língua na simplificação
sintática em textos do português voltada à
acessibilidade digital / Arnaldo Candido Junior;
orientador Sandra Maria Aluísio. -- São Carlos, 2013.
225 p.
Tese (Doutorado - Programa de Pós-Graduação em
Ciências de Computação e Matemática Computacional) --
Instituto de Ciências Matemáticas e de Computação,
Universidade de São Paulo, 2013.
1. Análise da língua. 2. Simplificação sintática.
I. Sandra Maria Aluísio, orient. II. Título.




\section{Agradecimentos}

Em primeiro lugar, agradeço a Deus por esta oportunidade de estudo e desenvolvimento pessoal.

Agradeço à Amanda, Arnaldo, Maria e Michelle assim como a toda a minha família pelos laços que foram criados e que não podem ser desfeitos.

Agradeço à Sandra Maria Aluísio, pela orientação exemplar, pela paciência e pela dedicação nos últimos dois anos.

Agradeço à Ann Copestake pela oportunidade de estudo e desenvolvimento junto ao projeto Delphin.

Agradeço aos amigos da Link House Trust, Ammy, Ary, Arijita, Avradeep, Christian, Daniela, Diana, Helen, Julien, Kent, Lily, Pilar, Thomas, Tierry, Sonya, William, Yvette, e todos os demais; aos trustees e wardens, em particular a Lil e Mel Robson e Shirley pelo acolhimento.

Agradeço aos amigos "das antigas" de São Carlos: Ariani, Carolina, Caroline, Eliane, Evandra, Eloize, Fernando, Erick, Jefferson, Lucia, Marco, Marcelo, Pedro; assim como os novos amigos Fernando, Jhonata, Lianet, Marcio, Takeu, e aos recém-chegados do laboratório; e todos os demais pela convivência e amizade.

Agradeço aos professores do NILC Gladis, Graça, Oto, Thiago e todos os outros, pelo exemplo e pela orientação.

Agradeço a todos os colegas de mestrado, aos amigos do ICMC e da USP em geral.

Agradeço à FAPESP (processo 2008/08963-4), ao CNPq (201407/2010-8) e à CAPES (DS-3680951/D) por terem permitido o desenvolvimento do trabalho financiando a pesquisa em diferentes períodos.

Agradeço a todas as pessoas não foram mencionadas nestas palavras mais do que breves, mas que foram e são pessoas importantes na minha vida. 

Pedi, e dar-se-vos-á; buscai, e encontrareis; batei, e abrir-se-vos-á.

Porque, todo aquele que pede, recebe; e, o que busca, encontra; e, ao que bate, abrir-se-lhe-á. 



\section{Resumo}

O Processamento de Línguas Naturais é uma área interdisciplinar cujas pesquisas podem ser divididas em duas grandes linhas: análise e síntese da língua. Esta pesquisa de doutorado traz contribuições para ambas. Para a análise da língua, um modelo integrativo capaz de unir diferentes níveis linguísticos é apresentado e avaliado em relação aos níveis morfológico, (incluindo subníveis léxico e morfossintático), sintático e semântico. Enquanto análises tradicionais são feitas dos níveis mais baixos da língua para os mais altos, em uma estratégia em cascata, na qual erros dos níveis mais baixos são propagados para os níveis mais altos, o modelo de análise proposto é capaz de unificar a análise de diferentes níveis a partir de uma abordagem bidirecional. O modelo é baseado em uma grande rede neural, treinada em córpus, cujos padrões de treinamento são extraídos de tokens presentes nas orações. Um tipo de recorrência denominado coativação é aplicado no modelo para permitir que a análise de um padrão modifique e seja modificada pela análise de outros padrões em um mesmo contexto. O modelo de análise permite investigações para as quais não foi originalmente planejado, além de apresentar resultados considerados satisfatórios em lematização e análise morfossintática, porém ainda demandando aprimoramento para a tarefa de análise sintática. A ferramenta associada a esse modelo permitiu investigar a recorrência proposta e a interação bidirecional entre níveis da língua, incluindo seus subníveis. Experimentos para coativação e bidirecionalidade foram realizados e considerados satisfatórios. Para a área de síntese da língua, um modelo de simplificação sintática, tarefa considerada como adaptação de texto para texto, baseado em regras manuais é aplicado em textos analisados sintaticamente, tendo como objetivo tornar os textos sintaticamente mais simples para leitores com letramento rudimentar ou básico. A ferramenta associada a esse modelo permitiu realizar simplificação sintática com medida-f de $77,2 \%$, simplificando aproximadamente $16 \%$ de orações em textos do gênero enciclopédico. 



\section{Abstract}

Natural Language Processing is an interdisciplinary research area that encompasses two large research avenues: language analysis and language synthesis. This thesis contributes for both of them. In what concerns language analysis, it presents an integrative model that links different levels of linguistic analysis. The evaluation of such model takes into consideration several levels: morphologic (including lexical and morph-syntactic sub-levels), syntactic and semantic. Whereas traditional analysis are undertaken from the lower levels to the upper ones, propagating errors in such direction, the model proposed herein is able to unify different levels of analysis using a bidirectional approach. The model is based on a large-scale neural network trained in corpus, which extracts its training features from tokens within the sentences. A type of recurrence denominated co-activation is applied to the model to make the analysis of a pattern able to modify (and to be modified by) the analysis of other patterns in a same context. This model may be used for purposes different from those for which it was conceived and yields satisfactory results in lemmatization and part-of-speech analysis, but still needs work on syntactic analysis. The tool associated to this model makes it possible to analyze the proposed recurrence language and the bidirectional influence of different levels on each other, including sub-level interaction. Experiments on both co-activation and bidirectional level integration were performed, and the results were considered satisfactory. On the other hand, in what concerns language synthesis, this thesis presents a rule-based model of syntactic simplification (one of text adaptation techniques), applicable to syntactically parsed texts in order to render them simpler for low literacy readers. The tool associated to this model makes it possible to carry out the task of syntactic simplification in Portuguese language. Such tool achieved $77.2 \%$ of f-measure in a task that simplified approximately $16 \%$ of the sentences of an encyclopedic text. 



\section{Índice de Figuras}

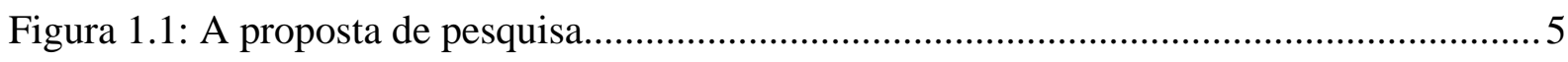

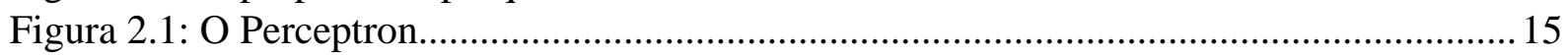

Figura 2.2: Interpretação geométrica de problemas lógicos para duas entradas....................... 17

Figura 2.3: Exemplo de topologia MLP completamente conectada, com uma camada

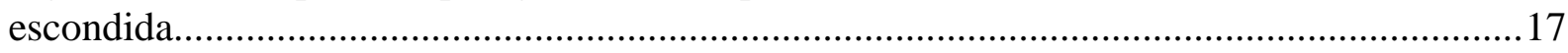

Figura 2.4: Exemplo de topologia MLP parcialmente conectada, com recorrência.................18

Figura 2.5: Árvore de constituintes acrescida de funções sintáticas.......................................22

Figura 2.6: Árvore de constituintes do Palavras, seguindo o conjunto de etiquetas do

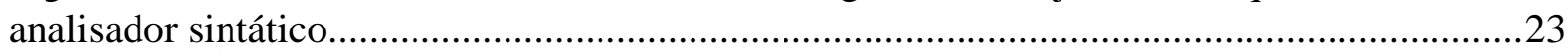

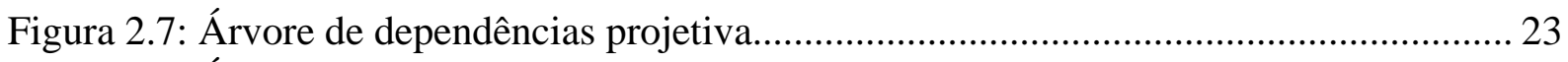

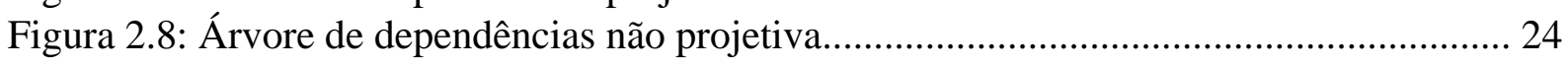

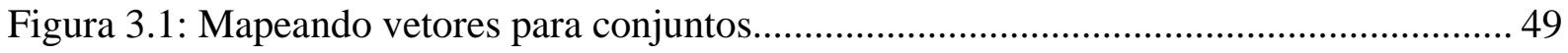

Figura 3.2: Diferentes representações para alguns tipos de lexias complexas..........................58

Figura 3.3: Representação para entidades nomeadas com aninhamento................................59

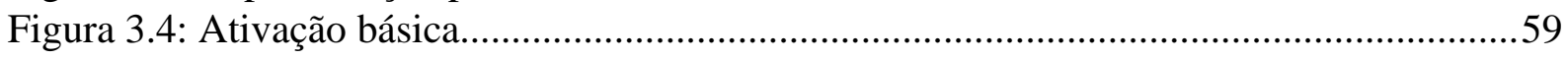

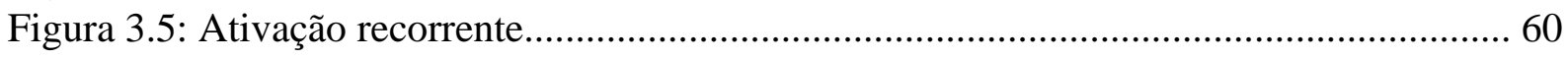

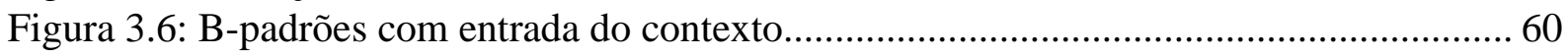

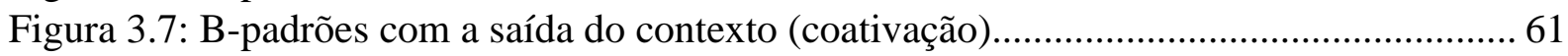

Figura 3.8: Três iterações da coativação para janela 1 ...........................................................62

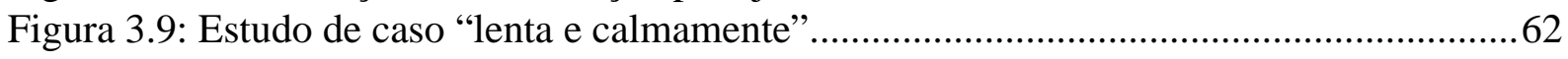

Figura 3.10: Duas topologias para ativação da árvore ......................................................... 63

Figura 3.11: Análises com núcleo à esquerda na estratégia menos granular............................64

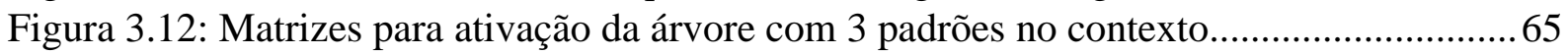

Figura 3.13: Coativação baseada em árvore de um contexto com três padrões para o primeiro

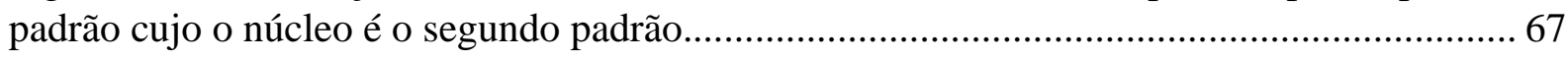

Figura 3.14: Representação simplificada da coativação baseada em árvore para contexto com

três padrões em duas iterações.............................................................................................. 68

Figura 3.15: Uma das solução para o problema do ou-exclusivo com uma camada escondida.

Figura 3.16: Ou-exclusivo em uma instância combinando recorrência local e contexto baseado

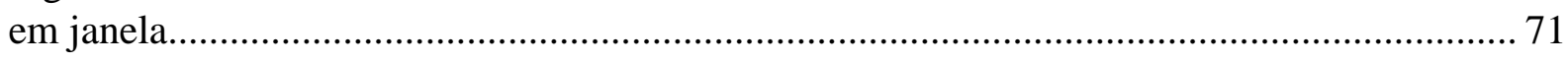

Figura 3.17: Propagação neural simples envolvendo a camada escondida.............................72

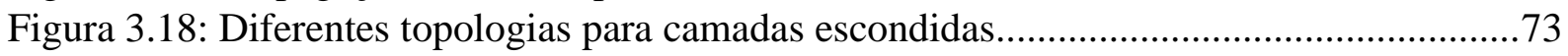

Figura 3.19: Arquitetura baseada em camadas................................................................... 74

Figura 4.1: Estatísticas para casos do córpus de desenvolvimento.......................................... 98

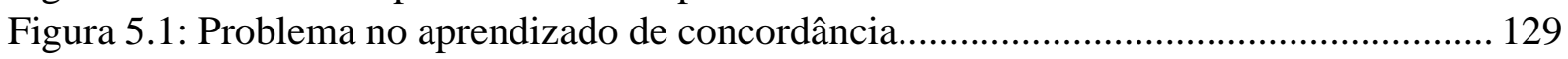

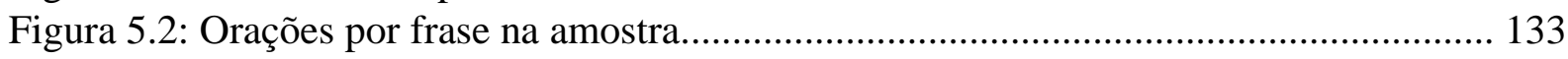

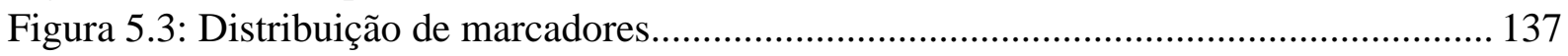





\section{Índice de Algoritmos}

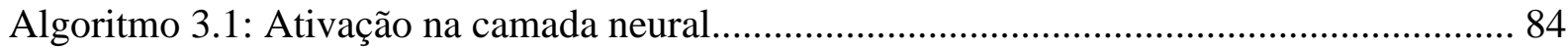

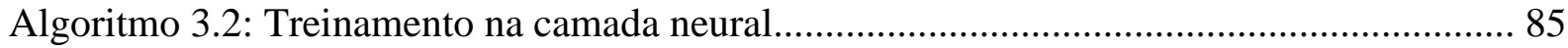

Algoritmo 3.3: Ativação e treinamento de instâncias com recorrência local...........................88

Algoritmo 3.4: Ativação e treinamento do contexto baseado em janela...................................89

Algoritmo 3.5: Ativação e treinamento do contexto baseado em árvore.................................. 89

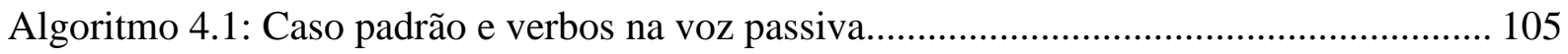

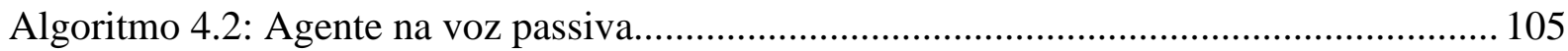

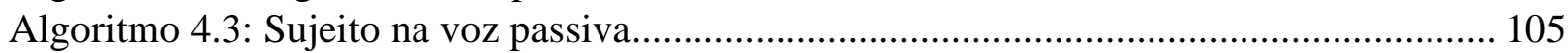

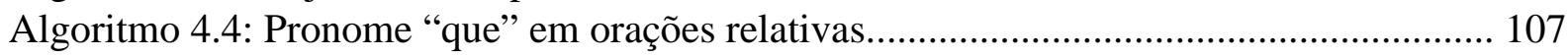

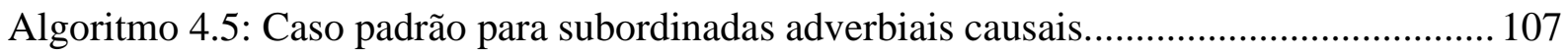

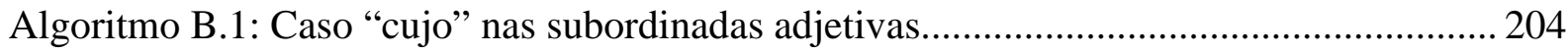

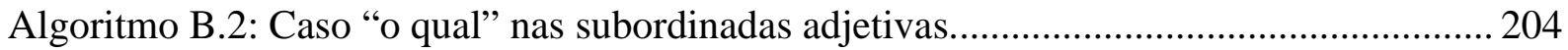

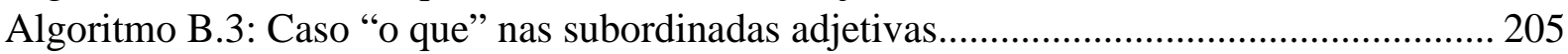

Algoritmo B.4: Caso 1 para subordinadas adverbiais condicionais.....................................205

Algoritmo B.5: Caso 2 para subordinadas adverbiais concessivas.......................................206

Algoritmo B.6: Grupo de casos 1 para subordinadas adverbiais condicionais.......................206

Algoritmo B.7: Grupo de casos 2 para subordinadas adverbiais condicionais......................207

Algoritmo B.8: Grupo de casos 1 para subordinadas adverbiais consecutivas......................208

Algoritmo B.9: Grupo de casos 1 para subordinadas adverbiais conformativas...................209

Algoritmo B.10: Grupo de casos 1 para subordinadas adverbiais finais............................... 210

Algoritmo B.11: Grupo de casos 1 para subordinadas adverbiais temporais........................211

Algoritmo B.12: Caso "antes que" para subordinadas adverbiais temporais.........................212 



\section{Índice de Exemplos}

Exemplo 2.1: A notação IOB para análise sintática parcial...................................................25

Exemplo 2.2: Produções de uma gramática gerativa didática................................................25

Exemplo 2.3: Desambiguação de "como" via gramáticas de restrições (BICK, 2000)...........28

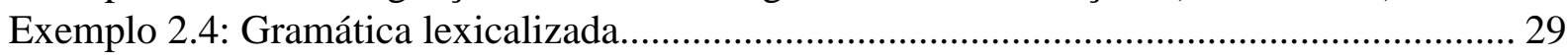

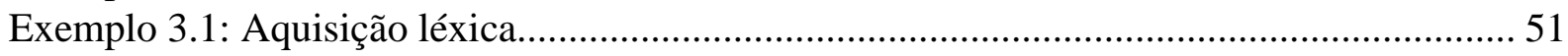

Exemplo 3.2: Modelagem da recorrência recorrência local.................................................52

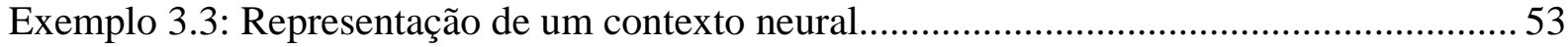

Exemplo 3.4: B-padrões com entrada do contexto................................................................... 54

Exemplo 3.5: Coativação da janela (recorrência com b-padrões baseada na saída do contexto).

Exemplo 3.6: A-padrões (de treinamento) com pseudo-neurônios para o contexto baseado em

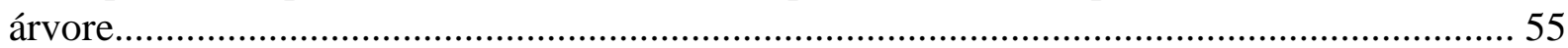

Exemplo 3.7: Ativação de um b-padrão (dos neurônios de saída).............................................56

Exemplo 3.8: Ativação de um c-padrão (processamento dos pseudo-neurônios de saída)......56

Exemplo 3.9: B-padrão para análise integrativa bidirecional..............................................57

Exemplo 3.10: B-padrão com um ancestral indireto.............................................................68

Exemplo 3.11: C-padrões com saídas positivas e negativas para "separou clipes de metais" e

"separou clipes de grampos", contendo três níveis diferentes da árvore de dependência

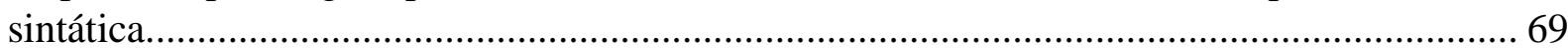

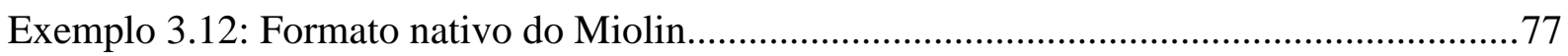

Exemplo 3.13: Pré-processamentos da camada de E/S.........................................................79

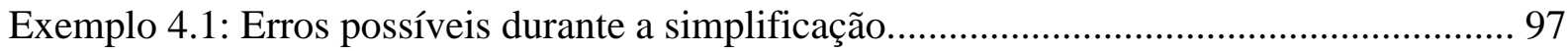

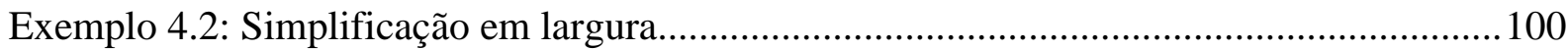

Exemplo 4.3: Simplificação em profundidade.................................................................... 100

Exemplo 4.4: Caso em que profundidade é melhor que largura......................................... 100

Exemplo 4.5: Possíveis tratamentos para elipses............................................................... 101

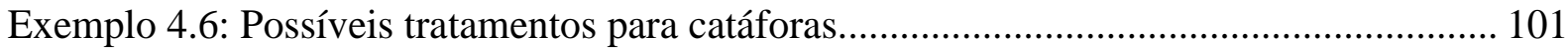

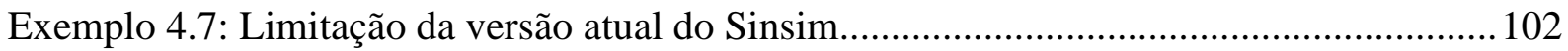

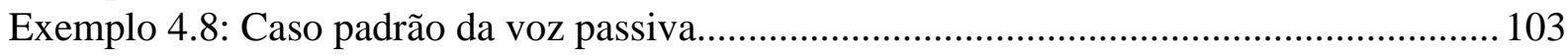

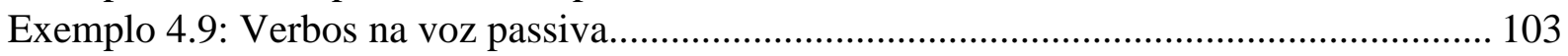

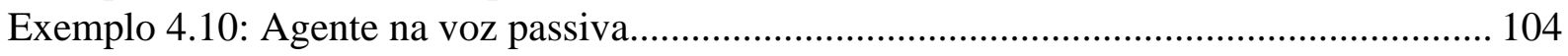

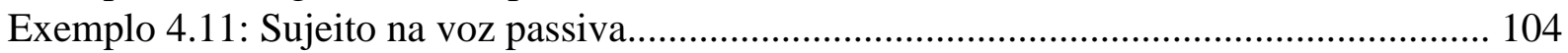

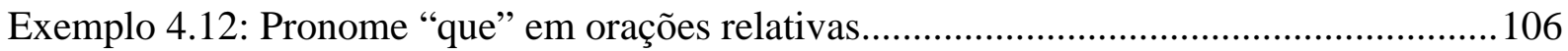

Exemplo 4.13: Caso padrão para subordinadas adverbiais causais........................................ 107

Exemplo 4.14: Casos não processados para subordinadas causais......................................... 108

Exemplo 5.1: Notação de eventos para um experimento...................................................... 113

Exemplo 5.2: Políticas exemplificadas para lexeme_perseguiu.......................................... 120

Exemplo 5.3: Extração de sufixos e geração de troncos....................................................... 124

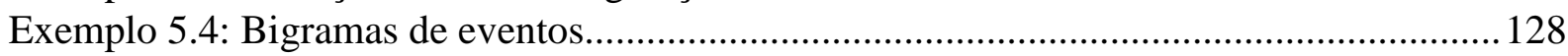

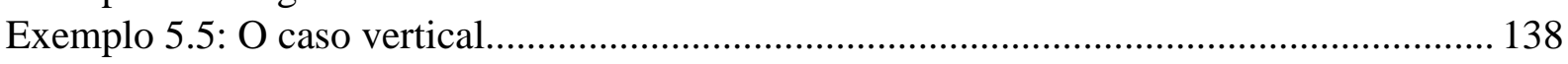

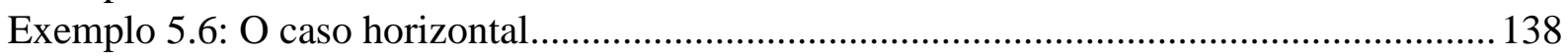

Exemplo B.1: Casos não tratados nas subordinadas adjetivas.............................................203

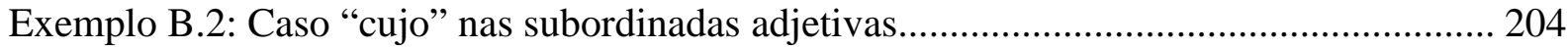

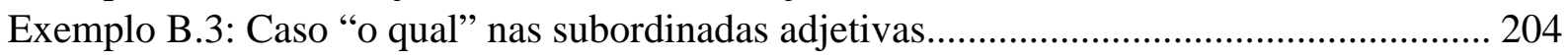

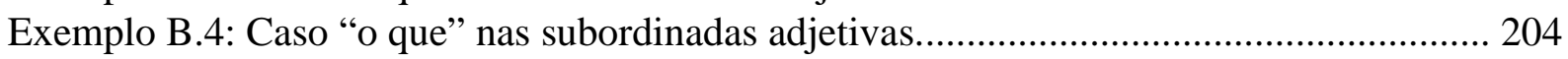

Exemplo B.5: Caso 1 para subordinadas adverbiais condicionais........................................205 
Exemplo B.6: Caso 2 para subordinadas adverbiais concessivas.......................................2205

Exemplo B.7: Grupo de casos 1 para subordinadas adverbiais condicionais......................... 206

Exemplo B.8: Grupo de casos 2 para subordinadas adverbiais condicionais......................... 207

Exemplo B.9: Grupo de casos 3 para subordinadas adverbiais condicionais......................... 207

Exemplo B.10: Grupo de casos 1 para subordinadas adverbiais consecutivas......................208

Exemplo B.11: Grupo de casos 2 para subordinadas adverbiais consecutivas.......................208

Exemplo B.12: Grupo de casos 3 para subordinadas adverbiais consecutivas.......................209

Exemplo B.13: Grupo de casos 1 para subordinadas adverbiais conformativas.....................209

Exemplo B.14: Caso "como" para subordinadas adverbiais conformativas...........................210

Exemplo B.15: Grupo de casos 1 para subordinadas adverbiais finais.................................210

Exemplo B.16: Grupo de casos 1 para subordinadas adverbiais temporais...........................211

Exemplo B.17: Caso "antes que" para subordinadas adverbiais temporais...........................212

Exemplo B.18: Grupo de casos 2 para subordinadas adverbiais temporais...........................212

Exemplo B.19: Grupo de casos 3 para subordinadas adverbiais temporais............................213 


\section{Índice de Tabelas}

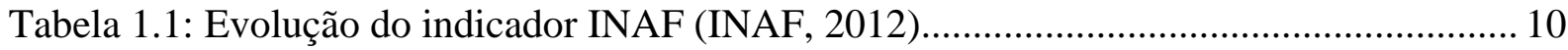

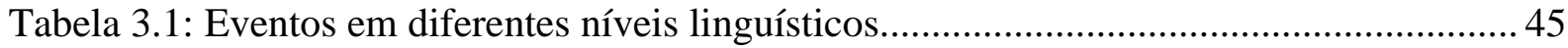

Tabela 3.2: Granularidade de eventos observáveis e latentes................................................. 46

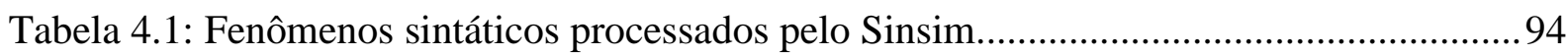

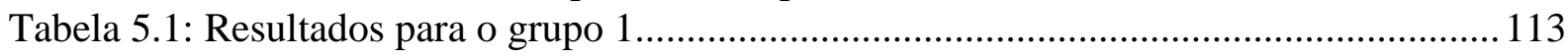

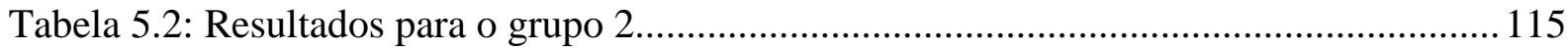

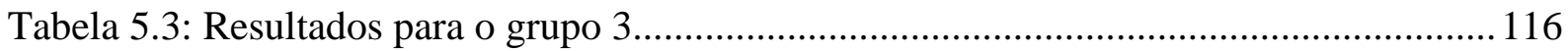

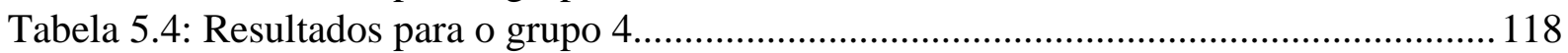

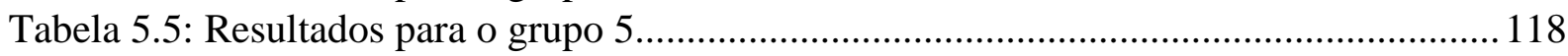

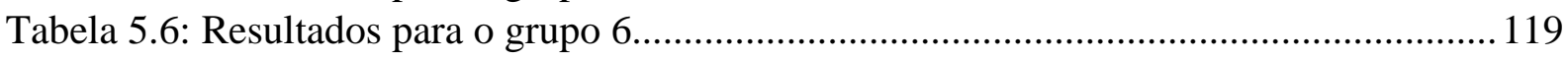

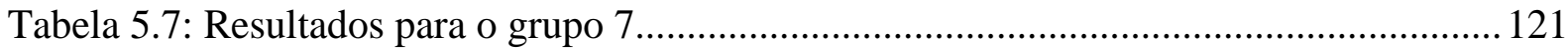

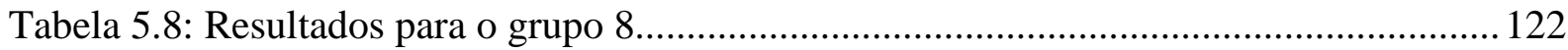

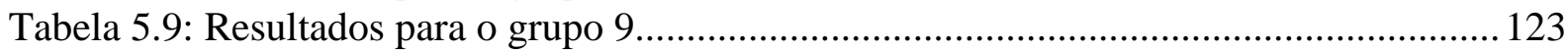

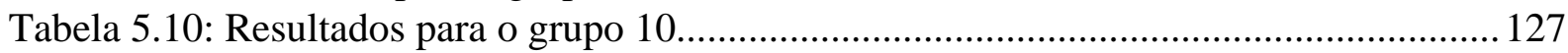

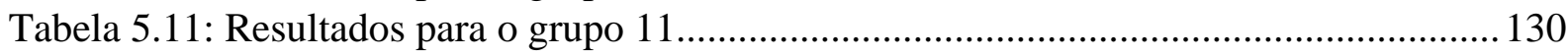

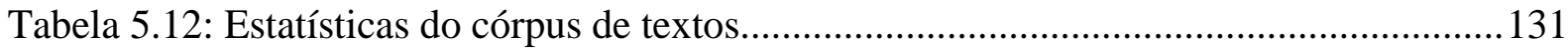

Tabela 5.13: Estatísticas do subcórpus de textos balanceado............................................ 132

Tabela 5.14: Casos de anotação no córpus de frases.............................................................. 133

Tabela 5.15: Estatísticas para cada milhão de lexemas........................................................134

Tabela 5.16: Precisões, coberturas e medidas-f estimadas por marcador discursivo...............135

Tabela 5.17: Médias ponderada das medidas estimadas................................................... 136

Tabela B.1: Marcadores discursivos tratados e fenômenos associados.................................213

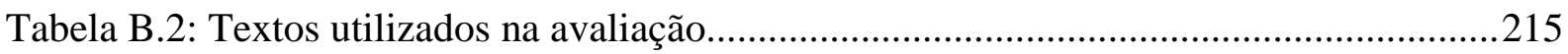





\section{Lista de abreviaturas}

Json: JavaScript Object Notation

Miolin: Modelo Implementado para Operações Linguístico-Neurais

Molin: Modelo Linguístico-Neural

MLP: Multi-Layer Perceptron

NILC: Núcleo Interinstitucional de Linguística Computacional

PLN: Processamento da Língua Natural

PorSimples: Português Simples

PoS: Part of Speech

Sinsim: Sintaxe Simplificada 



\section{Sumário}

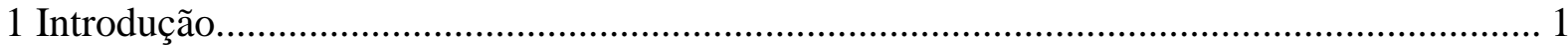

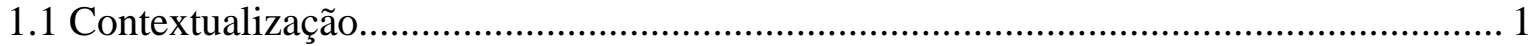

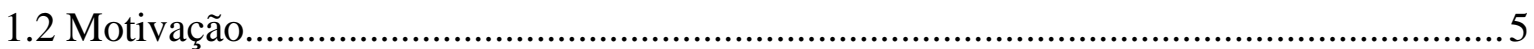

1.3 Objetivos, questões de pesquisa, inovações e contribuições..............................................10

1.4 Organização da monografia...................................................................................12

2 Revisão da literatura e fundamentação teórica....................................................................14

2.1 Redes neurais artificiais Perceptron e MLP.......................................................... 14

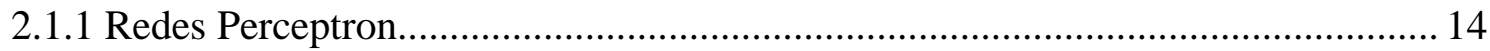

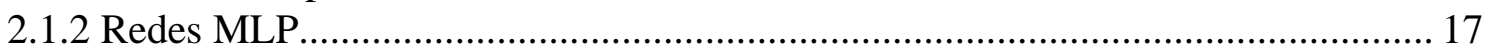

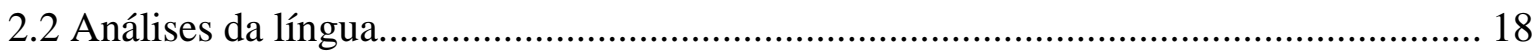

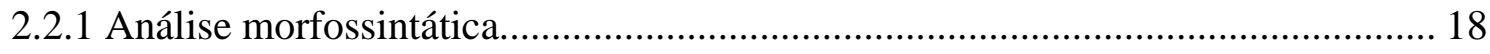

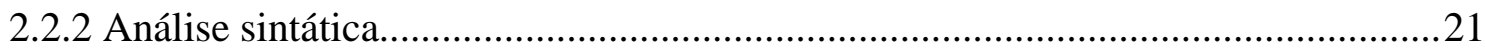

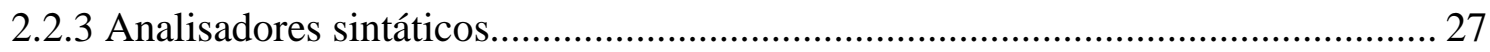

2.2.4 Trabalhos relacionados ao modelo Molin.............................................................30

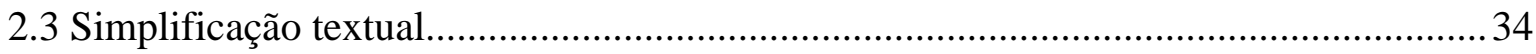

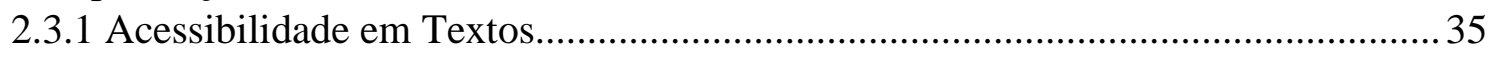

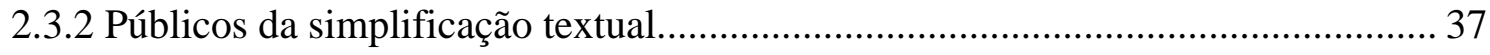

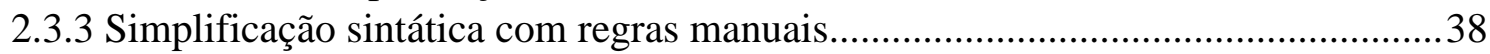

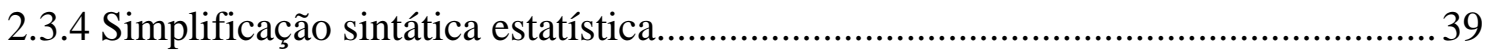

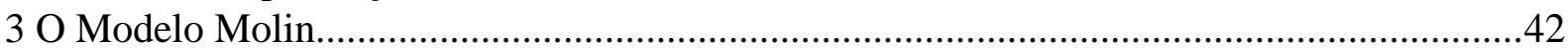

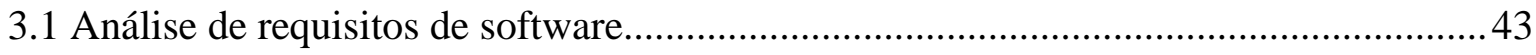

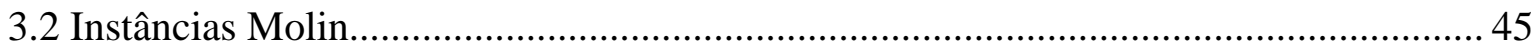

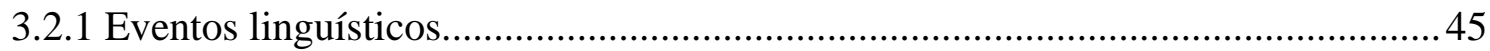

3.2.2 Padrões neurais: neurônios, atributos e classes...................................................... 47

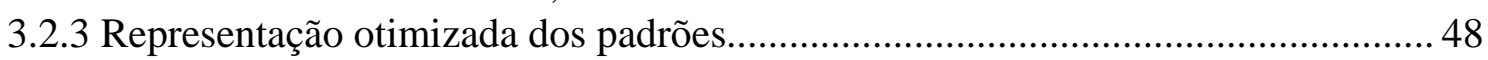

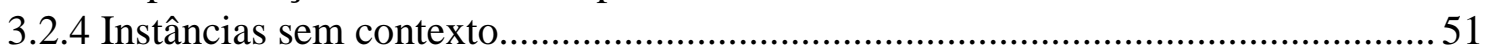

3.2.5 Instâncias com contexto de janela.......................................................................... 53

3.2.6 Instâncias com contexto de árvore......................................................................55

3.2.7 Lexias complexas no contexto baseado em árvore................................................57

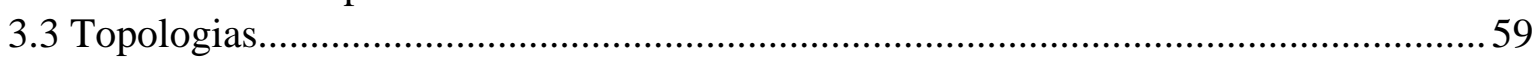

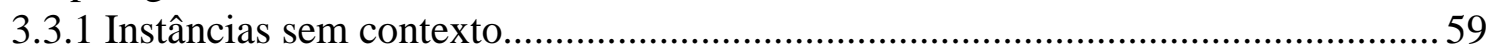

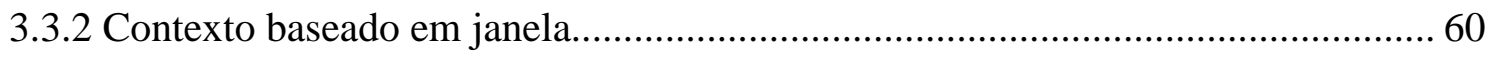

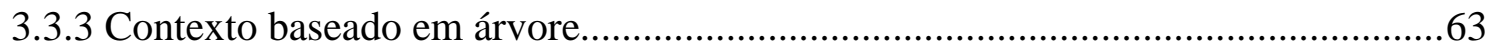

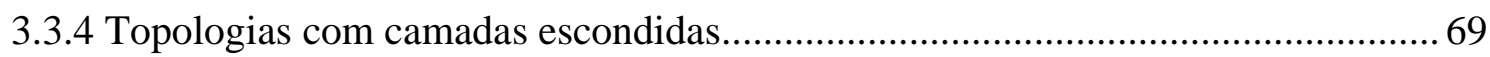

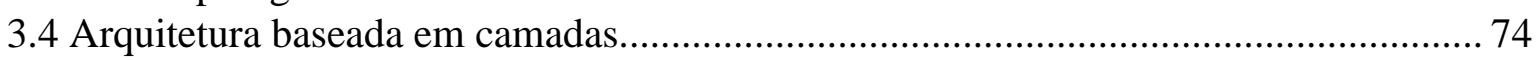

3.4.1 Camada de entrada e saída..............................................................................

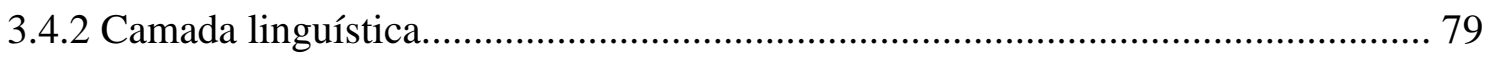

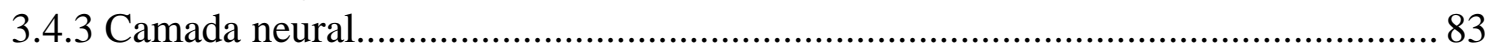

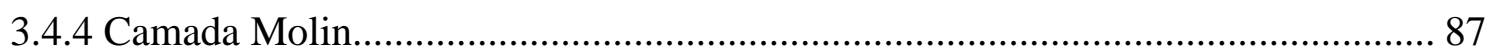

3.5 Comparação do Molin com trabalhos realizados.......................................................... 91

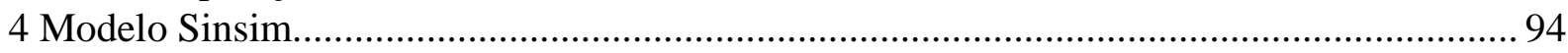

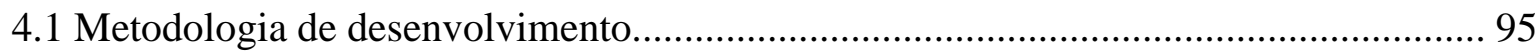

4.1.1 Requisitos de software: precisão.................................................................... 96

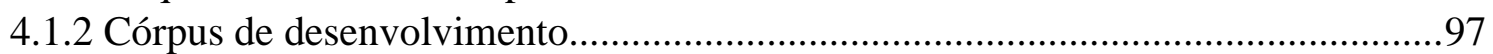

4.2 Exemplos de fenômenos sintáticos.............................................................................99

4.2.1 Operações comuns para diversos fenômenos sintáticos............................................99 


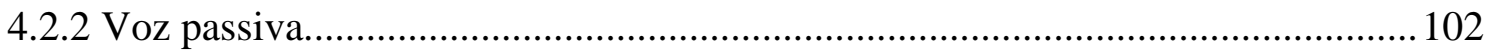

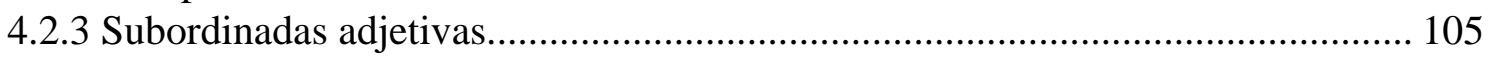

4.2.4 Subordinada adverbial causal..................................................................... 107

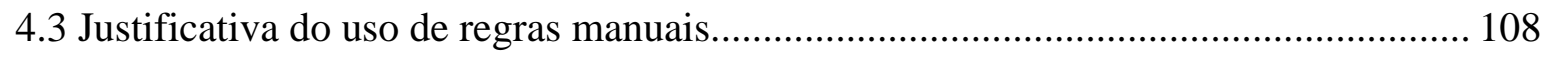

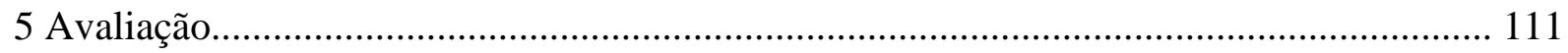

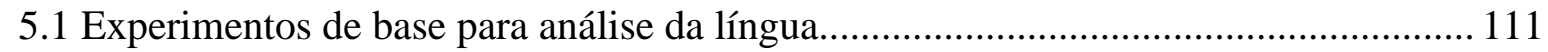

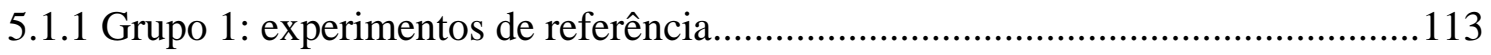

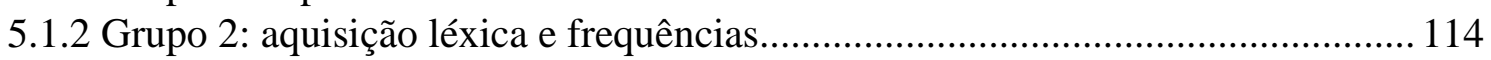

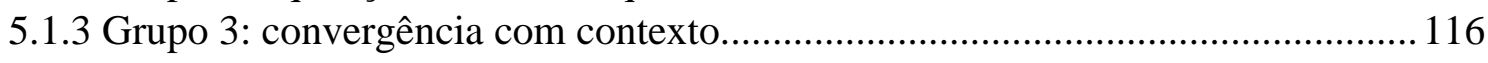

5.1.4 Grupo 4: funções de ativação e de ajuste de pesos............................................ 117

5.1.5 Grupo 5: coativação em janela e recorrência local ............................................. 118

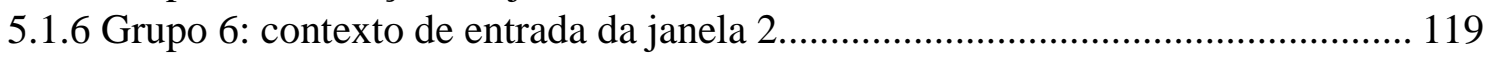

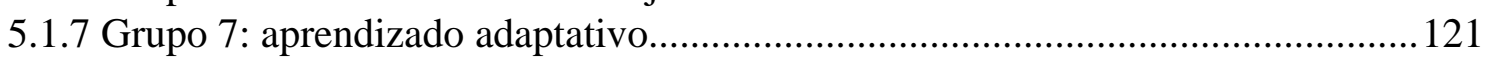

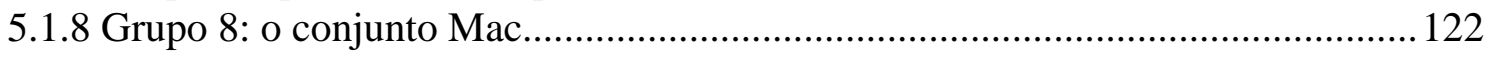

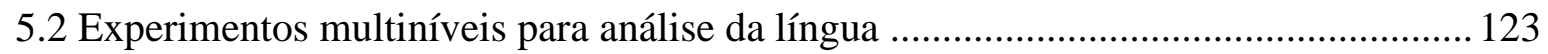

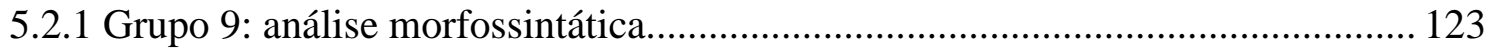

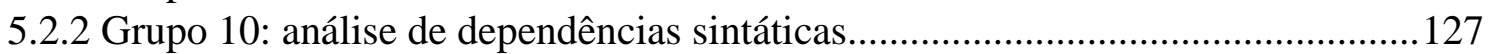

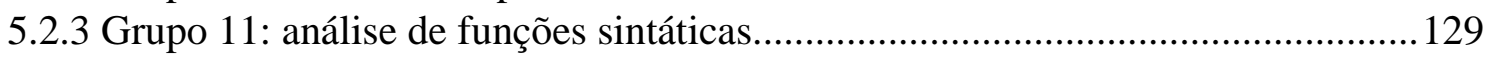

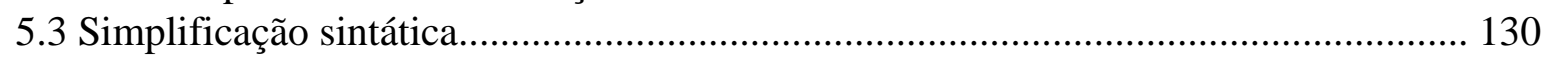

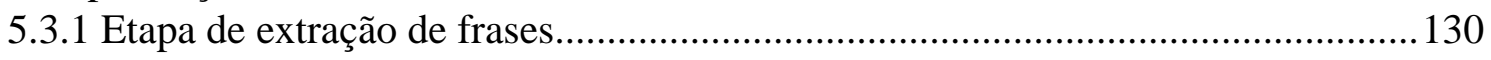

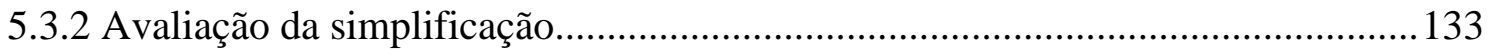

5.3.3 Questões sobre a qualidade da simplificação.................................................... 137

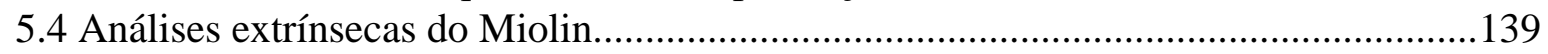

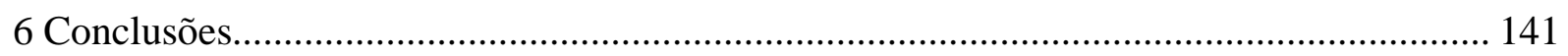

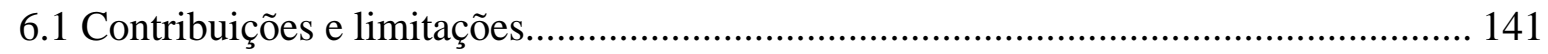

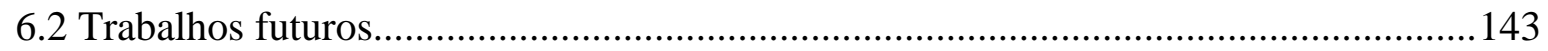

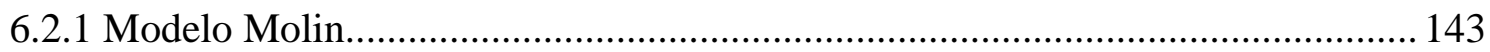

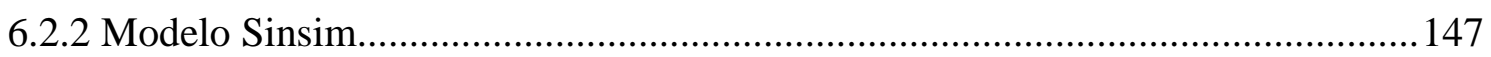

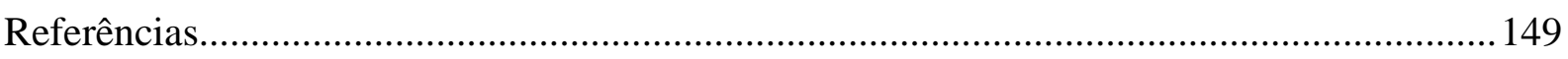

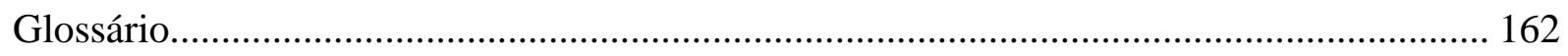

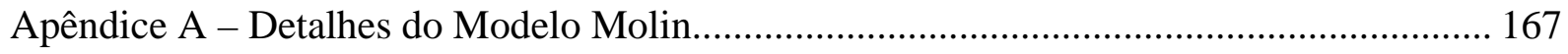

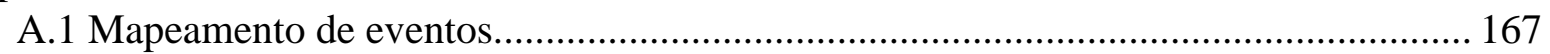

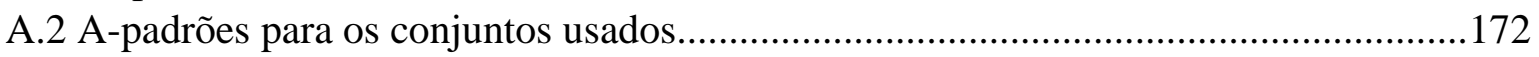

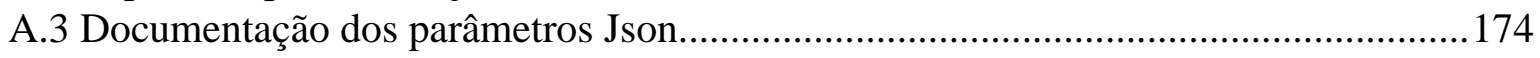

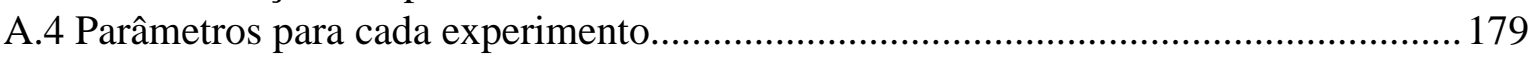

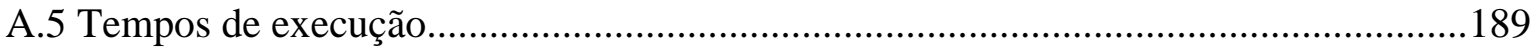

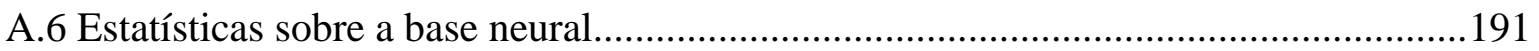

Apêndice B - Detalhes do Modelo Sinsim........................................................................ 203

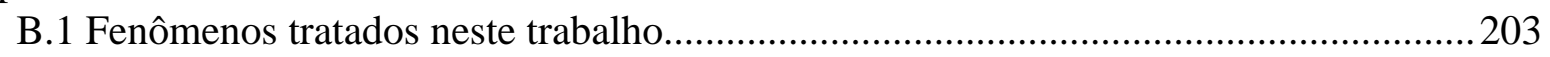

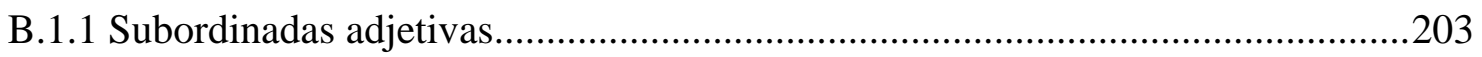

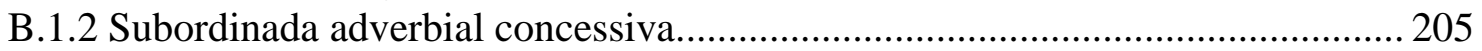

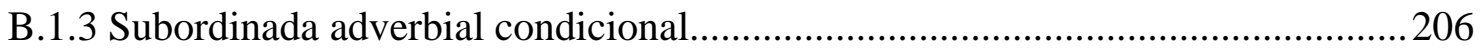

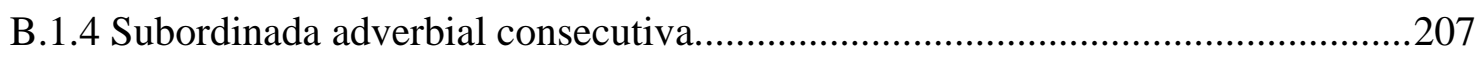

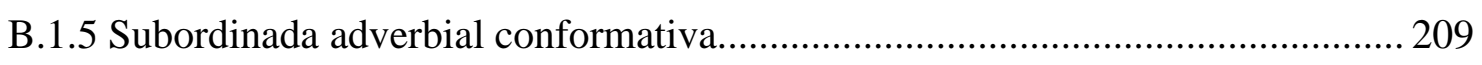

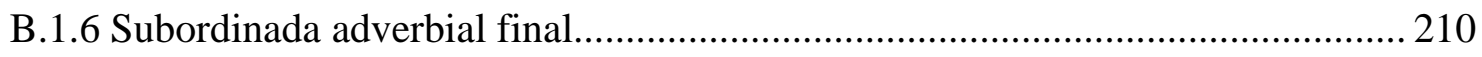

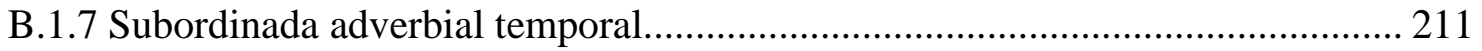

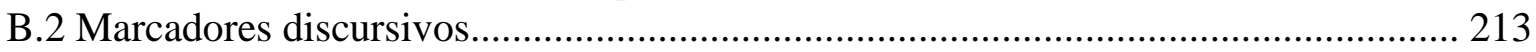

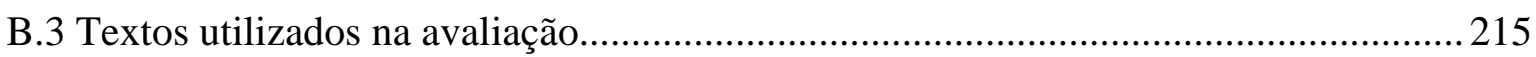


Apêndice C - Código fonte codificado.. 



\section{Introdução}

\subsection{Contextualização}

O Processamento da Língua Natural (PLN) é um campo de pesquisa fortemente interdisciplinar, baseado em conhecimentos de Linguística, Psicolinguística, Linguística Cognitiva, Linguística de Córpus, Inteligência Artificial, Estatística, Lógica, Ciência da Computação, entre outras áreas. Pesquisas da área de PLN tendem a oferecer uma vasta gama de aplicações ${ }^{\mathrm{g}, 1}$, tais como sumarizadores automáticos (DAS \& MARTINS, 2007; RIBALDO et al., 2012), tradutores de máquina (GUPTA, 2011; CALLISON-BURCH et al., 2010), sistemas de perguntas e respostas (RAMPRASATH \& HARIHARAN, 2012; GUPTA \& GUPTA, 2012), revisores gramaticais (KINOSHITA et al., 2007; NUNES \& OLIVEIRA, 2000; NUNES et al., 1999), simplificadores textuais (CANDIDO JR et al., 2009b; WATANABE et al., 2009), sistemas de apoio à escrita (FELTRIM et al., 2006; MAX, 2006), ambientes voltados ao ensino de línguas (BURSTEIN et al., 2007; ALUÍSIO \& OLIVEIRA, 1995), entre outras.

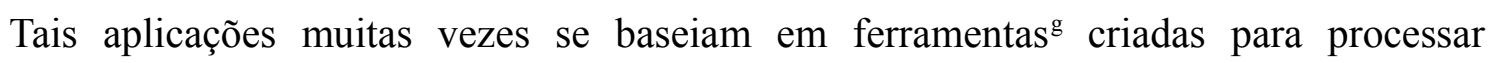
diferentes aspectos da língua. Dentre as ferramentas, podemos citar as seguintes: analisadores morfológicos (BICK, 2000), morfossintáticos (TUFIS \& MASON, 1998; RATNAPARKHI, 1996; BRILL, 1995), morfossintáticos com lematização (SCHMID, 1994a, 1995), analisadores sintáticos parciais (SIDDHARTHAN, 2004), analisadores sintáticos completos de constituintes (SILVA et al., 2010; WING \& BALDRIDGE, 2006), de dependências (FERNANDES \& MILIDIÚ, 2012; BICK, 2000), ou de ambas (COLLINS, 2003), simplificadores lexicais (CANDIDO JR et al., 2009b), sintáticos (SIDDHARTHAN, 2006; CANDIDO JR et al., 2011) e retóricos (WILLIAMS, 2004), desambiguadores de sentidos semânticos (NANCY \& VÉRONIS, 1998), anotadores de papéis semânticos ${ }^{\mathrm{g}}$ (GILDEA \& JURAFSKY, 2001), reconhecedores de entidades nomeadas ${ }^{\mathrm{g}}$ (nomes próprios e outros) (SUNDHEIM, 1995), categorizadores semânticos ${ }^{\mathrm{g}}$ (BICK, 2000), resolvedores anafóricos (SUNDHEIM, 1995), anotadores retóricos (PARDO \& NUNES, 2006).

1 A notação "g" (como em aplicações ${ }^{g}$ ) indica termos que também estão definidos no glossário deste trabalho. 
As ferramentas para o PLN precisam lidar com as unidades estruturais da língua ${ }^{\mathrm{g}}$, assim

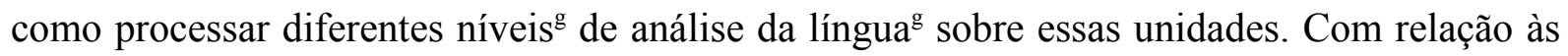
unidades estruturais, não há uma única taxonomia em uso, embora as diferentes definições sejam semelhantes. $\mathrm{Na}$ área de Ciências Cognitivas, quatro unidades básicas são comumente utilizadas: fonemas, lexemas ${ }^{\mathrm{g}}$, frases ${ }^{\mathrm{g}}$ (sentences) e textos (WILLINGHAM, 2006). Já Halliday (1970 apud YEIBO, 2011), a partir de um viés gramatical, adota cinco unidades: morfema, lexema, sintagma $^{\mathrm{g}}$ (phrase) e oração ${ }^{\mathrm{g}}$ (clause). Observa-se que outros elementos, como letras e sílabas, podem ser vistos como unidades estruturais. Diante dessa variação, este trabalho adota cinco unidades básicas: fonema, morfema, lexema, frase e texto (orações e sintagmas são considerados subdivisões de frases).

Em relação aos níveis de processamento da língua, ou ainda, níveis de estudo da língua, a variação é ainda maior. Morris (1938 apud MONTAGUE, 1974), a partir do ponto de vista da semiótica, define três níveis na língua: sintático, semântico e pragmático. Bolshakov e Gelbukh (2004) adotam quatro categorias: fonologia, morfologia, sintaxe, semântica e pragmática, sendo as duas últimas agrupadas no mesmo nível devido a sua similaridade. Millward e Hayes (2011) indicam que existem pelo menos 5 níveis (ou sistemas, na terminologia dos autores) comuns a todos os idiomas: fonológico, morfológico, léxico, sintático e semântico. Os autores também definem um sexto nível opcional para os idiomas que possuem um sistema de escrita definido (o nível gráfico). Dias da Silva et al. (2007) apresentam 5 níveis, de forma semelhante a Millward e Hayes, porém sem a inclusão dos níveis gráfico e léxico e com a inclusão do nível pragmático-discursivo. Jurafsky e Martins (2008) propõem 6 grupos de conhecimento da língua: fonética e fonologia, morfologia, sintaxe, semântica, pragmática e discurso. D'hondt e Östman (2009) definem sete níveis: fonético e fonológico, prosódico (estudo da entonação na fala), morfológico, sintático, léxico-semântico, pragmático e retórico.

A variação entre níveis de análise da língua apresenta uma correlação com a área de atuação de cada pesquisador (Psicolinguística, Linguística tradicional, Linguística Computacional, entre outras), bem como de sua subárea de pesquisa. Por exemplo, um pesquisador cujo trabalho se concentra em sintaxe pode julgar conveniente agrupar os níveis fonético e fonológico em um único nível, enquanto um pesquisador da área de reconhecimento de fala pode decidir fundir os níveis superiores pragmático e discursivo. Os trabalhos com enfoque didático normalmente apresentam definições para cada nível, enquanto 
que pesquisas sobre o estado da arte raramente definem que tipo de informação compõe cada nível de análise.

Observa-se que os níveis de processamento são associados a mais de uma unidade da língua. Por exemplo, o nível semântico inclui informações sobre a semântica dos lexemas, assim como das frases. É comum a organização desses níveis em uma estrutura hierárquica diretamente relacionada às unidades estruturais da língua associadas a cada nível. Este trabalho adota os níveis definidos por Jurafsky e Martins (2008), além do acréscimo dos subníveis especificados:

- Fonético e fonológico: relacionado à análise dos fonemas da língua, assim como dos sons (sinais de áudio) capazes de realizá-los.

- Morfológico: relacionado aos morfemas utilizados na construção de palavras, incluindo subníveis: (a) o grupo dos afixos, isto é, prefixos, sufixos, radicais, raízes, e suas subdivisões, por exemplo, morfemas derivacionais utilizados para formação de palavras ou flexionais, o que inclui as desinências, utilizados nas diferentes formas de realizar uma palavra; (b) o grupo da análise morfológica, o que inclui a análise de gênero, número, grau, modos e tempos das conjugações verbais, entre outros; (c) as classes gramaticais como substantivo e verbo (grupo morfossintático); e (d) o subnível léxico, relacionado aos lexemas e lemas ${ }^{g}$ (ou formas canônicas, por exemplo, o infinitivo impessoal no caso dos verbos, o masculino singular no caso de substantivos e adjetivos), compostos pelos morfemas, e utilizados na produção das frases.

- Sintático: relacionado ao arranjo dos lexemas em uma frase, o que inclui as dependências sintáticas entre lexemas, o agrupamento de lexemas em constituintes sintáticas (abordagem alternativa à análise de dependências) e as funções sintáticas dos lexemas (ou das constituintes conforme a abordagem de análise) que desempenham na frase, por exemplo, sujeito, objeto direto, entre outras. A análise de sintagmas e orações são considerados subníveis de análise do nível sintático.

- Semântico: está relacionado principalmente ao sentido dos lexemas e das frases (observa-se que morfemas também carregam sentidos) e inclui tarefas como a categorização semântica e anotação de papéis semânticos. A primeira é definida neste trabalho como a a junção entre a anotação de hiperônimos (por exemplo, todo "bombeiro" é um humano) e a anotação de entidades nomeadas (por exemplo, "João" 
é um humano ou pessoa, "São Paulo" é uma localização, "janeiro" é um tempo e "20 kg" é uma quantidade). A segunda tarefa identifica quais lexemas (ou grupos de lexemas) atuam como argumentos de um determinado verbo ou predicado complexo (que inclui mais de um lexema) e os classifica em categorias como agente, instrumento, paciente, entre outras de um dado conjunto de etiquetas predeterminado.

- Pragmático: relacionado ao propósito do falante ao produzir frases, incluindo análises de informações que não são explicitadas na frase, e que, caso não sejam inferidas, prejudicam a compreensão do texto produzido para o leitor/ouvinte. Abrange também o conhecimento extralinguístico, isto é, informações que não são explicitadas no texto e que podem ser inferidas apenas se o contexto e as circunstâncias nas quais o texto foi produzido estiverem claras para o leitor/ouvinte.

- Discursivo: relacionado às motivações para a produção do texto, assim como as estratégias utilizadas para sua estruturação. Um texto pode ser estruturado em nível de microcomponentes, quando explicita-se as relações de contraste, exemplificação, reformulação, dentre outras, entre as partes de tal texto, como em nível de macrocomponentes, quando usamos a estrutura esquemática ou esquema de um gênero, categorizando tais textos como uma estória, um texto científico, uma notícia, ou outros gêneros.

Ferramentas e aplicações de PLN também podem estar relacionadas a dois domínios de pesquisa: análise e síntese da língua (DIAS DA SILVA et al., 2007). Certas áreas, como a Tradução Automática, exploram os dois domínios. Em relação aos níveis da língua, é comum que essas ferramentas realizem análises encadeadas, feitas ascendentemente (bottom-up), ou seja, dos níveis mais baixos para os mais elevados, embora existam alguns trabalhos no sentido contrário (LEVINSON, 1974), e ferramentas que integram níveis de análise, com diferentes graus de bidirecionalidade (COLLOBERT, 2011; SINGH et al., 2009; HAJIČ et al., 2009; BICK, 2000).

Este trabalho propõe duas contribuições para a área de PLN, detalhadas na Seção 1.3: (a) um modelo geral para análise da língua em seus diferentes níveis; e (b) um modelo para simplificação sintática, processo para reconstruir a estrutura sintática das frases de um texto de modo a torná-lo mais simples, tanto para pessoas lerem como para sistemas computacionais analisarem.

O primeiro modelo, denominado Molin (MOdelo LInguístico-Neural), explora a frente 
de análise da língua, aplicando redes neurais artificiais ${ }^{\mathrm{g}}$ construtivas baseadas em Perceptron $^{\mathrm{g}}$ em análises integrativas ${ }^{\mathrm{g}}$ e bidirecionais $^{\mathrm{g}}$ nos níveis morfológico (incluindo morfossintaxe), sintático e semântico, e pode ser estendido para outros tipos de análise, servindo de base para criação de ferramentas mais gerais de PLN.

O segundo modelo, denominado Sinsim (modelo para SINtaxe SIMplificada), atua na frente de síntese, e foi desenvolvido para ser integrado a aplicações de simplificação textual, definida como qualquer processo para reduzir a complexidade de um texto tentando manter seu significado e informação (MAX, 2006). O Sinsim aplica simplificação sintática em textos buscando deixar as orações e seus componentes em uma ordem mais natural e dividir frases grandes separando as orações que as compõem. Um recorte é feito em frases contendo orações subordinadas e na voz passiva, entretanto, um caso de oração coordenada é incluída, dado o uso comum de marcadores discursivos ${ }^{\mathrm{g}}$ (FÁVERO et al., 2005 apud CASTELANO et al., 2011) entre os dois tipos de orações.

A Figura 1.1 apresenta uma visão geral da proposta de pesquisa na qual esse trabalho se baseou. As duas frentes de trabalho são interligadas, de modo que o modelo para análise da língua foi concebido para prover informação necessária para o modelo de simplificação sintática, ao mesmo tempo em que o segundo é usado como um avaliador extrínseco do primeiro. Contudo, a integração entre os dois modelos ainda não foi possível, devido a questões discutidas na Seção 5.4. A integração dos modelos foi planejada para ser aplicada na área de acessibilidade de leitura, em particular digital, para tornar textos de diferentes gêneros e domínios mais acessíveis ao publico alvo com níveis de letramento (literacy) rudimentar e básico (AÇÃO EDUCATIVA, 2007). Mais detalhes sobre as dificuldades de leitura e o público alvo citado acima são dados na Seção 1.2.

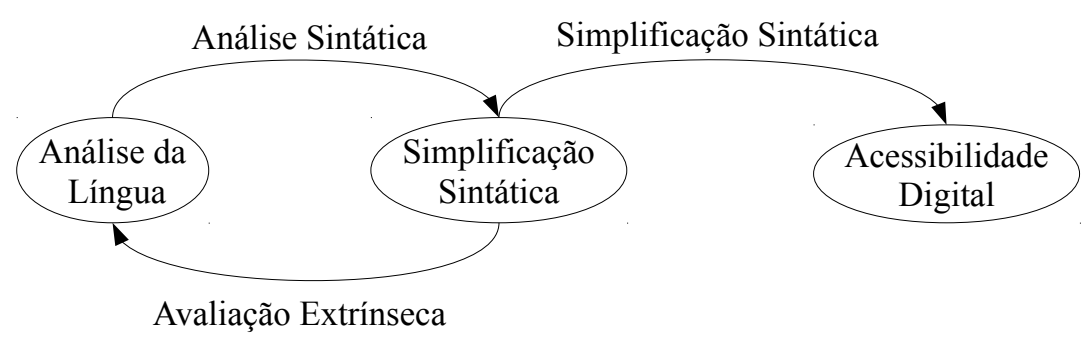

Figura 1.1: A proposta de pesquisa.

\subsection{Motivação}

O modelo Molin foi proposto após o início do desenvolvimento do modelo Sinsim. 
Durante o início da pesquisa, em 2008, verificou-se a escassez de recursos linguísticos voltados para a Língua Portuguesa, em especial analisadores sintáticos, cenário que vem mudando nos últimos anos, graças a uma série de esforços para a construção de analisadores sintáticos (AFONSO et al., 2002; FERNANDES \& MILIDIÚ, 2012; WING \& BALDRIDGE, 2006), além de outras ferramentas e recursos.

O modelo de simplificação sintática foi desenvolvido com base no analisador sintático Palavras (BICK, 2000), cuja licença é proprietária e foi comprada pelo NILC (Núcleo Interinstitucional de Linguística Computacional) em 2006. Seu desempenho é considerado bom, teoricamente atingindo $99 \%$ de anotação correta para morfossintaxe e $97 \%$ para dependências sintáticas, mesmo com um conjunto variado de etiquetas, segundo testes do autor. Porém o analisador possui três limitações principais, razão pela qual optou-se pelo desenvolvimento de um novo analisador de língua para o modelo de simplificação sintática: (a) quando problemas de análise são identificados, as mudanças no código fonte podem solucionar a análise de um caso, porém prejudicar a análise de outros casos mais frequentes, e, por isso, nem sempre podem ser realizadas, limitando a correção de alguns problemas importantes do ponto de vista da simplificação sintática; (b) apenas o próprio autor pode ajustar o código fonte (embora ele seja bastante acessível); (c) o custo da licença de uso do analisador é muito alto para usuários não corporativos, o que restringe seriamente a distribuição livre do simplificador sintático gerado, uma vez que muitos usuários não teriam acesso ao analisador sintático.

Um segundo fator de motivação para a proposta do modelo Molin é o seu uso em futuras pesquisas abarcando a área de inferência textual (DAGAN \& GLICKMAN, 2004; GIAMPICCOLO et al., 2008; BENTIVOGLI et al., 2010; PADÓ \& THATER 2011), definida como uma relação unidirecional entre um texto $\mathrm{T}$ e um segundo texto hipótese $\mathrm{H}$, que ocorre quando o conteúdo de $\mathrm{H}$ pode ser inferido do conteúdo de T. A tarefa também é chamada de acarretamento textual, embora este trabalho opte pelo termo inferência textual, seguindo a terminologia defendida por Zaenen et al. (2005). Esta área de pesquisa foi fortemente estudada durante os 2 anos iniciais do doutorado e deixada para o futuro devido à carência de recursos e sistemas em português para a sua realização competitiva.

O modelo também deve ser utilizado no futuro em outras ferramentas do PLN, nas quais o estado da arte abrange análises em níveis mais profundos da língua, sejam elas semânticas, como a desambiguação de sentido e a anotação de papéis semânticos, ou discursivas, por 
exemplo, a resolução anafórica (via identificação dos referentes dos pronomes de um texto, por exemplo). Para essas ferramentas, os problemas relacionados são mais acentuados no caso da Língua Portuguesa, que possui poucos modelos disponíveis, seja em versões específicas para a língua portuguesa, ou ainda, em versões independentes de língua treinadas para o Português.

Como terceira motivação, este trabalho procurou preencher uma lacuna nas pesquisas existentes, que consiste em avaliar a influência dos níveis mais profundos da língua durante a análise dos níveis mais rasos, já que as tradicionais abordagens tendem a ser ascendentes (bottom-up), ou seja, dos níveis mais baixos (análise morfológica, seguida da sintaxe, por exemplo) para os níveis mais altos (como a semântica, pragmática e discursivo). Contudo existem pesquisas em abordagens descendentes, principalmente aplicando a sintaxe no reconhecimento da fala (LEVINSON, 1974) e combinando sintaxe com papéis semânticos (HAJIČ et al., 2009). Este trabalho apresenta uma metodologia que combina as análises ascendentes e descendentes de forma integrada, com foco nos níveis morfológico (incluindo subníveis léxico e morfossintático), sintático (incluindo dependências e funções sintáticas) e semântico (incluindo categorização semântica). Singh et al. (2009) destacam que as análises ascendentes, em cascata na terminologia dos autores, são problemáticas pelo fato de um nível acumular os erros dos níveis anteriores.

Na frase "Jogue lixo no lixo.", o lexema "lixo" aparece repetido, porém com sentidos diferentes (e categorias semânticas diferentes) em cada ocorrência. Na primeira ocorrência, trata-se de um objeto ou material, enquanto que, na segunda ocorrência refere-se a um recipiente. A categoria semântica de cada ocorrência pode ser resolvida pela sintaxe (análise seguindo a direção sintaxe - categoria semântica), de forma que a função sintática de objeto direto indique a categoria semântica objeto, e a função sintática de objeto preposicional (ou objeto indireto) defina a a categoria semântica recipiente. É importante observar que a associação estabelecida não tem por objetivo desambiguar todas as possíveis ocorrências dos lexemas, já que estes podem ocorrer em diferentes funções sintáticas, mas serve como base para desambiguação para a ocorrência exemplificada na frase acima. Outro fator a ser levado em conta é que as categorias semânticas e sentidos associados ao lexema podem diferir, de modo que as categorias apresentadas foram propostas especificamente para o exemplo. $\mathrm{O}$ exemplo ainda pode ser adaptado para utilizar outro tipo de informação relacionada, por exemplo, combinando sentidos semânticos do lexema em questão com a análise sintagmática, 
já que a primeira ocorrência insere-se em um sintagma verbal (cujo verbo é o núcleo) e a segunda em um sintagma preposicional (por sua vez, contido em um sintagma verbal).

Em direção oposta (categoria semântica - sintaxe), nas frases "Pensa em silêncio." e "Pensa em casa.", são os sentidos associados a "casa" e "silêncio" que diferenciam se o sintagma preposicional é o objeto preposicional (“em casa”) ou um adjunto adverbial (“em silêncio"). Duran et al. (2010) apresentam outros casos nos quais a semântica de lexemas e lexias complexas ${ }^{\mathrm{g}}$ interferem na análise sintática. Uma motivação do trabalho consiste em investigar as possíveis vantagens (caso existam) que modelos bidirecionais de análise possuem em relação a modelos unidirecionais tradicionais.

Para o modelo Sinsim, a principal motivação foi a demanda de simplificação sintática junto ao projeto PorSimples (Português Simples, Simplificado) (ALUÍSIO et al., 2008; CANDIDO JR et al., 2009a; 2009b; ALUÍSIO \& GASPERIN, 2010; GASPERIN et al., 2010; WATANABE et al., 2010a; 2010b; CANDIDO JR et al., 2011), desenvolvido no NILC, e financiado pela FAPESP (Fundação de Amparo à Pesquisa do Estado de São Paulo) e pela Microsoft Research (proc. Nro. 2007/54565-8) durante o período de Novembro de 2007 a Abril de 2010, cujo objetivo foi usar a adaptação de textos, que incluem a simplificação textual e a elaboração textual, para torná-los mais acessíveis a leitores com baixo nível de alfabetização, em particular, leitores com os níveis de alfabetização rudimentar e básico. Apesar do foco nesse perfil de leitor, as tecnologias podem ser expandidas para outros públicos, como portadores de deficiências cognitivas herdadas (por exemplo, surdez e dislexia) ou adquiridas (por exemplo, devido a traumatismos, aneurismas, derrames e afasia), alfabetizandos, falantes não nativos da Língua Portuguesa, dentre outros.

O modelo Sinsim é proposto como uma reestruturação do trabalho apresentado por Candido Jr et al. (2009a), que teve como base o manual de simplificação do Projeto PorSimples (SPECIA et al., 2008). Enquanto a arquitetura original prioriza igualmente precisão e cobertura, o Sinsim dá uma importância maior à precisão, uma vez que os erros resultantes de um sistema de simplificação podem prejudicar mais a leitura do texto, do que as simplificações corretas podem facilitá-la, em especial, quando tais erros levam à agramaticalidade. Acreditamos que, em se tratando do público-alvo, a questão é mais acentuada, pois os leitores já estão sobrecarregados com a tarefa de compreensão do texto para terem também que identificar e corrigir erros oriundos de um sistema automático (em particular, remoções podem causar erros graves, quando grandes porções da frase são removidas). Outra diferença importante é em relação à abrangência do 
Modelo Sinsim quanto aos fenômenos sintáticos ${ }^{\mathrm{g}}$ quando comparado à versão de Candido Jr et al. (2009a). Enquanto o modelo original trata orações subordinadas, coordenadas, voz passiva, entre outros fenômenos, o Sinsim foca no estudo de orações subordinadas e voz passiva. Embora o número de fenômenos seja menor, o número de subcasos analisados em cada fenômeno é maior, pois, no decorrer da pesquisa, foram levantados diversos subcasos não previstos originalmente no manual de simplificação do projeto PorSimples. A escolha pelo processamento de orações subordinadas e voz passiva se deu em virtude desses fenômenos serem considerados mais difíceis para leitores com necessidades especiais quando comparados a outros fenômenos como coordenação (CHAPPELL, 1985; JONES et al., 2006; ABEDI et al., 2011).

O projeto PorSimples, no qual esta pesquisa se inseriu, foi motivado pela necessidade de fornecer à população brasileira textos mais acessíveis. O Instituto Paulo Montenegro e a Organização não Governamental Ação Educativa criaram e implementaram o INAF (Indicador Nacional de Alfabetismo Funcional) (INAF, 2012), baseado em entrevistas e testes cognitivos aplicados a amostras representativas da população brasileira, compostas por 2.000 pessoas entre 15 e 64 anos de idade, residentes em zonas urbanas e rurais em todas as regiões do país. As análises são realizadas desde 2001 para identificar os níveis de alfabetismo da população adulta brasileira, avaliando problemas das pessoas com baixo nível de letramento, isto é, daquelas com problemas para utilizar a leitura e escrita no dia a dia (RIBEIRO, 2006). Os quatro graus de letramento (literacy) medidos pelo INAF são assim definidos: (a) analfabetos, não são capazes de realizar a decodificação de frases ou palavras; (b) alfabetizados em nivel rudimentar, capazes de localizar informações explícitas em textos curtos; (c) alfabetizados em nível básico, conseguem lidar com textos um pouco maiores e realizar algumas inferências e (d) alfabetizados em nível pleno, leem textos longos orientando-se por subtítulos, realizam inferências e sínteses, são capazes de cruzar informações e comparar dois textos diferentes. A avaliação do INAF aponta que, em 2007, 9\% da amostra da população analisada não era alfabetizada, enquanto o percentual de alfabetizados dos níveis rudimentar (25\%) e básico (38\%) chegava a 63\%. Esse era o cenário quando o projeto PorSimples iniciou. A Tabela 1.1 traz os resultados completos até 2012 e apresenta a evolução do índice desde 2001 (utiliza-se médias móveis até o ano 2005). Nota-se que o foco do projeto PorSimples e, consequentemente, do modelo Sinsim são os leitores com níveis de letramento rudimentar e básico. Em 2012, o percentual de alfabetizados dos níveis rudimentar e básico ainda é alto (68\%), reforçando a necessidade de adaptações textuais para dar suporte à compreensão de leitura desse público. 
Tabela 1.1: Evolução do indicador INAF (INAF, 2012).

\begin{tabular}{lrrrrrrr}
\hline Nível & $\mathbf{2 0 0 1 / 2 0 0 2}$ & $\mathbf{2 0 0 2 / 2 0 0 3}$ & $\mathbf{2 0 0 3 / 2 0 0 4}$ & $\mathbf{2 0 0 4} / \mathbf{2 0 0 5}$ & $\mathbf{2 0 0 7}$ & $\mathbf{2 0 0 9}$ & $\mathbf{2 0 1 1 / 2 0 1 2}$ \\
\hline Analfabeto & $12 \%$ & $13 \%$ & $12 \%$ & $11 \%$ & $9 \%$ & $7 \%$ & $6 \%$ \\
Rudimentar & $27 \%$ & $26 \%$ & $26 \%$ & $26 \%$ & $25 \%$ & $21 \%$ & $21 \%$ \\
Básico & $34 \%$ & $36 \%$ & $37 \%$ & $38 \%$ & $38 \%$ & $45 \%$ & $47 \%$ \\
Pleno & $26 \%$ & $25 \%$ & $25 \%$ & $26 \%$ & $28 \%$ & $25 \%$ & $26 \%$ \\
\hline
\end{tabular}

\subsection{Objetivos, questões de pesquisa, inovações e} contribuições

Os objetivos deste trabalho são estudar abordagens inovadoras (bidirecionais) para análise da língua (Modelo Molin) e desenvolver recursos para aumentar a acessibilidade da população a textos produzidos, principalmente em meio digital, como os textos disponíveis na Web em Português do Brasil, por meio da simplificação sintática (Modelo Sinsim).

As questões de pesquisa são relacionadas ao modelo Molin, cuja avaliação é mais exploratória do que a do Sinsim, já que o modelo neural está inserido em um contexto ainda pouco investigado de análise da língua. Assim, neste trabalho, investiga-se se:

- O desempenho da análise bidirecional da língua é igual ou superior ao desempenho das tradicionais análises ascendentes.

- A recorrência é importante nas análises linguísticas. Em especial, é investigado o impacto do método de recorrência proposto, baseado em contextos neurais ${ }^{\mathrm{g}}$, e denominado de coativação ${ }^{\mathrm{g}}$.

Segundo nossos conhecimentos, as seguintes características do modelo Molin são inovadoras:

- A análise bidirecional baseada em redes neurais de larga escala (exemplificada em detalhes na Seção 3.2.6) baseada em coativação, estudada principalmente por meio da interação entre lexemas no mesmo contexto, de forma que, durante o processo de análise, um lexema possa influenciar os demais, isto é, as análises dos demais em diferentes níveis, e ser influenciado por eles. Esse formalismo foi escolhido por diferentes razões, incluindo: (a) o fato do processamento da língua no cérebro humano ser realizado por redes neurais de grande escala; (b) a capacidade das redes neurais artificiais lidarem com incertezas por meio de pontuações (isso é importante na recorrência, pois permite que a rede utilize suas próprias predições para efetuar analises adicionais); e (c) o fato de prevenirem explosões no espaço de busca quando 
comparadas a modelos baseados em regras (uma única somatória de pesos pode equivaler a diversas regras).

- A abordagem recorrente denominada coativação proposta para processar contextos neurais, uma abstração para agrupar os padrões ${ }^{\mathrm{g}}$ derivados dos lexemas da língua em grupos (os contextos) referentes a frases (apresentada nas seções 3.2.5 e 3.2.6). Em abordagens relacionadas orientadas a contextos neurais e recorrência (SCHMID, 1994b; SOCHER et al., 2010), um padrão de análise $p_{1}$ pode afetar outro padrão de análise $p_{2}$, porém, quando isso ocorre, $p_{2}$ não pode afetar a análise de $p_{1}$, o que é permitido na abordagem apresentada neste trabalho.

- Uma notação otimizada para cenários de alta esparsidade, que permite a adição de neurônios $^{\mathrm{g}}$ e sinapses $^{\mathrm{g}}$ sob demanda durante a etapa de treinamento da rede, em contraste com notações tradicionais que precisam ser definidas antes do treinamento ser iniciado, durante a etapa modelagem (Seção 3.2.3). A notação é semelhante a proposta por Carlson et al., (1999), mas se baseia em cadeias de caracteres em vez de índices do tipo inteiro, sendo mais adequada para tarefas de PLN, nas quais lexemas são convertidos em atributos.

- Aprendizado a partir de múltiplos tutores ${ }^{g}$ com correlação da informação. Os tutores dão origem aos conjuntos de treinamento usados pela rede, sejam eles provenientes de anotadores humanos ou software para anotação (semi-)automática. Essa característica é possibilitada pelo modelo, apesar de não ter sido explorada neste trabalho. O processo básico consiste em combinar tutores treinados em diferentes tarefas para gerar um nova instância ${ }^{\mathrm{g}}$ multitarefa. Por exemplo, um tutor treinado em análise sintática pode ser combinado com um tutor treinado em análise semântica para anotar um conjunto de dados utilizado para treinar uma nova instância que realize ambas as análises, correlacionando informações diferentes de cada uma (Seção 6.2.1).

Em relação às contribuições do modelo Sinsim, destaca-se a expansão e reimplementação focada em precisão das operações de simplificação sintática para voz passiva e subordinação definidas no manual do projeto PorSimples, para a Língua Portuguesa. O Sinsim foi empregado com sucesso em duas aplicações de PLN: o Facilita (WATANABE et al., 2009), voltado para apresentar conteúdo facilitado para leitores com nível de letramento rudimentar; e o Simplifica (CANDIDO JR et al., 2009b; SCARTON et al., 2010), uma ferramenta de 
autoria voltada a autores que desejam tornar seus textos mais simples para o mesmo público-alvo. Isto quer dizer que as duas aplicações acima já receberam a versão mais atual da simplificação sintática, resultado desta tese de doutorado, embora ainda seja preservada a versão inicial, para comparações, no site do PorSimples² .

Em relação às contribuições do Modelo Molin, destaca-se a aplicação de redes neurais artificiais de larga escala para processar a língua, seguindo a proposta iniciada pelo projeto Senna $^{3}$ (COLLOBERT et al., 2011; COLLOBERT, 2011) e a análise da língua em diferentes granularidades. As instâncias geradas podem utilizar informações de granularidade grossa, por exemplo, as classes gramaticais, e informações de granularidade fina, por exemplo, os lexemas da língua, além de informações de níveis de granularidade intermediários ${ }^{4}$, por exemplo, sufixos (mais detalhes são apresentados na Seção 3.2.1).

Outras contribuições do Molin são mais pontuais, incluindo o fato do modelo Molin ser independente de língua, interpretável (permitir a extração do conhecimento adquirido de forma simples), escalável (para lidar com redes neurais artificiais de grandes dimensões) e expansível (o modelo pode ser instanciado para um determinado conjunto de tarefas que pode acomodar novas tarefas em uma fase de treinamento posterior). Essas características serão detalhadas na Seção 3.1 .

A proposta do modelo Molin é moldada e otimizada para o cenário de processamento majoritariamente sequencial presente em redes neurais artificiais implementadas em software, em contraste ao processamento altamente paralelizável das redes neurais biológicas. Apesar disso, elementos nos quais a proposta se baseia podem servir como hipóteses plausíveis para o processamento da língua natural no cérebro humano, já que esse mecanismo ainda não é bem compreendido.

\subsection{Organização da monografia}

Este trabalho é organizado como segue. O Capítulo 2 apresenta a fundamentação teórica sobre redes neurais artificiais assim como a revisão da literatura para análise e simplificação da língua, particularmente em morfossintaxe e sintaxe. Ênfase é dada em trabalhos integrativos, isto é, que agregam diferentes níveis de análise da língua, e trabalhos que aplicam redes neurais artificiais às tarefas investigadas nesta pesquisa. O Capítulo 3 discute a

2 http://caravelas.icmc.usp.br/wiki/index.php/Principal

3 http://ronan.collobert.com/senna/

4 A granularidade é relacionada a quantidade de itens de análise. Por exemplo, existem mais lexemas do que sufixos, assim a granularidade de lexemas é mais fina. 
concepção do Molin, apresentando uma análise de requisitos de software que guiaram o desenvolvimento do protótipo do modelo e detalhando a metodologia de pesquisa seguida para criar topologias ${ }^{g}$, instâncias Molin e seus padrões, para desenvolver a arquitetura de software empregada em um protótipo capaz de implementar instâncias, e para mapear recursos como glossários ${ }^{\mathrm{g}}$ e córpus $^{\mathrm{g}}$ para arquivos de treinamento do modelo. O Capítulo 4 refere-se à metodologia seguida durante a criação do Sinsim, apresentando os requisitos de software que dirigiram o projeto do modelo, o córpus empregado em sua implementação, exemplos de regras de simplificação sintática seguidas pelo modelo, além de uma análise sobre as perspectivas do uso de simplificação sintática baseada em aprendizado de máquina no estado da arte atual. O Capítulo 5 apresenta a avaliação de instâncias Molin nas tarefas de análise morfológica (incluindo morfossintaxe) e sintática (incluindo dependências e funções sintáticas), incluindo avaliações multiníveis e avaliações extrínsecas. O Capítulo 5 também traz a avaliação do modelo Sinsim aplicada a um córpus do gênero enciclopédico e o combinado dos dois modelos. Por fim, o Capítulo 6 apresenta as conclusões do trabalho com respeito às contribuições e limitações do trabalho, além de apresentar as propostas para trabalhos futuros. 


\section{Revisão da literatura e fundamentação teórica}

Este capítulo apresenta a fundamentação teórica e os trabalhos relacionados aos modelos desenvolvidos nesta pesquisa de doutorado (Molin e Sinsim). O modelo Sinsim se baseia em redes neurais artificiais (tratadas na Seção 2.1), um conjunto de modelos e formalismos matemáticos inspirados no funcionamento do cérebro humano para a análise de diferentes níveis e subníveis da língua. Em particular, o Molin é aplicado às análises morfológica e morfossintática (Seção 2.2.1) e sintática (Seção 2.2.2). Trabalhos relacionadas ao modelo Sinsim são discutidos na Seção 2.3.

\subsection{Redes neurais artificiais Perceptron e MLP}

\subsubsection{Redes Perceptron}

A pesquisa em redes neurais artificiais foi iniciada por Mcculloch e Pitts (1943 apud ROJAS, 1996), com a construção do primeiro neurônio artificial. Os autores modelaram neurônios artificiais a partir de circuitos elétricos, cuja a ativação é feita para um conjunto de valores binários de entrada (entradas são referenciadas por padrões e seus valores individuais são referenciados por atributos ${ }^{\mathrm{g}}$ ) e resulta em um valor binário de saída (saídas também são chamadas de classes $^{\mathrm{g}}$, no cenário de aprendizado supervisionado). O neurônio é dito disparado $^{\mathrm{g}}$ quando sua saída é 1 (de forma mais geral, quando sua saída é maior que 0,5).

Em 1949, Hebb (1949 apud ROJAS, 1996) apresentou sua teoria, segundo a qual sinapses (interligações entre neurônios biológicos) são fortalecidas quando os neurônios conectados são disparados juntos, e enfraquecidas em caso contrário. O trabalho de Hebb deu origem a abordagens para aprendizado em redes neurais artificiais conhecidas como aprendizado Hebbiano. Em 1958, Rosenblat (1958) propôs o modelo para neurônios artificiais Perceptron, que é inspirado na proposta de Mcculloch e Pitts, porém pondera os atributos por meio de pesos. A Figura 2.1 ilustra o Perceptron. 


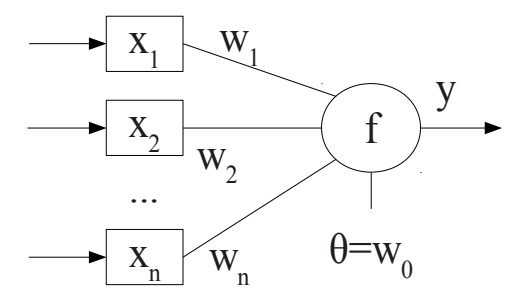

Figura 2.1: O Perceptron.

Na Figura 2.1, o neurônio artificial é representado pelo círculo, enquanto atributos são representados por retângulos. Para $n$ atributos $x_{i}$, são associados $n$ pesos $w_{i}$. Inibição é associada a pesos negativos. A saída $y$ será 1 ou $0^{5}$ de acordo com a função de ativação $f$, aplicada sobre a soma ponderada dos neurônios de entrada. A constante $\theta$ é associada ao limiar de ativação (também chamado de bias), que afeta o disparo do neurônio. Para a função de ativação Passo, apresentada pela Equação (2.2) a partir da somatória ponderada de pesos da Equação (2.1), basta que o limiar seja superado pelas demais entradas para que a ativação seja realizada.

$$
\begin{aligned}
& v=\theta+\sum_{i=1}^{n} x_{i} w_{i} \\
& y=\begin{array}{l}
1, \text { se } v \geq 0 \\
0, \text { caso contrário }
\end{array}
\end{aligned}
$$

Observa-se que, para simplificar a representação da constante em $\theta$ em figuras e algoritmos, este trabalho adota a constante como o oposto do limiar de ativação. Além disso, por conveniência, os atributos são armazenados em neurônios de entrada que não passam pelo processo de ativação tradicional, simplificando a metodologia discutida no Capítulo 3. Essa camada de entrada não deve ser confundida com a camada escondida ${ }^{\mathrm{g}}$, discutida na Seção 2.1.2. Uma exceção é a sinapse correspondente à constante $\theta$, (denotada no texto por sinapse $\theta$ ou sinapse especial ${ }^{\mathrm{g}}$ ) que não é associada a um neurônio de entrada ${ }^{6}$, e seu peso é utilizado na integra no cálculo (o que equivale a combinar essa sinapse com um neurônio de ativação constante, com valor 1).

O treinamento supervisionado de redes Perceptron consiste em ativar os neurônios para os padrões de entrada de um dado conjunto de treinamento e ajustar os pesos das sinapses de acordo com o erro cometido pela rede durante essas ativações. O erro da rede é definido como

5 Alternativamente, a saída pode ser representada por -1 e 1 , desde que seja feitos os devidos ajustes nas funções de ativações. No Miolin, a saída mais baixa é representada sempre por 0 , otimizando o processo ao permitir remover neurônios desativados do cálculo.

6 Além disso, por conveniência, o protótipo apresentado no Capítulo 3 armazena o peso e a taxa de aprendizado da sinapse especial juntamente com seu neurônio de saída associado. 
a diferença entre a saída obtida $y$ e a saída desejada $d$. A Equação (2.3) apresenta os ajustes de peso comumente utilizados em redes Perceptron, definido no passo (2.3b). Na equação, $x_{i, t}, y_{t}$ e $d_{t}$, correspondem ao conjunto de entradas $x_{i}$ e às saídas obtidas $(Y)$ e desejadas $(D)$ para o $t$-ésimo padrão, respectivamente. $\mathrm{O}$ termo $\eta$ representa a taxa de aprendizado associada à rede. A sinapse especial é representada por $w_{0, t}$, enquanto $x_{0, t}$ é definido com o valor constante 1. As demais sinapses são representadas por $w_{i>0, t}$.

$$
\begin{aligned}
& w_{i, 0}=0 \\
& \Delta w_{i, t+1}=\eta x_{i, t}\left(d_{t}-y_{t}\right) \\
& w_{i, t+1}=w_{i, t}+\Delta w_{i, t+1}
\end{aligned}
$$

O algoritmo para ajuste de pesos para Redes Perceptron é aplicado ao modelo Molin e detalhado na Seção 3.4 .3 (juntamente com o algoritmo para ativação da rede). Este trabalho usa taxas de aprendizado $\eta$ decrescentes e individuais para cada neurônio e saídas continuas para vários experimentos do Capítulo 5 (baseados na função sigmoide logística detalhada na Seção 2.1.2), e também com função de ativação inspirada no modelo MLP (também detalhado na Seção 2.1.2).

Minsky e Papert (1969 apud ROJAS, 1996) realizaram uma análise extensiva do modelo Perceptron, incluindo limitações quanto ao uso do modelo. Uma limitação importante, provada pelos autores, é a incapacidade do Perceptron de resolver o problema do ou-exclusivo, embora ele possa resolver outras funções lógicas (e-lógico, ou-lógico, não-lógico, entre outras). Esse problema, assim como os demais problemas de aprendizado de máquina supervisionado, possui uma interpretação geométrica. No caso do Perceptron, essa interpretação é útil para mostrar a limitação relacionada ao problema do ou-exclusivo, conforme apresentado na Figura 2.2 para uma versão baseada em duas entradas $x_{1}$ e $x_{2}$, de três funções lógicas (e-lógico, ou-lógico e ou-exclusivo). Os quatro padrões possíveis $(0,0),(0,1)$, $(1,0)$ e $(1,1)$, no qual 1 é associado a verdadeiro e 0 a falso) são mostrados juntamente com suas saídas esperadas. Nessa interpretação, padrões de entrada tratados pelo modelo são separados a partir de um hiperplano (ou reta, no caso do exemplo) de modo que a ativação ou não de um padrão é definida de acordo com sua posição em relação ao hiperplano de referência. No caso do ou-exclusivo, são necessários pelo menos dois hiperplanos para separar os padrões corretamente, o que não é possível no Perceptron clássico. 


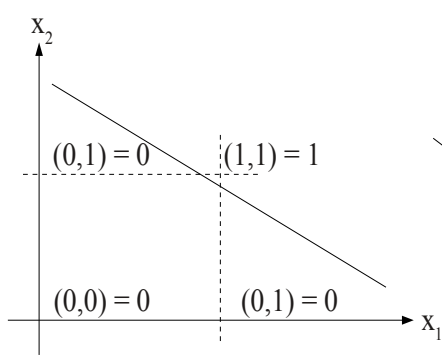

(b) e-lógico

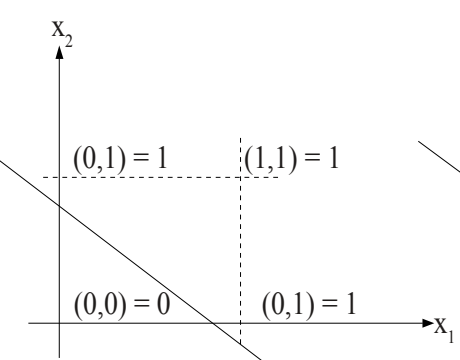

(c) ou-lógico

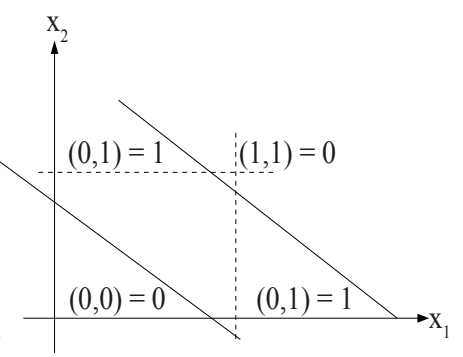

(d) ou-exclusivo

Figura 2.2: Interpretação geométrica de problemas lógicos para duas entradas.

Apesar das limitações, modelos Perceptron não apresentam problemas de convergência devido a mínimos locais, e, dentro do escopo deste trabalho, favorecem análises interpretativas do conhecimento obtido pelo modelo Molin, razão pela qual foram escolhidos em detrimento às redes MLP.

\subsubsection{Redes MLP}

Após o trabalho de Minsky e Papert (1969 apud ROJAS, 1996), houve pouco interesse em redes neurais artificiais Perceptron, até que, em 1986, Rumelhart et al. (1986) propuseram o modelo MLP (Multi-layer Perceptron ${ }^{\mathrm{g}}$ - Perceptron Multi-Camada), uma modificação do modelo Perceptron com saídas não lineares, continuas e diferenciais variando entre 0 e 1 (na representação utilizada neste trabalho). O modelo é baseado no uso de camadas escondidas, e tem a capacidade de solucionar o problema do ou-exclusivo utilizando o algoritmo de treinamento Backpropagation. A Figura 2.3 apresenta um exemplo da topologia de uma rede MLP completamente conectada com uma camada escondida. Seguindo-se a convenção em uso neste trabalho, entradas são mapeadas para neurônios de entrada que não passam pela ativação convencional, o que resulta em três camadas: a camada de entrada $I$, a camada escondida $H$ e a camada de saída $O$.

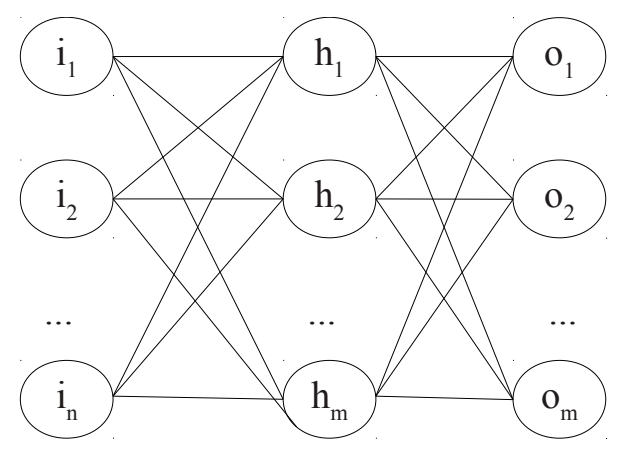

Figura 2.3: Exemplo de topologia MLP completamente conectada, com uma camada escondida. 
A Figura 2.4 apresenta uma topologia de Rede Neural parcialmente conectada, na qual a recorrência é utilizada. Dentro do contexto de aprendizado supervisionado, o uso de recorrência permite utilizar a saída de padrões já classificados para classificar padrões subsequentes (o que é útil, por exemplo, em séries temporais) ou ainda para reclassificar o mesmo padrão com informações adicionais fornecidas pelos neurônios de saída. Nota-se que essa variação demanda versões adaptadas do algoritmo Backpropagation.

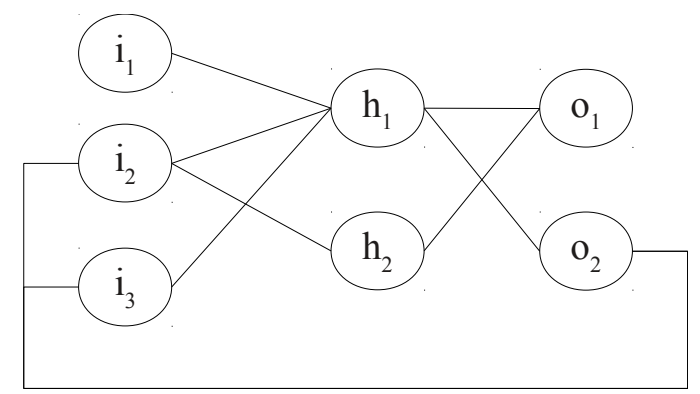

Figura 2.4: Exemplo de topologia MLP parcialmente conectada, com recorrência.

Para redes MLP, a função de ativação deve ser diferenciável e continua. A equação (2.4) apresenta a função sigmoide logística, uma das funções comumente utilizadas em redes MLP, em que $v$ é calculado com base na Equação (2.1) apresentada previamente na Seção 2.1.1). Observa-se que, a equação é aplicada a cada neurônio da camada escondida e da camada de saída (nessa ordem) e que os valores de entrada se referem sempre a saída dos neurônios da camada imediatamente anterior ao neurônio em ativação.

$$
y=\frac{1}{1+e^{-v}}
$$

O ajuste de pesos para redes MLP é derivado da função sigmoide logística pela aplicação da Regra Delta (WIDROW \& HOFF, 1960), o que resulta em uma alteração da equação de ajustes de peso Perceptron apresentada na Seção 2.1.1 no passo (2.3b) resultando em (2.5).

$$
\Delta w_{i, t+1}=\eta x_{i, t} y_{t}\left(1-y_{t}\right)\left(d_{t}-y_{t}\right)
$$

\subsection{Análises da língua}

\subsubsection{Análise morfossintática}

A análise morfossintática, também conhecida como PoS analysis e tagging, é o processo de identificar as categorias gramaticais dos lexemas presentes em uma frase. Esta seção foca nos modelos mais influentes na tarefa de análise morfossintática. A maior parte dos 
trabalhos tratam a Língua Inglesa, embora as metodologias aplicadas sejam independente de língua e possam ser adaptadas a outros idiomas. Os modelos tendem a apresentar a acurácia entre 96 e 97\%, se baseando em informações extraídas da vizinhança do lexema em análise. Nesse caso, os modelos podem se basear apenas em informações sobre lexemas e correlatos ${ }^{\mathrm{g}}$ (números, sinais de pontuação, entre outros), seus antecessores, ou combinar informações sobre lexemas e correlatos sucessores e antecessores.

As abordagens discutidas nesta seção se baseiam em estatística ou aprendizado de máquina, com atributos gerados a partir dos próprios lexemas e de sua vizinhança, o que inclui classes gramaticais (da vizinhança, previamente identificadas), sufixos flexionais, informações sobre capitalização (para facilitar o reconhecimento de nomes próprios), além de outras, por exemplo, troncos $^{\mathrm{g}}$ (stems) de lexemas. Como lexemas são utilizados na integra em diferentes abordagens, o aprendizado de máquina tende a ser feito a partir dos muitos atributos gerados.

Córpus podem servir de avaliação (benchmark) para a tarefa de anotação morfossintática, a exemplo do Penn TreeBank (MARCUS \& MARCINKIEWICZ, 1993), criado para a Língua Inglesa atualmente com mais de 7 milhões de lexemas anotados morfossintaticamente (além de anotação para outras tarefas, porém em conjuntos menores), ou do Mac-Morpho (ALUÍSIO et al., 2003a, 2003b, 2004), disponibilizado para a Língua Portuguesa durante o projeto Lácio-Web um córpus de 1,2 milhão de palavras, e usado no treinamento de três analisadores morfossintáticos disponíveis para o Português: o TBL (BRILL, 1995), o Treetagger (SCHMID, 1994a; 1995) e o Mxpost (RATNAPARKHI, 1996).

Brill (1995) aplicou aprendizado transformacional dirigido a erros (TransformationBased Error-Driven Learning) na tarefa de análise morfossintática. A técnica consiste em aprender um conjunto inicial de regras sobre morfossintaxe a partir de córpus anotados, aplicar as regras aprendidas no córpus, e refinar as regras com base nos erros cometidos. Assim, o processo gera tanto regras gerais, quanto regras específicas, de forma que as últimas possam corrigir erros de anotação cometidas pelas primeiras. O modelo pode se basear tanto nos lexemas vizinhos (granularidade mais fina) quanto nas etiquetas morfossintáticas dos lexemas vizinhos (granularidade mais grossa). Lexemas vistos em treinamento possuem regras diretamente relacionadas a eles, além informações fornecidas pela vizinhança. A anotação de lexemas não vistos em treinamento basicamente depende das informações fornecidas pela vizinhança. O modelo avaliado na Língua Inglesa chegou a acurácia de 96,6\% 
nos testes realizados pelos autores com 1,1 milhões de lexemas do córpus Penn TreeBank.

Schmid (1994a; 1995) aplica modelos de Markov (BAUM \& PETRIE, 1966) com uma versão modificada de árvores de decisão ID3 (QUINLAN, 1983) na tarefa de anotação morfossintática. O trabalho difere de abordagens semelhantes baseadas em modelos ocultos de Markov, nas quais etiquetas morfossintáticas são vistas como eventos ocultos e lexemas são considerados observações. Em outras palavras, com o uso de modelos ocultos, a sequência de lexemas é considerada como informação dada, enquanto que, na abordagem de Schmid, a probabilidade de ocorrência de sequência dos lexemas em análise é incluída no cálculo. O trabalho de Schmid se baseia modelos de Markov de segunda ordem $(k=2)$, aplicando suposições adicionais para simplificar o cálculo, segundo as quais a probabilidade de ocorrência do lexema em análise depende apenas da etiqueta morfossintática correspondente, e a probabilidade da etiqueta morfossintática em análise depende apenas das etiquetas anteriores, mas não dos lexemas anteriores. O autor identificou que o cálculo pode ser comprometido devido ao uso de trigramas (a etiqueta em análise e as duas etiquetas anteriores para $\mathrm{k}=2$ ) raros. Para estimar valores de trigramas raros, são utilizadas árvores de decisão. A acurácia do modelo chega a 96,3\% nos testes realizados, também com base no Peen Treebank, para 1 milhão de lexemas. Uma característica do modelo destacada pelo autor é fato dele possuir bom desempenho mesmo em córpus de tamanho reduzido.

Modelos de Markov, no domínio da análise morfossintática, buscam a melhor sequência global de etiquetas gramaticais para uma dada frase, ao invés da análise local baseada em lexemas e informações adicionais de contexto. Uma vez que seja possível calcular a probabilidade de uma dada cadeia, o problema passa a ser encontrar a cadeia ótima com probabilidade máxima entre as cadeias possíveis. O tempo de processamento do problema é exponencial em função do tamanho da cadeia e dos valores assumidos pelas etiquetas, mas pode ser convertido para tempo polinomial graças ao algoritmo baseado em programação dinâmica proposto por Viterbi (1967) e descoberto independentemente por diferentes autores (JURAFSKY \& MARTINS, 2008).

Ratnaparkhi (1996) aplica técnicas de entropia máxima (NIGAM et al., 1999) para a tarefa de anotação morfossintática, chegando à acurácia de 96,6\% segundo testes do autor, treinado sobre o córpus Peen TreeBank com textos do Wall Street Journal. O anotador morfossintático desenvolvido extrai atributos léxicos e morfológicos (sufixos) sobre os lexemas anteriores e posteriores ao lexema em análise, além das classes gramaticais para os 
lexemas anteriores já classificados.

Modelos estatísticos baseados em entropia máxima detectam a distribuição condicional de probabilidades mais uniforme dado um conjunto de dados sujeito a um conjunto de restrições. Isso equivale a assumir o tratamento mais uniforme possível para dados desconhecidos. Essa abordagem possui uma vantagem em relação a modelos bayesianos, já que a primeira não assume independência entre atributos como os segundos, tornando-se mais robusta quando existem atributos fortemente dependentes (NIGAM et al., 1999).

Mccallum et al. (2000) propõem o uso conjunto de modelos ocultos de Markov com a abordagem de máxima entropia na tarefa de análise morfossintática. O processo consiste em calcular localmente a probabilidade de cada lexema estar relacionado a cada categoria gramatical com base em máxima entropia e então, de forma similar às abordagens baseadas em modelos ocultos de Markov, buscar a sequência de classificações que otimiza a frase globalmente. Assim, uma classe gramatical localmente ótima para um dado lexema pode ser descartada caso comprometa a análise dos lexemas subsequentes, sendo substituída por outra classe gramatical. O processo combina a liberdade na escolha nos atributos provida pela abordagem de máxima entropia com a análise global dos modelos ocultos de Markov.

A técnica de campos aleatórios condicionais (conditional random fields) (LAFFERTY et al., 2001) é uma abordagem proposta para tratar uma limitação presente em modelos de Markov: estados de origem com poucos estados de destino tendem a ser privilegiados na análise de sequências. Campos aleatórios condicionais buscam ajustar as transições de forma a penalizar estados com poucos destinos. Lafferty et al. (2001) aplicam a técnica na análise morfossintática e discutem cenários nos quais a abordagem se sai melhor que modelos ocultos de Markov clássicos e modelos ocultos de Markov combinados com técnicas de máxima entropia.

Para a Língua Portuguesa, Aires (2000) compara os analisadores morfossintáticos disponibilizados pelo NILC, atingindo 97\% de acurácia em uma abordagem que combina a saída dos analisadores. Detalhes sobre trabalhos mais recentes sobre análise morfossintática são apresentados por Martinez (2011).

\subsubsection{Análise sintática}

Sintaxe é um termo originado do Grego que significa arranjo ou disposição (JURAFSKY \& MARTINS, 2008). Assim, a análise sintática é o estudo da disposição dos lexemas em uma frase. $\mathrm{O}$ estudo pode ser dividido em funções sintáticas (por exemplo, sujeito 
e predicado), constituintes (por exemplo, sintagmas nominais e verbais) e dependências sintáticas.

A Figura 2.5 apresenta uma árvore sintática de constituintes para a frase "O gato perseguiu o rato". Também são ilustradas as funções sintáticas nos nós internos da árvore.

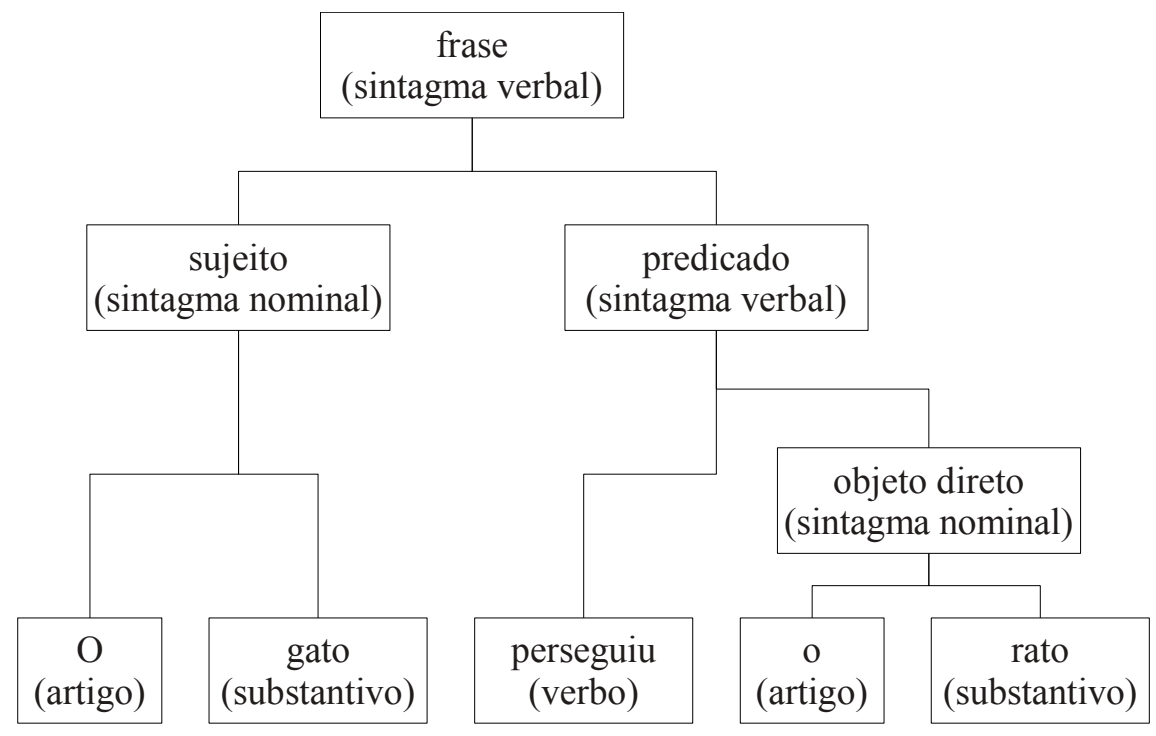

Figura 2.5: Árvore de constituintes acrescida de funções sintáticas.

Observa-se que existe alguma variação nas representações. Por exemplo, o analisador sintático Palavras identifica o objeto direto como filho da frase, e não como filho do predicado, como mostrado na Figura 2.6, que traz o resultado da análise do Palavras, via a ferramenta disponibilizada no site VISL $^{7}$ (Visual Interactive Syntax Learning - Aprendizado de Sintaxe Interativo e Visual). Os nós apresentados na Figura 2.6 seguem a convenção do analisador sintático, incluindo funções sintáticas (por exemplo, "UTT”, “S”, "P”, “Od"), sintagmas (por exemplo "g" e "v"), classes gramaticais ("pron", "h" e outras) e os lexemas propriamente ditos (as folhas).

7 http://beta.visl.sdu.dk/visl/pt/parsing/automatic/trees.php 


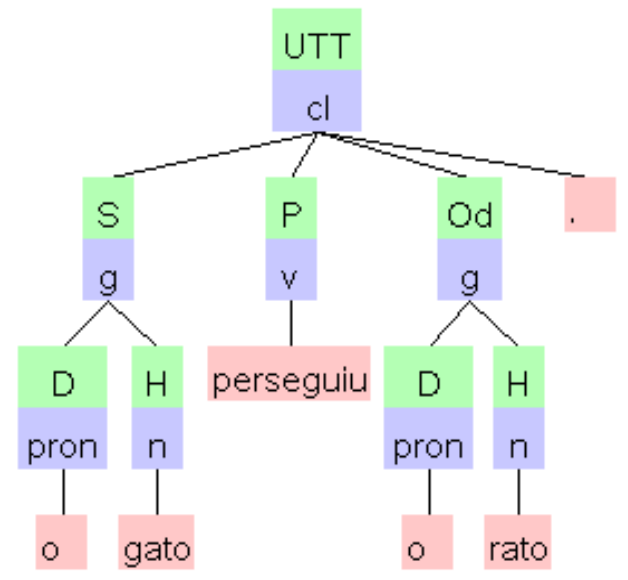

Figura 2.6: Árvore de constituintes do Palavras, seguindo o conjunto de etiquetas do analisador sintático.

A Figura 2.7 apresenta uma árvore de dependências ${ }^{8}$ sintáticas para a mesma frase. A árvore é composta por núcleos (raiz e nós internos) e dependentes (nós internos e folhas), sendo que nós internos exercem os dois papéis. Por exemplo, "perseguiu" é o núcleo de "gato", enquanto o segundo é um dos dois dependentes do primeiro. A Figura 2.7 não apresenta as funções sintáticas, mas a análise de funções sintáticas pode ser feita juntamente com a análise de dependências, geralmente associadas as arestas da árvore. Por exemplo, a aresta que interliga o nó "gato" ao nó "perseguiu" carrega a função sintática de sujeito nessa representação. A árvore é mostrada na representação infixa, na qual um percurso em ordem (também chamado de percurso in-ordem) recupera a frase original com a ordenação correta dos lexemas.

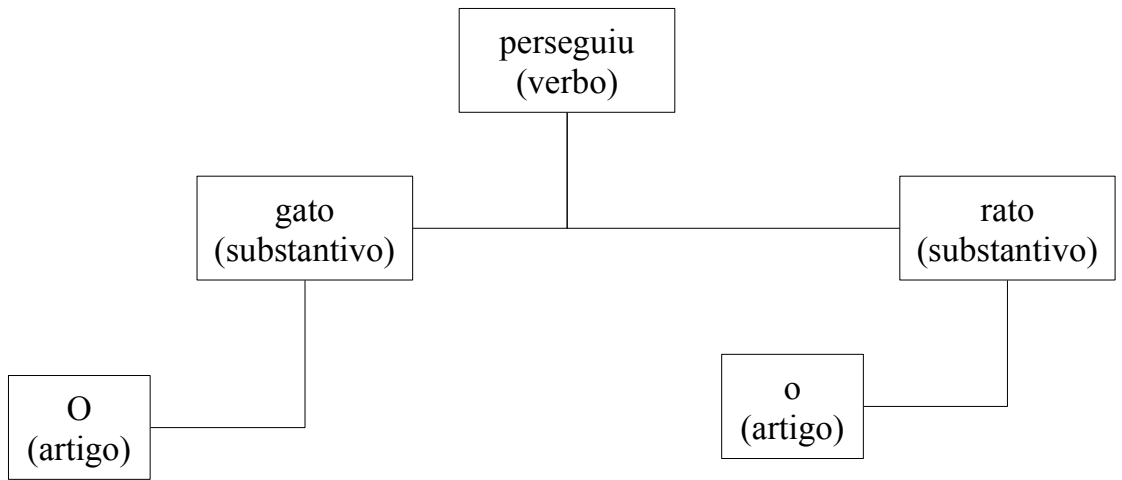

Figura 2.7: Árvore de dependências projetiva.

Observa-se que, na Língua Portuguesa, existem casos em que a representação infixa não permite que um percurso em ordem da árvore resulte na frase original. A Figura 2.8 ilustra o

8 Trabalhos da literatura também podem usar o termo "grafo de dependências" de acordo como a análise de dependências é realizada. 
exemplo para a frase "este é o dia mais quente de Janeiro", no qual "quente" possui um dependente à sua esquerda ("mais") que, por sua vez, possui um dependente à direita de “quente" ("de"). Ao percorrer a árvore em ordem o sintagma preposicional "de Janeiro" seria visitado antes do lexema "quente". Técnicas para análise sintática de dependências podem ser projetivas (projective dependencies) ou não projetivas (non-projective dependencies). As últimas são capazes de processar os casos das Figuras 2.7 e 2.8 sem alterações na estrutura de dependências. Já as primeiras são capazes de analisar apenas frases semelhantes à da Figura 2.7. Para o processamento da frase 2.8 , é necessário alterar alguns núcleos e dependentes de modo a permitir que uma busca em ordem recupere a frase original, o que pode ser feito transformando "de" em dependência de "quente".

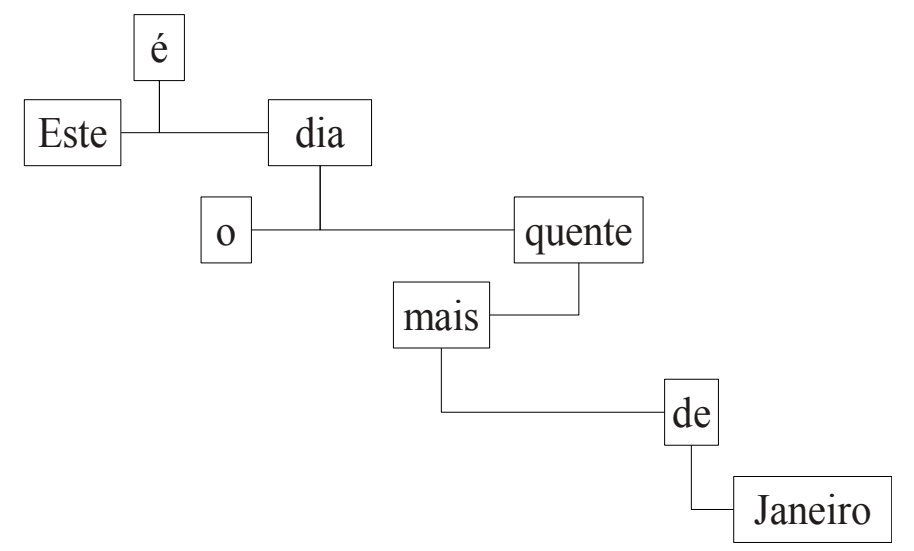

Figura 2.8: Árvore de dependências não projetiva.

Em árvores de constituintes, os lexemas e correlatos são folhas, e nós internos são as constituintes sintáticas. Já em árvores de dependências, todos os nós são lexemas e correlatos. As representações são intercambiáveis, e, de fato, o analisador sintático Palavras gera sua árvore de constituintes com base na árvore de dependências previamente gerada. Embora as representações sejam equivalentes, a representação escolhida afeta a estrutura dos algoritmos de análise.

Abordagens para realizar análise sintática automaticamente podem ser divididas em dois grupos: parcial ou total. A análise parcial é principalmente relacionada a constituintes sintáticas, geralmente denotada seguindo a representação IOB, ou uma de suas variantes. Na notação, B (begin) indica o começo de uma constituinte, I (inside) um lexema contido na constituinte e $\mathrm{O}$ (outside) um elemento exterior a qualquer constituinte, conforme mostrado no Exemplo 3.1. As siglas SN e SV referem-se a sintagmas nominais e verbais, respectivamente. $\mathrm{Na}$ análise, constituintes e seus limites são definidos parcialmente: apenas o início das constituintes mais baixas na árvore de constituintes é explicito. O Exemplo 3.1 
indica as três constituintes da frase: sintagma nominal, sintagma verbal e sintagma nominal, mas não permite identificar que o segundo e terceiros sintagmas fazem parte de um sintagma verbal maior, que, por sua vez, é parte do outro sintagma verbal maior que agrega o primeiro sintagma nominal.

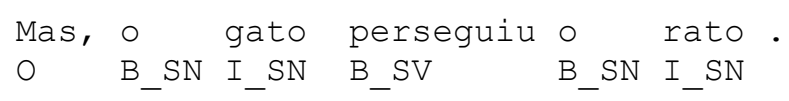

Exemplo 2.1: A notação IOB para análise sintática parcial.

A análise sintática parcial baseada na notação IOB é muito semelhante à análise morfossintática, de forma que algoritmos e abordagens em uso na segunda tarefa (como classificadores de sequências) podem ser utilizados diretamente na primeira. Observa-se que técnicas que não geram a árvore sintática completa, mas incluem informações adicionais (por exemplo, constituintes mais profundas para segmentar orações dentro da frase) também são consideradas análises parciais.

A análise sintática total busca recuperar a árvore sintática de dependências ou de constituintes de uma dada frase. Gramáticas gerativas, um modelo conceitual criado para explicar que frases podem ser realizadas pelos falantes de uma língua, assim como seu processo de produção, podem ser aplicadas ao processo de análise sintática total. O Exemplo 2.2 apresenta as produções de uma gramática didática (toy grammar), capaz de gerar a frase “o gato perseguiu o rato" (entre outras), bem como sua árvore de constituintes associada. Formalmente, uma gramática é uma quádrupla ordenada composta por um conjunto de símbolos não terminais (no exemplo, $\mathrm{S}$ - frase; SN - sintagma nominal; SV - sintagma verbal; V - verbo), um conjunto com o alfabeto ou símbolos terminais da gramática (no caso, os lexemas representados em minúsculas), um conjunto de produções e um símbolo inicial ("S" no exemplo). Produções permitem identificar como não terminais (à direita nas produções) convertem-se em outros não terminais e em terminais (à esquerda na produção). A representação dada no Exemplo 2.2 permite identificar os quatros componentes da gramática de acordo com as convenções em uso (por exemplo, "S" para produção inicial e maiúsculas para terminais). O símbolo “|” define alternância, que no exemplo 2.2 significa que a produção SN gerará uma cadeia contendo um dos dois possíveis terminais ("gato" e "rato").

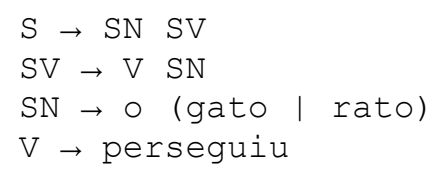

Exemplo 2.2: Produções de uma gramática gerativa didática. 
Construções utilizadas nas gramáticas para descrever línguas tendem a ser livres de contexto, ou seja, uma produção não depende das produções vizinhas ou dos terminais vizinhos para ser aplicada. Contudo, Jurafsky e Martins (2008) apontam trabalhos que apresentam casos sensíveis ao contexto para o Alemão ${ }^{9}$.

Gramáticas gerativas e suas variações podem ser empregadas na construção de analisadores sintáticos de constituintes ou de dependências sintáticas, por meio de análises ascendentes (bottom-up), isto é, das folhas da árvore até a raiz, ou descendentes (top-down) da raiz até a folha. Além disso, tais gramáticas podem ser estendidas com o acréscimo de probabilidades em suas produções. Assim, quando mais de uma árvore é admissível, a desambiguação pode ser feita com base na árvore mais provável. Jurafsky e Martins (2008) discutem as análises ascendentes e descendentes detalhadamente, indicando vantagens de desvantagens de cada uma, suas estratégias de processamento, e algoritmos baseados em programação dinâmica, semelhantes ao algoritmo de Viterbi (1967), criados para reduzir substancialmente o tempo de processamento gasto na análise das possíveis árvores.

A ambiguidade, ubíqua em todos os níveis de análise da língua, é também um problema durante a análise sintática, nesse caso denominada de ambiguidade estrutural. Diversas frases aceitam múltiplas árvores sintáticas. Um exemplo pode ser visto em "muitos jovens e idosos foram afetados pela doença", pois "muitos" pode referir-se apenas a "jovens" ou a "jovens e idosos". Uma variação de um exemplo comumente usado para ilustrar ambiguidade estrutural é a frase "Maria viu João com o binóculo subindo a montanha", na qual não fica totalmente claro qual dos dois estava subindo a montanha e qual estava segurando o binóculo. Embora, por senso comum, um leitor humano possa optar por uma das quatro variações possíveis, todas elas podem ocorrer naturalmente na língua, sendo necessário contexto adicional para uma desambiguação definitiva. Um caso semelhante para o Inglês é "I know you like your brother", que pode ser traduzido como "eu sei que você gosta de seu irmão" ou "eu conheço você como seu irmão". Técnicas automáticas de análise sintática da língua não atingem tal nível de sofisticação no estado da arte atual, geralmente sendo aceitável como correta qualquer uma das análises possíveis.

A frase de exemplo anterior ilustra também o conceito de dependências de longa

9 O modelo conceitual de gramáticas livres de contexto ou sensíveis ao contexto é associado a máquinas teóricas com memória infinita. Contudo, um projetista de gramática pode reduzir o nível de uma gramática (até mesmo para o nível regular) se for levado em conta que um leitor humano possui uma memória de trabalho relativamente limitada, e se um dado limite aceitável de memória for fixado. Nesse caso, o processo para redução de níveis deve ser feito cuidadosamente de modo a evitar uma explosão nos números de produções durante a conversão entre os tipos. 
distância, isto é, o posicionamento não canônico de nós da árvore, isto é, nós que aparecem em posições não usuais. Na situação em que Maria porta os binóculos ("binóculo" é normalmente associado ao verbo "ver") e João sobe a montanha (assumindo que Maria não apenas viu João com os binóculos, mas o viu realizando uma ação). Nesse caso, além de "João" exercer o papel objeto direto de "viu”, também é utilizado como sujeito de "subir", sendo separado de seu predicado por "com os binóculos"10.

\subsubsection{Analisadores sintáticos}

Como visto na Seção 2.2.2, analisadores sintáticos podem ser divididos em parciais como o usado por Siddharthan (2006) ou completos, por exemplo, o proposto por Collins (2003). Podem ainda ser baseados em regras manuais, como o desenvolvido por Bick (2000) ou em conhecimento adquirido automaticamente de córpus, como o de Collins. Essa dicotomia às vezes aparece na literatura como analisadores simbólicos (DOUGHERTY, 1994), normalmente baseados em regras manuais (BICK, 2000), ou estatísticos (COLLINS, 2003), treinados a partir de treebanks (córpus anotados sintaticamente).

A análise de constituintes é geralmente avaliada com as medidas Parseval (BLACK et al., 1991), que consistem na precisão (número de constituintes corretamente identificadas em relação ao número de constituintes identificadas), na cobertura (número de constituintes corretamente identificadas em relação ao número de constituintes corretas na frase) e em uma terceira medida crossing brackets que leva em conta as constituintes identificadas incorretamente cujas bordas cruzam as constituintes corretas.

A análise de dependências é geralmente avaliada com as medidas interligação rotulada (labeled attachment score) e interligação não rotulada (unlabeled attachment score). Na primeira, as arestas da árvore de dependências, suas direcionalidades e seus rótulos sintáticos são analisados. Na segunda, apenas as arestas e direcionalidades são levadas em conta. Em ambas, a pontuação não é considerada. As medidas foram utilizadas nas edições de 2006, 2008 e 2009 da conferência CoNLL (Conference on Computational Natural Language Learning) (STEVENSON \& CARRERAS, 2009), cujo objetivo é o uso de aprendizado de máquina para diferentes tarefas do PLN, e, nas edições indicadas, focou-se em avaliações conjuntas para análise de dependências independente de língua e análise de dependências integrada com análise semântica, incluindo modelos testados em Língua Portuguesa em sua edição de 2006 (MÀRQUEZ \& KLEIN, 2006).

10 Embora existam interpretações na qual o sujeito de "subir" (“João”) é epilítico, ou seja, foi omitido. 
Siddharthan (2006) aplica a análise sintática parcial para detectar limites de orações na Língua Inglesa. A técnica empregada consiste no uso de redes sem camadas escondidas do tipo Winnow (CARLSON et al., 1999), e, juntamente com algoritmos adicionais empregados no processo, serve de base para a simplificação sintática de textos da Língua Inglesa. Os limites das orações são detectados com acurácia de $91,1 \%$ no córpus de avaliação criado pelo autor a partir de frases do Penn TreeBank.

Bick (2000) aplica gramáticas de restrições (constraint grammars) no analisador sintático Palavras, criado para analisar a Língua Portuguesa, com acurácia de 97\% para anotação de dependências e 99\% para anotação morfossintática. Gramática de restrições é um formalismo gramatical combinado com regras para anotação da língua em diferentes níveis. $\mathrm{O}$ Exemplo 2.3, apresenta o formalismo, sendo dividido em duas partes: (a) as definições dos lexemas com suas possíveis desambiguações e (b) as regras de desambiguação. O lexema para exemplificar o formalismo é o altamente ambíguo "como", no contexto da frase de exemplo é "nunca como peixe". A regra exemplificada permite desambiguar "como" como um verbo finito transitivo.

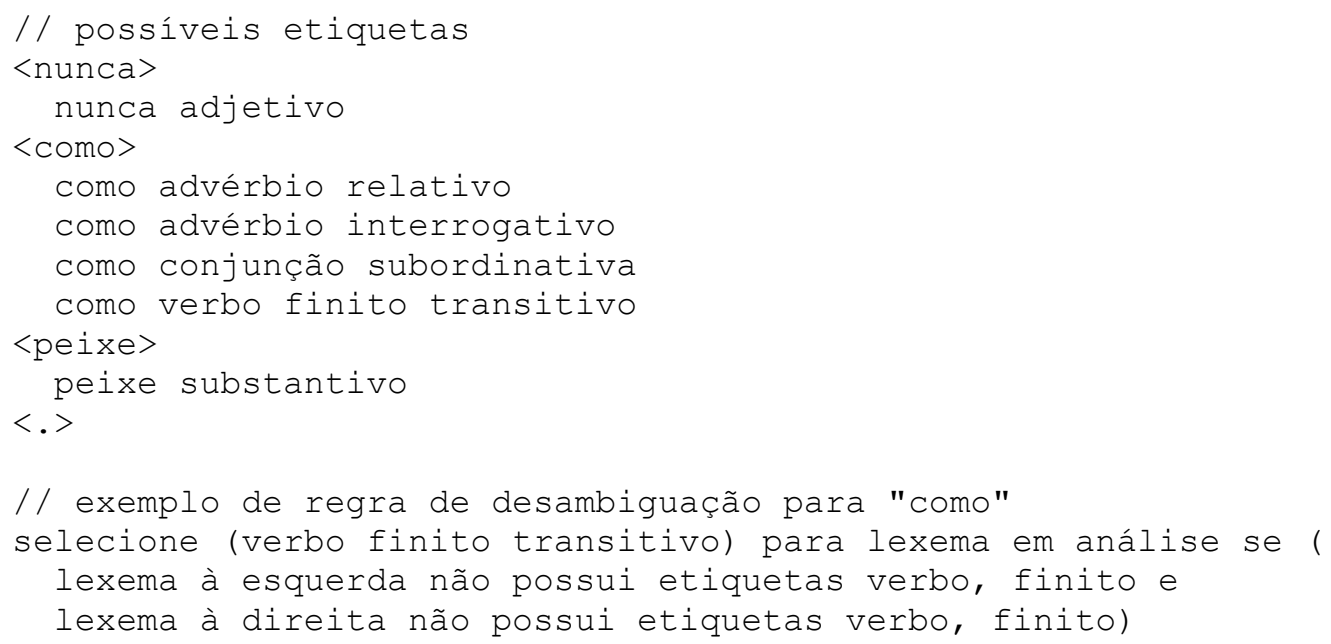

Exemplo 2.3: Desambiguação de “como" via gramáticas de restrições (BICK, 2000).

Gramáticas de restrições podem ser aplicadas a diferentes níveis da língua, sendo facilmente adaptadas, por exemplo, para analisar funções sintáticas. No analisador Palavras é aplicada para o nível morfológico (incluindo morfossintaxe), sintático, e semântico (categorização semântica). Collins (2003) estende gramáticas gerativas para o conceito de gramáticas lexicalizadas, como mostrado no Exemplo 2.4 para a oração "A IBM comprou a Lotus", adaptado para a Língua Portuguesa a partir do trabalho do autor para o Inglês, porém sem subcategorização gramatical para simplificar o exemplo (que indicaria verbos transitivos 
diretos, artigos definidos, substantivos próprios ou comuns, entre outros). No exemplo, a produção TOP é a produção inicial, sendo a árvore gerada de forma descendente. Gramáticas lexicalizadas incluem lexemas nos nomes de suas produções, além de outras informações, como etiquetas morfossintáticas, funções sintáticas e constituintes sintáticas. Isso provoca um número explosivo de produções da gramática, de modo que o autor propõe técnicas para lidar com lexemas raros e com a esparsidade nas produções.

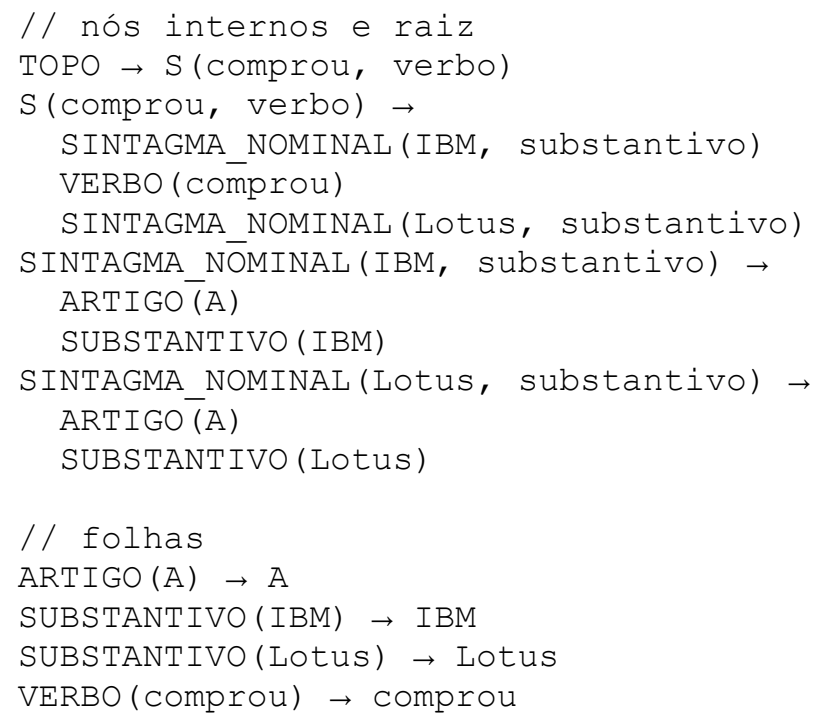

Exemplo 2.4: Gramática lexicalizada.

As produções também são associadas a probabilidades, de modo que é possível eleger a árvore sintática mais provável quando múltiplas são aceitas. A vantagem das gramáticas lexicalizadas consiste no fato da relação entre os lexemas ser levada em conta durante as estimativas de probabilidades sobre as possíveis árvores sintáticas. A importância dos lexemas na análise pode ser ilustrada pelo famoso exemplo definido por Chomky (1957 apud JURAFSKY \& MARTINS 2008), em tradução livre "ideias verdes incolores dormem furiosamente". O fragmento de texto apresentado é sintaticamente correto, contudo não faz sentido, isto é, é semanticamente inválido, razão pela qual ele não ocorra espontaneamente em línguas naturais. Do ponto de vista de uma gramática lexicalizada, a probabilidade de "dormem" derivar "furiosamente" deve ser bem pequena, assim como a probabilidade de "ideia" derivar "verde"

As produções, suas probabilidades e os demais itens da gramática são obtidos a partir de um treinamento realizado no Penn TreeBank. Collins (2003) faz uma análise sistemática da

11 Recentemente, o sintagma nominal "ideias verdes" tem aparecido com frequência e pode ser interpretado como "ideias ecologicamente corretas". Contudo, observa-se que esse uso de "verdes", seja no Português ou no Inglês não existia quando Chomky criou seu exemplo. 
metodologia proposta, avaliada em três modelos diferentes, com níveis de sofísticação crescente nos atributos utilizados em cada modelo. $\mathrm{O}$ autor avalia os modelos tanto na análise de constituintes quanto na análise de dependências. Para constituintes, o modelo tem precisão e cobertura globais de até 88,0 e $88,3 \%$, respectivamente. Para dependências, esses números chegam a 91,0\% na medida interligação não rotulada. É interessante notar que um atributo utilizado no modelo estatístico mede as adjacências entre as constituintes na árvore sintática. Sem o atributo, precisão e cobertura caem para 76,5 e 75,0\%, respectivamente.

A Língua Portuguesa tradicionalmente possui menos recursos para tarefas de PLN quando comparada ao Inglês. No âmbito da análise sintática, uma série de esforços vem sendo realizados para mudar esse quadro. Wing e Baldridge (2006) geram uma gramática lexicalizada a partir do córpus Floresta Sintá(c)tica (AFONSO et al., 2002), chegando a $80,6 \%$ de acurácia na análise de dependências. Silva et al. (2010) apresentam um comparativo entre três modelos de análise sintática diferentes originalmente disponíveis para a Língua Inglesa, porém treinando-os em dois TreeBanks do Português e avaliando-os na análise de constituintes. O melhor modelo apontado pelos autores atinge a medida- $\mathrm{f}^{12}$ de $89,33 \%$, sendo baseado em uma gramática $X$-bar, que busca identificar constituintes básicas ou canônicas utilizadas para construir as constituintes das diferentes línguas.

\subsubsection{Trabalhos relacionados ao modelo Molin}

Esta seção destina-se a comparar trabalhos relacionados às inovações apresentadas neste trabalho, relacionadas ao modelo Molin. Os trabalhos discutidos aqui referem-se a: (a) representações otimizadas para grandes conjuntos de atributos; (b) redes neurais recorrentes para análises não integrativas da língua; e (c) análises integrativas da língua, com diferentes graus de bidirecionalidade.

Em relação à representação otimizada (discutida na Seção 3.2.3), o trabalho mais relacionado ao modelo Molin, é a arquitetura SnoW (Sparse Network of Winnows - Rede Esparsa de Winnows), proposta por Carlson et al., (1999). A arquitetura tem como objetivo prover aprendizado de máquina (incluindo redes neurais artificiais Perceptron) para tarefas baseadas em grandes conjuntos de atributos, de modo que todos os atributos não precisam ser conhecidos a priori no início do treinamento, o que é importante em tarefas de PLN, já que cada lexema de uma língua pode derivar um atributo correlacionado. $\mathrm{Na}$ representação

12 É comum a terminologia medida-fl em diversos trabalhos, embora este trabalho use simplesmente medida-f, já que nos trabalhos analisados aplicam a média harmônica não ponderada na precisão e na cobertura. 
utilizada por Carlson et al., cada atributo é mapeado para um índice, e um padrão de aprendizado é composto pelos índices dos atributos não nulos.

Em relação a redes neurais recorrentes para análises da Língua, Schmid (1994b) aplica redes neurais artificiais Perceptron para análise morfossintática. O número de atributos de entrada é o produto $c j$, em que $c$ indica o número de classes gramaticais e $j$ o tamanho da janela de análise, baseada no lexema em análise e sua vizinhança. Dessa forma, existem $c$ atributos de entrada para o lexema de entrada, cada um indicando a probabilidade do lexema de entrada estar associado a uma determinada classe. Essas probabilidades são levantadas de córpus de treinamento com base em unigramas. O mesmo vale para atributos de entrada relacionados às classes dos lexemas e correlatos posteriores na janela. Para lexemas e correlatos anteriores, a recorrência é aplicada, e seus atributos são preenchidos de acordo com as predições da rede. A saída da rede é sua predição do lexema em análise pertencer a cada uma das $c$ classes gramaticais.

Socher et al. (2010) convertem lexemas e correlatos em vetores numéricos de 100 posições, utilizados em uma rede neural com camadas escondidas para realizar análise de constituintes. O conjunto de padrões iniciais corresponde às folhas da árvore de constituintes. $\mathrm{Na}$ primeira iteração, as folhas são comparadas duas a duas, de modo que apenas folhas vizinhas são analisadas. O resultado é uma lista de possíveis constituintes, também denotadas em vetores numéricos de tamanho 100, acrescidas da confiança da rede nas constituintes detectadas. As constituintes selecionadas são inseridas na análise, enquanto as folhas que as compõem são removidas, e o processo é repetido, até que não seja possível gerar novas constituintes. Nessa estratégia, o treinamento consiste em ajustar os pesos da rede neural para prover as estimativas da constituinte estar correta, bem como, gerar a representação vetorial dos nós da árvore.

O trabalho de Collins (2002), embora não seja um caso clássico de recorrência neural, se assemelha a abordagens recorrentes, ao permitir uma análise global entre os possíveis conjuntos de etiquetas para uma frase durante a tarefa de análise morfossintática. $\mathrm{O}$ autor aplica uma abordagem similar a de modelos ocultos de Markov para análise sintática, combinada com o algoritmo de Viterbi para reduzir o tempo de análise. A diferença é que o algoritmo de Viterbi é utilizado para percorrer pontuações de uma rede Perceptron (análise discriminativa) em vez de probabilidades, indicando vantagens no uso de modelos discriminativos em vez de modelos gerativos. Pesos da rede são ajustados de acordo com a 
sequência encontrada pelo algoritmo de Viterbi baseado em pontuações, chegando a acurácia de $97,07 \%$ na análise morfossintática. O modelo dos autores supera o desempenho do MST Parser (MCDONALD et al., 2006), que possui interligação não rotulada 91,4\% para a Língua Portuguesa, e do MALT Parser (NIVRE et al., 2006), que possui 91,22\% de interligação não rotulada.

Na Língua Portuguesa, Fernandes e Milidiú (2012) reportam a interligação não rotulada de 92,66\% na análise não rotulada (sem funções sintática) de dependências projetivas com base em Perceptron. Até o momento, esse é o melhor resultado baseado em aprendizado de máquina para análise de dependências em Língua Portuguesa. Os atributos utilizados são principalmente os lexemas e correlatos na vizinhança do lexema em análise, e as classes gramáticas do lexema em análise e de sua vizinhança, detectadas em um processo ad hoc. Em uma abordagem guiada por entropia, os autores buscam levantar o melhor conjunto de atributos para a tarefa de classificação. Classificadores gerados devem indicar se o conjunto de atributos apresentados caracteriza uma relação de dependência ou não. Sucessivas consultas ao classificador baseado em Perceptron permitem recuperar a árvore de dependências completa.

O projeto Senna (Collobert et al., 2011) aplica análises integrativas da língua, na qual modelos integrativos podem ser avaliados especificamente para uma dada tarefa, um ainda, de forma ideal, globalmente para várias tarefas, de modo que modelos melhores se sobressaiam em diferentes tarefas. As tarefas avaliadas inicialmente por Collobert et al. (2011) são análise morfossintática, análise sintática parcial, reconhecimento de entidades nomeadas, e anotação de papéis semânticos. A abordagem se baseia em redes neurais multicamada, nas quais a definição de neurônio é mais relaxada (seguindo outros trabalhos da literatura apresentados neste capítulo). Segundo essa definição, a saída de um neurônio não é necessariamente binária ou variando entre 0 e 1 . A primeira camada na abordagem de Collobert et al. mapeia lexemas e correlatos (incluindo o contexto), além de outros atributos, para representações vetoriais de atributos. A segunda camada aplica uma combinação linear entre a representação vetorial definida na primeira camada. A terceira camada normaliza a saída entre 0 e 1 . A quarta camada aplica uma nova combinação linear entre as camadas anteriores, porém com número diferente de neurônios para ajustar-se às classes de saída. Em uma metodologia extensiva, são investigadas redes neurais treinadas especificamente para uma tarefa, redes neurais treinadas para diferentes tarefas com algum grau de bidirecionalidade e redes neurais em cascata, nas 
quais usa-se a saída das ativações da análise morfológica como parte dos atributos de entrada da análise sintática sintática parcial, e assim por diante.

Os autores também examinam métodos não supervisionados para lidar com o problema dos lexemas raros. Por exemplo, o padrão contendo o atributo referente ao lexema "França", relativamente raro no treinamento é acrescido de atributos referentes a lexemas similares, como "Alemanha" e "Croácia", que são levantados por um método não supervisionado antes de ser processado pela rede neural. Isso equivale a ter uma frase como "Alementa+Croácria+...+França reduziu impostos.”. Nesse caso, o sujeito continua sendo simples e singular, de forma que os lexemas extras inseridos no mesmo padrão de treinamento servem apenas para prover estatísticas extras não cobertas pelo lexema raro. Além disso, Collobert et al. examinam dois modos de análise na abordagem supervisionada, um baseado em janelas de matrizes, nos quais lexemas e correlatos são analisados individualmente (sendo incluso na análise seus contextos) e outro baseado em convolução de matrizes ${ }^{13}$, nos quais atributos globais da frase são extraídos de padrões comparados dois a dois (lexemas e correlatos contra cada verbo identificado). A abordagem baseada em convolução de matrizes foi criada especificamente para a tarefa de anotação de papéis semânticos. Nessa tarefa, os autores mostram que, a anotação de papéis semânticos, normalmente associada à análise sintática completa, pode ser realizada com análise sintática parcial, atingindo resultados satisfatórios. Para a tarefa de análise morfossintática, os autores obtêm uma acurácia de 97,2\%. No caso de análise sintática total baseada em constituintes, implementada posteriormente em Collobert (2011) com base em matrizes de convolução de forma muito semelhante a anotação de papéis semânticos, é obtida a medida-f de 89,1\%.

Singh et al. (2009) propõe um modelo probabilístico bidirecional robusto baseado em campos aleatórios condicionais com uma modificação para tratar duas tarefas simultaneamente com probabilidades deduzidas por amostragem Monte-Carlo. O modelo dos autores é aplicado à segmentação de entidades nomeadas e à anotação de entidades nomeadas. Contudo, o modelo foca apenas no nível semântico (entidades nomeadas) e em apenas duas tarefas muito proximamente relacionadas (segmentação e anotação de entidades nomeadas). $\mathrm{O}$ Molin, por outro lado, foi aplicado a diferentes níveis da e subníveis da língua. Os autores também apontam alguns trabalhos bidirecionais para outras tarefas.

A edição de 2009 da conferência CoNLL apresenta alguns trabalhos que integram análise sintática e e reconhecimento de papéis semânticos, com base em uma avaliação 13 A matriz de convolução é mais proximamente relacionada a matriz $\mathrm{C}$. 
dividida em diferentes critérios: o uso das medidas de avaliação (medida-f ou interligação (não-)rotulada), tarefa (análise sintática de dependência ou de papéis semânticos), integratividade (modelos integrativos e não integrativos). Medidas-f para abordagens híbridas não são diretamente comparáveis a este trabalho, pois a tarefa de análise de papéis semânticos não foi explorada ainda. Entre os trabalhos focados em sintaxe, destaca-se o trabalho de Bohnet (2009), que, apesar de focar-se apenas em dependências, atinge a interligação rotulada de $82,64 \%$, a partir de um modelo probabilístico. Parte dos trabalhos apresentados na conferência modelam a probabilidade de co-ocorrência entre etiquetas sintáticas e semânticas, baseados em probabilidades.

Um exemplo de abordagem que dá mais ênfase ao processamento da língua descendente baixo é discutido no trabalho Levinson (1974), correlacionando os níveis sintático e fonético com o uso de análise sintática para melhorar o reconhecimento de fala. A abordagem discutida pelo autor permite apresentar fragmentos de áudio a um reconhecedor de fala que gera suas possíveis transcrições. As transcrições, por sua vez, são apresentadas a um analisador sintático, servindo de base para a criação de árvores sintáticas. Árvores bem formadas e com probabilidades maiores de geração podem então ser usadas para selecionar e ranquear as melhores transcrições.

\subsection{Simplificação textual}

A simplificação textual visa aumentar a inteligibilidade do texto, tornando-o mais fácil de ser lido por um determinado público, sendo definida por Max (2006) como qualquer processo que reduza a complexidade de um texto enquanto tenta preservar seu significado e informação. Durante o processo, é comum a redução no tamanho dos períodos ${ }^{\mathrm{g}}$, enquanto o texto resultante pode ser aumentado levemente, devido a reestruturações, divisões e ajustes em suas frases, ou mesmo diminuído, quando técnicas de sumarização são utilizadas. Neste texto, segue-se a classificação de Young (1999), que define a sumarização como um caso de simplificação textual. A simplificação textual, juntamente com a elaboração textual (acréscimos, redundâncias e paráfrases no texto que atuam em sua compreensibilidade, isto é, a facilidade do texto ser compreendido), fazem parte de uma área maior, a adaptação textual (também chamada de text-to-text generation ${ }^{14}$ ), conceito complementar à geração textual.

Margarido et al., (2008) solicitaram a leitores enquadrados no perfil do projeto PorSimples para realizarem a leitura de alguns textos de jornais, e constataram dificuldades $14 \mathrm{https}: / /$ sites.google.com/site/texttotext2011/ 
dos leitores na leitura de textos longos (cerca de mais de meia página de texto em formatação padrão). Nessa mesma avaliação, os mesmos textos sumarizados foram melhor compreendidos pelos leitores. Embora o resultado ainda precise passar por uma validação mais rigorosa, ele sugere que, o uso de simplificação textual é mais indicado que o de elaboração textual para a audiência composta por leituras com níveis de letramento rudimentar e básico.

Neste trabalho, o foco da simplificação se dará no nível sintático, embora ela possa ocorrer em diferentes níveis:

- Léxico/semântico: a simplificação léxica é definida por Urano (1998) como a substituição de lexemas incomuns por um vocabulário mais básico, ou seja, por lexemas frequentes da língua, dominadas por um número maior de falantes. Carrol et al. (1999) aplicam simplificação léxica (além de sintática) a partir de sinônimos da Wordnet (FELLBAUM 1998), utilizando o Oxford Psycholinguistic Database (Banco de Dados Psicolinguístico Oxford), recurso baseado na base léxica MRC $^{15}$ (Medical Research Council), para decidir o sinônimo mais adequado para a simplificação.

- Sintático: a simplificação sintática tem como objetivo reduzir o tamanho dos períodos e sua complexidade, de forma que cada oração seja pequena a ponto de tratar de uma única informação, e possa ser interpretada independentemente (MAX, 2006).

- Discursivo: consiste em alterar a estrutura textual para tornar o texto mais claro. Williams (2004), investiga o papel da teoria Rhetorical Structure Theory (MANN e THOMPSON, 1988) na simplificação textual, reordenando as orações e alterando marcadores discursivo. A sumarização pode ser enquadrada nessa categoria.

Neste trabalho, o nível escolhido foi o sintático, embora durante o projeto PorSimples a simplificação léxica tenha sido também investigada (MUNIZ et. al., 2011; WATANABE et. al., 2010).

\subsubsection{Acessibilidade em Textos}

O conjunto de diretrizes Web Content Accessibility Guidelines (WCAG - Diretrizes para Acessibilidade de Conteúdo Web) ${ }^{16}$ foi criado para tratar de questões de acessibilidade em conteúdos Web, com o objetivo de universalizar o acesso à informação. Em particular, o item 
3.1 (Fazer o conteúdo textual legível e compreensível) do WCAG 2.0 trata da tarefa de tornar um texto da Web mais acessíveis para diferentes públicos. Por exemplo, o Item 3.1.5 sugere o uso de material complementar para textos que requeiram habilidades de leitura superiores ao nível de edução secundário americano (secondary education level), equivalente à nona série no Brasil.

Preocupações com a complexidade dos textos não se restringem apenas ao conteúdo da Web. A Plain Language ${ }^{17}$ (Linguagem Simples - também conhecida como Plain English), motivada pela existência de textos governamentais e jurídicos de difícil leitura para o público em geral, foi criada durante a década de 70 nos Estados Unidos, para tratar de questões sobre a complexidade dos textos da Língua Inglesa. As recomendações podem ser expandidas para outros gêneros textuais (por exemplo, textos jornalísticos) e adaptadas para outras línguas. Algumas recomendações de como escrever e organizar as informações em Plain Language são:

- Usar sintaxe simples.

- Escolher lexemas simples e evitar jargões, palavras estrangeiras e termos jurídicos.

- Explicar somente uma ideia por oração.

- Evitar a formalidade quando desnecessário.

- Minimizar o uso de abreviações.

- Usar termos e conceitos importantes de maneira consistente.

- Usar a voz ativa.

- Usar verbos em vez de substantivos para exemplificar sua ação.

- Fazer orações com 20 palavras em média (esse tamanho, estimado para o Inglês, é dependente de língua).

Como uma parte razoável das recomendações estão ligadas direta ou indiretamente à sintaxe, um simplificador sintático automático pode ser um apoio importante durante a adequação de diferentes textos a recomendações da Plain Language.

A Simple English Wikipedial ${ }^{18}$ (Wikipédia de Inglês Simplificado) é um esforço para tornar a versão de Língua Inglesa da Wikipédia ${ }^{19}$ acessível para leitores com menor nível de letramento, o que é feito com o uso de vocabulário e gramática simplificados, por meio de simplificações realizadas por humanos. Entre o público-alvo, encontram-se crianças, leitores 
com necessidades especiais, como problemas cognitivos, e aprendizes de Inglês como segunda língua.

No contexto brasileiro, a lei federal 10098/2000 busca garantir que o conteúdo em páginas governamentais sejam escritos em uma linguagem simples e direta, removendo assim barreiras de comunicação e assegurando direitos dos cidadãos ao acesso a informação e comunicação. Contudo, Martins e Filgueiras (2007) mostram que a grande parte das páginas analisadas ainda precisam de reformulações profundas de modo a atender a Plain Language.

\subsubsection{Públicos da simplificação textual}

Simplificadores sintáticos são considerados ferramentas neste trabalho, já que, são incluídos em aplicações maiores, voltadas à simplificação textual em diferentes níveis. Pesquisas na área têm focado em públicos distintos (GASPERIN et al., 2009a), entre eles:

- Alfabetizandos: Lal e Ruger (2002) usam um sumarizador bayesiano baseado na Wordnet e no banco de dados psicolinguístico MRC para adaptar textos para crianças em fase escolar.

- Falantes não nativos: Burstein et al. (2007) aplicam a simplificação de textos para ensino de Inglês a falantes do Espanhol como língua materna. A ferramenta desenvolvida pelos autores utiliza simplificação léxica por meio da análise de frequências dos itens lexicais candidatos à substituição. Lexemas cognatos entre as duas línguas têm preferência.

- Leigos em áreas técnicas: Elhadad (2006) explora o uso de simplificação léxica no contexto médico para facilitar a leitura de laudos médicos pelos pacientes. As regras de simplificação são extraídas de córpus e da $W e b$, em um processo não supervisionado. Durante a simplificação, também é levado em conta o nível de conhecimento do leitor.

- Deficientes auditivos: Inui et al. (2003) propõem um sistema baseado em regras probabilísticas para portadores de surdez. Medidas de inteligibilidade foram criadas a partir de questionários respondidos por professores com deficiência auditiva. Diferentes paráfrases para uma dada oração são geradas e um classificador baseado em aprendizado de máquina seleciona as mais simples. Os autores consideram os resultados satisfatórios, embora existam erros como conjugação verbal e regência.

- Portadores de afasia: Devlin e Unthank (2006), seguindo o trabalho de Carrol et al. (1999), propõem o uso de uma interface Web criada para permitir que portadores de 
afasia tenham acesso a conteúdo digital simplificado.

Observa-se que, textos complexos são um desafio não só para os públicos citados, mas também para aplicações de PLN. Chandrasekar et al. (1996), defendem a ideia que textos complexos, especialmente com períodos longos prejudicam o desempenho de diversas aplicações automáticas (sumarizadores, tradutores de máquina, sistemas para recuperação de informações, analisadores sintáticos, entre outros), que poderiam ter seu desempenho melhorado com o uso de simplificação textual (particularmente a sintática). Sobre essa perspectiva, a simplificação textual pode ser vista simultaneamente como uma ferramenta (integrada em aplicações maiores) e uma aplicação de PLN (destinada a diferentes públicos alvo).

\subsubsection{Simplificação sintática com regras manuais}

Esta seção apresenta esforços da literatura no sentido de simplificar textos sintaticamente a partir de regras desenvolvidas manualmente. Alguns dos trabalhos citados também estendem a simplificação a outros níveis da língua.

Carroll et al. (1999) propõem o uso simplificações sintáticas voltadas a portadores de afasia e outros transtornos cognitivos que afetam a linguagem (por exemplo, em decorrência de derrames). Os módulos de análise do sistema proposto proveem análise morfológica (incluindo morfossintaxe), sintática e resolução anafórica. Os módulos para geração operam na morfologia dos lexemas, aplicam simplificação léxica e simplificação sintática.

Klebanov et al. (2004) processam textos aplicando a divisão de frases grandes e restruturações na ordem das frases do texto visando melhorar o desempenho de sistemas de perguntas e respostas. Em uma avaliação preliminar, os autores verificaram que a implementação do modelo possui precisão de 0,50 e cobertura de 0,30. Na mesma linha, Vickrey e Koller (2008) avaliam o uso de simplificação sintática para apoiar a tarefa de anotação de papéis semânticos.

Siddharthan (2004; 2006) desenvolveu uma arquitetura para simplificação de uso geral com foco na criação de textos coesos. O simplificador, voltado a língua inglesa, trata apostos, cláusulas relativas, orações coordenadas e orações subordinadas, sendo baseado em análise sintática parcial. O objetivo da arquitetura é tornar textos mais acessíveis para um público-alvo geral, em vez de focar em um determinado público-alvo ou aplicação.

Max (2006) utiliza um simplificador sintático para o Inglês integrado a um processador de texto. O simplificador é baseado em regras manuais de reescrita para a saída de um analisador 
sintático (de forma semelhante ao modelo Sinsim). As simplificações resultantes são classificadas por uma medida de sua complexidade e potencial mudança de significado e então o autor escolhe, com base nestas informações, as simplificações preferidas.

Para a Língua Portuguesa, Barreiro e Cabral (2009) desenvolveram o sistema ReEscreve, um parafraseador de uso geral, mas que pode ser utilizado para gerar paráfrases mais simples das frases originais. As paráfrases podem reduzir o número de palavras, a ambiguidade e a complexidade do texto. Candido Jr et al. (2009a) descrevem o simplificador sintático precursor ao Sinsim, baseado em regras e avaliado a partir de textos em Português.

Burstein (2009) desenvolveu o Text Adaptor, uma ferramenta de autoria focada em professores de idioma estrangeiro, capaz de aplicar elaboração textual (inserindo sinônimos adjacentes a palavras difíceis), sugerir simplificação sintática, sumarizar texto e destacar palavras polissêmicas que possam gerar ambiguidade. O sistema também pode disponibilizar informações complementares na língua nativa do aluno. Além disso, o sistema ainda sugere orações passíveis de simplificação no nível sintático.

Jonnalagadda e Gonzalez (2009), inspirados na abordagem empregada por Siddharthan (2006), aplicam simplificação sintática baseada em regras manuais aliada com detecção de corretude gramatical para o domínio de biomédico. O trabalho busca melhorar o desempenho de sistemas de extração de informação sobre interações entre proteínas. Além de tratar fenômenos sintáticos, os autores removem expressões formuláicas do textos (como "o objetivo deste trabalho é", no equivalente para a Língua Portuguesa, entre outras).

De Belder and Moens (2010) usam o analisador sintático de Stanford ${ }^{20}$ para selecionar os apostos, orações relativas, alguns casos de subordinação e de coordenação. Os fenômenos são simplificados a partir de regras criadas manualmente. O trabalho apontou que, com o conjunto de regras utilizadas, não é possível reduzir a dificuldade de leituras de textos satisfatoriamente para o público infantil. Os autores sugerem outros métodos para esse propósito, como sumarização e elaboração léxica.

\subsubsection{Simplificação sintática estatística}

Chandrasekar e Srinivas (1997) investigaram a indução de regras sintáticas a partir de córpus anotados com etiquetas morfossintáticas, além de etiquetas morfológicas extras para concordância e informação de subcategorização. A partir da extração de correspondências sintáticas, regras foram geradas para aumentar a velocidade e a taxa de acertos de analisadores

20 http://nlp.stanford.edu/software/lex-parser.shtml 
sintáticos.

Daelemans et al. (2004) comparam aprendizado de máquina e regras manuais para simplificar legendas de programas televisionados para portadores de deficiências auditivas. $\mathrm{Na}$ abordagem baseada em aprendizado de máquina, um modelo para simplificação é aprendido a partir de córpus paralelos contendo a transcrição de legendas. Atributos utilizados são relacionadas aos lexemas, lemas, classes gramaticais, sintagmas, entre outros, resultando em 30 atributos no total. Entretanto, a abordagem automática não apresentou o desempenho desejado, cometendo erros como remover sujeitos de orações ou lexemas de lexias complexas. O aprendizado de regras se saiu levemente melhor, com medida-f (JURAFSKY \& MARTINS, 2008) de $21 \%$ contra $15 \%$ para aprendizado automático, no caso da Língua Inglesa. A abordagem baseada em regras manuais pode ser melhorada a partir da inclusão de mais regras, enquanto a abordagem baseada em regras automáticas pode ser melhorada com o uso de córpus de treinamento maiores.

Petersen (2007) aplica simplificação textual (incluindo a sintática) à tarefa de ensino de línguas. O modelo proposto pela autora permite identificar o nível de proficiência de um leitor, e realizar simplificação sintática e sumarização de acordo com esse nível. O processo de simplificação sintática é estatístico e se baseia em um córpus paralelo de notícias e suas versões simplificadas.

Specia (2010) analisa técnicas de tradução de máquina baseada em aprendizado a partir de córpus para simplificar textos automaticamente. As operações de simplificação léxica realizadas pelo modelo desenvolvido se saem bem no geral. As operações no nível sintático tendem a restringir-se a divisões simples de frases, enquanto operações como mudança na ordem dos componentes das frases e orações são evitadas. Assim, o modelo é particularmente cauteloso no nível sintático, o que se alinha com a proposta de foco em precisão adotada neste trabalho. A autora aponta que mais operações sintáticas podem vir a ser realizadas com a inserção de informações sobre níveis mais profundos da língua no modelo.

Existem também abordagens mistas. Por exemplo, Napoles e Dredze (2010) aplicam aprendizado de máquina para selecionar frases que devam ser simplificadas sintaticamente por meio de regras manuais. Gasperin et al. (2009b; 2009c) também seguem nesta direção, gerando um classificador para indicar quais frases devem ser simplificadas para textos em Português.

Inui et al. (2003) combinam simplificação sintática baseada em regras para portadores de 
deficiências cognitivas com aprendizado de máquina. A partir de 100 regras criadas manualmente, os autores geram diversas paráfrases para cada frase e treinam um classificador para escolher as mais simples. Apesar dos resultados apresentados serem satisfatórios, foram encontrados alguns tipos de erros presentes na geração de paráfrases, como problemas de conjugação de verbos e de regência. 


\section{Modelo Molin}

O modelo de análise de língua proposto nesta tese de doutorado com o objetivo de permitir a geração de analisadores morfológicos, sintáticos, semânticos (e outros) é baseado em redes neurais artificiais, cujos padrões são baseados em lexemas e correlatos (números, sinais de pontuação, entre outros) presentes em frases de um córpus de treinamento. A modelagem é dirigida a padrões, isto é, inicialmente os padrões a serem tratados pela rede são propostos, a seguir topologias e instâncias Molin são definidas para processar esses padrões, e só então a arquitetura de software do modelo é definida. A arquitetura é seguida por uma fase de implementação, e, por fim, por uma fase de calibragem na qual os parâmetros são ajustados para otimizar o desempenho do modelo. A implementação utilizada neste trabalho é chamada de Miolin (Modelo Implementado de Operações Linguístico-Neurais), um protótipo que permite realizar parte da modelagem prevista pelo Molin realizada nesta pesquisa. $\mathrm{O}$ protótipo recebe um nome diferente do modelo teórico, pois implementa apenas um subconjunto de suas análises.

Este capítulo apresenta a metodologia empregada na concepção do Molin. Primeiramente, são discutidos os requisitos de software (SOMMERVILLE, 2010) que guiaram o desenvolvimento do modelo (Seção 3.1). A seguir, a Seção 3.2 detalha diferentes instâncias Molin, isto é, versões do modelo com parâmetros e topologia definidas, discute a modelagem otimizada dos padrões e apresenta a terminologia empregada no trabalho referente a eventos linguísticos, padrões neurais, neurônios, atributos e classes. A Seção 3.3 discute diferentes topologias definidas para uso em instâncias Molin, ressaltando suas características e limitações, bem como estruturas de dados a serem inferidas pela rede neural artificial (como árvores de dependência, mapeada por uma matriz genérica). A Seção 3.4 apresenta a arquitetura baseada em camadas empregada para construir o protótipo Miolin, incluindo pré-processamentos realizados nos dados para uso nos experimentos, recursos linguísticos tratados pelo protótipo, a abordagem para mapeamento de eventos utilizada, e algoritmos para tratar problemas de redes neurais artificiais e possibilitar o processamento de instâncias Molin. Por fim, a Seção 3.5 compara o modelo com trabalhos apresentados no 
Capítulo 2.

\subsection{Análise de requisitos de software}

Sete requisitos de software (SOMMERVILLE, 2010) principais guiaram o desenvolvimento do modelo, de suas instâncias e do protótipo. Segundo esses requisitos, o modelo deve, idealmente, ser: genérico; integrativo; bidirecional; expansível; independente de língua; interpretável; e escalável.

O primeiro requisito, a generalidade, foi definido para que o modelo possa ser ajustado a diferentes tarefas do PLN. Para tal, criou-se uma estrutura de instâncias, que podem ser aplicadas a tarefas diferentes (por exemplo, análise morfológica, morfossintática, lematização, análise sintática, entre outras), na qual cada instância conta com pontos fortes e limitações distintas em relação a tarefa a que se destina.

O segundo requisito consiste em garantir ao modelo a capacidade de realizar análises integrativas. A Seção 3.2 apresenta exemplos para análise morfossintática, lematização, análise sintática baseada em dependências e categorização semântica.

O terceiro requisito, a bidirecionalidade, permite que a rede neural possa correlacionar informações de dois níveis analisados livremente, nos dois sentidos, independentemente de hierarquia entre os níveis. O mesmo vale para subníveis de um dado nível. Esse tipo de análise é obtido com o uso de recorrência neural, o que possibilita que toda a informação de saída seja convertida em entrada durante um processo retroalimentado, independentemente do nível ao qual as informações se referem. Este requisito é a primeira justificativa para o uso de redes neurais artificiais, consideradas robustas para lidar com recorrência.

O quarto requisito, a expansibilidade, permite que o modelo treinado originalmente para um conjunto de tarefas $T$, seja retreinado para uma nova tarefa $t^{\prime}$, sem perder a capacidade de analisar $T$. A representação de atributos baseada em listas nominais (apresentada na Seção 3.2.3) permite que novos neurônios e sinapses sejam facilmente adicionados, sem necessidade de reestruturar neurônios e sinapses anteriores ou sua representação.

O quinto requisito, a independência de língua, permite ao modelo ser adaptado para diferentes línguas. Este requisito é uma das justificas para o uso de aprendizado de máquina, já que os algoritmos da área podem identificar automaticamente estruturas específicas de cada língua, quando baseados em boas modelagens, bem como as informações relevantes para processá-las, em particular tomando-se como base respectivos córpus anotados para 
aprendizado supervisionado ou semi-supervisionado.

O sexto requisito diz respeito a interpretabilidade do modelo. Devido a natureza exploratória deste trabalho, é desejável que as instâncias do modelo possam ser interpretadas facilmente, o que motivou a escolha de Perceptron em detrimento de abordagens multicamada como as redes MLP na implementação do protótipo Miolin. Nota-se que diferentes pesquisas apontam métodos para extração de conhecimento de topologias mais elaboradas (KUMAR, 2012; AZAMATHULLA, HAQUE, 2012; ANDREWS et al., 1995), levando à revisão do tradicional conceito referente a pouca interpretabilidade das redes neurais artificiais, frequentemente denominadas como "caixas pretas". O modelo Perceptron, modificado para usar a função de ativação sigmoide logística, foi escolhido no protótipo por ter como vantagem o fato de permitir a extração de conhecimento de forma mais simples e imediata, pois o relacionamento entre os neurônios de entrada e os neurônios de saída é sempre monotônico, ou seja, em uma rede treinada, um dado neurônio de entrada sempre inibirá, sempre estimulará, ou nunca afetará um dado neurônio de saída. Por outro lado, uma desvantagem dessa abordagem é sua limitação no processamento de problemas semelhantes ao problema do ou-exclusivo (discutido na Seção 3.3.4).

O sétimo item é um requisito não funcional, segundo o qual o modelo deve ser escalável. As palavras da língua se flexionam de diferentes formas (por gênero, grau, número, ente outras), dando origem a diversos lexemas, fenômeno acentuado para os verbos devido às suas conjugações. Em diversas instâncias Molin, lexemas dão origem a pelo menos um neurônio. Nesse cenário, manter a escalabilidade diante do número de neurônios e de sinapses é importante, pois, idealmente, a instância Molin precisa conhecer todas as palavras flexionadas de um glossário de uma língua e, adicionalmente, conhecer nomes próprios ao menos parcialmente. Para manter o modelo escalável, este trabalho apresenta uma abordagem para recuperar apenas os neurônios e as sinapses importantes para um dado padrão, resultando em um processamento consideravelmente menor. A abordagem otimizada em uso (discutida na Seção 3.2.3) é uma segunda justificativa para o uso de redes neurais artificiais no trabalho.

Há ainda outros requisitos nos quais a modelagem se baseou. Por exemplo, no caso de requisitos não funcionais, o modelo deve buscar inspirações no funcionamento cognitivo no cérebro humano. Um requisito funcional extra consiste em o modelo dever indicar o nível de confiança $^{\mathrm{g}}$ (ativações próximas 0,5 indicam baixa confiança, e ativações próximas a 1 ou 0 indicam alta confiança em saídas positivas ou negativas, respectivamente) em relação às suas 
predições, o que é uma das justificativas por traz da escolha do uso da função sigmoide logística no protótipo ao invés da função Passo, tradicionalmente aplicada a redes Perceptron.

\subsection{Instâncias Molin}

\subsubsection{Eventos linguísticos}

Neste trabalho, eventos linguísticos ${ }^{\mathrm{g}}$, ou simplesmente eventos, são extraídos a partir de lexemas e correlatos presentes em textos. Por exemplo, a partir do lexema "gato" da oração “O gato pegou o rato", é possível extrair-se os seguintes eventos para a análise morfossintática (Part of Speech Tagging - PoS):

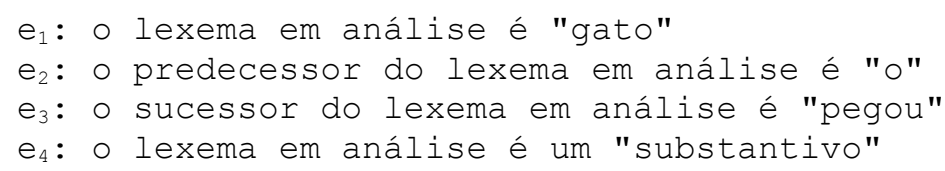

Os eventos $e_{1}, e_{2}$ e $e_{3}$ são chamados de eventos observáveis, pois são visíveis na oração original. $\mathrm{O}$ evento $e_{1}$ corresponde ao próprio lexema em análise. Os eventos $e_{2}$ e $e_{3}$ são importantes na tarefa de análise morfossintática por representarem informação de contexto importantes para desambiguar lexemas ambíguos. Por exemplo, "canto" é ambíguo no nível morfossintático, pois pode referir-se a um substantivo ("o canto da sala") ou a um verbo ("eu canto pouco"). O evento $e_{4}$ é chamado de evento latente e deve ser detectado automaticamente pelo modelo baseado em aprendizado de máquina. A Tabela 3.1 ilustra exemplos de eventos observáveis e inferíveis nos níveis linguísticos morfológico, léxico, sintático e semântico.

Tabela 3.1: Eventos em diferentes níveis linguísticos.

\begin{tabular}{llllll}
\hline Nível linguístico & o & gato & pegou & o & rato \\
\hline Morfológico (morfemas) & suffix_o & suffix_o & suffix_ou & suffix_o & suffix_o \\
Morfológico (flexão) & $\begin{array}{l}\text { morph_- } \\
\text { singular }\end{array}$ & $\begin{array}{l}\text { morph__ } \\
\text { singular }\end{array}$ & $\begin{array}{l}\text { morph_ } \\
\text { present }\end{array}$ & $\begin{array}{l}\text { morph_ } \\
\text { singular }\end{array}$ & $\begin{array}{l}\text { morph_ } \\
\text { singular }\end{array}$ \\
Lexical (lexemas) & lexeme_o & lexeme_gato & lexeme_pegou & lexeme_o & lexeme_rato \\
Lexical (lemas) & lemma_o & lemma_gato & lemma_pegar & lemma_o & lemma_rato \\
Morfossintático & pos_article & pos_noun & pos_verb & pos_article & pos_noun \\
Sintático (dependências) & head_lexeme_- head_lexeme_ & & head_lexeme_ head_lexeme_ \\
gato & pegou & & rato & pegou \\
Sintático (funções) & & syn_subject & syn_predicator & & syn_object \\
Semântico (papéis) & & role_agent & & & role_pacient \\
Semântico (sentidos) & & & sense_perseguir_1 &
\end{tabular}




\begin{tabular}{llllll}
\hline Nível linguístico & o & gato & pegou & o & rato \\
\hline Vários (contexto) & post_lexeme_ & pre_pos_ & pre_pre_lexeme_ & pre_sense__ & pre_moph_ \\
& gato, $\ldots$ & article,$\ldots$ & $0, \ldots$ & perseguir_1, $\ldots$ & singular, $\ldots$ \\
\hline
\end{tabular}

É importante observar que o exemplo para dependências sintáticas merece tratamento diferenciado. Primeiramente, o mesmo lexema pode ocorrer mais de uma vez dentro da mesma frase / contexto (por exemplo, é comum a ocorrência repetida da preposição “de”). Em segundo lugar, tomando-se por base o sétimo requisito funcional, a escalabilidade, é preciso restringir a inferência aos eventos ligados em um mesmo contexto (ou seja, na mesma frase). Essa medida também visa melhorar a predição, já que eventos que não são relevantes no contexto são ignorados. Em terceiro lugar, o modelo deve ser ajustado para comparar lexemas (mais especificamente, os padrões derivados a partir deles) dois a dois, o que exige um algoritmo diferenciado em relação aos demais eventos. Observa-se ainda, que esse nível é de fundamental importância tanto na análise de funções sintáticas, quanto na anotação de papéis semânticos, o que justifica o tratamento diferenciado que recebe.

Os eventos tratados por uma determinada instância Molin definem os níveis de granularidade no qual a instância opera. Idealmente, diferentes granularidades devem ser contempladas, já que eventos de granularidade grossa permitem fazer generalizações (útil para padrões não vistos em treinamento) e eventos de granularidade fina permitem tratar casos particulares e exceções da língua. A Tabela 3.2 apresenta as granularidades para diferentes categorias de eventos. A tabela segue a convenção de nomes dos eventos em uso no protótipo. Eventos não tratados nesta pesquisa também são apresentados, pois eles devem ser avaliados em trabalhos futuros. Apenas os eventos do tipo "lexeme" e "suffix" são observáveis, sendo os demais latentes.

Tabela 3.2: Granularidade de eventos observáveis e latentes.

\begin{tabular}{llll}
\hline Evento & Exemplo & Detalhes & Granularidade \\
\hline morph & morph_singular & singular (morfologia) & grossíssima \\
pos & pos_noun & substantivo (PoS) & grossíssima \\
syn & syn_subject & sujeito (função sintática) & grossíssima \\
semgroup & semgroup_animal & animal (grupo semântico) & grossíssima \\
semgroup+semcat & semcat_bird & passáro (categoria semântica) & grossa \\
pos+possub & possub_definite & artigo definido (subcategoria gramatical) & grossa \\
syn+synsub & synsub_auxiliary & verbo auxiliar (subfunção sintática) & grossa \\
syn+synsub+synval & synval_transitive & verbo transitivo (valência sintática) & grossa \\
role & role_agent & agente (papel semântico) & grossa
\end{tabular}




\begin{tabular}{llll}
\hline Evento & Exemplo & Detalhes & Granularidade \\
\hline suffix & suffix_as & sufixo (morfologia) & média \\
lemma & lemma_perseguir & lema (nível léxico) & fina \\
head_lemma & head_lemma_perseguir_ & núcleo (análise de dependência) & fina \\
dep_lemma & dep_lemma_gato & dependente (análise de dependência) & fina \\
sense & sense_lemma_perseguir_1 & um sentido (desambiguação semântica) & finíssima \\
lexeme & lexema_perseguiu & lexema (nível léxico) & finíssima \\
\hline
\end{tabular}

No protótipo, as categorias morph e possub são semelhantes, porém a primeira está mais relacionada à flexão das classes gramaticais, enquanto a segunda à subcategorização das categorias gramaticais. Em relação às divisões no nível sintático, syn refere-se às principais funções sintáticas, synsub às subcategorias de funções sintáticas e synval a informações relacionadas a valência ${ }^{g}$. Diferentes correlatos de lexemas também são processados pelo protótipo, detalhes sobre eles são apresentados na Seção 3.4.1. Mapeamentos de eventos relativos aos recursos em uso nos experimentos são descritos na Seção 3.4.2 e no Apêndice A.1.

\subsubsection{Padrões neurais: neurônios, atributos e classes}

Eventos observáveis são mapeados para atributos e eventos latentes para classes. Classes referentes a diferentes níveis linguísticos são analisadas juntas atendendo à análise integrativa definida pelo segundo requisito de software. Um padrão neural é definido como um conjunto de atributos e de classes. Atributos e classes, por sua vez, são mapeados para neurônios de entrada e saída, respectivamente. Como resultado, os termos "evento" e "neurônio" são equivalentes, o primeiro mais utilizado no escopo linguístico do Molin e o segundo no escopo neural. Da mesma forma, evento observável equivale, no contexto neural, a atributo ou neurônio de entrada (este último é um pouco mais genérico devido à recorrência, na qual classes derivam neurônios de entrada) e evento inferível equivale à classe ou neurônio de saída.

Neste trabalho padrões são representados em uma notação inspirada em Json (JavaScript Object Notation) (CROCKFORD et al., 2006). O padrão é baseado em neurônios de entrada $I$ e neurônios de saída $O$. Em um exemplo simples para a tarefa de análise morfossintática, no qual a entrada corresponde a um lexema em análise e seu contexto (lexemas predecessor e sucessor) e saída a possíveis classes gramaticais ou PoS, padrões tem a forma genérica ${ }^{21}$ :

21 Os nomes dos neurônios nos padrões serão apresentados em Inglês, seguindo-se as convenções em uso no 
$\{I:$ [lexeme, pre_lexeme, post_lexeme], o: [pos] $\}$

Como exemplo, para o lexema "gato" na oração "O gato pegou o rato", um padrão tem a forma:

\section{$\{I:[g a t o, o$, pegou $], O:[$ noun $]\}$}

Por serem nominais, atributos desses padrões não podem ser processados por diversos tipos de algoritmos de aprendizado de máquina, incluindo redes neurais artificiais. É necessária uma etapa de processamento para transformá-los em atributos numéricos (binários em algumas instâncias Molin e variando entre zero e um em outras), que também é aplicada às classes. Assim, após a conversão, existem 12 atributos e três classes:

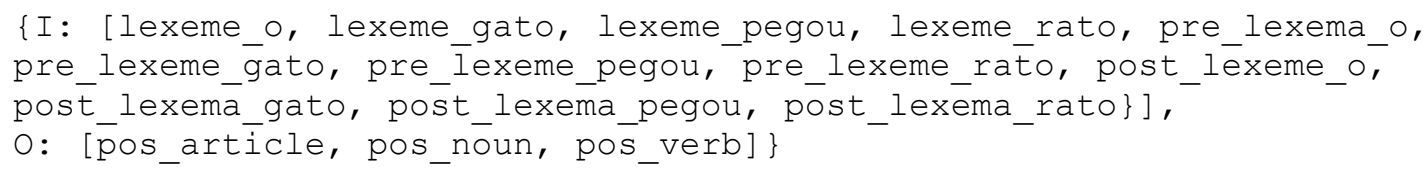

Normalmente, os atributos numéricos derivados de um mesmo atributo nominal original são mutuamente exclusivos, ou seja, apenas um dos quatro atributos referentes ao lexema em análise pode estar ativo em um dado padrão. O padrão do exemplo (extraído de "gato") se transforma em:

$$
\{I:[0,1,0,0,1,0,0,0,0,0,1,0], 0:[0,1,0]\}
$$

Observa-se que padrões desse tipo são esparsos, especialmente, quando o número de lexemas mapeados é elevado (o exemplo mapeou apenas três lexemas). A saída após a conversão é multirrótulo por natureza, o que é desejável, pois, primeiramente, diferentes classes nominais podem ser preditas nas instâncias Molin (por exemplo, a classe gramatical e o lema de um dado lexema), e, em segundo lugar, devido ao modelo ter liberdade para apontar mais de uma opção para uma classe nominal ${ }^{22}$. Esse comportamento também permite instâncias Molin que dispensem expansão de contrações na tarefa de análise morfossintática, associando, por exemplo, a contração “das” às classes gramaticais preposição (“de”) e artigo (“as”), embora esse cenário não seja explorado neste trabalho.

\subsubsection{Representação otimizada dos padrões}

$\mathrm{Na}$ instância Molin exemplificada até o momento, cada lexema pode derivar até três atributos numéricos (por exemplo, lexema_gato, pre_lexema_gato e post_lexema_gato). Nesse cenário, o número de neurônios pode chegar a ser três vezes maior que o número de protótipo, definidas para facilitar o treinamento de modelos para outros idiomas.

22 Múltiplas classes referentes ao mesmo atributo nominal original indicam incerteza na predição ou problemas multiclasse (os últimos detalhados o Apêndice A.1). 
lexemas do glossário de treinamento ${ }^{23}$. A dimensionalidade é ainda agravada pelo fato de algumas classes gramaticais (especialmente os verbos), possuírem um alto número de flexões. Além disso, outras instâncias Molin podem converter cada lexema para mais de três atributos. Um modelo de redes neurais artificiais que mapeie todos esses lexemas e se baseie na notação tradicional resultará em padrões altamente esparsos e com tempo de processamento alto, caso nenhuma otimização seja feita, devido ao tempo necessário para percorrer tal vetor.

No Molin, os neurônios são nomeados em vez de indexados, de forma que os padrões usam uma representação vetorial baseada em cadeias de caracteres (strings), na qual os as cadeias correspondem aos nomes do neurônios que mapeiam. Para o exemplo baseado em vetores de números da Seção 3.2.2, a representação otimizada correspondente é:

$\{$ I: [lexeme_gato, pre_lexeme_o, post_lexeme_pegou], $0:$ [pos_noun]\}

A Figura 3.1 representa a equivalência entre vetores binários referentes a dois atributos $x$ e $y$ e os conjuntos mapeados pela representação otimizada na forma de listas de literais.

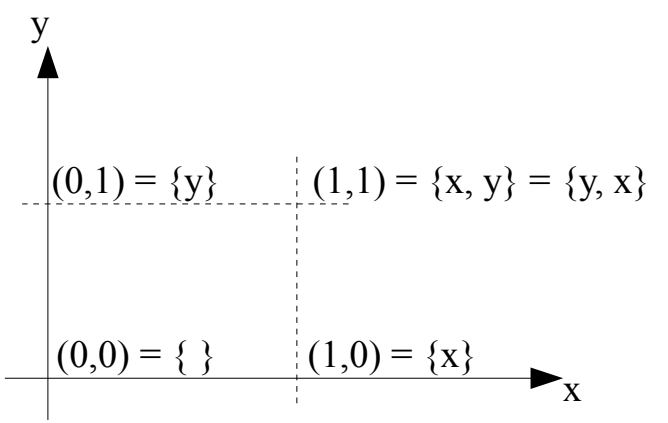

Figura 3.1: Mapeando vetores para conjuntos.

Observa-se que nessa notação a ordem não é importante, de forma que o padrão apresentado, pode ser reescrito como, por exemplo:

$\{I:$ [pre_lexeme_o, lexeme_gato, post_lexeme_pegou], $0:$ [pos_noun] $\}$

Por convenção, quando não for explicitado, neurônios de entrada ou saída possuem ativação 1. Outros valores de ativação, relacionados a conjuntos difusos, também são mapeáveis pela representação otimizada, por listas de objetos. Por exemplo, para definir-se uma ativação de 0,5 no neurônio pre_lexeme_o, usa-se:

$\{I:[\{$ pre_lexeme_o: 0.5$\}$, lexeme_gato, $\ldots], 0:[\ldots]\}$

O padrão apresentado acima é um padrão de treinamento, no qual $O$ (também referenciado por $D$ nas seções referentes a treinamento) corresponde a saída desejada da rede. Para padrões classificados, a saída obtida será denotada por $O^{\prime}$ (representado por $\mathrm{O}_{-}$na

23 Para isso acontecer, cada lexema relacionado a cada lema (incluindo variações raras) teria que ser incluído no conjunto de treinamento usado após a aquisição léxica e precisariam em diferentes posições da frase. 
notação $J_{s o n}$ e também referenciado por $Y$ nas seções referentes a treinamento) como em:

$\{\mathrm{I}:$ [lexeme_gato, pre_lexeme_o, post_lexeme_pegou],

$O_{-}:[\{$pos_noun: 0.98$\left.\}]\right\}$

A notação otimizada permite ainda a repetição de neurônios, o que é explorado na tarefa de análise morfossintática para repetição de lexemas predecessores e sucessores em janelas maiores que 1. Isso equivale a duas sinapses interligando um dado neurônio de entrada repetido duas vezes a um dado neurônio de saída, e reforça a influência do neurônio de entrada sobre o neurônio de saída. A força de ambas as sinapses é a mesma, embora os neurônios repetidos possam ter diferentes valores de ativação.

Observa-se que, segundo essa representação, a diferença entre neurônio de entrada e neurônio de saída é mais difusa, primeiro, devido à existência de neurônios de entrada derivados de neurônios de saída, e segundo, à flexibilidade representacional. Por exemplo, os dois padrões abaixo são perfeitamente possíveis em uma mesma instância Molin (embora essa possibilidade não tenha sido explorada neste trabalho):

$\{I:[$ lexeme_gatas], O: [lemma_gato, morph_plural, morph_female]\},

$\{$ I: [lemma_gato, morph_plural, morph_female], o: [lexemé_gatas]\},

A instância em questão pode ser treinada para a tarefa de lematização, na qual o lexema é informado e seu lema é recuperado, e na tarefa de flexão (também chamada de conjugação, no caso dos verbos), na qual o lema e informações morfológicas são apresentadas como entrada e a saída é a forma flexionada correspondente. Observa-se ainda que, o uso de contexto é útil para tratar a ambiguidade presentes nas duas tarefas. Nesse cenário, a posição do lexema no padrão é o que definirá se ele é neurônio de entrada / atributo / evento observável ou neurônio de saída / classe / evento latente.

A partir da representação otimizada, é possível recuperar apenas os neurônios e as sinapses relevantes para o processamento de um dado padrão. No padrão de exemplo em uso, apenas quatro neurônios e quatro sinapses seriam recuperados a partir de um conjunto muito maior. Nas instâncias Molin avaliadas neste trabalho, grandes padrões em geral não contam com mais de 40 neurônios de entrada (incluindo recorrentes) e de saída. Neurônios e sinapses podem ser armazenados em disco, por meio de um banco de dados, ou mantidos em memória, em uma estrutura hash, por exemplo. O protótipo Miolin se baseia em um banco de dados com um cache em memória elevado, de forma a manter o máximo de informação possível na memória e acelerar o tempo de treinamento.

A representação otimizada foi proposta com base no requisito de software não funcional 
referente à escalabilidade. Contudo, ela também atende ao requisito referente à interpretabilidade (devido ao mapeamento de eventos para neurônios e a presença dos nomes neurônios na representação dos padrões) e expansibilidade, pois novos neurônios podem ser adicionados sob demanda, de acordo com os padrões definidos para o treinamento de novas tarefas, possibilitando o aprendizado a partir de diferentes tarefas por diferentes tutores (discutido previamente na Seção 1.2). Em particular, a característica de expansibilidade torna a representação otimizada mais geral que a representação tradicional.

As instâncias Molin avaliadas neste trabalho são treinadas pelo menos duas vezes, sendo a primeira uma fase de aquisição léxica ${ }^{\mathrm{g}}$ baseada no glossário Unitex- $\mathrm{Pb}$ (MUNIZ, 2004; MUNIZ et al., 2005). Nas fases posteriores, lexemas não vistos durante a aquisição léxica são substituídos pelo evento genérico unknown_lexeme. A substituição é importante para avaliar como as instâncias do modelo se comportam com informação não vista durante o treinamento.

Uma vantagem adicional da representação otimizada, é seu uso em aquisição léxica não supervisionada. Por exemplo, utilizando as predições do evento lexema desconhecido como informações de treinamento do lexema recém-adquirido. No caso de boas predições, classificações futuras do lexema recém-adquirido em contextos diversos poderão ser mais bem sucedidas. Está característica (aquisição léxica não supervisionada), contudo, não é explorada neste trabalho.

\subsubsection{Instâncias sem contexto}

Definir os neurônios de entrada e de saída para uma instância Molin é a etapa mais importante na modelagem, não só devido ao modelo utilizar uma abordagem dirigida a padrões, mas também pelo fato deles estarem relacionados diretamente à criação do conjunto de padrões sobre os quais a rede neural artificial deve aprender. Exemplos de instância sem contexto são apresentados no Exemplo 3.1.

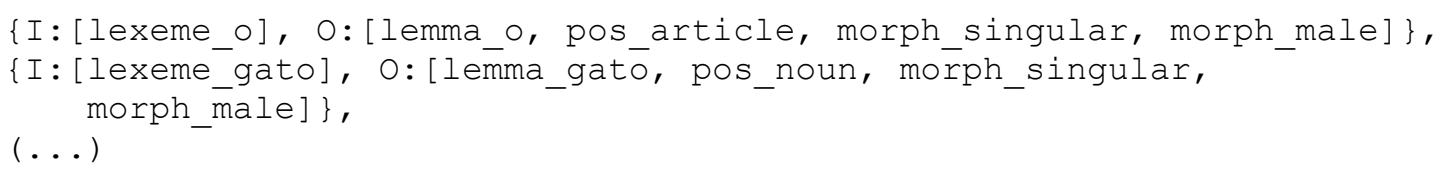

Exemplo 3.1: Aquisição léxica.

Durante a aquisição léxica, os lexemas não são substituídos pelo evento genérico unknown_lexeme. Nessa fase, o modelo aprende os lexemas de um determinado idioma. Nos exemplos, cada lexema é associado a seu lema, sua categoria gramatical e informações 
morfológicas. Esse procedimento é importante por duas razões. Primeiro, alguns lexemas podem não aparecer na etapa de treinamento (posterior a aquisição léxica), então, tê-los na base é importante para melhorar a classificação de novos padrões. Segundo, diversas sinapses utilizadas na otimização por semente, são estabelecidas já nesta etapa.

$\mathrm{Na}$ otimização por semente, categorias de eventos (as sementes ${ }^{\mathrm{g}}$, isto é, geralmente lexemas e correlatos) são utilizadas para recuperar o conjunto que deriva a saída $O^{\prime}$ da rede neural. Apenas neurônios de saída que possuem sinapses estabelecidas com a semente são considerados candidatos à saída $O^{\prime}$. No protótipo, para reduzir o tempo de processamento, é importante controlar as sinapses estabelecidas pelas sementes (outras implementações podem vir a utilizar outras estratégias de otimização diferentes das sementes). Por exemplo, "lexeme_gato" estabelece sinapse apenas com "lemma_gato", mas não com lemas de outros lexemas. Assim, é possível excluir-se os demais lemas, dado que são irrelevantes na análise do lexema em questão. Deve existir exatamente uma semente por padrão, embora em trabalhos futuros, múltiplas sementes possam ser incluídas. A Seção 5.2.1 apresentará uma instância sem lexema (g9e1), cujas sementes são troncos (stems) extraídos dos lexemas originais.

Instâncias sem contexto podem, ainda, usar recorrência local, como mostrado no Exemplo 3.2.

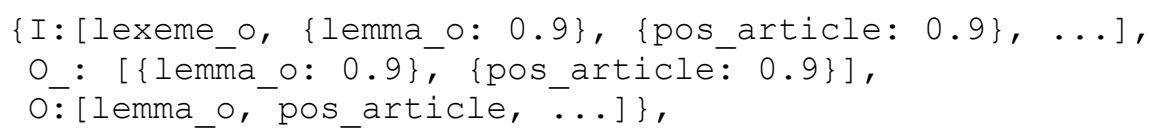

Exemplo 3.2: Modelagem da recorrência recorrência local.

$\mathrm{O}$ padrão original, antes da aplicação de recorrência, será chamado de $a$-padrão ${ }^{g}$. O Exemplo 3.2 mostra os neurônios de entrada lemma_o e pos_article gerados após a recorrência local. Essa versão modificada do a-padrão será referenciada como $b$-padrão $o^{g}$. protótipo Miolin permite incluir regras para se definir quais neurônios de saída serão convertidos em entrada. Esses novos neurônios de entrada não fazem parte dos padrões do conjunto de treinamento original, sendo gerados em tempo de execução para receberem valores da ativação de $O^{\prime}$ (definidos como 0,9 no exemplo). Assim, os neurônios recorrentes são recuperados de $O^{\prime}$ e não de $O$ (cujos valores de ativação são sempre definidos como 1).

$\mathrm{Na}$ recorrência local, neurônios mutuamente exclusivos competem, o que pode, em teoria, melhorar a classificação. Por exemplo, se ambos os neurônios pos_noun e pos_verb forem ativados na tarefa de análise morfossintática, o mais forte pode inibir o mais fraco 
(levando-se em conta o peso das sinapses que estabeleceram entre si e com a semente), aumentando o grau de confiança da rede. A Figura 3.16 da Seção 3.3.4 apresenta outro uso potencial de recorrência local, combinada com coativação para a solução de um problema do tipo ou-exclusivo. A Seção 5.1.5 apresenta um experimento (g5e4) específico para avaliar a recorrência local.

Tendo em vista o requisito funcional da generalidade, os a-padrões são genéricos, e podem ser aplicados até mesmo a tarefas que não façam parte do escopo do PLN. Por exemplo, as redes Perceptron em uso no protótipo permitem resolver os problemas conjunção (e-lógico), disjunção (ou-lógico) e negação (não-lógico), desde que os padrões contem com uma semente que recuperem o(s) neurônio(s) de saída referente(s) a verdadeiro e falso.

\subsubsection{Instâncias com contexto de janela}

Contextos neurais são uma abstração criada para representar uma frase no escopo neural, mantendo a generalidade da camada neural para aplicação em outros problemas. Em um contexto, a ordem dos padrões faz diferença ${ }^{24}$, e diferentes contextos precisam ser delimitados por um padrão contendo um pseudo-neurônio ${ }^{g}$ (convencionou-se chamar esse pseudo-neurônio de change_context no protótipo) referente ao evento de mudança de contexto. Essa abstração também é importante para a coativação, pois nela os diferentes padrões de um contexto são ativados intercaladamente em um processo iterativo (mais detalhes na Seção 3.3.2). Um exemplo de contexto é mostrado no Exemplo 3.3:

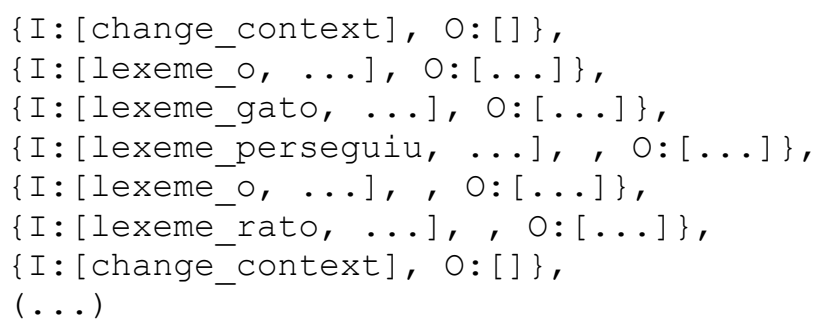

Exemplo 3.3: Representação de um contexto neural.

No contexto baseado em janela, a análise de um padrão influencia e é influenciada pela análise dos seus padrões vizinhos. Para isso, neurônios de entrada ou de saída podem ser utilizados, ou ainda, subconjuntos destes definidos a partir de regras no protótipo. O Exemplo 3.4 apresenta a análise baseada em neurônios de entrada. Seguindo a terminologia proposta na Seção 3.2.4, padrões originais serão referenciados como a-padrões, enquanto que os padrões

24 A ordem dos padrões não deve ser confundida com a ordem dos neurônios de um dado padrão. 
derivados devido ao contexto baseado em janela serão referenciados por b-padrões.

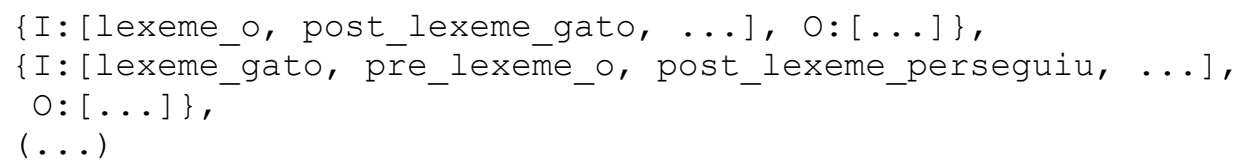

Exemplo 3.4: B-padrões com entrada do contexto.

Esse tipo de instância permite desambiguar a classe gramatical de lexema_canto em frases como "O canto da sala." ou "Eu canto pouco.", como exemplificado na Seção 3.2.1. No Exemplo 3.4, a entrada gerada pelo contexto são os eventos pre_lexeme e post_lexeme. Nota-se que esses eventos, gerados em tempo de execução juntamente com seus b-padrões relacionados, devem estabelecer sinapses diferentes dos lexemas que os originaram, justificando o aumento de dimensionalidade que acarretam. Além disso, a representação otimizada permite manter o problema tratável, mesmo com o aumento da dimensionalidade. A instância de exemplo usa a janela de tamanho 1, baseada em padrão predecessor e um padrão sucessor, embora outras instâncias possam utilizar janelas maiores. No caso de janelas grandes, repetições de neurônios podem ocorrer nos padrões, conforme exposto na Seção 3.2.3.

O Exemplo 3.5 apresenta a saída do contexto via recorrência de contexto, definida como coativação. O processo consiste em derivar neurônios de entrada a partir de neurônios de padrões presentes no contexto.

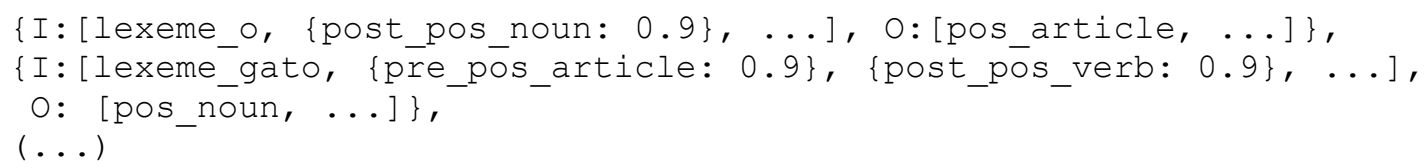

Exemplo 3.5: Coativação da janela (recorrência com b-padrões baseada na saída do contexto).

Para simplificar o Exemplo 3.5, $O^{\prime}$ foi omitido, embora seja ele que derive os novos eventos em $I$ no b-padrão. A instância do Exemplo 3.5 usa uma granularidade mais grossa para predizer as classes gramaticais do que a instância do Exemplo 3.4. Na primeira, é possível aprender que lexemas precedidos por artigos são substantivos. Já na segunda, é possível aprender que lexemas precedidos pelos lexemas "uma", "os", "as" e outros são substantivos. Assim, as duas representações armazenam o conhecimentos similares. A Seção 3.3.2 apresenta as iterações da coativação com contexto baseado em janela e esquematiza o processo na Figura 3.8. 


\subsubsection{Instâncias com contexto de árvore}

O contexto baseado em árvore é uma abstração no escopo neural para permitir o processamento de árvores de dependências sintáticas. Enquanto o contexto baseado em janela correlaciona informações horizontalmente entre vizinhos, o contexto baseado em árvore permite correlacionar informações verticalmente entre pais e filhos de uma árvore.

Uma primeira tentativa de modelagem, seria:

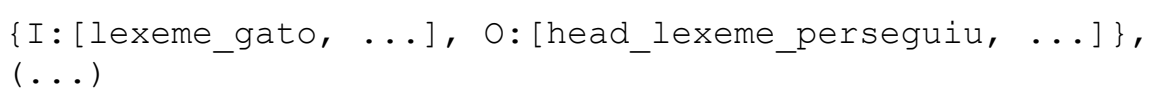

Instâncias com padrões nesse formato não são ideais para o processamento das dependências, pois quaisquer eventos head_lexeme podem fazer parte da saída, quando idealmente apenas eventos relacionados aos lexemas presentes no contexto deveriam ser considerados. Outro problema é que a representação não trata lexemas repetidos, de modo que não é possível identificar-se qual é o verdadeiro nó pai quando dois lexemas com o mesmo nome ocorrem no mesmo contexto. Para resolver esse problema, novos pseudo-neurônios foram adicionados ao modelo, resultando em padrões na forma:

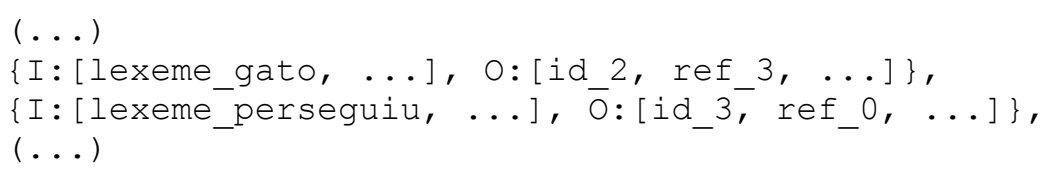

Exemplo 3.6: A-padrões (de treinamento) com pseudo-neurônios para o contexto baseado em árvore.

No caso do contexto baseado em árvore, os padrões que contém pseudo-neurônios serão chamados de a-padrões. Os pseudo-neurônios id identificam unicamente cada a-padrão de um contexto, enquanto os pseudo-neurônios ref permitem denotar o nó pai do a-padrão corrente, a raiz da árvore recebe o pseudo_neurônio ref_0. Diferentemente do contexto baseado em janela, os padrões são divididos em três variações, sendo que a-padrões derivam b-padrões e c-padrões $^{\mathrm{g}}$. B-padrões são utilizados durante o processamento de neurônios de saída dos a-padrões originais, exceto pelos pseudo-neurônios. C-padrões visam identificar a estrutura da árvore, sendo relacionados aos pseudo-neurônios dos a-padrões original. O processamento, nesse caso, consiste em identificar nó pai (isto é, o padrão pai) de um padrão com a ajuda de c-padrões. As ativações de b-padrões e c-padrões são ilustradas nos exemplos 3.7 e 3.8 , respectivamente.

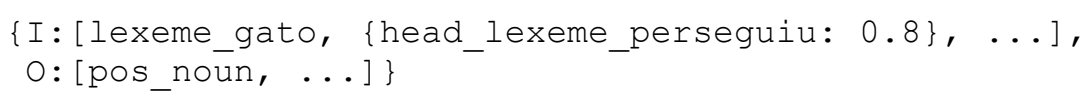


Exemplo 3.7: Ativação de um b-padrão (dos neurônios de saída).

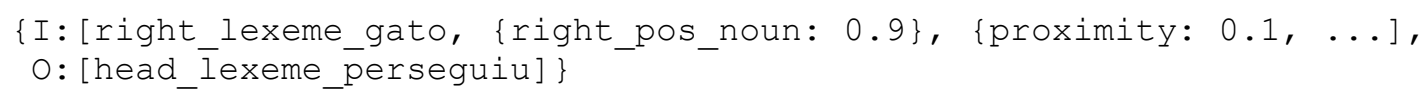

Exemplo 3.8: Ativação de um c-padrão (processamento dos pseudo-neurônios de saída).

Um a-padrão gera um único b-padrão (embora neurônios da vizinhança possam ser inseridos devido a coativação). Já os c-padrões são gerados pela combinação de a-padrões tomados dois a dois, com complexidade $O\left(n^{2}\right)$, em que $n$ é o número de a-padrões (embora neurônios de outros a-padrões possam ser inseridos no processo). A geração de b-padrões e c-padrões é exemplificada nas figuras 3.8 e 3.13 das seções 3.3.2 e 3.3.3, respetivamente. Ao final da classificação, ambas as saídas são combinadas e reconvertidas em a-padrões. A avaliação pode ser feita nos a-padrões originais (abordagem do protótipo) ou nos b-padrões e c-padrões gerados.

Os exemplos 3.7 e 3.8 trazem coativação nas duas direções ${ }^{25}$. O b-padrão recebe a saída do c-padrão head_lexeme_perseguiu, enquanto o c-padrão recebe a saída do padrão right_pos_noun (derivada de pos_noun). A Seção 3.3.4 apresenta as iterações da coativação com contexto baseado em árvore e esquematizará o processo na Figura 3.18, além de apresentar outras topologias e eventos que podem ser empregados em c-padrões.

Novos eventos latentes relacionados ao posicionamento dos lexemas como right_lexeme (no Exemplo 3.8) e left_lexeme são incluídos nos c-padrões, pois diversas categorias de lexemas tem ordens preferidas para seus núcleos, por exemplo, artigos sempre tem seus núcleos à sua esquerda na Língua Portuguesa. A ordem também é importante para identificar constituintes sintáticas, sendo a ordem S-V-O (sujeito-verbo-objeto) a mais usada no Português. No exemplo, é usado o evento proximity, gerado em tempo de execução, permitindo privilegiar lexemas mais próximos em detrimento a lexemas muito distantes no contexto. A proximidade $p$ entre dois padrões (ou seja, a proximidade dos lexemas na frase original) com posições $i$ e $j$ em um dado contexto é definida como mostrado na Equação (3.1):

$$
p=\frac{1}{|j-i|}
$$

O Exemplo 3.9 apresenta um b-padrão para um contexto baseado em janela e árvore, que combina diferentes tarefas do PLN, incluindo papéis semânticos e desambiguação de sentido.

25 Retro-alimentação entre b-padrões e c-padrões também são referenciadas por coativação, já que, c-padrões combinam informações de dois a-padrões diferentes por natureza. 


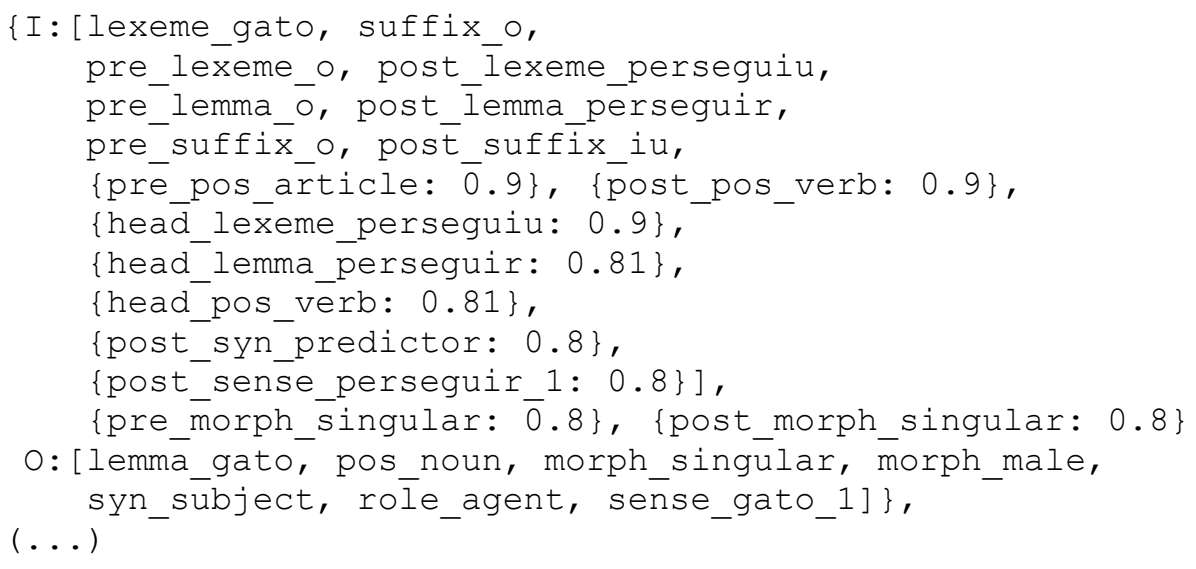

Exemplo 3.9: B-padrão para análise integrativa bidirecional.

No Exemplo 3.9, diversas análises são integradas na saída $O^{\prime}$ (morfológica, gramatical, sintática e semântica), exemplificando o segundo requisito funcional (análise integrativa). A coativação é definida para os níveis léxico (post_lemma_perseguir), morfológico (pre_morph_singular), gramatical (pre_pos_article), sintático (head_lexeme_perseguiu, head_lemma_perseguir e post_syn_predicator), e semântico (post_sense_perseguir_1). Embora a instância não explore todas as combinações possíveis, ela apresenta eventos diferentes gerados por coativação de modo a garantir a análise bidirecional proposta no Molin, dado que neurônios de entrada de diferentes níveis interagem livremente com neurônios de saída de diferentes níveis, com variados níveis de granularidade. Nota-se que eventos head tem os valores estimados pelo produto entre os neurônios no b-padrão pai e os neurônios que indicam a confiança da rede no c-padrão correspondente.

\subsubsection{Lexias complexas no contexto baseado em árvore}

Lexias complexas incluem entidades nomeadas, locuções de diferentes categorias (por exemplo, a locução conjuntiva "se bem que"), expressões da língua coloquial ("dar um tempo"), expressões formuláicas do gênero científico (“o propósito desta pesquisa foi”, “o objetivo deste artigo é"), entre outros. A Figura 3.2 ilustra diferentes representações para lexias complexas, no processamento de dependências: 


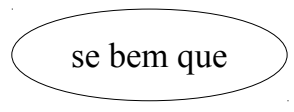

(a) aglutinante

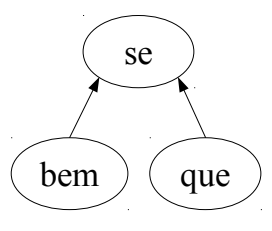

(b) rasa

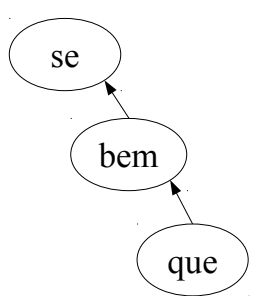

(c) profunda

Figura 3.2: Diferentes representações para alguns tipos de lexias complexas.

O analisador sintático Palavras utiliza a representação aglutinante para diferentes lexias complexas incluindo nomes próprios e locuções. Neste trabalho, as representações não aglutinantes são mais convenientes (especialmente a profunda), por diferentes razões. Em primeiro lugar, algumas lexias complexas são mais flexíveis com relação a colocação de seus lexemas, ou seja, nem sempre seus lexemas integrantes são adjacentes na oração, permitindo inclusão de lexemas, como em "o propósito desta pesquisa de doutorado foi", em que "de doutorado" foi acrescentado à expressão exemplificada acima. Outro exemplo é locução prepositiva "a pedido", que pode ocorrer com lexemas separados como em "a meu pedido". O mesmo ocorre, com intensidade aumentada, para predicados complexos (aqueles que não são constituídos por somente um verbo) (DURAN et al., 2011b) da língua inglesa (como exemplo, o verbo "let down" em "The president didn't let his electors down." - "O presidente não desapontou seus eleitores.”) ou da língua portuguesa (exemplos são os predicados "pegar mal", "cair bem", entre outros, que também permitem a inclusão de lexemas, como em "pegou muito mal", por serem menos idiomáticos, e, portanto, mais flexíveis). Segundo, representações não aglutinantes são mais flexíveis em relação a ambiguidade. Por exemplo, a locução conjuntiva "de sorte que" (como em "Trabalhou duro, de sorte que conseguiu o aumento") não ocorre na oração "Ele será o funcionário de sorte que receberá o aumento", mas pode ser erroneamente aglutinada devido a ambiguidade léxica. Em terceiro lugar, o tratamento não aglutinante aumenta a capacidade da análise de categorias de entidades nomeadas, que podem ocorrer de forma aninhada, como na Figura 3.3. 


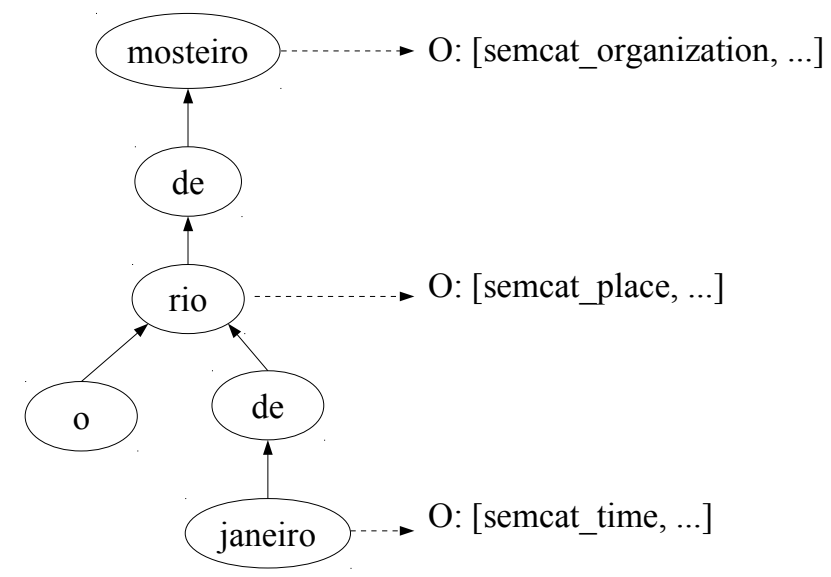

Figura 3.3: Representação para entidades nomeadas com aninhamento.

Nota-se que, diferentemente das locuções, as entidades nomeadas podem ter representações mais ricas que a representação rasa ou profunda, já que cada lexema carrega sentido próprio e pode estabelecer relações de dependência sintática mais livremente.

\subsection{Topologias}

\subsubsection{Instâncias sem contexto}

A Figura 3.4 apresenta uma ativação básica a partir da função sigmoide logística, com valores de saída de exemplo, na qual o único neurônio de entrada é lexeme_canto. Valores de sinapses e de sinapses especiais $\theta$ não são mostrados para simplificar o exemplo.

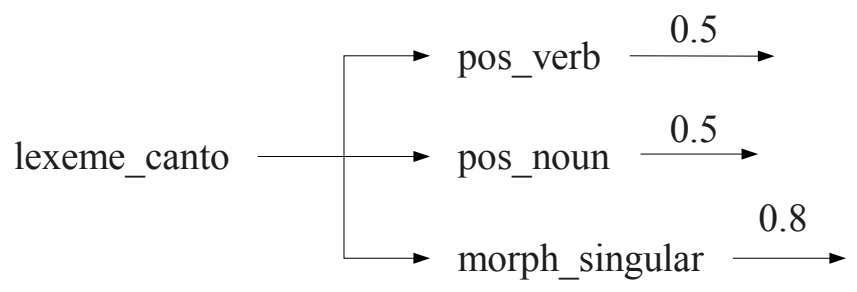

Figura 3.4: Ativação básica.

Instâncias sem contexto podem utilizar ativações tradicionais, como na Figura 3.4, ou ainda fazer uso de recorrência local, como mostrado na Figura 3.5 (ativação recorrente para duas iterações). Na Figura 3.5, as regras de recorrência se aplicam somente a eventos pos. Como resultado, a primeira ativação de morph_singular é descartada. Os eventos pos_noun e pos_verb são mutuamente exclusivos nos padrões de treinamento da instância hipotética tomada como exemplo. Como resultado do treinamento, ambos devem se inibir mutuamente. No exemplo hipotético, pos_noun é mais frequente que pos_verb. Como resultado, o primeiro tem ativação maior e inibe mais o segundo do que o contrário, observando-se que os pesos das 
sinapses podem interferir nesse comportamento.

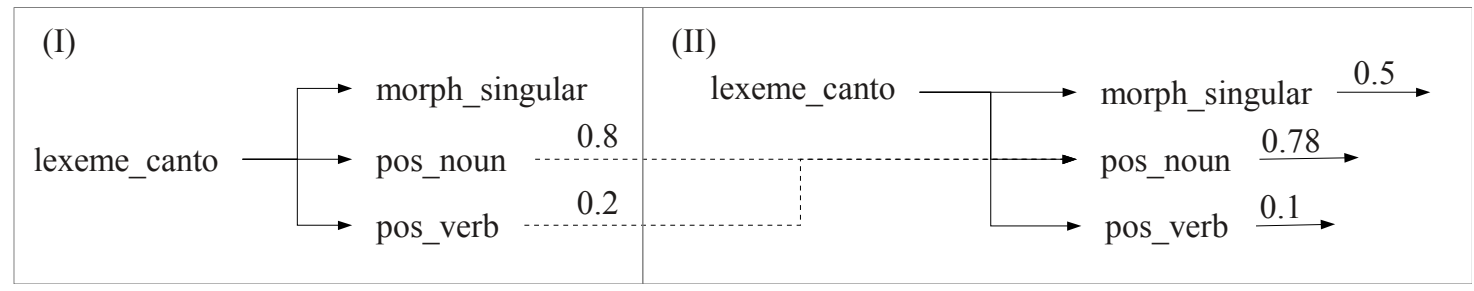

Figura 3.5: Ativação recorrente.

\subsubsection{Contexto baseado em janela}

O conjunto de entradas de um b-padrão no contexto baseado em janela é afetado pelos a-padrões vizinhos de seu a-padrão original, ou de forma simplificada, de seus b-padrões vizinhos. Um dado b-padrão pode receber neurônios de entrada de seus vizinhos, da saída de seus vizinhos ou de ambas as fontes. A Figura 3.6 apresenta duas etapas de ativação para o primeiro e o segundo padrão de "o canto de a parede", respectivamente, para a tarefa de análise morfossintática por contexto de neurônios de entrada baseado em janela de tamanho 1 . Quando apenas a entrada do contexto ${ }^{\mathrm{g}}$ é utilizada, o processamento pode ser realizado em uma única iteração. O exemplo é simplificado, de modo que post_lexeme_de é omitido de (II).

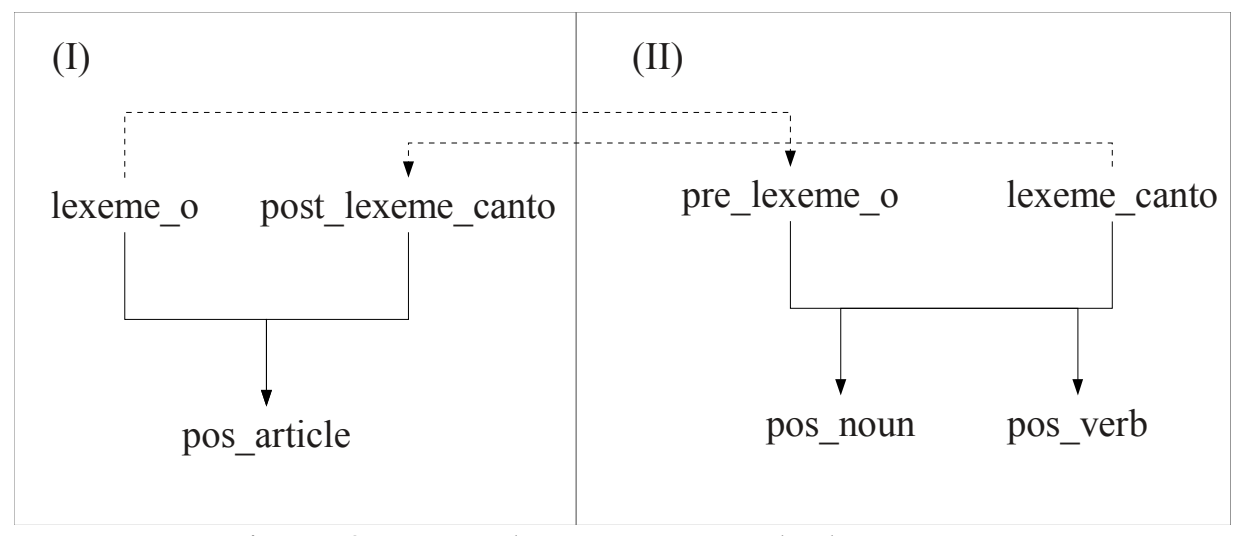

Figura 3.6: B-padrões com entrada do contexto.

O uso da saída do contextog é chamado de coativação e implica em pelo menos duas iterações para convergência por padrão, conforme exemplificado na Figura 3.7. A medida em que ativações intercaladas ocorrem, os padrões recebem novos neurônios de entrada gerados pela coativação, afetando a topologia da rede. A Figura 3.7 apresenta quatro etapas da coativação para a janela 1 no exemplo "o canto de a parede". As etapas (I) e (II) pertencem à primeira iteração, enquanto as etapas (III) e (IV) à segunda iteração. Para simplificar o 
exemplo, o processo foi reduzido e os padrões são mostrados de forma incompleta (ignorou-se a possível saída pos_pronoun para lexeme_o e omitiu-se a iteração entre o padrão contendo lexeme_canto e o padrão contendo lexeme_de).

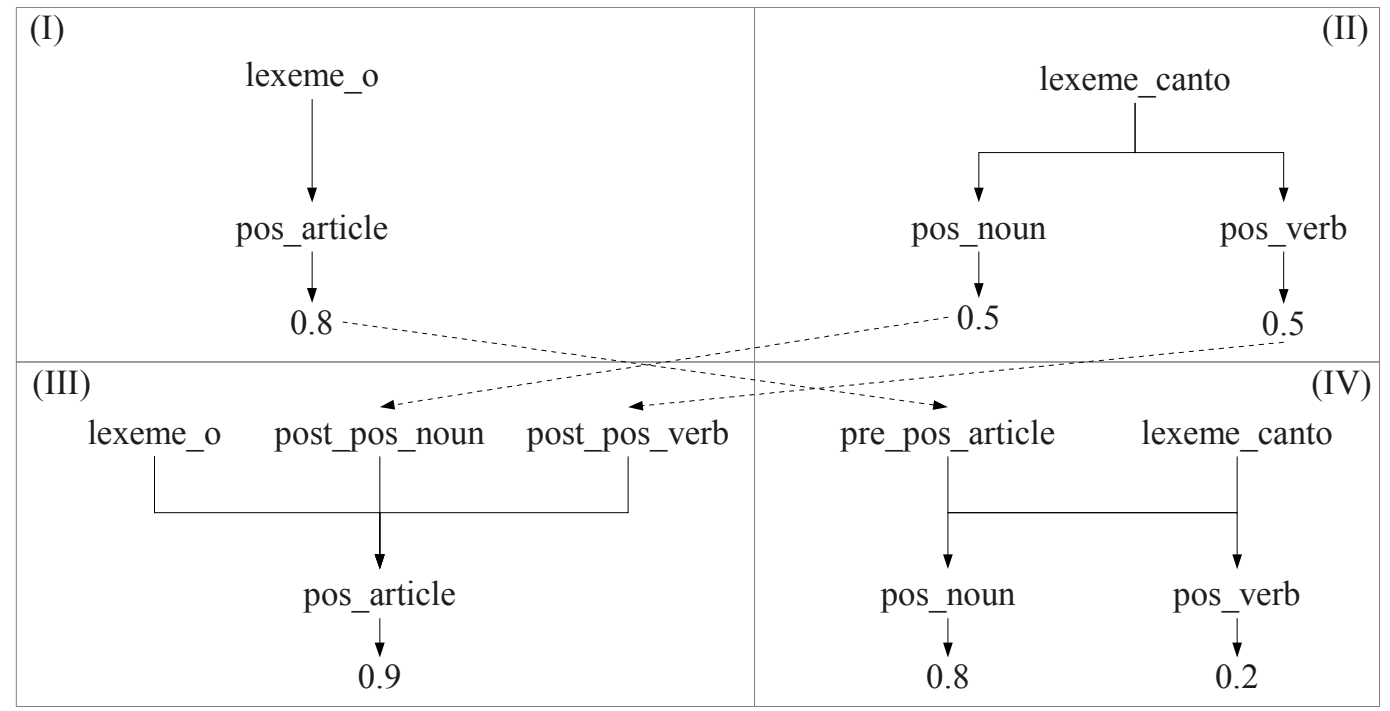

Figura 3.7: B-padrões com a saída do contexto (coativação).

O exemplo hipotético da Figura 3.7 presume um treinamento no qual lexeme_canto foi associado a pos_verb ou pos_noun em um número balanceado de padrões, de modo que é incerto tratar-se de um verbo ou substantivo logo após a primeira iteração (etapa II). A partir da saída pos_article no primeiro b-padrão, é gerado o neurônio pre_pos_article no segundo b-padrão. No exemplo, o neurônio pre_pos_article estabeleceu sinapses de modo a estimular pos_noun e inibir pos_verb, como mostrado na etapa (IV). O processo pode continuar em iterações adicionais, por exemplo fortalecendo a saída pos_article devido ao fortalecimento de post_pos_noun e o enfraquecimento de post_pos_verb. Esse caso particular entre reforço de artigos à esquerda e substantivos à direita é confirmado experimentalmente e será retomado no experimento g5e1 da Seção 5.1.5. O exemplo para fortalecer pos_verb e inibir pos_noun no segundo padrão do exemplo "eu canto pouco" é análogo ao exposto na Figura 3.7.

A Figura 3.8 apresenta de forma genérica o processo de coativação em três iterações para $n$ padrões $b_{i}$ em um contexto baseado em janela 1 . 


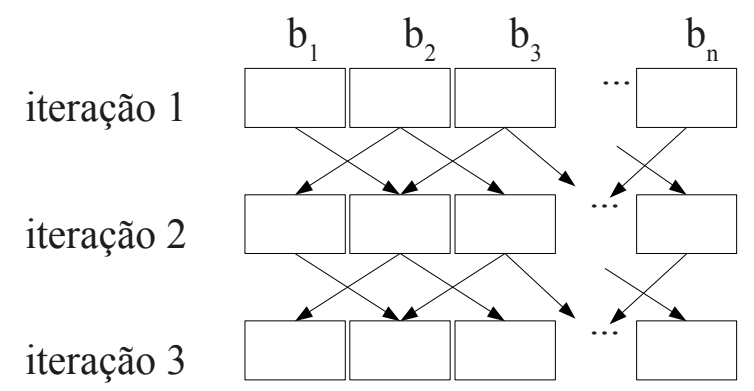

Figura 3.8: Três iterações da coativação para janela 1.

A Figura 3.9 apresenta um estudo de caso para a oração "Viveu a vida lenta e calmamente.". Em casos semelhantes, lexemas geralmente usados como substantivos e adjetivos ("lenta") comportam-se como advérbios quando são sucedidos pela conjunção "e" e por outro advérbio. O objetivo do exemplo é apresentar a flexibilidade de instâncias baseadas em janela com base em eventos reais da língua. Novamente, para simplificar o exemplo, foram omitidas partes dos possíveis neurônios, além dos pesos das sinapses.

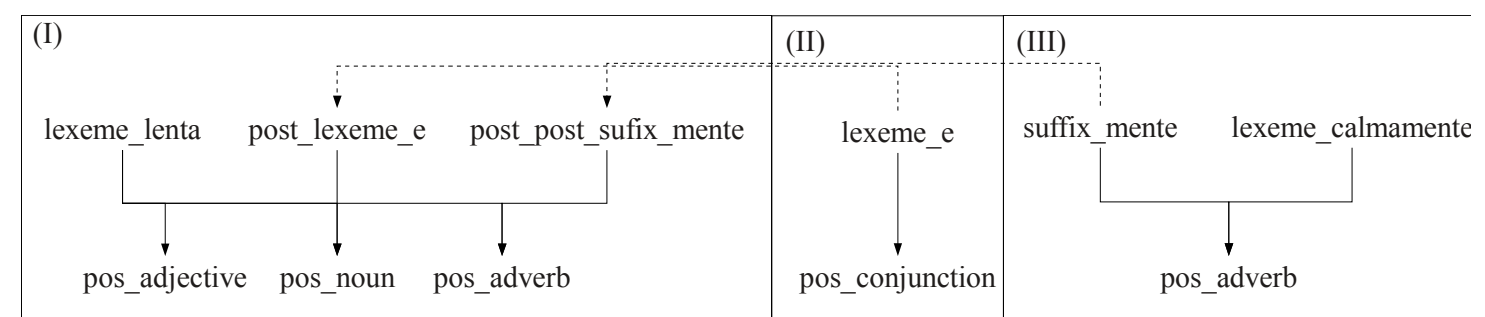

Figura 3.9: Estudo de caso "lenta e calmamente".

Pressupõem-se, como requisito para um aprendizado bem sucedido, que ambos post_lexeme_e e post_post_suffix_mente estimulem o neurônio pos_adverb, mas que isoladamente não sejam suficientemente fortes para dispará-lo, isto é, tornar sua ativação maior que 0,5 (resultando em um e-lógico). Da mesma maneira, pressupõem-se que esses neurônios de contexto devam inibir em conjunto pos_noun e pos_adjective, mas que não sejam capazes de tornar sua ativação menor ou igual a 0,5 quando ocorram isoladamente. $O$ peso das sinapses envolvidas é o fator que determina se o aprendizado bem sucedido ou não.

No exemplo, a rede neural artificial deve aprender que um lexema seguido pelo lexema “e”, seguido por um lexema terminado em "mente" deve ser um advérbio. Contudo, há aprendizados similares com o mesmo efeito. Por exemplo, que um lexema seguido por uma conjunção, seguida por um advérbio deve ser um advérbio (caso menos granular baseado em recorrência). Ou ainda, que um lexema seguido por lexeme_e, seguido por lexeme_calmamente deve ser um advérbio (caso mais granular devido a remoção do sufixo). 
Nesse cenário, cabe ao projetista da instância Molin definir qual aprendizado é o mais adequado, ou ainda, optar por incluir todos os eventos possíveis e deixar esta decisão por conta da rede neural artificial. Idealmente, o aprendizado deve ser menos granular, evitando que a rede tenha que reaprender o mesmo caso com pequenas variações (por exemplo, para "lenta e suavemente"), mas não a ponto de induzir erros de classificação. O aprendizado mais granular pode ser indesejável em alguns casos, quando será referenciado por de aprendizado pontual ${ }^{g}$.

A versão atual do protótipo Miolin não pode tirar total proveito do estudo de caso devido a otimização por semente. No exemplo, a entrada lexeme_lenta e a saída pos_adverb estabeleceriam sinapses devido ao padrão de treinamento. Contudo, um processo análogo precisaria ser feito para todos os lexemas que possam se comportar como advérbios. A solução, reservada como trabalho futuro, é alterar a otimização por semente de modo que alguns neurônios de saída específicos de baixa granularidade (como neurônios pos) sejam sempre inclusos em $O^{\prime}$ para verificar sua ativação, independentemente das sinapses estabelecidas.

\subsubsection{Contexto baseado em árvore}

Assim como no contexto baseado em janela, os b-padrões do contexto baseado em árvore também são afetados por seus vizinhos, mas também podem ser afetados por c-padrões. Por sua vez, c-padrões podem ser afetados pelos b-padrões. Diferentes instâncias podem possuir diferentes estratégias para gerar topologias para c-padrões. A Figura 3.10 ilustra duas possíveis topologias para a ativação de c-padrões, com granularidades diferentes. Para simplificar o exemplo, apenas neurônios derivados de lexemas são mostrados na entrada, excluindo-se neurônios especiais para árvore (como proximity), e outros tipos de neurônios do contexto. Observa-se, contudo, que, a ativação de c-padrões pode utilizar neurônios de saída do contexto de b-padrões, graças a coativação. Assim, instâncias mais complexas podem utilizar classes gramaticais e outras informações para decidir qual dos nós é o pai, quando aplicável.

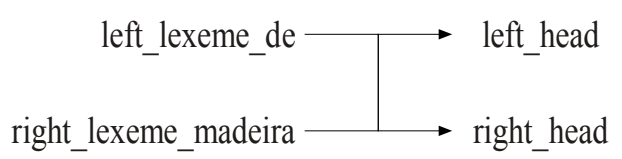

(a) estratégia menos granular

\section{right_lexeme_madeira $\longrightarrow$ head_right_lexeme_de}

(b) estratégia mais granular

Figura 3.10: Duas topologias para ativação da árvore. 
Considerando o domínio linguístico do problema no qual a rede neural artificial é aplicada, a estratégia menos granular é ideal para identificar a relação de dependência entre classes gramaticais (por exemplo, artigos modificam o que estiver a sua direita). Na Língua Portuguesa, o evento pre_lexeme_de indica que, para a grande maioria dos casos, se o lexema em análise é um substantivo, seu núcleo será seu antecessor, isto é, o lexema "de" (por exemplo, "de" é o núcleo de "madeira" em “a casa de madeira"). É fácil generalizar esse caso para outros padrões fazendo-se com que a sinapse entre left_lexeme_de e head_left seja altamente estimulante e a sinapse entre left_lexeme_de e head_right seja altamente inibitória. Como a associação é válida apenas para substantivos, neurônios pos podem ser incluídos na instância para evitar associações incorretas (por exemplo, “de" não é o núcleo de "a" em "a casa da madeira").

Por outro lado, há cenários em que a desambiguação depende mais da afinidade ${ }^{\mathrm{g}}$ entre os lexemas do que entre suas classes gramaticais, o que limita a estratégia menos granular, e motiva a estratégia mais granular. A Figura 3.11 apresenta exemplos em que o lexema dependente determina o lexema núcleo. Nas partes (a) e (c) é utilizado o lexema "vencendo" em "Disse que não pagou a conta vencendo.". No exemplo, "vencendo" será interpretado como modificador de "conta", ou seja, a data de pagamento da conta está para expirar. Nas partes (b) e (d), o lexema "vencendo" é substituído por "soluçando". Neste caso, "soluçando" será interpretado como modificador de "disse" (embora "pagou” também possa ser associado "soluçando" devido a ambiguidade inerente da língua). Ativações de exemplo são mostradas, e considera-se no exemplo que lexemas à direita estimulem de forma similar os neurônios de saída left_head e right_head.

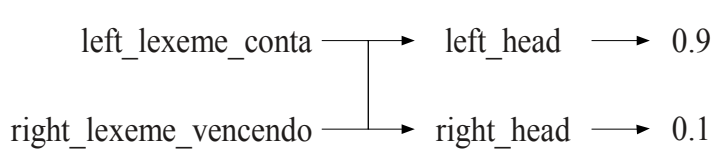

(a)

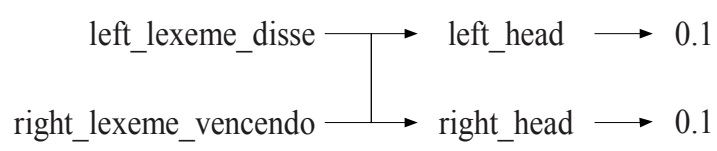

(c)

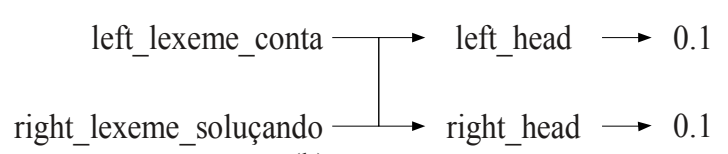

(b)

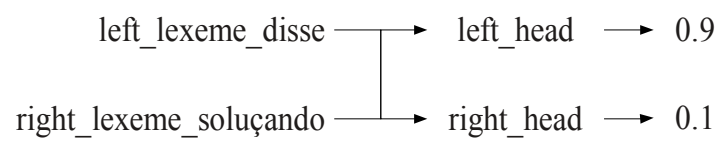

(d)

Figura 3.11: Análises com núcleo à esquerda na estratégia menos granular.

Nesse cenário, ou o neurônio left_lexeme_conta estimulará mais fortemente a sinapse left_head, ou left_lexeme_disse o fará. No primeiro caso, as análises de (b) e (d) ficam comprometidas, e lexeme_soluçando será considerado mais proximamente relacionado a 
lexeme_conta do que a lexeme_disse. No segundo caso, as análises de (a) e (c) são prejudicadas, pois lexeme_vencendo será considerado mais relacionado a lexeme_conta do que a lexeme_disse.

A estratégia mais granular da Figura 3.10 pode lidar com limitações da estratégia menos granular, identificando afinidade entre lexemas e correlatos. Por outro lado, a estratégia mais granular prejudica a generalização, pois para que a instância aprenda que lexeme_de tende a ser o núcleo de todos os lexemas imediatamente à sua direita, são necessários vários padrões para cobrir as combinações de lexeme_de e seus possíveis co-ocorrentes à direita. A granularidade fina pode prejudicar bastante o aprendizado de acordo com o tamanho do conjunto de padrões de treinamento. Esse problema ilustra o aprendizado pontual descrito previamente na Seção 3.3.2. Nota-se que o aprendizado pontual não se trata de memorização (overfitting), pois está mais relacionado à topologia utilizada ao invés do processo de treinamento. Embora cada estratégia tenha suas vantagens e desvantagens, é possível tirar proveito das qualidades de ambas em uma topologia com camadas escondidas, conforme será apresentado na abordagem híbrida (entre outras) pela Figura 3.18 da Seção 3.3.4.

A Figura 3.12 ilustra matrizes para a ativação da árvore para as duas estratégias apresentadas. Para simplificar o exemplo, é utilizado um contexto com apenas três padrões. Como um padrão não pode ser seu próprio pai (um lexema não pode ser seu próprio núcleo), a diagonal não é processada. Na estratégia menos granular, é possível, simultaneamente, em uma única ativação, verificar se há relação de dependência entre dois padrões nas duas direções possíveis, pois as saídas left_head e right_head são utilizadas nos padrões derivados, resultando em uma matriz triangular superior. Já na estratégia mais granular, é preciso de duas ativações, uma para verificar se o padrão à direita é o pai, e outra para verificar se o padrão à esquerda é o pai, resultando em uma matriz quase simétrica (isto é, com os devidos ajustes nos c-padrões complementares).

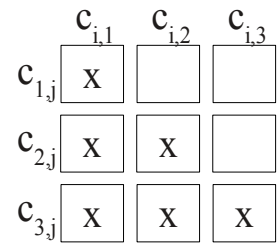

(a) estratégia menos granular

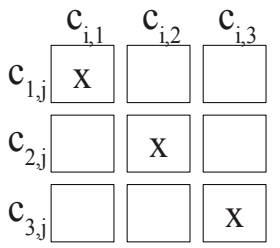

(b) estratégia mais granular

Figura 3.12: Matrizes para ativação da árvore com 3 padrões no contexto.

Seja $C$ a matriz da estratégia menos granular e $C^{\prime}$ a matriz da estratégia mais granular para a oração "eu canto pouco", os padrões (simplificados) têm a forma: 


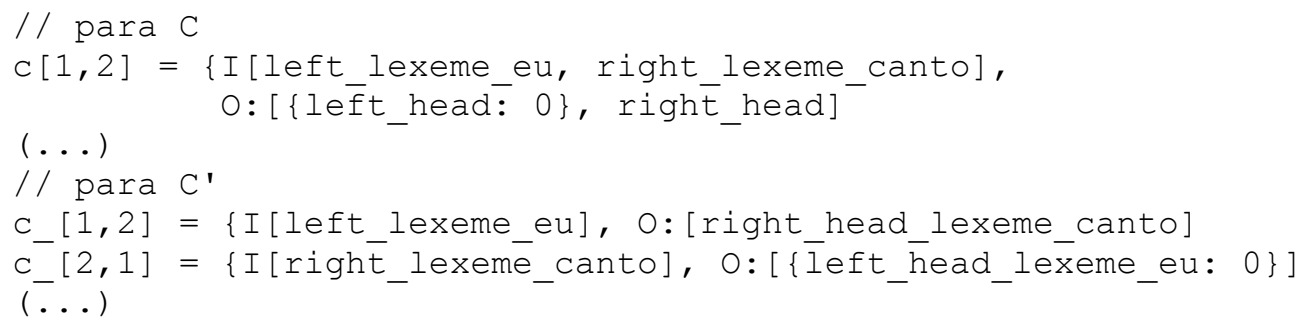

A árvore é gerada a partir das maiores ativações da matriz. Por exemplo, para a estratégia mais granular, o pai de $a_{1}$ será $a_{2}$ se a saída $c_{1,2}^{\prime}$ apresentar maior ativação que a saída $c_{1,3}^{\prime}$ ou $a_{3}$ caso contrário (considerando-se que ambos as saídas sejam superiores à 0,5 ). Para casos em que nenhuma delas atinja o corte, o projetista da instância Molin deve decidir se o resultado final do pós-processamento da matriz deve levar a uma árvore de dependências ou a um grafo de dependências. No primeiro caso, usa-se o candidato a nó pai com maior ativação, mesmo quando esta ativação seja menor ou igual a 0,5 . No segundo caso, é possível definir que apenas candidatos nós pais com ativações superiores a 0,5 sejam selecionados de fato, de forma que a instância possa apresentar à aplicação que a utiliza análises parciais, em que há nós cujos pais não foram identificados, o que indica que a instância está pouco segura sobre a análise completa de uma oração. Além disso, a abordagem baseada em grafo de dependência pode indicar nós com dois pais, destacando casos ambíguos da língua. $\mathrm{O}$ protótipo Miolin usa sempre a maior ativação para determinar um nó, simplificando a avaliação de instâncias. Contudo, não há garantias que o resultado final da análise seja uma árvore, já que existe a possibilidade de erros de classificação levarem a grafos cíclicos, embora isso não tenha sido observado nos experimentos.

A Figura 3.13 apresenta um exemplo de coativação para o contexto baseado em árvore. No exemplo, um contexto contendo três a-padrões é apresentado e pressupõem-se que: o núcleo do primeiro a-padrão seja o segundo a-padrão; que a classificação de dependências tenha sido realizada com exito; e que o primeiro a-padrão não seja núcleo de nenhum padrão (por exemplo como em "eu canto pouco"). Para simplificar o exemplo, apenas a influência do primeiro padrão nos demais é mostrada. As ativações dos c-padrões podem ser retro-alimentadas pela ativação dos b-padrões (primeiro caso da Figura 3.13). Nesse caso, para a frase de exemplo, o neurônio de saída pos_pronoun do primeiro b-padrão pode se tornar entrada na segunda iteração dos c-padrões, gerando, por exemplo, left_pos_pronoun. Já a saída da ativação dos c-padrões pode derivar neurônios de entradas dos b-padrões em sua segunda iteração (segundo caso na figura). Por exemplo, head_lexeme_canto para o primeiro 
b-padrão e dep_lexeme_eu para o segundo b-padrão.

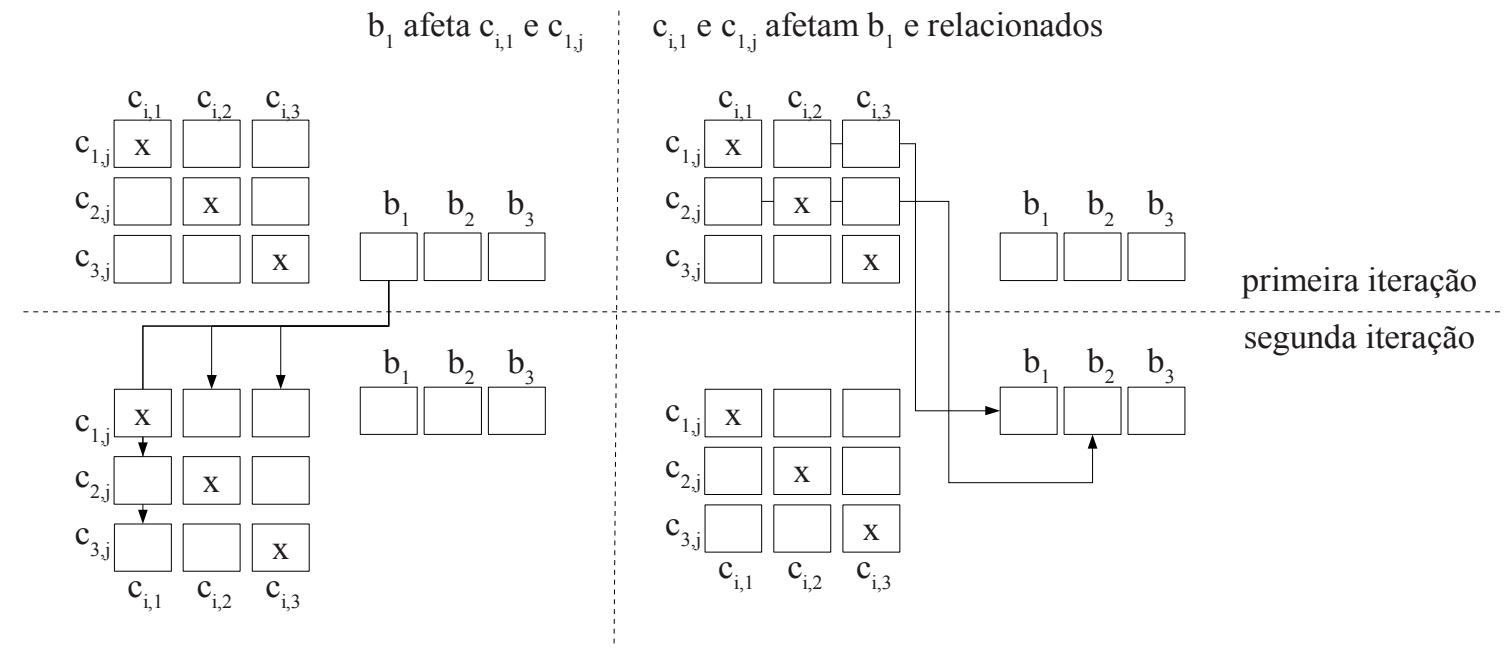

Figura 3.13: Coativação baseada em árvore de um contexto com três padrões para o primeiro padrão cujo o núcleo é o segundo padrão.

Ambos os processos foram projetados para acontecem simultaneamente. O protótipo funciona de forma um pouco distinta. Em vez de transmitir informações entre b-padrões para c-padrões apenas na segunda iteração, o processo já é feito na primeira iteração, com o objetivo de acelerar a análise. No protótipo, um b-padrão do contexto baseado em árvore pode influenciar a si mesmo (quando a recorrência está ativa), seus padrões vizinhos (quando o contexto baseado em janela está ativo), e os c-padrões relacionados ( $b_{1}$ influencia $c_{1,2}, c_{1,3}, c_{2,1}$ e $c_{2,1}$ para a estratégia mais granular de ativação de árvore no exemplo). Já um c-padrão influencia apenas b-padrões, não podendo se auto-influenciar ou influenciar diretamente outros c-padrões nas iterações subsequentes, devido a organização do Miolin. Contudo, c-padrões podem se afetar indiretamente ao afetarem b-padrões. Um b-padrão pode ser influenciado pelo c-padrão relacionado a seu núcleo ou pelos c-padrões referentes a seus possíveis dependentes sintáticos (alternativa não explorada na protótipo). Por essa razão, o padrão de saída $c_{1,2}$ afeta $b_{2}\left(b_{2}\right.$ recebe informações sobre o seu dependente) enquanto $c_{2,1}$ afeta $b_{1}\left(b_{1}\right.$ recebe informações sobre seu núcleo).

A Figura 3.14 apresenta uma versão simplificada e mais genérica da Figura 3.13. Observa-se que, no protótipo, o vetor B também transmite informações para a matriz $\mathrm{C}$ em uma mesma iteração (B é ativado primeiro). 


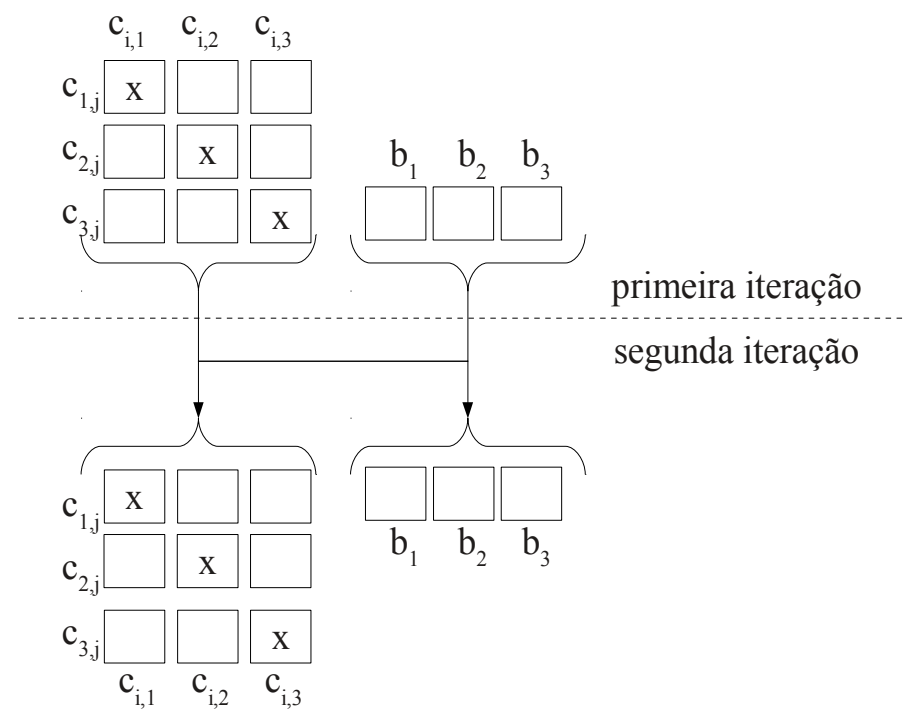

Figura 3.14: Representação simplificada da coativação baseada em árvore para contexto com três padrões em duas iterações.

No protótipo, apenas o c-padrão com maior ativação é utilizado para derivar a coativação do b-padrão correspondente, de modo a reduzir a dimensionalidade. Nota-se que, devido a erros de classificação, o c-padrão pode não ser o núcleo correto referente a um b-padrão em análise. Na versão atual do protótipo, apenas um ancestral direto (evento head) é permitido por b-padrão, mesmo quando houver mais de um ancestral plausível ${ }^{26}$. Múltiplos ancestrais diretos, ancestrais indiretos (head_head, entre outros), descendentes diretos (dep), descendentes indiretos (dep_dep, entre outros) são previstos em trabalhos futuros. O exemplo 3.10 é apresentado o b-padrão com ancestrais direto e indireto para o primeiro "o" em "O gato perseguiu o rato.":

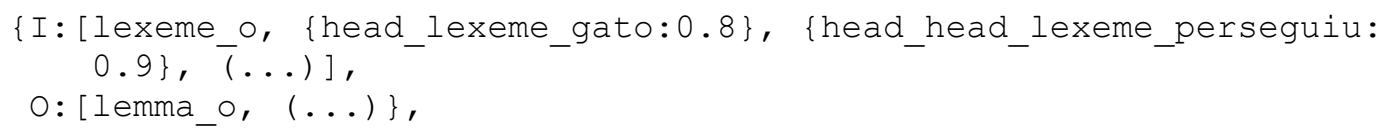

Exemplo 3.10: B-padrão com um ancestral indireto.

Para a análise c-padrões, existem casos em que a afinidade de lexemas que determina a relação de dependência é originada de descendentes indiretos, o que justifica instâncias com ancestrais indiretos ou descendentes indiretos. Por exemplo, em "separou clipes de grampos" o fragmento "de grampos" depende de "separou" ("grampos" é o neto de "separou" na árvore de dependência); já em "separou clipes de metal", o fragmento "de metal" depende de “clipes", ("metal" como neto de "clipes", embora haja uma certa ambiguidade nesse caso em

26 Essa condição é relaxada no protótipo quando o núcleo inferido para um b-padrão muda entre uma iteração e outra, de forma que o b-padrão receba informações sobre o novo núcleo sem deixar de armazenar informações sobre o núcleo antigo. 
relação a "separou"). Assim, no primeiro caso seriam derivados os c-padrões de treinamento $c_{1}$ e $c_{2}$ do Exemplo 3.11, enquanto que, no segundo caso, o contexto permitiria derivar os c-padrões $c_{3}$ e $c_{4}$.

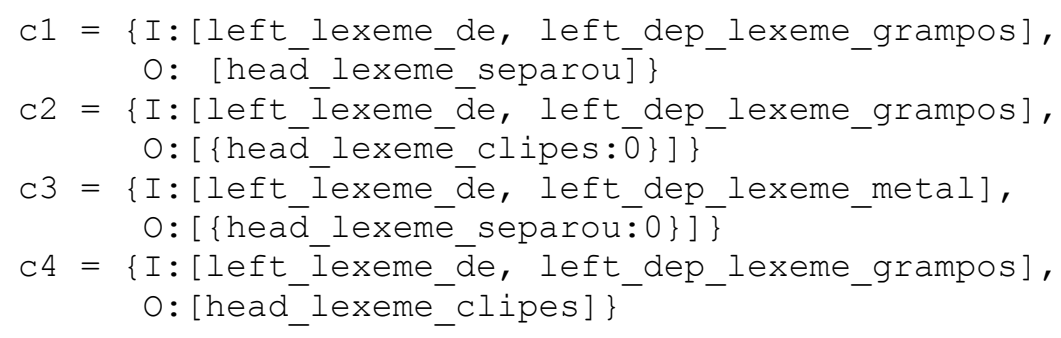

Exemplo 3.11: C-padrões com saídas positivas e negativas para "separou clipes de metais" e "separou clipes de grampos", contendo três níveis diferentes da árvore de dependência sintática.

\subsubsection{Topologias com camadas escondidas}

Redes Perceptron em uso no protótipo não são capazes de resolver o problema do ou-exclusivo, uma severa limitação no processamento de padrões não linearmente separáveis. O objetivo desta seção é apresentar alguns exemplos de padrões da língua que possuem um comportamento similar ao do ou-exclusivo. Como a versão corrente do Protótipo não permite camadas escondidas $^{27}$, os exemplos são teóricos e visam propor soluções para problemas identificados nas topologias implementadas, bem como mostrar diferentes opções disponíveis a um projetista de instâncias Molin.

A Figura 3.15 apresenta o problema do ou-exclusivo. Não há necessidade de interpretabilidade em camadas intermediárias, contudo, para facilitar o exemplo, neurônios da camada escondida foram nomeados de acordo com os papéis que desempenham na análise. Observa-se que há outras soluções possíveis para o mesmo problema.

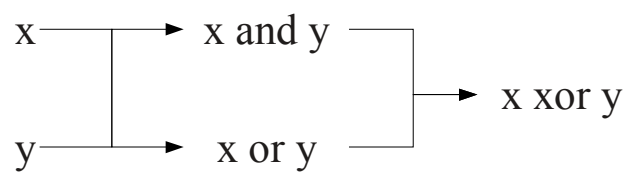

Figura 3.15: Uma das solução para o problema do ou-exclusivo com uma camada escondida.

As sinapses são omitidas do exemplo. No caso do neurônio intermediário "x or y" (ou-lógico), as sinapses estabelecidas com as entradas x e y devem ser fortes o suficiente para que esse neurônio dispare (apresente ativação maior que 0,5 ) para qualquer uma das duas

27 Algumas instâncias são multicamada devido ao uso de recorrência, porém sem uso de camadas escondidas (compostas por neurônios que não são neurônios de entrada ou de saída). 
entradas, independentes se ocorram isoladamente ou não. Já em "x and y" (e-lógico), as sinapses devem ter força para causar o disparo apenas quando as duas possíveis entradas ocorrem juntas. Por fim, "x xor y" deve ser estimulado por "x or y" e inibido (a uma taxa maior) por " $\mathrm{x}$ and $\mathrm{y}$ ", de modo que o disparo ocorra apenas quando uma das entrada ocorra.

Esse problema é aplicado na análise concordância em número. Por exemplo, "aberto” é dependente de "ambiente" em "ambiente de publicação aberto", enquanto "aberta" é dependente de "publicação" em "ambiente de publicação aberta". Para o problema em questão é muito mais vantajoso permitir que a rede neural possa identificar relações de dependências com base em informações morfológicas do que com base em afinidade de lexemas, o que geraria aprendizado pontual.

A solução para o caso com camadas escondidas para evitar aprendizado pontual é mais simples e elegante. Basicamente, para a modelagem menos granular de c-padrões, left_suffix_a e right_suffix_o devem ter um efeito inibitório tanto em right_head e left_head quando co-ocorrem. Contudo, seu comportamento não é monotônico, pois quando não ocorrem simultaneamente, é permitido que afetem a saída positivamente, já que não há problema de concordância (de gênero) detectado. $O$ mesmo vale combinações como left_suffix_o e right_suffix_a, para left_suffix_os e right_suffix_o, entre outras. Observa-se que a modelagem escolhida entre as várias possíveis é o que definirá a flexibilidade e as limitações de uma instância. Outra instância mais flexível, pode, por exemplo, tratar o mesmo problema com coativação, baseando a análise nos eventos morph_singular, morph_plural, morph_male e morph_female.

Um estudo de caso combinando o problema do ou-exclusivo com recorrência local e contexto baseado em janela é apresentado na Figura 3.16. Para a análise de "programas" em "vários programas foram adquiridos", a saída esperada deve conter morph_plural. Contudo, no contexto "tu programas bem", o mesmo lexema é associado a morph_singular. No exemplo, suffix_s deve exercer influência positiva em morph_plural e negativa em morph_singular, para maioria dos casos, considerando-se que lexeme_programas ocorra mais na forma de substantivo. Contudo, quando lexeme_programas é um verbo, o neurônio recorrente pos_verb deve apresentar o comportamento contrário. Nota-se que existem outras soluções para resolver o mesmo problema. A solução apresentada pode, inclusive ser estendida para o Inglês. Por exemplo "dogs" (“cães”) é plural na maioria dos contextos (como em "The dogs bark." - "Os cães latem.”), contudo, deve ser associado a singular quando 
tratar-se de um verbo ("The spy dogs her target." - "A espiã persegue seu alvo."). O comportamento pode ser generalizado facilmente para vários casos semelhantes do Inglês em que o mesmo lexema associado há um substantivo no plural também é usado como verbo na terceira pessoa do singular.

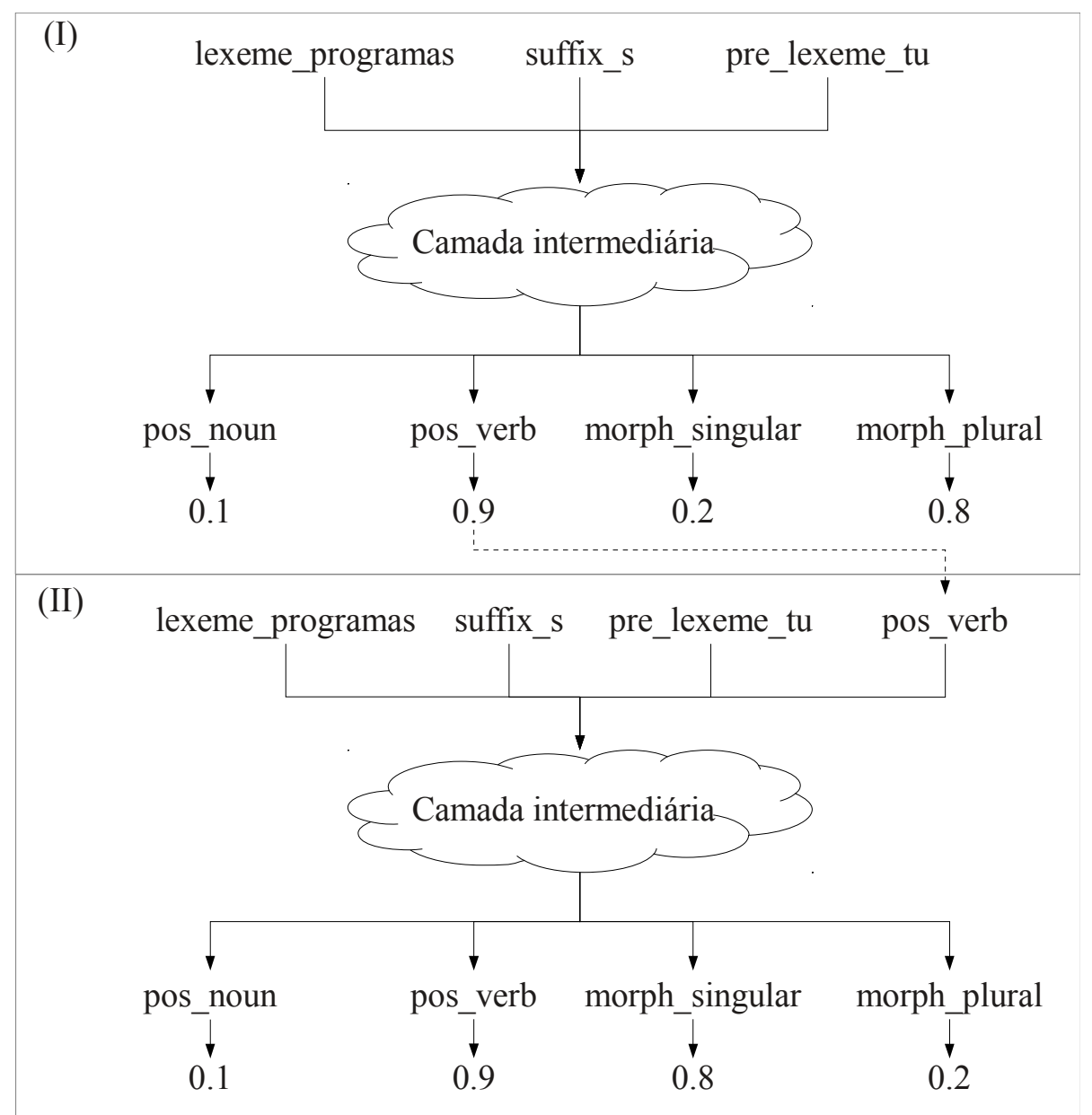

Figura 3.16: Ou-exclusivo em uma instância combinando recorrência local e contexto baseado em janela.

Idealmente, redes com camadas escondidas não devem apresentar desempenho inferior a redes Perceptron. Devido a isso, sugere-se que o número de neurônios em camadas escondidas de uma instância Molin seja maior igual ao número de neurônios de entrada ou ao número de neurônios de saída, conforme mostrado na Figura 3.17 (sinapses omitidas no exemplo devem ser consideradas com pesos próximos de zero). 


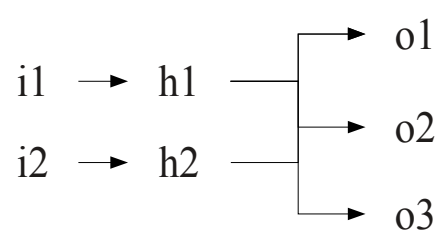

(a) $|\mathrm{I}|<|\mathrm{O}|$

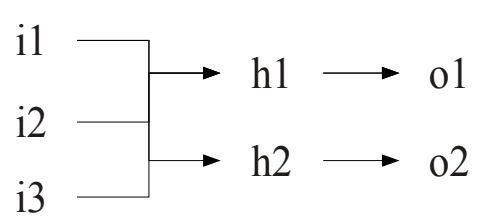

(b) $|\mathrm{I}|>|\mathrm{O}|$

Figura 3.17: Propagação neural simples envolvendo a camada escondida.

No caso de instâncias Molin, esse número se refere apenas aos neurônios que estão participando de uma dada ativação, e não ao total de neurônios disponíveis. Quando o número de neurônios ocultos é igual ou superior ao número de neurônios de entrada, a camada escondida $H$ pode simplesmente propagar a entrada $I$ para a saída $O$ (item (a) da Figura 3.17). Já quando o número de neurônios ocultos é igual ou superior ao número de neurônios de saída, a camada intermediária pode proceder com a classificação e simplesmente repassar o resultado para a camada de saída. Com isso, a instância com uma camada escondida se comporta de forma similar a uma instância sem camada escondida, embora não idêntica, já que aqui a função de ativação é aplicada em duas camadas diferentes.

A Figura 3.18 apresenta diferentes estratégias para topologias com camadas escondidas. O exemplo se baseia em c-padrões, por terem mais características relacionadas ao processamento de camadas escondidas do que os b-padrões (como a verificação de concordância em gênero e número). São apresentadas topologias para processar um c-padrão de exemplo, extraído de dois b-padrões $l$ (à esquerda) e $r$ (à direita). No exemplo, $l_{1}$ e $l_{2}$ são eventos de entrada quaisquer associados a $l$, enquanto $r_{l}$ e $r_{2}$ são eventos quaisquer associados a $r$. Os lexemas são destacados como $l x$ e $r y$, associados a $l$ e $r$, respectivamente. Especificamente para o caso dirigido a lemas, $l x$ e associado ao $l x_{l}$, enquanto $r y$ é associado a dois possíveis lemas, $r y_{1}$ e $r y_{2}$. 


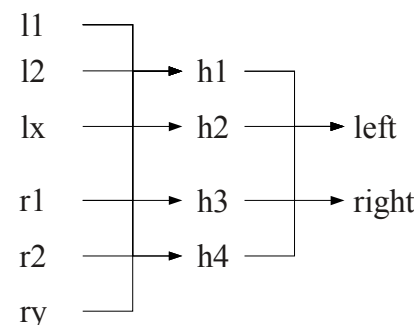

automática

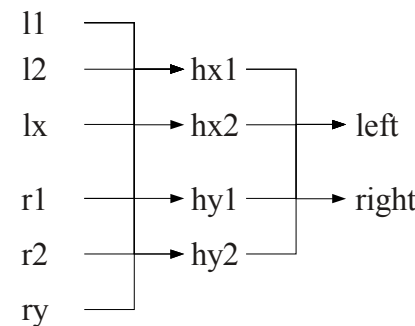

dirigida a padrão

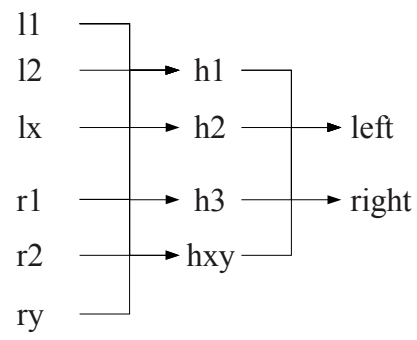

dirigida a afinidade (lexemas)
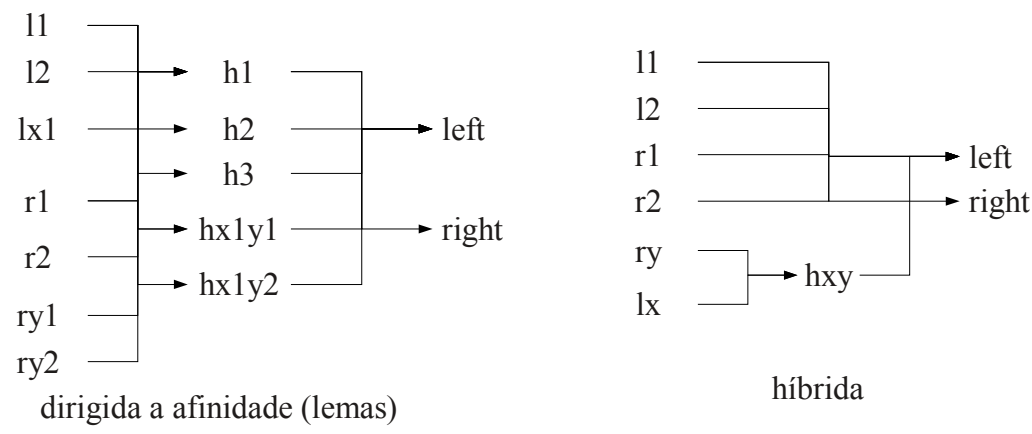

Figura 3.18: Diferentes topologias para camadas escondidas.

A topologia automática se baseia em um número fixo de neurônios na camada escondida. Conforme discutido nessa seção, é ideal que esse número seja maior ou superior ao número de neurônios de entrada ou maior ou superior ao número de neurônios de saída. Como esse número varia de padrão para padrão nas instâncias Molin, é ideal que a regra se aplique pelo menos para a maioria dos padrões. Os neurônios da camada escondida podem assumir papéis cuja a interpretação é direta, como no exemplo da Figura 3.15, ou ainda papéis de interpretabilidade difícil. Esses papéis podem variar ainda, de acordo com o c-padrão em análise, devido a variação nos neurônios de saída e de entrada ativos (e suas respectivas sinapses) entre um c-padrão e outro.

$\mathrm{Na}$ topologia dirigida a padrões, lexemas e correlatos determinam os neurônios intermediários presentes em cada ativação. A topologia aumenta o número de neurônios escondidos disponíveis na base de dados, assim como o número das sinapses associadas a esses neurônios, embora o número de neurônios e sinapses ativos em uma ativação c-padrão permaneça similar. Este cenário aumenta a granularidade da análise devido à introdução de novos neurônios, e permite que a camada de saída receba informações mais detalhadas sobre os lexemas que estão em processamento, embora isso pode acentuar o aprendizado pontual. De forma mais genérica, os neurônios intermediários podem ser associados a qualquer grupo de atributos discriminativos (sementes de modo geral e lemas) sobre os padrões ao análise, em vez de apenas lexemas e correlatos. 
$\mathrm{Na}$ topologia dirigida a afinidade, os atributos discriminativos são utilizados para gerar parte dos neurônios da camada escondida, enquanto o restante da camada pode ser completado segundo a topologia genérica ou dirigida a padrões. O objetivo dessa topologia é permitir que a afinidade entre neurônios discriminativos seja levada em conta durante a análise. $\mathrm{O}$ processo equivale a um produto cartesiano aplicado sobre neurônios discriminativos, gerando neurônios cujos nomes são associados a bigramas de nomes de eventos. No segundo exemplo referente a topologia dirigida à afinidade, lemas são utilizados, exemplificando neurônios de entrada que não possuem ativação máxima, pois lemas são recuperados por coativação da análise de b-padrões, com diferentes níveis de confiança. $\mathrm{O}$ segundo caso é interessante por mitigar o aprendizado pontual, ao mesmo tempo em que permite que afinidades sejam utilizadas na análise, uma vez que a camada intermediária recebe neurônios gerais e neurônios granulares referente às afinidades. Observa-se que lemas foram utilizados, de forma a acentuar associações mais genéricas.

Por fim, a topologia híbrida combina características das redes Perceptron e diferentes estratégias camadas escondidas apresentadas. O projetista de uma topologia Molin deve levar em conta o tipo de aprendizado que as instâncias devem fazer, de forma a obter melhores resultados e minimizar o aprendizado pontual. Trabalhos futuros incluem o comparativo das diferentes topologias apresentadas apoiadas sobre dados empíricos nas tarefas do PLN.

\subsection{Arquitetura baseada em camadas}

A Figura 3.19 apresenta a arquitetura baseada em camadas utilizada no protótipo Miolin.

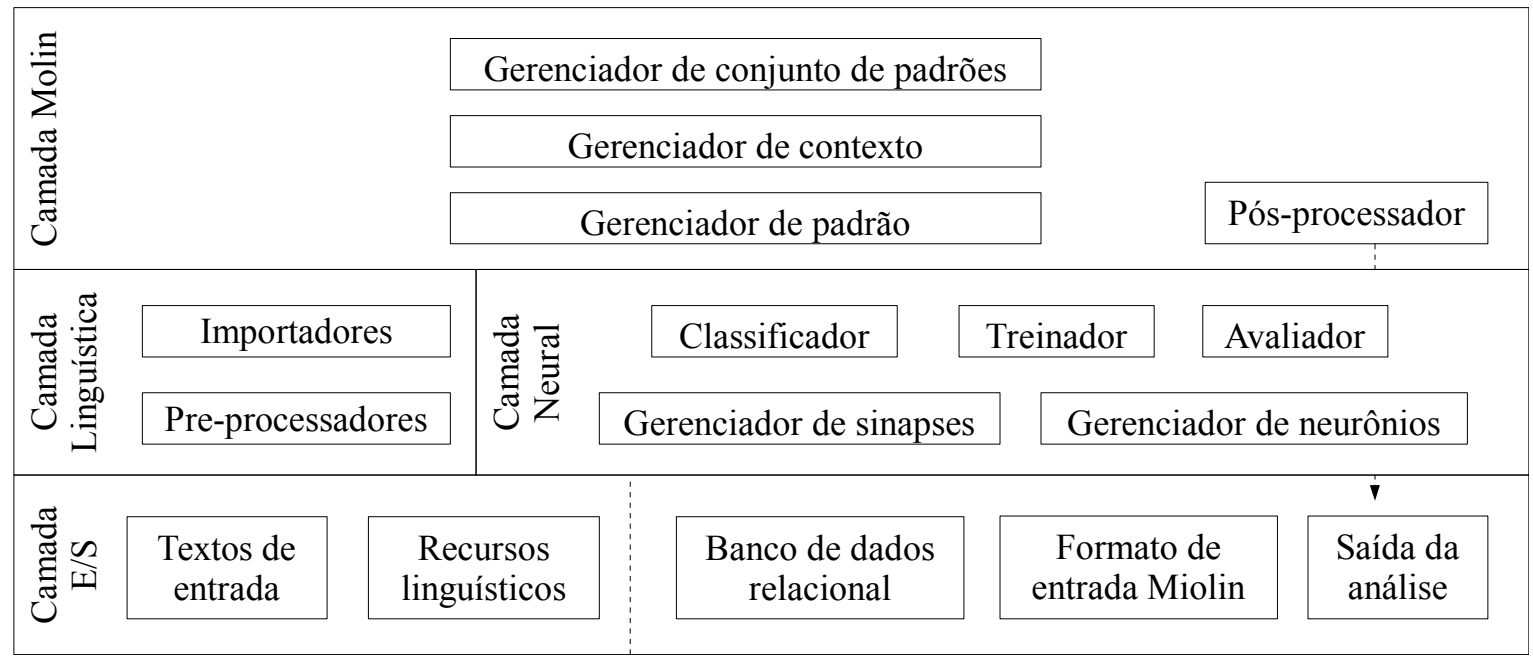

Figura 3.19: Arquitetura baseada em camadas. 
Cada camada é baseada em um conjunto de módulos que proveem as funcionalidades necessárias para o protótipo. As funções das camadas são:

- Camada de Entrada e Saída (E/S) (Seção 3.4.1): a mais simples das camadas, relacionada aos dados processados. Dados são separados em linguísticos e neurais, em um esforço para manter a camada neural genérica. Dados da tarefa linguística são não estruturados (os textos para análise) ou (semi-)estruturados (recursos linguísticos como glossários e córpus anotados). Dados para a tarefa neural referem-se aos padrões de treinamento no formado Json em uso no Miolin, a base relacional neural, e a saída da análise realizada por uma dada instância Molin.

- Camada linguística (Seção 3.4.2): atua como uma ponte para a camada neural, acessando recursos linguísticos providos da camada de entrada e saída e convertendo-os em padrões para o processamento da camada neural por meio de tokenizadores e importadores de diversos formatos linguísticos (semi)-estruturados. Como a camada neural é independente da língua, a camada linguística deve utilizar boas estratégias para converter os dados, mapeando eventos linguísticos para neurônios artificiais de forma estratégica. A Seção 3.4.2 apresenta os recursos utilizados nos experimentos do Capítulo 5, bem como a metodologia escolhida para mapeamento de eventos. Observa-se que essa camada não realiza operações como a construção de árvores de dependência, tarefa delegada à camada Molin, com base em abstrações para a tarefa de modo a manter a camada genérica.

- Camada neural (Seção 3.4.3): provê acesso aos algoritmos para manipular redes neurais artificiais. Os módulos proveem as funcionalidades de classificação, treino e avaliação (realizada para um padrão, enquanto a camada Molin permite avaliação de um conjunto de padrões), e interagem com o banco de dados de neurônios e sinapses.

- Camada Molin (Seção 3.4.4): processa parte das instâncias definidas no modelo Molin, recebendo a-padrões gerados da camada linguística, convertendo-os em b-padrões e, opcionalmente, c-padrões, e repassando a conversão para a camada neural. A camada possui módulos para lidar com padrões individuais, com contextos de padrões e com conjuntos de padrões (datasets) compostos por vários contextos. $\mathrm{O}$ módulo gerenciador de padrões armazena padrões, além de permitir sua ativação e treinamento. $\mathrm{O}$ módulo de contexto contém parte das inovações apresentadas neste trabalho. Ele é responsável por combinar a-padrões em um contexto, por gerar a 
coativação, e por prover abstrações de janela de lexemas e árvore de dependências. O módulo gerenciador de conjuntos de padrões é responsável por processar parte da avaliação Molin e acessar as funcionalidades de treinamento e classificação da camada neural para grandes conjuntos de padrões. Por fim, um pós-processador é utilizado para converter a análise em formato amigável para aplicações que dependam das funcionalidades providas pelo protótipo.

\subsubsection{Camada de entrada e saída}

A camada de saída é relacionada ao formato nativo baseado em Json do Miolin e a importação e processamento de recursos. O Exemplo 3.12 apresenta um exemplo da versão corrente do formato nativo.

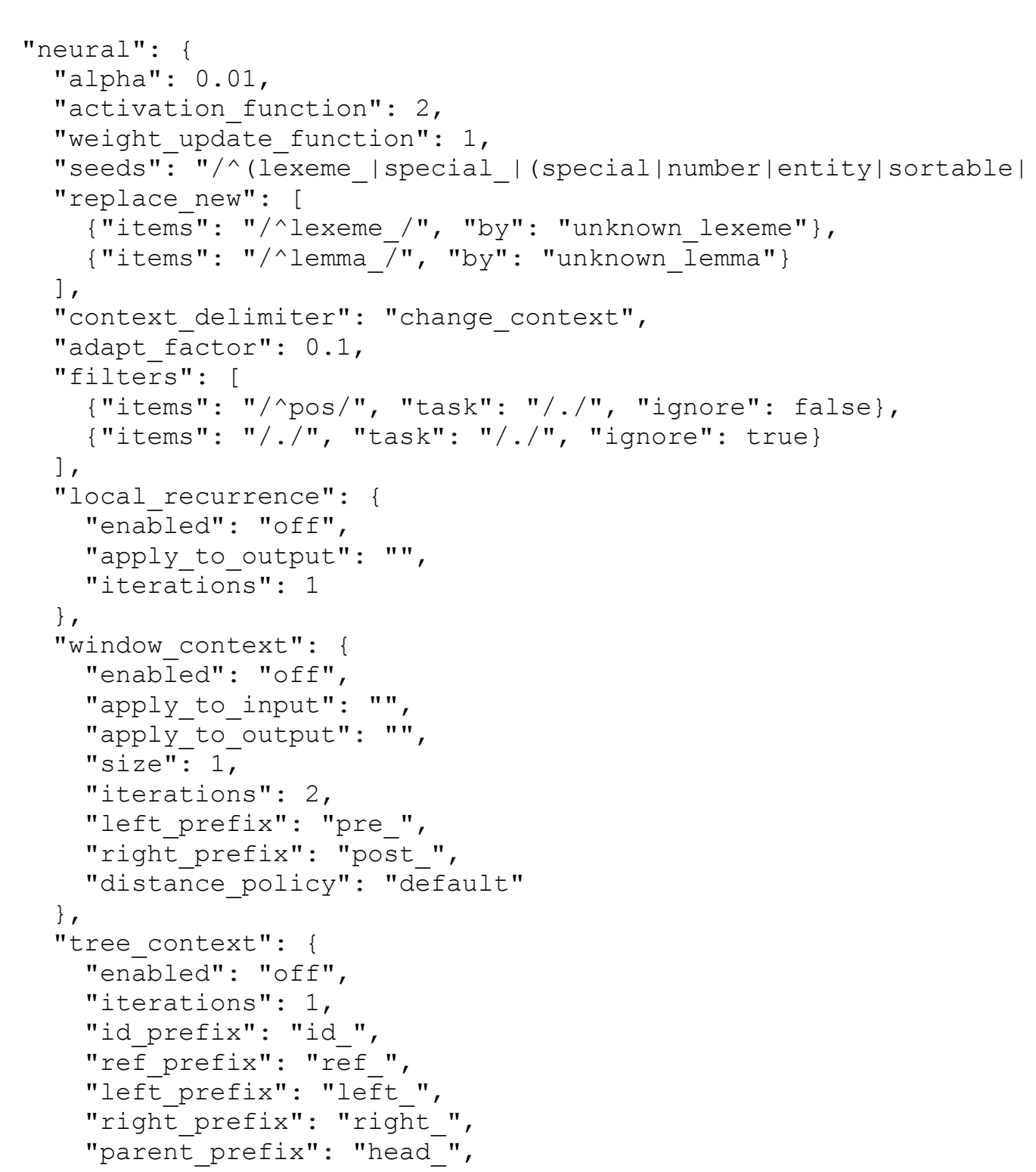




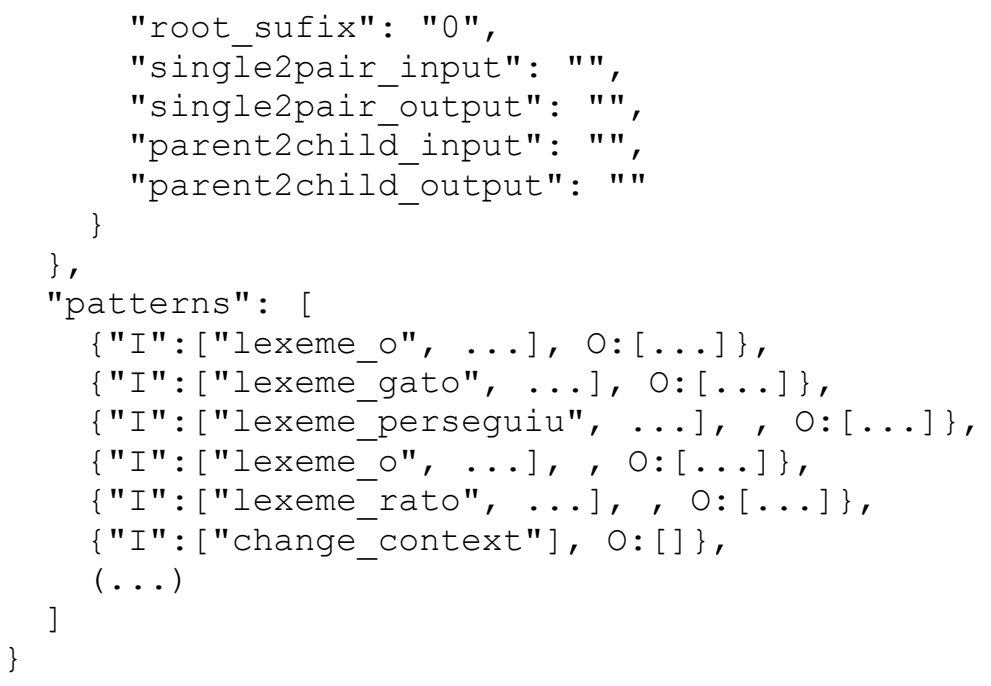

Exemplo 3.12: Formato nativo do Miolin.

O formato é similar para dados de entrada e para a saída processada. No primeiro caso, $O^{\prime}$ não é permitido, $O$ pode estar presente em conjuntos de treinamento. No segundo caso, pontuações da classificação são adicionadas no elemento $O^{\prime}$. Parte elementos Json da seção neural estão relacionados a aspectos técnicos do protótipo e não serão detalhados. O Apêndice A.3 contém a documentação de todos os elementos. Os principais elementos são:

- alpha: a taxa de aprendizado mínima da rede. O protótipo usa taxas de aprendizado decrescentes individuais para as sinapses. Mais detalhes sobre elas serão apresentados na Seção 3.4.3.

- activation_function: permite alternar entre a função Passo e a função sigmoide na ativação de b-padrões e c-padrões.

- weight_update_function: permite alternar entre a função de atualização de pesos tradicional para redes Perceptron e a função tradicional para redes MLP.

- seeds: específica quais são as sementes em cada padrão. O uso de barras delimitadoras permite denotar expressões regulares (WALL et al., 2000) para identificar diferentes tipos de sementes (o mesmo vale para diversos elementos do formato nativo), como em "/semente/". Na versão corrente, cada a-padrão deve conter exatamente uma seed, com exceção de padrões com o pseudo-neurônio para mudança de contexto.

- replace_new: permite gerar eventos genéricos relativos a lexemas e lemas desconhecidos para fases posteriores a aquisição léxica.

- context_delimiter: o pseudo-neurônio que sinaliza a mudança de contexto. 
- filters: permite definir filtros ordenados que podem ser aplicados aos neurônios de saída. Um filtro pode indicar que um neurônio deve ser mantido ou removido da análise. Quando mais de um filtro se aplica, a ação é tomada com base no primeiro filtro aplicável. Quando nenhum filtro se aplica, a ação tomada é manter o neurônio na análise. Filtros podem variar com a tarefa, por exemplo, variando para treinamento e teste de um padrão, de forma a atender requisitos de alguns dos experimentos. Além disso, a tarefa também afeta como os neurônios são filtrados. Para treinamento, neurônios filtrados são removidos antes da ativação de um padrão. Para teste, eles participam da ativação e são ignorados nas fases posteriores da análise.

- local_recurrence: permite definir os parâmetros da recorrência local, incluindo o número de iterações em uso e a regra que define quais neurônios de saída participam da recorrência.

- window_context: permite definir os parâmetros do contexto baseado em janela, incluindo a entrada e a saída do contexto, os novos nomes dos neurônios derivados do contexto e as iterações quando a coativação estiver em uso.

- tree_context: análogo a window_context, mas para o contexto baseado em janela. Seus parâmetros controlam as iterações da coativação, quais neurônios de entrada e de saída dos c-padrões serão transferidos para b-padrões e o inverso, as regras para derivar nomes dos novos neurônios gerados e os nomes dos pseudo-padrões que determinam a árvore de dependência.

Esta camada também é responsável por pré-processar recursos linguísticos. Essa tarefa inclui normalizar dados de entrada para reduzir a dimensionalidade da rede. Embora a representação seja eficiente em dimensionalidades altas, a redução de dimensionalidade é benéfica em alguns cenários para evitar aprendizado pontual. Por exemplo, o tratamento de capitalização dos lexemas permite gerar um evento único para diferentes capitalizações. $\mathrm{O}$ Exemplo 3.13 ilustra diversos cenários de normalização, incluindo possibilidades não cobertas pela versão atual do protótipo. Comentários são denotados por barras duplas.

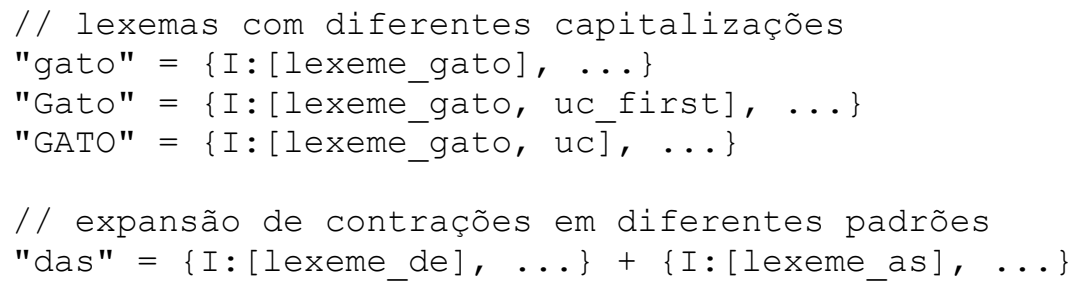




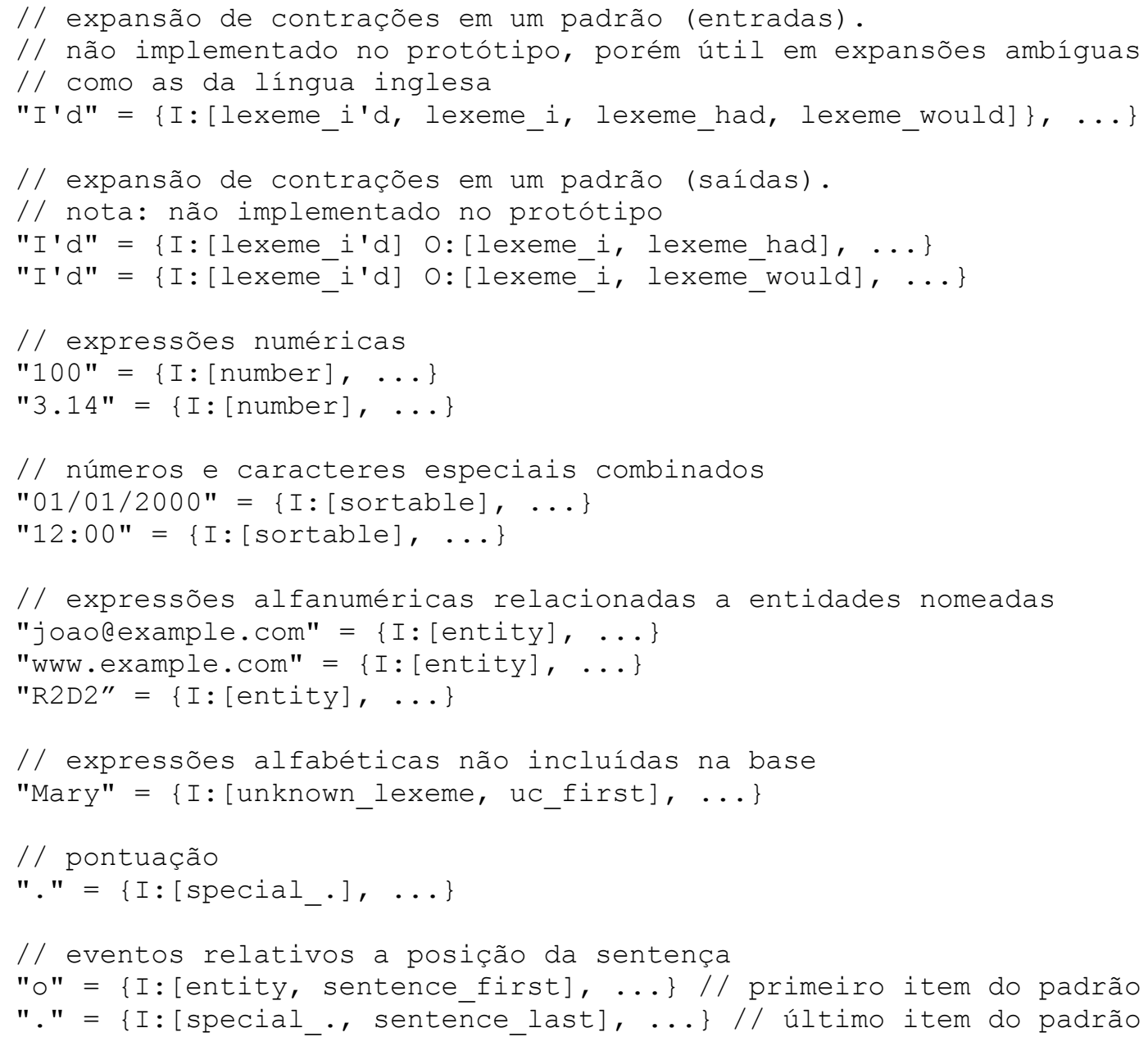

Exemplo 3.13: Pré-processamentos da camada de E/S.

As tarefas de normalização incluem: converter lexemas e correlatos em neurônios; extrair eventos extras dos lexemas quando aplicável, como eventos relacionados a sufixos e capitalização (por exemplo, útil em camadas superiores para reconhecer entidades nomeadas compostas por substantivos simples como "A Odisseia"); processar expansões (incluindo casos ambíguos); e detectar alguns tipos de entidades nomeadas.

\subsubsection{Camada linguística}

$\mathrm{Na}$ versão atual do protótipo, três recursos linguísticos são processados pela camada linguística: o glossário Unitex-PB, baseado no formato Dela (Dictionnarie Electronique du $L A D L$ - Dicionário Eletrônico LADL) (MUNIZ, 2004; MUNIZ et al., 2005); o córpus Mac-Morpho (ALUÍSIO et al., 2003a, 2003b, 2004), um córpus para treinamento de anotadores morfossintáticos; e o $\mathrm{PLN}-\mathrm{Br}^{28}$, projeto aprovado pelo CNPq (Conselho Nacional 
de Desenvolvimento Científico e Tecnológico) no âmbito do edital CTInfo/MCT/CNPq ${ }^{\circ}$ 011/2005, que gerou um grande córpus de textos jornalísticos da Língua Portuguesa (BRUCKSCHEN, 2008). Neste trabalhou usou-se a versão Full do PLN-Br anotada pelo analisador sintático Palavras para prover anotação de dependências e funções sintáticas. Para a tarefa de classificação, a camada linguística é capaz de importar também texto não anotado.

O glossário Unitex (referenciado por Dela) contem 878 mil lexemas, incluindo algumas repetições de lexemas devido à ambiguidade de classe gramaticais (mas não devido à ambiguidade de flexão). O tamanho do glossário é elevado devido às muitas conjugações verbais possíveis, à presença de lexemas que estão caindo em desuso, e também devido algum ruído na geração automática de lexemas a partir de gramáticas criadas para a tarefa. Como resultado, após a aquisição léxica, existem aproximadamente 878 mil neurônios na base. $\mathrm{O}$ número de sinapses é ainda maior, pois lexemas estabelecem sinapses com suas classes gramaticais e outras informações morfológicas.

O córpus Mac-Morpho (referenciado por Mac) contém aproximadamente 1,2 milhões de lexemas flexionados e correlatos, incluindo classes gramaticais para os lexemas mas não outras informações como eventos morfológicos. Foi usada a versão do córpus para treinamento de anotadores morfossintáticos.

O córpus PLN-Br (referenciado como Pln) em sua versão Full permitiu a geração de mais de 38 milhões de a-padrões (incluindo padrões para a mudança de contexto). A anotação do Palavras permitiu incluir lexemas e correlatos, lemas, informação morfológica, dependências sintáticas, funções sintáticas e anotação semântica (referente a categorias léxicas).

Exemplos de a-padrões dos três recursos são apresentados no Apêndice A.2. Os córpus foram divididos em subcórpus menores para os experimentos, usando-se a a notação “córpus-LN", em que $L$ é uma letra do alfabeto referente ao tamanho do subcórpus ("a" para um contexto com pelo menos 10 a-padrões; "b" para aproximadamente 100 a-padrões; "c" para aproximadamente mil a-padrões; e assim por diante para potências de 10) e $N$ um número referente ao deslocamento em relação ao córpus original. Aproximações são realizadas para acomodar contextos inteiros (o que é particularmente importante para os dois casos "a" e "b"). Por exemplo "Pln-f2" indica um subcórpus referente a segunda porção do PLN-Br dividido em partes de 1 milhão de a-padrões (aproximadamente). Letras maiúsculas indicam o complemento de um subcórpus (por exemplo, Pln-G1 contém todos os a-padrões 
que não fazem parte de Pln-g1). Por fim, deslocamentos podem ser negativos, denotados por apóstrofe, indicam padrões extraídos da porção final de um córpus (por exemplo, Mac-b2' corresponde a, aproximadamente, os últimos 100 a-padrões do Mac-Morpho). Apóstrofes possuem menor precedência que números (em outras palavras, Mac-B2' deve ser lido como o complemento de Mac-b2').

O processo de mapeamento de etiquetas dos recursos para eventos da rede neural usou uma estratégia para facilitar o aprendizado em redes neurais artificiais, em primeiro lugar, lidando com a atomicidade dos eventos, em segundo lugar lidando com questões de especificidade/generalidade.

Idealmente, eventos devem ser atômicos, isto é, não ser compostos por outros eventos menores. Essa distinção, contudo, nem sempre é clara. Por exemplo, o Palavras possui a etiqueta " $1 \mathrm{~s}$ " (primeira pessoa do singular). Por um lado, a etiqueta corresponde pode ser considerada relacionada a um evento átomo: a primeira pessoa do singular. Nesse caso, o evento "1s" faria parte de um grupo com seis eventos átomos ("1s", "2s", "3s", "1p", "2p", “3p"). Por outro lado, a etiqueta pode ser interpretada como referente a dois eventos átomos distintos: o número (singular) e a pessoa (primeira). Nesse caso, haveria dois grupos de eventos átonos, um para a pessoa (com eventos "1", “2" e "3") e outro para o número (com eventos s e p). Neste caso em particular, a segunda alternativa é melhor, pois verbos devem concordar em número com substantivos na função de sujeito, de modo que é melhor comparar números (singular e plural) diretamente do que inferi-los de acordo com uma das seis possíveis pessoas da primeira alternativa. De modo geral, no mapeamento, priorizou-se escolhas mais estratégicas em relação ao estabelecimento de sinapses potencialmente úteis, embora as tarefas de PLN ao qual a instância Molin se destina também devam ser levadas em conta.

Em relação à especificidade e generalidade de algumas etiquetas, buscou-se trazer mais opções de granularidade. Por exemplo, o Palavras utiliza uma etiqueta para nomes próprios (PROP) e uma para substantivos comuns $(\mathrm{N})$. No protótipo, a etiqueta para nomes próprios é mapeada para os eventos pos_proper (indica um nome próprio) e pos_noun (indica um substantivo). O objetivo desse mapeamento duplo é permitir que padrões contendo nomes próprios tirem proveito das sinapses estabelecidas por pos_noun (em uma instância com coativação ou recorrência local), já que todo o nome próprio também é um substantivo. Assim, o neurônio pos_proper e seus derivados não precisam aprender a realizar ativações 
típicas de substantivos já aprendidas por pos_noun, minimizando o aprendizado pontual.

O protótipo aplica mapeamentos duplos regularmente nas etiquetas do Palavras, para permitir que a rede neural artificial estabeleça melhores sinapses. Contudo, também existem casos de agrupamento de etiquetas diferentes, como verbo auxiliar finito (FMV) e no infinitivo (IMV). Nesse caso em particular, o agrupamento foi feito, pois outras etiquetas também são utilizadas para indicar a finitude de um verbo, de modo que as duas etiquetas são redundantes. Nem todas as etiquetas redundantes foram removidas, por estarem relacionadas a níveis diferentes. Por exemplo, as etiquetas para o caso dativo syn_dative (@DAT) e morph_dative (DAT), relacionadas a níveis da língua diferentes. Além disso, há casos de mapeamentos nulos em todos os recursos, relativos principalmente a informações pouco revelantes para os experimentos ou que demandem estratégias diferenciadas não cobertas pelas versões de contexto processáveis pelo protótipo.

Unitex-PB, Palavras e Mac-Morpho usam conjuntos de classes gramaticais levemente distintos. O Palavras substitui algumas classes gramaticais por outras para melhorar a análise de dependência. Por exemplo, a classe "det" (determinante) engloba artigos e alguns pronomes (capazes de modificar nomes como "este", "nosso", entre outros). Observa-se que ambos os conjuntos são semelhantes, com poucas exceções. Isso deve ser levado em conta em comparativos, principalmente entre o PLN-Br (Palavras) e o Mac-morpho.

Casos de etiquetas não mapeadas incluem etiquetas para indicar se orações são declarativas, interrogativas ou afirmativas. Esse caso demanda alguns ajustes no protótipo para que a pontuação seja filha da raiz durante a análise de dependências (atualmente tratada como filha do padrão anterior) e que eventos dep sejam incluídos na análise. Assim, o núcleo da oração poderia disparar os eventos declarativo, interrogativo ou afirmativo sempre que uma as pontuações correspondentes ocorrerem na última posição da oração (identificada pelo evento sentence_last). Trabalhos futuros incluem uma revisão nas etiquetas mapeadas até o momento para tratar casos como esse. O mapeamento completo das etiquetas dos recursos se encontra disponível no Apêndice A.1.

Entidades nomeadas são tratadas pela abordagem aglutinante no Palavras. Para mapeá-las para instâncias Molin, as entidades foram desmembradas. Isso melhora o desempenho das instâncias, mas ainda não é o cenário ideal, pois durante o desmembramento, perde-se a classe gramatical e diversas informações sobre os lexemas constituintes. Por exemplo em "Rio de Janeiro", "Rio" recebe as informações da entidade nomeada original, 
enquanto que "de" e "Janeiro" apenas recebem informações de dependência na abordagem profunda. Pontuações também são associadas a seus lexemas (ou correlatos) predecessores. Em um caso especial raro, pontuações no início da oração (por exemplo, travessões) são associadas à raiz. Trabalhos futuros também envolvem melhorar o processo de extração de entidades nomeadas aglutinadas e de análise de pontuações.

Outra função da camada linguística é prover funcionalidades de pré-processamento linguístico do texto, por exemplo convertendo textos para a nova ortografia, em vigor desde 2009.

\subsubsection{Camada neural}

O Algoritmo 3.1 apresenta versões simplificadas de funções e estruturas de dados para a ativação de padrões e neurônios na camada neural. Neurônios e sinapses são representados por estruturas de dados. Devido às características das instâncias Molin, a mesma estrutura de dados é utilizada para neurônios de entrada e de saída, já que não há distinção entre eles na base de dados. Cada neurônio armazena também o valor do peso da sinapse especial $\theta$ associada. O peso da sinapse especial é sempre incluído na integra na ativação, não sendo associado a nenhum neurônio de entrada. A estrutura de dados para sinapse armazena o peso da sinapse e os neurônios associados. A camada neural provê a ativação de padrões criados pela camada Molin conforme a função pattern_activation, e não distingue b-padrões de c-padrões. A ativação de um padrão consiste em ativações individuais de cada candidato a saída, de acordo com a função neuron_activation. O protótipo permite as funções passo e sigmoide logística na ativação (apresentadas previamente na Seção 2.1), contudo, para simplificar o algoritmo, apenas a segunda foi exibida.

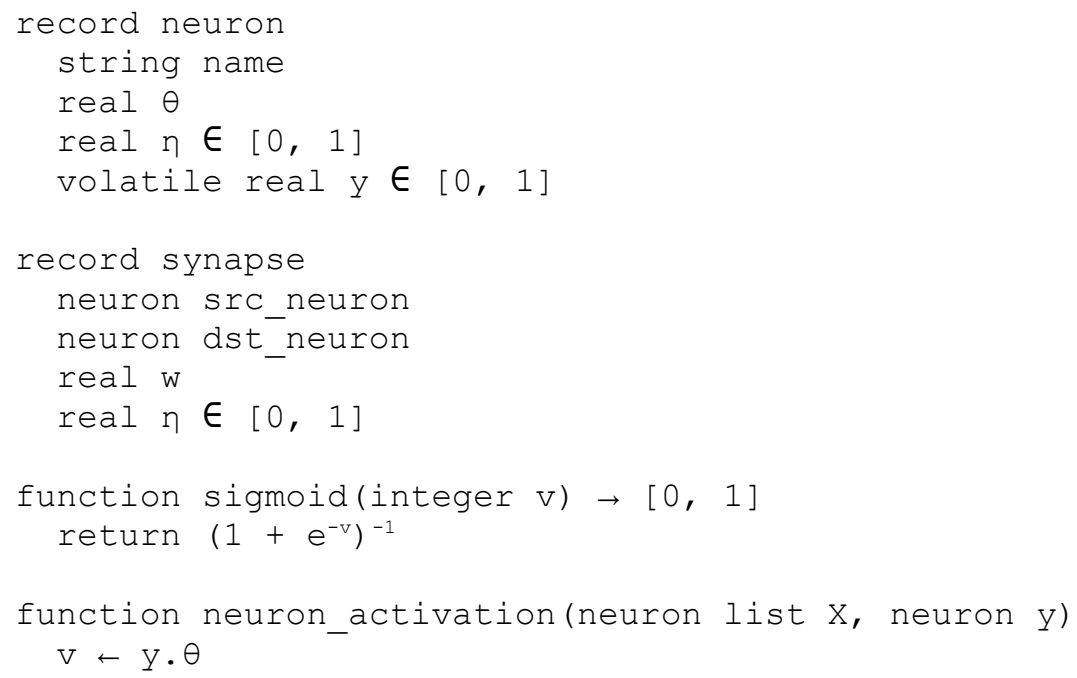




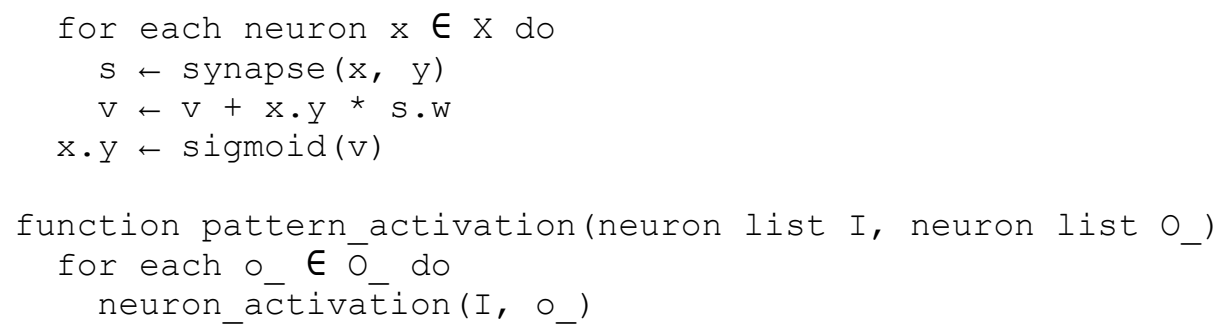

Algoritmo 3.1: Ativação na camada neural.

O ajustes de pesos para o treinamento provido pela camada neural é realizado padrão a padrão, um por vez, (online learning) em contraste ao ajuste realizado para o conjunto de padrões inteiro (offline learning). Na camada Molin, quando contextos são ativados, o aprendizado é algo intermediário entre online e offline (embora mais próximo de online), uma vez que grupos de padrões (o contexto neural) são treinados juntos.

O protótipo se baseia em taxas de aprendizado $\eta$ decrescentes, processo também conhecido como annealed learning rate (BÖS \& AMARI, 1999). Devido ao domínio do problema, optou-se pelo uso de taxas de aprendizado individuais para cada sinapse (incluindo sinapses $\theta$ ), já que apenas neurônios e sinapses mais frequentes se beneficiariam da taxas de aprendizados maiores, enquanto uma grande quantidade de lexemas raros (ou outros eventos raros) poderiam surgir no treinamento muito depois de a taxa de aprendizado ter assumido o seu valor mínimo. A abordagem também favorece a inserção de neurônios e sinapses $a$ posteriori (em abordagens neurais construtivas), bem como o aprendizado de novas tarefas em uma instância, minimizando interferências nas tarefas aprendidas anteriormente, cujo o aprendizado já se estabilizou. As taxas são introduzidas em ambas as estruturas de dados, já que neurônios armazenam informações sobre sinapses especiais $\theta$ por conveniência. $O$ taxa de aprendizado para uma sinapse $i$ no $t$-ésimo ajuste de pesos no qual a sinapse participa é definido pela Equação (3.2), em que $\alpha$ é um parâmetro definido pela instância Molin que representa valor mínimo para a taxa de aprendizado de uma sinapse.

$$
\begin{aligned}
& \eta_{i, 0}=1 \\
& \eta_{i, t+1}=t^{-1}, \text { if } t^{-1}>\alpha \\
& \alpha, \text { otherwise }
\end{aligned}
$$

O Algoritmo 3.2 apresenta as funções relacionadas ao treinamento providas pela camada neural. A função pattern_training recebe um padrão de treinamento completo, incluindo a entrada $I$, a saída desejada $O$ com ativações 1 e a saída obtida $O^{\prime}$ pré-ativada pelas funções de ativação. Os pesos de cada neurônio de saída são ajustados de acordo com sua ativação e sua presença ou ausência em $O$ e O' com a ajuda da função neuron_training. Os 
pesos podem ser ajustados de acordo com o ajuste para redes Perceptron ou MLP, embora o algoritmo apresente apenas a versão MLP por simplicidade.

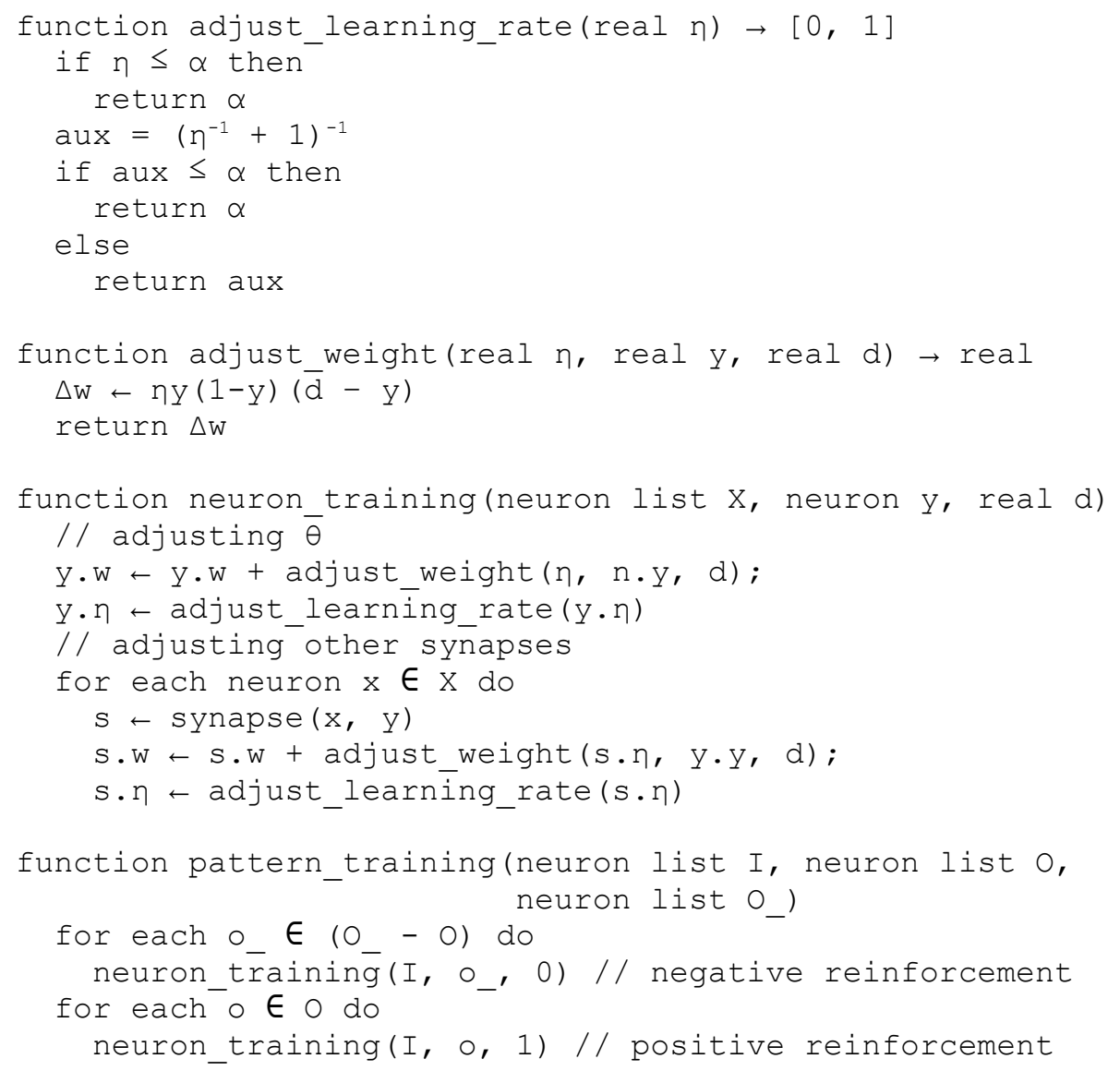

Algoritmo 3.2: Treinamento na camada neural.

A Avaliação é feita em conjunto pelo módulo avaliador da camada neural e o módulo gerenciador de conjuntos de padrões, já que ela é referente a conjuntos completos de padrões e não a padrões individuais. Como a análise foca em pequenos subconjuntos de neurônios e sinapses de um universo de neurônios e sinapses muito maior na base de dados, faz sentido adaptar as métricas de avaliação para lidar com conjuntos. O protótipo utiliza as seguintes métricas e avaliação:

- Msee (Extended Mean Square Error - erro quadrático médio estendido): o erro quadrático médio é uma medida clássica na avaliação de redes neurais artificiais. A versão estendida em uso no trabalho ignora neurônios e sinapses que não façam parte da ativação sendo avaliada, o que também é ideal para reduzir o tempo de processamento necessário para o teste. Seja I um conjunto de padrões de entrada pertencente ao conjunto de padrões de treinamento IS. Sejam DI e YI os conjuntos de neurônios de saída para as saídas desejada e obtida em relação a entrada I, 
respectivamente. Seja o um neurônio de saída em DI ou YI. Sejam yI,o e dI,o as saídas desejadas e obtidas de o. A medida Msee é definida em ().

$$
\operatorname{msee}(I S)=\sum_{I \in I S} \frac{\sum_{o \in Y_{I} \cup D_{I}}\left(d_{I, o}-y_{I, o}\right)^{2}}{\left|Y_{I} \cup D_{I}\right|}
$$

- Jac (Mean Jaccard Index - índice de Jaccard médio): o índice de Jaccard (MALAKASIOTIS et al., 2007) é aplicado para medir similaridade entre conjuntos, conforme (3.4a), sendo denotado por $j$. A medida Jac, definida em (3.4b), consiste no índice de Jaccard médio para o conjunto de padrões de avaliação. Neurônios de saída que não foram disparados (ou seja, possuem ativação menor ou igual a 0,5 ) são removidos de $Y_{I}$.

$$
\begin{aligned}
& j(I)=\frac{\left|D_{I} \cup Y_{I}\right|}{\left|D_{I} \cap Y_{I}\right|} \\
& j a c(I S)=\frac{\sum_{I \in I S} j(I)}{|I S|}
\end{aligned}
$$

- Dic (Mean Dice's Coefficient - coeficiente de Dice médio): o coeficiente de Dice (MALAKASIOTIS et al., 2007) é outra medida comumente empregada para medir similaridade entre conjuntos, conforme (3.5b), sendo denotada por $d c$. A medida é similar ao índice de Jaccard, além de guardar semelhanças com medida-F, amplamente utilizada na área de recuperação de informações e aprendizado de máquina, combinando as medidas precisão e cobertura em uma análise orientada a classes. Assim como o índice de Jaccard, o coeficiente de Dice é aplicado neste trabalho para conjuntos de neurônios (de um dado padrão), em contraste a conjuntos de padrões. Apenas neurônios disparados são considerados na análise.

$$
\begin{aligned}
& d c(I)=\frac{2\left|D_{I} \cup Y_{I}\right|}{\left|D_{I}\right|+\left|Y_{I}\right|} \\
& \operatorname{dic}(I S)=\frac{\sum_{I \in I S} d c(I)}{|I S|}
\end{aligned}
$$

- Jacf (Fuzzy Jac): uma versão da medida Jac para conjuntos difusos (fuzzy sets). Em conjuntos difusos, um elemento pode pertencer parcialmente a um conjunto, de acordo com um grau de pertinência. Graus de pertinência são obtidos pelas ativações dos neurônios de saída em $Y_{I}$ e pelos elementos $D_{I}$, cuja a pertinência é sempre 1. A união e a interseção entre esses dois conjuntos é realizada de acordo com as 
definições de conjuntos difusos. O mesmo se aplica à norma do conjunto, que corresponde ao somatório dos graus de pertinência de seus elementos.

- Dicf (Fuzzy Dic): caso análogo a Jacf para a medida Dic. Nos experimentos, normalmente ambas as medidas Dicf e Jacf são menores que suas versões clássicas, e são interpretadas como o grau de confiança da instância em suas predições.

- YinD ( $Y$ is subset of $D-Y$ pertence a $D)$ : percentual de padrões nos quais a saída obtida pertence a saída desejada (incluindo casos em que os dois conjuntos são iguais). Apenas neurônios disparados são considerados. Instâncias Molin tendem a trazer menos neurônios da saída esperada, devido à forma como a otimização por semente funciona, elevando levemente essa medida.

- DinY ( $D$ is subset of $Y-D$ pertence a $Y$ ): caso complementar a YinD, no qual são computados casos em que a saída desejada pertence à saída obtida.

- DeY ( $D$ equal to $Y-D$ igual a $Y$ ): percentual de instâncias cuja a saída obtida e a esperada são iguais, sendo uma medida próxima da acurácia.

De modo geral, as medidas permitem analisar a similaridade entre as saídas desejada e obtida (Jac, Dic, Jacf e Dicf), a confiança da rede (Msee, Jacf e Dicf), o equilíbrio entre precisão e cobertura (YinD e DinY) e as predições perfeitas (DeY).

\subsubsection{Camada Molin}

A camada Molin recebe a-padrões da camada linguística ou da camada neural, gera novos padrões e os repassa para a camada neural. Para isso, a camada Molin se baseia em algoritmos que atuam sobre os algoritmos da camada neural, de forma a prover recorrência local, além de entrada e saída (coativação) para os contextos baseados em janela e árvore. Estruturas como árvores de dependência ou contextos de lexemas da camada linguística não são acessíveis à camada Molin, que deve prover abstrações para lidar com essas estruturas da camada linguística.

O Algoritmo 3.3 apresenta uma versão simplificada do módulo responsável por recorrência local no protótipo. A função para treinamento apenas dispara o treinamento convencional (assim como pattern_training, também demanda exemplos pré-ativados). Já a função de ativação é responsável por converter neurônios de saída em neurônios de entrada (com a ajuda da função recurrent_expansion) e iterar de acordo com as definições da instância. $\mathrm{O}$ exemplo se baseia em parâmetros e funções globais não detalhadas para manter o 
exemplo simples. Os parâmetros local_recurrence_enabled e recurrent_iterations controlam quando a recorrência está ativa e o número de iterações a ser usadas durante a ativação, respectivamente. A função match_recorrent_output implementa a seleção de neurônios de saída recorrentes baseada em regras. A-padrões e b-padrões não são diferenciados explicitamente, para manter o exemplo simples.

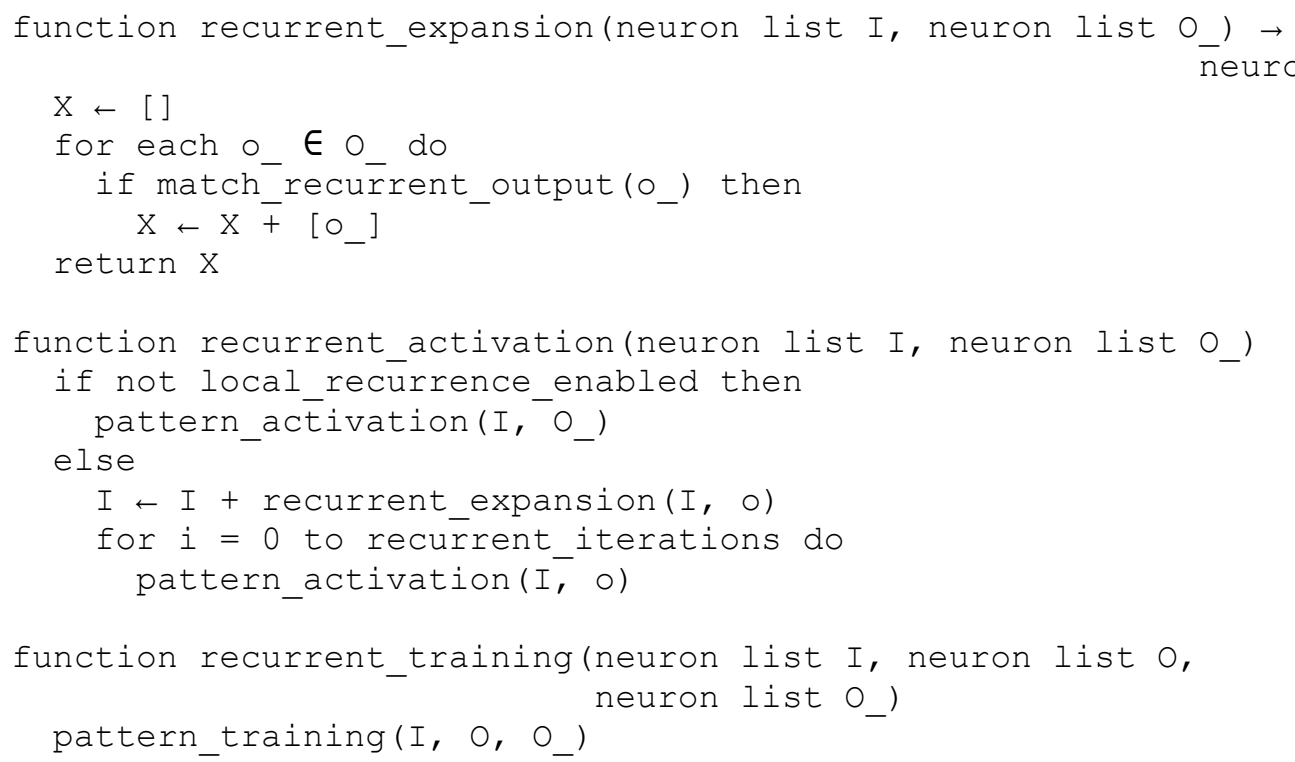

Algoritmo 3.3: Ativação e treinamento de instâncias com recorrência local.

O Algoritmo 3.4 apresenta uma versão simplificada do módulo de contexto baseado em janela. A estrutura pattern é definida para servir de base para contextos neurais. $\mathrm{O}$ treinamento de contextos neurais é baseado no treinamento recorrente, que por sua vez usa o treinamento de padrões simples. A função de ativação é responsável pelos recursos do contexto baseado em janela, basicamente invocando funções para adicionar neurônios de entrada nos padrões referentes a entrada ou saída de seus vizinhos e iterando um número definido de vezes. Novos neurônios são gerados pela função window_expand, que não foi detalhada para manter o exemplo compacto.

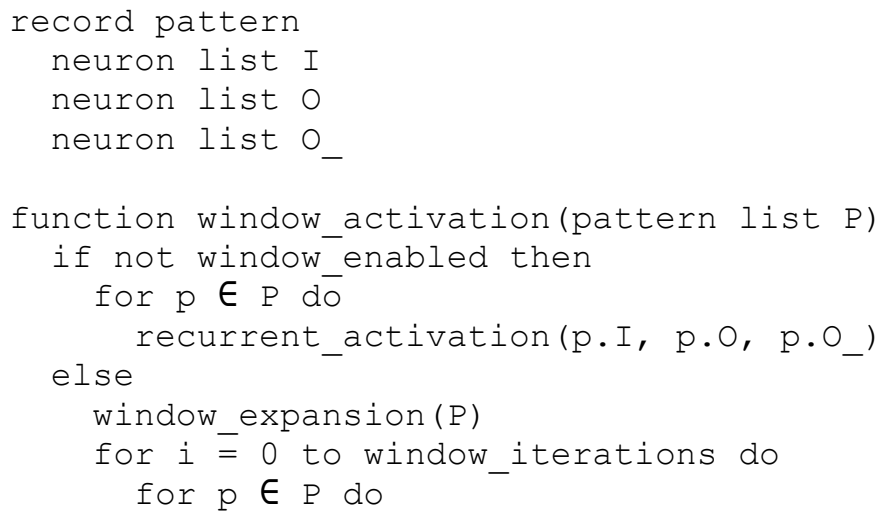




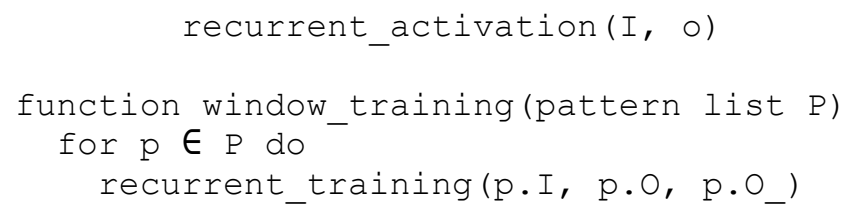

Algoritmo 3.4: Ativação e treinamento do contexto baseado em janela.

No protótipo, a-padrões são transformados diretamente em b-padrões durante o contexto baseado em janela, ilustrado na Figura 3.8 da Seção 3.3.2. Um tratamento é realizado para evitar que neurônios gerados pela recorrência local sejam incluídos como entrada de contexto. Isso evita duplicações indesejadas quando a coativação do contexto baseado em janela é combinada com a recorrência local. O protótipo também permite que neurônios derivados mantenham-se sempre atualizados em relação neurônios originais. Para isso, usou-se o padrão de projeto Proxy (GAMMA et al., 1995).

O Algoritmo 3.5 apresenta uma visão geral do contexto baseado em árvore. Diversas funções não foram explicitadas para simplificar o exemplo e mantê-lo compacto. A-padrões do contexto baseado em árvores não podem ser utilizados diretamente no treinamento, pois seus pseudo-neurônios prejudicariam o treinamento e ativação. A função $a \_t o \_b$ remove os pseudo-neurônios de um a-padrão, gerando o vetor $B$ descrito na Figura 3.8 da Seção 3.3.2. Os b-padrões gerados, por sua vez, podem ser acrescidos conforme o contexto em janela e a recorrência local estejam ativados. A função $a \_t o \_c$ gera a matriz $C$ descrita na Figura 3.14 da Seção 3.3.3.

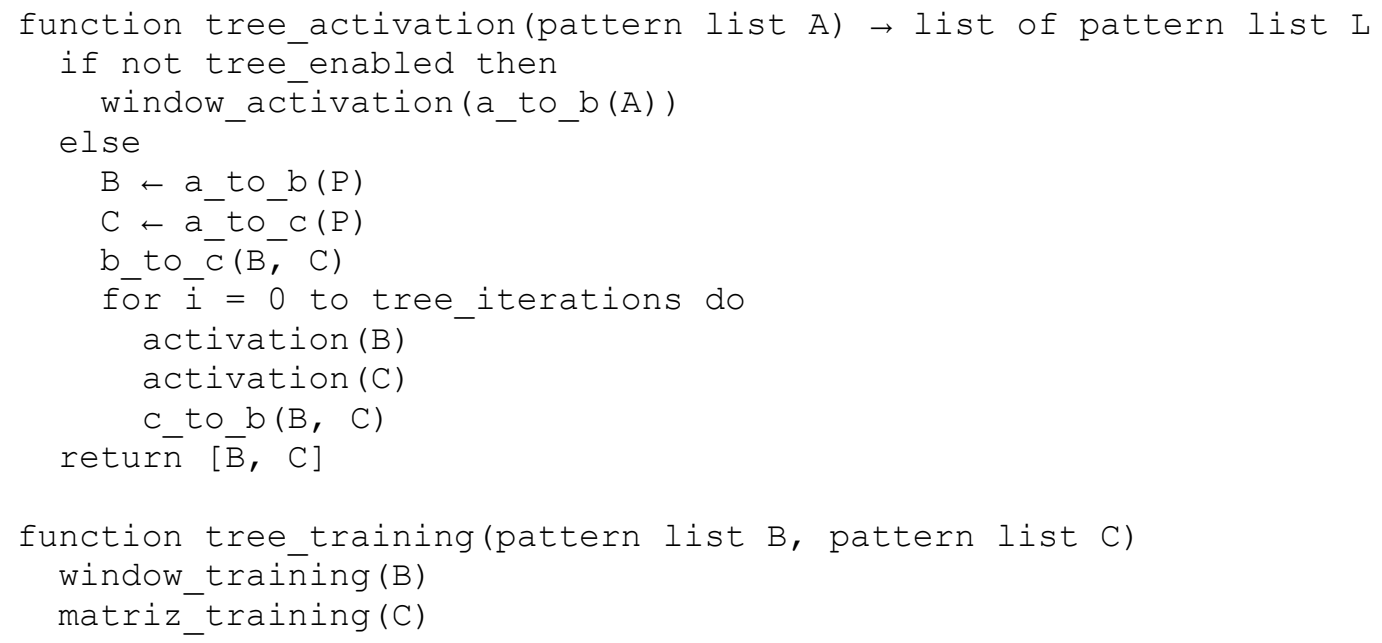

Algoritmo 3.5: Ativação e treinamento do contexto baseado em árvore.

A função $b \_t o \_c$ é responsável por transferir neurônios de entrada e de saída de b-padrões para c-padrões, enquanto a função $c \_t o \_b$ faz o procedimento contrário (correlacionando a saída dos c-padrões com os b-padrões que referenciam e inserindo nos 
b-padrões filhos os neurônios de seus pais). A primeira, só precisa ser aplicada uma vez, pois os números de neurônios em cada c-padrão permanecem estáveis durante o processamento. Já a segunda precisa ser aplicada a cada iteração, pois após uma mudança na predição de um nó pai, o b-padrão correspondente precisa ser atualizado por um processo no qual neurônios relativos ao nó pai antigo são opcionalmente removidos e neurônios relativos ao novo nó pai são adicionados. Quando um b-padrão tem seu nó pai alterado, o protótipo não remove neurônios do nó pai anterior, se limitando a acrescentar neurônios referentes ao novo nó pai. Contudo, os neurônios relativos ao nó pai anterior são penalizados nesse caso, já que são ponderados pelo valor de ativação correspondente na Matriz $C$, que é menor que o valor correspondente para o novo nó pai.

Por fim, a função matriz_training percorre a matriz $C$ e reforça positiva ou negativamente os neurônios de cada c-padrões, conforme o caso. É importante observar que a matriz $C$, seja sua versão menos granular ou mais granular $\left(C^{\prime}\right)$, contém mais exemplos negativos que positivos. Isso é natural, já que para um dado lexema (a-padrão) existe apenas um núcleo (nó pai), o que resulta no exemplo positivo, enquanto que todos os demais lexemas e correlatos na frase transformam-se em exemplos negativos para o lexema em análise. É preciso tratar esse desbalanceamento para evitar que a instância opte por sempre predizer o caso majoritário, isto é, não associar nenhum pai a nenhum b-padrão. Estratégias para trazer o balanceamento incluem subamostragem de exemplos negativos ou sobre-amostragem de exemplos positivos (BATISTA et al., 2004, 2005; CASTRO \& BRAGA, 2011), esta última em uso no protótipo.

Optou-se por incluir-se uma linha e uma coluna extra na matriz $C$ para análise de elementos raiz, referente a uma pseudo-raiz. Candidatos a raízes levam a padrões cuja ativação indica se o candidato é um filho da pseudo-raiz. Se, por um lado, é possível identificar a raiz em um contexto quando ela não é classificada como filha de nenhum outro padrão, por outro lado, a inserção da pseudo raiz permite criar sinapses extras, que facilitam o processo de identificação de raízes.

O protótipo também gera o evento proximity, não apresentado no exemplo, que favorece relações de dependência candidatos mais próximos em detrimento a candidatos mais afastados. O protótipo também implementa o padrão de projeto Decorador (GAMMA et al., 1995), o que possibilita composição entre recorrência local, contexto baseado em janela e contexto baseado em árvore em qualquer ordem (os exemplos simplificados exploram apenas 
uma ordem hierárquica, no qual o contexto baseado em árvore é o topo e a recorrência local é a base). Outros padrões de projeto são empregados também, como a Fábrica Abstrata para gerar gerenciadores de contexto e de conjunto de padrões e DAO/DTO (Data Access Object / Data Transfer Object - objeto para acesso a dados / objeto para transferência de dados) (CRAWFORD \& KAPLAN, 2003) para manipular neurônios e sinapses na base de dados.

\subsection{Comparação do Molin com trabalhos realizados}

Esta seção contrasta o Molin com trabalhos relacionados detalhados no Capítulo 2 (especialmente abordagens neurais da Seção 2.2.4).

Em relação as avaliação, particularmente na análise de dependências, a metodologia deste trabalho usa uma medida similar a interligação não rotulada (DeY para o subnível de dependências sintáticas), porém sem o uso de medidas relacionadas à interligação rotulada, isto é, combinando-se rótulos e arestas em uma única avaliação. Ao invés disso, rótulos são avaliados separadamente, de forma similar à medida label accuracy, usada na edição de 2009 da CoNLL. Isso torna difícil compará-lo com análisadores sintáticos da Seção 2.2.3.

Em relação a representação dos dados, proposta de Carlson et al (1999) permite atributos adicionados após o primeiro treinamento se um novo ciclo de treinamento for realizado, em uma abordagem neural construtiva, como no Molin. Contudo, a representação Molin representação é baseada em cadeias de caracteres, possuindo similaridade com a estrutura de dados hash, sendo mais adequada a tarefas de PLN, enquanto a representação de Carlson é baseada em índices inteiros, possuindo similaridade com a estrutura de dados matriz (1999).

Em relação à recorrência neural, no modelo proposto por Schmid (1994b), a saída de um padrão à esquerda é a entrada de um padrão à direita, mas nunca o contrário, em contraste com o método de recorrência proposto neste trabalho, no qual padrões modificam e são modificados por seus vizinhos, independente de ocorrerem à esquerda ou à direita. Além disso, em comparação à abordagem do Molin, o modelo proposto por Schmid (1994b) trata apenas um nível (morfossintático) e se baseia em uma rede neural de pequena escala.

De forma semelhante, no trabalho de Socher et al. (2010), um nó já identificado na árvore, influencia um nó em análise, porém o nó em análise não pode influenciar o nó previamente detectado. $\mathrm{Na}$ abordagem Molin, por outro lado, nós (na árvore de dependências) influenciam-se uns aos outros livremente, de forma que o mesmo nó influencia e é 
influenciado por seu vizinho.

Em relação a integratividade e bidirecionalidade, A abordagem de Fernandes e Milidiú (2012) é baseada principalmente em atributos léxicos, com pouca interação entre diferentes níveis da língua, a partir de uma rede neural de pequena escala sem bidirecionalidade.

O analisador Palavras (BICK, 2000) possui algum grau de bidirecionalidade, devido ao uso de gramáticas de restrições, permitindo que categorias semânticas sejam utilizadas para determinar funções sintáticas (por exemplo, uma regra pode fazer uso da categoria "humano" para identificar o sujeito de uma oração quando a ordem sujeito-verbo-objeto não é utilizada), ao mesmo tempo em que funções sintáticas são utilizadas na análise de papéis semânticos, em um complemento à parte do analisador. Apesar disso, a análise dos níveis da língua é feita principalmente de forma ascendente, como indicado pelo próprio autor:

"Parsing is here viewed as a progression through different levels of analysis, with disambiguated morphological tags allowing syntactic mapping and disambiguation, syntactic tags allowing instantiation of valency patterns and all three contributing to semantic disambiguation."

Hajič et al. (2009) comparam modelos com alto grau de bidirecionalidade, mas apenas entre dependências sintáticas e papéis semânticos, indicando que ainda são necessárias mais investigações para avaliar se bidirecionalidade apresenta vantagens de fato aos modelos. Nos modelos apresentados pelos autores, classificadores ou métodos estatísticos são usados para estimar a probabilidade de eventos sintáticos e semânticos coocorrerem. Uma limitação dessas abordagens é o fato de serem pouco expansíveis para tratar mais de dois níveis (ou subníveis da Língua), limitando-se a relações de sintaxe e semântica. O Molin, por outro lado, examina mais níveis (morfologia, morfossintaxe, sintaxe com dependências e funções, e semântica baseada categorias) e pode integrar facilmente mais de níveis (ou subníveis) na análise, devido à abordagem neural escolhida.

O projeto Senna (Collobert et al., 2011) é o trabalho mais proximamente relacionado ao modelo Molin. Em primeiro lugar, devido ao fato de Collobert et al. (2011) defenderem análises integrativas da língua, e proporem metodologias neurais para a tarefa. Em segundo lugar, os autores também aplicam uma forma de bidirecionalidade (indireta), em uma das etapas do trabalho mais geral. Os autores observam que as avaliações (benchmarks) da área para diferentes ferramentas do PLN são feitas separadamente, e, na maioria das vezes, com atributos muito específicos, voltadas à tarefa em questão, defendendo a construção de modelos que integrem tarefas da língua, com atributos mais genéricos, e menos dependentes de tarefas específicas. Nota-se que o conceito defendido por Collobert et al. não é novo, pois 
Caruana (1997) ilustra diferentes abordagens integrativas (aprendizado multitarefa, na terminologia do autor) para tarefas de aprendizado de máquina não relacionadas ao PLN. Como os autores investigam tanto análises em cascata como análises integrativa, a parte do trabalho relacionada a bidirecionalidade é relativamente reduzida, devido ao foco de trabalho em tarefas maiores, sendo baseada no ajuste intercalado de pesos das duas primeiras camadas da rede para as diferentes tarefas. Observa-se que nesse caso, um nível da língua afeta o outro, ao afetar pesos neurais relacionados principalmente a neurônios ligados a atributos léxicos, contudo, a interação entre os níveis é muito indireta. Na bidirecionalidade do Molin, por outro lado, a interações entre níveis mais rasos ou profundos é direta. Nota-se ainda que as análises em cascata podem utilizar uma iteração mais direta entre diferentes níveis da língua, mas nesse caso, uma interação unidirecional.

Collins (2002) combina de forma interessante redes neurais com análises globais da frase inspiradas em modelos ocultos de Markov, contudo é difícil adaptá-lo para cenários multirrótulos (sejam rótulos diferentes do mesmo nível da língua ou de níveis diferentes), o que limita sua aplicação em cenários integrativos e bidirecionais. Por essa razão, o Molin utiliza uma abordagem mais simples (e mais limitada) na análise da frase, embora Singh et al. (2009) proponham métodos para lidar com cenários multirrótulo em abordagens baseadas em modelos ocultos de Markov e variantes. O classificador gerado difere da abordagem apresentada neste trabalho por focar-se apenas no nível sintático (análise de dependência), sem integração ou bidirecionalidade entre outros níveis. Além disso, não existem interações entre nós da árvore da forma apresentada na abordagem Molin. 


\section{Modelo Sinsim}

O modelo Sinsim é baseado em regras criadas manualmente a partir das regras descritas no manual de simplificação do projeto PorSimples (SPECIA et al., 2008), que posteriormente foram refinadas neste doutorado. A parte do modelo implementada neste trabalho consiste em regras para tratar orações subordinadas adverbiais e adjetivas (também conhecidas por cláusulas relativas), orações na voz passiva e um dos tipos de coordenadas sindéticas. Os fenômenos sintáticos são mostrados na Tabela 4.1, que indica os fenômenos processados na coluna "Implementado". Além dos fenômenos, também são apresentados os identificadores relativos a cada um, para futura referência.

Tabela 4.1: Fenômenos sintáticos processados pelo Sinsim.

\begin{tabular}{|c|c|c|}
\hline id & Fenômeno & Implementado \\
\hline $\mathrm{a}$ & Oração fora da ordem sujeito-verbo-objeto & \\
\hline $\mathrm{b}$ & Oração na voz passiva & $\checkmark$ \\
\hline $\mathrm{c}$ & Oração subordinada substantiva apositiva especificadora (aposto) & \\
\hline d & Oração subordinada adjetiva restritiva (relativa restritiva) & $\sqrt{ }$ \\
\hline $\mathrm{e}$ & Oração subordinada adjetiva explicativa (relativa explicativa) & $\sqrt{ }$ \\
\hline$f$ & Oração subordinada adverbial causal & $\sqrt{ }$ \\
\hline $\mathrm{g}$ & Oração subordinada adverbial comparativa & \\
\hline $\mathrm{h}$ & Oração subordinada adverbial concessiva & $\sqrt{ }$ \\
\hline i & Oração subordinada adverbial condicional & $\sqrt{ }$ \\
\hline $\mathrm{j}$ & Oração subordinada adverbial consecutiva & $\sqrt{ }$ \\
\hline $\mathrm{k}$ & Oração subordinada adverbial conformativa & $\sqrt{ }$ \\
\hline 1 & Oração subordinada adverbial final & $\sqrt{ }$ \\
\hline $\mathrm{m}$ & Oração subordinada adverbial temporal & $\sqrt{ }$ \\
\hline $\mathrm{n}$ & Oração coordenada sindética alternativa & \\
\hline o & Oração coordenada sindética conclusiva & \\
\hline $\mathrm{p}$ & Oração coordenada sindética adversativa & $\sqrt{ }$ \\
\hline q & Oração coordenada assindética & \\
\hline $\mathrm{r}$ & Oração coordenada sindética aditiva & \\
\hline s & Adjunto adverbial & \\
\hline $\mathrm{t}$ & Oração reduzida & \\
\hline $\mathrm{u}$ & Oração coordenada sindética explicativa & \\
\hline
\end{tabular}




\begin{tabular}{llc}
\hline id & Fenômeno & Implementado \\
\hline $\mathrm{w}$ & Oração subordinada adverbial proporcional & \\
\hline
\end{tabular}

Outros fenômenos foram implementados na pesquisa de doutorado de Amanda Rocha Chaves, no ICMC-USP, (em particular, orações coordenadas e apostos) ou reservados como trabalhos futuros (orações subordinadas comparativas, proporcionais e aquelas fora da ordem sujeito-verbo-objeto). Durante o projeto PorSimples, optou-se pelo não processamento de alguns fenômenos (por exemplo, orações reduzidas, que não ofereciam problemas ao seu entendimento). Observa-se que orações subordinadas adverbiais concessivas e orações coordenadas sindéticas adversativas são muito semelhantes e puderem ser tratadas pela mesma regra. Além disso, o Palavras não oferece informação sintática suficiente para diferenciar o caso concessivo (ou seja, a subordinação) do caso adversativo (ou seja, da coordenação). A diferenciação é normalmente feita pelos marcadores discursivos em uso, que coincidem para orações concessivas e adversativas.

A metodologia de desenvolvimento aplicada ao Sinsim, incluindo os requisitos de software levantados e informações sobre o córpus de desenvolvimento, é apresentada na Seção 4.1. Exemplos de regras e discussão das diferentes operações de simplificação são mostradas na Seção 4.2. A Seção 4.3 apresenta as justificativas pela escolha de regras manuais em detrimento ao uso de aprendizado de máquina.

\subsection{Metodologia de desenvolvimento}

O projeto e desenvolvimento de um simplificador sintático via regras com foco em um determinado público-alvo é divido em diferentes fases, incluindo: (a) estudo das necessidades do público-alvo; (b) análise dos fenômenos sintáticos adequados para tal audiência; (c) formulação de manuais de simplificação; (d) refinamento das regras de simplificação com base em evidências obtidas de córpus; (e) implementação e avaliação do desempenho das regras a partir de sua precisão e cobertura; e (f) avaliação do impacto das regras junto ao público-alvo. Como a tarefa é complexa, este trabalho se restringiu aos itens itens (d) e (e), pois os itens (a) a (c) e (f) foram realizadas durante o projeto PorSimples. Além disso, os itens realizados neste doutorado, visaram uma melhoria no simplificador sintático construído durante os primeiros anos do PorSimples, tanto com relação ao seu desempenho como a organização de seu código e estruturas de dados. Esta seção trata do idem (d), apresentando a metodologia para criar o simplificador sintático, enquanto o item (e) é discutido na Seção 5.3. 


\subsubsection{Requisitos de software: precisão}

Quatro princípios guiaram o desenvolvimento do Sinsim, bem como de suas regras. São eles:

1. O foco das regras deve ser a precisão, em detrimento da cobertura (conforme discutido no Exemplo 4.1).

2. Regras de simplificação devem buscar gerar frases curtas, mesmo que isso aumente o tamanho do texto resultante.

3. Orações devem seguir ordens mais naturais como, por exemplo, cronológica, causa e efeito, condição e ação, ação e objetivo, ideia geral e detalhe, regra e exceção, entre outras. Observa-se que, em alguns casos, as ordens podem ser conflitantes.

4. A ordem dos componentes de uma oração deve ser sujeito-verbo-objeto e a topicalização ${ }^{\mathrm{g}}$ (inserção no início da oração) de adjuntos adverbiais deve ser evitada quando possível.

O primeiro requisito é considerado o mais importante, pois durante o decorrer do projeto PorSimples, foi constatada a importância do foco em precisão, já que erros levam orações indesejadas (agramaticais) que substituem as orações esperadas como saída para o um dado texto de entrada. O Exemplo 4.1 apresenta os erros possíveis durante o processo de simplificação.

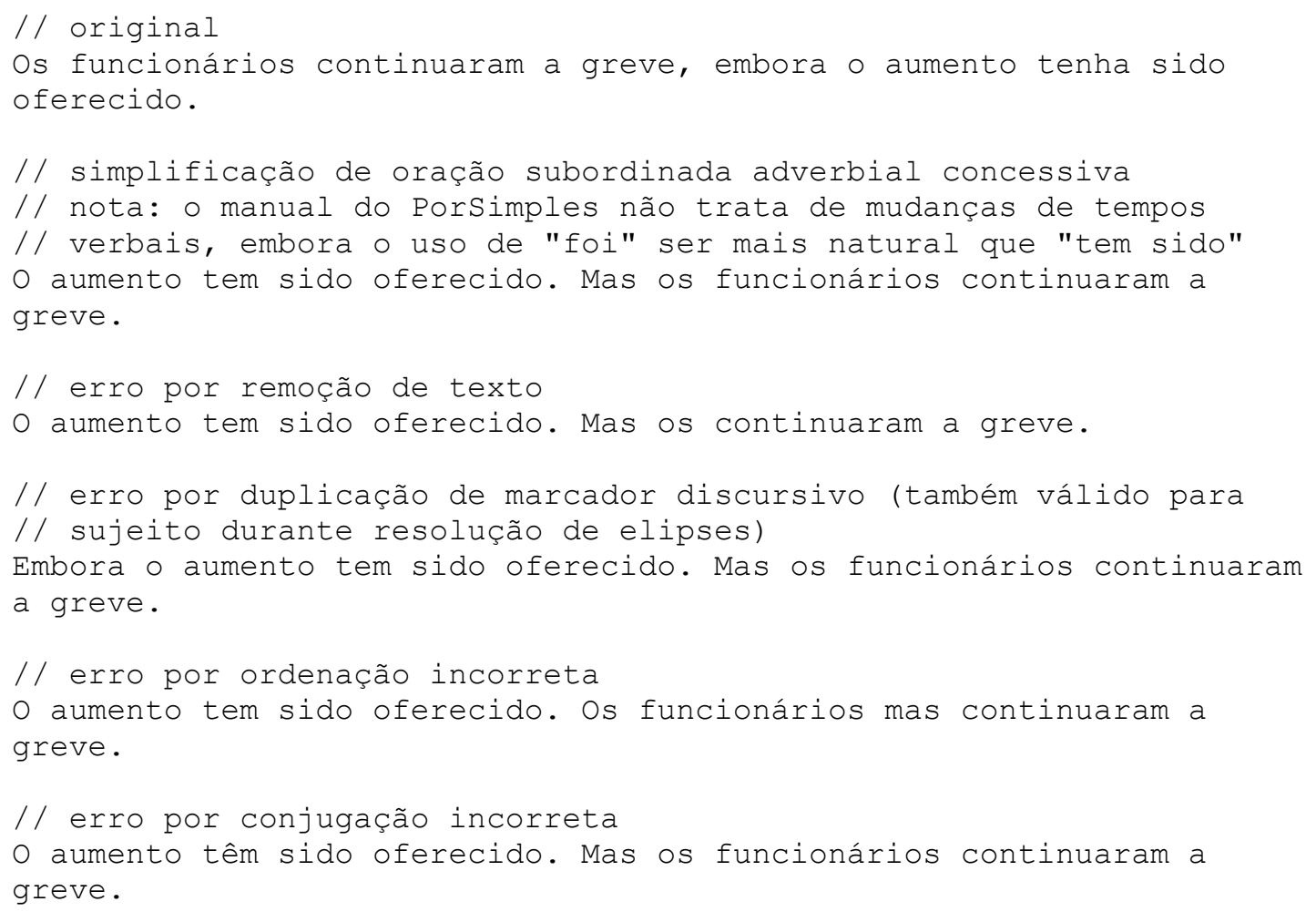


Exemplo 4.1: Erros possíveis durante a simplificação.

O efeito de simplificações bem sucedidas na compreensão do texto pode ser anulado ou mesmo revertido devido à presença de orações simplificadas incorretamente. Mudanças aleatórias em uma oração como a inserção, remoção, reordenação ou conjugação verbal podem facilmente levar à agramaticalidade e comprometem a compreensão do texto como um todo. De acordo com a gravidade de um erro de remoção, porções significativas da oração original podem ser perdidas. Esses possíveis erros são particularmente graves no cenário ao qual o simplificador sintático apresentado se destina, dado que o leitor já está sobrecarregado com a leitura do texto em si.

O quarto requisito de software será implementado em versões futuras do Sinsim.

\subsubsection{Córpus de desenvolvimento}

Um córpus de frases, cobrindo cada fenômeno sintático, incluindo diferentes $\operatorname{casos}^{\mathrm{g}} \mathrm{de}$ um mesmo fenômeno sintático, foi utilizado no processo de teste e refinamento das regras do manual do PorSimples. Para as regras apresentadas neste trabalho de doutorado, foram levantados 156 períodos (buscou-se exemplos representativos) de notícias em um córpus de textos do gênero jornalístico. Os exemplos negativos compõem-se principalmente de frases não simplificáveis (que não podem ser tratadas por nenhuma das regras de simplificação) que possuem marcadores discursivos em comum com frases simplificáveis. Os exemplos negativos contribuem para a avaliação da precisão do Sinsim, em uma análise baseada em precisão e cobertura. Observa-se que esse córpus é utilizado apenas para desenvolvimento. Um segundo córpus, bem maior, baseado no gênero enciclopédico foi utilizado na avaliação do modelo, sendo composto por frases não analisadas durante o processo de desenvolvimento.

No córpus de desenvolvimento, aproximadamente $66 \%$ das frases são simplificadas corretamente por pelo menos uma regra. As frases não simplificadas correspondem a aproximadamente $27 \%$ do total. As restantes (cerca de $7 \%$ ) correspondem a frases incorretamente simplificadas ou frases que deveriam ser simplificadas mas não foram (caso mais comum), em ambos os casos, devido a erros nas regras de simplificação, mas não devido a erros na análise sintática.

A Figura 4.1 apresenta estatísticas para os casos do córpus de desenvolvimento. Cada caso é normalmente representado por uma ou mais frases no córpus, incluindo exemplos negativos. 


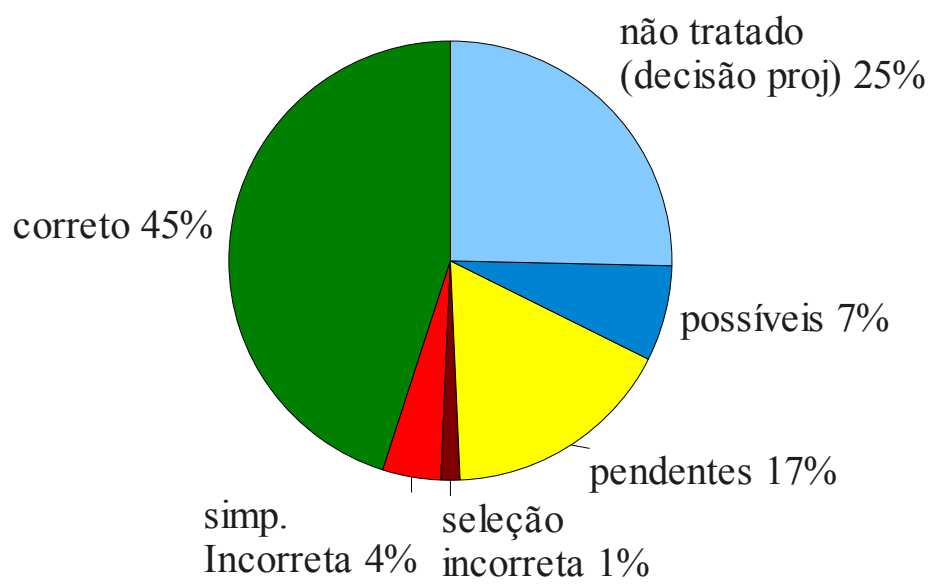

Figura 4.1: Estatísticas para casos do córpus de desenvolvimento.

A simplificação incorreta e seleção incorreta afetam a precisão do modelo. Na primeira (simplificação incorreta), orações são corretamente selecionadas para a simplificação, mas são incorretamente simplificadas. Na segunda (seleção incorreta), orações que não deveriam ser selecionadas para a simplificação são processadas pelas regras.

A cobertura do modelo é afetada pelos casos não tratados, possíveis ou pendentes. Nenhum dos três grupos são processados pela versão corrente do modelo, porém há diferenças entre casos de um grupo e outro. Casos não tratados não são processados devido a decisões de projeto, seja por serem considerados simples o suficiente, por serem pouco representativos, ou por dependerem de informações pouco confiáveis ou indisponíveis no analisador sintático. Casos possíveis podem vir a ser tratados em trabalhos futuros, e não foram considerados na análise principalmente por serem pouco representativos. Casos pendentes são de prioridade maior, pois permitem boas simplificações, sendo os primeiros a serem processados em trabalhos futuros.

A decisão de projeto de focar na precisão reflete nas estatísticas apresentadas, já que apenas 5\% dos casos problemáticos afetam a precisão, enquanto que $45 \%$ dos casos apresentados afetam a cobertura. Com isso, o modelo torna-se mais útil em cenários de simplificação complemente automatizados, mantendo-se relevante em cenários simplificações semi-automático, isto é, revisadas por humanos, em que a simplificação automática serve de suporte à escrita de textos adaptados a um dado público alvo, por pessoas como jornalistas ou professores.

Para extrairem-se os dados apresentados na Figura 4.1, as frases utilizadas para o desenvolvimento de uma determinada regra são testadas também na análise das demais regras. 
Isso é feito com o objetivo de identificar interferências entre regras. Por exemplo, uma árvore sintática com formato inesperado pode ser gerada após a aplicação de uma dada regra e impedir o correto processamento da frase por outra regra.

Existem algumas considerações sobre as estatísticas extraídas do córpus de desenvolvimento. Primeiramente, cada caso traz aproximadamente o mesmo número de orações, porém, em córpus de aplicações, muitos casos tratados não são representativos, apresentando poucas ocorrências ou mesmo não ocorrendo. Assim, as estatísticas do córpus de desenvolvimento diferem bastante das estatísticas do córpus de avaliação. Em segundo lugar, os casos não são ortogonais, isto é, existem orações que podem ser classificadas em mais de um caso. Em terceiro lugar, parte dos erros apresentados refere-se a subcasos de casos sendo corretamente processados. Esses subcasos são pouco frequentes em sua maioria e devem ser incorporados aos casos principais assim que os erros forem corrigidos. Em quarto lugar, erros devido à análise sintática não foram computados nas estatísticas do córpus de desenvolvimento, já que elas visam guiar o processo de refinamento das regras. Erros devido à análise sintática são, contudo, considerados no córpus de avaliação. Em quinto lugar, é preciso considerar que há casos não previstos no levantamento apresentado. Por fim, muitos casos foram agrupados, pois os marcadores discursivos associados demandam o mesmo tratamento (uma listagem completa dos marcadores discursivos, sua ambiguidade quando existir e os fenômenos associados pode ser encontrada no Apêndice B.2).

\subsection{Exemplos de fenômenos sintáticos}

Esta seção apresenta exemplos de operações comuns a diversos fenômenos sintáticos. $\mathrm{Na}$ Seção 4.2.1, casos de quatro diferentes fenômenos são cobertos, incluindo: reordenação de componentes de uma oração (voz passiva na Seção 4.2.2), resolução anafórica de pronomes relativos (orações subordinadas adjetivas na Seção 4.2.3), reordenação de orações (oração subordinada adverbial causal na Seção 4.2.4) e divisão de orações com resolução de elipses ${ }^{\mathrm{g}}$ (também na Seção 4.2.4). As demais regras são semelhantes às apresentadas nesta seção, e são incluídas na Seção B.1 para fins de reprodutibilidade de experimentos. Os exemplos serão apresentados com contrações expandidas (por exemplo “de elas" em vez de “delas”).

\subsubsection{Operações comuns para diversos fenômenos sintáticos}

O Sinsim atua sobre a saída do Palavras no formato de árvores de constituintes sintáticos, embora testes baseados no Miolin também sejam realizados a partir de árvores de 
dependências sintáticas. Por busca em largura, cada nó da árvore é verificado por cada regra de simplificação. Quando uma regra de simplificação é aplicada a um nó, a frase pode ter seus componentes reordenados e/ou ser divida em duas orações, resultando em uma ou mais frases geradas. A escolha pela busca em largura se justifica em casos como o apresentado no Exemplo 4.2.

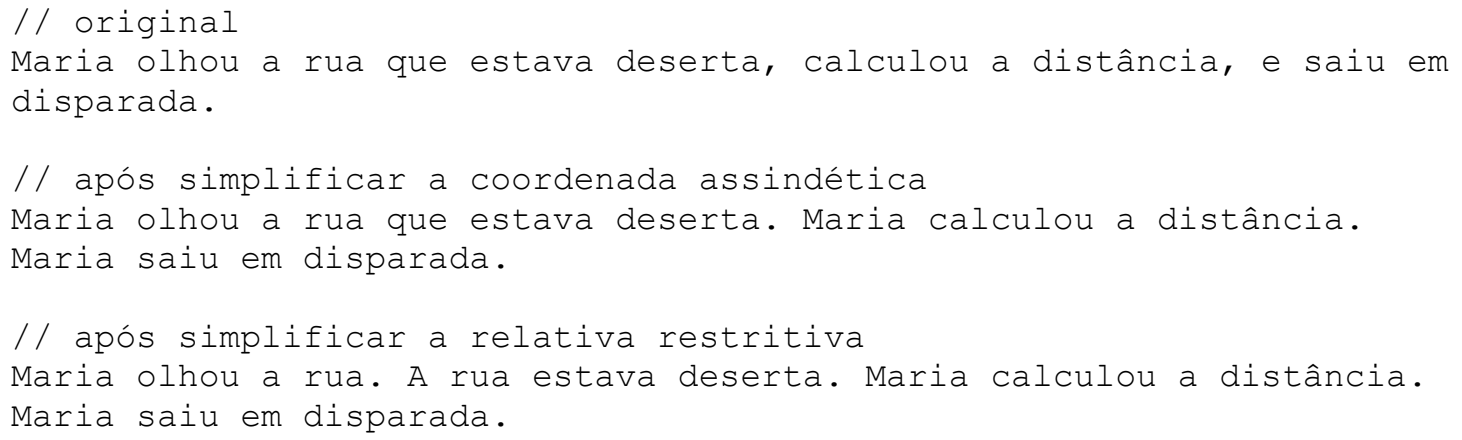

Exemplo 4.2: Simplificação em largura.

Para a mesma oração, uma simplificação em profundidade se basearia primeiro na oração subordinada relativa, o que resultaria em:

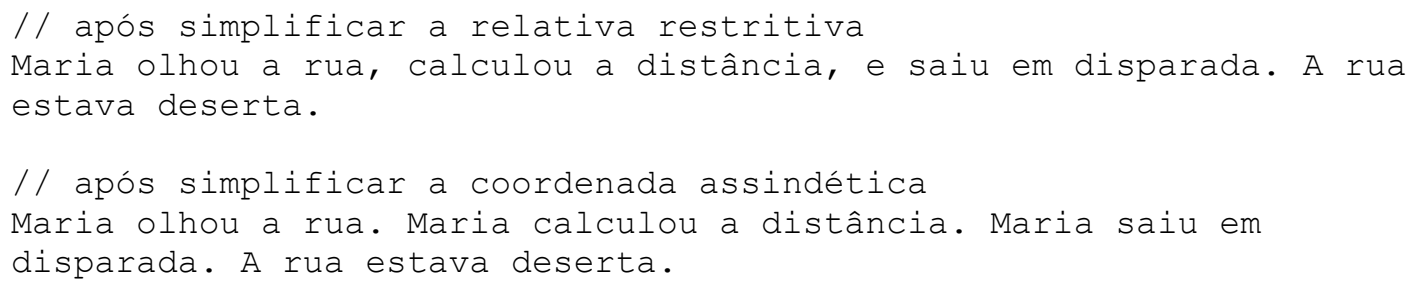

Exemplo 4.3: Simplificação em profundidade.

A simplificação do Exemplo 4.2 é considerada mais natural que a simplificação do Exemplo 4.3. O Exemplo 4.4 apresenta um caso mais raro no qual a simplificação em profundidade se sai levemente melhor. A simplificação em largura foi adotada, já que o caso de exemplo em que a profundidade se sai melhor é mais raro, além do fato de a análise em largura ser amplamente pesquisada (GASPERIN et al., 2010; SIDDHARTHAN, 2004).

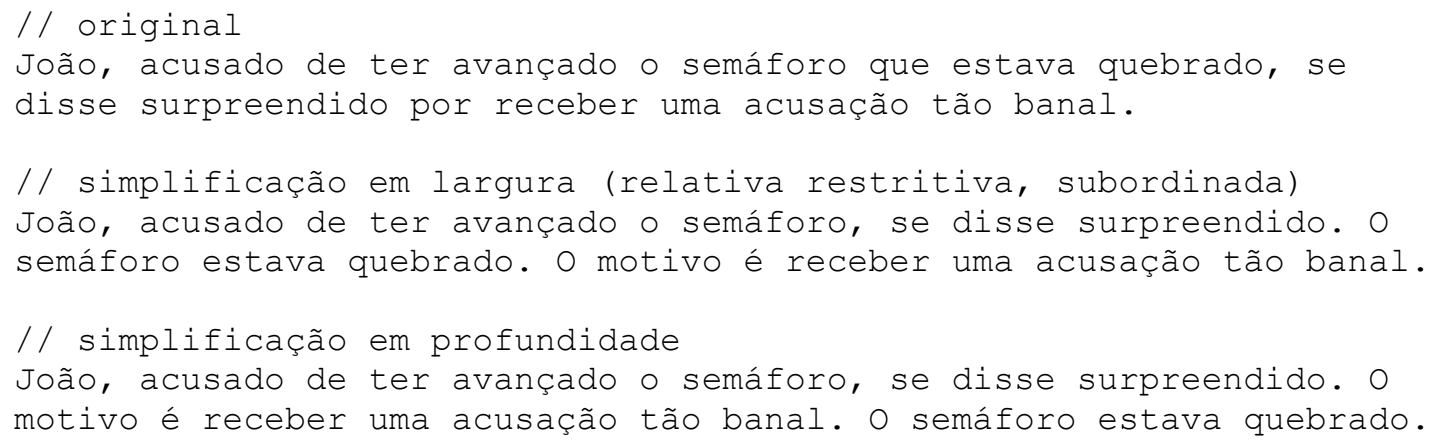

Exemplo 4.4: Caso em que profundidade é melhor que largura 
Nos exemplos, há diversas repetições do sujeito durante o processo de simplificação. Embora tais repetições sejam consideradas pouco naturais por leitores de nível pleno, elas são ideais para leitores de nível rudimentar, cuja memória de trabalho pode ser sobrecarregada em frases longas repletas de orações, anáforas ${ }^{\mathrm{g}}$ e elipses (WILLIAMS \& REITER, 2003, 2008)

As regras de simplificação possuem mais necessidades em comum além da busca em largura, pois divisões de orações podem provocar problemas devido a elipses, conforme discutido no Exemplo 4.5, e reordenações de orações podem levar ao surgimento da catáfora ${ }^{\mathrm{g}}$ (caso análogo a anáfora quando o referente é definido posteriormente no texto em vez de antecipadamente), conforme mostrado no Exemplo 4.6.

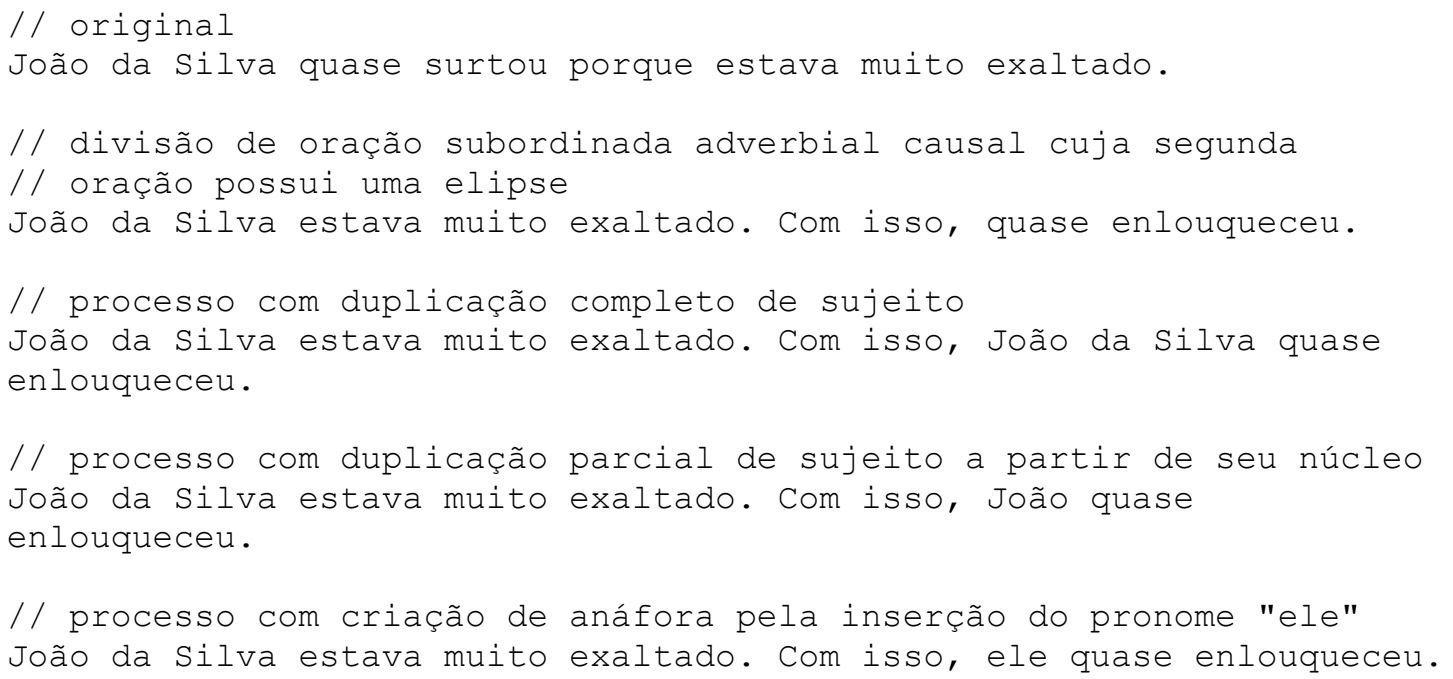

Exemplo 4.5: Possíveis tratamentos para elipses.

Tendo em vista leitores com nível de letramento rudimentar, o Sinsim utiliza a duplicação completa de sujeito, embora o uso da duplicação parcial do sujeito também esteja em análise, devido ao fato de contribuir para diminuir o tamanho do texto simplificado. $\mathrm{O}$ Exemplo 4.6 apresenta uma reordenação de uma oração que gerou uma catáfora.

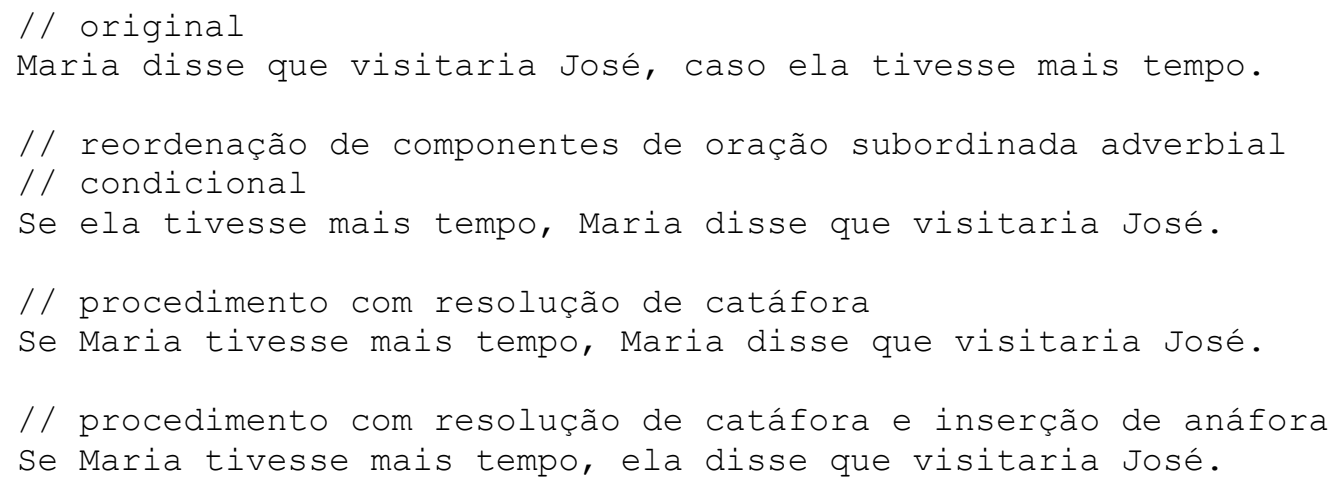

Exemplo 4.6: Possíveis tratamentos para catáforas. 
A versão atual do Sinsim não trata o surgimento de catáforas, embora a abordagem para resolução da catáfora (sem a inserção de anáfora) esteja planejado para trabalhos futuros. Outro fator importante é tornar fixa a posição dos marcadores discursivos para evitar problemas que possam comprometer a gramática, como apresentados no Exemplo 4.7, que também deve ser corrigido em trabalhos futuros.

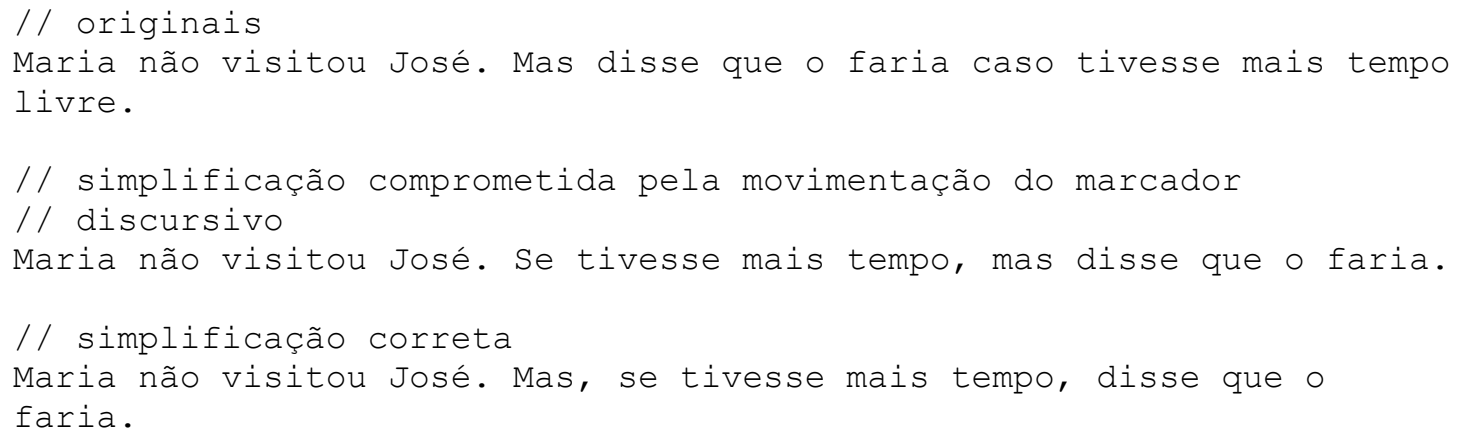

Exemplo 4.7: Limitação da versão atual do Sinsim.

\subsubsection{Voz passiva}

O Exemplo 4.8 apresenta casos da voz passiva. No caso padrão, a oração possui apenas dois verbos, o verbo "ser" possui a função de auxiliar, o agente da passiva está presente, assim como o sujeito não pronominal definido está definido. O processo de simplificação consiste em tornar o sujeito em objeto direto, o agente da passiva em sujeito, remover o verbo auxiliar e conjugar o verbo principal para refletir as alterações. A conjugação de verbos é realizada com a ajuda do glossário Unitex-Pb (MUNIZ et al., 2005). Caso o verbo não possa ser flexionado (por exemplo, um neologismo que não faz parte do glossário), a simplificação é cancelada e a oração original é restaurada.

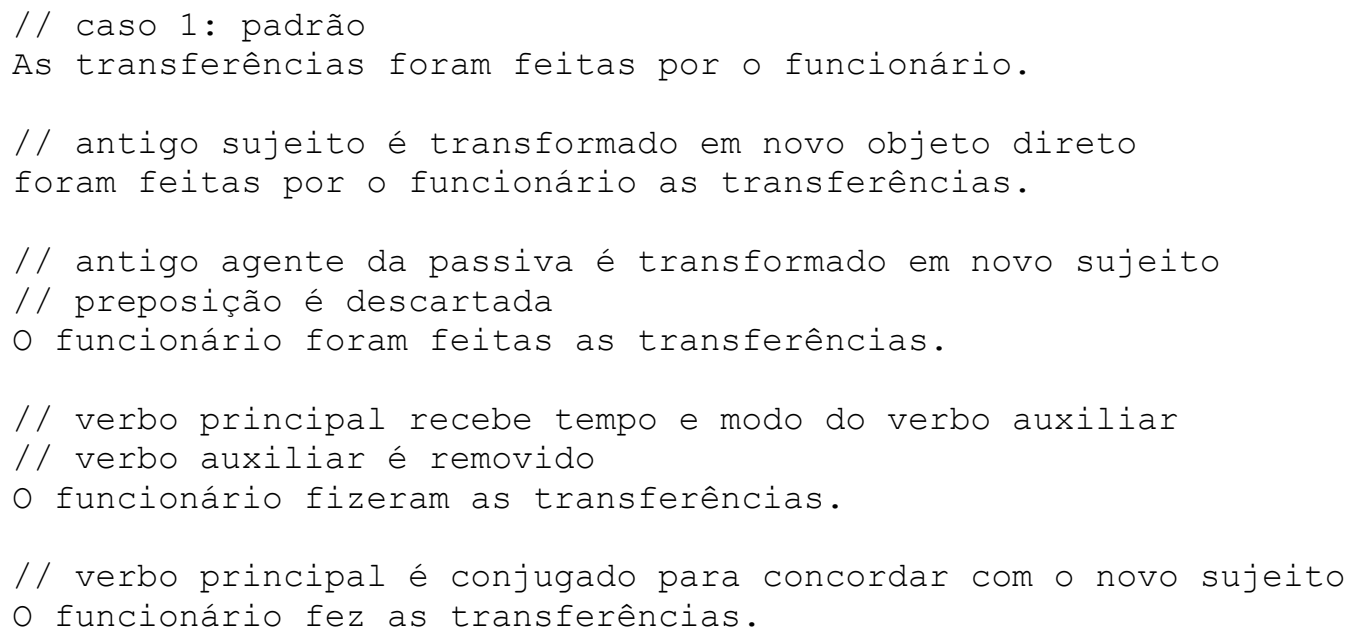


Exemplo 4.8: Caso padrão da voz passiva.

O Exemplo 4.9 apresenta casos relacionados a verbos. Orações referentes a esses casos podem ter mais que dois verbos (casos tratados corretamente), seu predicado pode aparecer dividido (caso possível de ser tratado) ou pode fazer uso de verbos usados em definições formais e semiformais (por exemplo, é/são chamada(s), é/são definida(s)).

Para mais que dois verbos, o verbo principal deve ser conjugado exatamente como o verbo "ser", e a concordância com o sujeito deve ser feita para o verbo auxiliar flexionado. Se houver quatro verbos, o verbo auxiliar original no infinitivo não é alterado. O predicado ainda pode aparecer dividido, um caso mais raro que não foi tratado por ser pouco frequente. Em um outro caso, verbos usados em definições podem ser utilizados, o que muda razoavelmente o processo de simplificação. Este último caso ainda não é tratado pelo Sinsim, pois depende de uma lista compilada de verbos e expressões usadas em definições. No escopo de um mestrado realizado no NILC no contexto de extração automática de termos, Teline (2004) traz uma lista de expressões usadas em definições que pode ser utilizada em trabalhos futuros para estes casos, para, por exemplo, não realizar simplificações.

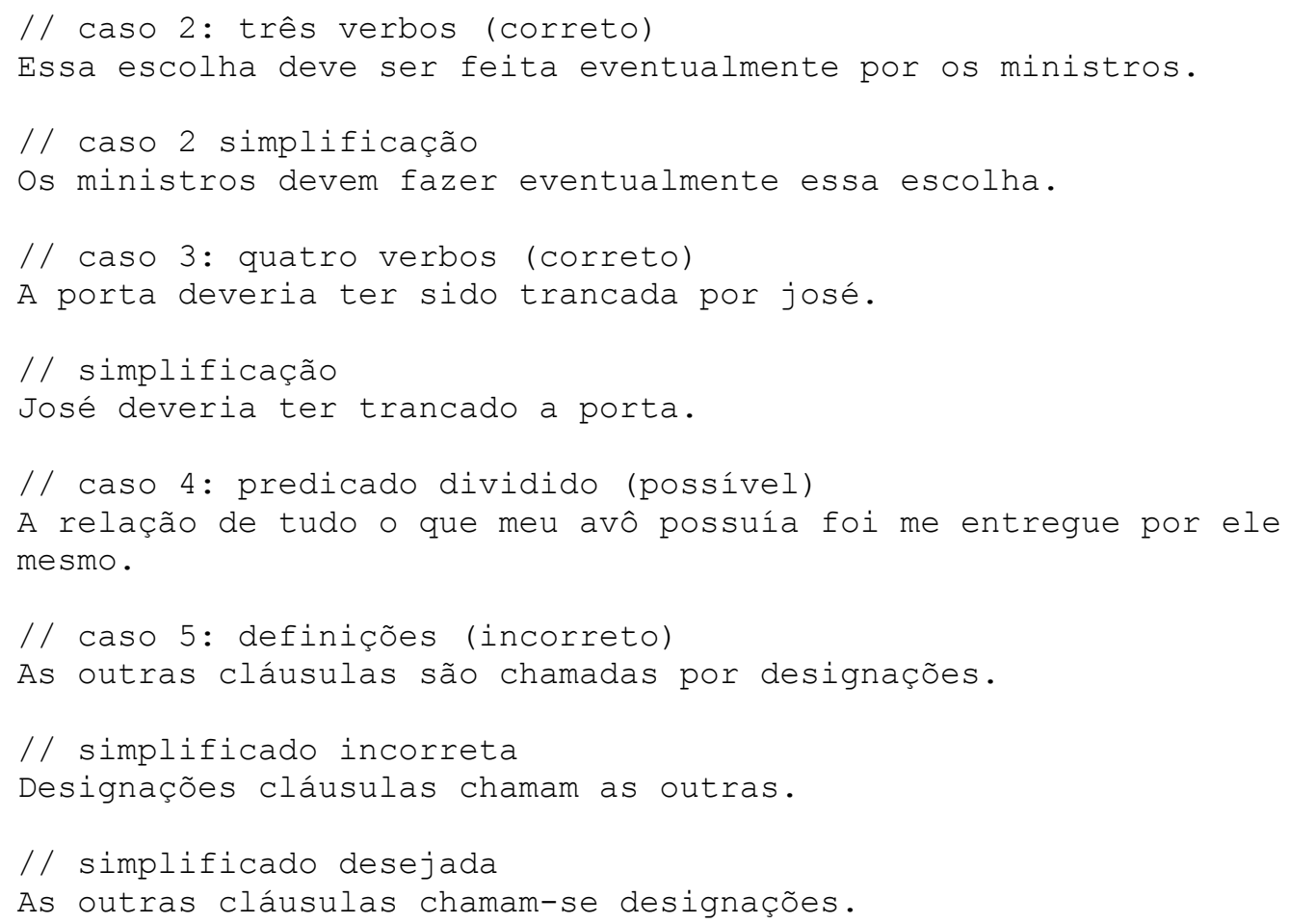

Exemplo 4.9: Verbos na voz passiva.

O Exemplo 4.10 apresenta casos relacionados ao agente da passiva. Dois casos são apresentados. No primeiro, uma oração sem agente da passiva leva a uma simplificação com 
sujeito indeterminado. No segundo, uma oração com agente oblíquo é transformada em uma oração com sujeito pronominal.

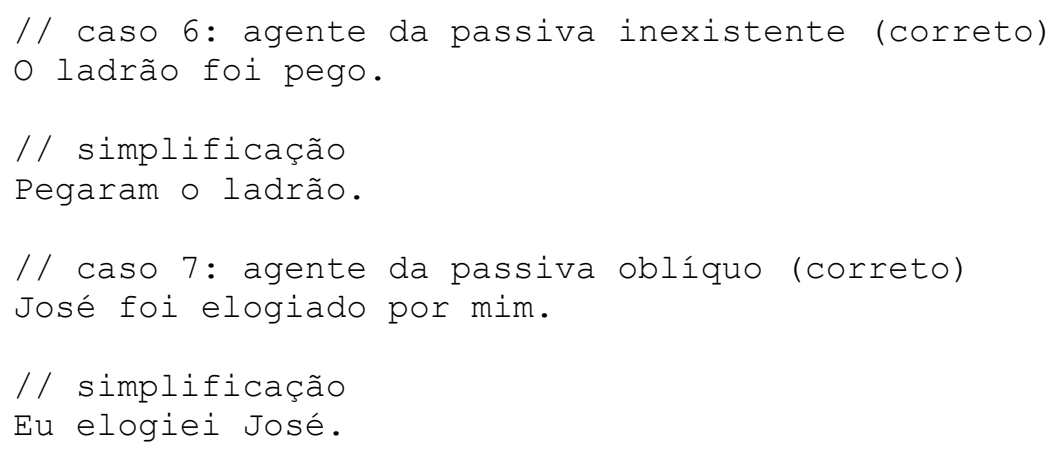

Exemplo 4.10: Agente na voz passiva.

O Exemplo 4.11 apresenta casos relacionados ao sujeito da oração original. Quando o sujeito é pronominal ou oculto, é necessário criar um objeto direto composto por pronome oblíquo atono.

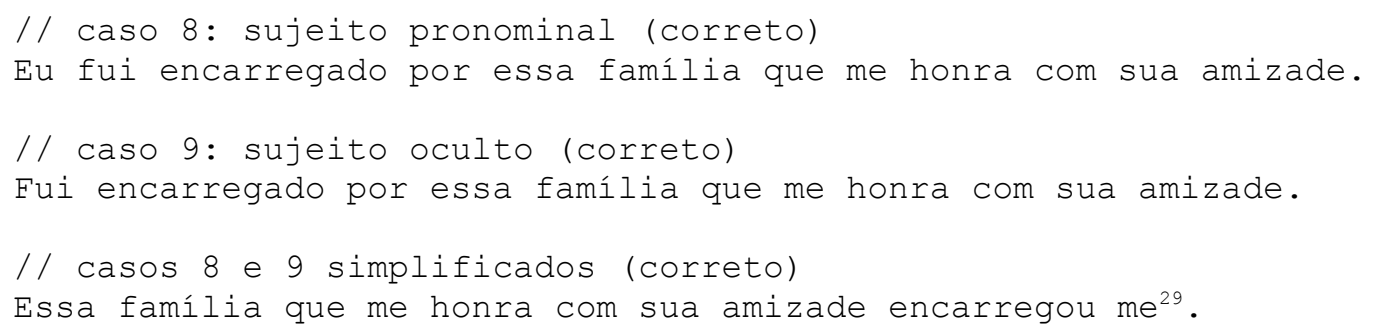

Exemplo 4.11: Sujeito na voz passiva.

Além dos casos apresentados, dois outros não são processados por serem considerados muito simples. São eles a voz passiva em trechos de orações com elipses ("a planta era cultivada naquela salinha, mal iluminada por um lampião") e voz passiva sindética ("vendem-se casas").

O Algoritmo 4.1 apresenta os passos para simplificar o caso padrão e os casos relacionados a verbos. É importante observar que o código correspondente é disparado para cada nó da árvore sintática, em uma busca em largura. Os algoritmos 4.2 e 4.3 apresentam versões modificadas do Algoritmo 4.1 para tratar casos de agentes da passiva e de sujeitos, respectivamente. Os algoritmos foram simplificados, uma vez que a versão implementada do Sinsim utiliza um único algoritmo mais geral para tratar todos os casos identificados.

1.0 pré-requisitos

1.1 oração deve ser raiz

1.2 lema do último verbo auxiliar deve ser "ser"

29 A correção da hifenização dos pronomes junto aos verbos é uma tarefa simples, deixada para trabalhos futuros. 


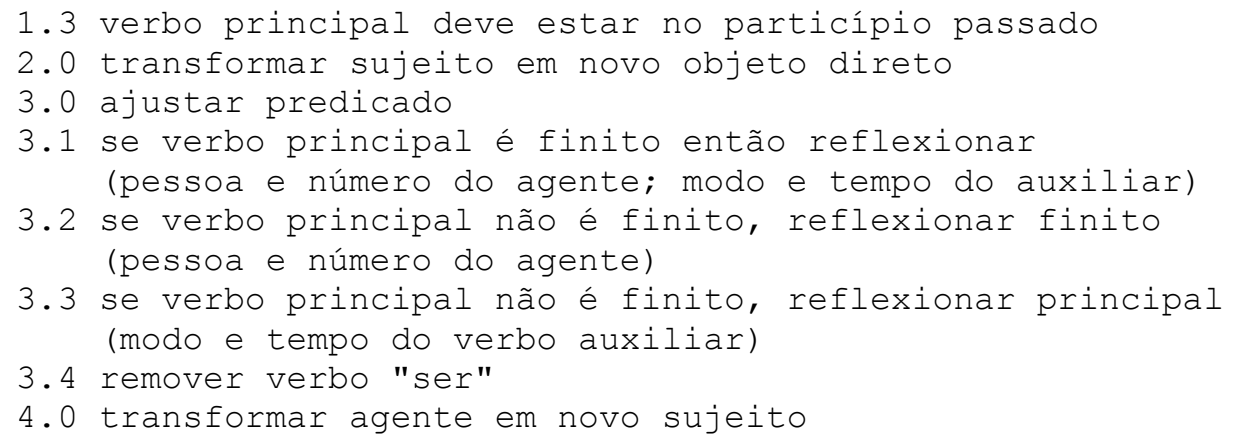

Algoritmo 4.1: Caso padrão e verbos na voz passiva.

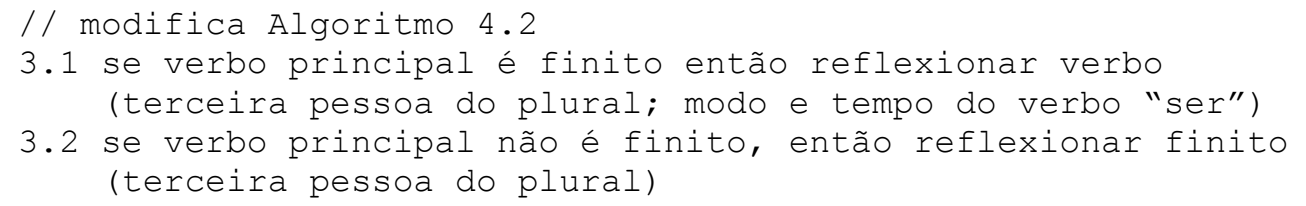

Algoritmo 4.2: Agente na voz passiva.

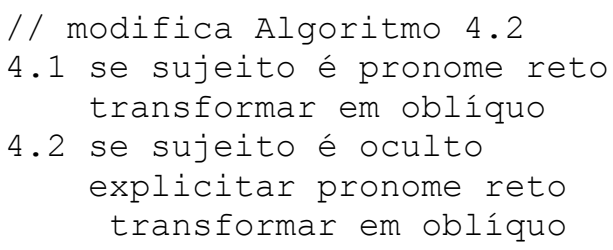

Algoritmo 4.3: Sujeito na voz passiva.

\subsubsection{Subordinadas adjetivas}

Do ponto de vista sintático, as orações subordinadas adjetivas explicativas se diferenciam das restritivas pela presença de vírgulas, e, devido à sua similaridade, possuem os mesmos casos e são tratadas pela mesma regra de simplificação. O Exemplo 4.12 apresenta os casos relacionados ao pronome relativo "que".

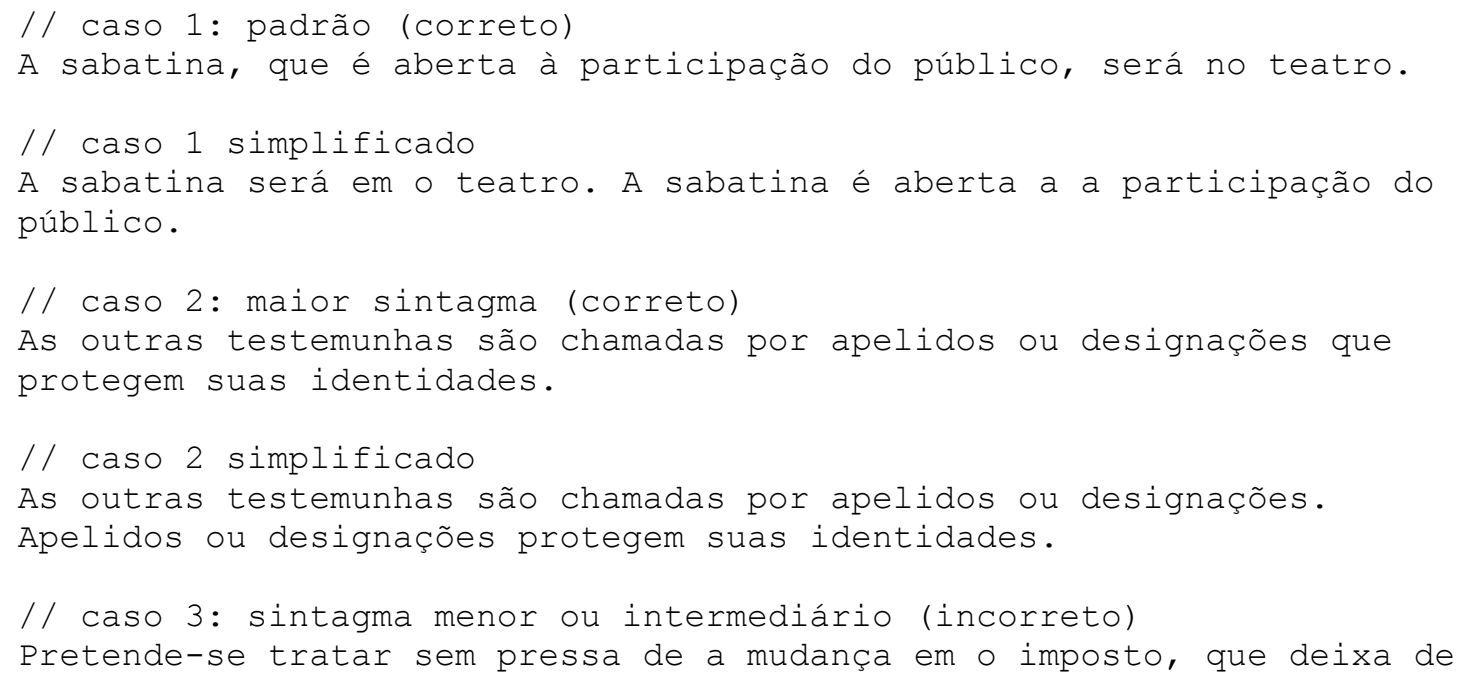




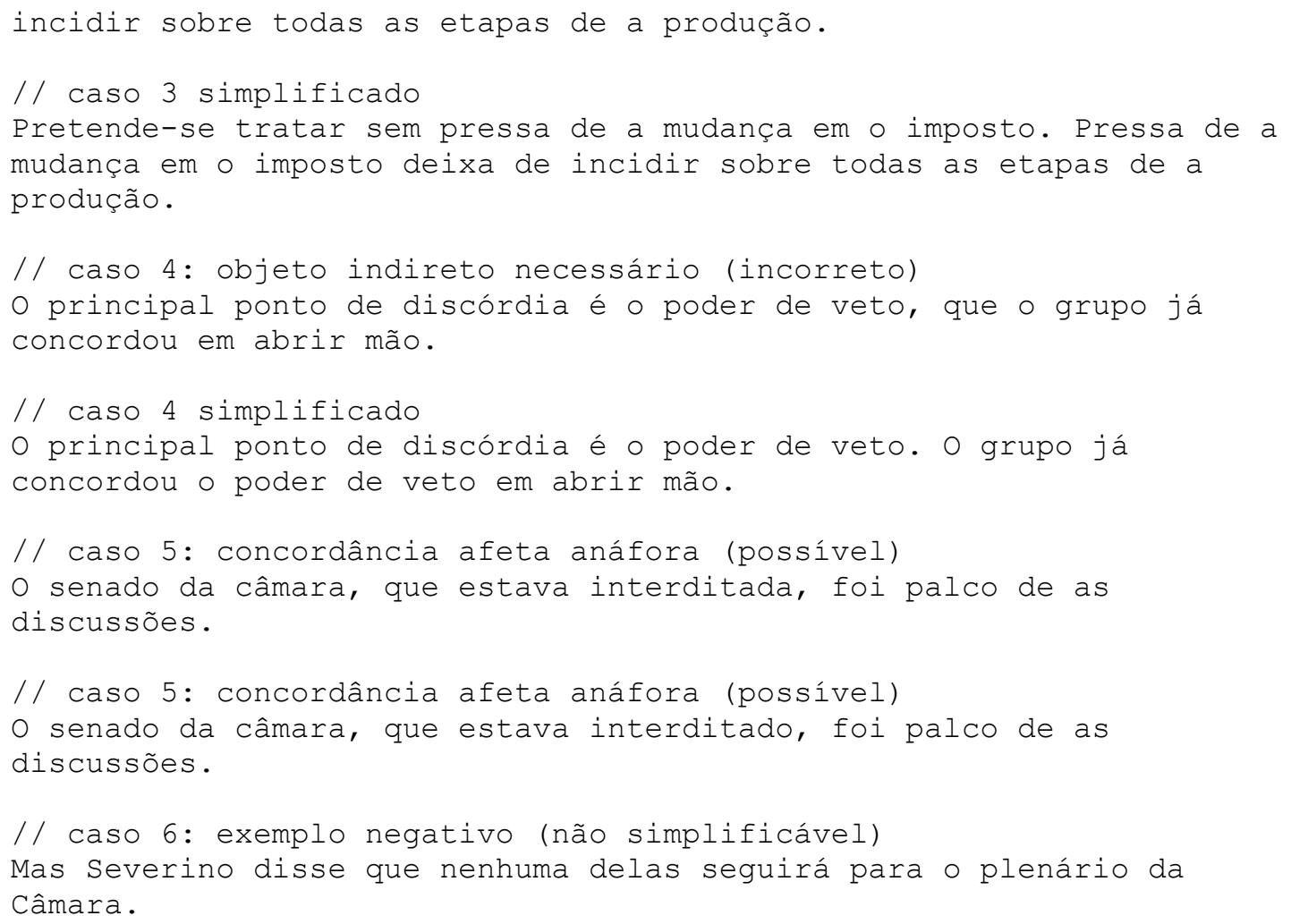

Exemplo 4.12: Pronome "que" em orações relativas.

No caso padrão, o sintagma nominal que antecede a anáfora não é composto por outros sintagmas, o que simplifica o processo de resolução. Dois casos foram identificados para sintagmas compostos. No primeiro, a anáfora referencia o maior sintagma composto. No segundo, a anáfora referencia sintagmas de tamanho intermediário ou o menor sintagma. $\mathrm{O}$ primeiro foi tratado por ser considerado o mais comum. Em trabalhos futuros, métodos estatísticos devem ser aplicados para facilitar a resolução anafórica. Existem orações cujo referente da anáfora deve ser transformado em objeto indireto em vez de objeto direto, como mostrado no Caso 4, do Exemplo 4.12. Neste exemplo, não há preposição indicando que a anáfora possui função sintática de objeto indireto. A versão da oração com a preposição seria “(...) veto, de que o grupo (...)”. Essa variante compromete a análise sintática e a simplificação por consequência. Por fim, foi observado que em alguns casos menos frequentes, é possível utilizar a concordância em gênero e número para resolver a anáfora, como mostrado no Caso 5, do Exemplo 4.12. O Algoritmo 4.4 detalha o processamento do pronome "que" em orações relativas.

1.0 pré-requisitos

1.1 oração deve iniciar por "que" ou "preposição que"

1.2 oração não deve ser raiz

1.3 oração deve ser precedida por sintagma nominal 


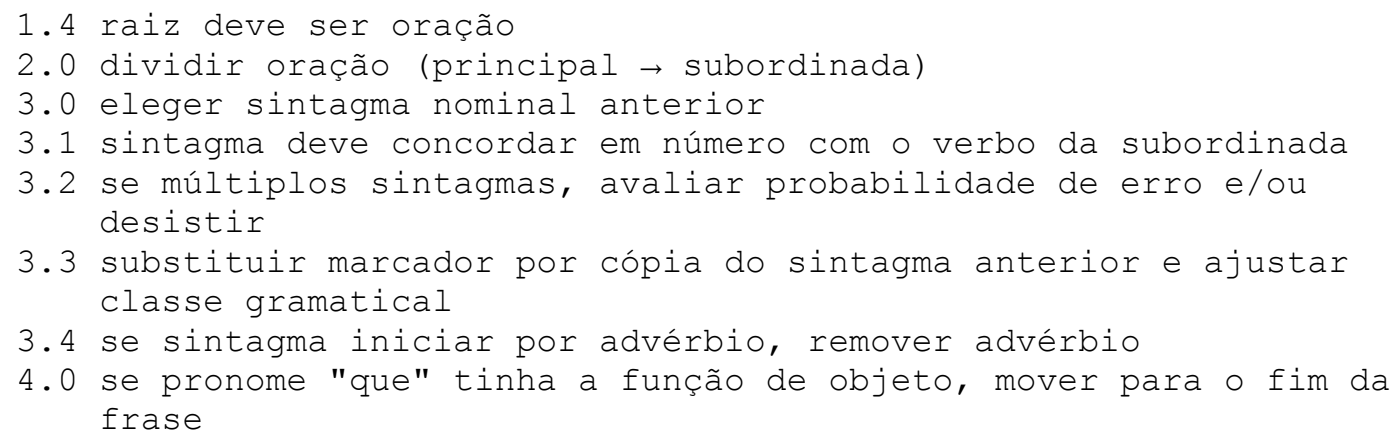

Algoritmo 4.4: Pronome "que" em orações relativas.

Os marcadores discursivos "como", "onde", "quando", "quem" e "quanto" também podem ser utilizados em orações relativas, mas não foram tratados por serem muito ambíguos ou por raramente serem utilizados em orações relativas, em um total de 5 casos não processados. Os pronomes "o que", "o qual" ("a qual", "os quais", "as quais") e "cujo" (“cuja", "cujos", "cuja") possuem um tratamento similar ao pronome "que" e são documentados no Apêndice B.1.

\subsubsection{Subordinada adverbial causal}

O Exemplo 4.13 apresenta o caso padrão de orações adverbiais causais para os marcadores “já_que", "porquanto", “a_vez_que", "visto_que”, tradados pelo Algoritmo 4.5. O processo envolve dividir a frase, e, se for o caso, reordenar as orações geradas na ordem oração principal - oração subordinada (como no Exemplo 4.13), e resolver sujeitos elípticos (por exemplo, convertendo "O que o homem quer em o espaço, visto que mal conhece a Terra?” para “O homem mal conhece a Terra. Com isso, o que o homem quer em o espaço?”).

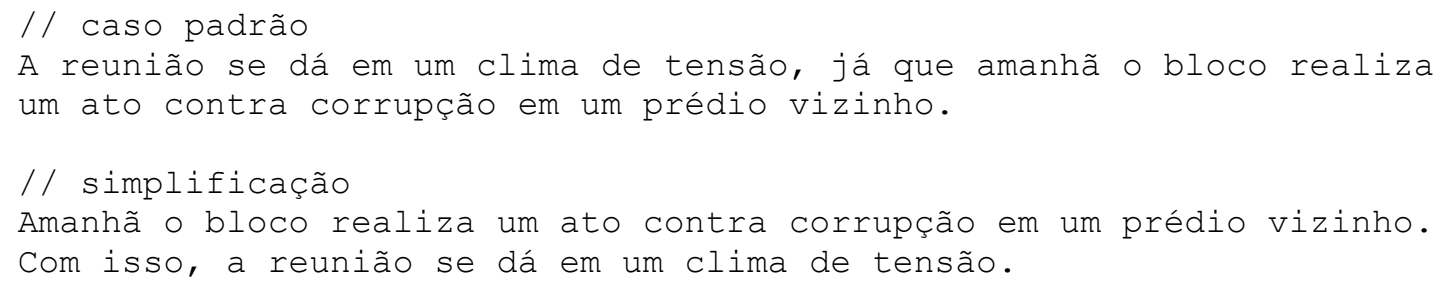

Exemplo 4.13: Caso padrão para subordinadas adverbiais causais.

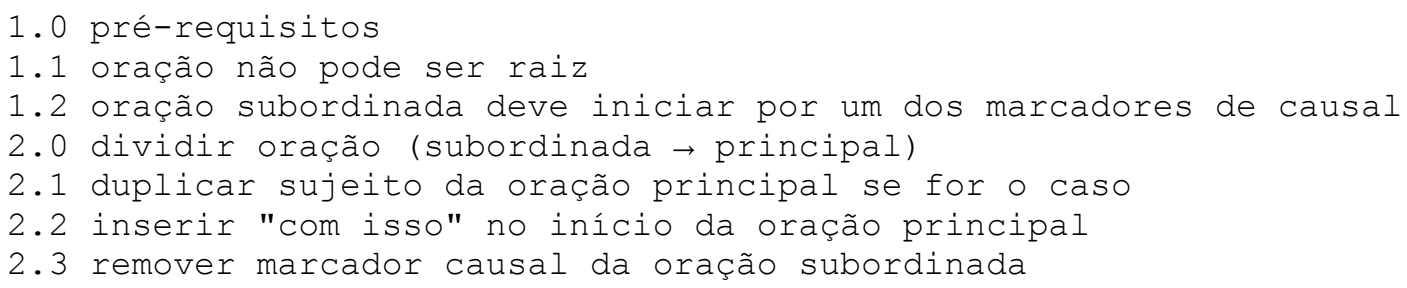

Algoritmo 4.5: Caso padrão para subordinadas adverbiais causais. 
O Exemplo 4.14 apresenta os casos não processados para orações subordinadas adverbiais causais, incluindo as razões associadas.

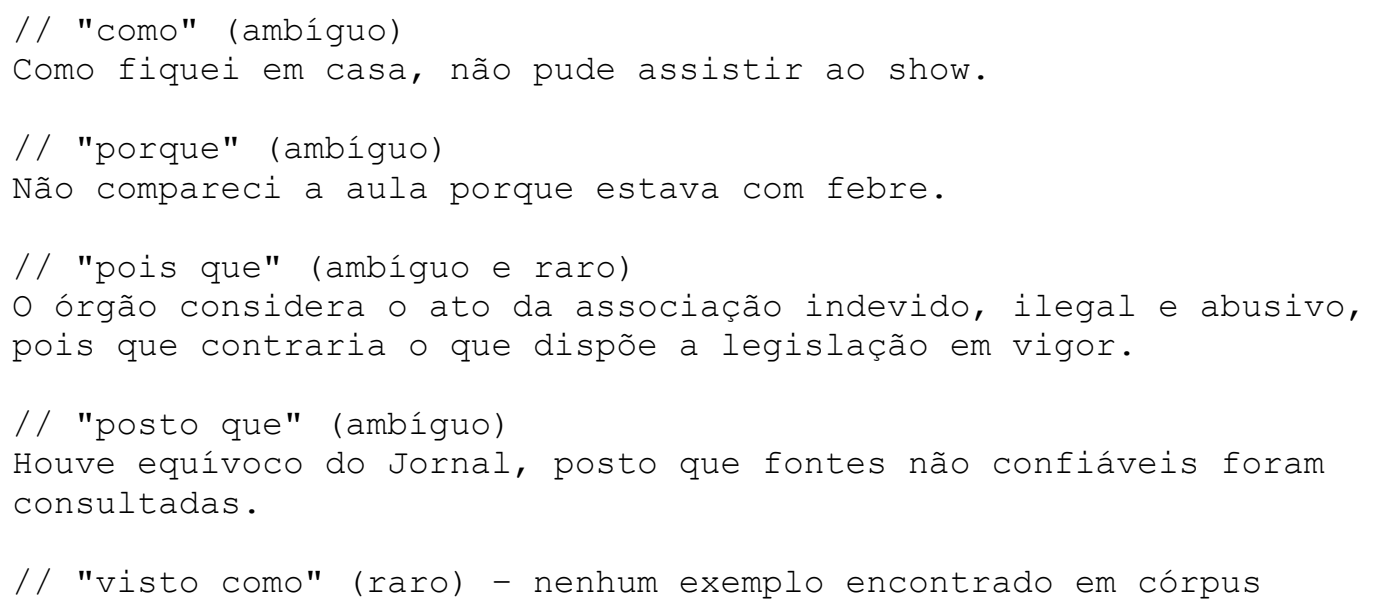

Exemplo 4.14: Casos não processados para subordinadas causais.

\subsection{Justificativa do uso de regras manuais}

Uma possível justificativa para o uso de aprendizado de máquina para a tarefa de simplificação sintática é o fato dela ser uma das inúmeras metodologias desenvolvidas para a tarefa de tradução de máquina. Sob essa perspectiva, o processo de simplificação pode ser visto como a tradução de um texto complexo em uma versão simplificada na mesma língua.

Apesar de trabalhos como o de Wubben et al. (2012) seguirem nessa direção, existem diferenças entre os cenários de uso de um simplificador sintático e de um tradutor automático que dificultam a adaptação de metodologias entre os dois cenários. Em primeiro lugar, tradutores automáticos não priorizam reduzir o tamanho das frases geradas, o que é importante na simplificação sintática. Em segundo lugar, e mais importante, a audiência em cada cenário é muito distinta. Para tradução automática, normalmente pressupõem-se leitores com conhecimento nulo ou muito limitado da língua fonte. Assim, mesmo uma tradução com muitos erros, pode permitir a esses leitores ter algum entendimento sobre o texto, aumentando a sua compreensão. Já na simplificação automática, os leitores possuem alguma compreensão do texto fonte, que pode vir a ser prejudicada no texto simplificado se houver erros no processo de simplificação.

Outra forma de entender a tarefa de simplificação é compreendê-la como uma de várias tarefas que recebem, atualmente, o rótulo de aptação textual, sendo inclusive foco de uma das oficinas da conferência ACL 2011 (Association for Computational Linguistics Conference). 
Tendo um texto em uma dada língua natural, a geração de texto para texto produz uma saída em língua natural, que obedece a um conjunto de restrições. As várias subtarefas desta área de pesquisa são: compressão frasal cujo objetivo é produzir sentenças mais curtas; fusão sentencial, que produzem uma junção de várias frases em uma única; paráfrases, que são diferentes realizações textual de um dado significado. Essas subtarefas são aplicadas em sistemas de sumarização multi-documentos, sistemas de perguntas e respostas e sistemas de simplificação e elaboração textual (GANITKEVITCH et al., 2012).

Durante o desenvolvimento do modelo foi observado que o uso de aprendizado de máquina automático ou outros métodos estatísticos especificamente voltados a simplificação sintática ainda é um desafio grande para o estado da arte atual, considerando a Língua Portuguesa como alvo.

O primeiro problema observado é que, na Língua Portuguesa, não existem recursos de grande porte para simplificação sintática baseada em aprendizado de máquina, tais como a Simple English Wikipedia, o que também é válido para diversas outras línguas. Nesse sentido, o simplificador sintático baseado em regras manuais gerado, pode ser utilizado para anotar grandes recursos, com o objetivo de apoiar simplificadores treinados a partir de técnicas de aprendizado de máquina ou outros métodos estatísticos, o que é o análogo ao uso do analisador sintático Palavras (baseado em regras manuais) no treinamento de instâncias Molin. Modelos baseados em aprendizado de máquina treinados por um modelo baseado em regras manuais podem posteriormente ser corrigidos por humanos por meio de aprendizado diferencial, com potencial de superar seu tutor automático.

Um segundo problema é que, mesmo com grandes recursos anotados como a Simple English Wikipedia, os passos utilizados na simplificação não são explicitados; cabe aos modelos inferirem todas as transformações pelas quais o texto fonte passou. Para agravar a questão, algoritmos completos devem ser latentes pelo mecanismo de aprendizado de máquina. $\mathrm{O}$ processo de inferência é nivelado por baixo, pois caso a regra com a menor probabilidade de inferência não seja detectada ou seja incorretamente substituída por outra regra similar, o resultado fica facilmente comprometido. Além disso, há muitos casos e subcasos com diferenças sutis, que podem demandar algoritmos similares, mas não idênticos.

Uma terceira questão a ser pensada no uso de aprendizado de máquina é a alta dimensionalidade intrínseca ao problema. As regras podem incluir inserção, remoção, substituição de texto e reordenação de componentes sintáticos da oração. Para a inserção, os 
blocos a serem inseridos podem ser fixos (por exemplo, marcadores discursivos) ou variar a cada oração (por exemplo, uma resolução anafórica do pronome "que" ou resolução de elipses). A remoção precisa detectar o nó sintático correto na árvore. Operar acima do nó desejado leva à remoção de segmentos desejados na oração simplificada, e remoções abaixo do nó desejado levam a segmentos indesejados. Assim como as inserções, as substituições podem incluir substituições fixas (por exemplo, marcadores discursivos) ou variáveis (por exemplo, inflexão de verbos para ajuste da concordância). A reordenação de componentes também necessita ser precisa como a remoção, pois mover um nó mais inferior ou superior ao desejado aumenta as chances da oração simplificada tornar-se agramatical. 


\section{Avaliação}

Este capítulo apresenta grupos de experimentos realizados para avaliar o modelo Molin, assim como a avaliação do modelo Sinsim. A Seção 5.1 apresenta oito grupos de experimentos, com os experimentos de referência no primeiro grupo e experimentos para ajustes de parâmetros nos demais. Seção 5.2 apresenta três grupos de experimentos para a avaliação multinível centrada em análise morfossintática, análise de dependências sintáticas e análise de funções sintáticas, com a inclusão de outros níveis e subníveis a avaliação dessas três tarefas. Parâmetros utilizados nos experimentos Molin, assim como os tempos de execução de cada experimento, são encontrados nos apêndices A.4 e A.5, respectivamente. O modelo Sinsim é avaliado na Seção 5.3. A Seção 5.4 apresenta uma avaliação extrínseca do Molin incluindo uma análise de sua interação com o Sinsim.

\subsection{Experimentos de base para análise da língua}

Experimentos de base se baseiam nos conjuntos Dela (aquisição léxica), Mac (análise morfossintática) e Pln (análise morfossintática e sintática, embora apenas a primeira seja explorada nesta seção), apresentados previamente na Seção 3.4.2. Nas análises busca-se minimizar Msee (referente aos erros quadráticos médios) e maximizar DeY (referente à saída desejada coincidir com a saída obtida), já que estas medidas afetam todas as demais. Para uma comparação com trabalhos da área, a média harmônica entre YinD e DinY é o que mais se aproxima da acurácia, geralmente usada na análise morfossintática e também a interligação não rotulada geralmente aplicada na análise sintática de dependências. Observa-se que DeY não corresponde à acurácia devido às caraterísticas multirrótulo do Molin, sendo sempre menor que a média harmônica entre YinD e DinY.

Os experimentos tendem a utilizar os parâmetros dos experimentos anteriores, exceto quando explicitamente indicado o contrário. Os parâmetros iniciais utilizam a função sigmoide logística como função de ativação da rede, a taxa mínima de aprendizado como 0,1 e a função de ajuste de pesos para redes Perceptron. Primeiramente, são apresentados experimentos de base, com parâmetros obtidos a partir de experimentos preliminares. Após 
esse grupo, são apresentados experimentos para indicar o comportamento do protótipo em relação a diferentes parâmetros.

Os córpus para a maioria dos experimentos iniciais são o Pln-f1 (aproximadamente o primeiro milhão de padrões) para treinamento e o Pln-e11 para teste (os 100 mil padrões subsequentes). A maioria dos experimentos passam por uma época ${ }^{\mathrm{g}}$ de treinamento para aquisição léxica e pelo menos outra época para aprender diferentes tarefas. Na aquisição léxica são aprendidos lemas, classes gramaticais e traços morfológicos (eventos morph) a partir de lexemas e correlatos, incluindo eventos especiais (unknown_lexeme, uc_first, first_in_sentence, entre outros). Um problema detectado durante os experimentos foi o evento unknown_lexeme sendo associado a lemas válidos ao invés do evento unknown_lemma. Isso ocorreu devido a: (a) erros ortográficos no córpus em lexemas com lemas válidos; (b) a novos lexemas, cujos lemas coincidiam com lemas pré-existentes; (c) outros fatores. Um pré-processamento foi realizado nos arquivos de treinamento para corrigir esses casos, convertendo-se lemas para o evento unknown_lemma.

$\mathrm{O}$ experimento em destaque foi mapeado para um arcabouço de testes preparado para regerar resultados a cada mudança pela qual o protótipo passou. Este arcabouço é apresentado codificado no Apêndice C. Alguns experimentos extras não foram detalhados por não fazerem parte do arcabouço. Tais experimentos são muito semelhantes aos experimentos destacados, ou tiveram apenas a finalidade de ajudar a escolha de parâmetros ou ainda foram relacionados a questões de menor importância na investigação realizada. Alguns deles serão mencionados durante a análise dos experimentos principais para prover informação complementar sobre as instâncias, sendo referenciados por experimentos adicionais.

Como existe muita variação entre os eventos, as seguintes convenções apresentadas no Exemplo 5.1 são utilizadas para denotar os eventos em um experimento:

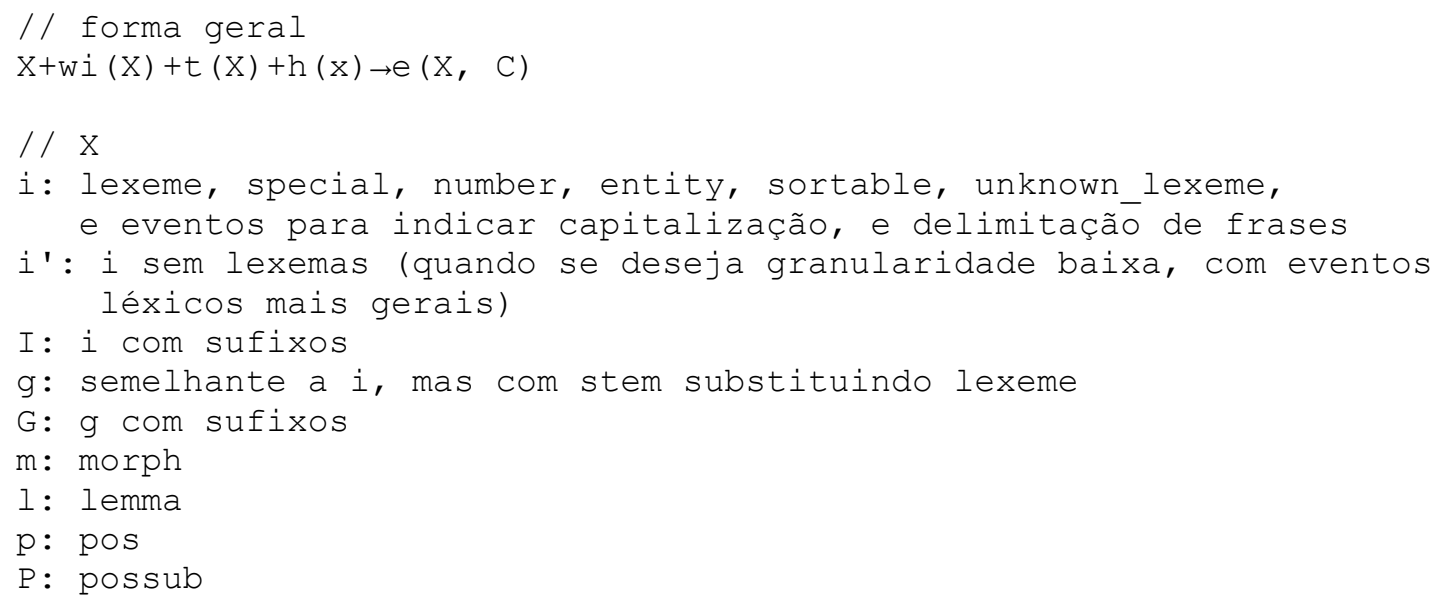




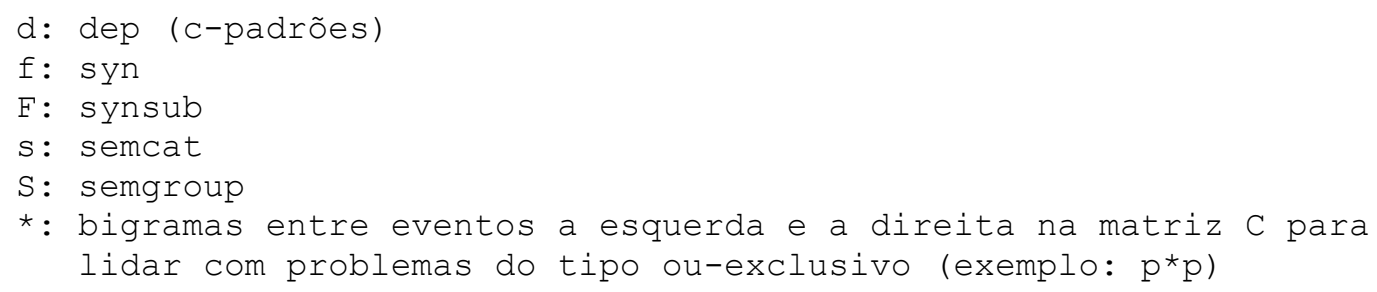

Exemplo 5.1: Notação de eventos para um experimento.

O elemento $X$ representa um conjunto de eventos. O primeiro termo $(X)$ indica os eventos usados como entrada do b-padrão em análise (sejam entradas originalmente ou saídas devido à recorrência). $\mathrm{O}$ segundo termo $\left(w_{i}(X)\right)$ indica os eventos de entrada ou de saída da vizinhança do b-padrão em análise, onde $i$ define o tamanho da janela. O terceiro termo $(t(X))$ denota os eventos utilizados na análise de c-padrões. O quarto termo $(h(x))$ denota os eventos importados do b-padrão pai (definido na análise de c-padrões) para o b-padrão em análise. $\mathrm{O}$ quinto termo $(e(X, C))$ refere-se aos eventos avaliados nos a-padrões gerados a partir da combinação de b e c-padrões (quando aplicável). O elemento $C$ presente no quinto termo representa o córpus em análise e, quando ausente, indica que o córpus Pln-f foi utilizado.

\subsubsection{Grupo 1: experimentos de referência}

Este grupo apresenta avaliações de referência para as tarefas de: (a) análise morfológica sem morfossintaxe ou lemas (g1e1); (b) lematização (g1e2); (c) análise morfossintática (g1e3); (d) análise de dependências (g1e4), com medidas semelhantes à análise de interligação não rotulada; (e) análise de funções sintáticas (g1e5); e (f) análise de categorias semânticas (g1e6). A Tabela 5.1 apresenta os resultados para o grupo de experimentos.

Tabela 5.1: Resultados para o grupo 1.

\begin{tabular}{llllllllll}
\hline Exp. & Detalhes & Msee & Jac & Dic & Jacf & Dicf & YinD & DinY & DeY \\
\hline g1e1 & i+w1(i)->e(m) & 0,0358 & 0,9333 & 0,9430 & 0,6643 & 0,7010 & 0,9301 & 0,9530 & 0,8917 \\
g1e2 & i+w1(i)->e(l) & 0,0228 & 0,9805 & 0,9824 & 0,9224 & 0,9523 & 0,9799 & 0,9864 & 0,9747 \\
g1e3 & i+w1(i)->e(p) & 0,0292 & 0,9259 & 0,9302 & 0,7896 & 0,8405 & 0,9447 & 0,9429 & 0,9127 \\
g1e4 & i+w1(i)+t(i',1*1,pP*pP)->e(d) & 0,3715 & 0,7486 & 0,7486 & 0,7347 & 0,7441 & 0,7702 & 0,7486 & 0,7486 \\
g1e5 & i+w1(i)+t(i',l*1,pP*pP) & 0,0387 & 0,8254 & 0,8332 & 0,5715 & 0,6257 & 0,9278 & 0,8362 & 0,8037 \\
& +h(i'lp)->e(f) & & & & & & & & \\
g1e6 & i+w1(i)->e(s) & 0,0125 & 0,9201 & 0,9232 & 0,4727 & 0,5009 & 0,9727 & 0,9262 & 0,9105 \\
\hline
\end{tabular}

Estes experimentos tem como objetivo servir de baseline para análise multiníveis e de comparação com os experimentos de ajustes de parâmetros. Os experimentos g1e4, contudo, não é um baseline, sendo o melhor experimento na análise de c-padrões para dependências 
sintáticas, criado para apoiar experimentos que dependam da árvore sintática de dependências, como o experimento g1e5.

Em relação às análises no nível morfológico e seus subníveis, g1el aplica lexemas, correlatos, eventos relativos à capitalização e eventos relativos ao limite das frases na tarefa de análise morfológica, recuperando número, gênero, grau, tempos verbais, entre outras informações morfológicas, apresentando DeY de 0,8917. G1e2 aplica a mesma análise para lematização, atingindo DeY de 0,9747, resultado considerado satisfatório. G1e3 apresenta resultados de YinD $(0,9447)$ e DinY $(0,9429)$, o que foi considerado satisfatório por tratar-se de um baseline.

Em relação a análises no nível sintático, g1e4 apresenta resultados similares aos de Collins (2003) quando o atributo referente a adjacências não é incluso (também não presente no protótipo Miolin). O experimento faz uso de bigramas de eventos, discutidos na Seção 5.2.2. Observa-se que o resultado de g1e4 é extraído de a-padroes após a mesclagem entre b e c-padrões. Se a análise for efetuada nos c-padrões, os resultados devem variar, já que a matriz C tem um número maior de padrões, combinando a-padrões dois a dois. Os resultados de g1e5 ficaram abaixo do esperado, uma vez que o experimento depende g1e4 que ainda apresenta desempenho baixo. Além disso, devido à otimização por semente, cada lema precisa ter ocupado no conjunto de treinamento todas as funções sintáticas que pode exercer. Como isso não ocorre, observa-se o valor DinY $(0,8165)$ consideravelmente menor que YinD $(0,9334)$. Não conhecemos avaliações (benchmarks) sobre a categorização semântica provida pelo Palavras, de modo que não foi possível avaliar se os resultados de g1e6 são satisfatórios.

Observa-se que este grupo de experimentos, assim como a maioria dos demais é treinado sobre o conjunto Pln-f, que foi apenas anotado pelo Palavras sem correção humana. O grupo de experimentos g8 mostra que esses valores são muito similares para valores em um córpus revisado por humanos (o conjunto Mac-f).

\subsubsection{Grupo 2: aquisição léxica e frequências}

Este grupo tem como objetivo validar a etapa de aquisição léxica das instâncias Molin e o aprendizado sem janela. Durante a aquisição léxica, o parâmetro replace_new é ignorado. Para lexemas com apenas uma classe gramatical e um lema, o aprendizado é direto. Ativações para lexemas com mais de uma classe gramatical ou lema tenderão a predizer os últimos valores aprendidos. Em particular, verbos possuem chances de ativação um pouco maiores que outras classes depois do aprendizado léxico, pois aparecem mais vezes em suas inúmeras 
flexões, o que faz com que suas sinapses especiais sejam atualizadas positivamente com mais frequência.

A Tabela 5.2 apresenta os experimentos g2e1 e g2e2 após a aquisição léxica e g2e3 e g2e4 após treinamento sobre o conjunto Pln-f. G2e1 usa em sua avaliação o mesmo conjunto usado no treinamento relativo à aquisição léxica (Dela). G2e2 avalia a instância gerada por aquisição léxica na tarefa de análise morfossintática (Pln-f), servindo com um baseline para g2e4. G2e3 avalia o decaimento da avaliação feita em g2e1 após o treinamento no conjunto Pln-f1. Por fim, g2e4 avalia uma instância sem janela, treinada sobre Pln-f1 e avaliada sobre Pln-e11. Esses experimentos também permitiram coletar as primeiras estatísticas sobre neurônios e sinapses gerados em diversas instâncias e depurar o protótipo Miolin.

Tabela 5.2: Resultados para o grupo 2.

\begin{tabular}{llllllllll}
\hline Exp. & Detalhes & Msee & Jac & Dic & Jacf & Dicf & YinD & DinY & DeY \\
\hline g2e1 & i->e(p, dela) & 0,0700 & 0,9563 & 0,9701 & 0,9308 & 0,9549 & 0,9174 & 1,0000 & 0,9174 \\
g2e2 & i->e(p, dela-pln-e11) & 0,3454 & 0,6732 & 0,7266 & 0,6449 & 0,7284 & 0,5664 & 0,8401 & 0,5423 \\
g2e3 & i->e(p, pln-e11-dela) & 0,1266 & 0,9208 & 0,9237 & 0,6645 & 0,7912 & 0,9470 & 0,9299 & 0,9121 \\
g2e4 & i->e(p) & 0,0492 & 0,8902 & 0,8927 & 0,7177 & 0,7912 & 0,8999 & 0,9338 & 0,8831 \\
\hline
\end{tabular}

No experimento g2e1, o valor DeY não é 1, já que há ambiguidade gramatical nos lexemas (dois padrões com o mesmo lexema aparecem com saídas diferentes devido a essa ambiguidade). Como existem mais lexemas com uma única classe gramatical do que lexemas ambíguos, as sinapses especiais dos neurônios pos são ajustadas positivamente com maior frequência. Como resultado, esses neurônios ficaram disparados em qualquer ativação em que participaram, resultando em DinY próximo a 1 (percentual de padrões cuja a saída desejada é um subconjunto da obtida). Isso indica que g2e1 tende a predizer mais neurônios do na saída obtida do que o número de neurônios na saída esperada.

No experimento g2e2, aplicado ao conjunto Pln-e11, as frequências dos lexemas mudam o resultado da avaliação. No conjunto Dela, cada lexema é apresentado à instância com frequência 1, enquanto em Pln-e11 há repetições de lexemas. Como resultado, valor DeY foi menor, pois basta um lexema muito frequente com classificação incorreta para reduzir DeY. A medida DinY dessa vez não foi próxima a 1, pois existem diferenças idiossincráticas entre os conjuntos de avaliação, ou seja, alguns lexemas podem ser anotados com classes diferentes de um conjunto para outro. Além disso, o mapeamento apresentado no Apêndice A.1 não é perfeito. 
O experimento g2e3 consistiu em avaliar o conjunto Dela após o aprendizado do conjunto Pln-f1. Como esperado, a medida referente ao erro quadrático médio (Msee) aumentou em relação a g2e1, enquanto as demais apresentam uma leve diminuição.

Os experimento g2e4 teve por objetivo avaliar como instâncias se saem quando não há informação de contexto suficiente. Idealmente, a instância deve predizer casos mais frequentes no treinamento, já que sinapses e sinapses especiais frequentes terão seus pesos ajustados positivamente com mais frequência do que as sinapses mais raras. Por exemplo, se pos_verb for o caso mais frequente para lexeme_canto, então a instância deve predizer pos_verb com maior ativação que pos_noun. Isso é importante para mostrar que instâncias baseadas em contexto podem utilizar frequências quando o contexto não é suficiente para uma boa predição. A diferença de g2e4 em relação a g2e2 indica que as frequências estão sendo devidamente gerenciadas pela instância. Nota-se que esse experimento é comparável a g1e3.

Um experimento adicional para pos_noun e pos_verb foi realizado, no qual conjuntos de treinamentos fíctícios com diferentes proporções entre pos_noun e pos_verb foram utilizados. Todos os padrões tinham pos_noun ou pos_verb, mas não ambos. Dadas épocas suficientes, observa-se que a saída obtida dos dois neurônios tendeu às suas distribuições no conjunto de treinamento. Por exemplo, quando pos_verb ocorre em $75 \%$ dos padrões, sua saída é próxima a 0,75 . Esse resultado indica que existem instâncias cujas saídas podem ser utilizadas como probabilidades (modelo gerativo), embora redes neurais sejam normalmente modelos discriminativos.

\subsubsection{Grupo 3: convergência com contexto}

Este grupo de experimentos analisa a convergência da rede neural artificial com base em épocas e em diferentes tamanhos de córpus. A Tabela 5.3 apresenta os resultados do grupo.

Tabela 5.3: Resultados para o grupo 3.

\begin{tabular}{llllllllll}
\hline Exp. & Detalhes & Msee & Jac & Dic & Jacf & Dicf & YinD & DinY & DeY \\
\hline g3e1 & i+w0(i)->e(p) & 0,0492 & 0,8903 & 0,8928 & 0,7177 & 0,7913 & 0,9000 & 0,9338 & 0,8831 \\
g3e2.1 & i+w1(i)->e(p) (g1e3) & 0,0292 & 0,9259 & 0,9302 & 0,7896 & 0,8405 & 0,9447 & 0,9429 & 0,9127 \\
g3e2.2 & i+w1(i)->e(p) (2a. ep) & 0,0266 & 0,9323 & 0,9365 & 0,8064 & 0,8516 & 0,9477 & 0,9486 & 0,9197 \\
g3e2.3 & i+w1(i)->e(p) (3a. ep) & 0,0253 & 0,9357 & 0,9397 & 0,8147 & 0,8570 & 0,9497 & 0,9514 & 0,9235 \\
g3e2.4 & i+w1(i)->e(p) (4a. ep) & 0,0245 & 0,9380 & 0,9419 & 0,8203 & 0,8606 & 0,9508 & 0,9534 & 0,9261 \\
g3e2.5 & i+w1(i)->e(p) (5a. ep) & 0,0239 & 0,9398 & 0,9436 & 0,8243 & 0,8632 & 0,9521 & 0,9547 & 0,9283
\end{tabular}




\begin{tabular}{llllllllll}
\hline Exp. & Detalhes & Msee & Jac & Dic & Jacf & Dicf & YinD & DinY & DeY \\
\hline g3e3.1 & i+w1(i)->e(p, pln-b) & 0,1776 & 0,8217 & 0,8568 & 0,6801 & 0,7710 & 0,7632 & 0,9211 & 0,7105 \\
g3e3.2 & i+w1(i)->e(p, pln-c) & 0,1496 & 0,7699 & 0,7949 & 0,6248 & 0,7270 & 0,7882 & 0,8269 & 0,6925 \\
g3e3.3 & w1(i)->e(p, pln-d) & 0,0867 & 0,8107 & 0,8212 & 0,6467 & 0,7377 & 0,8882 & 0,8370 & 0,7791 \\
g3e3.4 & w1(i)->e(p, pln-e) & 0,0477 & 0,8891 & 0,8948 & 0,7186 & 0,7917 & 0,9350 & 0,9049 & 0,8717 \\
g3e3.5 & w1(i)->e(p, pln-E) & 0,0173 & 0,9536 & 0,9565 & 0,7984 & 0,8275 & 0,9617 & 0,9661 & 0,9451 \\
\hline
\end{tabular}

O experimento g3e1 é uma variação de g2e2 com uma diferença sútil: o segundo (g2e2) não usa janela, ou seja, o aprendizado é totalmente online, enquanto que o primeiro (g3e3) usa a janela 0 , ou seja, o conjunto de padrões do mesmo contexto são atualizados juntos em vez de um a um. Como os experimentos são muito similares, com variações mínimas em seus resultados, da ordem de $10^{-4}$.

$\mathrm{O}$ experimento g3e 2 consistiu em avaliar a convergência do experimento de referência g1e3. Como o conjunto de treinamento é grande, observou-se uma convergência em poucas épocas. Contudo, em instâncias para aplicações reais, é conveniente usar épocas adicionais para obter resultados ótimos.

Para g3e3.1 usou-se o conjunto Pln-b1 para treinamento e Pln-b2 para teste. O caso análogo vale entre g3e3.2, g3e3.3 e g3e3.4, para os conjuntos Pln-c, Pln-d e Pln-e, respectivamente. O experimento g3e3.5 usou o subcórpus Pln-e1' (os últimos 100 mil padrões do córpus Pln) para avaliação e o subcórpus Pln-E1' (os demais padrões) para treinamento. Os resultados indicam que, além das épocas adicionais, as instâncias também podem se beneficiar de conjuntos de treinamento maiores para melhorar seus resultados. Para essa instância em particular, os resultados sugerem que o tamanho de córpus ótimo ainda não foi atingido dado os recursos disponíveis, isto é, pela análise de convergência, instâncias baseadas em conjuntos com mais de 38 milhões de padrões podem superar o desempenho de g3e3.5. O resultado obtido é próximo aos resultados do estado da arte para análises morfossintáticas.

\subsubsection{Grupo 4: funções de ativação e de ajuste de pesos}

Este grupo de experimentos consiste em testar as funções de ativação (sigmoide logística e passo) e de ajuste de pesos (Perceptron e MLP), como apresentado na Tabela 5.4 para duas combinações entre função de ativação e de ajuste de pesos. A terceira combinação, o uso de ajuste de pesos Perceptron e ativação sigmoide é coberto pelo experimento de referência g1e3. A quarta combinação, o ajuste de pesos MLP combinado com função de 
ativação leva a ajustes sempre nulos, razão pela qual não é explorado.

Tabela 5.4: Resultados para o grupo 4.

\begin{tabular}{llllllllll}
\hline Exp. & Detalhes & Msee & Jac & Dic & Jacf & Dicf & YinD & DinY & DeY \\
\hline g4e1 & i + w1(i)->e(p) (pas-per) & 0,0351 & 0,9282 & 0,9337 & 0,9282 & 0,9337 & 0,9444 & 0,9467 & 0,9104 \\
g4e2 & i + w1(i)->e(p) (sig-mlp) & 0,0466 & 0,8923 & 0,8979 & 0,6800 & 0,7660 & 0,9258 & 0,9117 & 0,8756 \\
\hline
\end{tabular}

Em relação à ativação Passo com ajuste Perceptron apresentada em g4e1, o experimento de referência g1e3 combinado de ajuste Perceptron e ativação sigmoide se saiu levemente melhor, além de também permitir estabelecer graus de confiança sobre a saída e definir desempates para a análise de b-padrões pai, quando mais de um se aplica, devido a ativação sigmoide. O uso da função de ativação sigmoide logística combinado com o ajuste MLP em $\mathrm{g} 4 \mathrm{e} 2$ apresentou resultados piores que o experimento de referência g1e3. Contudo isso se deve à menor velocidade de convergência do ajuste de pesos MLP, pois, em experimentos adicionais com mais épocas, foi verificado que ambos convergem para valores bem similares.

\subsubsection{Grupo 5: coativação em janela e recorrência local}

Este grupo avalia o impacto da coativação em relação ao número de iterações realizadas. Os resultados para o grupo são mostrados na Tabela 5.5 .

Tabela 5.5: Resultados para o grupo 5 .

\begin{tabular}{|c|c|c|c|c|c|c|c|c|c|}
\hline Exp. & Detalhes & Msee & Jac & Dic & Jacf & Dicf & YinD & DinY & DeY \\
\hline g5e1 & $\mathrm{i}+\mathrm{w} 1(\mathrm{p})->\mathrm{e}(\mathrm{p})(2 \mathrm{it})$ & 0,0354 & 0,9057 & 0,9100 & 0,7771 & 0,8310 & 0,9284 & 0,9366 & 0,8927 \\
\hline g5e2 & & & & & & & & & \\
\hline g5e3 & $\mathrm{i}+\mathrm{w} 1(\mathrm{p})->\mathrm{e}(\mathrm{p})(0 \mathrm{it})$ & 0,0333 & 0,9084 & 0,9131 & 0,7837 & 0,8346 & 0,9350 & 0,9339 & 0,8944 \\
\hline g5e4 & $\mathrm{ip}->\mathrm{e}(\mathrm{p})$ & 0,0745 & 0,7948 & 0,8161 & 0,7108 & 0,7634 & 0,8587 & 0,7899 & 0,7343 \\
\hline
\end{tabular}

O experimento g5e1 utiliza coativação para neurônios pos aplicada em duas iterações, o que equivale a uma versão menos granular do experimento g1e3. Os resultados obtidos superam os resultados do experimento g2e4 (análise sem contexto), validando a coativação, embora não superem o experimento de referência g1e3, que ainda é mais vantajoso por ser mais granular. As maiores sinapses da base neural para o experimento g5e1 foram [pre_pos_determiner, pos_noun] e [post_pos_noun, pos_article], validando a iteração de exemplo entre artigos à esquerda e substantivos à direita apresentada na Seção 3.3.2.

O experimento g5e 2 consiste em uma análise com três iterações, e apresentou resultados semelhantes ao experimento g5e1, porém levemente inferiores. Mais investigações são 
necessárias para explicar o comportamento obtido no experimento atual, pois em experimentos adicionais, análises com três iterações levaram a resultados levemente superiores do que análises com duas iterações, enquanto análises com quatro iterações apresentaram os mesmos resultados da análise em três iterações.

O experimento g5e3 avalia a coativação ótima, na qual a saída esperada do contexto é exatamente igual a sua saída desejada. Tal processo é feito apenas para fins de comparação, pois estabelece um limite superior para a coativação baseada em eventos pos. O processo é realizado com a ajuda da saída desejada da vizinhança disponível durante o tempo de treinamento, que é aplicada também na avaliação, substituindo a saída obtida da vizinhança tanto no treinamento quanto na avaliação. Observa-se que instâncias com duas e três iterações mantiveram-se próximas do seu limite superior, o que é o comportamento desejado.

O experimento g5e4 testou a recorrência local de neurônios pos sendo realizado para manter a análise exploratória completa. Nota-se que, além dos neurônios locais, a entrada do contexto também é utilizada no processo. Os resultados foram consideravelmente piores que os resultados do experimento de referência g1e3. Os resultados negativos são expressivos, pois essa instância já está próxima ao seu ponto de convergência segundo experimentos adicionais. Embora não esteja descartada a hipótese de erro no protótipo, uma vez que o módulo para recorrência local foi o menos testado, tais resultados eram esperados, levando-se em conta o fato de que neurônios de saída do mesmo padrão começam a competir entre si na recorrência local.

\subsubsection{Grupo 6: contexto de entrada da janela 2}

Este grupo avalia o uso de janelas de contexto de tamanho 2 (para neurônios de entrada do contexto), a partir de diferentes políticas de criação de contexto, com resultados apresentados na Tabela 5.6.

Tabela 5.6: Resultados para o grupo 6.

\begin{tabular}{llllllllll}
\hline Exp. & Detalhes & Msee & Jac & Dic & Jacf & Dicf & YinD & DinY & DeY \\
\hline g6e1 & i+w2(i)->e(p) (padrão) & 0,0284 & 0,9288 & 0,9333 & 0,7937 & 0,8429 & 0,9474 & 0,9436 & 0,9151 \\
g6e2 & i+w2(i)->e(p) (prefixo sim.) & 0,0335 & 0,9143 & 0,9195 & 0,7737 & 0,8289 & 0,9369 & 0,9335 & 0,8987 \\
g6e3 & i+w2(i)->e(p) (decaimento) & 0,0307 & 0,9232 & 0,9279 & 0,7844 & 0,8367 & 0,9418 & 0,9404 & 0,9090 \\
\hline
\end{tabular}

Três políticas de construção de janelas maiores que 1 foram definidas e comparadas: padrão (g6e1), prefixo simples (g6e2) e prefixo simples com decaimento de ativação (g6e3). 
O Exemplo 5.2 apresenta exemplos de cada uma. Na política padrão, os prefixos de um neurônio de contexto (pre e post nas instâncias testadas) são repetidos de acordo com a distância entre o padrão original e o padrão que originou o neurônio de contexto (resultando em neurônios adicionais pre_pre e post_post para janela de tamanho 2). Na política de prefixo simples, prefixos não são repetidos, e na política de prefixo simples com decaimento, os valores de ativação dos neurônios de contexto são ponderados de acordo com a distância entre seu padrão e o padrão em análise, de forma similar a neurônios proximity, segundo a Equação 3.1 da Seção 3.2.6.

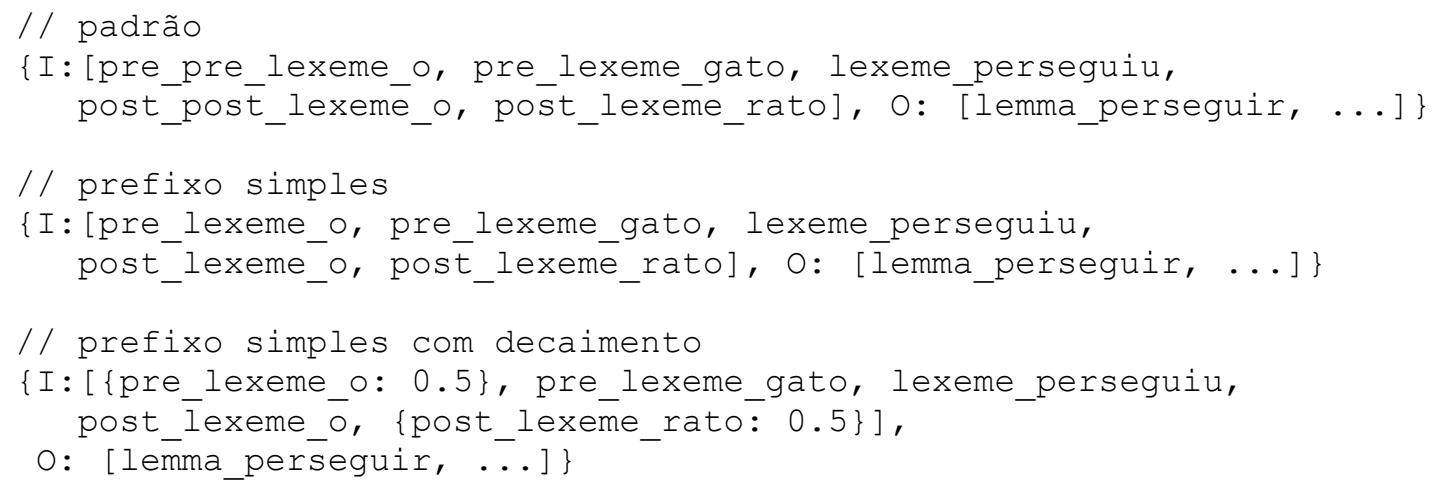

Exemplo 5.2: Políticas exemplificadas para lexeme_perseguiu.

Como esperado, g6e1 foi o experimento que apresentou os melhores resultados do grupo. Instâncias como as do experimento g6e2 não conseguem diferenciar neurônios originados de padrões próximos de neurônios provenientes de padrões mais distantes, o que compromete a análise. Para o experimento g6e3 tal diferenciação seria possível com o uso de camadas escondidas, levando-se em conta a ativação de cada neurônio como informação para determinar sua distância.

O experimento g6e1 apresentou resultados levemente melhores em relação ao experimento de referência g1e3. Em épocas suficientes (aproximadamente 10), avaliadas em experimentos adicionais, ambas as abordagens convergem para valores praticamente idênticos. Assim, a janela de tamanho 1 é mais vantajosa em relação à janela de tamanho 2, pois ambas apresentam resultados similares, porém a primeira é mais econômica em termos de neurônios e sinapses para isso. Não foi possível determinar se casos como o exemplo "lenta e suavemente" (Seção 3.3.2) são pouco frequentes a ponto de não influenciar significativamente os resultados, ou se suas análises foram prejudicadas devido à forma como a otimização por semente é implementada. 


\subsubsection{Grupo 7: aprendizado adaptativo}

Este grupo avalia o uso de aprendizado adaptativo (ou semi-supervisionado) na tarefa de análise morfossintática. Nos experimentos, cada instância é treinada em três fases: (a) aquisição léxica a partir do conjunto Dela; (b) aprendizado supervisionado tradicional de Pln-f1; (c) aprendizado adaptativo do conjunto Pln-e11. A avaliação é realizada sobre o conjunto Pln-e12.

$\mathrm{Na}$ estratégia de aprendizado adaptativo proposta, neurônios de saída de um dado padrão que possuem ativações altas permitem ajustar positivamente as sinapses relacionadas ao padrão. Da mesma forma, neurônios com ativações baixas permitem o ajuste de pesos negativos nas sinapses relacionadas. O parâmetro adapt_factor é utilizado como base para estimar a confiança da instância em suas predições. Neurônios de saída com ativação menor do que adapt_factor induzem ajustes negativos (verdadeiros negativos) com valor esperado 0 . Neurônios com ativações maiores ou iguais ao complemento de parâmetro (1 - adapt_factor) induzem ajustes positivos (verdadeiros positivos), com valor esperado 1. A Tabela 5.7 apresenta os resultados obtidos de diferentes valores do parâmetro.

Tabela 5.7: Resultados para o grupo 7.

\begin{tabular}{llllllllll}
\hline Exp. & Detalhes & Msee & Jac & Dic & Jacf & Dicf & YinD & DinY & DeY \\
\hline g7e1 & i+w1(i)->e(p) (ad 0,00) & 0,0279 & 0,9304 & 0,9346 & 0,7931 & 0,8436 & 0,9478 & 0,9462 & 0,9178 \\
g7e2 & i+w1(i)->e(p) (ad 0,01) & 0,0311 & 0,9086 & 0,9119 & 0,7765 & 0,8293 & 0,9612 & 0,9150 & 0,8989 \\
g7e3 & i+w1(i)->e(p) (ad 0,05) & 0,0431 & 0,8576 & 0,8633 & 0,7701 & 0,8150 & 0,9430 & 0,8650 & 0,8413 \\
g7e4 & i+w1(i)->e(p) (ad 0,10) & 0,0515 & 0,8256 & 0,8320 & 0,7570 & 0,7984 & 0,9341 & 0,8335 & 0,8069 \\
g7e5 & i+w1(i)->e(p) (ad 0,25) & 0,0510 & 0,8540 & 0,8605 & 0,7814 & 0,8135 & 0,9212 & 0,8702 & 0,8343 \\
g7e6 & i+w1(i)->e(p) (ad 0,50) & 0,0490 & 0,8656 & 0,8709 & 0,7879 & 0,8195 & 0,9209 & 0,8871 & 0,8494 \\
\hline
\end{tabular}

No experimento de referência g7el não foi usado nenhum ajuste de pesos durante a avaliação no conjunto Pln-e12. Nos demais, diferentes valores para o parâmetro adapt_factor foram utilizados. Em todos os casos, o modo adaptativo piorou o modelo aprendido. A piora nos resultados atinge seu ápice por volta do valor 0,10 .

Os resultados indicam que, quando uma instância for utilizada como base para ensinar outra instância, uma degradação no aprendizado é esperada. Mais investigações são necessárias para verificar se isso vale para todas as instâncias ou para instâncias específicas. Esses resultados negativos são um fator importante a ser considerado no projeto de instâncias tutoras. Por exemplo, uma instância treinada em análise sintática e outra treinada em análise semântica sendo usadas para treinar uma terceira instância capaz de realizar as duas tarefas e 
estabelecer correlações entre ambos os aprendizados.

Uma outra abordagem consiste em usar a ativação obtida pela instância tutora como ativação esperada na instância em treinamento, o que vale para cada neurônio de saída de cada padrão de treinamento. Essa abordagem deverá ser analisada em trabalhos futuros.

\subsubsection{Grupo 8: o conjunto Mac}

Este grupo avalia o uso instâncias de experimentos anteriores aplicadas a um segundo conjunto de treinamento (Mac). Seguindo o padrão, foi utilizado o conjunto Mac-f1 para treinamento e Mac-e11 para avaliação (além do recurso Dela para aquisição léxica). A Tabela 5.8 apresenta os resultados para o grupo.

Tabela 5.8: Resultados para o grupo 8 .

\begin{tabular}{llllllllll}
\hline Exp. & Detalhes & Msee & Jac & Dic & Jacf & Dicf & YinD & DinY & DeY \\
\hline g8e1 & i+w1(i)->e(p,mac-f) & 0,0195 & 0,9270 & 0,9314 & 0,8224 & 0,8809 & 0,9539 & 0,9299 & 0,9137 \\
g8e2 & i+w1(p)->e(p,mac-f) & 0,0224 & 0,9194 & 0,9239 & 0,8082 & 0,8693 & 0,9475 & 0,9210 & 0,9059 \\
g8e3 & i+w1(ip)->e(p,mac-f) & 0,0180 & 0,9324 & 0,9371 & 0,8377 & 0,8911 & 0,9552 & 0,9351 & 0,9184 \\
\hline
\end{tabular}

Os resultados em g8e1 e g8e2 são comparáveis aos experimentos g1e3 e g5e2. O experimento g8e3 é similar a um experimento da Seção 5.2.1, também com resultados comparáveis. Enquanto o primeiro experimento apresentou resultados praticamente similares ao seu correspondente no conjunto $\mathrm{Pln}$, os demais apresentaram resultados levemente melhores aos seus respectivos experimentos Pln.

Os resultados contrariaram as expectativas iniciais, segundo as quais a avaliação no conjunto Pln seria superior. É importante notar que a avaliação não se baseia exatamente em acertos e erros do ponto de vista linguístico, pois há erros linguísticos, ou ruído, em ambos os recursos, tanto para treinamento, quanto para avaliação. Como resultado, por vezes, o que é considerado um acerto da instância é na verdade um erro do ponto de vista linguístico. Da mesma maneira, aquilo que é considerado um erro da instância por conta de ruído pode estar correto do ponto vista linguístico, embora este último caso deve ocorrer com bem menos frequência que o primeiro. Assim, a avaliação consiste em verificar o quão bem a instância mimetiza seu tutor, reproduzindo até mesmo o ruído, mesmo porque seria difícil que uma instância supere seu próprio tutor, pelo menos quando um único tutor está em uso. O conjunto Pln, por ter sido originado de anotação automática, deveria ser mais facilmente mimetizável em teoria, pois um anotador automático como o Palavras erra metodicamente, cometendo o 
mesmo erro repetidas vezes, enquanto que o Palavras é limitado às suas regras gramaticais, consideravelmente mais simples que o comportamento humano. Como exemplo temos que o manual de anotação do Mac-Morpho (NILC, 2013) indica que anotadores devem anotar o lexema "um" como numeral ou como artigo indefinido, de acordo com a semântica do texto. Já o Palavras, tende a utilizar apenas a anotação artigo indefinido quando outros números estão ausentes e quando o lexema ocorre em sua grafia extensa (isto é, quando o dígito "1" não é utilizado). Uma hipótese para o desempenho levemente superior das instâncias Mac reside no diferença entre conjunto de etiquetas de ambos os recursos, o que poderia indicar que o conjunto Mac é ligeiramente mais simples. Outra hipótese está relacionada a anotação de entidades nomeadas, que também difere em ambos os recursos, já que o Palavras usa a abordagem aglutinante, enquanto, no conjunto Mac, cada entidade continua dividida em lexemas, anotando todas as partes da entidade nomeada com a mesma etiqueta (o que também tem o efeito colateral de estabelecer sinapses entre preposições como "de" com etiquetas como “pos_noun”).

\subsection{Experimentos multiníveis para análise da língua}

\subsubsection{Grupo 9: análise morfossintática}

Este grupo avalia o impacto dos níveis morfológico, sintático e semântico na análise morfossintática. O experimento de referência para este grupo é g1e3. Os experimentos g5e2 e g5e4 também são considerados experimentos de referência, pois testam como o nível morfossintático influencia a si mesmo, seja por coativação (g5e2) ou recorrência local (g5e4). A Tabela 5.9 contém os resultados para o grupo. Nota-se que a análise é feita principalmente sobre a medida $\mathrm{DeY}$, que permitiu visualizar mais diferenças entre os experimentos que as demais, uma vez que os resultados são próximos dos resultados do experimentos de referência.

Tabela 5.9: Resultados para o grupo 9.

\begin{tabular}{llllllllll}
\hline Exp. & Detalhes & Msee & Jac & Dic & Jacf & Dicf & YinD & DinY & DeY \\
\hline g1e3 & i+w1(i)->e(p) & 0,0292 & 0,9259 & 0,9302 & 0,7896 & 0,8405 & 0,9447 & 0,9429 & 0,9127 \\
g9e1 & I+w1(I)->e(p) & 0,0266 & 0,9317 & 0,9354 & 0,8070 & 0,8518 & 0,9502 & 0,9476 & 0,9206 \\
g9e2 & G+w1(G)->e(p) & 0,0260 & 0,9035 & 0,9076 & 0,7716 & 0,8241 & 0,9433 & 0,9189 & 0,8913 \\
g9e3 & i+w1(il)->e(p) & 0,0285 & 0,9291 & 0,9332 & 0,7910 & 0,8417 & 0,9471 & 0,9464 & 0,9168 \\
g9e4 & i+w1(m)->e(p) & 0,0288 & 0,9268 & 0,9310 & 0,7889 & 0,8404 & 0,9459 & 0,9444 & 0,9141
\end{tabular}




\begin{tabular}{|c|c|c|c|c|c|c|c|c|c|}
\hline Exp. & Detalhes & Msee & Jac & Dic & Jacf & Dicf & YinD & DinY & DeY \\
\hline g9e5 & $\mathrm{i}+\mathrm{w} 1(\mathrm{ip})->\mathrm{e}(\mathrm{p})$ & 0,0278 & 0,9291 & 0,9333 & 0,8016 & 0,8481 & 0,9471 & 0,9457 & 0,9165 \\
\hline g9e6 & $\mathrm{i}+\mathrm{w} 1(\mathrm{ipP})->\mathrm{e}(\mathrm{p})$ & 0,0274 & 0,9306 & 0,9347 & 0,8038 & 0,8494 & 0,9484 & 0,9461 & 0,9184 \\
\hline g9e7 & $\mathrm{i}+\mathrm{w} 1$ (is) $->\mathrm{e}(\mathrm{p})$ & 0,0290 & 0,9274 & 0,9314 & 0,7874 & 0,8395 & 0,9459 & 0,9460 & 0,9153 \\
\hline g9e8 & $\mathrm{i}+\mathrm{w} 1(\mathrm{iS})->\mathrm{e}(\mathrm{p})$ & 0,0289 & 0,9271 & 0,9310 & 0,7880 & 0,8399 & 0,9459 & 0,9456 & 0,9152 \\
\hline g9e9 & $\begin{array}{l}\mathrm{i}+\mathrm{w} 1(\mathrm{i})+\mathrm{t}\left(\mathrm{l}^{*} \mathrm{l}, \mathrm{pP} \mathrm{P}^{*} \mathrm{pP}\right)+\mathrm{h}(\mathrm{p}) \\
->\mathrm{e}(\mathrm{p})\end{array}$ & 0,0261 & 0,9312 & 0,9353 & 0,8174 & 0,8574 & 0,9509 & 0,9459 & 0,9189 \\
\hline g9e10 & $\begin{array}{l}\mathrm{i}+\mathrm{w} 1(\mathrm{i})+\mathrm{t}\left(\mathrm{l}^{*} \mathrm{l}, \mathrm{pP} \mathrm{P}^{*} \mathrm{pP}\right)+\mathrm{h}(\mathrm{l}) \\
->\mathrm{e}(\mathrm{p})\end{array}$ & 0,0255 & 0,9339 & 0,9378 & 0,8179 & 0,8581 & 0,9520 & 0,9480 & 0,9220 \\
\hline g9e11 & $\begin{array}{l}\mathrm{i}+\mathrm{w} 1(\mathrm{i})+\mathrm{t}(1 * 1, \mathrm{pP} * \mathrm{pP})+\mathrm{h}(\mathrm{f}) \\
->\mathrm{e}(\mathrm{p})\end{array}$ & 0,0255 & 0,9340 & 0,9378 & 0,8178 & 0,8581 & 0,9523 & 0,9480 & 0,9222 \\
\hline
\end{tabular}

Em relação ao nível morfológico, g9e1 avalia a influência de sufixos. O Exemplo 5.5 ilustra o processo de extração de sufixos. A lista de sufixos foi obtida da gramática de flexão utilizada no glossário Dela, com alguns acréscimos manuais e contém cerca de 40 sufixos. Quando múltiplos sufixos são detectados, o maior deles é utilizado. Apenas sufixos flexionais são utilizados, sufixos derivacionais não foram extraídos (por exemplo, em "processamento" é extraído o sufixo "o", mas não o sufixo "mento").

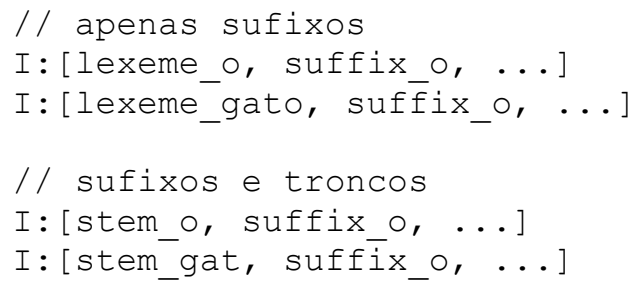

Exemplo 5.3: Extração de sufixos e geração de troncos

Os resultados de g9e1 superaram g1e3, por dois motivos. Primeiro, uma análise de granularidade grossa é provida pelos eventos suffix. Segundo, e mais importante, os sufixos proveem informações relevantes sobre lexemas desconhecidos. Por exemplo, para o lexema desconhecido "tuitar" ("to tweet"), ausente do glossário, o evento "suffix_ar" provê uma indicação de tratar-se de um verbo.

O experimento g9e2 combina troncos e seus respectivos sufixos associados. Quando o próprio lexema coincide com o maior sufixo encontrado, o lexema é mantido (por exemplo, convertendo-se lexeme_o para stem_o). Houve uma piora considerável nos resultados com o uso de troncos, embora mais análises sejam necessárias para indicar se a piora se deve simplesmente à uma convergência mais lenta, aos próprios troncos em uso, à qualidade do gerador de troncos utilizado, ou ainda à ausência de camadas escondidas nas instâncias.

O experimento g9e3 avaliou-se o impacto da coativação para lemas, com três iterações. 
Esse experimento é similar ao experimento g5e2, porém inclui também a entrada de contexto. G9e3 apresenta resultados muito semelhantes aos do experimento g9e5 (baseado em eventos lexemas combinados com eventos pos em vez de lemas), ambos apresentando uma leve melhora em relação ao experimento de referência g1e3, porém realizando a análise em uma granularidade mais fina (lexemas e lemas).

O experimento g9e4 avalia o impacto das informações de flexão como singular, plural, entre outras na análise morfossintática. Foi observado um leve impacto na tarefa de análise morfossintática, tornando a convergência levemente mais rápida.

O experimento g9e5 combina a entrada e a saída morfossintática do contexto, o que supera os resultados g5e1 por uma pequena margem. Devido aos experimentos adicionais, optou-se por três iterações em g5e5. O resultado obtido é interessante por indicar que a granularidade fina é usada quando disponível, enquanto que a instância pode utilizar a granularidade grossa para processar casos não cobertos (ou pouco cobertos) pela granularidade fina.

O experimento g9e6, é uma versão modificada do g9e5 incluindo as subcategorias gramaticais (por exemplo, artigo definido e pronome interrogativo), superado g9e5 por uma pequena margem e reforçando a importância da coativação na análise.

Ainda em relação ao nível morfológico, um experimento adicional testou o treinamento do conjunto Pln-f1 com a aquisição léxica ativada durante o treinamento do conjunto Pln-f1. A mudança produz dois efeitos, um positivo e um negativo. O efeito positivo se deve ao fato de lexemas adquiridos durante o treinamento de um padrão no conjunto Pln poderem ser utilizados em padrões futuros se esse lexema reaparecer eventualmente. O efeito negativo consiste no fato da instância não saber lidar com eventos desconhecidos no conjunto de avaliação Pln-e11, pois quando a aquisição léxica é desativada para o conjunto Pln-f1, sinapses são geradas entre unknown_event, unknown_lemma e os diferentes eventos pos, de forma que a rede pode predizer a classe gramatical mais frequente para lexemas desconhecidos na ausência de contexto suficiente, além de usar eventos pre_unknown_lexeme e post_unknown_lexeme para ajudar no processamento dos padrões próximos. No experimento, o efeito positivo foi maior que o efeito negativo, resultando em resultados levemente melhores que os do experimento g3e4.1, porém esses resultados não serão incluídos por terem sido gerados em outra árvore de código do protótipo, não podendo ser comparados diretamente com g1e3. 
Em relação ao nível semântico, os experimentos g9e7 e g9e8 avaliaram o uso de categorias e grupos semânticos, respectivamente, na tarefa de análise morfossintática. Grupos semânticos possuem uma granularidade um pouco mais grossa que categorias semânticas, ambos detalhados no Apêndice A.1. Os dois experimentos apresentaram resultados semelhantes, levemente superiores ao experimento de referência g1e3. Observa-se que a análise semântica da versão do Palavras em uso ainda encontra-se em fase de desenvolvimento. Mesmo esta análise incompleta já é suficiente para melhorar levemente a análise morfossintática. Este experimento também foi proposto para avaliar o impacto do nível semântico (superiores na hierarquia de níveis da língua) na análise de um grupo mais baixo (a determinação das classes gramaticais, ou análise morfossintática). Os resultados próximos entre os experimentos do grupo e o grupo de referência g1e3 não permitem concluir-se que esse subnível semântico está melhorando a análise morfossintática, mas sugere a importância da análise bidirecional.

Um experimento adicional combinou os atributos morfológicos e semânticos (suffix, morph, lexeme, lemma, pos, possub, semcat e semgroup), mas não foi incluído no arcabouço de testes devido ao tempo elevado para rodar o experimento (cerca de quatro horas). Esse experimento apresentou DeY de 0,9313. Indicando que os vários subníveis combinados melhoram a análise. Nota-se que esse experimento não supera g3e3.5 (entrada de contexto treinada sobre o conjunto o córpus Pln-E1'), o que é natural, já que g3e3.5 se baseia em um conjunto de treinamento muito maior (Pln-E1' é cerca de 38 vezes maior que Pln-f1).

Em relação ao nível sintático, g9e9, g9e10 e g9e11 permitiram extrair eventos do tipo pos, lemma e syn, respectivamente, dos núcleos sintáticos obtidos pela análise de dependência e usar esses eventos como entrada na análise de b-padrões graças à coativação. Nota-se que essa interação ocorre entre um b-padrão pai e um b-padrão filho na árvore sintática, enquanto os c-padrões usados são usados no processo para identificar possíveis pais. Assim, o subnível de dependências fez parte do processo apoiando a escolha de eventos morfológicos (g9e10), morfossintáticos ( $(\mathrm{g} 9 \mathrm{e} 9)$, e sintáticos ( $\mathrm{g} 9 \mathrm{e} 11)$. Todos os casos levaram a melhoras superiores às providas pelos experimentos semânticos g9e7 e g9e8. O resultado é interessante, pois a análise de dependências provida ainda não é a ideal devido ao protótipo (embora a análise semântica também sofra limitações uma vez que o Palavras forneça apenas um nível básico de categorização semântica para substantivos). Os resultados na direção sintaxe - morfossintaxe foram considerados satisfatórios para validar a bidirecionalidade do modelo. 


\subsubsection{Grupo 10: análise de dependências sintáticas}

Este grupo avalia o impacto dos níveis morfológico, sintático (funções) e semântico na análise de dependências. O experimento de referência para este grupo é gle4. Conforme discutido na Seção 5.1.1, g1e4 não se trata de um baseline, sendo a melhor instância para análise de dependências, já que o protótipo ainda não atingiu o estado da arte para essa análise, e o uso de dependências é importante nas avaliações de morfossintaxe e de funções sintáticas. A Tabela 5.10 apresenta os resultados para o grupo. Observa-se que as medidas da Tabela 5.10 não proveem de c-padrões, e sim dos a-padrões obtidos após a análise da matriz C e do vetor $\mathrm{B}$.

Tabela 5.10: Resultados para o grupo 10.

\begin{tabular}{llllllllll}
\hline Exp. & Detalhes & Msee & Jac & Dic & Jacf & Dicf & YinD & DinY & DeY \\
\hline g1e4 & i+w1(i)+t(i',l*l,pP*pP) & 0,3715 & 0,7486 & 0,7486 & 0,7347 & 0,7441 & 0,7702 & 0,7486 & 0,7486 \\
& ->e(d) & & & & & & & & \\
g10e1 & i+w1(i)+t(i')->e(d) & 0,5460 & 0,6029 & 0,6029 & 0,5921 & 0,5991 & 0,6148 & 0,6029 & 0,6029 \\
g10e2 & i+w1(i)+t(i'sS)->e(d) & 0,4729 & 0,6634 & 0,6634 & 0,6460 & 0,6556 & 0,6774 & 0,6634 & 0,6634 \\
g10e3 & i+w1(i)+t(i'l)->e(d) & 0,4841 & 0,6527 & 0,6527 & 0,6358 & 0,6457 & 0,6685 & 0,6527 & 0,6527 \\
g10e4 & i+w1(i)+t(i'pP)->e(d) & 0,4726 & 0,6629 & 0,6629 & 0,6518 & 0,6596 & 0,6909 & 0,6629 & 0,6629 \\
g10e5 & i+w1(i)+t(i'lpP)->e(d) & 0,4394 & 0,6891 & 0,6891 & 0,6695 & 0,6809 & 0,7128 & 0,6891 & 0,6891 \\
g10e6 & I+w1(I)+t(I')->e(d) & 0,5483 & 0,6008 & 0,6008 & 0,5902 & 0,5968 & 0,6139 & 0,6009 & 0,6008 \\
g10e7 & i+w1(i)+t(1*l)->e(d) & 0,4225 & 0,7020 & 0,7020 & 0,6797 & 0,6923 & 0,7228 & 0,7020 & 0,7020 \\
g10e8 & i+w1(i)+t(i',pP*pP)->e(d) & 0,4135 & 0,7144 & 0,7144 & 0,7059 & 0,7133 & 0,7391 & 0,7144 & 0,7144 \\
g10e9 & i+w1(i)+t(i',m*m, & 0,4347 & 0,7124 & 0,7124 & 0,7102 & 0,7128 & 0,7233 & 0,7124 & 0,7124 \\
& pP*pP)->e(d) & & & & & & & & \\
\hline
\end{tabular}

O experimento g10e1 é o baseline deste grupo de experimentos, apresentando a análise de dependências quando apenas os lexemas e correlatos são conhecidos. G10e2 apresenta o uso de categorização semântica, o que melhora a análise de dependências, sendo outro indicativo da utilidade de análise bidirecionais. G10e3 apresenta o uso de lemas na análise, o que também é superior ao baseline, mas não chega a superar o uso de informações semânticas. G10e4 aplica categorias gramaticais e subcategorias, também melhorando a análise se aproximando dos resultados da análise semântica. G10e5 aplica lemas combinados com categorias gramaticais e suas subcategorias, superando a análise semântica. G10e6 é baseado em sufixos, contudo os sufixos não se mostraram muito úteis na tarefa, embora mais investigação seja necessária para compreender os resultados resultados desse experimento.

G10e7 gera bigramas entre lemas a direta e a esquerda na matriz $\mathrm{C}$, conforme mostrado 
no Exemplo 5.4. Bigramas de eventos são uma estratégia para resolver o problema do ou-exclusivo em redes neurais artificiais Perceptron. Em g10e7, também funcionam para permitir que a afinidade entre lemas seja levada em conta na análise, eliminado-se o risco de aprendizado pontual. A desvantagem em seu uso é o fato de problemas do tipo ou-exclusivo precisarem ser conhecidos de antemão pelo projetista da rede neural artificial, o que nem sempre é possível. Os resultados de G10e7 superam os experimentos anteriores deste grupo, o que é esperado devido a afinidades terem sido computadas na instância.

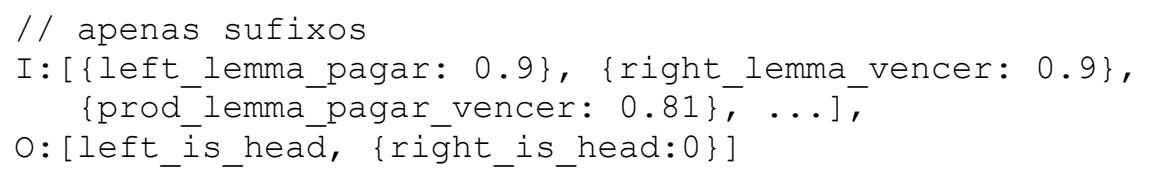

Exemplo 5.4: Bigramas de eventos.

G10e8 se baseia tanto afinidade entre classes gramaticais à esquerda e à direita nos c-padrões, como na afinidade entre as subcategorias gramaticais, superando g10e7.

G10e9 gera bigramas de eventos entre as classes morfológicas masculino, feminino, singular, plural e pessoas verbais em uma tentativa de aprender concordância para guiar a análise de dependências. Contudo, o aprendizado não é satisfatório, pois o Palavras gera subárvores para coordenação como a mostrada no item (a) da Figura 2.5, enquanto o formato ideal para o protótipo é mostrado no item (b). A árvore do item (a) leva a instância a aprender que substantivos femininos modificam substantivos masculinos, a recíproca também é verdadeira. A análise de singular e plural e de pessoas verbais também é afetada. Isso prejudica identificar que adjetivos concordam em gênero e número com os substantivos que modificam. Da mesma maneira, a rede também fica impedida de aprender corretamente que pronomes concordam em número e pessoa com os verbos que modificam. A solução, reservada para trabalhos é ajustar a anotação do Palavras em uma etapa de pré-processamento.

Por fim, o experimento de referência g1e4 equivale aos experimentos g10e7 e g10e8, combinando afinidades entre lemas, entre classes gramaticais e entre subcategorias gramaticais. 


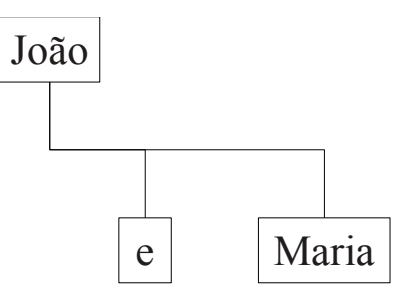

(a)

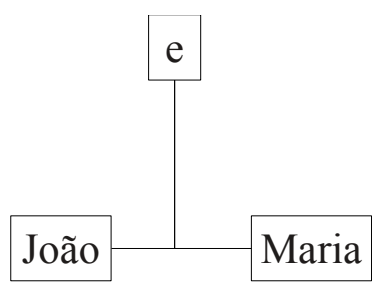

(b)

Figura 5.1: Problema no aprendizado de concordância.

Todos os experimentos utilizam o evento proximity durante a análise. Sem esse neurônio de entrada para c-padrões, a medida DeY de g10e1 cai para cerca de 0,35 , conforme experimentos adicionais. Também foi verificado o uso de neurônios "inter_pos" em experimentos adicionais. Esses neurônios indicam classes gramaticais separando os lexemas em análise. Por exemplo, o c-padrão que compara lexeme_eu e lexeme pouco em "eu canto muito pouco" receberia os eventos inter_pos_verb e inter_pos_adverb para indicar que existe um verbo e advérbio separando o lexema da esquerda do lexema da direita. Repetições de neurônios de entrada são aceitas quando existem classes gramaticais repetidas separando os lexemas em análise. Com eventos inter_pos, o valor de DeY do experimento g10e1 cai para cerca de 0,47. Mais investigações são necessárias para explicar esse comportamento.

\subsubsection{Grupo 11: análise de funções sintáticas}

Este grupo avalia o impacto dos níveis morfológico, sintático (dependências) e semântico na análise de funções sintáticas. $O$ experimento de referência para este grupo é g1e5. Nota-se que g1e5 também não é um baseline, pois seu objetivo foi melhorar a aplicação de funções sintáticas em outros níveis. Contudo, os resultados de g1e5 foram similares aos do baseline do grupo, g11e3. Esse fato demanda mais investigação e possivelmente está relacionado está relacionado a parâmetros definidos no arcabouço de testes. Observa-se que o experimento se baseia em lemas (g11e3) combinados com gramaticais (g11e1). Nota-se ainda que este grupo usa os melhores parâmetros durante a análise de dependências sintáticas, de modo a detectar de forma mais eficiente os b-padrões pai do padrão em análise, otimizando a interação entre o padrão em análise e informações de diferentes níveis dos padrões do contexto. A Tabela 5.11 apresenta os resultados para o grupo. 
Tabela 5.11: Resultados para o grupo 11.

\begin{tabular}{|c|c|c|c|c|c|c|c|c|c|}
\hline Exp. & Detalhes & Msee & Jac & Dic & Jacf & Dicf & YinD & DinY & DeY \\
\hline g1e5 & $\begin{array}{l}\mathrm{i}+\mathrm{w} 1(\mathrm{i})+\mathrm{t}\left(1^{*} 1, \mathrm{pP} \mathrm{P}^{*} \mathrm{pP}\right) \\
+\mathrm{h}\left(\mathrm{i}^{\prime} \mathrm{l}\right)->\mathrm{e}(\mathrm{f})\end{array}$ & 0,0387 & 0,8254 & 0,8332 & 0,5715 & 0,6257 & 0,9278 & 0,8362 & 0,8037 \\
\hline g11e1 & $\begin{array}{l}\mathrm{i}+\mathrm{w} 1(\mathrm{i})+\mathrm{t}\left(1 * 1, \mathrm{pP} \mathrm{P}^{*} \mathrm{pP}\right) \\
+\mathrm{h}\left(\mathrm{i}^{\prime} \mathrm{pP}\right)-\mathrm{e}(\mathrm{f})\end{array}$ & 0,0387 & 0,8254 & 0,8332 & 0,5715 & 0,6257 & 0,9281 & 0,8361 & 0,8037 \\
\hline $\mathrm{g} 11 \mathrm{e} 2$ & $\begin{array}{l}\mathrm{i}+\mathrm{w} 1(\mathrm{i})+\mathrm{t}\left(\mathrm{l}^{*} 1, \mathrm{pP} \mathrm{P}^{*} \mathrm{pP}\right) \\
+\mathrm{h}\left(\mathrm{I}^{\prime}\right)->\mathrm{e}(\mathrm{f})\end{array}$ & 0,0389 & 0,8230 & 0,8305 & 0,5731 & 0,6266 & 0,9324 & 0,8333 & 0,8018 \\
\hline g11e3 & $\begin{array}{l}\mathrm{i}+\mathrm{w} 1(\mathrm{i})+\mathrm{t}\left(1 * 1, \mathrm{pP} \mathrm{P}^{*} \mathrm{pP}\right) \\
+\mathrm{h}\left(\mathrm{i}^{\prime} \mathrm{l}\right)-\mathrm{e}(\mathrm{f})\end{array}$ & 0,0411 & 0,8083 & 0,8162 & 0,5584 & 0,6144 & 0,9346 & 0,8174 & 0,7862 \\
\hline g11e4 & $\begin{array}{l}\mathrm{i}+\mathrm{w} 1(\mathrm{i})+\mathrm{t}\left(1^{*} 1, \mathrm{pP} \mathrm{P}^{*} \mathrm{pP}\right) \\
+\mathrm{h}\left(\mathrm{i}^{\prime} \mathrm{f}\right)-\mathrm{e}(\mathrm{f})\end{array}$ & 0,0394 & 0,8207 & 0,8286 & 0,5675 & 0,6223 & 0,9307 & 0,8309 & 0,7987 \\
\hline g11e5 & $\begin{array}{l}\mathrm{i}+\mathrm{w} 1(\mathrm{i})+\mathrm{t}\left(\mathrm{l}^{*} 1, \mathrm{pP} \mathrm{P}^{*} \mathrm{pP}\right) \\
+\mathrm{h}\left(\mathrm{i}^{\prime} \mathrm{fF}\right)-\mathrm{e}(\mathrm{f})\end{array}$ & 0,0388 & 0,8251 & 0,8327 & 0,5719 & 0,6256 & 0,9317 & 0,8343 & 0,8037 \\
\hline g11e6 & $\begin{array}{l}\mathrm{i}+\mathrm{w} 1(\mathrm{i})+\mathrm{t}\left(1 * 1, \mathrm{pP} \mathrm{P}^{*} \mathrm{pP}\right) \\
+\mathrm{h}(\mathrm{s})->\mathrm{e}(\mathrm{f})\end{array}$ & 0,0404 & 0,8111 & 0,8189 & 0,5625 & 0,6173 & 0,9351 & 0,8204 & 0,7894 \\
\hline $\mathrm{g} 11 \mathrm{e} 7$ & $\begin{array}{l}\mathrm{i}+\mathrm{w} 1(\mathrm{i})+\mathrm{t}(1 * 1, \mathrm{pP} * \mathrm{pP}) \\
+\mathrm{h}(\mathrm{S})->\mathrm{e}(\mathrm{f})\end{array}$ & 0,0409 & 0,8083 & 0,8161 & 0,5637 & 0,6176 & 0,9339 & 0,8180 & 0,7865 \\
\hline
\end{tabular}

O experimento g11e1 aplica classes gramaticais dos núcleos sintáticos de cada lexema, superado o baseline do grupo. G11e2 aplica sufixos dos núcleos sintáticos, também melhorando a análise de funções sintáticas. G11e3 trata-se do baseline deste grupo, atingindo DeY de 0,7862. G11e4 se baseia nas funções sintáticas dos b-padrões pai, o que levou a uma melhora verificável na análise em relação ao baseline. G11e5 aplica funções sintáticas e subcategorias sintáticas na análise, com resultados muito próximos a g11e2. Por fim, g11e6 (categorias semânticas) e g11e7 (grupos semânticos) apresentam resultados semelhantes aos do baseline. Nota-se que, a exceção dos dois últimos experimentos, as demais análises deste grupo são feitas de forma ascendente.

\subsection{Simplificação sintática}

\subsubsection{Etapa de extração de frases}

Enquanto o córpus de frases para desenvolvimento do modelo Sinsim foi baseado no gênero jornalístico, o córpus de frases utilizados na avaliação é do gênero enciclopédico. A mudança tem o objetivo de avaliar como o modelo Sinsim se sai em um gênero diferente do qual foi projetado. Para isso, dois córpus foram criados, o primeiro, um córpus de textos de artigos em destaque da Wikipédia em Português e o segundo, um córpus de frases amostradas do primeiro córpus por meio de regras de extração. Há também um subcórpus do primeiro 
córpus, no qual os domínios da Wikipédia são balanceados.

As regras de extração tem o objetivo de extrair as frases mais relevantes para uma avaliação baseada em precisão e cobertura, sendo desenvolvidas para recuperar exemplos positivos e negativos de frases para cada regra de simplificação. As regras são puramente léxicas, sendo aplicadas antes da análise de classes gramaticais e de sintaxe. Para a voz passiva, a extração é feita para uma sequência de dois ou mais possíveis verbos na qual um deles é uma forma conjugada do verbo "ser". No caso das orações subordinadas, as regras de extração consistem na presença dos marcadores discursivos em uso em cada regra de simplificação.

As regras foram aplicadas sobre o córpus de artigos em destaque da Wikipédia em Português para os anos 2010 e 2011. Os textos relativos a 2011, foram baseados em uma lista preliminar de artigos planejados para destaque, porém, nem todos foram efetivamente destacados (a listagem dos textos utilizados encontra-se no Apêndice B.3). A Tabela 5.12 apresenta estatísticas sobre os artigos. Observa-se que o número de regras de extração aplicadas é diferente do número de frases extraídas, já que uma mesma frase pode ser selecionada por diferentes regras de extração.

Tabela 5.12: Estatísticas do córpus de textos.

\begin{tabular}{lr}
\hline Estatística & Valor \\
\hline Textos & 165 \\
Fases & 83.656 \\
Lexemas e correlatos & 1.226 .880 \\
Regras de extração aplicadas & 57.735 \\
Frases extraídas & 31.080 \\
\hline
\end{tabular}

A avaliação foi baseada em amostragem, de forma que no máximo 30 frases foram extraídas por cada regra de extração. As frases extraídas são divididas entre exemplos positivos e exemplos não tratados. Estes últimos, por sua vez, são divididos em exemplos negativos e exemplos ambíguos, isto é, orações que não são simplificadas devido à ambiguidade. Foi observado que algumas regras de extração recuperam muitas frases não tratadas e poucos exemplos positivos, de forma que as amostras obtidas não possuem exemplos positivos suficientes para proceder com avaliação. Esse caso é considerado como ruído e impediu o processamento dos marcadores discursivos "se" (orações subordinadas adverbiais condicionais) e "como" (diversas orações subordinadas).

A Tabela 5.13 apresenta estatísticas para um subcórpus de textos no qual os diferentes 
domínios da Wikipédia em Português são balanceados. Para isso, extraiu-se 32 textos dos 13 domínios, em uma média de três textos por domínios. Observa-se que alguns domínios não possuíam três textos destacados na Wikipédia no córpus de textos. Os domínios são: arte, biografias, ciências da natureza, ciências exatas, ciências sociais, cultura e sociedade, esporte, entretenimento, geografia, história, música, religião e tecnologia.

Tabela 5.13: Estatísticas do subcórpus de textos balanceado.

\begin{tabular}{lr}
\hline Estatística & Valor \\
\hline Caracteres por lexema & 5,22 \\
Lexemas por frase & 21,17 \\
Lexemas por texto & 8,47 \\
Lexemas simples & $75,52 \%$ \\
Frases por texto & 400,34 \\
Voz passiva & $15,11 \%$ \\
Total de frases & 13,09 \\
Frases simplificadas & $16,71 \%$ \\
\hline
\end{tabular}

$\mathrm{Na}$ Tabela 5.13, lexemas simples se referem ao percentual de lexemas que fazem parte na lista de lexemas simples adaptada por pesquisadores do projeto PorSimples a partir do Dicionário Ilustrado de Português (BIDERMAN, 2005), que contém 5.900 entradas e foi criado para a audiência composta por crianças e adolescentes e também de textos simplificados para crianças da seção "Para seu Filho Ler" do Jornal gaúcho Zero Hora ${ }^{30}$ e da lista de palavras concretas de Janczura et al. (2007). O número de frases simplificadas automaticamente também é apresentado.

A Figura 5.2 apresenta a distribuição de orações por frase no subcórpus balanceado. Frases sem orações normalmente referem-se a títulos, referências, legendas de figuras, entre outros. Foi observado que $60 \%$ das frases possuem mais de uma oração. 


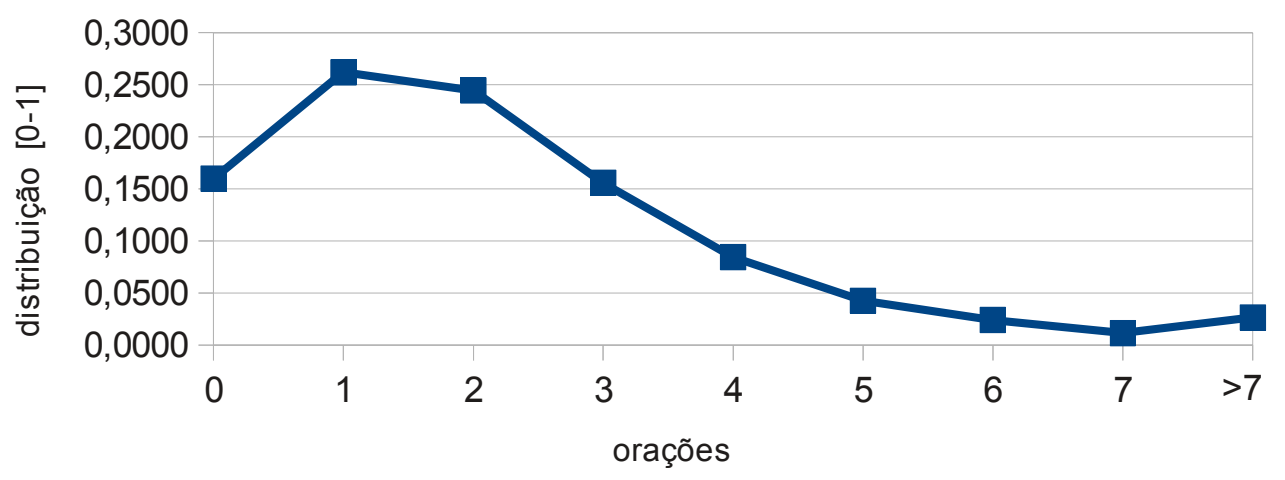

Figura 5.2: Orações por frase na amostra.

A Tabela 5.14 apresenta três casos de anotação nas amostras: (a) quando a regra esperada é aplicada (corretamente ou não); (b) quando é aplicada uma regra diferente da que seria utilizada por um anotador humano seguindo o manual de anotação do projeto PorSimples para os fenômenos tratados neste trabalho (o que ainda pode gerar resultados corretos para fenômenos sintáticos similares); e (c) quando nenhuma regra é aplicada (verdadeiros negativos e falsos negativos).

Tabela 5.14: Casos de anotação no córpus de frases.

\begin{tabular}{ll}
\hline Casos & Subcasos \\
\hline Sinsim aplicou mesma regra & Simplificação correta (verdadeiros positivos) \\
do anotador humano & $\begin{array}{l}\text { Simplificação incorreta } \\
\text { Simplificação incorreta devido ao analisador sintático }\end{array}$ \\
Sinsim aplicou regra diferente & No lugar de outra simplificação, mas correta (verdadeiros positivos) \\
do anotador humano & No lugar de outra simplificação, com erros devido ao analisador sintático \\
& Em oração não simplificável, gerando erros \\
& Em oração não simplificável, gerando erros devido analisador sintático \\
Sinsim não aplicou nenhuma & Verdadeiros negativos \\
regra & Não aplicação devido à regra \\
& Não aplicação devido ao analisador sintático \\
\hline
\end{tabular}

\subsubsection{Avaliação da simplificação}

A amostra extraída foi manualmente anotada por um anotador e usada para estimar diferentes estatísticas, incluindo o número de aplicações das regras de extração a cada milhão de lexemas, a precisão das regras de extração, e a precisão e a cobertura das regras de simplificação.

A análise da aplicação de regras foi baseada em aplicações por milhões de lexemas, em vez de número de frases simplificadas. Isso foi realizado, pois a análise por frases é menos informativa, uma vez que existem grandes períodos repletos de fenômenos sintáticos, assim 
como períodos com uma única oração sem nenhum fenômeno simplificável. Além disso, um fenômeno simplificado incorretamente torna o período inteiro incorreto, o que gera interferência na análise dos fenômenos co-ocorrentes que foram corretamente simplificados. As amostras são compostas por frases contendo exemplos positivos e e frases contendo exemplos não tratados (negativos ou ambíguos). No total, 1.243 frases foram anotadas e utilizadas em estimativas para cada milhão de palavras, apresentadas na Tabela 5.15. Frases com mais de um marcador discursivo são repetidas, de modo que cada fenômeno seja avaliado individualmente, independentemente dos demais.

Tabela 5.15: Estatísticas para cada milhão de lexemas.

\begin{tabular}{lr}
\hline Estatística & Valor \\
\hline Total de exemplos (aplicações de regras de extração) & 70.834 \\
Exemplos positivos simplificáveis por humanos & 33.906 \\
Exemplos corretamente selecionados para simplificação & 27.714 \\
Simplificações corretas com análise sintática correta & 23.969 \\
Simplificações corretas & 22.222 \\
\hline
\end{tabular}

O total de exemplos se refere ao número de ocorrências de exemplos positivos e não tratados a cada milhão de lexemas em um córpus do gênero enciclopédico para a Língua Portuguesa. Essa é a única estatística extraída do córpus inteiro, enquanto as demais são estimativas.

Exemplos positivos simplificados por humanos representam a estimativa de exemplos que um humano seguindo o manual de simplificação do projeto PorSimples seria capaz de simplificar (apenas para os fenômenos sintáticos analisados neste trabalho). Como humanos podem simplificar corretamente os exemplos ambíguos, eles são incluídos na estimativa. Observa-se que, para um anotador humano, exemplos ambíguos se dividem em exemplos positivos e negativos. Assim, o número de exemplos positivos simplificados por humano refere-se à uma estimativa para o número real de exemplos positivos a cada milhão de lexemas. Observa-se que não são incluídos fenômenos muito raros (cuja a amostra foi de tamanho zero) ou com muito ruído (com apenas exemplos não tratados na amostra).

Exemplos corretamente selecionados para simplificação correspondem a exemplos positivos selecionados por uma das regras de simplificação, embora uma parte deles possa ser incorretamente simplificada devido a problemas nas regras. Exemplos com erro de análise sintática não foram considerados nessa estimativa. A estimativa tem por objetivo avaliar quão bem a seleção de exemplos para a simplificação é realizada e não deve ser confundida com as 
regras de extração, que também foram criadas para recuperar exemplos negativos.

A estimativa de simplificações corretas com a análise sintática correta é calculada removendo-se exemplos com erros introduzidos pelo analisador sintático. A medida é útil para separar erros causados por problemas nas regras dos erros causados por problemas na análise sintática.

Por fim, as simplificações corretas correspondem à estimativa para um cenário de uso real. Observa-se que o problema de posicionamento de marcadores discursivos apresentado no Exemplo 4.7 da Seção 4.2.1 não foi levado em conta na análise de simplificações corretas (o que também é valido para a avaliação com análise sintática correta).

É importante observar que o número real para as três últimas estimativas deve ser levemente superior, já que fenômenos com ruído ou casos raros não foram incluídos na análise. O critério utilizado para a exclusão de fenômenos raros baseou-se em remover das estimativas fenômenos cujas amostras tiveram menos de sete exemplos positivos simplificáveis por anotadores humanos.

A Tabela 5.16 apresenta precisões, coberturas e medidas-f médias (denotadas por "p", "c" e "f", respectivamente) de cada marcador discursivo de simplificação tratado (no caso da passiva, usa-se o verbo "ser" em vez de marcadores discursivos) para simplificações corretamente selecionadas para simplificação (denotadas por "sel”), simplificações corretas com análise sintática correta (denotadas por "ana") e simplificações corretas (denotadas por "sim"). As médias foram ponderadas pela frequência do marcadores (ou verbo "ser") para cada milhão de lexemas.

Tabela 5.16: Precisões, coberturas e medidas-f estimadas por marcador discursivo.

\begin{tabular}{lccccccccc}
\hline \multicolumn{1}{c}{ Marcador } & p-sim & p-ana & p-sel & c-sim & c-ana & c-sel & f-sim & f-ana & f-sel \\
\hline a fim de & 0,931 & 1,000 & 1,000 & 0,967 & 0,964 & 0,964 & 0,949 & 0,982 & 0,982 \\
a fim de que & 0,909 & 1,000 & 1,000 & 0,500 & 0,588 & 0,588 & 0,645 & 0,741 & 0,741 \\
ainda que & 0,714 & 1,000 & 1,000 & 0,636 & 0,714 & 0,714 & 0,673 & 0,833 & 0,833 \\
antes que & 0,400 & 0,400 & 0,400 & 0,750 & 0,750 & 0,750 & 0,522 & 0,522 & 0,522 \\
assim que & 1,000 & 1,000 & 1,000 & 1,000 & 1,000 & 1,000 & 1,000 & 1,000 & 1,000 \\
conforme & 0,500 & 0,563 & 0,563 & 0,818 & 1,000 & 1,000 & 0,621 & 0,720 & 0,720 \\
cujo & 0,583 & 0,700 & 1,000 & 0,462 & 0,588 & 0,588 & 0,515 & 0,639 & 0,741 \\
de forma que & 0,714 & 0,833 & 0,833 & 0,857 & 1,000 & 1,000 & 0,779 & 0,909 & 0,909 \\
de modo que & 0,655 & 0,950 & 0,950 & 0,966 & 1,000 & 1,000 & 0,781 & 0,974 & 0,974 \\
depois de & 0,667 & 0,750 & 1,000 & 0,931 & 0,923 & 0,923 & 0,777 & 0,828 & 0,960 \\
depois que & 0,778 & 0,875 & 1,000 & 0,947 & 1,000 & 1,000 & 0,854 & 0,933 & 1,000
\end{tabular}




\begin{tabular}{lccccccccc}
\hline \multicolumn{1}{c}{ Marcador } & p-sim & p-ana & p-sel & c-sim & c-ana & c-sel & f-sim & f-ana & f-sel \\
\hline a fim de & 0,931 & 1,000 & 1,000 & 0,967 & 0,964 & 0,964 & 0,949 & 0,982 & 0,982 \\
embora & 0,870 & 0,952 & 1,000 & 0,885 & 1,000 & 1,000 & 0,877 & 0,976 & 1,000 \\
já que & 0,880 & 0,957 & 1,000 & 0,862 & 0,958 & 0,958 & 0,871 & 0,957 & 0,979 \\
mesmo que & 0,842 & 0,941 & 1,000 & 0,760 & 0,850 & 0,850 & 0,799 & 0,893 & 0,919 \\
o qual & 0,933 & 0,933 & 1,000 & 0,600 & 0,652 & 0,652 & 0,730 & 0,768 & 0,789 \\
o que & 0,769 & 0,769 & 0,769 & 0,909 & 0,909 & 0,909 & 0,833 & 0,833 & 0,833 \\
para que & 0,826 & 0,950 & 0,950 & 0,840 & 0,905 & 0,905 & 0,833 & 0,927 & 0,927 \\
passiva & 0,833 & 0,882 & 1,000 & 0,720 & 0,773 & 0,773 & 0,773 & 0,824 & 0,872 \\
porque & 0,769 & 0,952 & 0,952 & 1,000 & 1,000 & 1,000 & 0,870 & 0,976 & 0,976 \\
que & 0,769 & 0,833 & 1,000 & 0,765 & 0,857 & 0,857 & 0,767 & 0,845 & 0,923 \\
segundo & 0,611 & 0,733 & 0,733 & 0,875 & 0,917 & 0,917 & 0,720 & 0,815 & 0,815 \\
uma vez que & 0,880 & 1,000 & 1,000 & 0,893 & 0,957 & 0,957 & 0,886 & 0,978 & 0,978 \\
\hline
\end{tabular}

Devido à restrição de sete exemplos positivos simplificáveis por anotadores humanos, apenas 31,5\% dos marcadores puderam ser analisados na Tabela 5.16. Apesar disso, observa-se que esses marcadores correspondem a $82,5 \%$ do número estimado de exemplos simplificáveis por humanos, enquanto os $17,5 \%$ restantes contém muito ruído, são muito raros, ou não são processados devido à ambiguidade. Os resultados indicam um bom desempenho das regras de simplificação, cobrindo os marcadores mais importantes, ou seja, mais frequentes e menos ambíguos, o que também é confirmado pela proporção entre simplificações corretas e exemplos simplificados por humanos da Tabela 5.15.

A Tabela 5.17 apresenta as médias ponderadas pela frequência de cada marcador discursivo das precisões e coberturas, apresentando uma visão geral do desempenho do Sinsim em córpus reais.

Tabela 5.17: Médias ponderada das medidas estimadas.

\begin{tabular}{lrrr}
\hline Medida & Precisão & Cobertura & Medida-f \\
\hline Seleção de exemplos & $99,05 \%$ & $82,24 \%$ & $89,86 \%$ \\
Simplificação com análise sintática correta & $85,66 \%$ & $82,24 \%$ & $83,92 \%$ \\
Simplificação & $79,42 \%$ & $75,09 \%$ & $77,20 \%$ \\
\hline
\end{tabular}

Embora a precisão para a seleção de exemplos pareça muito elevada, o resultado é esperado, pois a abordagem em uso priorizou a precisão em detrimento à cobertura, já que apenas os marcadores menos ambíguos são tratados. Em uma análise alternativa, na qual os exemplos raros são incluídos, a cobertura e a medida-f da simplificação (com erros de análise sintática inclusos) diminuem para $62,18 \%$ e $70,18 \%$, respectivamente, enquanto a precisão se mantem. 
A Figura 5.3 apresenta a distribuição dos marcadores discursivos (e verbo "ser") associados a cada fenômeno sintático dado sua frequência a cada milhão de lexemas. A pureza de cada marcador, definida como a taxa de exemplos positivos $^{31}$ em relação ao tamanho da amostra, também é apresentada. Esses dados são úteis para identificar os marcadores mais frequentes e com menos ruído, que correspondem aos candidatos ideais para formulação de regras de simplificação por ocorrerem com frequência e serem menos suscetíveis a erros de simplificação por serem menos ambíguos.

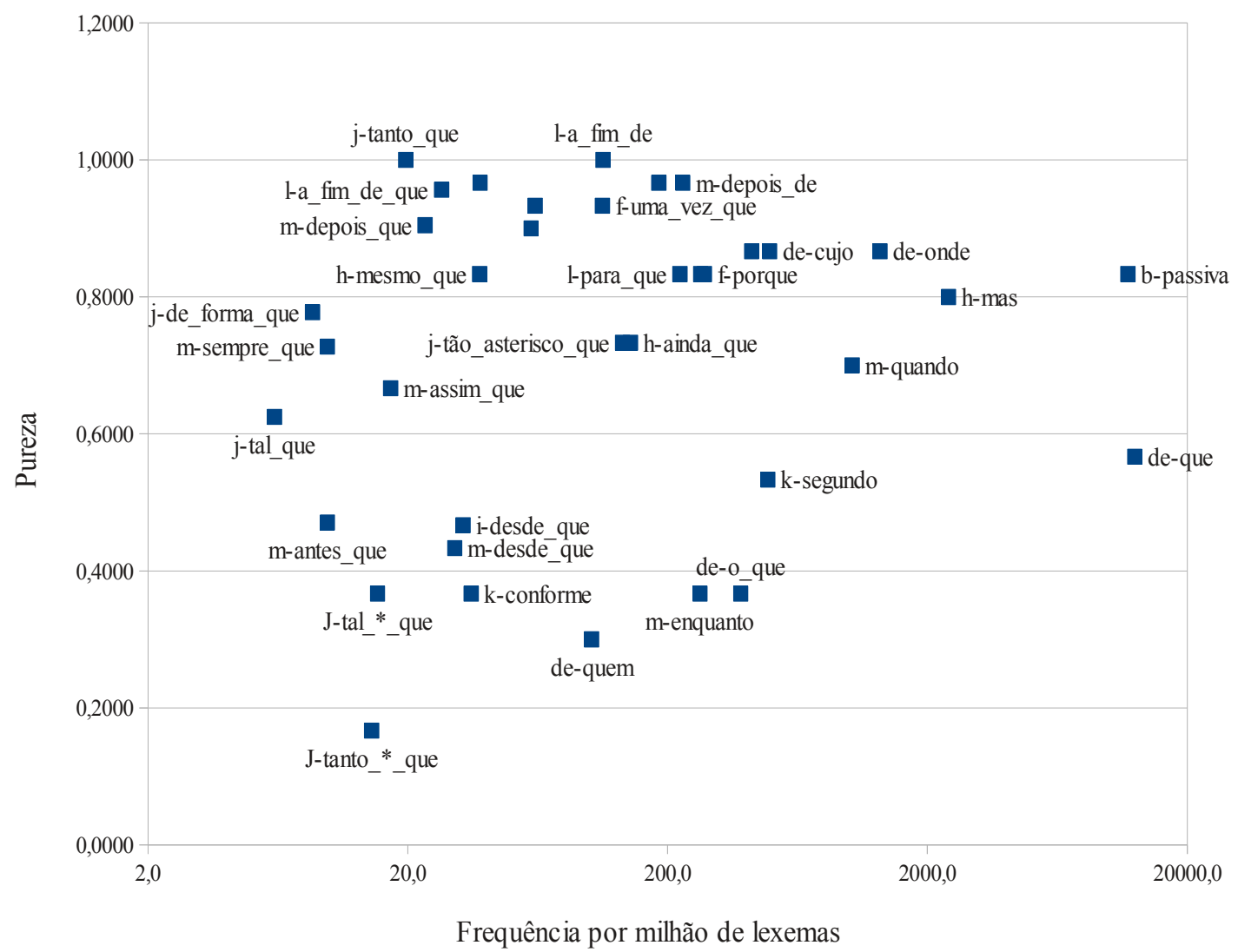

Figura 5.3: Distribuição de marcadores.

\subsubsection{Questões sobre a qualidade da simplificação}

Enquanto a Seção 5.3.2 focou-se em aspectos quantitativos de simplificações, esta seção apresenta aspectos qualitativos de casos considerados corretos. Além da limitação em relação ao posicionamento de alguns marcadores discursivos mostrada no Exemplo 4.7 da Seção 4.2.1, existem outros fatores impactando na qualidade do texto simplificado mesmo quando não há erros no processo simplificação.

31 A medida pureza não deve ser confundida com precisão. A primeira consiste no uso de exemplos positivos e negativos, independentemente da análise do modelo. A segunda é realizada sobre verdadeiros positivos e falsos positivos. 
Três casos foram identificados, e são apresentados de acordo com a seguinte notação: orações são representadas por letras maiúsculas; concatenação de orações representam coordenação; parênteses indicam subordinação; $c, c_{1}$ e $c_{2}$ são marcadores discursivos; e o símbolo “ $\rightarrow$ ” representa o processo de simplificação. Os casos são:

- $\mathrm{A}(\mathrm{B}(\mathrm{c} 1 \mathrm{C})) \rightarrow \mathrm{A}(\mathrm{B})$. c2 $\mathrm{C}:$ o caso vertical. Neste cenário, é mais natural ler-se $c_{2}$ conectando $C$ a $A$. Contudo, $c_{l}$ originalmente conectava $C$ a $B$, conforme mostrado no Exemplo 5.5. Apesar do resultando ser aceitável em vários exemplos, pode ser interessante limitar a simplificação a orações de cujo nível na árvore sintática é dois, de modo que orações de nível três só seriam simplificadas se sua oração pai for simplificada por alguma outra regra antes.

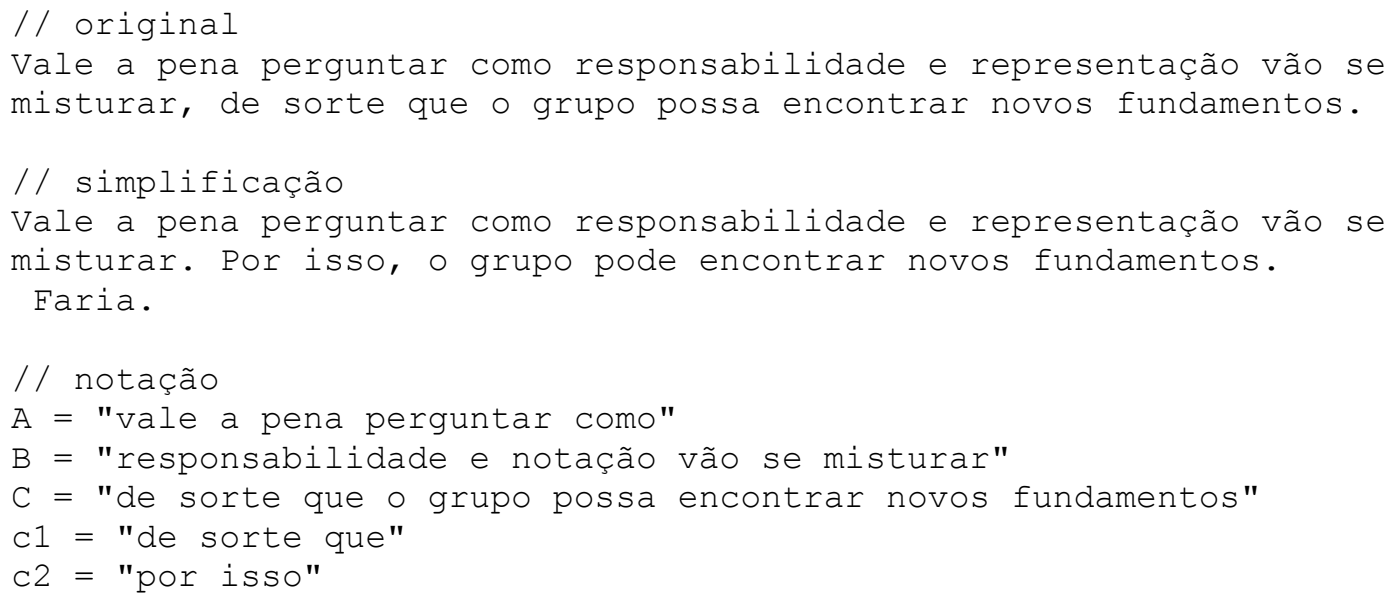

Exemplo 5.5: O caso vertical.

- $\mathrm{A}(\mathrm{c} 1 \mathrm{~B}) \mathrm{CD} \rightarrow \mathrm{ACD}$. c2B: o caso horizontal. Nesse cenário, $c$ corretamente conecta $A$ e $B$, mas longos períodos com coordenações e outros fenômenos não tratados distanciam $A$ e $B$, o que, embora gere um texto resultante correto, pode vir sobrecarregar a memória de trabalho do público-alvo. O Exemplo 5.6 ilustra o caso horizontal. A solução proposta para esse caso consiste na simplificação de mais fenômenos sintáticos, pois com a simplificação em largura das coordenações, o problema é adequadamente tratado.

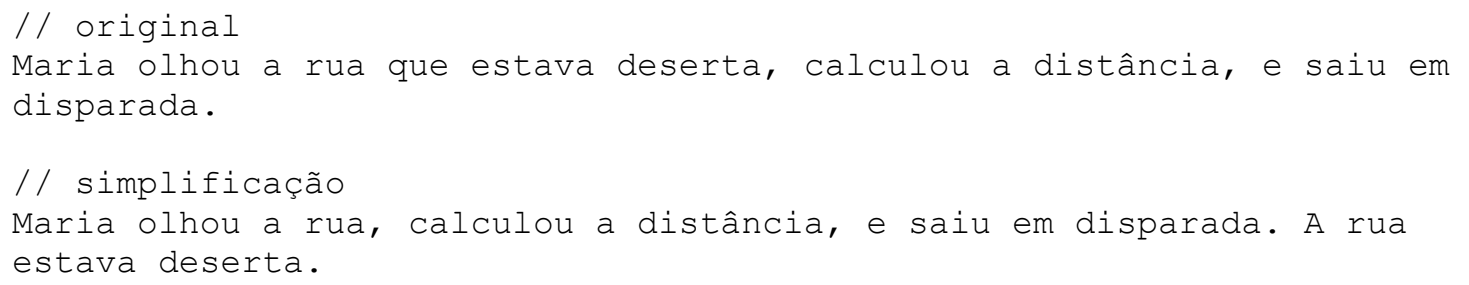

Exemplo 5.6: O caso horizontal. 
- O caso misto: esse caso ocorre quando o caso vertical e horizontal aparecem combinados, e são mais prováveis em períodos muito longos, o que pode se tornar um problema mais acentuado em outros gêneros textuais, por exemplo, no gênero literário para alguns estilos.

Adicionalmente, mesmo quando uma frase tenha sido corretamente simplificada, sua compreensão pode ser afetada, caso uma outra frase anterior importante no texto não tenha sido corretamente processada, reforçando a importância do foco em precisão na simplificação sintática automática.

\subsection{Análises extrínsecas do Miolin}

Esta seção apresenta duas análises extrínsecas do Molin: (a) combinado com o Sinsim para simplificara voz passiva em uma análise reduzida; e (b) análises de sinapses para tarefas para as quais as instâncias não foram inicialmente planejadas.

A primeira análise extrínseca, planejada na proposta deste trabalho foi o uso do Miolin integrado ao Sinsim. Contudo, o desempenho relativamente baixo da análise sintática prejudicou a realização dessa análise. Em virtude disso, o foco na integração entre as duas ferramentas foi diminuído. Em vez de uma avaliação com todos os fenômenos, foi avaliada apenas voz passiva, com 15 frases da amostra utilizadas em seus experimentos. Das 15 frases, apenas sete orações são simplificáveis, cinco corretamente, sendo uma frase simplificada incorretamente pelo Sinsim e outra não simplificada devido a problemas no Palavras. Em uma simulação manual do algoritmo de simplificação da voz passiva, feita sobre a saída do Miolin para o experimento g1e5, verificou-se que nenhuma das 15 frases são simplificadas pelo algoritmo da voz passiva devido a erros presentes na saída do experimento g1e5. O algoritmo faz uma série de checagens, incluindo se a oração possui sujeito, agente da passiva, verbo auxiliar com lema "ser" e verbo principal no particípio passado. As checagens baseadas em precisão abortam a análise em caso de problemas. Mesmo uma oração menor "O rato foi pego pelo gato" não pode ser simplificada, pois a instância não detectou que "pego" é o verbo principal da oração. Nota-se que todas as demais checagens não apontaram problemas para essa oração. De certo modo, o Miolin acabou provendo uma avaliação sobre o foco em precisão do Sinsim. Como planejado, o Sinsim evita simplificações se o analisador sintático apresenta problemas ou não está seguro a respeito de sua saída.

Em virtude dos problemas apresentados, uma segunda avaliação extrínseca foi proposta 
para instâncias Molin, baseada em análises para as quais a instância não foi originalmente planjeda. Primeiramente analisou-se o uso de artigo precedendo quatro os lexemas "Ceára", "Bahia", "Brasília" e "Alagoas". Para isso usou-se a base gerada no experimento g1e2, comparando-se a sinapse que interliga o evento pre_lexeme_em ao lema de cada um dos quatro lexemas. Como esperado, sinapses para lemma_brasília ("em Brasília") e lemma_alagoas (“em Alagoas”) existem e possuíram pelo menos cinco ocorrências (deduzidas a partir da taxa de aprendizado decrescente), que sofreram apenas ajustes de pesos positivos. Sinapses para lexeme_ceára ("no Ceará") e lexeme_bahia (“na Bahia”) não foram encontradas. Caso tais sinapses fossem encontradas, era esperado que sua frequência fosse bem reduzida em relação a "Brasília" e "Alagoas". Esse resultado é interessante por indicar que o modelo está capturando usos da língua, isto é, armazenando informações internamente a respeito do uso de artigos pelos falantes de diferentes dialetos do Português do Brasil. Nota-se que não há uma regra uniforme para uso desses artigos, de forma que um falante os usa ou os deixa de usar conforme as convenções em do seu dialeto.

$\mathrm{Na}$ mesma abordagem de análise, verificou-se que é possível estudar colocações (lexemas que ocorrem frequentemente juntos) a partir da base neural. Em g1e2, a primeira e a quarta sinapses mais fortes que interligam eventos post a lemma_vinho tem como eventos de origem post_lexeme_branco e post_lexeme_tinto, respectivamente (a segunda e a terceira sinapses são relacionadas a artigos e preposições, isto é, stopwords), o que indica que a rede neural artificial também está armazenando informações a respeito de colocações. 


\section{Conclusões}

Neste trabalho apresentou-se um modelo integrativo bidirecional para análise de língua baseado em redes neurais artificiais de grande porte (Molin), bem como um modelo para simplificação sintática baseada em regras (Sinsim). O modelo de análise busca explorar a bidirecionalidade entre os níveis da língua, um tema que tem sido explorado a literatura apenas para combinações específicas entre níveis da língua. O Molin também aplica uma abordagem de recorrência criada especificamente para esse propósito. O modelo Sinsim busca disponibilizar recursos de Simplificação para a Língua portuguesa.

\subsection{Contribuições e limitações}

As principais inovações realizadas pelo modelo de análise da língua são: (a) a coativação, uma forma de recorrência colaborativa entre diferentes padrões pertencentes ao mesmo contexto neural, na qual um padrão influencia e é influenciado por outros padrões no mesmo contexto; e (b) a análise bidirecional da língua baseada em redes neurais artificiais de grande porte baseada na coativação. Além disso, o modelo de análise de língua também propõe uma representação ideal para abordagens neurais aplicadas ao PLN, admite aprendizado a partir de múltiplos tutores e permite extração de conhecimento sobre a língua a partir da força das sinapses. Neste último caso, a análise pode ser feita a partir das taxas de aprendizado das sinapses, que influenciam sempre monotonicamente seus neurônios de destino devido ao uso de redes neurais artificiais Perceptron.

O modelo de análise de língua permitiu obter quatro resultados positivos: (a) a coativação, a primeira questão de pesquisa investigada, validada experimentalmente a partir da interação entre artigos à esquerda e substantivos à direita na Seção 5.1.5; (b) a análise bidirecional, a segunda questão de pesquisa, validada principalmente na Seção 5.2.1. (c) a análise morfossintática e a lematização atingiram valores próximos do estado da arte (Seção 5.1), que tem se mantido estável nos últimos anos; (d) a extração de conhecimento de instâncias do modelo para uso em análises para as quais as instâncias não foram originalmente planejadas, conforme discutido na Seção 5.4, o que foi facilitado dado o foco em 
interpretabilidade do modelo. Entre as principais contribuições relacionadas ao Molin, encontram-se a metodologia proposta neste trabalho e o protótipo gerado, que permite investigar interações multinível independentemente de idioma, não se restringindo ao Português, oferecendo a capacidade de processar várias instâncias Molin.

O modelo de análise de língua também levou a dois resultados negativos: (a) a análise sintática ainda não atingiu resultados semelhantes aos melhores analisadores sintáticos disponíveis; e (b) com isso, a avaliação extrínseca do Molin aplicado ao Sinsim foi prejudicada, razão pela uma segunda avaliação extrínseca baseada em análises para as quais o Molin não foi originalmente planejado ter sido realizada. Entre as limitações, destaca-se o fato de testes de significância estatísticas não terem sido realizados, o que é importante para confirmar as melhoras nas análises bidirecionais e na coativação. A análise de significância é um processo caro no contexto desta pesquisa, uma vez que aproximadamente 57 experimentos foram realizados devido a natureza exploratório do trabalho. Nota-se que na literatura, os trabalhos analisados também não se basearam em testes de significância estatística, com poucas exceções, como o trabalho de Hajič et al. (2009). Uma segunda limitação é escassez de recursos semânticos para o Português, sendo o PropBank-Br (Duran et al., 2012) o principal recurso disponível, porém este não pôde ser integrado na análise devido à contemporaneidade desta pesquisa com a disponibilização do recurso.

Em particular, os resultados relativamente baixos da análise sintática devem-se em partes ao caráter exploratório deste trabalho. Nota-se que Collobert et al. (2011) e Collobert (2011) aplicaram quatro semanas de treinamento em seus modelos (particularmente relacionado à parte não supervisionada), enquanto que a maioria das instâncias Molin foram treinado em apenas uma época e apenas usando uma parcela do córpus disponível. Outro possível problema relacionado a análise sintática de dependências é a falta de mais atributos relacionados à árvore sintática, pois os resultados obtidos neste trabalho foram semelhantes ao de Collins (2003) para a Língua Inglesa, quando o autor remove um atributo indicando quando um nó em análise é relacionado a ancestrais previamente analisados de seus vizinhos imediatos. Além disso, o estado da arte relacionado à análise sintática continua evoluindo, com modelos já consagrados que foram mais refinados ainda. Nesse cenário, torna-se cada vez mais difícil que novos modelos superem o estado da arte de imediato, pois também necessitam de tempo para amadurecer.

Uma terceira limitação é relacionada a metodologia aplicada para análise sintática, 
verifica-se o fato da análise sintática ter sido realizada em um córpus anotado automaticamente (PLN-Br) por outro modelo (o Palavras), que não passou por uma revisão por humanos. Observa-se que esse fato não foi considerado um problema na análise morfossintática, pois o córpus MacMorpho, revisado por humanos, levou a resultados semelhantes ao córpus anotado automaticamente.

Para o modelo de simplificação sintática, a contribuição do trabalho é uma ferramenta que pode ser integrada a aplicações voltadas ao público-alvo composto por alfabetizados de nível rudimentar e básico, de modo a prover uma melhor acessibilidade textual a esse audiência. $\mathrm{Na}$ análise quantitativa foi verificado que a versão implementada do modelo apresentou uma boa precisão (foco do modelo), cerca de 79,5\%, mantendo uma cobertura de 75\%. Para o gênero enciclopédico, foram estimadas cerca 22 mil simplificações corretas a cada milhão de lexemas, dados os fenômenos sintáticos analisados (voz passiva e orações subordinadas), o que abarca cerca de $16 \%$ das orações desse gênero. É importante salientar que o modelo pôde ser aplicado a outros gêneros e domínios textuais, mesmo tendo sido desenvolvido para o gênero jornalístico. Sua limitação é a ausência de processamento para orações coordenadas, uma vez que estas foram consideradas menos importantes que orações subordinadas na voz passiva.

\subsection{Trabalhos futuros}

\subsubsection{Modelo Molin}

Com relação à parte implementacional/codificadora do modelo, trabalhos futuros incluem:

- Importar eventos adicionais do glossário Dela, como por exemplo, a etiqueta ABREV referente a siglas e abreviaturas.

- Melhorar o processo de extração de entidades nomeadas a partir de recursos aglutinantes como o conjunto Pln anotado pelo Palavras. O objetivo é gerar padrões mais adequados ao treinamento de instâncias Molin, já que estas não se baseiam em aglutinação.

- Refinar o mapeamento de etiquetas do Palavras, incluindo transformar suas categorias gramaticais de eventos possub para pos com o objetivo de melhorar os resultados das instâncias já testadas. Testar a inserção de novos eventos relativos a 
casos ainda não tratados adequadamente, como determinar (por meios neurais) se as frases são declarativas, interrogativas ou exclamativas. Isso também inclui melhorar o processo de análise da pontuação em frases.

- Aprimorar o processo de extração de sufixos, de modo que instâncias baseada em sufixos aninhados possam ser testadas (por exemplo, gerando os eventos suffix_s, suffix_o e suffix_nh para lexeme_passarinho) e generalizá-lo para também gerar eventos relativos a prefixos e radicais.

- Melhorar a otimização por semente de modo a permitir que alguns neurônios sempre sejam incluídos em $O^{\prime}$ (por exemplo, eventos pos), além de aceitar padrões com mais de uma semente.

- Permitir a otimização por semente iterativa. Nessa proposta, neurônios de saída podem ser utilizados como sementes, e uma semente pode dar surgimento a outras. Atualmente, isto é possível apenas para lemas. Dessa forma, tira-se proveito de eventos menos granulares para recuperação de eventos. Por exemplo, dada uma instância cujos lexemas "professora", "professor", "professores”, “professorinha", entre outros sejam associadas a categoria semântica "humano", na versão atual, cada variação deve estar presente no córpus de treinamento (pós aquisição léxica) para que semcat_human seja recuperado em $O^{\prime}$ para todos os casos.

- Permitir descendentes e ancestrais indiretos na análise. Essa proposta é importante devido ao exposto no Exemplo 3.11 da Seção 3.3.3.

- Incluir testes de significância estatística para no arcabouço de testes.

- Processar a matriz $C$ parcialmente. Os núcleos sintáticos de lexemas como artigos e adjetivos aparecem comumente nas suas imediações à direita. Assim, faz pouco sentido procurar por núcleos muito distantes no início da frase ou em seu final. O processamento da matriz pode ser otimizado se as relações de dependências forem verificadas primeiro nas adjacências do padrão em análise, e o processo for concluído assim que a classificação detectar o nó pai com uma boa confiança. Nesse caso, há questões a serem analisadas no treinamento para casos que demandem ajustes de pesos para c-padrões não que não foram pré-ativados.

- Investigar a poda de neurônios e sinapses. Após o treinamento, sinapses com valores próximos de zero são estabelecidas e geram pouco impacto na ativação de seu neurônio de saída. O processo de poda consiste em remover essas sinapses a partir de 
um parâmetro que indique quais são os valores indesejados dos pesos (negativos ou positivos). Isso beneficia também a otimização por semente. Neurônios de entrada cuja a maioria ou totalidade das sinapses forem removidas durante a poda podem ser removidos também.

Com relação à parte metodológica/experimental do modelo:

- Avaliar instâncias para análise sintática com base no córpus Floresta Sintá(c)tica.

- Avaliar instâncias para análise sintática com mais atributos referentes a árvores parcialmente analisadas, de modo a melhorar os resultados obtidos.

- Avaliar instâncias para desambiguação de sentido com base em sentidos semânticos do glossário TeP 2.0 (MAZIERO et al., 2008).

- Avaliar instâncias para etiquetar papéis semânticos (DURAN \& ALUÍSIO, 2012; DURAN \& ALUÍSIO, 2011a).

- Avaliar instâncias com eventos para ancestrais e dependentes (diretos ou indiretos).

- Avaliar a transferência de conhecimento entre instâncias Molin por meio de instância tutora e instância em treino, bem como a degradação relacionada. Experimentos iniciais nesse sentido foram realizado na Seção 5.1.7, contudo, mais análises precisam ser feitas para avaliar-se a degradação adequadamente. Um exemplo é o uso da ativação obtida da instância tutora como ativação esperada na instância em treino.

- Aprender a mesma tarefa de múltiplos tutores. Um possível uso dessa abordagem consiste em partir de recursos grandes com alto ruído (como o conjunto Pln anotado pelo Palavras), seguido pelo aprendizado de recursos menores, porém com menos ruído (por exemplo, os subconjuntos anotados automaticamente do TreeBank Floresta Sintá(c)tica com seus diferentes níveis de revisão por anotadores humanos). Isso permite que a rede neural artificial gerada possa usar o conhecimento do recurso com alto ruído para casos não cobertos pelo treinamento do tutor de baixo ruído

- Aprender diferentes tarefas de diferentes tutores. Assim, as tarefas podem ser aprendidas sob demanda, e a instância resultante pode ser indefinidamente estendida com a adição de mais tarefas ou refinamento das existentes. Em um uso avançado desta característica, conhecimentos obtidos de dois tutores diferentes podem ser correlacionados. Por exemplo, uma instância do modelo pode ser treinada para uma dada tarefa (como análise de dependências sintáticas) enquanto outra instância é 
utilizada em uma segunda tarefa (como análise de papéis semânticos), o que possibilita gerar-se uma terceira instância treinada a partir de um recurso anotado por essas duas anteriores (de recursos anotados por elas). Esse recurso, em tese, possibilitaria a instância em treino estabelecer correlações entre o conhecimento fornecido por suas instâncias tutoras.

- Avaliar instâncias com aquisição lexical não supervisionada, conforme descrito na Seção 3.2.3.

- Usar inferência textual no nível sintático, seguindo a proposta de Yuret et al. (2012), como um segundo avaliador extrínseco do Molin. Na proposta, pares texto-hipótese (T-H) da inferência textual são gerados a partir de frases individuais, ou seja, os textos são mono-frases. Hipóteses $\mathrm{H}$ são validadas quando o analisador sintático avaliado identifica corretamente as estruturas sintáticas dos textos T.

- Avaliar a remoção de padrões para classes gramaticais fechadas e incorporação de seus eventos em padrões pai. Por exemplo, em "O gato perseguiu o rato.", o padrão para lexeme_gato poderia conter o evento modifier_o ao passo que o padrão para lexeme_o poderia ser removido da análise, já que a classe gramatical artigo é fechada e pequena. Um fator a ser considerado nesse caso é o fato de o processo tornar-se dependente de algoritmos clássicos, que não processam incertezas tão bem quanto a abordagem baseada em redes neurais artificiais. Por exemplo, em "a letra o", o evento lexeme_o deve ser associado a um substantivo e não à classe fechada artigo.

Com relação à parte conceitual do modelo:

- Incluir como entrada nos c-padrões informações sobre dependências já realizadas. Por exemplo, se um verbo toma como argumentos um sintagma nominal com função sintática de sujeito e um sintagma preposicional com função sintática de objeto preposicional, e a classificação já os encontrou, convêm incluir um evento para dizer isso na análise de outros candidatos a dependentes para evitar que sejam atribuídos dois sujeitos diferentes ao mesmo verbo.

- Avaliar instâncias com camadas escondidas e as diferentes estratégias para criação de neurônios dessa camada.

- Estender o modelo para unidades menores da língua. No modelo proposto, o processamento é centrado na unidade lexema ou em unidades proximamente relacionadas, como troncos e lemas. As unidades menores como morfemas e 
fonemas (em transcrições de córpus falados) também apresentam ambiguidades cuja resolução pode ser apoiada com o uso de redes neurais artificiais.

- Estender o modelo para níveis superiores da língua, com eventos que transponham contextos. Tarefas como a resolução anafórica extrapolam o nível sentencial. A anotação de estruturas retóricas se baseia em partes na análise de marcadores discursivos também estabelecem relações entre diferentes frases. Assim, o modelo precisa de abstrações adicionais ao contexto neural para lidar com estruturas maiores como seções, capítulos, textos completos, entre outras.

- Permitir o uso de memória episódica na desambiguação de sentidos e na categorização semântica. Essa proposta também depende de eventos que extrapolam o nível sentencial. Uma instância que armazene os últimos sentidos ou as últimas categorias detectadas para os lexemas pode tirar proveito dessa informação na análise dos mesmos lexemas que se repetem em contextos subsequentes.

- Desenvolver representações neurais para as informações contidas no texto (isto é, relativas a frases anteriores à frase em análise) e propor métodos para a geração de língua com base no conhecimento atual das instâncias Molin e na representação neural em questão.

\subsubsection{Modelo Sinsim}

Com relação à parte implementacional do modelo, trabalhos futuros incluem:

- Fixar marcadores discursivos durante inversões de orações, conforme discutido no Exemplo 4.7 da Seção 4.2.1.

- Adicionar tratamento nas regras para evitar o surgimento de catáforas após reordenações de orações ou de componentes de uma oração.

- Aumentar a interação entre Molin e Sinsim, criando um conversor para transformar a saída baseada em árvores de dependência sintática do Molin em árvores de constituintes sintáticas utilizadas pelo Sinsim.

- Incluir casos marcados como pendentes nas análises do modelo e corrigir simplificações incorretas.

- Processar orações subordinadas comparativas e proporcionais e outros fenômenos sintáticos ainda não tratados, como orações reduzidas e orações fora da ordem sujeito-verbo-objeto. 
- Incorporar fenômenos de tratamento de coordenações no modelo no modelo e nos testes realizados.

- Considerar evitar simplificações de orações com nível 3 na árvore sintática devido ao caso horizontal exposto na Seção 5.3.3.

Com relação à parte metodológica do modelo:

- Avaliar o uso de estatística para resolver anáforas causadas pelos pronomes "que", "o qual" (e suas variações em gênero e número) e outros para tratar os problemas apontados na discussão do caso 3 do Exemplo 4.12 da Seção 4.2.3.

- Avaliar o modelo junto ao público-alvo, verificando se as simplificações obtidas estão apoiando favoravelmente a leitura dos textos. 


\section{Referências}

ABEDI, J.; LEON, S.; KAO, J.; BAYLEY, R.; EWERS, N.; HERMAN, J.; MUNDHENK, K. 2011. Accessible Reading Assessments for Students with Disabilities: The Role of Cognitive, Grammatical, Lexical, and Textual/Visual Features (CRESST Report 785). Los Angeles: National Center for Research on Evaluation, Standards, and Student Testing, University of California, 2011.

AFONSO, S.; BICK, E.; HABER, R.; SANTOS, D: Floresta sintá(c)tica: A treebank for Portuguese. In: Proc. of LREC 2002, Las Palmas de Gran Canaria, Spain, 2002. p. 1698-1703.

AIRES, R. V. X. (2000). Implementação, Adaptação, Combinação e Avaliação de Etiquetadores para o Português do Brasil. MsC Thesis. 2000.

ALUÍSIO, S. M.; OLIVEIRA, O. N. A Case-Based Approach for Developing Writing Tools Aimed at Non-native English Users. Lecture Notes in Artificial Intelligence 1010, 1995. p. 121-132.

ALUÍSIO, S. M.; PELIZZONI J.; MARCHI, A. R.; OLIVEIRA, L.; MANENTI, R.; MARQUIAFÁVEL, V. An account of the challenge of tagging a reference corpus of Brazilian Portuguese. In: PROPOR 2003, Lecture Notes on Artificial Intelligence. Faro, Portugual: Springer Verlag, 2003. v. 1.

ALUÍSIO, S. M.; PINHEIRO, G. M.; FINGER, M.; NUNES, M. G. V.; TAGNIN, S. E. The lacio-web project: overview and issues in Brazilian Portuguese corpora creation. In: Corpus Linguistics 2003 (also as UCREL Technical Report, Vol 16 Part). Lancaster, UK: Lancaster University, 2003. v. 16, p. 14-21.

ALUÍSIO, S. M.; PINHEIRO, G. M.; MANFRIN, A. M. P.; OLIVEIRA, L. H. M.; GENOVES JR., L. C.; TAGNIN, S. E. O. The lácio-web: Corpora and tools to advance brazilian portuguese language investigations and computational linguistic tools. In: LREC 2004. Lisboa, Portugal: Elra, 2004. p. 1779-1782.

ALUÍSIO, S. M.; SPECIA, L.; PARDO, T. A. S.; MAZIERO, E. G.; FORTES, R. P. M. Towards Brazilian Portuguese Automatic Text Simplification Systems. In: Proceedings of The Eight ACM Symposium on Document Engineering (DocEng 2008), pp. 240-248, São Paulo, Brasil, 2008.

ALUÍSIO, S.M.; GASPERIN, C. Fostering Digital Inclusion and Accessibility: The PorSimples project for Simplification of Portuguese Texts. Proceedings of the NAACL HLT 2010 Young Investigators Workshop on Computational Approaches to Languages of the Americas. New York: ACL, 2010. v. 1. p. 46-53.

AMARAL, E.; ANTÔNIO, S.; PATROCINIO, M. F. Novo Manual Nova Cultural: Redação Gramática. Barueri, São Paulo: Nova Cultural, 1999. 624 p. 
AZAMATHULLA H. M.; HAQUE, A. A. M. Knowledge extraction from trained neural network scour model at culvert outlets. Neural Computing \& Applications, p. 1-5, 2012. DOI 10.1007/s00521-012-1164-2.

ANDREWS R.; DIEDERICH J.; TICKLE, A. B. Survey and critique of techniques for extracting rules from trained artificial neural networks. Knowledge-Based Systems, v. 8, n. 6, p. 373-389, 1995.

BAUM, L. E.; PETRIE, T. Statistical Inference for Probabilistic Functions of Finite State Markov Chains. Annals of Mathematical Statistics, 1966. v. 37, n. 6, p. 1554-1563.

BARREIRO, A.; CABRAL, L. M. ReEscreve: a translator-friendly multi-purpose paraphrasing software tool. In: Proceedings of the Workshop Beyond Translation Memories: New Tools for Translators. The Twelfth Machine Translation Summit. Ontario, Canada, 2009. p. 1-8.

BATISTA, G. E. A. P. A.; PRATI, R. C.; MONARD, M. C. A study of the behavior of several methods for balancing machine learning training data. SIGKDD Explor. Newsl. 2004. v 6, n. 1

BATISTA, G. E. A. P. A.; PRATI, R. C.; MONARD, M. C. Balancing strategies and class overlapping. Advances in Intelligent Data Analysis: Lecture Notes in Computer Science. Berlin: Springer, 2005. v. 3646, p. 24-35.

BENTIVOGLI, L.; CLARK, P.; DAGAN, I; DANG, H. T.; GIAMPICCOLO, D. The sixth PASCAL recognizing textual entailment challenge. Gaithersburg, Maryland, US: National Institute of Standards and Technology, 2010.

BICK, E. The parsing system "Palavras": Automatic grammatical analysis of Portuguese in a constraint grammar framework. Thesys $(\mathrm{PhD})$ - University of Århus, Aarhus, Denmark, 2000.

BICK, E. Automatic SemanticRole Annotation for Portuguese. Eckhard Bick. Automatic SemanticRole Annotation for Portuguese. Quinto Workshop em Tecnologia da Informação e da Linguagem Humana. 2007.

BIDERMAN, M. T. C. Dicionário Ilustrado de Português. 1. ed . São Paulo: Editora Ática, 2005.

BLACK, E.; ABNEY, S.; FLICKINGER, D.; GDANIEC, C.; GRISHMAN, R.; HARRISON, P.; HINDLE, D.; INGRIA, R.; JELINEK, F.; KLAVANS, J.; LIBERMAN, M.; MARCUS, M.; ROUKOS, S.; SANTORINI, B.; STRZALKOWSKI, T. A procedure for quantitatively comparing the syntactic coverage of english grammars. In: Proceedings of the DARPA Speech and Natural Language Workshop, 1991. p. 306-311.

BOLSHAKOV, I. A.; GELBUKH, A. Computational Linguistics: Models, Resources, Applications. Tresguerras, México: Instituto Politécnico Nacional, 2004.

BOHNET, B. Multilingual Efficient Parsing of Syntactic and Semantic Dependency Structures. In: Proceedings of the Thirteenth Conference on Computational Natural Language Learning (CoNLL 2009). Boulder, Colorado: Association for Computational Linguistics, 2009. p. 67-72. 
BÖS, S.; AMARI, S. Annealed online learning in multilayer neural networks. On-line Learning in Neural Networks, New York, NY, USA: Cambridge University Press, 1999.

BRILL, E. Transformation-Based Error-Driven Learning and Natural Language Processing: A Case Study in Part of Speech Tagging. Computational Linguistics, 1995.

BRUCKSCHEN, M.; MUNIZ, F.; SOUZA, J.G.C.; THIESEN, J.; FUCHS, K. I.; MUNIZ, M.; GONÇALVES, P.N.; VIEIRA, R.; ALUÍSIO, S.M. Anotação Lingüística em XML do Corpus PLN-BR (NILC-TR-08-09). São Carlos, SP: Série de Relatórios do Núcleo Interinstitucional de Lingüística Computacional NILC, 2008.

BURSTEIN, J.; SHORE, J.; SABATINI, J.; LEE, Y.; VENTURA, M. The Automated Text Adaptation Tool. In: Proceedings of Human Language Technologies: The Annual Conference of the North American Chapter of the Association for Computational Linguistics (NAACL-HLT). New York, USA: Association for Computational Linguistics, 2007. p 3-4.

BURSTEIN, J. Opportunities for Natural Language Processing Research in Education . In: Proceedings of the 10th International Conference on Computational Linguistics and Intelligent Text Processing (CICLing 09). Mexico City, Mexico: Springer-Verlag, 2009. p. 6-27.

CANDIDO JR, A.; MAZIERO, E. G.; SPECIA, L.; GASPERIN, C.; PARDO, T. A. S.; ALUÍSIO, S. M. Supporting the Adaptation of Texts for Poor Literacy Readers: a Text Simplification Editor for Brazilian Portuguese. In: Fourth Workshop on Innovative Use of NLP for Building Educational Applications, Boulder, Colorado, 2009b. p. 34-42.

CANDIDO JR, A.; OLIVEIRA, M.; ALUÍSIO, S. M. Simplifica: um Sistema Web de Autoria de Textos Simplificados. In: Simpósio Brasileiro de Sistemas Multimídia e Web (Webmedia 2009), 2009a. v. 2, p. 55-58.

CANDIDO JR, A.; COPESTAKE, A.; SPECIA, L.; ALUÍSIO, S. M. Towards an on-demand Simple Portuguese Wikipedia. In: Second Workshop on Speech and Language Processing for Assistive Technologies, 2011. p. 137-147.

CALLISON-BURCH, C.; KOEHN, P.; MONZ, C.; POST, M.; SORICUT, R.; SPECIA, L. Proceedings of the Seventh Workshop on Statistical Machine Translation. Montréal, Canada: Association for Computational Linguistics, 2010.

CARLSON, A.; CUMBY, C.; ROSEN, J.; AND ROTH, D. The SNoW learning architecture. Technical Report UIUCDCS-R-99-2101, UIUC Computer Science Department, 1999.

CARROLL, J.; MINNEN, G.; PEARCE, D.; CANNING, Y.; DEVLIN, S.; TAIT, J. Simplifying Text for Language-Impaired Readers. In: Proceedings of the 9th Conference of the European Chapter of the ACL (EACL). Bergen, Norway: Association for Computational Linguistics, 1999. p. 269-270.

CARUANA, R. Multitask Learning. Machine Learning. Kluwer Academic Publishers, 1997. v. 28, p. 41-75.

CASTELANO, K. L.; ALMEIDA, J. M.; LUQUETTI, E. C. F. Análise do Marcador Discursivo "Aí" em Relatos de Pré-Adolescentes. Revista discente do Centro de 
Estudos Linguísticos e Literários da Universidade Federal de Ouro Preto (UFOP), Mariana, Minas Gerais, v. 1, n. 1, 2011. ISSN 2179-0221.

CASTRO, C. L.; BRAGA, A. P. Aprendizado supervisionado com conjuntos de dados desbalanceados. Sba Controle \& Automação, 2011. v.22, n.5, p. 441-466.

CHANDRASEKAR, R.; DORAN, C.; SRINIVAS, B. Motivations and Methods for Text Simplification. In: Proceedings of the Sixteenth International Conference on Computational Linguistics (COLING 96), Copenhagen, Denmark: Association for Computational Linguistics, 1996. p. 1041-1044.

CHANDRASEKAR, R.; SRINIVAS, B. Automatic Induction of Rules for Text Simplification. Knowledge-Based Systems, 1997. v. 10, p. 183-190.

CHAPPELL, G. E. Description and assessment of language disabilities of junior high school students. In: Communication skills and classroom success: Assessment of language-learning disabled students. San Diego: College- Hill Press, 1985. p. 207-239.

CHOMSKY, N. Syntactic Structures. The Hague/Paris: Mouton, 1957. ISBN 3-11-017279-8.

COLLINS, M. Discriminative training methods for hidden Markov models: theory and experiments with perceptron algorithms. In: Proceedings of the ACL-02 conference on Empirical methods in natural language processing. Stroudsburg, PA, USA: Association for Computational Linguistics, 2002. v. 10, p. 1-8. DOI=10.3115/1118693.1118694.

COLLINS, M. Head-Driven Statistical Models for Natural Language Parsing. Comput. Linguist. Cambridge, MA, USA: MIT Press, 2003. v. 29, n. 4 p. 589-637. DOI 10.1162/089120103322753356.

COLLOBERT, R. Deep Learning for Efficient Discriminative Parsing. In: International Conference on Artificial Intelligence and Statistics (AISTATS), 2011.

COLLOBERT, R.; WESTON, J.; BOTTOU, L.; KARLEN, M.; KAVUKCUOGLU K.; KUKSA, P. Natural Language Processing (Almost) from Scratch. Journal of Machine Learning Research (JMLR), 2011.

CRAWFORD, W. E.; KAPLAN, J. J2EE Design Patterns. O'Reilly Media, 2003.

CROCKFORD, D; NETWORK WORKING GROUP. The application/json Media Type for JavaScript Object Notation (JSON). Disponível em: $<$ https://tools.ietf.org/html/rfc4627>. Accessed in: 15 may 2012.

D'HONDT, S.; ÖSTMAN, J.O.; VERSCHUEREN, J. The Pragmatics of Interaction. John Benjamins Publishing Company, 2009. ISBN 9789027207814.

DAS, D.; MARTINS A. F. T. A Survey on Automatic Text Summarization. Carnegie Mellon University, 2007. Technical Report.

DAGAN, I.; GLICKMAN, O. Probabilistic Textual Entailment: Generic applied modeling of language variability. In: PASCAL workshop on Text Understanding and Mining. Grenoble, France: Xerox Research Centre Europe, 2004.

DAELEMANS, W.; HOTHKER, A.; SANG, E. T. K. Automatic Sentence 
Simplification for Subtitling in Dutch and English. In: Proceedings of the 4th Conference on Language Resources and Evaluation. Lisbon, Portugal, 2004. p. 1045-1048.

DE BELDER, J.; MOENS, M. Text simplification for children. In: Proceedings of the SIGIR Workshop on Accessible Search Systems. Geneva, Switzerland, 2010. p. 19-26.

DEVLIN S.; UNTHANK, G. Helping aphasic people process online information. In: Proceedings of the ACM SIGACCESS 2006, Conference on Computers and Accessibility. Portland, Oregon, USA, 2006. p. 225-226.

DIAS-DA-SILVA, B. C.; MONTILHA, G.; RINO, L. H. M.; SPECIA, L.; NUNES, M. G. V.; OLIVEIRA JR., O. N.; MARTINS, R. T.; PARDO, T. A. S. Introdução ao Processamento das Línguas Naturais e Algumas Aplicações. Série de Relatórios do NILC. NILC-TR-07-10. São Carlos, 2007, 121p.

DOUGHERTY, R. C. Natural Language Computing: An English Generative Grammar in Prolog. Psychology Press, 1994. ISBN 0805815252.

DURAN, M. S.; AMANCIO, M. A.; ALUISIO, S. M. Assigning Wh-Questions to Verbal Arguments in a Corpus of Simplified Texts. In: International Conference on Computational Processing of Portuguese Language (PROPOR 2010), 2010, Porto Alegre. PROPOR 2010 Extended Activities Proceedings, 2010. v. 1. p. 1-16.

DURAN, M. S.; ALUÍSIO, S. M. Propbank-Br: a Brazilian Portuguese corpus annotated with semantic role labels. In: The 8th Brazilian Symposium in Information and Human Language Technology, 2011, Cuiabá/MT. Proceedings of the 8th Brazilian Symposium in Information and Human Language Technology, 2011. v. 1. p. 164-168.

DURAN, M. S.; RAMISCH, C.; ALUÍSIO, S. M.; VILLAVICENCIO, A. Identifying and Analyzing Brazilian Portuguese Complex Predicates. In: Proceedings of Multiword Expressions: from Parsing and Generation to the Real World (MWE 2011), Portland-OR, USA, 2011, p. 74-82.

DURAN, M. S.; ALUÍSIO, S. M. Propbank-Br: a Brazilian Treebank annotated with semantic role labels. In: Eight International Conference on Language Resources and Evaluation (LREC'12). Paris: European Language Resources Association (ELRA), 2012. v. 1. p. 1862-1867.

ELHADAD, N. Comprehending technical texts: Predicting and defining unfamiliar terms. In: Proceedings of the American Medical Informatics Association Symposium (AMIA 06). Washington, DC: [s.n.], 2006. p. 239-243 .

FÁVERO, L. L.; ANDRADE, M. L. C. V. O.; AQUINO, Z. G. O. Oralidade e escrita: perspectivas para o ensino de língua materna. 5. ed. São Paulo:Cortez, 2005.

FELLBAUM, C. WordNet: an electronic lexical database. Cambridge, Massachusetts: The MIT Press, 1998. ISBN: 0-262-06197-X.

FELTRIM, V. D. ; TEUFEL, S. ; NUNES, M. G. V. ; ALUÍSIO, S. M. Argumentative Zoning Applied to Critiquing Novices Scientific Abstracts. In: Computing Attitude and Affect in Text: Theory and Applications. 1ed.: Springer, 2006, v. 20, p. 233-246. 
FERNANDES, E. R.; MILIDIÚ, R. L. Entropy-Guided Feature Generation for Structured Learning of Portuguese Dependency Parsing. In: Computational Processing of the Portuguese Language, Lecture Notes in Computer Science, 2012. v 7243, p $146-156$.

GAMMA, E.; HELM, R.; JOHNSON, R.; VLISSIDES, J. Design Patterns: Elements of Reusable Object-Oriented Software. Reading, USA: Addison Wesley, 1995.

GANITKEVITCH, J.; VAN DURME, B.; CALLISON-BURCH, C. Monolingual Distributional Similarity for Text-to-Text Generation. In: Proceedings of SEM 2012: The First Joint Conference on Lexical and Computational Semantics, Montreal, Canada: Association for Computational Linguistics, 2012. v. 1.

GASPERIN, C.; SPECIA, L.; PEREIRA, T.; ALUÍSIO, S. Learning When to Simplify Sentences for Natural Text Simplification. In: XXIX Congresso da Sociedade Brasileira de Computação (CSBC 2009). Encontro Nacional de Inteligência Artificial (ENIA 2009), Bento Gonçalves, RS: [s.n.], 2009a. p. 809-818.

GASPERIN, C.; MAZIERO, E.; SPECIA, L.; PARDO, T.; ALUÍSIO, S. M. Natural language processing for social inclusion: a text simplification architecture for different literacy levels. In: CSBC 2009 - XXIX Congresso da Sociedade Brasileira de Computação, 2009, Bento Gonçalves, RS. SEMISH 2009 - XXXVI Seminário Integrado de Software e Hardware, 2009b. p. 387-401.

GASPERIN, C.; SPECIA, L.; PEREIRA, T.; ALUÍSIO, S. M. Learning When to Simplify Sentences for Natural Text Simplification. In: CSBC 2009 - XXIX Congresso da Sociedade Brasileira de Computação, 2009, Bento Gonçalves, RS. ENIA 2009 Encontro Nacional de Inteligência Artificial, 2009. p.809-818

GASPERIN, C.; MAZIERO, E.; ALUÍSIO, S.M. Challenging Choices for Text Simplification, In: Proceedings of Computational Processing of the Portuguese Language, 9th International Conference (PROPOR 2010), Porto Alegre, RS: Springer 2010. v. 6001, p. 40-50.

GIAMPICCOLO, D.; DANG, H. T.; MAGNINI, B.; DAGAN, I. The Fourth PASCAL Recognizing Textual Entailment Challenge. In: Proceedings of Text Analysis Conference (TAC) 2008. Gaithersburg, Maryland: National Institute of Standards and Technology, 2008.

GILDEA, D.; JURAFSKY, D. Automatic Labeling of Semantic Roles. Computational Linguistics, 2001, v. 28, p 245-288.

GRISHMAN, R.; SUNDHEIM, B. Message Understanding Conference - 6: A Brief History. In: International Conference on Computational Linguistic. Stroudsburg, USA: Association for Computational Linguistics, 1996. p. 466-471.

GUPTA, S. A survey of Data Driven Machine Translation (Technical Report). Mumbai: Department of Computer Science and Engineering Indian Institute of Technology, 2011.

GUPTA, P.; GUPTA. V. A Survey of Text Question Answering Techniques. International Journal of Computer Applications. New York, USA: Foundation of Computer Science, 2012. v. 53 n. 4, p. 1-8. 
HAJIČ, J.; CIARAMITA, M.; JOHANSSON, R.; KAWAHARA, D.; MARTÍ, M. A.; MÀRQUEZ, L.; MEYERS, A.; NIVRE, J.; PADÓ, S.; ŠTĚPÁNEK, J.; STRAŇÁK, P.; SURDEANU, M.; XUE, N.; ZHANG, Y. The CoNLL-2009 Shared Task: Syntactic and Semantic Dependencies in Multiple Languages. In: Proceedings of the Thirteenth Conference on Computational Natural Language Learning (CoNLL 2009). Boulder, Colorado: Association for Computational Linguistics: 2009. p. 1-18.

HALLIDAY, M.A.K. Language Structure and Language Function. In: New Horizons in Linguistics. Harmondswoth: Penguin Books, 1970.

HARRIS, M. D. Introduction to natural language processing. Reston, Virginia: Reston Publishing Company, 1985. ISBN 9780835932547.

INAF. $\quad 2007.2007 . \quad$ Disponível em: < http://www.ipm.org.br/download/bol_inaf_2007_12.pdf >. Acesso em: 27 out. 2012.

INUI, K.; FUJITA, A.; TAKAHASHI, T.; IIDA, R.; IWAKURA, T. Text simplification for reading assistance: a project note. In: Proceedings of the Second International Workshop on Paraphrasing. Sapporo, Japan: [S.1.], 2003. p. 9-16

JANCZURA, G. A.; CASTILHO, G. M.; ROCHA, N. O. Normas de concretude para 909 palavras da língua portuguesa. Psic.: Teor. e Pesq., 2007. v. 23, p. 195- 204.

JONES, F. W.; LONG, K.; FINLAY, W. M. L. Assessing the reading comprehension of adults with learning disabilities. Journal of Intellectual Disability Research, v. 50, n. 6, p. 410-418, 2006.

JONNALAGADDA, S.; GONZALEZ, G. Sentence Simplification Aids Protein-Protein Interaction Extraction. In: Proceedings of the 3rd International Symposium on Languages in Biology and Medicine. Jeju Island, South Korea, 2009. p. 109-114.

JURAFSKY, D.; MARTIN, J. H. Speech and Language Processing: An Introduction to Natural Language Processing, Computational Linguistics and Speech Recognition, 2ed. New Jersey: Prentice Hall, 2008. ISBN 013122798X.

KINOSHITA, J.; SALVADOR, L. N.; MENEZES, C. E. D. CoGrOO: Um Corretor Gramatical acoplável ao OpenOffice. Quinto Workshop em Tecnologia da Informação e da Linguagem Humana. Rio de Janeiro, 2007.

KLEBANOV. B.; KNIGHT, K.; MARCU, D. Text Simplification for Information-Seeking Applications. In: On the Move to Meaningful Internet Systems. Berlin: Springer-Verlag, 2004. v. 3290, p. 735-747.

KUMAR, K. Knowledge Extraction From Trained Neural Networks. International Journal of Information \& Network Security (IJINS), v. 1, n. 4, pp. 282-293, 2012. ISSN: 2089-3299.

LAFFERTY, J. D.; MCCALlUM, A.; PEREIRA, F. C. N. Conditional Random Fields: Probabilistic Models for Segmenting and Labeling Sequence Data. In: Proceedings of the Eighteenth International Conference on Machine Learning (ICML '01). San Francisco: Morgan Kaufmann Publishers Inc., 2001. p. 282-289.

LAL, P., RUGER, S. Extract-based summarization with simplification. In: Proceedings 
of Document Understanding Conferences (DUC). New York, USA: National Institute of Standards and Technology, 2002.

LEVINSON. S. E. The Effects of Syntactic Analysis on Word Recognition Accuracy. AT \& T Bell: Lab. Tech. Jour. 1978. v. 57, n. 5, p. 1627-1644.

MALAKASIOTIS, P.; ANDROUTSOPOULOS, I. Learning Textual Entailment using SVMs and String Similarity Measures. In: Proceedings of the ACL-PASCAL Workshop on Textual Entailment and Paraphrasing. Prague: Association for Computational Linguistics, 2007. p. 42-47.

MARGARIDO, P. R. A.; PARDO, T. A. S.; ANTONIO, G. M.; FUENTES, V. B.; AIRES, R.; ALUÍSIO, S. M.; FORTES, R. P. M. Automatic Summarization for Text Simplification: Evaluating Text Understanding by Poor Readers. In: VI Workshop em Tecnologia da Informação e da Linguagem Humana (TIL 2008). Vila Velha: Springer Berlin, 2008. p. 310-315.

MÀRQUEZ, L.; KLEIN, D. Proceedings of the Tenth Conference on Computational Natural Language Learning (CoNLL-X). New York City: Association for Computational Linguistics, 2006.

MCCALluM, A.; FREITAG, D.; PEREIRA, F. C. N. Maximum Entropy Markov Models for Information Extraction and Segmentation. In: Proceedings of the Seventeenth International Conference on Machine Learning. San Francisco, CA, USA: Morgan Kaufmann Publishers Inc., 2000. p. 591-598. ISBN 1-55860-707-2.

MCCULLOCH, W.; PITTS, W. A Logical Calculus of the Ideas Immanent in Nervous Activity. Bulletin of Mathematical Biophysics, 1943. v. 5, p. 115-133.

MCDONALD, R.; LERMAN, K.; PEREIRA, F. Multilingual dependency analysis with a two-stage discriminative parser. In: Proceedings of the Tenth Conference on Computational Natural Language Learning (CoNLL-X '06). Stroudsburg, PA, USA: Association for Computational Linguistics, 2006. p. 216-220.

MANN, W. C.; THOMPSON, S. A. Rhetorical structure theory: Toward a functional theory of text organization. Text, [S.1.], v. 8, n. 3, p. 243-281, 1988.

MARCUS, M. P.; MARCINKIEWICZ, M. A.; Santorini, B. Building a large annotated corpus of English: the penn treebank. Comput. Linguist. Cambridge, MA, USA: MIT Press, 1993. v. 19, n. 2, p. 313-330.

MARTINEZ, A. R. Part-of-speech tagging. Wiley Interdisciplinary Reviews: Computational Statistics. Wiley Periodicals, 2011. v. 4, n. 1, p. 107-113. DOI: 10.1002/wics. 195.

MARTINS, S.; FILGUEIRAS, L. Métodos de Avaliação de Apreensibilidade das Informações Textuais: uma Aplicação em Sítios de Governo Eletrônico. In: Proceeding of Latin American Conference on Human-Computer Interaction (CLIHC 2007). Rio de Janeiro, 2007.

MARTINS, T. B. F.; GHIRALDELO, C. M.; NUNES, M. G. V.; OLIVEIRA JR, O. N. Readability formulas applied to textbooks in brazilian portuguese. São carlos: Notas do ICMC, N. 28, $\quad 11 \mathrm{p} . \quad 1996 . \quad$ Disponível em 
$<$ http://www.nilc.icmc.usp.br/nilc/download/Reltec28.pdf>. Acesso em: 23 jan. 2013.

MAX, A. Writing for Language-impaired Readers. In: Proceedings of Seventh International Conference on Intelligent Text Processing and Computational Linguistics (CICLing). Mexico City: Springer Lecture Notes in Computer Science, 2006. p. 567570.

MAZIERO, E.G.; PARDO, T.A.S.; DI FELIPPO, A.; DIAS-DA-SILVA, B.C. A Base de Dados Lexical e a Interface Web do TeP 2.0 - Thesaurus Eletrônico para o Português do Brasil. In: VI Workshop em Tecnologia da Informação e da Linguagem Humana (TIL). Vila Velha, ES: Springer Berlin, 2008. p. 390-392.

MILLWARD, C.M.; HAYES, M. A Biography of the English Language. Cengage Learning, 2011. ISBN 9780495906414.

MINSKY, M.; PAPERT, S. Perceptrons: An Introduction to Computational Geometry. Cambridge, MA: MIT Press, 1969.

MORRIS, C. Foundations of the Theory of Signs. In: International Encyclopedia of Unified Science 1, 1938.

MUNIZ, M. C. M. A construção de recursos lingüístico-computacionais para o português do Brasil: o projeto Unitex-PB. Dissertação (Mestrado) - Instituto de Ciências Matemáticas de São Carlos, USP, fev. 2004.

MUNIZ, M. C. M.; NUNES, M. G. V.; LAPORTE, E. Unitex-pb, a set of flexible language resources for Brazilian Portuguese. In: Workshop on Technology of Information and Human Language (TIL). UNISINOS, São Leopoldo, Brazil, 2005. p. 2059-2068.

MUNIZ, F.; WATANABE, W. M.; SCARTON, C. E.; ALUÍSIO, S. M. Extração de Termos de Manuais Técnicos de Produtos Tecnológicos: uma Aplicação em Sistemas de Adaptação Textual. In: Anais do SEMISH 2011 - XXXVIII Seminário Integrado de Software e Hardware, em conjunto com o CSBC 2011 - XXXI Congresso da Sociedade Brasileira de Computação. Natal-RN, 2011. p. 1293-1306.

NANCY, I.; VÉRONIS, J. Introduction to the special issue on word sense disambiguation: the state of the art. Comput. Linguist. Cambridge, MA, USA: MIT Press, 1998. v. 24, n. 1, p. 2-40. ISSN 0891-2017.

NAPOLES, C.; DREDZE, M. Learning simple Wikipedia: a cogitation in ascertaining abecedarian language. In: Proceedings of the NAACL HLT 2010 Workshop on Computational Linguistics and Writing: Writing Processes and Authoring Aids (CL\&W '10). Association for Computational Linguistics, 2010. p. 42-50.

NIGAM, K.; LAFFERTY, J.; MCCALLUM, A. Using maximum entropy for text classification. In: IJCAI-99 Workshop on Machine Learning for Information Filtering, 1999. p. 61-67.

NILC. Conjunto de Etiquetas (Tagset) do Mac-Morpho. Disponível em: $<$ http://www.nilc.icmc.usp.br/lacioweb/downloads/Manual_Mac_Morpho_v10.zip>. Acesso em: 10 jan. 2013. 
NIVRE, J.; HALL，J.; NILSSON，J.; ERYIĞIT， G.; MARINOV， S. Labeled Pseudo-Projective Dependency Parsing with Support Vector Machines\}. In: Proceedings of the Tenth Conference on Computational Natural Language Learning $(C o N L L-X)$. New York City: Association for Computational Linguistics, 2006. p. 221-225.

NUNES, M. G. V.; OLIVEIRA JR., O. N. O processo de desenvolvimento do Revisor Gramatical ReGra. Anais do XX Congresso Nacional da Sociedade Brasileira de Computação (XXVII SEMISH). Curitiba: PUC-PR, 2000. v. 1, p. 6.

NUNES, M. G. V.; KUHN, D.; MARCHI, A. R.; NASCIMENTO, A. C.; ALUÍSIO, S.; OLIVEIRA JR., O. N. Novos Rumos para o ReGra: extensão do revisor gramatical do português do Brasil para uma ferramenta de auxílio à escrita. In: Proceedings do $I V$ Encontro para o Processamento Computacional da Língua Portuguesa Escrita e Falada (PROPOR'99). Portugal: Évora, 1999. p. 167-182.

PADÓ S.; THATER, S. Proceedings of the TextInfer 2011 Workshop on Textual Entailment. Edinburgh, Scottland, UK: Association for Computational Linguistics, 2011.

PARDO, T. A. S.; NUNES, M. G. V. DiZer: an Automatic Discourse Analyzer for Brazilian Portuguese. In the Proceedings of the $V$ Best MSc Dissertation/PhD Thesis Contest (CTDIA). Ribeirão Preto, SP, 2006.

PETERSEN, S. E. Natural Language Processing Tools for Reading Level Assessment and Text Simplification for Bilingual Education. PhD thesis. University of Washington, 2007.

QUINLAN, J. R. 1986. Induction of Decision Trees. Mach. Learn. 1, 1986. v. 1, p 81-106.

RAMPRASATH, M.; HARIHARAN, S. A Survey on Question Answering System. International Journal of Research and Reviews in Information Sciences (IJRRIS), 2012. v. 2, n. 1, p. 171-178.

RATNAPARKHI, A. A Maximum Entropy Model for Part-of-Speech Tagging. In: Proceedings of the Conference on Empirical Methods in Natural Language Processing (EMNLP-96), Philadelphia, 1996. p. 133-142.

RIBALDO, R.; AKABANE, A.T.; RINO, L.H.M.; PARDO, T.A.S. Graph-based Methods for Multi-document Summarization: Exploring Relationship Maps, Complex Networks and Discourse Information. In: Proceedings of the 10th International Conference on Computational Processing of Portuguese (LNAI 7243). Coimbra, Portugal , 2012. p. 260-271.

RIBEIRO, V. M. Analfabetismo e alfabetismo funcional no Brasil. Boletim INAF. São Paulo: Instituto Paulo Montenegro, 2006.

ROJAS, R. Neural Networks: A Systematic Introduction. Berlin: Springer, 1996. 453p. ISBN 3540605053.

ROSENBLATT, F. The Perceptron: A probabilistic model for information storage and organization in the brain. Psychological Review, v. 65, p. 386-408, 1958. 
RUMELHART, D. E.; HINTON, G. E.; WILLIAMS, R. J.; Learning Representations by Back-Propagation Errors. Nature, v.1, p. 533-536, 1986.

SINGH, S.; SCHULTZ, K.;MCCALLUM, A. Bi-directional Joint Inference for Entity Resolution and Segmentation Using Imperatively-Defined Factor Graphs. In: Proceedings of the European Conference on Machine Learning and Knowledge Discovery in Databases. Berlin, Heidelberg: Springer-Verlag, 2009. p. 414-429. DOI 10.1007/978-3-642-04174-7_27.

SCARTON, C.; OLIVEIRA JR, O. N.; CANDIDO JR, A.; GASPERIN, C.; ALUÍSIO, S. M. Simplifica: a tool for authoring simplified texts in Brazilian Portuguese guided by readability assessments. In: The 2010 Conference of the North American Chapter of the Association for Computational Linguistics - Human Language Technologies (NAACL-HLT 2010), Los Angeles, California. Proceedings of the NAACL HLT 2010 Demonstration Session, 2010. p. 41-44.

SCHMID, H. Probabilistic Part-of-Speech Tagging Using Decision Trees. In: Proceedings of International Conference on New Methods in Language Processing. Manchester, UK: 1994a.

SCHMID, H. Part-of-speech tagging with neural networks. In: Proceedings of the 15th conference on Computational linguistics. Stroudsburg, PA, USA: Association for Computational Linguistics, 1994b. v. 1, p. 172-176. DOI 10.3115/991886.991915.

SCHMID, H. Improvements in Part-of-Speech Tagging with an Application to German. Proceedings of the ACL SIGDAT-Workshop. Dublin, Ireland: Association for Computational Linguistics, 1995.

SIDDHARTHAN, A. Syntactic simplification and text cohesion. Thesis (Phd) University of Cambridge, Cambridge, 2004.

SIDDHARTHAN, A. Syntactic simplification and text cohesion. Research on Language \& Computation. Springer, 2006. v. 4, n. 1, p. 77-109.

SILVA, J.; BRANCO, A.; CASTRO, S.; REIS, R. Out-of-the-box robust parsing of Portuguese. In: Proceedings of the 9th Encontro para o Processamento Computacional da Lingua Portuguesa Escrita e Falada (PROPOR), Porto Alegre: Springer, 2010. v. 1. p. $75-85$.

SPECIA, L.; ALUISIO, S.M.; PARDO, T.A.S. Manual de Simplificação Sintática para o Português (Relatório Técnico NILC-TR-08-06), São Carlos: Universidade de São Paulo, 2008.

SPECIA, L. Translating from Complex to Simplified Sentences. In: 9th International Conference on Computational Processing of the Portuguese Language. Lecture Notes in Artificial Intelligence. Springer, 2010. v. 6001, p. 30-39.

SOCHER, R.; MANNING, C. D.; Ng, A. Y. Learning continuous phrase representations and syntactic parsing with recursive neural networks. In: Proceedings of the Deep Learning and Unsupervised Feature Learning Workshop of NIPS. Whistler, BC, Canada, 2010, pages 1-9.

SOMMERVILLE, I. Software Engineering, 9. ed. Harlow, England: Addison-Wesley, 
2010.

STEVENSON, S.; CARRERAS, X. Proceedings of the Thirteenth Conference on Computational Natural Language Learning (CoNLL-2009). Boulder, Colorado: Association for Computational Linguistics, 2009.

SUNDHEIM, B. M. Overview of results of the MUC-6 evaluation. In: Proceedings of the 6th conference on Message understanding (MUC6). Columbia, Maryland: Association for Computational Linguistics, 1995. p. 13-31, 19p. DOI: 10.3115/1072399.1072402. ISBN: 1-55860-402-2.

TELINE, M.F. Avaliação de Métodos de Extração Automática de Terminologia para textos em Português. Universidade de São Paulo, São Carlos, SP, Fevereiro 2004. Dissertação de Mestrado. 138 p.

TUFIS, D.; MASON, O. Tagging Romanian Texts: a Case Study for QTAG, a Language Independent Probabilistic Tagger. In: Proceedings of the First International Conference on Language Resources \& Evaluation (LREC). Granada, Spain, 1998. p. 589-596.

URANO, K. Lexical Simplification and Elaboration: A Pilot Study on Sentence Comprehension and Incidental Vocabulary Acquisition. 1998. Disponível em $<$ http://www.urano-ken.com/research/hawaii/es1672.html>. Acesso em: 23 jan. 2013.

VICKREY, D.; KOLLER, D. Sentence Simplification for Semantic Role Labelling. In: Proceedings of the ACL-HLT. 2008. p. 344-352.

VITERBI, A. Error bounds for convolutional codes and an asymptotically optimum decoding algorithm. IEEE Transactions on Information Theory, 1967. v. 13, n. 2, p. 260-269.

WALL, L.; CHRISTIANSEN, T.; ORWANT, J. Programming Perl, 3.ed. Sebastopol, US: O'Reilly \& Associates, 2000.

WATANABE, W. M.; CANDIDO JR., A.; UZÊDA, U. R.; FORTES, R. P. M.; PARDO, T. A. S.; ALUÍSIO, S. M. Facilita: reading assistance for low-literacy readers. In: $A C M$ International Conference on Design of Communication (SIGDOC 2009), Bloomington, 2009. v. 1, p. 29-36.

WATANABE, W. M.; CANDIDO JR. A.; AMANCIO, M. A.; OLIVEIRA, M.; PARDO, T. A. S.; Fortes, R. P. M.; Aluísio, S. M. (2010) Adapting web content for low-literacy readers by using lexical elaboration and named entities labeling. Proceedings of the W4A-7th International Cross-Disciplinary Conference on Web Accessibility 2010, 2010, Raleigh - NC. Proc. of W4A CoLocated with the 19th International World Wide Web Conference. Nova York: ACM Press, 2010. v. 1. p. 1-9.

WATANABE, W. M.; CANDIDO, A.; AMANCIO, M.A.; OLIVEIRA, M.; PARDO, T. A. S.; FORTES, R. P. M.; ALUÍSIO, S. M. Adapting Web content for low-literacy readers by using lexical elaboration and named entities labeling. New Review of Hypermedia and Multimedia, 2010. v. 16, p. 303-327.

WIDROW, B.; HOFF, M. E. Adaptive switching circuits. Defense Technical Information Center, p.1-2, 1960. 
WILLIAMS, S.; REITER, E. A corpus analysis of discourse relations for Natural Language Generation. In Proceedings of the Corpus Linguistics 2003 (CL2003). Lancaster, England, 2003. p 899-908.

WILLIAMS, S. Natural Language Generation (NLG) of discourse relations for different reading levels . Thesis (PhD) - University of Aberdeen, Aberdeen, 2004.

WILLIAMS S., REITER E. Generating basic skills reports for low-skilled readers. Natural Language Engineering, 2008. v. 14, n. 04.

WILlingHAM, D.T. Cognition: the thinking animal. Pearson/Prentice Hall, 2006. ISBN 9780131736887.

WING B.; BALDRIDGE, J. Adaptation of data and models for probabilistic parsing of portuguese. In: Proceedings of the 7th international conference on Computational Processing of the Portuguese Language (PROPOR'06). Berlin: Springer-Verlag, 2006. p. 140-149. DOI=10.1007/11751984_15.

WUBBEN, S.; BOSCH, A. V. D.; KRAHMER. E. Sentence simplification by monolingual machine translation. In: Proceedings of the 50th Annual Meeting of the Association for Computational Linguistics. Stroudsburg, PA, USA: Association for Computational Linguistics, 2012. p. 1015-1024.

YOUNG, D. J. Linguistic Simplification of SL Reading Material: Effective Instructional Practice? Modern Language Journal. Monterey, 1999. v. 83, n. 3, p. 350-366,.

YEIBO, E. Group Types as Style Markers in J. P. Clark-Bekederemo's Poetry. Theory and Practice in Language Studies. v. 1, n. 8, p. 928-934, 2011. DOI: 10.4304/tpls. 1.8.928-934.

YURET, D.; HAN, A.; TURGUT, Z. SemEval-2010 Task 12: Parser Evaluation Using Textual Entailments. In: Proceedings of the 5th International Workshop on Semantic Evaluation, Uppsala, Sweden: Association for Computational Linguistics, 2010, p. $51-56$.

ZAENEN, A.; KARTTUNEN, L.; CROUCH, R. Local Textual Inference: can it be defined or circumscribed? In: Proceedings of the ACL Workshop on Empirical Modeling of Semantic Equivalence and Entailment. Ann Arbor, Michigan: Association for Computational Linguistics, 2005. p. 31-36. 


\section{Glossário}

\section{Termos computacionais:}

Camada escondida: conjunto de neurônios que recebem sua entrada de um conjunto de neurônios de entrada ou de outra camada escondida, e as repassam para conjuntos de neurônios de saída, ou a outra camada escondida. Neste trabalho, o uso do termo é associado a topologias com apenas uma camada escondida.

Época: sub-etapa do treinamento em que todos os padrões de um determinado conjunto de padrões são apresentados à rede neural artificial para ajuste de pesos das sinapses.

Multi-layer Perceptron: topologia neural que faz uso de uma ou mais camadas escondidas.

Neurônio artificial: modelo matemático para o funcionamento de um neurônio, cujo funcionamento consiste em aplicar uma função de ativação no somatório ponderado de um conjunto de entradas utilizado em Redes Neurais Artificiais. Neurônios artificiais podem ser conectados a outros neurônios, gerando uma topologia complexa. Vide também neurônio na seção de termos específicos deste trabalho.

Perceptron: usado tanto para o modelo para neurônio artificial quanto para o modelo de redes neurais artificiais compostas por neurônios Perceptron e sem camadas escondidas.

Rede neural artificial: modelo matemático inspirado no funcionamento do cérebro humano aplicado, composto por neurônios artificiais, aplicado à diferentes problemas estatísticos e no campo da Inteligência Artificial, incluindo classificação de padrões (foco deste trabalho) e agrupamento de padrões. Implementações em software do modelo podem ser chamadas por rede neural artificial simulada, embora essa terminologia não seja utilizada neste trabalho.

Sinapse artificial: conexão entre a saída de um neurônio artificial (o neurônio de entrada) à entrada de outro neurônio artificial (o neurônio de saída). Vide também sinapse na seção de termos específicos deste trabalho.

Topologia neural: estratégia para interconexão de neurônios artificiais por sinapses. Neurônios podem ser agrupados em camadas, que definem quais conexões um neurônio pode estabelecer. Neste trabalho, também diz respeito ao número de neurônios em cada camada.

\section{Termos linguísticos:}

Anáfora: unidades linguísticas que referem-se a um signo linguístico previamente enunciado no texto ou frase. Pronomes podem exercer o papel de anáforas (e também catáforas).

Córpus: conjunto de textos compilado segundo uma metodologia para construção de 
córpus. Neste texto, optou-se pela grafia aportuguesada do termo "córpus" (singular e plural) em vez de sua versão latinizada (corpus/corpora).

Catáfora: unidades linguísticas que referem-se a um signo linguístico ainda não definido. Pronomes podem exercer o papel de catáforas (e também anáforas).

Entidade nomeada: também conhecida como entidade mencionada, é um subgrupo dos substantivos composto por nomes próprios (como pessoas, organizações, locais e acontecimentos), obras (e outros conceitos abstratos), valores numéricos (incluindo relacionados como datas), entre outros.

Elipse: omissão de termos de uma frase sem comprometer sua compreensão.

Frase: enunciado linguístico (AMARAL et al., 1999). É frequentemente composta por orações.

Lexia complexa: grupo de lexemas relacionados que compõe unidades maiores, por exemplo, entidades nomeadas, expressões da língua em que o significado do todo não é a composição do significado das partes (por exemplo, a expressão "chutar o balde") e locuções.

Marcador discursivo: também chamado de marcador conversacional, relaciona e conecta um período ou parágrafo ao período ou parágrafo anterior.

Nivel (de processamento da língua): informações linguísticas relacionadas, são eles: morfológico, sintático, semântico e pragmático-discursivo (DIAS-DA-SILVA et al., 2007).

Oração: estrutura linguística com sujeito e predicado (AMARAL et al., 1999). Pode haver mais de uma oração por frase.

Papel semântico: análise da semântica de lexemas que atuam como argumentos dos verbos, em categorias como tais agente, paciente, instrumento, entre outras.

Período: frase com pelo menos uma oração (AMARAL et al., 1999).

Sintagma: conjunto de lexemas subordinados a um núcleo, por exemplo, sintagma nominal, cujo núcleo é um substantivo. O termo possui correlação com lexia complexa, por exemplo a locução prepositiva "acima de", e com agrupamentos sintáticos, por exemplo, em adjunto adnominal.

Topicalização: destaque feito em um elemento da oração movendo-o para o início da oração.

Tronco de lexema: também chamado de stem, é o fragmento escrito de um lexema, do qual, geralmente, sufixos são removidos. Troncos podem coincidir com radicais ou raízes dos lexemas originais, embora isso nem sempre aconteça por serem gerados automaticamente.

Valência sintática: número de argumentos pertencentes a um predicado verbal.

Termos específicos deste trabalho ou com diferenças de uso em relação a outros trabalhos:

A-padrão: padrão alimentado a uma instância Molin. Quando recorrência ou contexto 
neural são empregados, a-padrões derivam b-padrões e c-padrões (para árvores).

Afinidade de lexema: correlação estatística entre dois lexemas na tarefa de análise de dependências sintáticas, geralmente associadas a restrições semânticas ou preferências pragmáticas presentes em lexemas e orações.

Análise bidirecional: análise integrativa na qual análises em níveis diferentes influenciam-se umas às outras, independentemente do nível a que se refiram e independentemente da hierarquia dos níveis da língua.

Análise/avaliação extrínseca: avaliação de uma tarefa computacional aplicada no escopo de outra tarefa. Por exemplo, a avaliação de um analisador sintático integrando-o a um simplificador sintático e analisando o resultado da simplificação.

Análise da língua: tarefa de analisar os diferentes níveis da língua, como morfologia, morfossintaxe, sintaxe e semântica.

Análise integrativa: análise que combina diferentes níveis da língua.

Aplicação (de PLN): modelos e suas implementações em software para realizar tarefas de pesquisa em PLN, por exemplo, sumarização, tradução, respostas a perguntas e revisão gramatical.

Aprendizado pontual: problema presente em algumas instâncias Molin, e que prejudica a generalização do aprendizado. No problema, há dois (ou mais) grandes grupos de neurônios, de forma que neurônios de um grupo estimulem/inibam neurônios de outro(s) grupo(s). O problema ocorre quando não há um neurônio genérico, e cada neurônio de um grupo precisa aprender a estimular/inibir cada neurônio do(s) outro(s) grupo(s). Não se trata de memorização (overfitting), estando relacionado com a topologia em uso.

Aquisição léxica: fase pela qual uma instância Molin internaliza e estabelece sinapses para lexemas da língua. Como a língua é aberta, isto é, novos lexemas são sempre criados, a aquisição léxica é sempre parcial, e, portanto, a instância deve aprender a lidar com lexemas não adquiridos por meio de eventos adequados para a tarefa.

Atributo: evento observável da língua (por exemplo, a ocorrência de um lexema) no escopo da camada neural do Molin. Atributos são neurônios de entrada. Vide evento.

B-padrão: padrão de uma das duas etapas de ativação de contextos baseados em árvore, que consiste no processamento dos neurônios de saída dos a-padrões originais, mas não de seus pseudo-neurônios.

C-padrão : padrão de uma das duas etapas da ativação de contextos baseados em árvore, que consiste na saída para construção da árvore, isto é, o processamento de pseudo-neurônios dos a-padrões originais.

Caso (de fenômeno sintático): subdivisão dos fenômenos sintáticos com base nas caraterísticas das orações que os constituem.

Categorização semântica: a junção entre a tarefa de reconhecimento de entidades nomeadas e de anotação de hiperônimos.

Classe: evento a ser inferido da língua (por exemplo, a classe gramatical de um lexema) 
no escopo da camada neural do Molin. Classes são neurônios de saída, e, quando há recorrência, derivam neurônios de entrada. Vide evento.

Coativação: recorrência neural a partir dos neurônios de saída presentes no contexto neural. É relacionada a b-padrões de diferentes a-padrões no contexto baseado em janela. No contexto baseado em árvores, pode também estar relacionada a um b-padrão e um c-padrão originados do mesmo a-padrão (o c-padrão englobará informações de um segundo a-padrão por natureza).

Confiança de evento: confiança da rede neural artificial em relação a um evento (latente ou observável). Valores próximos a 0,5 são interpretados como baixa confiança. Valores próximos de 1 ou 0 são interpretados como alta confiança de ocorrência ou não ocorrência do evento, respectivamente.

Contexto: contexto neural é a abstração de uma frase criada para manter a generalidade da camada neural do Molin. O uso do termo neste texto não é exatamente igual ao uso em trabalhos da literatura, nos quais o contexto normalmente refere-se a janelas de lexemas. Neste trabalho, o contexto neural pode dar origem a uma janela de lexemas (contexto baseado em janelas), bem como a estruturas arbóreas e matriciais (contexto baseado em árvores).

Correlato de lexema: grupo de eventos definidos para a geração de sementes. Normalmente compostos por lexemas conhecidos, lexemas desconhecidos, números, sinais de pontuação, e alguns tipos de entidades nomeadas alfanuméricas, como endereços Web. Observa-se que alguns eventos como números, são substituídos por um evento mais genérico, que também é considerado um correlato de lexema. Lexemas e correlatos podem ser referenciados por tokens em outros trabalhos.

Entrada de contexto: neurônios de entrada de um padrão derivados de neurônios de entrada de outros padrões no mesmo contexto neural.

Evento: um evento linguístico, seja ele diretamente observável (referente a atributo) ou latente (referente a classe). Intercambiável com o termo "neurônio".

Fenômeno (da língua): um fenômeno sintático, relacionado principalmente a subordinações, coordenações e voz passiva.

Ferramenta (de PLN): modelos e suas implementações para implementar ou gerar textos em língua natural, utilizados na construção de aplicações de PLN. Exemplos de ferramentas são analisadores sintáticos, anotadores de papéis semânticos, e resolvedores de anáforas.

Glossário: listas de lexemas de uma língua. O termo "dicionário", comum em outros trabalhos, não é usado, sendo reservado para uma lista de palavras acompanhadas de suas definições.

Instância: instanciação parametrizada do modelo Molin. Ou seja, um conjunto de neurônios e sinapses além dos parâmetros utilizados em sua geração. Para o termo correlato em aprendizado de máquina, vide "padrão".

Lexema: morfema lexical independente, que é utilizado na formação de palavras simples ou compostas. 
Lema: forma canônica de um lexema utilizada como entradas em dicionários.

Neurônio: nome dado a um evento no escopo neural do Molin. Intercambiável com o termo "evento". Neurônios de entrada são associados a atributos e derivados de classes (quando há recorrência ou coativação). Neurônios de saída são associados a classes. Vide também neurônio na seção de termos computacionais.

Neurônio disparado: termo para referir-se a ativações de neurônio maiores que 0,5. Nota-se que mesmo quando a ativação for menor que o valor estipulado, neurônios em instâncias Molin podem afetar outros neurônios.

Padrão: conjunto de atributos e, opcionalmente, classes, utilizado em conjuntos de treinamento para uma dada instância do modelo Molin. Corresponde ao termo instâncias em trabalhos de aprendizado de máquina. Neste trabalho, padrão não deve ser confundido com instância, que refere-se a uma instanciação do Molin.

Pseudo-neurônio: estrutura de controle usada em instâncias Molin para delimitar contextos neurônios e controlar a geração de padrões derivados de a-padrões.

Saída de contexto: neurônios de entrada de um padrão derivados de neurônios de saída de outros padrões no mesmo contexto neural.

Semente: evento observável usado para recuperar candidatos a eventos latentes, a partir das sinapses estabelecidas, com a finalidade de otimizar o processo de análise neural.

Sinapse: no escopo neural, é a relação unidirecional entre dois neurônios. Devido ao uso de redes neurais artificiais Perceptron, as sinapses sempre inibem ou sempre estimulam o neurônio de saída ao qual estão interligadas. No escopo linguístico, sinapses podem ser interpretadas como a correlação entre o evento de entrada e o evento de saída. Vide também sinapse na seção de termos computacionais.

Sinapse especial (ou sinapse $\theta$ ): sinapse com ativação de entrada sempre 1, cujo peso corresponde, neste trabalho, ao oposto do limiar de ativação do neurônio de saída.

Tutor: conjunto de padrões de treinamento para uma dada tarefa cujos os padrões se origem da mesma fonte (por exemplo, uma anotação manual feita por humanos ou (semi)-automática baseada em ferramentas). Também se refere a ferramenta que anotou o conjunto.

Unidade estrutural da língua: referem-se a fonemas, morfemas, lexemas, frases e textos. 


\section{Eventos do Mac-Morpho:}

$\operatorname{adj}=$ pos adjective

$\mathrm{adv}=$ pos adverb

$\mathrm{adv}-\mathrm{ks}=$ pos adverb, possub subordinating adv-ks-rel = pos_adverb, possub_relative, possub_subordinating

art $=$ pos article

in = pos_interjection

$\mathrm{ks}=$ pos conjunction, possub subordinating

$\mathrm{kc}=$ pos conjunction, possub coordinating $\mathrm{n}=$ pos_noun

npro = pos noun, possub proper // see also prop

nprop = pos_noun, possub_proper // see also

prop

num $=$ pos_numeral

pcp $=$ pos verb, morph participle

pden $=$ possadverb, possub_denotative

\section{Eventos do Palavras:}

$1 /$

// main pos categories

$1 /$

ADJ = pos_adjective // except participles

$\mathrm{ADV}=$ pos_adverb

$\mathrm{DET}=$ pos determiner $/ / \quad !=$ "<det $>$ "

// other tags will disambiguate pronoun, article, etc

IN $=$ pos_interjection

$\mathrm{N}=$ pos noun

NUM $=$ pos numeral

PRP = pos preposition

$\mathrm{SPEC}=$ pos_specifier

// other tags will disambiguate pronoun, article, etc

$\mathrm{V}=$ pos_verb

/ /

// hybrid pos categories

/1

<adv-rel $>=$ possub as adverb, possub subordinating

$\langle$ artd $\rangle=$ pos article, possub definite

<arti $>=$ pos_article, possub_indefinite

$<$ dem $>=$ pos_pronoun, possub_demonstrative

$\langle$ diff $>=$ pos pronoun, possub differentiator

<ident $>=$ pos pronoun, possub identator

<interr $>=$ pos pronoun, possub interrogative

$\langle$ poss $>=$ pos_pronoun, possub_possessive

<quant> = pos_pronoun, possub_quantifier

$\langle r e l\rangle=$ pos pronoun, possub relative

$\mathrm{EC}=$ pos adverb, possub prefix

$\mathrm{KC}=$ pos_conjunction, possub_coordinating // != eSUB

$<\mathrm{ks}>$

$\mathrm{KS}=$ pos_preposition, possub_subordinating // !=

eCOR, $\angle \mathrm{kC}>$

PROP $=$ pOs noun, possub proper

PERS = pos_pronoun, possub_personal

//

// pos sub-categories

//

$\langle$ adv $>=$ possub as adverb

$<\operatorname{advl}>=$ synsub_as_adverbial

$<$ card $>=$ possub cardinal

$\langle$ coll $\rangle=$ possub reflexive, possub collective, semgroup collective,

semcat_collective // duplicated in semantic tags

$\langle$ corr $\rangle=$ - possub_correlating

$\langle$ dei $\rangle=$ possub discourse deictic

<det $>=$ possub as determiner // != DET

$\langle$ foc $\rangle=$ possub focus marker $/ / \quad !=$ aFOC

<igual> = possüb_equālling

$\langle\mathrm{ks}\rangle=$ possub_as_subordinating // != @SUB, @KS

$\langle\mathrm{kC}\rangle=$ possub_as_conjunction $/ /$ != @COR, @KC

$\langle$ KOMP $\rangle$ = possub comparative

$<$ komp $>$ = possub comparative

$<\mathrm{n}\rangle=$ possub_as_noun $/ / \quad !=\mathrm{N}$ prep $=$ pos preposition

proadj = pos_pronoun, pos_determiner

prop = pos noun, possub proper // see also

nprop, npro

propess $=$ pos pronoun, possub personal

prosub = pos pronoun, pos specifier

pro-ks = pos_pronoun, possub_subordinating

pro-ks-rel = pos pronoun, possub relative,

possub subordinating

$\mathrm{v}=\mathrm{pos}$ verb

vaux $=\bar{p}$ os_verb, synsub_auxiliary

// null mapped

cur" // "R\$", "\$", etc (semantic currency or pos numeral or neither)

$<$ NUM-ord $>=$ possub_ordinal

$\langle$ prp $\rangle=$ possub as preposition // != PRP

$\langle$ reci $>$ possub reciprocal

// occurs together with pers, therefore no need to talk about pronoun

<refl> = possub reflexive

// occurs together with pers, therefore no need to talk about pronoun

$<$ setop $\rangle$ = possub_operational

$\langle$ si $\rangle$ possub_reflexive

// probable occurs together wtih pers, no need to put pronoun

$\langle$ sub $\rangle=$ possub_as_subordinating

/ /

// pos null mapped

// (redundant or undocumented or depends on new events)

/ /

$<*>\quad / /$ capitalization

$<* 1>\quad / /$ left quote attached

$<* 2>\quad / /$ right quote attached

$<-$ sam> // same word

$<$ ABBR $>\quad / /$ abbreviation

<ante-attr> // positional (pre adjective)

// undocumented (probably redundant)

<cjt-head> // undocumented (probably redundant)

$<$ DERP $>$ // prefixation

<DERS > // suffixation (aumentaive, or

diminutive, maybe others

$\langle$ cif $\rangle$

$\langle$ clb $\quad$ // clause bondary

$<$ clb-fs $>$ // undocumented and deprecated

$<$ hyfen> // hyphened word

<mente> // "ly" factoring (slow and calmly ==

slowly and calmly)

<NUM-fract> // applied to number only; not included

$<$ post-det>

positional (post determiner)

positional (post adjective)

<prop> // upper case in middle sentence

<prop1> // first upper case in middle sentence

<prop2> // second upper case in middle sentence

<sam-> // same world

//

// inflectional tags

$1 /$

0/1/3S = morph_first_person, morph_third_person, morph singular

$1=$ morph first person

$1 \mathrm{~S}=$ morph_first_person, morph_singular

$1 \mathrm{P}=$ morph_first_person, morph_plural

$1 / 3 \mathrm{~S}=$ morph_first_person, morph_third_person, morph singular

2 = morph second person

$2 \mathrm{~S}=$ morph_second_person, morph_singular 
$2 \mathrm{P}=$ morph_second_person, morph_plural

$3=$ morph third person

$3 \mathrm{~S}=$ morph_third_person, morph_singular

$3 \mathrm{P}=$ morph_third_person, morph_plural

$3 \mathrm{~S} / \mathrm{P}=$ morph_third person, morph singular, morph plural

$\mathrm{ACC}=$ morph accusative

$\mathrm{ACC} / \mathrm{DAT}=$ morph_accusative, morph_dative

COND = morph_coñditional

$\mathrm{DAT}=$ morph $\overline{\text { dative }}$

DAT PERS = morph dative // undocumented (no need pers expansion)

$F=$ morph_female

FUT $=$ morph future

$\mathrm{GER}=$ morph gerund

IMP $=$ morph imperative

IMPF $=$ morph

IND $=$ morph_indicative

INF $=$ morph infinitive

$\mathrm{M}=$ morph male

$\mathrm{M} / \mathrm{F}=$ morph male, morph female

$\mathrm{MQP}=$ morph more than perfect

NOM $=$ morph_nominative

NOM/PIV = morph nominative, morph prepositive

$\mathrm{P}=$ morph plural

$\mathrm{PCP}=$ morph participle

$\mathrm{PIV}=$ morph_prepositive

$\mathrm{PR}=$ morph_present

$\mathrm{PS}=$ morph perfect

$\mathrm{PS} / \mathrm{MQP}=$ morph perfect, morph_more_than_perfect

$\mathrm{S}=$ morph singular

$\mathrm{S} / \mathrm{P}=$ morph_singular, morph_plural

SUBJ $=$ morph_subjunctive

$\langle$ SUP $\rangle=$ morph superlative

VFIN $=$ morph finite

$1 /$

// syntactic tags

@\#AS- = syn_averbal_clause

Q\#FS- = syn_finite_clause // grouping fs and fmc

Q\#ICL- = syñ infinite_clause

$\mathrm{QA}=$ syn adjunct, syn adverbial

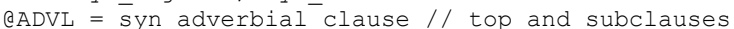

QAPP = syn_apposition

@AS- = syn_averbal_clause // note: @AS != @AS- ; @FS$==@ \mathrm{FS}$

@CO = syn coordinator $/ / \quad !=\mathrm{KC},\langle\mathrm{kC}\rangle$

QDAT $=$ syn direct object, synsub dative

@FS = syn_finite_clause // rare

QFS- = syñ_finitē_clause

@ICL = syn infinite clause $/ /$ rare

@ICL- = syn infinite clause

@N = syn adjunct, syñ adnominal

@PASS = syn_passive_agent

QPIV = syn_prepositional_object

@PRD = syn predicator

QPRED = syn predicative

QSUB = syn subordinator $/ / \quad !=\mathrm{KC},\langle\mathrm{kC}\rangle$

@SUBJ = syn_subject $/ /$ both "@SUBJ $>$ and @SUBJ $>>$ "

QVOK = syn_vocative

$\langle$ fmc $\rangle=$ synsub_main_verb

$\langle$ mv $>$ = synsub main verb

$\langle\mathrm{vm}\rangle=$ synsub_main_verb

$1 /$

// syntactic hibrid tags

/ /

QACC = syn_direct_object, synsub_accusative //

includes "@̄ACC $>>$ "

QACC-PASS = syn_passive_agent, synsub_accusative // for "se"

QACC-REFL = syn direct object, possub reflexive // for "se"

@A-ADVL = syn adverbial, synsub_participle_related

@A-PASS = syn_passive_agent,

synsub participle related

@A-PIV = syn prepositional object,

synsub_participle_related

QA-SC = syn predicative, synsub subject related, synsub participle related

@ADVL-A = syn adverbial clause,

synsub_participle_relatèd
@ADVL-AS = syn adverbial clause,

synsub in averb̄al clause

@ADVO = sȳn_adverbial_object, synsub_object_related

QADVS = syn_adverbial_object, synsub_subject_related

@N-PRED = sȳn_predicative, synsub_ingroup

$\mathrm{QOA}=$ syn adverbial object, synsub object related

@OC $=$ syn predicative

QSA = syn_adverbial_object, synsub_subject_related

QSC = syn_predicative, synsub_subjēet_related

<predco $>$ = syn_predicator, synsub_coordinated //

undocumented

//

$1 /$

AA-ADV = synsub adverbial argument,

synsub particip $\bar{l} e$ related

@AUX = synsub_auxiliary_complement

@COM = synsub_direct_comparator

@FAUX = synsub auxilíiary

// finite or infinite will be disambiguated by pos

@FMV = synsub_main_verb

// finite or infinite will be disambiguated by pos @FOC = synsub focus marker $/ /$ != <foc $>$

@IAUX = synsub auxiliary

// finite or infinite will be disambiguated by pos aIMV = synsub_main_verb

// finite or infinite will be disambiguated by pos @KOMP = synsub_comparative_argument

@NUM = synsub numeral chain

QP = synsub preposition argument

QPREF = synsub_prefix

@PRT-AUX = synsub_auxiliary_participle

QS = synsub_sentence_anaphor // "<S" = anaphor; "S>"

= clause modifier

$\langle$ aux $>$ = synsub auxiliary // undocumented

$<\mathrm{com}>=$ synsub_direct_comparator

$\langle o b j\rangle=$ possub_reflexive

//

// syntactic valency subcategory

//

$<+$ INF $>$ = synval_governing_infinitive

$<+$ interr $>$ = synval discourse

$<+\mathrm{n}\rangle=$ synval governing name

$<+$ num $>=$ synval_governing_number

$<$ num+> = synval_unit

$\langle+$ PRP $>$ = synval_governing_prepositional

$\langle\mathrm{PRP}+\rangle$ = synval prepositional argument

$\left\langle\mathrm{PRP}^{\wedge} \mathrm{Vp}\right\rangle$ = synval transitive, synval indirect

$\left\langle\mathrm{PRP}^{\wedge} \mathrm{vtp}\right\rangle=$ synval__transitive, synval_direct,

synval_indirect

$\left\langle\mathrm{PRP}^{\wedge} \mathrm{xp}\right\rangle=$ synval_auxiliary,

synval with prepositional,

synval with particle, synval with infinitive

$\left\langle\mathrm{PRP}^{\wedge} \mathrm{xtp} \overline{\mathrm{C}}^{-}=\right.$synval_auxiliary,

synval_accusative_subject

$\langle$ +que $>=$ synval_governing_que

$\langle\mathrm{qv}\rangle=$ synval impersonal

$\langle$ Va+DIR $>$ = synval transitive

$<$ va+LOC $>$ = synval transitive

$\langle\mathrm{va}\rangle=$ synval_intransitive, synval_adverbial

$\langle$ ve $\rangle$ = synval intransitive, synval ergative

$\langle\mathrm{vi}\rangle=$ synval intransitive

$\langle\mathrm{vK}\rangle=$ synval_copula, synval_with_predicative,

synval_with_subject_predicative

$\langle\mathrm{vq}\rangle=$ synval_cognitive

$\langle$ vr $\rangle$ = synval reflexive

$<$ vta+DIR> = synval transitive

$\langle$ vta+LOC $>$ = synval transitive

$\langle$ vtd $\rangle=$ synval_transitive, synval_direct,

synval_indirect

$\langle$ vtK $\rangle$ = synval copula, synval with predicative,

synval with_object_predicative

$\langle\mathrm{vt+QUAN} \overline{\mathrm{T}}\rangle=\overline{\text { synval_Eransitive }}$

$\langle\mathrm{vt}\rangle=$ synval_transitive, synval_direct

$\langle\mathrm{vt}+\mathrm{TID}\rangle=$ synval_transitive,

synval adverbial object,

synvāl with temporal

$\langle\mathrm{VU}\rangle=$ synval impersonal $^{-}$

$<\mathrm{x}+\mathrm{GER}>=$ synval_auxiliary, synval_with_gerund

$\langle\mathrm{x}+\mathrm{PCP}\rangle=$ synval auxiliary, synval with participle

$\langle\mathrm{x}\rangle=$ synval auxiliary, synval with infinitive

$\langle x t\rangle=$ synval_auxiliary, synvā_accusative_subject 
$1 /$

// syn null mapped

// (redundant or undocumented or depends on new events)

$1 /$

@AS" $\quad / /$ argment in averbal clause

@NPHR" // free noun phrase

@QUE" // @fs-que for "to be" (undocumented)

QSTA" // statement

@TOP" // topic constituent

बUTT" // utterance

<asarg>" // argument in averbal clause

<np-close>" // close attachment in a noun phrase

$<$ np-long $>$ " // distant attachment in a noun phrase

$<$ nosubj>" // verb with undefined subject

$<$ parkc-1>" // paired coordinatior (*so* ... that)

(need analysis)

$<$ parkc-2>"

(need analysis)

$<\mathrm{pp}>"$

or adj

$<$ prd $>"$

working)

$\langle\mathrm{v}-\mathrm{ks}>"$

that $==$ so that)

$<$ vpcjt>" // conjunction in verb level

coordination

<vpheadcjt>"

coordination

$<$ topkc>"

// first conjunction in verb level

// top level coordinator

$1 /$

// semantic categories

//

// abstract prototypes

$\langle$ ac $\rangle=$ semgroup_abstract, semcat_countable

$\langle$ ac-cat $\rangle=$ semgroup_abstract, semcat_category

<ac-sign> = semgroup_abstract, semcat_sign

$\langle a m\rangle=$ semgroup abstract, semcat mass

$\langle a x\rangle=$ semgroup_abstract, semcat_concept

$\langle$ dir $\rangle=$ semgroup_abstract, semcat_direction

$\langle$ conv $\rangle=$ semgroup_abstract, semcat_social_convention

$\langle$ meta $>$ = semgroup abstract, semcat_meta_noun

<unit $>$ = semgroup_abstract, semcat_unit

$/ /$ action prototypes

$\langle$ act $\rangle=$ semgroup_action, semcat_action

<act-beat> = semgroup_action, semcat beat

$\langle$ act-d $\rangle=$ semgroup action, semcat do

<act-s> = semgroup action, semcat speech

<act-trick> = semgroup_action, semcat_trick

<activity> = semgroup_action, semcat_activity

$\langle$ dance $>$ = semgroup_action, semcat_dance

$\langle$ fight $\rangle$ = semgroup action, semcat fight

$<$ process $>$ = semgroup action, semcàt process

$\langle$ sport $\rangle=$ semgroup_action, semcat_sport

$\langle$ talk $\rangle=$ semgroup_action, semcat_speech_situation

$<$ therapy $>$ = semgroup_action, semcat_therapy

// anatomical prototypes

$\langle a n\rangle=$ semgroup anatomical, semcat anatomical

<anmov $>=$ semgroup_anatomical, semcat_movable_anatomy

<anorg> = semgroup_anatomical, semcat_organ

$\langle$ anost $\rangle=$ semgroup anatomical, semcat bone

$\langle$ anzo $\rangle$ = semgroup anatomical, semcat animal anatomy

<anorn> = semgroup_anatomical, semcat_bird_ānatomy

<anich $>=$ semgroup_anatomical, semcat_fish_anatomy

<anent> = semgroup_anatomical, semcat_insect_anatomy

$\langle$ anbo $\rangle$ = semgroup anatomical, semcat plant anatomy

<pos-an> = semgroup anatomical, semcat body position

// animal prototypes

$<\mathrm{A}\rangle=$ semgroup_animal, semcat_animal

$\langle A A\rangle=$ semgroup

$<$ Adom $>$ = semgroup animal, semcat domestic animal

$<$ AAdom $>$ = semgroup animal, semcat domestic animal,

semcat_animal_group

$\langle\text { Aich }\rangle^{-}=$semgroup_animal, semcat_water_animal

$<$ Amyth $>$ = semgroup animal, semcat mythological animal

$\langle$ Azo $\rangle=$ semgroup animal, semcat land animal

$<$ Aorn $>=$ semgroup animal, semcat bir $\bar{d}$

$<$ Aent> = semgroup_animal, semcat_insect

$<$ Acell> = semgroup_animal, semcat_animal_cell

$/ /$ concept prototypes

$<$ domain $>$ = semgroup concept, semcat domain

$\langle$ game $\rangle=$ semgroup_concept, semcat_play <genre> = semgroup_concept, semcat_genre //

duplicated in palavras

<geom $>$ = semgroup_concept, semcat_geometry

<geom-line $>$ = semgroup_concept, semcat_line

<inst> = semgroup_concept, semcat_institution

$\langle$ ism $\rangle=$ semgroup concept, semcat ideology

$<$ ling $>=$ semgroup concept, semcat language

$<$ mach $>$ = semgroup_concept, semcat_machine

// clothing prototypes

$\langle\mathrm{Cl} \cap \mathrm{A}\rangle=$ semgroup_clothing, semcat_animal_clothing

$\langle\mathrm{CloH}\rangle=$ semgroup clothing, semcat human clothing

$<\mathrm{cloH}$-beauty $\rangle=$ semgroup_clothing,

semcat_beauty_clothing

$\langle\mathrm{cloH}-\bar{h}$ at $\rangle=$ semgroup_clothing, semcat hat

$<\mathrm{cloH}-$ shoe $\rangle=$ semgroup_clothing, semcat shoe

// collective prototypes

// <coll $\rangle$ = semgroup_collective, semcat_collective // duplicated!

$\langle$ coll-cc $\rangle=$ semgroup_collective,

semcat collective thing

$\langle\operatorname{coll}-\overline{\mathrm{B}}\rangle=$ semgroup collective,

semcat plant collective

$<$ coll-sem $>=$ semgroup_collective,

semcat semantic collective

<coll-tool $\rangle=$ semgroup_collective,

semcat collective tool

// feature prototypes

$\langle\mathrm{f}\rangle=$ semgroup_feature, semcat_feature

$<f-a n>=$ semgroup_feature, semcat_anatomical_feature

$\langle\mathrm{f}-\mathrm{c}\rangle=$ semgroup feature, semcat_feature,

semcat countable

$\langle\mathrm{f}-\mathrm{h}\rangle=$ = semgroup_feature, semcat_physical_feature,

semcat_human_feature

$<$ f-psych $>=$ semgroup_feature,

semcat psychological feature,

semcat_human_feature

$\langle f-q\rangle=$ semgroup_feature, semcat_quantifiable_feature

<f-right $>$ = semgroup_feature, semcat_human_feature,

semcat social feature

// food prototypes

$<$ drink $\rangle$ = semgroup_food, semcat_drink

$<$ food $>$ = semgroup_food, semcat_food

$\langle$ food-c $\rangle$ = semgroup food, semcat food,

semcat_countable

$\langle$ food- $\overline{\mathrm{h}}\rangle=$ semgroup food, semcat human prepared

$<$ food-c-h $>=$ semgroup_food, semcat_culinary,

semcat_countable

$\langle$ fruit $\overline{\rangle}=$ semgroup_food, semcat_fruit

<spice $>$ = semgroup_food, semcat_spice_food

// human prototypes

<grouphum $>$ = semgroup_human, semcat_human,

semcat_collective

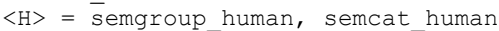

$\langle\mathrm{HH}\rangle=$ semgroup human, semcat human,

semcat collective

$<$ Hattr $\overline{>}=$ semgroup_human, semcat_attributive_human

$\langle$ Hbio $>$ = semgroup_human, semcat_biological_criteria

$<$ Hfam $>$ = semgroup human, semcat family human

$\langle$ Hideo $\rangle$ = semgroup human, semcat ideological human

$<$ Hmyth $>$ = semgroup human, semcat mythical humanoid

$<$ Hnat $>=$ semgroup_human, semcat_nationalit̄y

$<$ Hprof $>$ = semgroup human, semcat professional

$\langle$ Hsick $\rangle=$ semgroup_human, semcat_sick_human

$\langle$ Htit $>=$ semgroup human, semcat $\overline{t i t l e}$

$<$ pos-soc $>=$ semgroup_human, semcat_social_position

// part prototypes

$<$ part $>$ = semgroup_part, semcat_functional

$<$ part-build $\rangle=$ semgroup_part, semcat_structural

$<$ piece $>$ = semgroup part, semcat indistinctive

// perception prototypes

<percep-f $>$ = semgroup_perception

semcat_sense_feeling

<percep-l> = semgroup perception, semcat sound

$\langle$ percep-o $\rangle$ = semgroup perception, semcat smell

$<$ percep-t $>$ = semgroup_perception, semcat_taste

<percep-w $>$ = semgroup_perception, semcat_vision

// place and spatial prototypes:

$\langle$ civ $\rangle$ = semgroup spatial, semcat civitas

$\langle\mathrm{L}\rangle=$ semgroup_spatial, semcat_place

$<$ Labs $>$ = semgroup_spatial, semcat_place,

semcat_abstract

$<$ Lciv $>=$ semgroup spatial, semcat civitas

$<$ Lcover $>$ = semgroup spatial, semcat cover

$<$ Lh $>=$ semgroup_spatial, semcat_human_used_place 
$<$ Lopening $>$ = semgroup spatial, semcat_opening $<$ Lpath $>$ = semgroup spatial, semcat path

LLstar> = semgroup_spatial, semcat_space_located

$<$ Lsurf $>$ = semgroup_spatial, semcat_surface

$\langle$ Ltip $\rangle=$ semgroup_spatial, semcat_tip_place

<ttop $>$ = semgroup spatial, semcat natural place

$<$ Ltrap $>$ = semgroup_spatial, semcat_trap_place

$<$ Lwater $>$ = semgroup_spatial, semcat_water_place

// plant prototypes

$\langle\mathrm{B}\rangle=$ semgroup plant, semcat plant

$\langle\mathrm{BB}\rangle=$ semgroup plant, semcat plantation

$\langle$ Btree $>$ = semgroup plant, semcat tree

$\langle$ Bflo $\rangle=$ semgroup_plant, semcat_flower

$<$ Bbush $>$ = semgroup_plant, semcat'bush

$<$ Bveg $>$ = semgroup_plant, semcat_vegetable

// semantic product prototypes

$<$ sem $>$ = semgroup_semantic_prodcut,

semcat semiotic artifact

$\langle$ sem-c $\rangle=$ semgroup_semantic_prodcut,

semcat cognitive product

$\langle$ sem-1> = semgroup semantic prodcut,

semcat listen work

$\langle$ sem-nons $>=$ semgroup_semantic_prodcut,

semcat semantic rubbish

$\langle$ sem-r $\overline{\rangle}=$ semgroup semantic prodcut, semcat read work

$\langle$ sem-s $\rangle$ = semgroup semantic prodcut,

semcat speak work

$\langle$ sem-w $\rangle=$ semgroup_semantic_prodcut,

semcat watch work

<pict $\rangle=$ semgroup semantic prodcut, semcat picture

// state of affairs prototypes

<sit> = semgroup_state_of_affairs,

semcat_psychologícal

<state $\overline{>}=$ semgroup_state_of_affairs,

semcat state of affairs

<state-h> = semgroup_state_of_affairs,

semcat human state

// substance prototypes

$<\mathrm{cm}\rangle=$ semgroup substance, semcat concrete,

semcat mass

$<\mathrm{cm}-\mathrm{h}\rangle=$ semgroup_substance, semcat human made

$<\mathrm{cm}$-chem $>$ = semgroup substance, semcat chemical

$\langle\mathrm{cm}$-gas $\rangle=$ semgroup substance, semcat $\bar{g}$ as

$\langle\mathrm{cm}-$ liq $\rangle=$ semgroup substance, semcat liquid

$<\mathrm{cm}-\mathrm{rem}>$ = semgroup substance, semcat remedy

// thing prototypes

$\langle$ bar $\rangle=$ semgroup_thing, semcat_barrier

$\langle$ build $>$ = semgroup_thing, semcāt_building

$<$ con $\rangle$ = semgroup thing, semcat container

$\langle$ cord $\rangle$ = semgroup thing, semcat string object

$\langle\mathrm{cc}\rangle=$ semgroup thing, semcat countable

$\langle\mathrm{cc}-\mathrm{h}\rangle=$ semgroup thing, semcat artifact

$\langle\mathrm{cc}$-beauty $\rangle=$ semgroup thing, semcat ornamental

$\langle\mathrm{cc}$-board $\rangle=$ semgroup thing, semcat board object

$\langle$ cc-fire $\rangle=$ semgroup thing, semcat $\bar{f}$ ire objject

$\langle$ cc-handle $\rangle$ = semgroup_thing, semcat_hañle

$\langle c c-$ light $\rangle=$ semgroup_thing, semcat_Iight_object

$\langle c c-p a r t i c l e\rangle=$ semgroup thing, semcat particle

$\langle\mathrm{cc}-\mathrm{r}\rangle=$ semgroup thing, semcat read object

$\langle$ cc-rag $\rangle$ = semgroup thing, semcāt clöth object

$\langle$ cc-stone $\rangle=$ semgroup_thing, semcat_stone_object

$\langle$ cc-stick $\rangle=$ semgroup_thing, semcat_stick_object

<furn> = semgroup thing, semcat_furniture

$<$ Lbar $>$ = semgroup thing, semcat barrier //

undocmented

$<$ mat $>=$ semgroup thing, semcat material

$<$ mat-cloth $>=$ semgroup_thing, semcat_cloth_material

<tube $>$ = semgroup thing, semcat_tube_object

// time and event prototypes

$<$ dur $\rangle=$ semgroup time, semcat duration

<event> = semgroup_time, semcat_event // duplicated

in palavras

$<$ per $>$ = semgroup time, semcat time period

<temp $>$ = semgroup time, semcat point in time

// tool prototypes

$<$ tool $>$ = semgroup_tool, semcat_tool

<tool-cut> = semgroup_tool, semcat cutting tool

$<$ tool-gun $>$ = semgroup tool, semcat shooting tool

<tool-mus > = semgroup tool, semcat musical instrument

<tool-sail> = semgroup_tool, semcat_sailing_tool

// vehicle prototypes

$\langle\mathrm{V}\rangle$ = semgroup_vehicle, semcat_vehicle // duplicated

in palavras

$\langle\mathrm{VV}\rangle$ = semgroup_vehicle, semgroup_collective, semcat collective

$\langle$ Vwater $>$ = semgroup vehicle, semcat water vehicle

<Vair> = semgroup_vehicle, semcat_aír_vehícle

// weather prototypes

$\langle$ wea $\rangle$ = semgroup weather, semcat weather

$\langle$ wea-c $>$ = semgroup weather,

semcat weather phenomenon, semcat countable

<wea-rain> = semgroup_weather, semcat_rain

$<$ wea-wind $>$ = semgroup_weather, semcat_wind

// other

$\langle j h\rangle=$ semcat adjective for human noun

$\langle j n\rangle=$ semcat adjective_for_inanimate_noun

$\langle j a\rangle=$ semcat_adjective_for_animal

$\langle j b\rangle=$ semcat adjective for plant

$\langle$ col $\rangle=$ semcat color

$<$ nat $>$ = semcat nationality adjective

$\langle a t t r\rangle=$ semcat_attributive_adjective

$\langle\mathrm{vH}\rangle=$ semcat_verb_with_humān_subject

$\langle\mathrm{vN}\rangle=$ semcat_verb_with_inanimate_subject

$\langle$ sick $\rangle=$ semcat sick

$\langle$ sick-c $\rangle=$ semcat sick, semcat countable

/1

// semantic categories for proper nouns

// abstract entity categories

<brand $>$ = semgroup_entity, semgroup_abstract, semcat_brand

// <geñre> = semgroup_entity, semgroup_abstract, semcat disciplin

// duplicated in palavras

<school> = semgroup_entity, semgroup_abstract,

semcat school

<idea> ${ }^{-}=$semgroup_entity, semgroup_abstract,

semcat_idea

$<$ plan $\rangle^{-}=$semgroup_entity, semgroup_abstract,

semcat_plan

<author $>$ = semgroup_entity, semgroup_abstract, semcat author

<absname> = semgroup entity, semgroup abstract, semcat abstract name

<disease> = semgroup_entity, semgroup_abstract,

semcat physiological state // in particular:

disease

$/ /$ event entity

// <event> = semgroup_entity, semgroup_time,

semcat_event

// duplicated in palavras

history $>$ = semgroup entity, semgroup time,

semcat event,

semcāt_onetime_event

<occ $>=$ semgroup_entity, semgroup_time, semcat_event,

semcat organised event

<month> = semgroup entity, semgroup time,

semcat month name

// group entity categories

<groupind $>$ = semgroup_entity, semgroup_human_group,

semcat_people

<groupofficial> = semgroup entity

semgroup human group,

semcat board group

$\langle$ grouporḡ $\rangle=$ semgroup_entity, semgroup_human_group, semcat human group

// organisation/group entity categories

<admin> = semgroup_entity, semgroup_organization,

semcat_admin_body

<org $>=$ semgroup_entity, semgroup_organization,

semcat organization

$/ /$ inst̄ = semgroup entity, semgroup organization,

//semcat_site_organization // (restaurant) --

duplicated in pálavras

$<$ media $>$ = semgroup_entity, semgroup_organization,

semcat media organization

<party $>$ = semgroup_entity, semgroup_organization,

semcat institution

<suborg $>$ = semgroup_entity, semgroup_organization,

semcat_sub_organization

<company $>$ = semgroup entity, semgroup organization,

semcat organization

// numeric categories (ex. HAREM VALOR):

<amount> = semgroup_numeric, semcat_quantity_noun

$<$ cur $\rangle$ = semgroup numeric, semcat currency noun

<quantity> = semgroup entity, semgroup numeric,

semcat_quantity 


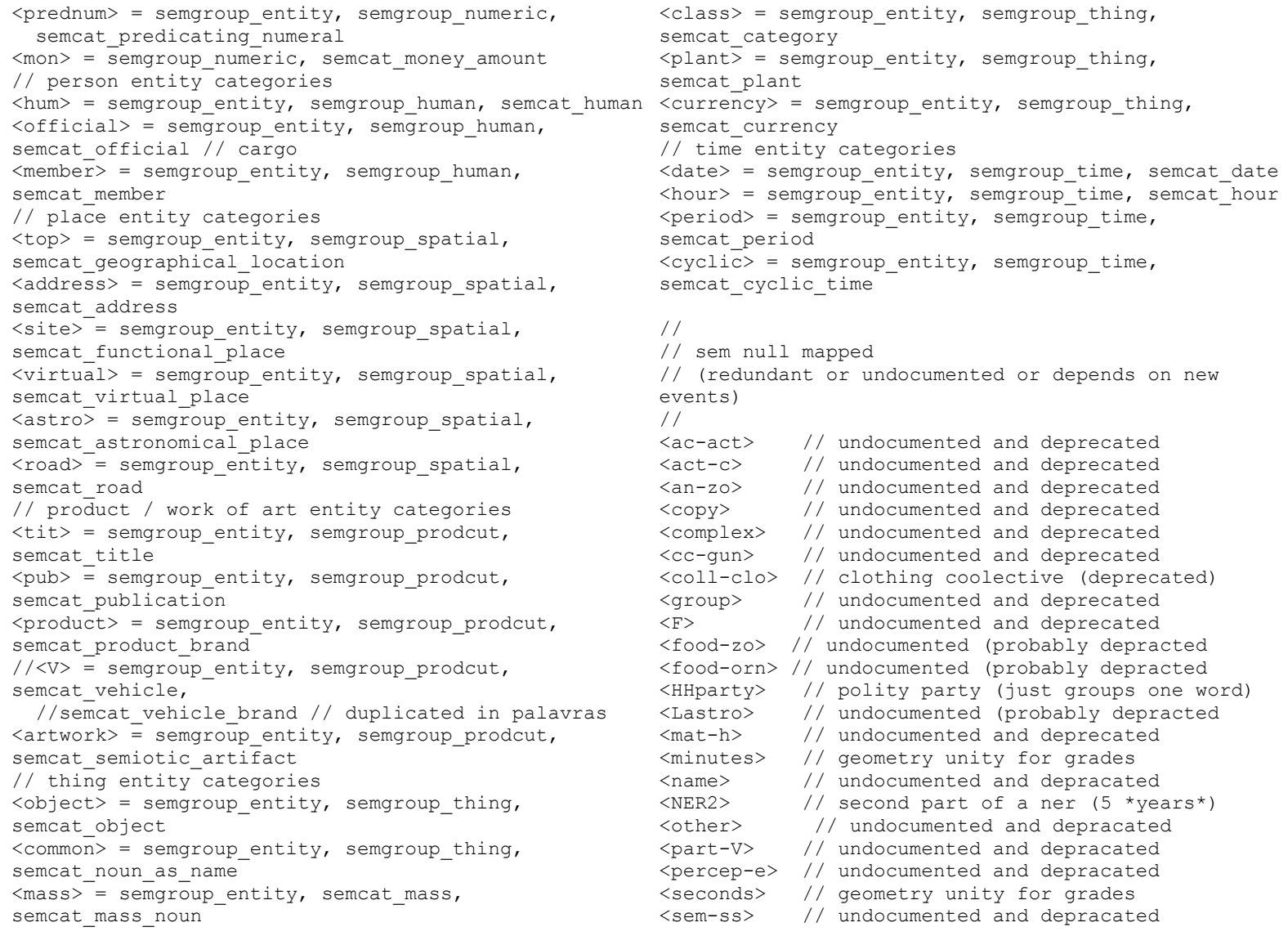

\section{A.2 A-padrões para os conjuntos usados}

\section{Fragmento Dela:}

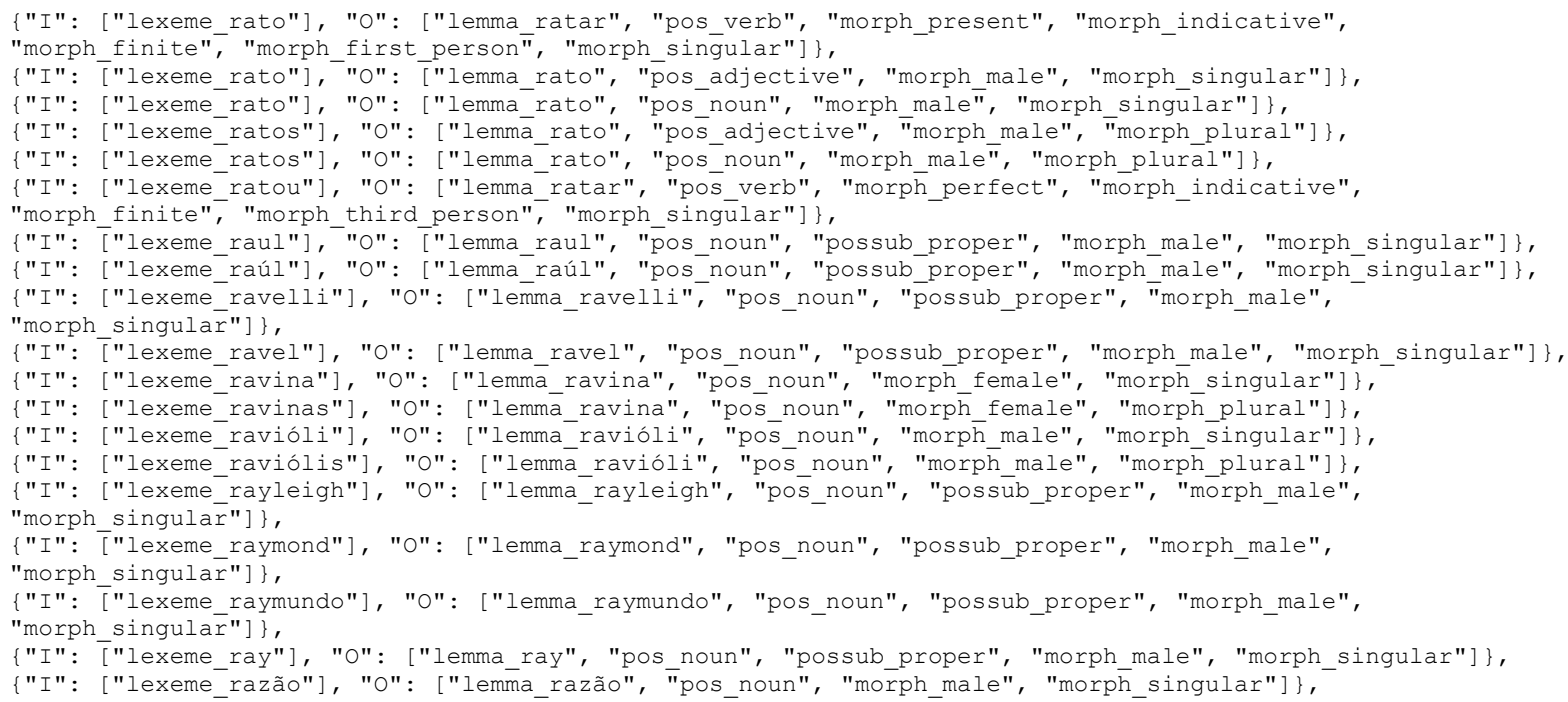

\section{Fragmento Mac:}

$\{$ "I": ["change_context"], "O": []\},

$\{" I ":$ ["lexeme_vocês", "uc_first", "sentence_first"], "O": ["pos_pronoun", "possub_personal"]\},

$\{" I ":$ ["lexeme_não"], "O": ["pos_adverb"]\},

$\{$ I": ["lexeme- sabem"], "O": ["pos verb"] $\}$

$\{" I ":$ ["lexeme_o"], "O": ["pos_pronoun", "possub_subordinating"]\},

\{"I": ["lexeme_que"], "O": ["pos_pronoun", "possub_subordinating"] \},

$\{" I ":$ ["lexeme é"], "O": ["pos verb"]\}, 
\{"I": ["lexeme O"], "O": ["pos article"]\},

$\{" I ":$ ["lexeme concreto"], "O": ["pos noun"]\},

$\{$ "I": ["lexeme_de"], "O": ["pos_preposition"]\},

$\{" I ":$ ["lexeme_a"], "O": ["pos_article"]\},

$\{" I ":$ ["lexeme_miséria"], "O": ["pos_noun"]\},

\{"I": ["special, "], "O": ["pos punctuation"]\},

$\{" I ":$ ["lexeme o"], "O": ["pos article"]\},

$\{$ "I": ["lexeme_concreto"], "O": ["pos_noun"]\},

$\{" I ":$ ["lexeme_de"], "O": ["pos_preposition"]\},

\{"I": ["lexeme_o"], "○": ["pos_article"]\},

$\{" I ":$ ["lexeme rato"], "O": ["pos noun"]\},

$\{" I ":$ ["special,$"]$, "O": ["pos punctuation"]\},

$\{" I ":$ ["lexeme_de"], "O": ["pos_preposition"]\},

$\{$ "I": ["lexeme_a"], "O": ["pos_article"]\},

$\left\{" I ":\right.$ ["lexeme ${ }^{-}$lama"], "O": ["pos noun"] $\}$

$\{" I ":$ ["special, "], "O": ["pos punctuation"]\},

$\{" I ":$ ["lexeme_de"], "O": ["pos_preposition"]\},

$\{" I ":$ ["lexeme_o"], "O": ["pos_article"]\},

$\{" I ":$ ["lexeme_lixo"], "O": ["pos_noun"]\},

$\{" I ":$ ["special_,"], "O": ["pos_punctuation"]\},

$\{" I ":$ ["lexeme $\overline{\mathrm{de}} "]$, "O": ["pos preposition"]\},

$\{$ "I": ["lexeme_a"], "O": ["pos_article"]\},

$\{$ "I": ["lexeme_casa"], "O": ["pos_noun"]\},

$\{$ "I": ["lexeme_de"], "O": ["pos_preposition"]\},

$\{" I ":$ ["lexeme_caixote"], "O": ["pos_noun"]\},

\{"I": ["special, "], "O": ["pos punctuation"]\},

$\{" I ":$ ["lexeme_de"], "O": ["pos_preposition"]\},

$\{" I ":$ ["lexeme_o"], "O": ["pos_article"]\},

$\{" I ":$ ["lexeme prego"], "O": ["pos noun"]\},

$\{$ "I": ["special_,"], "O": ["pos_punctuation"]\},

$\{" I ":$ ["lexeme $\bar{d} e "]$, "O": ["pos preposition"]\},

$\{" I ":$ ["lexeme_a"], "O": ["pos_article"]\},

$\{" I ":$ ["lexeme_morte"], "O": ["pos_noun"]\},

$\{" I ":$ ["lexeme_em"], "O": ["pos_preposition"]\},

$\{" I ":$ ["lexeme a"], "O": ["pos article"]\},

\{"I": ["lexeme-vala", "sentence_last"], "O": ["pos_noun"]\},

$\{" I ":$ ["special__."], "O": ["pos_punctuation"]\},

$\{$ "I": ["change_context"], "O": $\overline{[}]\}$,

\section{Fragmento Pln:}

$\{" I ":$ ["change context"], "O": []\},

\{"I": ["lexeme_o", "uc_first", "sentence_first"], "O": ["lemma_o", "pos_article", "possub_definite", "pos_determiner", "morph_male", "morph_singular", "syn_adjunct", "syn_adnominal", "id_1", "ref_2"]\}, $\{" I "$ : ["lexeme diretor"], "O": ["lemma_diretor", "semgroup_human", "semcat_professional", "pos_noun", "morph male", "morph singular", "syn subject", "id 2", "ref 12"]\},

\{"I": ["lexeme_de"], "O": ["lemma_de", "pos_preposition", "syn_adjunct", "syn_adnominal", "id_3", "ref_2"]\},

$\{" I " \overline{:}$ ["lexeme_o"], "O": ["lemma_o", "pos_article", "possub_definite", "pos_determiner", "morph_male", "morph singular", "syn adjunct", "syn adnominal", "id 4", "ref 5"]\},

\{"I": ["lexeme dima", "uc first"], "O": ["lemma dima", "semgroūp entity", "semgroup organization",

"semcat_organization", "pos_noun", "possub_proper", "morph_male", "morph_singular",

"synsub_preposition_argument", "id_5", "reféf_3"]\},

$\{$ "I": ["special ("], "O": ["id 6", "ref 5"]\},

\{"I": ["lexeme departamento", "uc first"], "O": ["lemma departamento", "compound lexeme",

"semgroup entī̄y", "semgroup human", "semcat human", "pōs noun", "possub proper", "morph male",

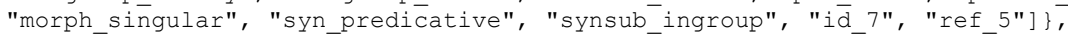

$\{" I ":$ ["lexeme_de"], "O": ["lemma_de", "compound_lexeme", "id_7.1", "ref_7"] \},

\{"I": ["lexeme_inspeção", "uc_first"], "O": ["lemma_inspeção", "compound_lexeme", "id 7.2", "ref 7"]\},

\{"I": ["lexeme municipal", "uc first"], "O": ["lemmā municipal", "compound lexeme", "íid 7.3", "réf 7"]\},

$\{" I ":$ ["lexeme de"], "O": ["lemma de", "compound lexeme", "id 7.4", "ref 7"] \}

$\{" I ":$ ["lexeme_alimentos", "uc_first"], "O": ["lemma_alimentos", "compound_lexeme", "id_7.5", "ref_7"]\},

$\{$ "I": ["speciā__)"], "O": ["id_8", "ref_7.5"]\},

$\{$ I": ["special-,"], "O": ["id $9 "$, "ref 8 "] \},

\{"I": ["lexeme luís", "uc first"], "O": ["lemma luís", "compound lexeme", "semgroup entity",

"semgroup_human", "semcat_human", "pos_noun", "possub_proper", "morph_male", "morph_singular",

"syn_apposition", "id_10", "ref_7"]\},

\{"I": ["lexeme_antôniō", "uc_fiřst"], "O": ["lemma_antônio", "compound_lexeme", "id_10.1", "ref_10"]\},

\{"I": ["lexeme colombo", "ucfirst"], "O": ["lemma_colombo", "compound_lexeme", "id 10.2", "ref-10"]\},

$\{" I ":$ ["special,"], "O": ["id 11", "ref 10.2"]\},

\{"I": ["lexeme disse"], "O": ["lemma dizēr", "synsub main verb", "pos verb", "morph perfect",

"morph_third_person", "morph_singular", "morph_indicative", "morph_fiñite", "syn_finite_clause", "id_12", "ref $0 \bar{c}]\}$,

$\{" I " \overline{:}$ ["lexeme_que"], "O": ["lemma_que", "pos_preposition", "possub_subordinating", "syn subordinator",

"id 13", "ref 18 "]\},

$\{$ \{" : ["lexeme em"], "O": ["lemma_em", "pos_preposition", "syn_adverbial_clause", "id_14", "ref_19"]\},

$\{" I ":$ ["lexeme_os"], "O": ["lemma_o", "pos_article", "possub_definite", "pos_determiner", "morph_male", "morph_plural", "syn_adjunct", "sȳn_adnomiñal", "id_15", "ref $\bar{f} \_17$ ]\},

\{"I": ["lexeme três"], "O": ["lemma_três", "possub_cardinal", "pos_numeral", "morph_male", "morph_plural", "syn adjunct", "syn adnominal", "id $16 "$, "ref $17 "] \overline{\}}$,

\{"I": ["lexeme_supermercados"], "O": ["Iemma_supermercado", "semgroup_concept", "semcat_institution", "pos_noun", "morph_male", "morph_plural", "sȳnsub_preposition_argument", "id_17", "ref_14"]\}, $\{" I ":$ ["lexeme foram"], "O": ["lemma ser", "synsub auxiliary", "pos verb", "morph perfect", "morph more thān perfect", "morph thīrd person", "morph plural", "mörph indicative", "morph finite", 


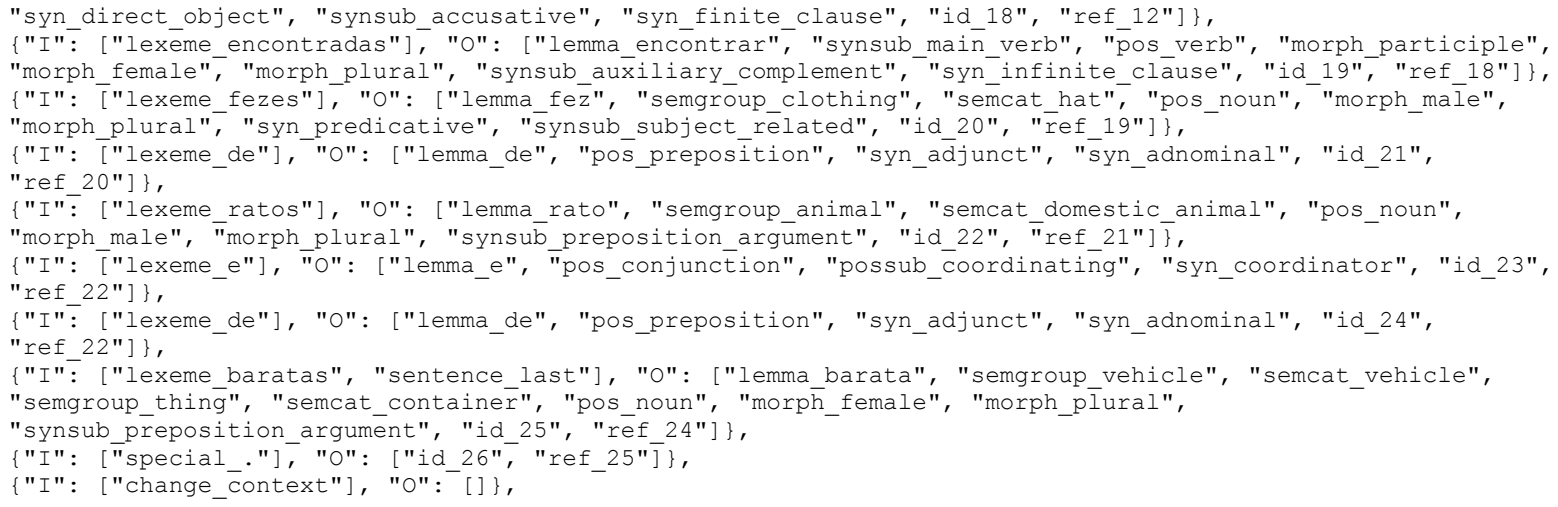

\section{A.3 Documentação dos parâmetros Json}

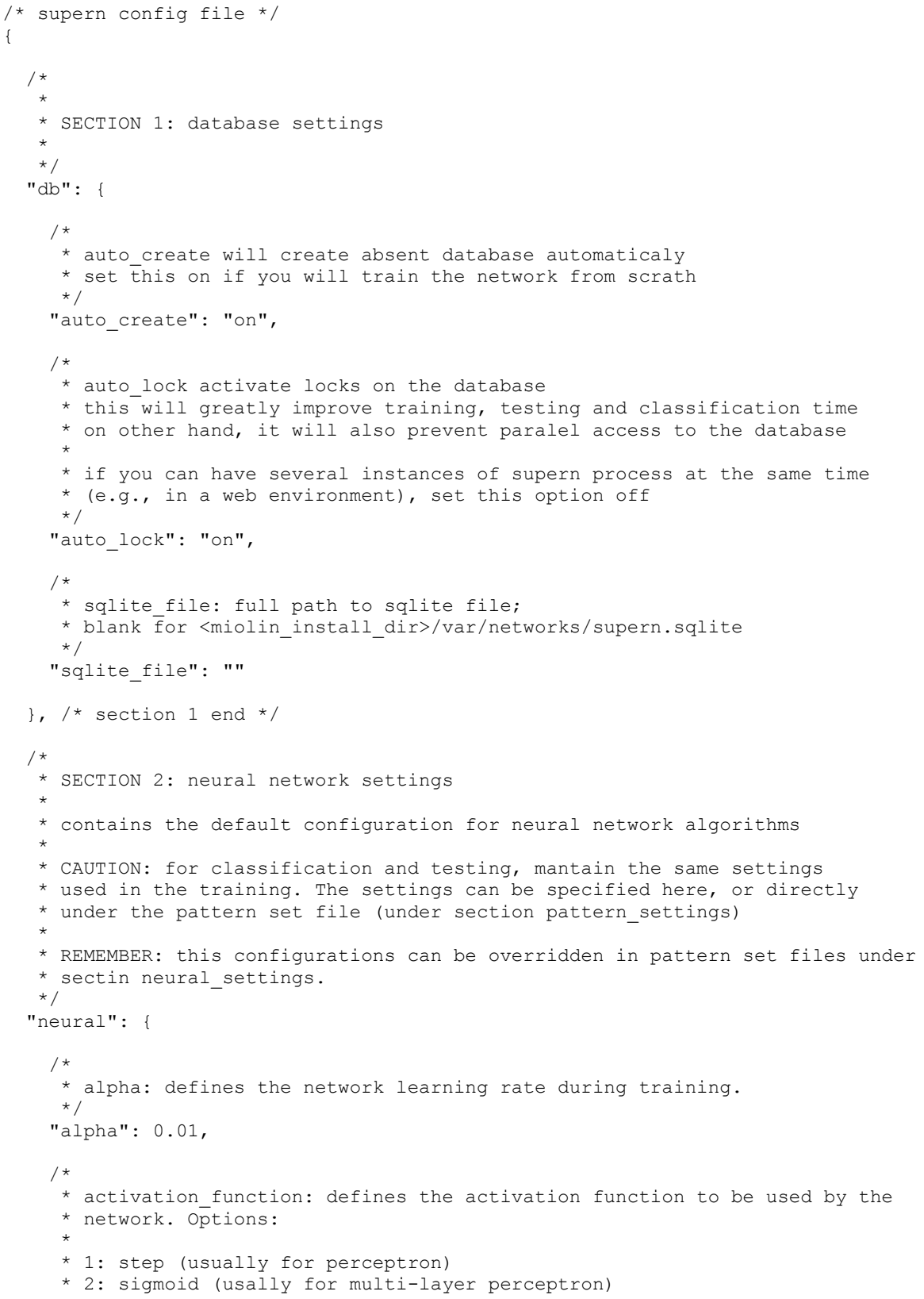




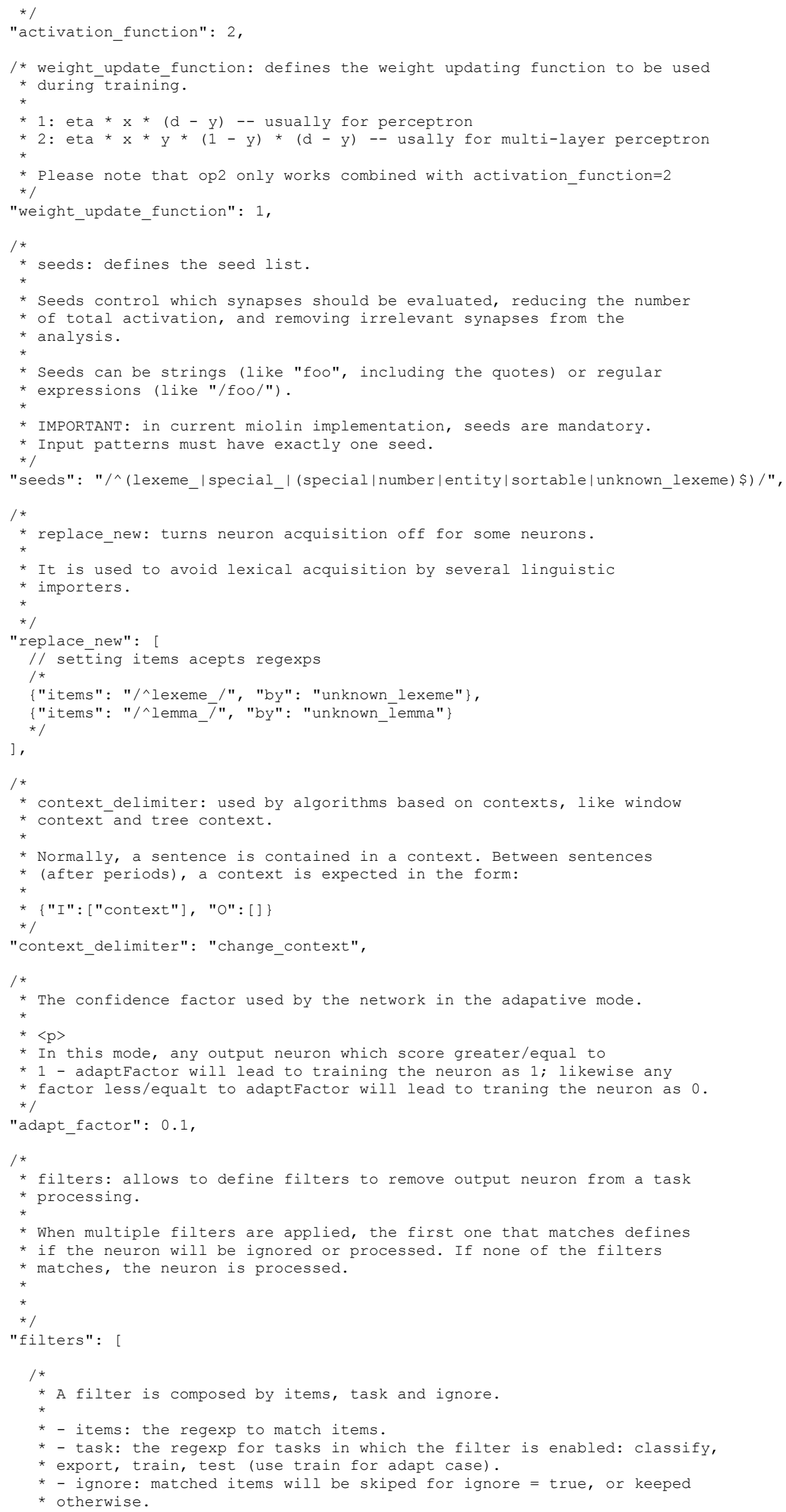




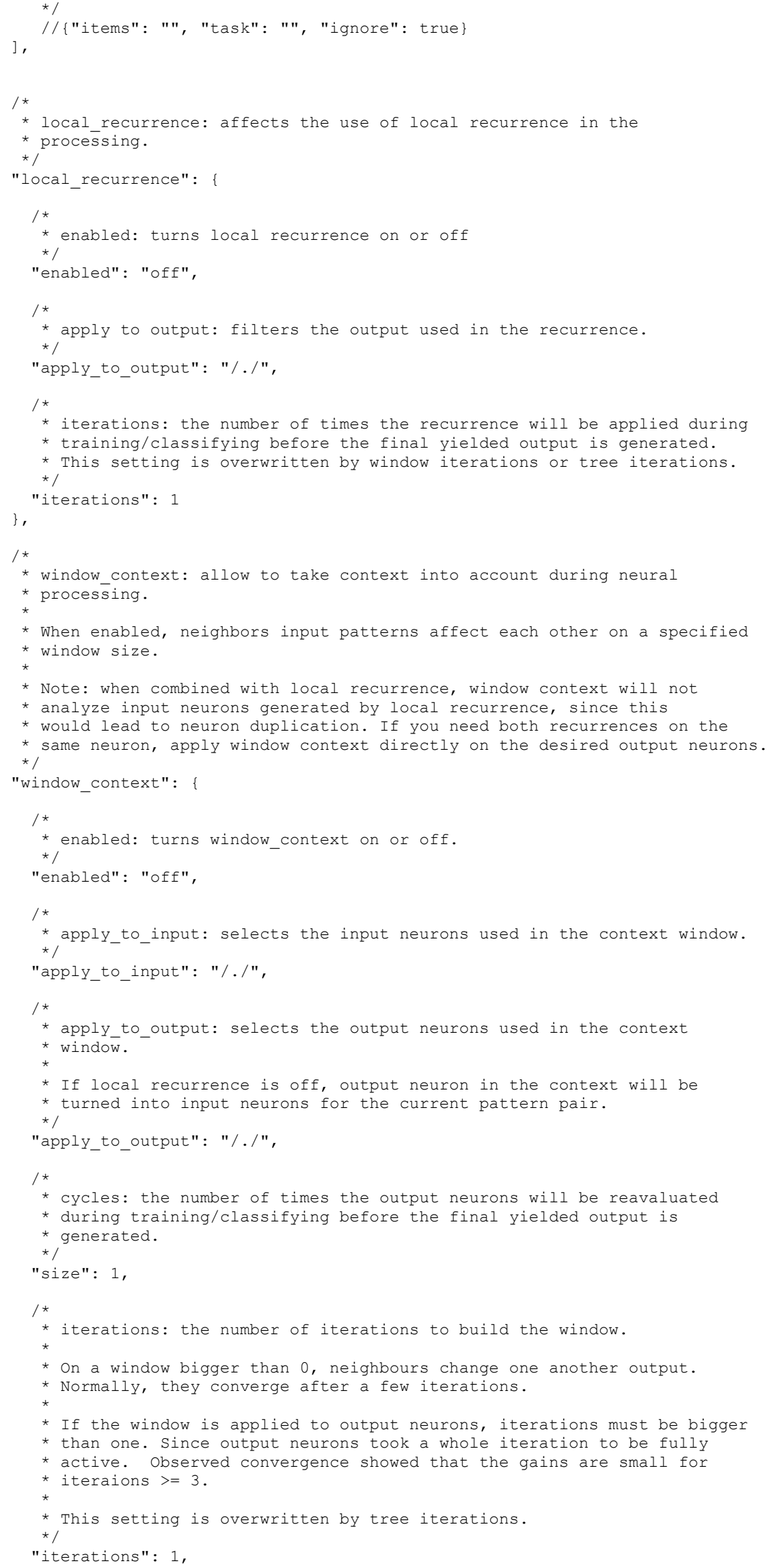




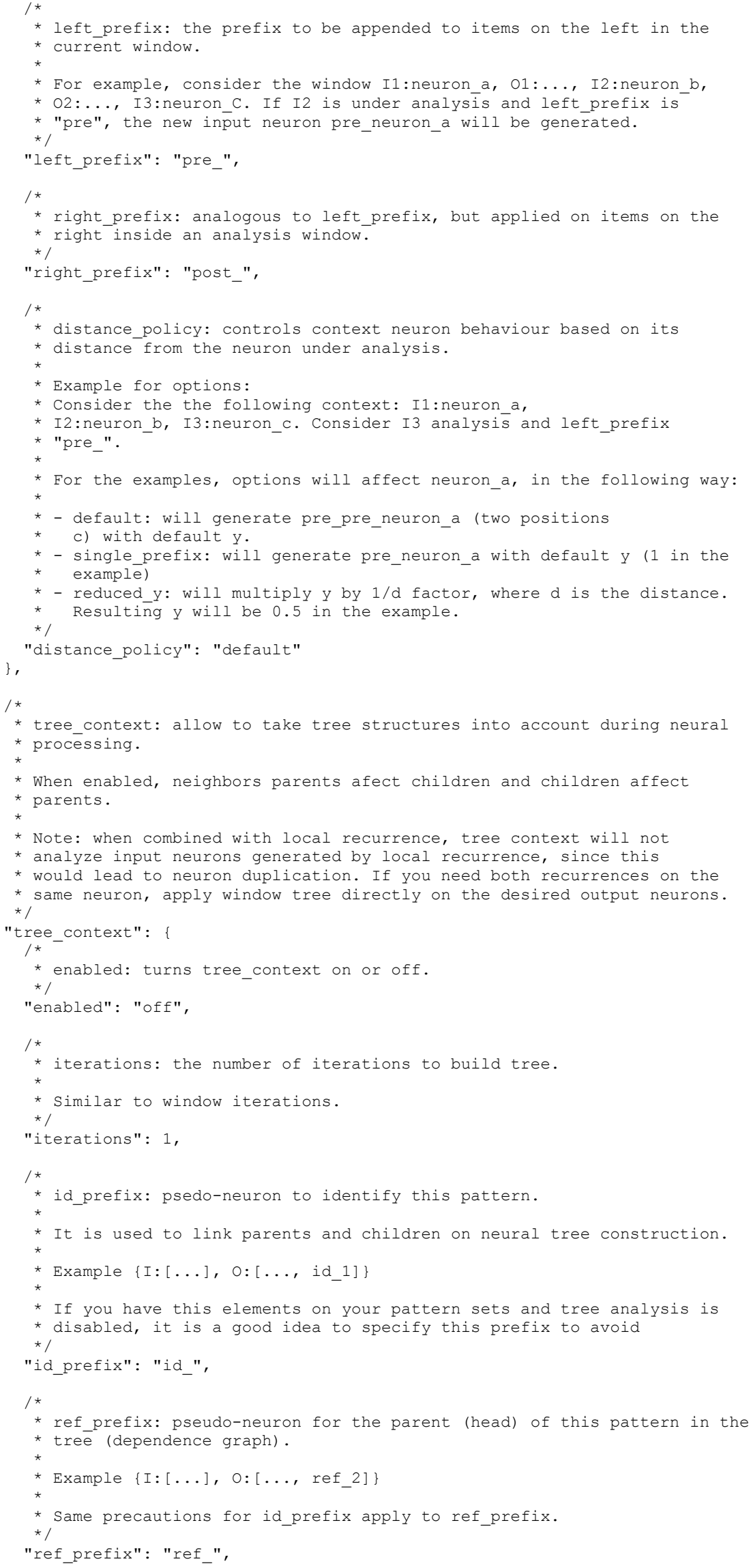




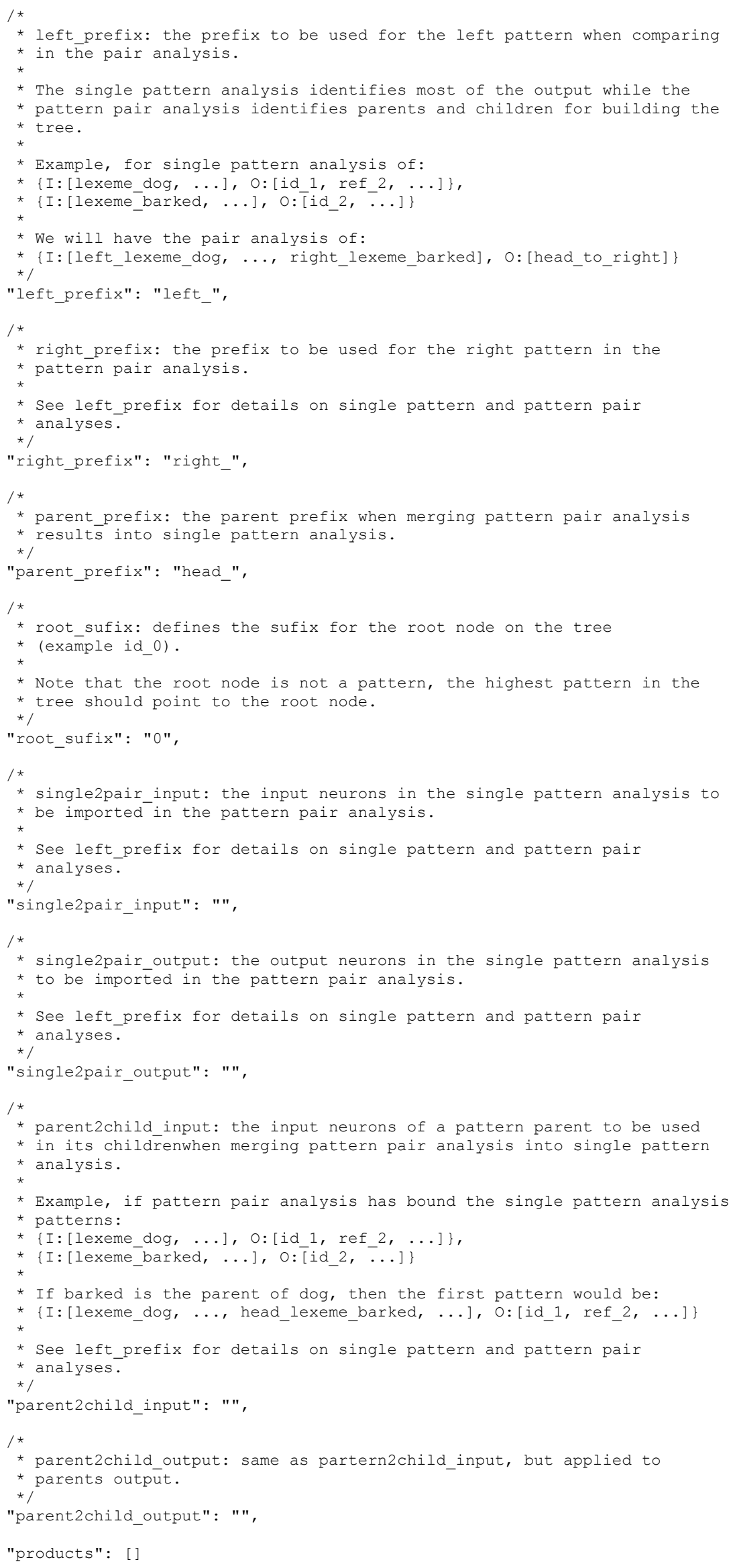




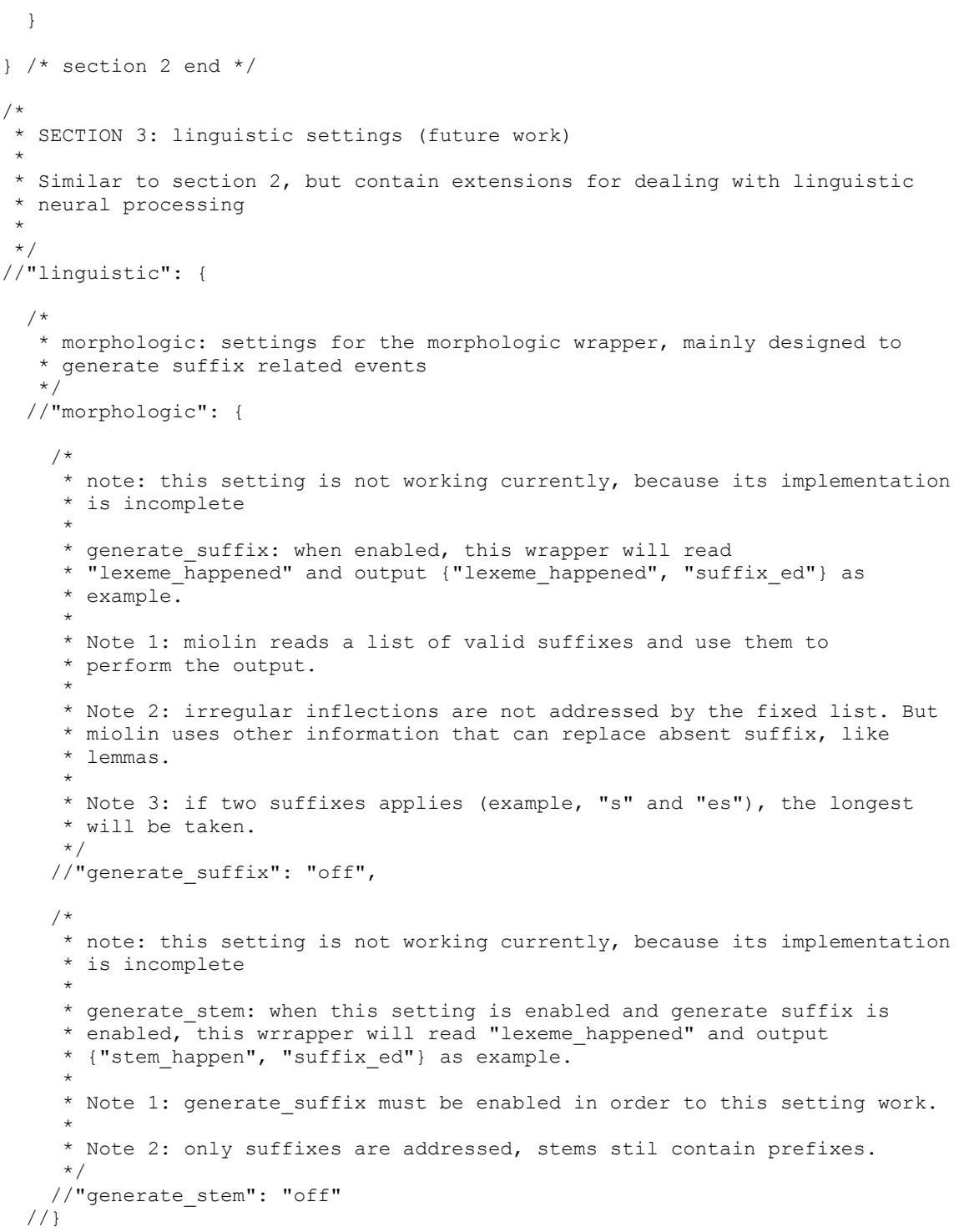

\section{A.4 Parâmetros para cada experimento}

Observa-se que os parâmetros para experimentos g0 são na verdade as configurações utilizadas para importar os recursos para o formato Json do protótipo. Os parâmetros são:

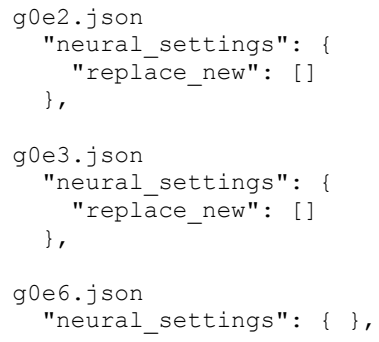




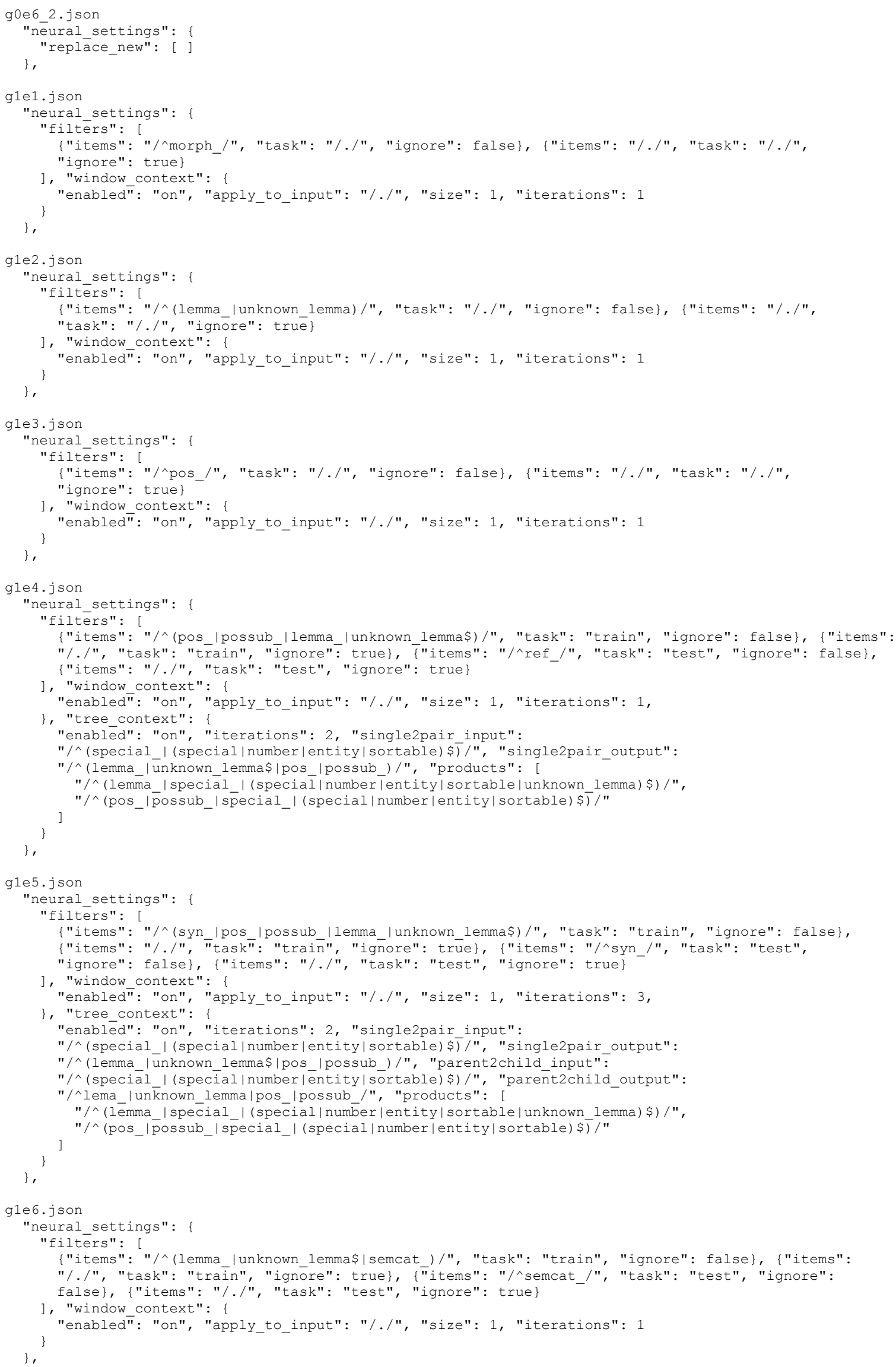




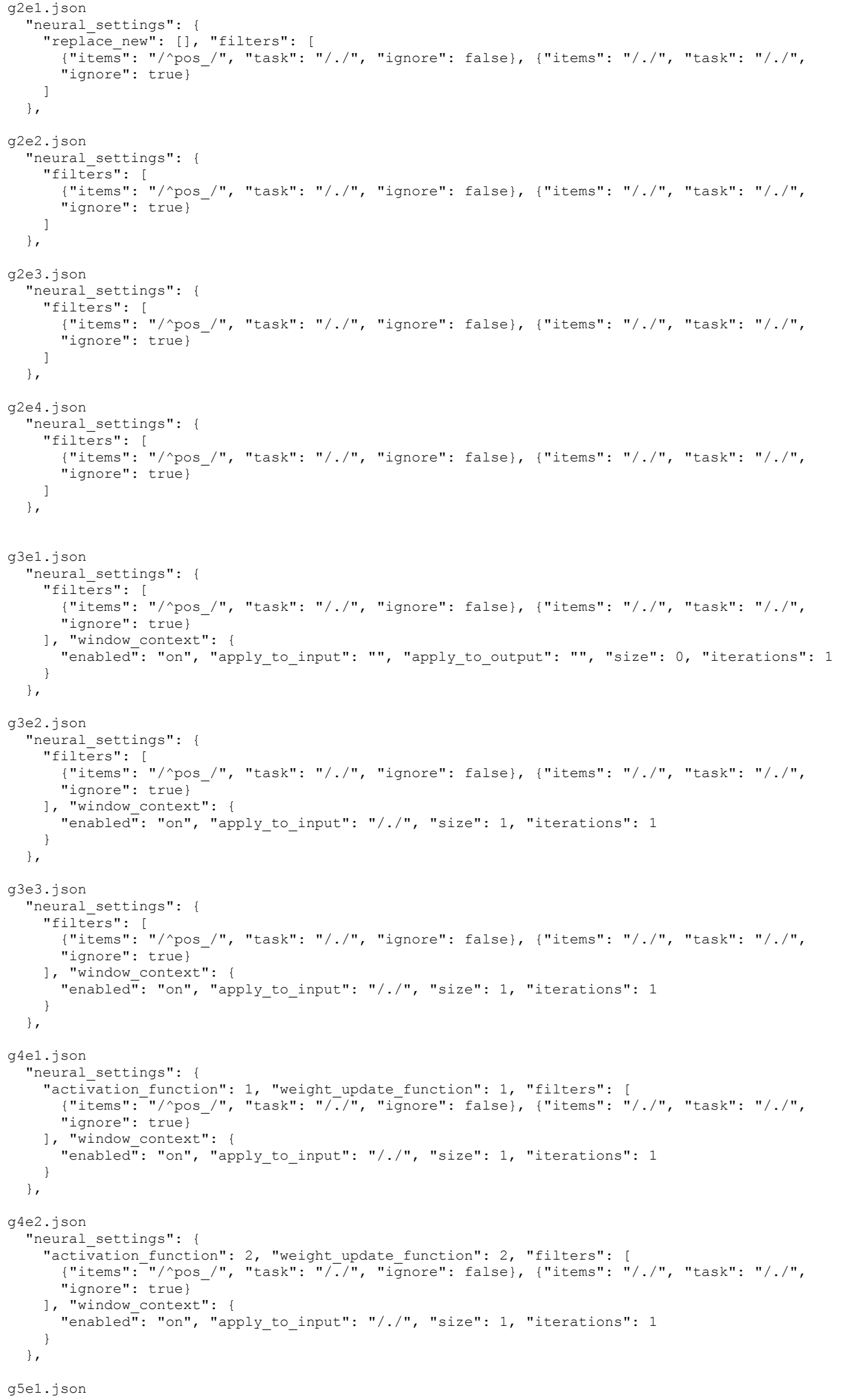




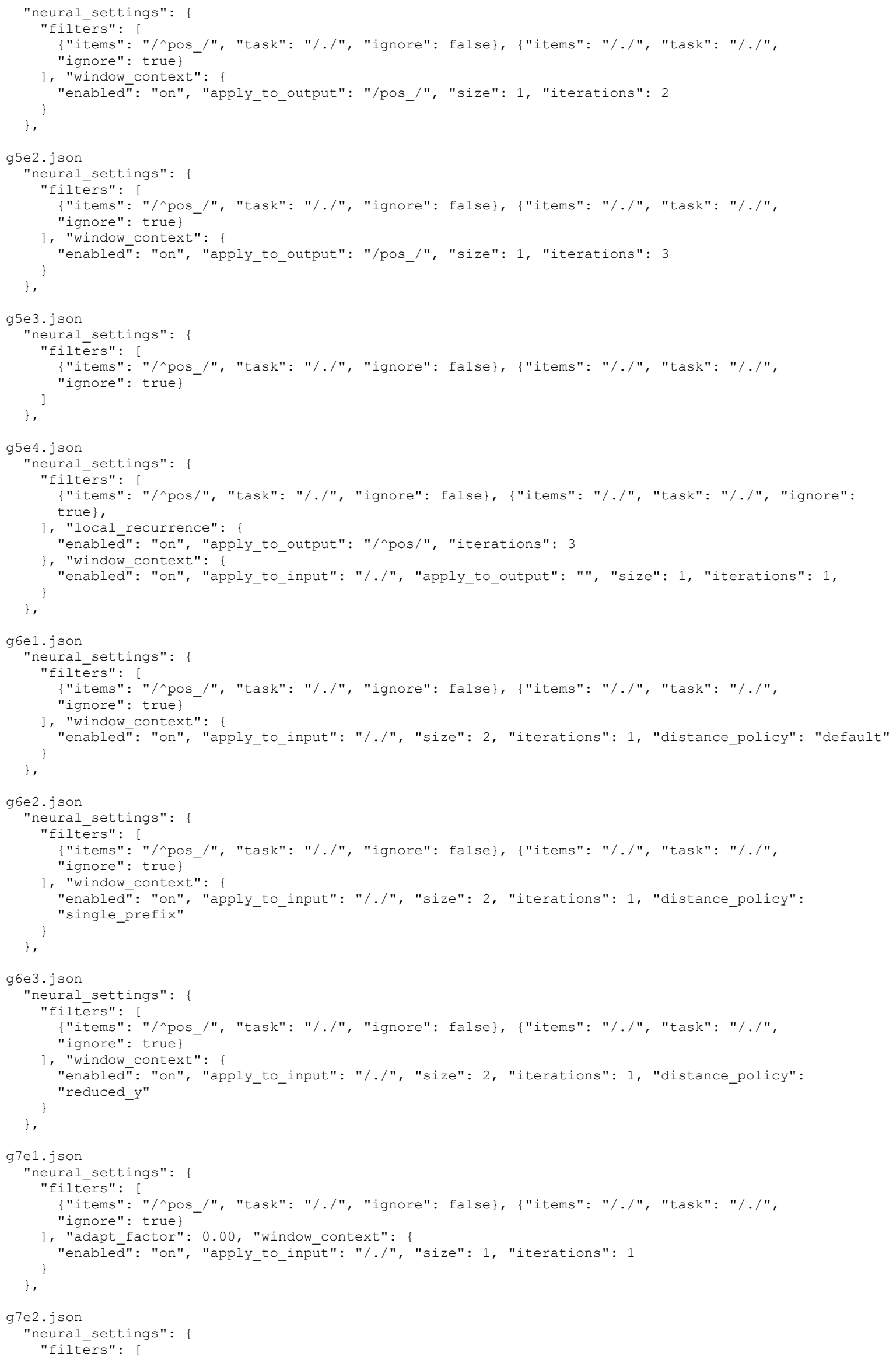




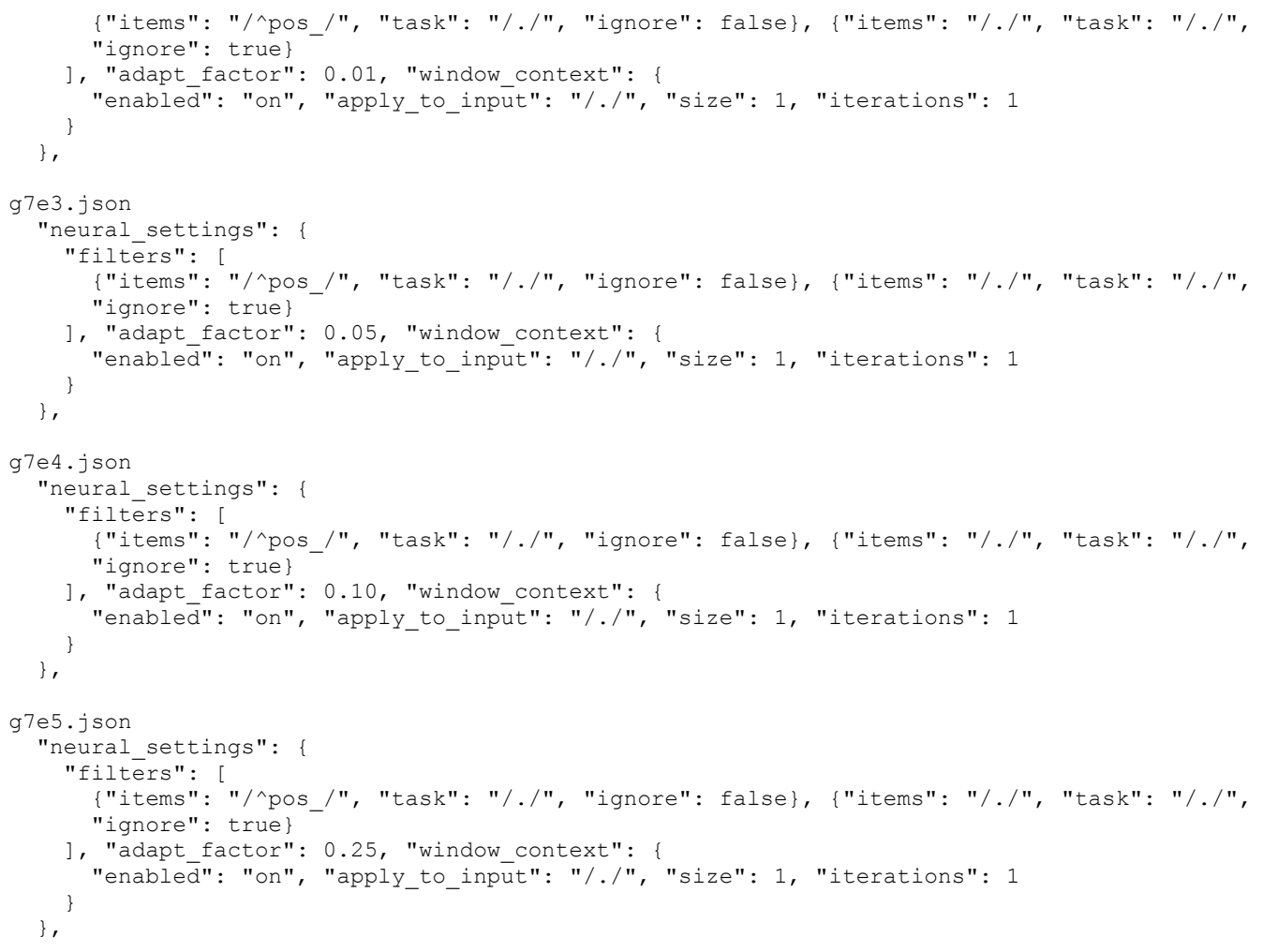




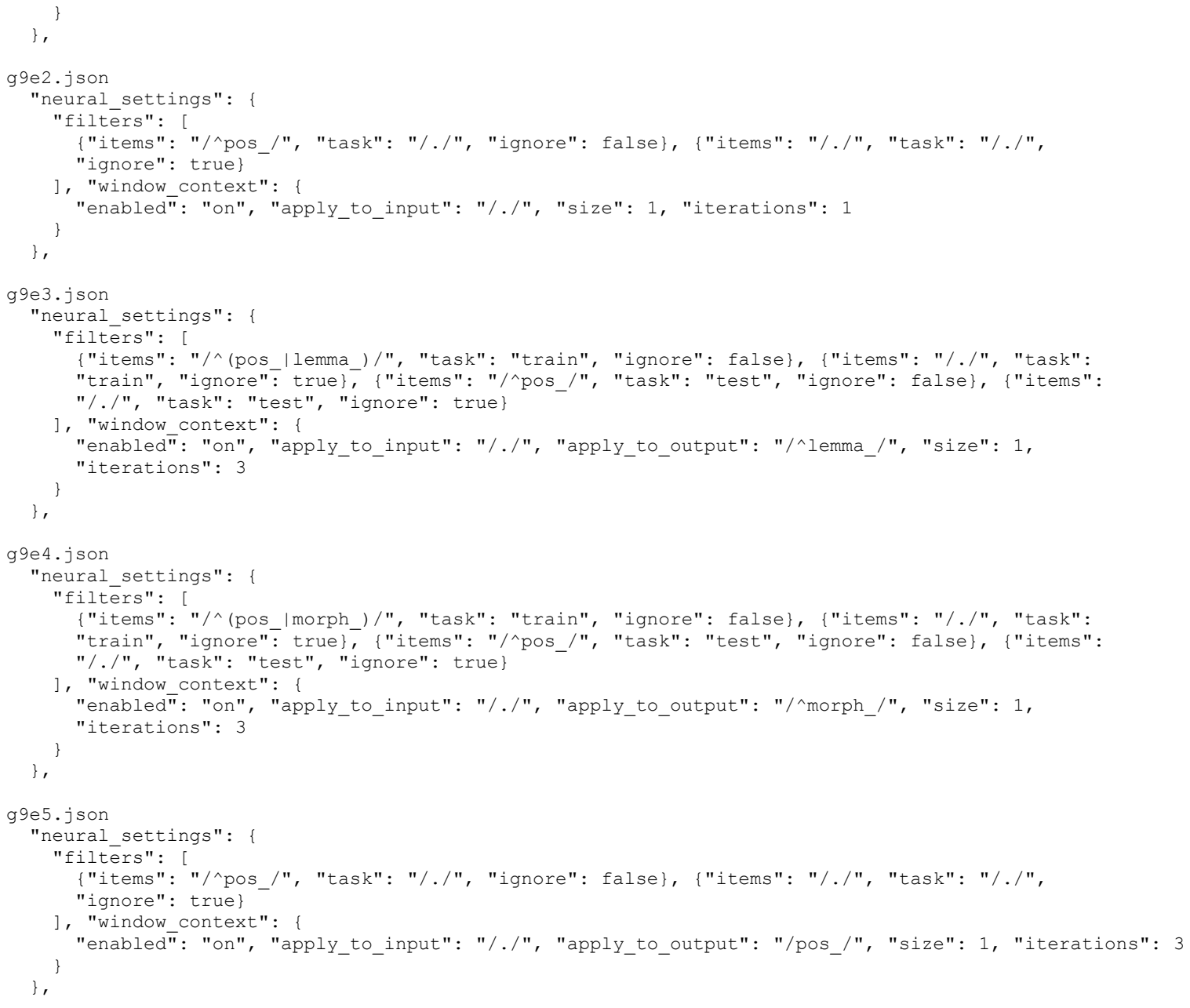




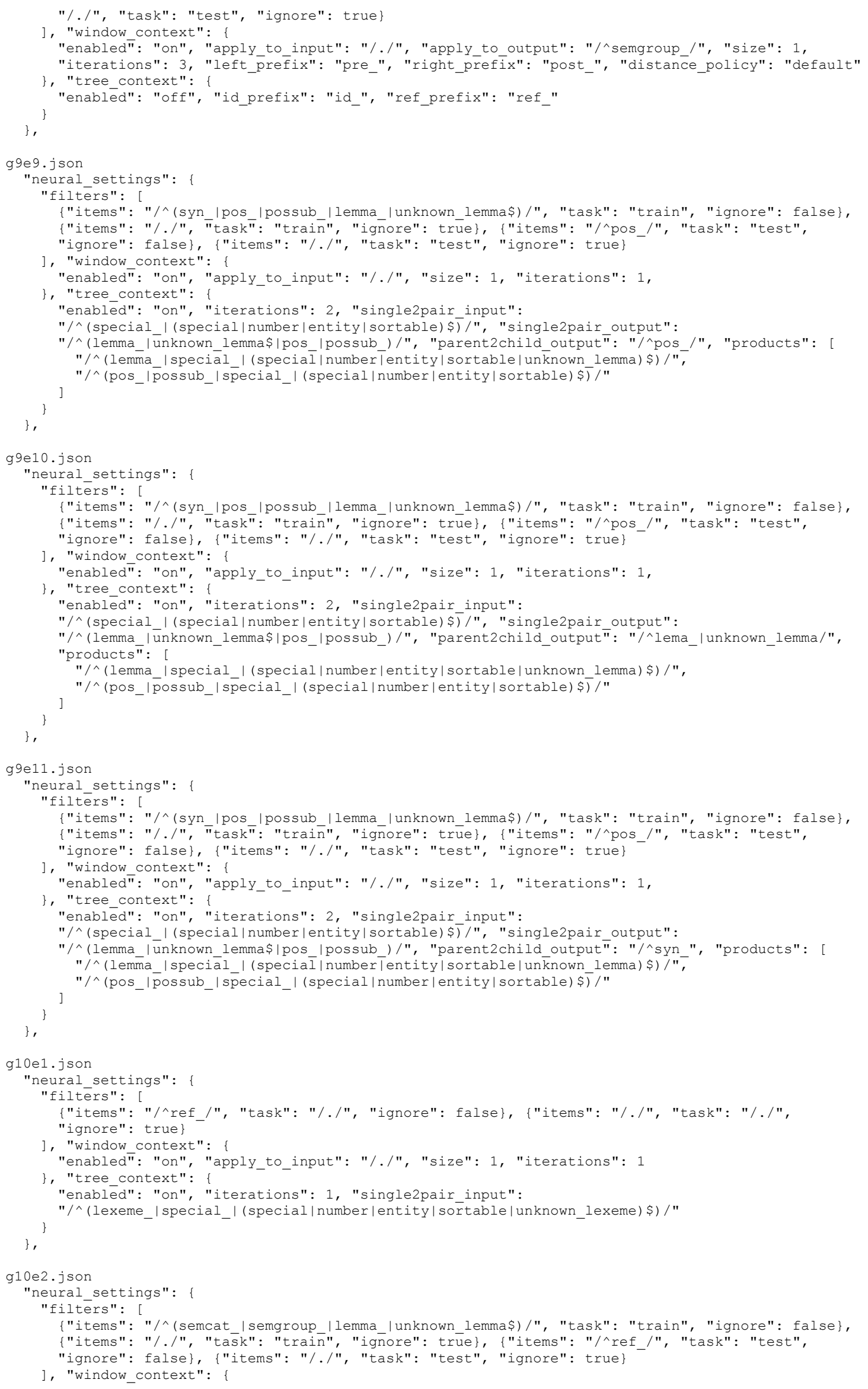




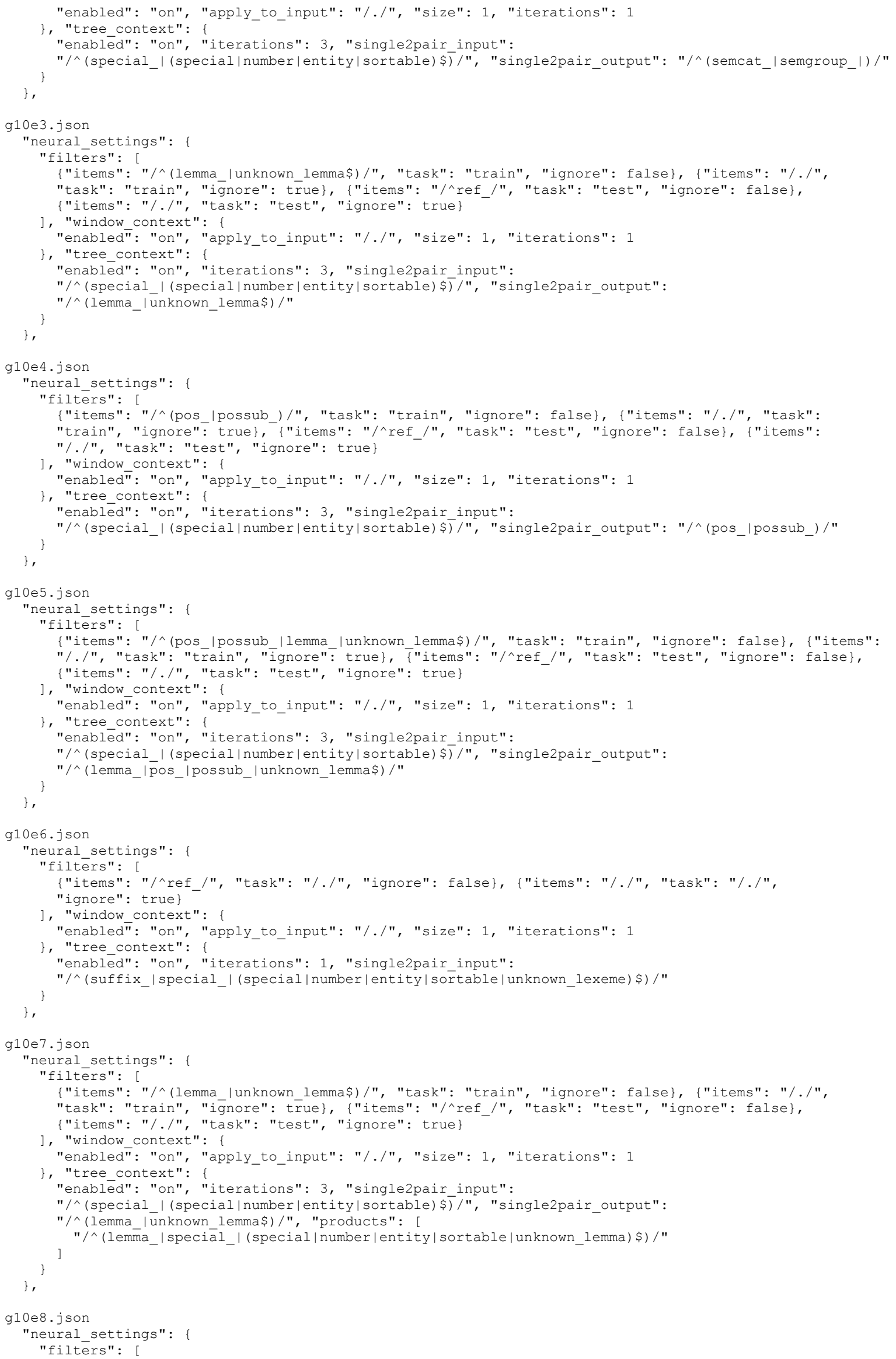




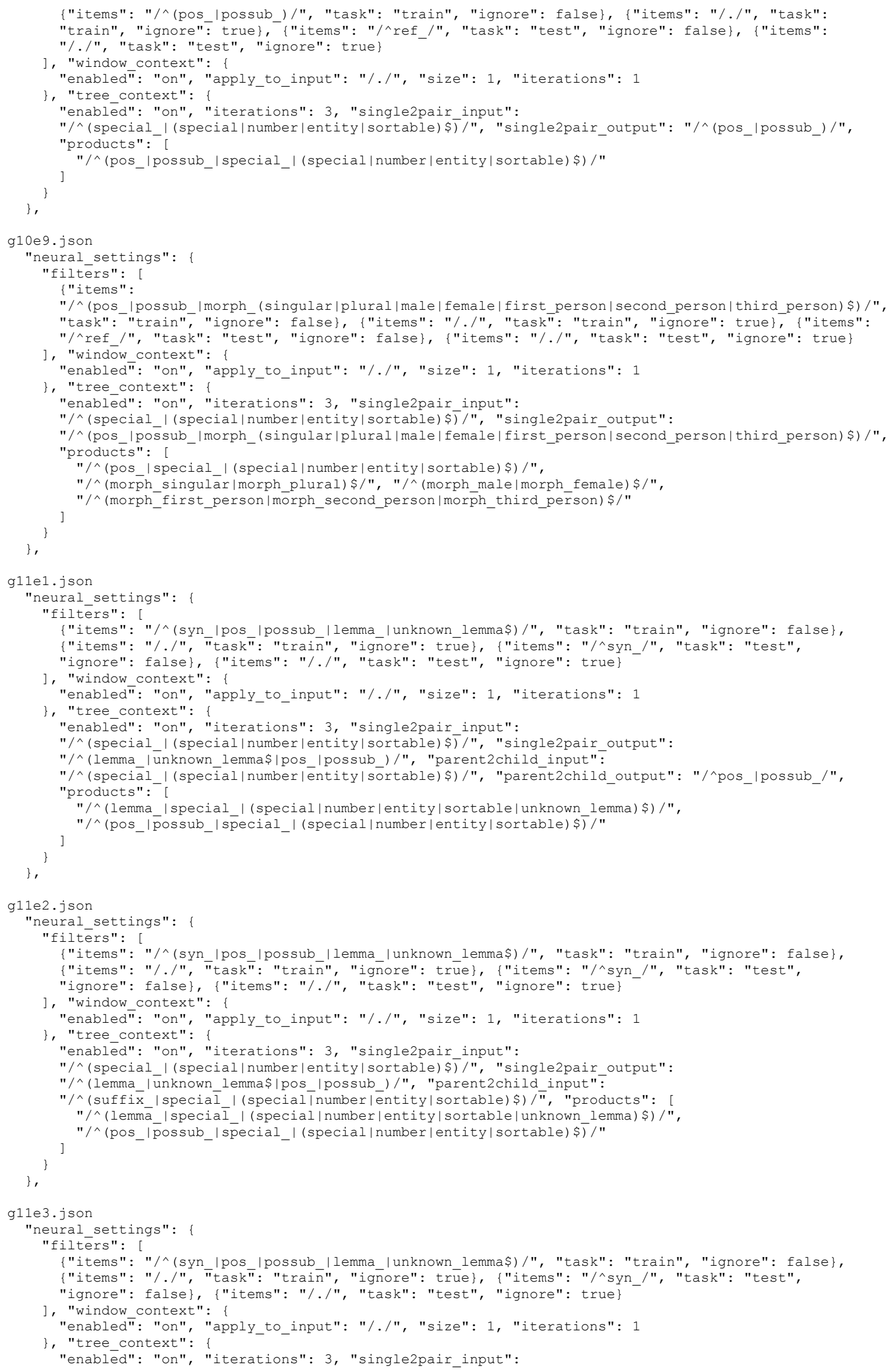


"/^(special | (special|number|entity|sortable)\$)/", "single2pair_output": "/^(lemma | unknown lemma\$pos |possub )/", "parent2child input":

"/^(speciāl_| (specīal|number|ēntity|sortable)\$)/", "parent2child_output":

"/^lema_|unk̄nown_lemma/", "products": [

"/^(lēemma_|special_| (special|number|entity|sortable|unknown_lemma) \$)/",

"/^(pos |possub | special | (special|number|entity|sortable) \$)/" \},

g11e4.json

"neural_settings":

"filters": [

\{"items": "/^(syn_lpos_|possub_|lemma_|unknown_lemma\$)/", "task": "train", "ignore": false\},

\{"items": "/./", "task": "train̄", "igñore": trūe\}, \{"items": "/^syn_", "task": "test",

"ignore": false\}, \{"items": "/./", "task": "test", "ignore": true\}

1, "window_context": \{

"enabled": "on", "apply_to_input": "/./", "size": 1, "iterations": 1

\}, "tree context": \{

"enablè": "on", "iterations": 3, "single2pair input":

"/^(special | (special|number|entity|sortable)\$)/", "single2pair output":

"/^(lemma_|ünknown_lemma\$|pos_|possub_)/", "parent2child_input":

"/^(speciāl_| (specīil|number|ēntity|sortable)\$)/", "parentzchild_output": "/^syn_/", "products": [

$" / \wedge($ lemma_|special_| (special|number|entity|sortable|unknown_lemma) \$)/",

/^(pos |possub_|special | (special|number|entity|sortable) \$)/"

\}

g11e5.json

"neural settings": \{

"filtêrs": [

\{"items": "/^(syn_|synsub|pos_|possub_|lemma_|unknown_lemma\$)/", "task": "train", "ignore":

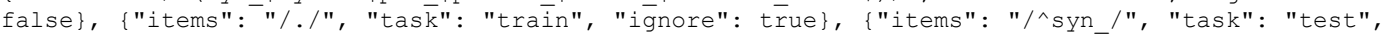

"ignore": false\}, \{"items": "/./", "task": "test", "ignore": true\}

], "window context": \{

"enabled": "on", "apply_to_input": "/./", "size": 1, "iterations": 1

\}, "tree context": \{

"enabled": "on", "iterations": 3, "single2pair input":

"/^(special | (special|number|entity|sortable)\$)/", "single2pair output":

"/^(lemma_|ünknown_lemma\$|pos_|possub_)/", "parent2child_input":

"/^(speciāl_| (specīal|number|entity|sortable)\$)/", "parent2child_output": "/^syn_|synsub_/",

"products":

"/^(lemma_|special_| (special|number|entity|sortable|unknown_lemma) \$)/", ]

"/^(pos | possub | special | (special|number|entity|sortable) \$)/"

\}

g11e6.json

"neural_settings":

"filtêrs": [

\{"items": "/^(syn_|semcat|pos_|possub_|lemma_|unknown_lemma\$)/", "task": "train", "ignore":

false\}, \{"items": "/./", "task": "traīn", "iḡnore": true\}, \{"items": "/^syn /", "task": "test",

"ignore": false\}, \{"items": "/./", "task": "test", "ignore": true\}

], "window_context": \{

"enabled": "on", "apply_to_input": "/./", "size": 1, "iterations": 1

\}, "tree context":

"enabled": "on", "iterations": 3, "single2pair input":

"/^(special | (special|number|entity|sortable)\$)/", "single2pair output":

"/^(lemma_| unknown_lemma\$pos_|possub_)/", "parent2child_input":

"/^(speciāl_l (special|number|entity|sortable)\$)/", "parent2child_output": "/^semcat_/", "products":

"/^(lemma | special | (special|number|entity|sortable|unknown lemma)\$)/" ]

"/^(pos_| p̄ossub_|special_| (special|number|entity|sortable)\$)/"

g11e7.json

"neural_settings":

"filters":

\{"items": "/^(syn | semcat|semgroup|pos |possub | lemma |unknown lemma\$)/", "task": "train",

"ignore": false\}, \{"items": "/./", "tašsk": "trāin", "ignore": Ērue\}, \{"items": "/^syn /",

"task": "test", "ignore": false\}, \{"items": "/./", "task": "test", "ignore": true\}

], "window_context": \{

"enabled": "on", "apply to input": "/./", "size": 1, "iterations": 1

\}, "tree context":

"enablèd": "on", "iterations": 2, "single2pair input":

"/^(special_| (special|number|entity|sortable)\$)/", "single2pair_output":

"/^(lemma_|ünknown_lemma\$|pos_|possub_)/", "parent2child_input":

"/^(speciāl_| (specīal|number|ēentity|sōrtable)\$)/", "pareñt2child_output": "/^semgroup /", "products": [

"/^(lemma_|special_| (special|number|entity|sortable|unknown_lemma) \$)/", 
$0,0266 \quad 0,9323 \quad 0,9365 \quad 0,8064 \quad 0,85160,9477$ $0,9486 \quad 0,9197$ ela:1m5s usr: $1 \mathrm{~m} 7 \mathrm{~s}$ sys:0m1s training ela: $8 \mathrm{~m} 1 \mathrm{~s}$ usr: $8 \mathrm{~m} 1 \mathrm{~s}$ sys:0m $2 \mathrm{~s}$ testing

$\begin{array}{llllll}0,0253 & 0,9357 & 0,9397 & 0,8147 & 0,8570 & 0,9497\end{array}$ $0,95140,9235$ ela: $1 \mathrm{~m} 2 \mathrm{~s}$ usr: $1 \mathrm{~m} 4 \mathrm{~s}$ sys:0m1s training ela: $8 \mathrm{~m} 19 \mathrm{~s}$ usr: $8 \mathrm{~m} 18 \mathrm{~s}$ sys:0m $2 \mathrm{~s}$ testing

$\begin{array}{llllll}0,0245 & 0,9380 & 0,9419 & 0,8203 & 0,8606 & 0,9508\end{array}$ $0,95340,9261$ ela: $1 \mathrm{~m} 1 \mathrm{~s}$ usr: $1 \mathrm{~m} 2 \mathrm{~s}$ sys:0m0s training ela: $8 \mathrm{~m} 25 \mathrm{~s}$ usr: $8 \mathrm{~m} 22 \mathrm{~s}$ sys:0m2s testing

$0,02390,9398 \quad 0,9436 \quad 0,82430,8632 \quad 0,9521$ $0,9547 \quad 0,9283$ ela:1m2s usr:1m3s sys:0m1s

g3e3.out training ela:0m6s usr:0m0s sys:0m0s testing $\begin{array}{llllll}0,1776 & 0,8217 & 0,8568 & 0,6801 & 0,7710 & 0,7632\end{array}$ $0,92110,7105$ ela:0m0s usr:0m0s sys:0m0s training ela:0m $2 \mathrm{~s}$ usr:0m1s sys:0m0s testing $\begin{array}{llllll}0,1496 & 0,7699 & 0,7949 & 0,6248 & 0,7270 & 0,7882\end{array}$ 0,8269 0,6925 ela:0m1s usr:0m2s sys:0m0s training ela:0m7s usr:0m6s sys:0m0s testing

$\begin{array}{lllllll}0,0867 & 0,8107 & 0,8212 & 0,6467 & 0,7377 & 0,8882\end{array}$ $0,8370 \quad 0,7791$ ela:0m9s usr:0m6s sys:0m0s training ela: $1 \mathrm{~m} 2 \mathrm{~s}$ usr:0m43s sys:0m0s testing $\begin{array}{lllllll}0,0477 & 0,8891 & 0,8948 & 0,7186 & 0,7917 & 0,9350\end{array}$ $0,90490,8717$ ela: $1 \mathrm{~m} 41 \mathrm{~s}$ usr: $1 \mathrm{~m} 5 \mathrm{~s}$ sys:0m0s

g3e3_5.out

trāining ela:320m41s usr:317m59s sys:1m52s testing $0,01730,95360,95650,79840,8275$ 0,9617

0,9661 0,9451 ela:1m51s usr:2m17s sys:0m10s

g4e1.out

training ela:12m16s usr:7m51s sys:0m $2 \mathrm{~s}$ testing

$0,0351 \quad 0,9282 \quad 0,9337 \quad 0,9282 \quad 0,9337 \quad 0,9444$ $0,94670,9104$ ela: $1 \mathrm{~m} 16 \mathrm{~s}$ usr: $1 \mathrm{~m} 4 \mathrm{~s}$ sys:0m0s

g4e2.out

training ela: $8 \mathrm{~m} 18 \mathrm{~s}$ usr: $8 \mathrm{~m} 15 \mathrm{~s}$ sys:0m2s testing

$\begin{array}{llllll}0,0466 & 0,8923 & 0,8979 & 0,6800 & 0,7660 & 0,9258\end{array}$ $0,91170,8756$ ela: $1 \mathrm{~m} 5 \mathrm{~s}$ usr: $1 \mathrm{~m} 5 \mathrm{~s}$ sys:0m1s

g5e1.out

training ela:9m13s usr:5m25s sys:0m2s testing

$\begin{array}{llllll}0,0354 & 0,9057 & 0,9100 & 0,7771 & 0,8310 & 0,9284\end{array}$ $0,93660,8927$ ela: $1 \mathrm{~m} 4 \mathrm{~s}$ usr:0m43s sys:0m0s

g5e2.out

training ela: $9 \mathrm{~m} 15 \mathrm{~s}$ usr: $5 \mathrm{~m} 27 \mathrm{~s}$ sys:0m 2 s testing

$\begin{array}{lllllll}0,0356 & 0,9044 & 0,9086 & 0,7764 & 0,8307 & 0,9273\end{array}$

$0,9360 \quad 0,8916$ ela:1m4s usr:0m44s sys:0m0s

g5e3.out

training ela: $9 \mathrm{~m} 19 \mathrm{~s}$ usr: $6 \mathrm{~m} 0 \mathrm{~s}$ sys:0m5s testing

$\begin{array}{llllll}0,0333 & 0,9084 & 0,9131 & 0,7837 & 0,8346 & 0,9350\end{array}$

$0,93390,8944$ ela:0m51s usr:0m43s sys:0m1s

g5e4.out

training ela: $11 \mathrm{~m} 25 \mathrm{~s}$ usr: $11 \mathrm{~m} 32 \mathrm{~s}$ sys:0m5s testing

$\begin{array}{llllll}0,0745 & 0,7948 & 0,8161 & 0,7108 & 0,7634 & 0,8587\end{array}$

$0,78990,7343$ ela:0m54s usr:0m56s sys:0m1s

g6e1.out

training ela:18m16s usr:13m55s sys:0m3s testing

$0,02840,92880,93330,79370,84290,9474$

$0,94360,9151$ ela:1m51s usr:1m52s sys:0m1s

g6e2.out

training ela:14m53s usr:10m41s sys:0m3s testing

$0,03350,91430,91950,77370,82890,9369$

$0,93350,8987$ ela:1m35s usr:1m35s sys:0m1s

g6e3.out

training ela: $10 \mathrm{~m} 29 \mathrm{~s}$ usr: $10 \mathrm{~m} 24 \mathrm{~s}$ sys:0m3s testing

$\begin{array}{llllll}0,0307 & 0,9232 & 0,9279 & 0,7844 & 0,8367 & 0,9418\end{array}$

$0,9404 \quad 0,9090$ ela:1m23s usr:1m25s sys:0m1s

g7e1.out

training ela: $7 \mathrm{~m} 23 \mathrm{~s}$ usr: $7 \mathrm{~m} 25 \mathrm{~s}$ sys:0m 2 s testing

$\begin{array}{llllll}0,0279 & 0,9304 & 0,9346 & 0,7931 & 0,8436 & 0,9478\end{array}$

$0,9462 \quad 0,9178$ ela: $1 \mathrm{mls}$ usr: $1 \mathrm{~m} 4 \mathrm{~s}$ sys:0m1s

g7e2.out

training ela:7m21s usr:7m24s sys:0m2s adaptative mode ela:0m38s usr:0m39s sys:0m0s testing

$\begin{array}{llllll}0,0311 & 0,9086 & 0,9119 & 0,7765 & 0,8293 & 0,9612\end{array}$

$0,9150 \quad 0,8989$ ela:0m59s usr: $1 \mathrm{~m} 1 \mathrm{~s}$ sys:0m0s

g7e3. out

training ela:7m28s usr:7m29s sys:0m $2 \mathrm{~s}$ adaptative mode ela:0m44s usr:0m45s sys:0m0s testing

$\begin{array}{llllll}0,0431 & 0,8576 & 0,8633 & 0,7701 & 0,8150 & 0,9430\end{array}$

$0,86500,8413$ ela:0m59s usr: $1 \mathrm{~m} 1 \mathrm{~s}$ sys:0m1s

g7e4.out

training ela:7m16s usr:7m19s sys:0m2s adaptative

mode ela:0m45s usr:0m46s sys:0m0s testing

$\begin{array}{llllll}0,0515 & 0,8256 & 0,8320 & 0,7570 & 0,7984 & 0,9341\end{array}$

$0,83350,8069$ ela:0m59s usr:1m2s sys:0m1s

g7e5.out

training ela: $7 \mathrm{~m} 41 \mathrm{~s}$ usr: $7 \mathrm{~m} 43 \mathrm{~s}$ sys:0m $2 \mathrm{~s}$ adaptative mode ela:4m29s usr:0m48s sys:0m1s testing

$0,0510 \quad 0,8540 \quad 0,8605 \quad 0,7814 \quad 0,81350,9212$

$0,87020,8343$ ela:0m56s usr:0m58s sys:0m1s

g7e6.out

training ela:7m20s usr:7m22s sys:0m2s adaptative mode ela:0m46s usr:0m48s sys:0m1s testing

$\begin{array}{llllll}0,0490 & 0,8656 & 0,8709 & 0,7879 & 0,8195 & 0,9209\end{array}$

$0,88710,8494$ ela:0m58s usr:1m0s sys:0m0s

g8e1.out

training ela: $9 \mathrm{~m} 37 \mathrm{~s}$ usr: $9 \mathrm{~m} 44 \mathrm{~s}$ sys:0m $2 \mathrm{~s}$ testing

$\begin{array}{lllllll}0,0195 & 0,9270 & 0,9314 & 0,8224 & 0,8809 & 0,9539\end{array}$

$0,92990,9137$ ela:1m0s usr:1m2s sys:0m0s

g8e2. out

training ela: $6 \mathrm{~m} 46 \mathrm{~s}$ usr: $6 \mathrm{~m} 51 \mathrm{~s}$ sys:0m $2 \mathrm{~s}$ testing

$\begin{array}{llllll}0,0224 & 0,9194 & 0,9239 & 0,8082 & 0,8693 & 0,9475\end{array}$

$0,9210 \quad 0,9059$ ela:0m44s usr:0m46s sys:0m0s

g8e3.out

training ela:9m59s usr:10m6s sys:0m3s testing

$\begin{array}{llllll}0,0180 & 0,9324 & 0,9371 & 0,8377 & 0,8911 & 0,9552\end{array}$

$0,93510,9184$ ela:1m1s usr: $1 \mathrm{~m} 3 \mathrm{~s}$ sys:0m0s

g9e1.out

training ela: $8 \mathrm{~m} 53 \mathrm{~s}$ usr: $10 \mathrm{~m} 3 \mathrm{~s}$ sys:0m5s testing

$\begin{array}{llllll}0,0266 & 0,9317 & 0,9354 & 0,8070 & 0,8518 & 0,9502\end{array}$

$0,9476 \quad 0,9206$ ela: $1 \mathrm{~m} 6 \mathrm{~s}$ usr: $1 \mathrm{~m} 14 \mathrm{~s}$ sys:0m1s

g9e2.out

training ela: $11 \mathrm{~m} 48 \mathrm{~s}$ usr:13m19s sys:0m4s testing

$0,0260 \quad 0,9035 \quad 0,9076 \quad 0,7716 \quad 0,8241 \quad 0,9433$

$0,91890,8913$ ela:3m30s usr:3m45s sys:0m1s

g9e3.out

training ela:8m59s usr: $9 \mathrm{~m} 4 \mathrm{~s}$ sys:0m4s testing

$\begin{array}{llllll}0,0285 & 0,9291 & 0,9332 & 0,7910 & 0,8417 & 0,9471\end{array}$

$0,94640,9168$ ela:0m44s usr:0m46s sys:0m1s

g9e4.out

training ela: $14 \mathrm{~m} 35 \mathrm{~s}$ usr: $14 \mathrm{~m} 42 \mathrm{~s}$ sys:0m6s testing

$\begin{array}{llllll}0,0288 & 0,9268 & 0,9310 & 0,7889 & 0,8404 & 0,9459\end{array}$

$0,9444 \quad 0,9141$ ela:1m4s usr:1m7s sys:0m0s

g9e5.out

training ela: $7 \mathrm{~m} 6 \mathrm{~s}$ usr: $7 \mathrm{~m} 12 \mathrm{~s}$ sys:0m $3 \mathrm{~s}$ testing

$\begin{array}{llllll}0,0278 & 0,9291 & 0,9333 & 0,8016 & 0,8481 & 0,9471\end{array}$

$0,94570,9165$ ela:0m51s usr:0m54s sys:0m1s

g9e6.out

training ela:19m58s usr:20m14s sys:0m6s testing

$\begin{array}{llllll}0,0274 & 0,9306 & 0,9347 & 0,8038 & 0,8494 & 0,9484\end{array}$

$0,94610,9184$ ela:1m31s usr:1m33s sys:0m1s

g9e7.out

training ela: $55 \mathrm{~m} 1 \mathrm{~s}$ usr: $56 \mathrm{~m} 3 \mathrm{~s}$ sys:0m10s testing

$\begin{array}{llllll}0,0290 & 0,9274 & 0,9314 & 0,7874 & 0,8395 & 0,9459\end{array}$

$0,9460 \quad 0,9153$ ela:4m19s usr:4m26s sys:0m1s

g9e8.out

training ela:13m46s usr:13m55s sys:0m5s testing

$\begin{array}{llllll}0,0289 & 0,9271 & 0,9310 & 0,7880 & 0,8399 & 0,9459\end{array}$

$0,94560,9152$ ela:1m16s usr:1m19s sys:0m1s 

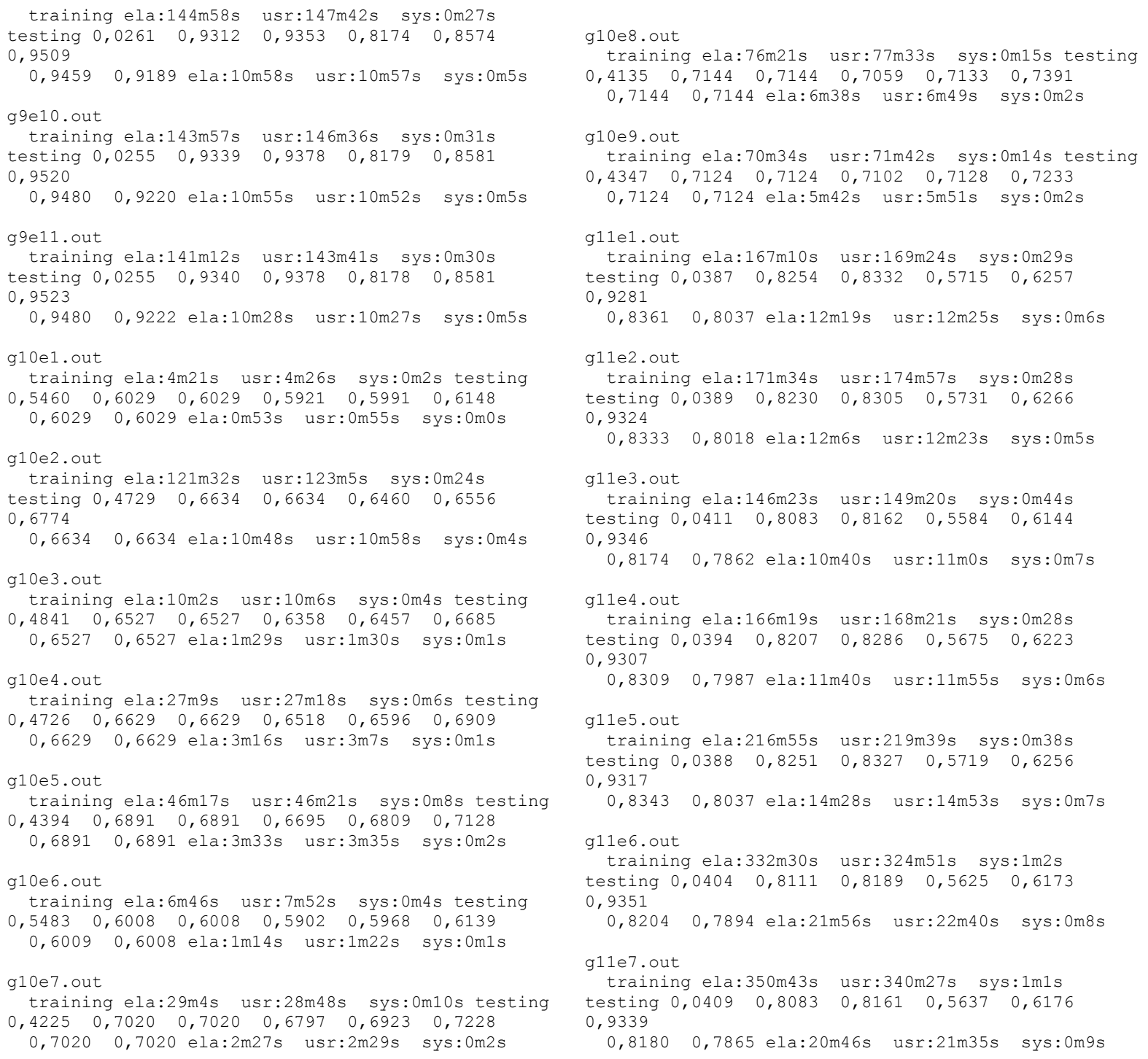

\section{A.6 Estatísticas sobre a base neural}

Esta seção apresenta estatísticas sobre as bases de dados de partes dos experimentos, além de mostrar exemplos de ativações e ajustes de peso na base neural. Por questões de espaço, apenas nove experimentos foram selecionados e detalhados nas estatísticas. As estatísticas compreendem o tamanho do experimento em disco (em megabytes), o número de neurônios e sinapses gerados, as categorias de neurônios e as maiores sinapses conectando cada (sub)categoria de neurônio. Para evitar ruído, apenas sinapses que tenham sido reforçadas pelo menos 20 vezes (com eta menor ou igual a 0,05 na última coluna) são incluídas. Os pesos dessas sinapses são detalhados na terceira coluna. O Apêndice está desatualizado em relação aos nomes dos experimentos, derivados da ordem que são executados devido a uma reordenação. 


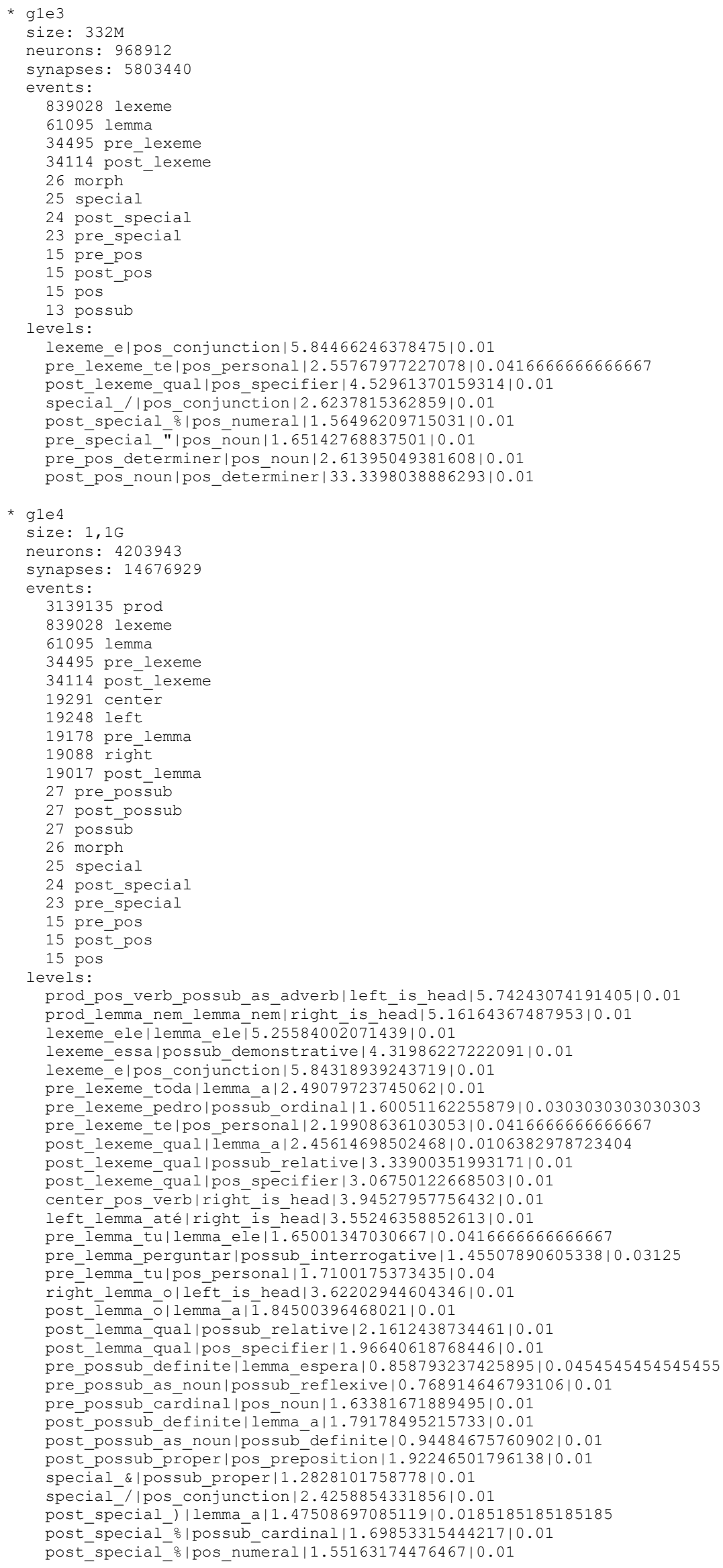


pre special, | lemma mas|0.803672812803871|0.01

pre special- ${ }^{-}$possub interrogative|1.4841872670620310.01

pre special "|pos noun|1.50543927431929|0.01

pre_pos_preposition|lemma_o|1.39519216788752|0.01

pre_pos_preposition|possub_proper|2.24953278564102|0.01

pre pos preposition|pos noun|2.48966891592501|0.01

post pos noun|lemma o|3.80270461131266|0.01

post_pos_noun|possub_definite|4.47683214253135|0.01

post_pos_noun|pos_article|4.18461959231429|0.01

* gle5

size: $1,2 \mathrm{G}$

neurons: 4204024

synapses: 16115149

events:

3139135 prod

839028 lexeme

61095 lemma

34495 pre_lexeme

34114 post_lexeme

19291 center

19248 left

19178 pre_lemma

19088 right

19017 post lemma

27 pre possub

27 post_possub

27 possub

26 morph

25 special

24 post special

23 pre_special

23 head_special

18 syn

18 pre_syn

18 post syn

15 pre_pos

15 post_pos

15 pos

levels:

prod pos verb possub as adverb|left is head/5.76890879219355/0.01

prod_lemma_cerca_number|right_is_heàd| $\overline{5} .29951435344119 \mid 0.01$

lexeme ele|lemma ele|5.309104077 $\overline{3} 224910.01$

lexeme essa|possub demonstrative|4.3823405745082310.01

lexeme quase|syn adverbial|3.94431697901038|0.01

lexeme elpos conjunction|5.83586508879123|0.01

pre lexeme tóda|lemma a|2.65342238159037|0.01

pre_lexeme_pedro|possub_ordinal|1.5837830387531310.0303030303030303

pre lexeme diferentemente|syn adverbial|2.84515265374765|0.032258064516129

pre lexeme telpos personal|2.22089206916872|0.0416666666666667

post lexemé qual| lemma a|2.67803156141991|0.0106382978723404

post_lexeme_qual|possub_relative|3.4494628632374|0.01

post_lexeme_cobrados|syn_adjunct|2.38595691298003|0.0384615384615385

post lexeme qual|pos specifier|3.13074507063658|0.01

center pos verb|right is head|4.03427455456599/0.01

left_lemma até|right is head|3.59147381432527|0.01

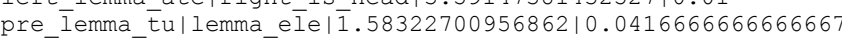

pre lemma perguntar|possub interrogative|1.52120976869197|0.03125

pre lemma antes|syn adverbial|2.49042818793558|0.01

pre lemma tulpos personal|1.71132530132596|0.04

right lemma alternolleft is head|3.59898087553612/0.01

post_Iemma_ōlemma_a|1.9 $\overline{3} 17 \overline{3} 002008891 \mid 0.01$

post lemma de|possub demonstrative|2.20809984125|0.01

post lemma aproximar|syn direct object|1.9881237704655|0.0188679245283019

post ${ }^{-}$lemma qual|pos specifier|2.03108936824696|0.01

pre_possub_definite|lemma_valor|0.933519697732893|0.01

pre_possub_as_noun|possub_reflexive|0.872605973839058|0.01

pre possub relative|syn adnominal|2.09186790155204|0.01

pre possub ordinal|pos noun|1.46365610940813|0.01

post possub definitel lemma a|1.905344339038410.01

post_possub_as_noun|possub_definite|0.948596529486689|0.01

post_possub_as_noun|syn_adjunct|2.04280399865094|0.01

post possub proper|pos preposition|1.94458735416925/0.01

special \&|possub proper|1.32953846649513|0.01

special_/|syn_coordinator|1.16979971261353|0.01

special_/|pos_conjunction|2.38608462044991|0.01

post_spécial I) lemma a|1.54358397480608|0.0185185185185185

post special )|possub cardinal|1.65701940090039|0.01

post special-) |syn prédicative|1.58059858350453|0.01

post_special_, |pos_personal|1.47292379695173|0.01

pre_special_'|lemma_ol0.732690864508454|0.01

pre_special - possub interrogative|1.47188856194821|0.01

pre special (|syn predicative|2.74058698996196|0.01

pre_special_(|pos_noun|1.62020606848302|0.01 
head special 일 lemma a|0.4489384405159|0.01

head special ${ }^{-}$- possub cardinal|0.85208885968173|0.01

head special-'! syn adverbial clause|0.909382808249404|0.0344827586206897

head_special_o|pos_numeral|0.872459795771252|0.01

pre_syn_adjunct|lemma_política|0.792017363615404|0.01

pre syn adjunct|possub possessive|0.604850242342087|0.01

pre syn subject|syn fiñite clause|2.47099005472793|0.01

pre_syn_subject|pos_verb|2.70658555354267|0.01

post_syn_infinite_clause|lemma_a|2.62761211624427|0.01

post syn subject|possub definite|2.42394257882941|0.01

post syn subject|syn adnominal|6.12254049449191|0.01

post syn direct object|pos verb|2.51874979299027|0.01

pre_pos_preposition|lemma_ō|1.28876891753008|0.01

pre_pos_preposition|possub_proper|1.9290858749262|0.01

pre pos noun|syn adnominal|2.82546948111257|0.01

pre pos preposition|pos noun|1.97616783056|0.01

post_pos_noun|lemma_ol3.73973473244221|0.01

post_pos_noun|possub_definite|4.5022240550988|0.01

post_pos_noun|syn_adnominal|3.82109817049765|0.01

post pos noun|pos article|4.20994597641562|0.01

* gle 6

size: $510 \mathrm{M}$

neurons: 1007650

synapses: 9152514

events:

839028 lexeme

61095 lemma

34495 pre_lexeme

34114 post lexeme

19178 pre_Iemma

19017 post_lemma

191 semcat

191 pre semcat

191 post semcat

26 morph

25 special

24 post_special

23 pre special

13 possub

12 pos

levels:

lexeme_ele|lemma_ele|5.81032776322768|0.01

lexeme campeão|semcat title|4.07145672020524|0.0113636363636364

pre lexeme toda|lemma a|2.4259703132741|0.01

pre_lexeme_as|semcat_hour|3.35176221111853|0.01

post__lexemé_ol lemma_à|3.85559074596001|0.01

post lexeme pontos|semcat predicating numeral|3.17636204702874|0.0147058823529412

pre lemma tullemma ele|1.86839864444677|0.0416666666666667

pre lemma volante|semcat title|2.24352540787567|0.0294117647058824

post__lemmā_ollemma_a|8.32 75615046329310.01

post_lemma_pontolsemcat_predicating_numeral|2.99970195205565|0.0120481927710843

pre_semcat_speak_work|lemma_a|0.995412156640253|0.01

pre semcat human group|semcat geographical location|1.21136421727972|0.0263157894736842

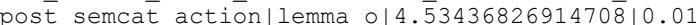

post_semcat_duration|semcat_quantity|2.08187051989609|0.01

specíal_\&|semcat_organization|0.524742058978542|0.01

post special )|lemma a|1.98114965947352|0.0185185185185185

post special \%| semcat quantity|3.15125438145671|0.01

pre special o lemma a|0.96250854099046210.01

pre_special_"|semcat_title|3.51558875905818|0.01

* g9e10

size: $1,2 \mathrm{G}$

neurons: 4203998

synapses: 16109761

events:

3139135 prod

839028 lexeme

61095 lemma

34495 pre_lexeme

34114 posṫlexeme

19291 center

19248 left

19178 pre lemma

19088 rightt

19017 post lemma

27 pre possub

27 post possub

27 possub

26 morph

25 special

24 post special

23 pre special 
18 syn

18 pre syn

18 post_syn

15 pre_pos

15 post pos

15 pos

levels:

prod_pos_verb_possub_as_adverb|left_is_head|5.76638623131029|0.01

prod_lemma_nem_lemma_nem|right_is_head|5.22831435759229|0.01

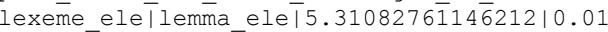

lexeme essa|possub demonstrative|4.3811143651878|0.01

lexeme quase|syn adverbial|3.95067127509489|0.01

lexeme_elpos_conjunction|5.8428954258174|0.01

pre lexeme tóda|lemma a|2.65053909335803|0.01

pre_lexeme_pedro|possub_ordinal|1.58183654699299|0.0303030303030303

pre lexeme diferentemente|syn adverbial|2.84677255114628|0.032258064516129

pre ${ }^{-}$lexeme telpos personal|2. $22522500937737 \mid 0.0416666666666667$

post lexeme qual| lemma a|2.67545017332832|0.0106382978723404

post_lexeme_qual|possub_relative|3.44879571451746|0.01

post lexeme cobrados|syn adjunct|2.40323179969253|0.0384615384615385

post lexeme qual|pos specifier|3.13247347406323|0.01

center pos verb|right is head|4.03453659818004/0.01

left lemma até|right is head|3.5828784791902210.01

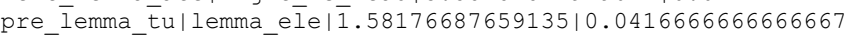

pre lemma perguntar|possub interrogative|1.52103834113925|0.03125

pre lemma antes|syn adverbíal|2.49176895967493|0.01

pre_lemma_tulpos_personal|1.71450816758834|0.04

right_lemma_alternolleft_is_head|3.59586272220686|0.01

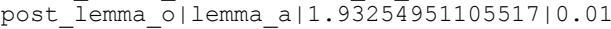

post lemma qual|possub relative|2.20836970502372|0.01

post lemma aproximar|syn direct object|1.98662825737501|0.0188679245283019

post_lemma_qual|pos_specifier|2.03284515833174|0.01

pre_possub_definite|lemma_valor|0.933311897290176|0.01

pre possub as noun|possub reflexive|0.865872504244447|0.01

pre possub relative|syn adnominal|2.09793878222109|0.01

pre possub ordinal|pos ñoun|1.44109000873441|0.01

post_possub_definite|lemma_a|1.90680891838693/0.01

post_possub_as_noun|possub_definite|0.943324658524025|0.01

post possub as noun|syn adjunct|2.01091633575059|0.01

post possub proper|pos preposition|1.95973807700661|0.01

special_\&|possub_proper|1.33616292154194|0.01

special_/|syn_coordinator|1.16864199252064|0.01

special_/|pos_conjunction|2.38838262770963|0.01

post special, |lemma ela|1.54345168681187|0.01

post special $\%$ possub cardinal|1.67148193515872|0.01

post_special_)|syn_prēdicative|1.58869942615325|0.01

post_special_o|pos_numeral|1.55778213200299|0.01

pre_special_, |lemmāmas|0.73482847603258|0.01

pre special-|possub interrogative|1.46909264525245|0.01

pre special (|syn prédicative|2.7311820586163|0.01

pre special" "|pos noun|1.58118920101233|0.01

pre_syn_adjunct|lemma_política|0.791828708547548|0.01 pre_syn_adjunct|possub_possessive|0.60505686310271|0.01 pre syn subject|syn finite clause|2.47480168344716/0.01 pre syn subject|pos verb|2.71014681534491|0.01

post_syn_infinite_clause|lemma_a|2.62455544550737|0.01 post_syn_subject|possub_definite|2.42920726202951|0.01 post syn subject|syn adnominal|6.12486742520279|0.01 post syn direct object|pos verb|2.51627137579758|0.01 pre pos preposition|lemma ól1.28298470997568|0.01

pre_pos_preposition|possub_proper|1.93098640307324|0.01 pre pos noun|syn adnominal|2.83396213410798|0.01

pre pos preposition|pos noun|1.96794086949392/0.01

post pos noun|lemma o|3.75665552434541|0.01

post_pos_noun|possub_definite|4.51354640529217|0.01

post_pos_noun|syn_adñominal|3.80513976233413|0.01

post_pos_noun|pos_article|4.22394260609287|0.01

* g9e11

size: $1,2 \mathrm{G}$

neurons: 4203997

synapses: 16099765

events:

3139135 prod

839028 lexeme

61095 lemma

34495 pre lexeme

34114 post lexeme

19291 centèr

19248 left

19178 pre_lemma

19088 right

19017 post lemma

27 pre possub 
27 post possub

27 possub

26 morph

25 special

24 post_special

23 pre_special

18 syn

18 pre_syn

18 post_syn

15 pre pos

15 post_pos

15 pos

levels:

prod_pos_verb_possub_as_adverb|left_is_head|5.77981434052638|0.01

prod lemma nem lemma nem|right is head|5.22385501059179|0.01

lexeme ele|lemma ele|5.30805005961255|0.01

lexeme-essa|possūb demonstrative|4.379572833361410.01

lexeme_quase|syn_adverbial|3.9425922006059210.01

lexeme_elpos_conjunction|5.84131647185061|0.01

pre lexeme toda|lemma a|2.58501018008062|0.01

pre lexeme pedro|possub ordinal|1.58602088351566|0.0303030303030303

pre lexeme diferentemente|syn adverbial|2.84934687879845|0.032258064516129

pre_lexeme_telpos_personal|2.2̄0639257196804|0.0416666666666667

post_lexeme_qual| Iemma_a|2.6794717621607|0.0106382978723404

post lexeme qual|possub relative|3.44791699809217|0.01

post lexeme cobrados|syn adjunct|2.39566231964378|0.0384615384615385

post_lexeme_qual|pos_specifier|3.13256608038941|0.01

centēr_pos_verb|right_is_head|4.03928683146915/0.01

left lemma até|right is head|3.57715536988654|0.01

pre lemma tu|lemma ele|1.58242918986728|0.0416666666666667

pre lemma perguntar|possub interrogative|1.52124401389155|0.03125

pre_lemma_antes|syn_adverbíal|2.49413973142105|0.01

pre_lemma_tu|pos_personal|1.7086942756013210.04

right lemma olle fet is head|3.62123758500557|0.01

post lemma ollemma a|1.93647945399216|0.01

post_lemma_qual|possub_relative|2.2183983460923|0.01

post_lemma_aproximar|sȳn_direct_object|1.98651475374884|0.0188679245283019

post_lemma_qual|pos_specifier|2.04098715752331|0.01

pre possub definite|lemma valor|0.939192402411175|0.01

pre possub as noun|possub reflexive|0.866501844900769|0.01

pre_possub_rēative|syn_ā̄nominal|2.1037926310524|0.01

pre_possub_ordinal|pos_ñoun|1.44404366765316|0.01

post_possub_definite|lemma_a|1.90763621876321|0.01

post possub as noun|possub definite|0.938257267678675|0.01

post possub as noun|syn adjunct|2.02732671723836|0.01

post_possub_proper|pos_preposition|1.95417206685361|0.01

special_\&|possub_proper|1.33513624716587|0.01

special_/|syn_coordinator|1.17416631314534|0.01

special /|pos conjunction|2.38898665311651|0.01

post special, lemma ela|1.54512604948347|0.01

post_special_o|possub_cardinal|1.67361617316575|0.01

post_special_) |syn_predicative|1.57753157969609|0.01

post_special_olpos_numeral|1.56250833044798|0.01

pre special, lemma mas|0.735275427526778|0.01

pre special ${ }^{-}$- possub interrogative|1.46912918529973|0.01

pre_special_(|syn_prédicative|2.82830995023264|0.01

pre_special_"|pos_noun|1.58276009104031|0.01

pre_syn_adjunct|lemma_política|0.785255691525244|0.01

pre syn adjunct|possub possessive|0.603493120776272|0.01

pre syn subject|syn fiñite clause|2.47438282397677|0.01

pre_syn_subject|pos_verb|2.70565315429319|0.01

post_syn_infinite_clause|lemma_a|2.62218465880792|0.01

post syn subject|possub definite|2.41863447020156|0.01

post syn subject|syn adnominal|6.14201758703906|0.01

post syn_direct object|pos verb|2.51764364296757|0.01

pre_pos_preposition|lemma_ōl1.29296170542172|0.01

pre_pos_preposition|possub_proper|1.93954631044258|0.01

pre pos noun|syn adnominal|2.81244005582804|0.01

pre pos preposition|pos noun|1.97461800272013/0.01

post pos noun|lemma o|3.73750108514024|0.01

post_pos_noun|possub_definite|4.50292643608025|0.01

post_pos_noun|syn_adnominal|3.79679152738132|0.01

post pos noun|pos article|4.21246712714499|0.01

* g9e1

size: $333 \mathrm{M}$

neurons: 969485

synapses: 5810102

events:

839028 lexeme

61095 lemma

34495 pre_lexeme

34114 post lexeme

191 suffix 


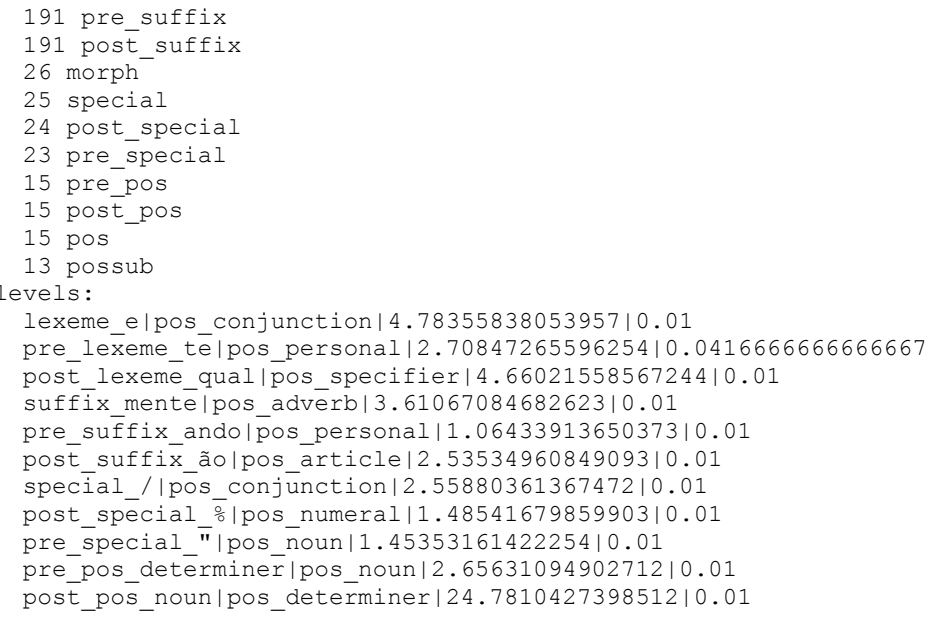

A seguir, são apresentados exemplos de ativação e ajustes de peso ilustrando a coativação com o vetor $\mathrm{B}$ ( $\mathrm{g} 5 \mathrm{e} 1)$ e a ativação simples para a matriz C (g10e1). No primeiro exemplo, o ajuste de pesos é feito para neurônios pos. Além disso, por questões de espaço, a primeira iteração de ativação de g5e1 é omitida. No segundo exemplo, ajustes são feitos para pseudo-neurônios dep, ou seja, são realizados na matriz C. Em ambos os exemplos, blocos iniciados por "activation" denotam a ativação de um único neurônio de saída, blocos denotados por "pattern" mostram b e c-padrões formados e blocos iniciados por "update" denotam ajustes de pesos.

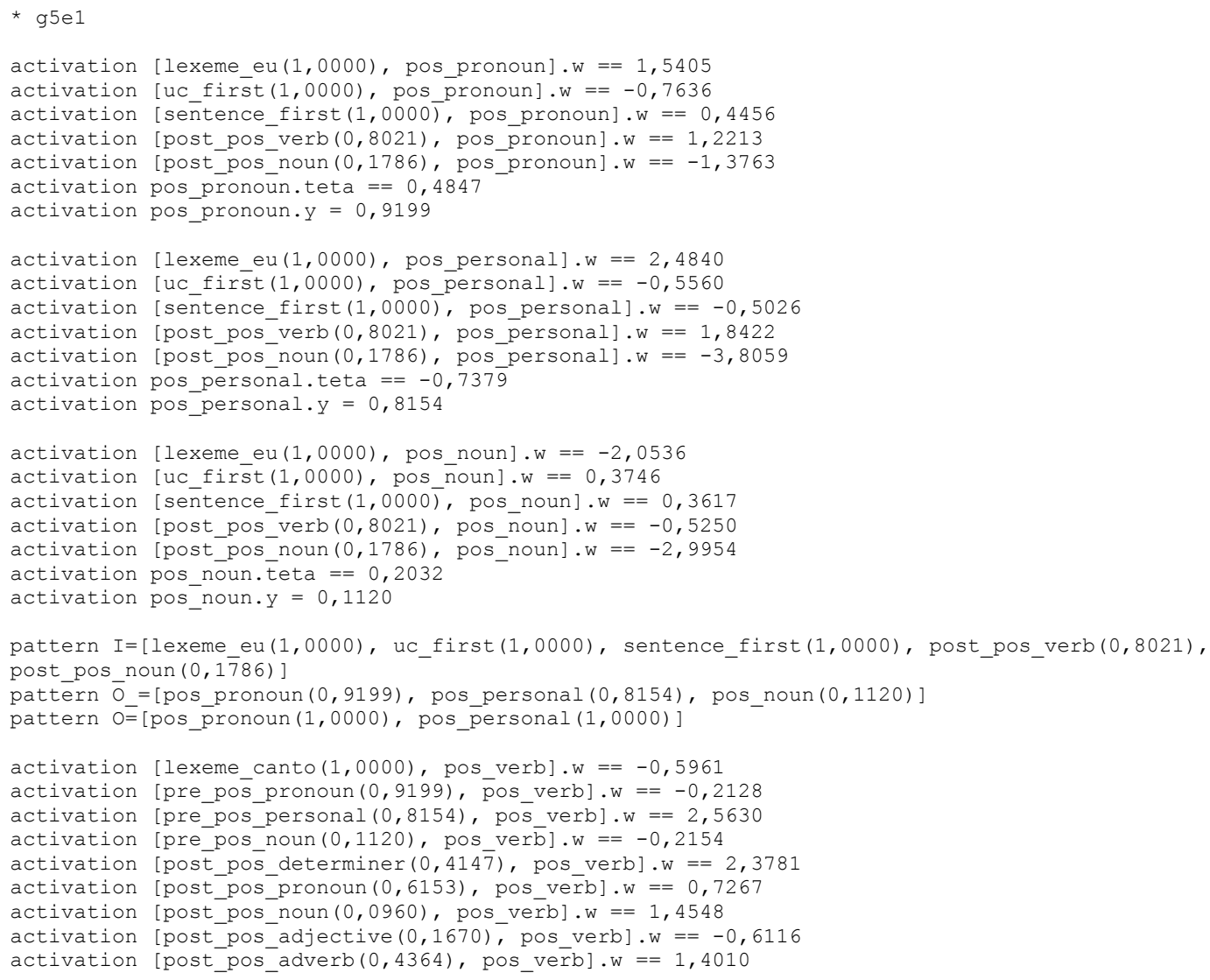




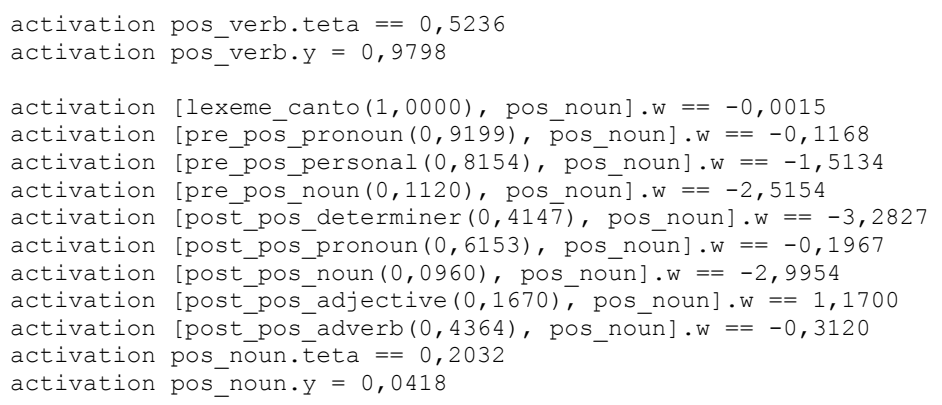

pattern I=[lexeme_pouco $(1,0000)$, sentence_last $(1,0000)$, pre_pos_verb $(0,9798)$, pre_pos_noun $(0,0418)]$ pattern $O_{-}=[$pos determiner $(0,4789)$, pos_pronoun $(0,5857)$, pos_noun $(0,1302)$, pos_adject $\bar{i} v e(0,1259)$, pos adverb $(0,4500)]$

pattern $O=[$ pos_pronoun $(1,0000)$, pos_adverb $(1,0000)]$

update: [lexeme_eu, pos_pronoun]. $w==1,5413(1,5405)$

update: [lexeme eu, pos pronoun].eta $==0,0100(0,0100)$

update: [uc first, pos pronoun]. $\mathrm{w}==-0,7628 \quad(-0,7636)$

update: [ucfirst, pos pronoun].eta $==0,0100(0,0100)$

update: [sentence_first, pos_pronoun].w $=0=0,4464(0,4456)$

update: [sentence_first, pos_pronoun]. eta $==0,0100(0,0100)$

update: [post pos verb, pos pronoun]. $\mathrm{w}==1,2221(1,2213)$

update: [post pos verb, pos pronoun]. eta $==0,0100(0,0100)$

update: [post_pos_noun, pos_pronoun]. $w==-1,3763(-1,3763)$

update: [post_pos_noun, pos_pronoun].eta $==0,0100(0,0100)$

update: pos_pronoun.teta $=\overline{0}, 4855(0,4847)$

update: pos pronoun.eta $=0,0100(0,0100)$

update: [lexeme_eu, pos_personal]. $w==2,4858(2,4840)$

update: [lexeme_eu, pos_personal].eta $==0,0100(0,0100)$

update: [uc first, pos personal].w $==-0,5541(-0,5560)$

update: [uc first, pos personal].eta $==0,0100(0,0100)$

update: [sentence first, pos_personal]. $w==-0,5008 \quad(-0,5026)$

update: [sentence_first, pos_personal].eta $==0,0100(0,0100)$

update: [post_pos_verb, pos_personal].w $==1,8440(1,8422)$

update: [post pos verb, pos personal].eta $==0,0100(0,0100)$

update: [post pos noun, pos personal]. $w=-3,8058 \quad(-3,8059)$

update: [post_pos_noun, pos_personal].eta $==0,0100(0,0100)$ 
update: pos personal.teta $=-0,7360(-0,7379)$

update: pos_personal.eta $=0,0100(0,0100)$

update: [lexeme_eu, pos_noun] $. \mathrm{w}==-2,0547 \quad(-2,0536)$

update: [lexeme eu, pos noun]. eta $==0,0100(0,0100)$

update: [uc first, pos noun]. $w=0,3735(0,3746)$

update: [uc first, pos noun].eta $==0,0100(0,0100)$

update: [sentence_first, pos_noun].w $=0,3606(0,3617)$

update: [sentence_first, pos_noun]. eta $==0,0100(0,0100)$

update: [post_pos_verb, pos_noun].w $==-0,5261(-0,5250)$

update: [post pos verb, pos noun]. eta $==0,0100 \quad(0,0100)$

update: [post pos noun, pos noun]. $\mathrm{w}==-2,9955(-2,9954)$

update: [post_pos_noun, pos_noun].eta $==0,0100(0,0100)$

update: pos noun. $\overline{\text { teta }}=0,2 \overline{0} 20(0,2032$

update: pos noun.eta $=0,0100(0,0100)$

update: [lexeme_canto, pos_verb] $. \mathrm{w}==-0,5949(-0,5961)$

update: [lexeme_canto, pos_verb].eta $==0,0526(0,0556)$

update: [pre_pos_pronoun, pos_verb].w $==-0,2127(-0,2128$

update: [pre pos pronoun, pos verb]. eta $==0,0100(0,0100)$

update: [pre pos personal, pos verb]. $\mathrm{w}==2,5632(2,5630)$

update: [pre_pos_personal, pos_verb].eta $==0,0100(0,0100)$

update: [pre_pos_noun, pos_verb] $. w==-0,2154(-0,2154)$

update: [pre pos noun, pos verb]. eta $==0,0100(0,0100)$

update: [post pos determiner, pos verb]. $w==2,3782(2,3781)$

update: [post pos determiner, pos verb].eta $==0,0100(0,0100)$

update: [post_pos_pronoun, pos_verb].w $==0,7268(0,7267)$

update: [post_pos_pronoun, pos_verb] .eta $==0,0100(0,0100)$

update: [post_pos_noun, pos_verb].w $==1,4548(1,4548)$

update: [post pos noun, pos verb]. eta $==0,0100(0,0100)$

update: [post pos adjective, pos verb]. $\mathrm{w}==-0,6116(-0,6116)$

update: [post_pos_adjective, pos_verb].eta $==0,0100(0,0100)$

update: [post_pos_adverb, pos_verb].w $==1,4011(1,4010)$

update: [post_pos_adverb, pos_verb].eta $==0,0100(0,0100)$

update: pos verb.teta $=0,5238(0,5236)$

update: pos_verb.eta $=0,0100(0,0100)$

update: [lexeme_canto, pos_noun].w $==-0,0039(-0,0015)$

update: [lexeme canto, pos noun]. eta $==0,0556(0,0588)$

update: [pre pos pronoun, pos noun]. $\mathrm{w}==-0,1172(-0,1168)$

update: [pre_pos_pronoun, pos_noun].eta $==0,0100(0,0100)$

update: [pre_pos_personal, pos_noun].w $==-1,5137(-1,5134)$

update: [pre_pos_personal, pos_noun].eta $==0,0100(0,0100)$

update: [pre_pos_noun, pos_noun]. $\mathrm{w}==-2,5154 \quad(-2,5154)$

update: [pre pos noun, pos noun]. eta $==0,0100(0,0100)$

update: [post_pos_determiner, pos_noun].w $==-3,2829(-3,2827)$

update: [post_pos_determiner, pos_noun].eta $==0,0100(0,0100)$

update: [post_pos_pronoun, pos_noun].w $==-0,1969(-0,1967)$

update: [post pos pronoun, pos noun].eta $==0,0100 \quad(0,0100)$

update: [post pos noun, pos noun].w $==-2,9955(-2,9955)$

update: [post_pos_noun, pos_noun].eta $==0,0100(0,0100)$

update: [post_pos_adjective, pos_noun].w $==1,1699(1,1700)$

update: [post_pos_adjective, pos_noun].eta $==0,0100(0,0100)$

update: [post pos adverb, pos noun].w $==-0,3122(-0,3120)$

update: [post pos adverb, pos noun]. eta $==0,0100 \quad(0,0100)$

update: pos_noun. $\overline{\text { teta }}=0,201 \overline{6}(0,2020)$

update: pos_noun.eta $=0,0100(0,0100)$

update: [lexeme pouco, pos pronoun].w $==-0,0507 \quad(-0,0549)$

update: [lexeme pouco, pos pronoun]. eta $==0,0100(0,0100)$

update: [sentence_last, pos_pronoun]. $\mathrm{w}==0,3175(0,3134)$

update: [sentence_last, pos_pronoun].eta $==0,0100(0,0100)$

update: [pre pos verb, pos pronoun]. w $==-0,4163(-0,4203)$

update: [pre pos verb, pos pronoun]. eta $==0,0100 \quad(0,0100)$

update: [pre_pos_noun, pos_pronoun]. $w=0,3564(0,3562)$

update: [pre_pos_noun, pos_pronoun].eta $==0,0100(0,0100)$

update: pos_pronoun.teta $=0,4896(0,4855)$

update: pos pronoun.eta $=0,0100(0,0100)$

update: [lexeme_pouco, pos_adverb]. $\mathrm{w}==-0,3487(-0,3542)$

update: [lexeme_pouco, pos_adverb]. eta $==0,0100(0,0100)$

update: [sentence_last, pos_adverb]. $\mathrm{w}_{\mathrm{s}}==0,0538(0,0483)$

update: [sentence last, pos adverb].eta $==0,0100(0,0100)$

update: [pre pos verb, pos àdverb].w $==0,0951(0,0897)$

update: [pre_pos_verb, pos_adverb].eta $==0,0100(0,0100)$

update: [pre_pos_noun, pos_adverb].w $==-0,2871(-0,2873)$

update: [pre pos noun, pos adverb].eta $==0,0100(0,0100)$

update: pos adverb.teta $=0,0348(0,0293)$

update: pos_adverb.eta $=0,0100(0,0100)$

update: [lexeme_pouco, pos_determiner]. $\mathrm{w}==0,1125(0,1173)$

update: [lexeme pouco, pos determiner].eta $==0,0100(0,0100)$

update: [sentence last, pos determiner]. $\mathrm{w}==0,6231(0,6279)$

update: [sentence_last, pos_determiner].eta $==0,0100(0,0100)$ 


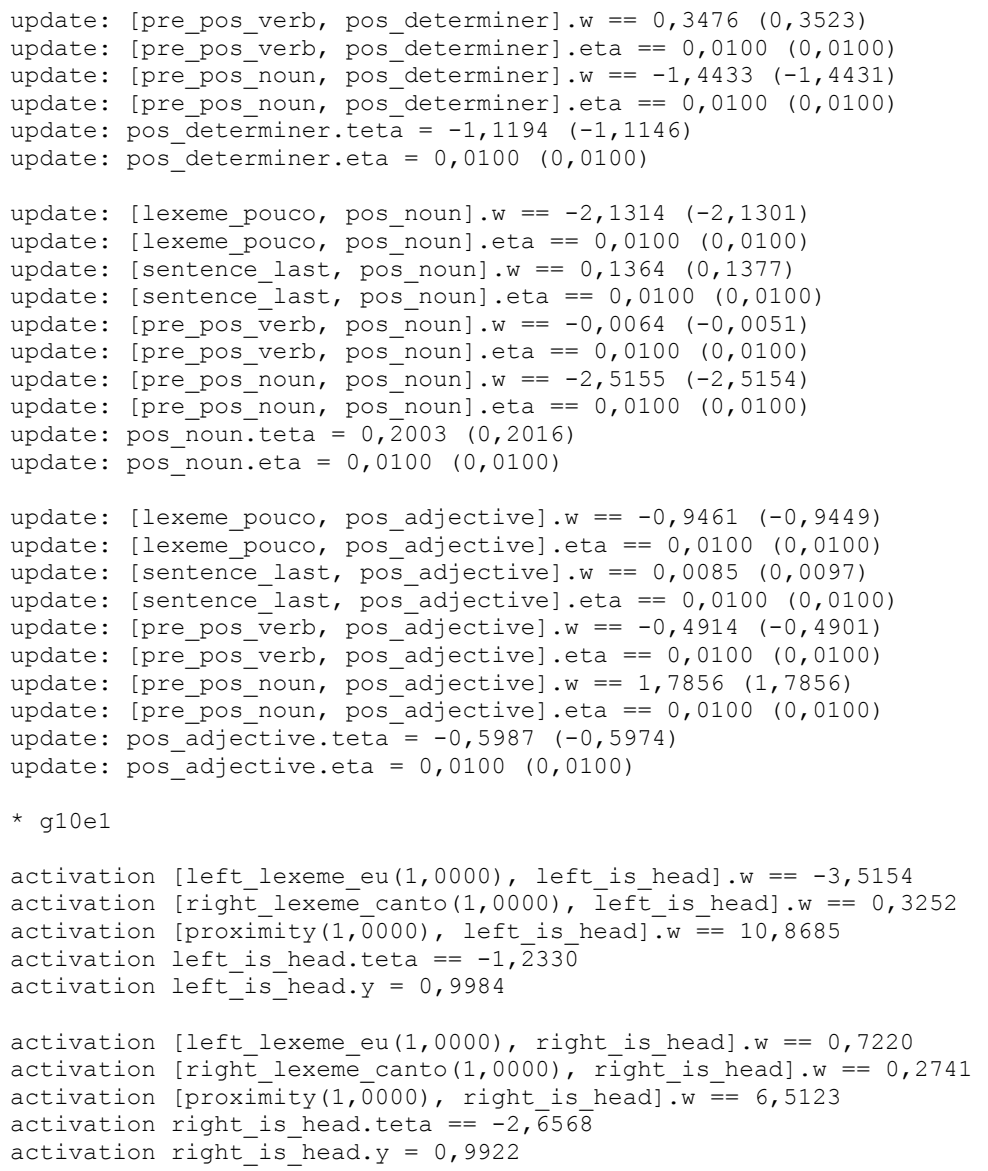

pattern I=[left lexeme eu(1,0000), right_lexeme_canto(1,0000), proximity (1,0000)] pattern o_=[left_is_head $(0,9984)$, right_is_head $(0,9922)]$ pattern $\mathrm{O}=[$ right_is_head $(0,0000)]$

activation [left_lexeme_eu $(1,0000)$, left_is_head] $. w==-3,5154$

activation [right_lexemé_pouco $(1,0000), \bar{l} e f \bar{t}$ is_head] $. w==-1,4286$

activation [proximity $(0, \overline{5} 000)$, left is head]. $w_{=}=10,8685$

activation left_is_head.teta $==-1, \overline{2} 33 \overline{0}$

activation left_is_head.y $=0,3224$

activation [left lexeme eu $(1,0000)$, right is head]. $w==0,7220$

activation [right lexeme pouco(1,0000), right is head].w $==-3,3239$

activation [proximity $(0, \overline{5} 000)$, right_is_head]. ${ }^{-}=6,5123$

activation right_is_head.teta $==-2, \overline{6} 56 \overline{8}$

activation right_is_head.y $=0,1189$

pattern I=[left_lexeme_eu(1,0000), right_lexeme_pouco (1,0000), proximity $(0,5000)]$ pattern $O_{-}=[$left_is_head $(0,3224)$, right_is_head $(0,1189)]$ pattern $\mathrm{O}=[\mathrm{]}$

activation [center lexeme eu $(1,0000)$, right is head] $\cdot \mathrm{w}==-2,6454$

activation $[\operatorname{root}(1,0000)$, right_is_head].w $==\overline{3}, 0953$

activation right_is_head.teta $==-\overline{2}, 6568$

activation right_is_head.y = 0,0991

pattern $I=[$ center_lexeme_eu $(1,0000), \operatorname{root}(1,0000)]$

pattern o_=[right_is_head $(0,0991)]$

pattern $\mathrm{O}^{-}=[]$

activation [left lexeme canto $(1,0000)$, left is head]. $\mathrm{w}==-1,3964$

activation [right lexeme pouco(1,0000), left is head]. w $==-1,4286$

activation [right_lexeme_pouco (1,0000), left_is_head]. W $=$

activation left_is_head.teta $==-1, \overline{2} 33 \overline{0}$

activation left is head.y $=0,9989$

activation [left lexeme canto $(1,0000)$, right is head] $. \mathrm{w}==-0,7722$

activation [right_lexeme_pouco $(1,0000)$, right_is $\bar{s}_{-}$head] $. w==-3,3239$

activation [proximity $(1,0000)$, right_is_head].w $=6,5123$

activation right is head.teta $==-2, \overline{6} 56 \overline{8}$

activation right ${ }^{-}$is head. $y=0,4401^{-}$ 
pattern $I=[$ left lexeme canto (1,0000), right lexeme pouco (1,0000), proximity $(1,0000)]$ pattern $O=[$ left is head $(0,9989)$, right is head $(0, \overline{4} 401)]$ pattern $\bar{O}=[$ left_is_head $(0,0000)]$

activation [center_lexeme_canto $(1,0000)$, right_is_head] $\cdot \mathrm{w}==-1,5329$ activation [root $(1,0000)$, right is head] $\cdot \mathrm{w}==\overline{3}, 0 \overline{95} 3$

activation right is head.teta $=\overline{=}-\overline{2}, 6568$

activation right_is_head.y $=0,2508$

pattern $I=[$ center_lexeme_canto $(1,0000), \operatorname{root}(1,0000)]$

pattern $0=[$ right is head $(0,2508)]$

pattern $\mathrm{O}=[$ right_is_thead $(0,0000)]$

activation [center_lexeme_pouco $(1,0000)$, right_is_head] $\cdot \mathrm{w}==-2,2359$

activation $[\operatorname{root}(1,0000)$, right_is head]. $w==\overline{3}, 0 \overline{9} 53$

activation right is head.teta $==-2,6568$

activation right_is_head.y $=0,1422$

pattern $I=[$ center_lexeme_pouco $(1,0000), \operatorname{root}(1,0000)]$

pattern $O_{-}=[$right_is_head $(0,1422)]$

pattern $\mathrm{O}=[]$

update: [left_lexeme_eu, left_is_head].w $==-3,5254(-3,5154)$

update: [left lexeme eu, left is head].eta $==0,0100(0,0100)$

update: [right lexeme canto, left is head]. $\mathrm{w}==0,3152(0,3252)$

update: [right lexeme canto, left is head].eta $==0,0100(0,0100)$

update: [proximity, left_is_head]. $\cdot \mathrm{w}=10,8585(10,8685)$

update: [proximity, left_is_head].eta $==0,0100(0,0100)$

update: left_is_head.tet $\bar{a}=-1,2430(-1,2330)$

update: left is head.eta $=0,0100(0,0100)$

update: [left_lexeme_eu, right_is_head]. $w==0,7220(0,7220)$

update: [left_lexeme_eu, right_is_head].eta $==0,0100(0,0100)$

update: [right_lexeme_canto, right_is_head].w $==0,2742(0,2741)$

update: [right lexeme canto, right is head]. eta $==0,0100 \quad(0,0100)$

update: [proximity, right_is_head]. w $=6,5124(6,5123)$

update: [proximity, right_is_head].eta $==0,0100(0,0100)$

update: right is head. tet $\bar{a}=-2,6568(-2,6568)$

update: right is head.eta $=0,0100(0,0100)$

update: [left_lexeme_eu, right_is_head].w $==0,7221(0,7220)$

update: [left_lexeme_eu, right_is_head].eta $==0,0100(0,0100)$

update: [right_lexemécanto, right__is_head].w $==0,2743(0,2742)$

update: [right lexeme canto, right is head].eta $==0,0100(0,0100)$

update: [proximity, right is head]. w $==6,5125(6,5124)$

update: [proximity, right_is_head].eta $==0,0100(0,0100)$

update: right_is_head.teta $=--2,6567(-2,6568)$

update: right_is_head.eta $=0,0100(0,0100)$

update: [left lexeme eu, right is head]. $w==0,7222(0,7221)$

update: [left_lexeme_eu, right_is_head].eta $==0,0100(0,0100)$

update: [right_lexeme_canto, right_is_head].w $==0,2744(0,2743)$

update: [right lexeme canto, right is head].eta $==0,0100(0,0100)$

update: [proximity, right is head]. $\mathrm{w}==6,5125(6,5125)$

update: [proximity, right ${ }^{-}{ }^{-}$head] .eta $==0,0100(0,0100)$

update: right_is_head.teta $=-2,6566(-2,6567)$

update: right_is_head.eta $=0,0100(0,0100)$

update: [left lexeme eu, left is head]. $\mathrm{w}==-3,5286(-3,5254)$

update: [left lexeme eu, left ${ }^{-}{ }^{-}{ }^{-}$head] .eta $==0,0100(0,0100)$

update: [right_lexeme_pouco, left_is_head].w $==-1,4318(-1,4286)$

update: [right_lexeme_pouco, left_is_head].eta $==0,0100(0,0100)$

update: [proximity, left_is_head].w $==10,8569(10,8585)$

update: [proximity, left is head].eta $==0,0100 \quad(0,0100)$

update: left is head.tet $\bar{a}=-1,2462(-1,2430)$

update: left_is_head.eta $=0,0100(0,0100)$

update: [left lexeme eu, right is head]. $\mathrm{w}==0,7210(0,7222)$

update: [left ${ }^{-}$lexeme eu, right ${ }^{-}$is head].eta $==0,0100(0,0100)$

update: [right_lexeme_pouco, right_is_head].w $==-3,3251(-3,3239)$

update: [right_lexeme_pouco, right_is_head].eta $==0,0100(0,0100)$

update: [proximity, right_is_head]. ${ }_{\mathrm{w}}==6,5119(6,5125)$

update: [proximity, right is head].eta $==0,0100(0,0100)$

update: right is head. tet $\bar{a}=-2,6578(-2,6566)$

update: right_is_head.eta $=0,0100(0,0100)$

update: [center_lexeme_eu, right_is_head].w $==-2,6463(-2,6454)$

update: [center lexeme eu, right is head]. eta $==0,0100 \quad(0,0100)$

update: [root, $\overline{r i g h t}$ is head] $. \mathrm{w} \overline{=}=\overline{3}, 0944 \quad(3,0953)$

update: [root, right_is_head].eta $==0,0100(0,0100)$

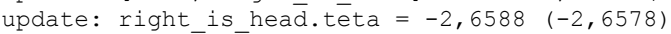

update: right is head.eta $=0,0100(0,0100)$

update: [left_lexeme_canto, right_is_head].w $==-0,7766(-0,7722)$ 


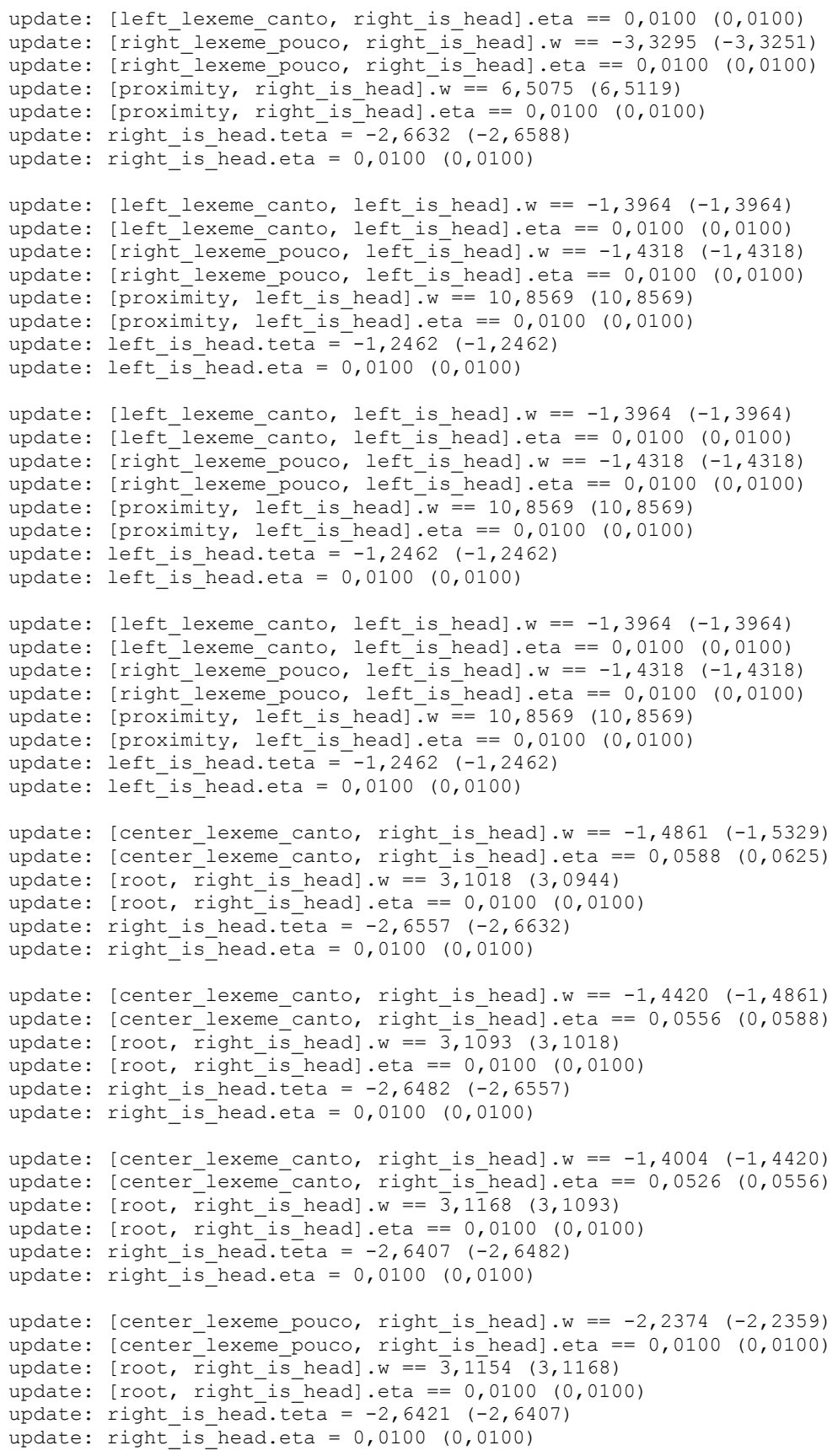




\section{Apêndice B - Detalhes do Modelo Sinsim}

\section{B.1 Fenômenos tratados neste trabalho}

\section{B.1.1 Subordinadas adjetivas}

Esta seção apresenta os casos restantes de orações subordinadas adjetivas não apresentados na Seção 4.2.3. A seguir, são mostrados os casos não tratados "como”, “onde”, "quando", "quem" e "quanto".

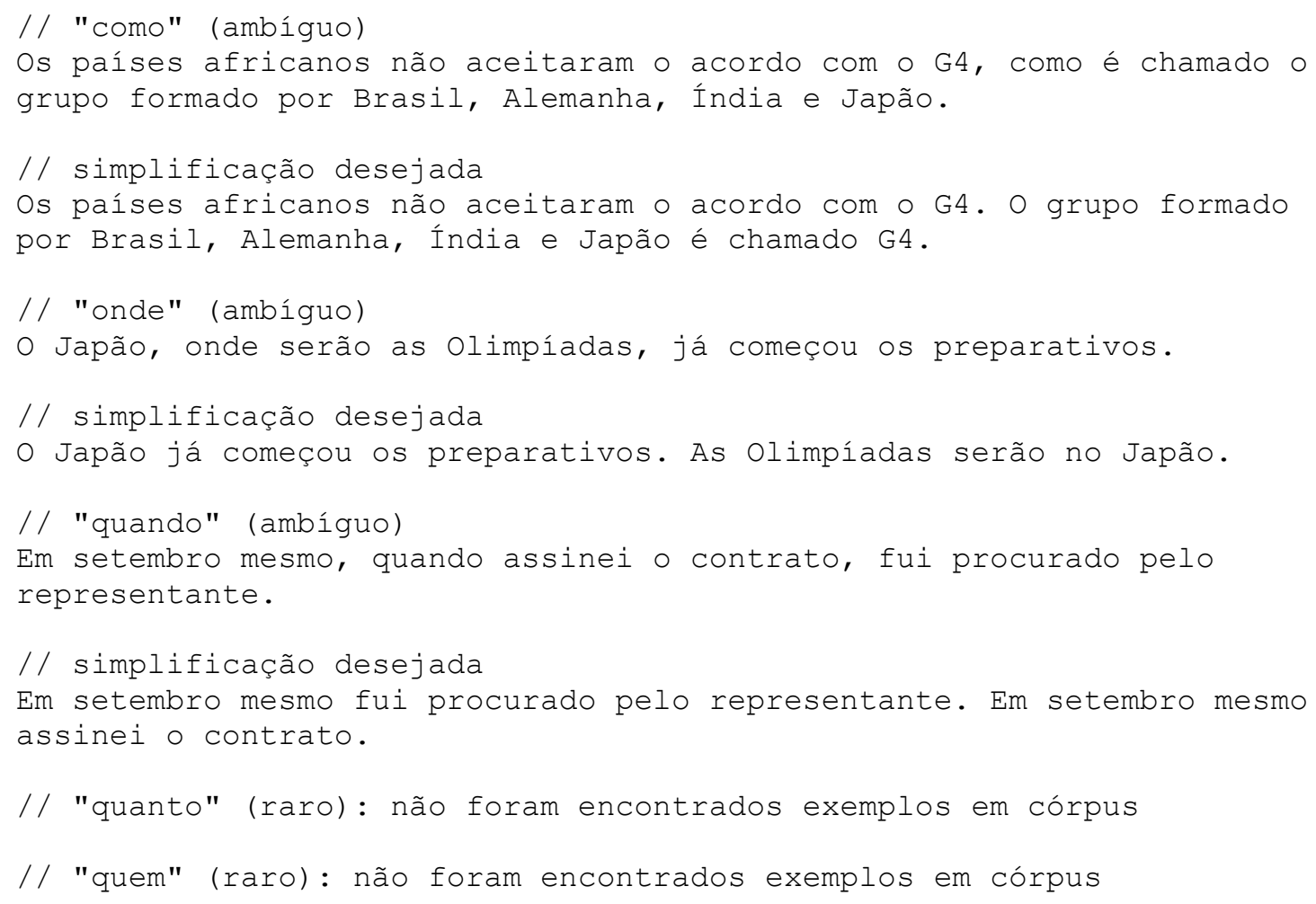

Exemplo B.1: Casos não tratados nas subordinadas adjetivas.

Caso "cujo".

// caso padrão (correto)

Silva deveria visitar ainda ontem as áreas mais atingidas, inclusive o prédio em São Paulo cujo desabamento matou 16 pessoas. 
16 pessoas.

Exemplo B.2: Caso “cujo" nas subordinadas adjetivas.

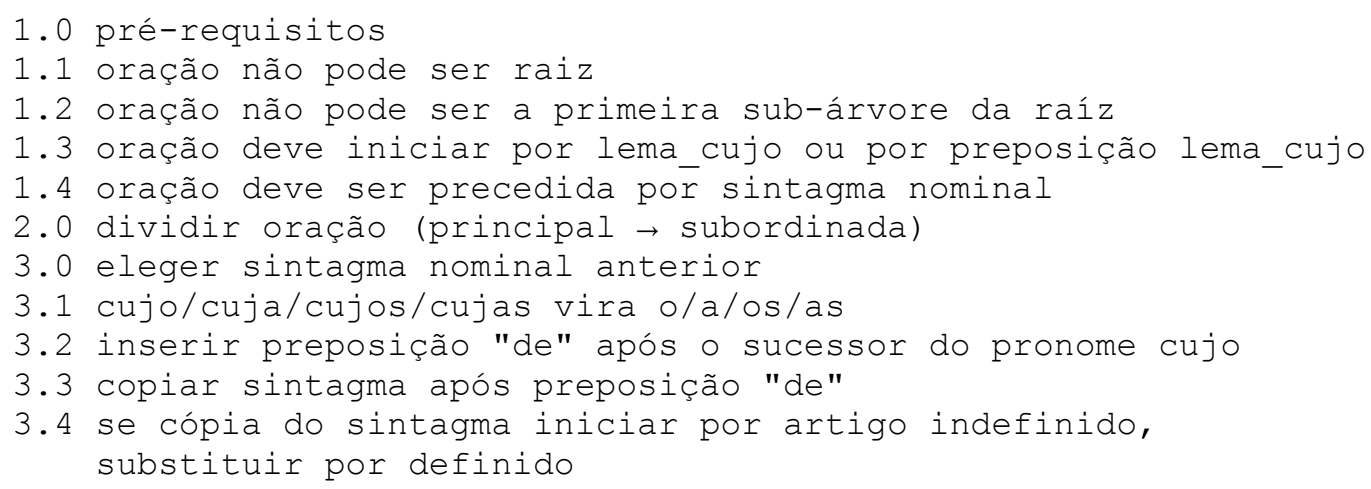

Algoritmo B.1: Caso "cujo" nas subordinadas adjetivas.

\section{Caso "o qual".}

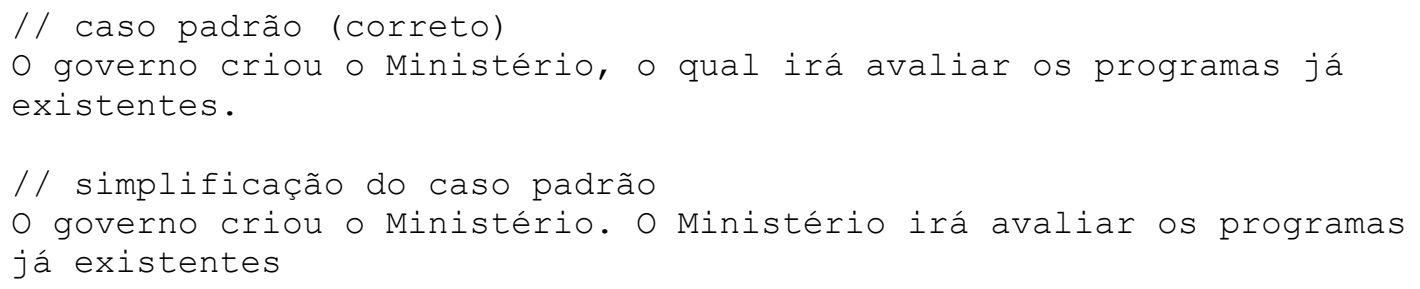

Exemplo B.3: Caso “o qual” nas subordinadas adjetivas.

// modifica Algoritmo 4.4

3.1.5 sintagma deve concordar em gênero com o verbo da subordinada e em número com o pronome

\section{Algoritmo B.2: Caso “o qual” nas subordinadas adjetivas.}

\section{Caso "o que".}

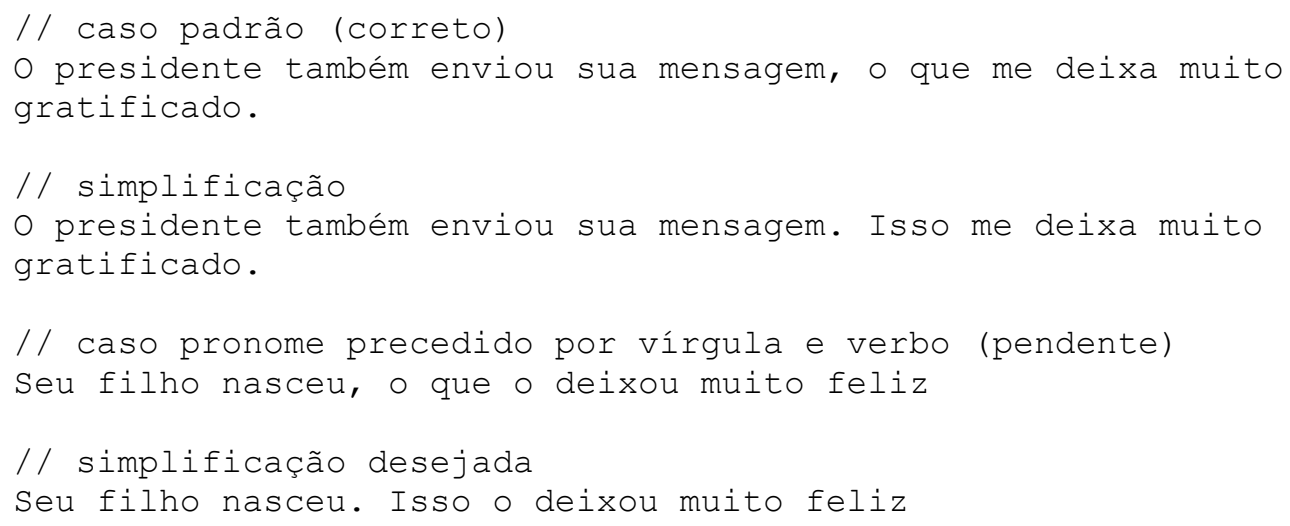

Exemplo B.4: Caso "o que" nas subordinadas adjetivas.

1.0 pré-requisitos

1.1 oração não pode ser raiz

1.2 oração não pode ser a primeira sub-árvore da raiz 
1.3 oração deve iniciar por "o que"

2.0 dividir oração (principal $\rightarrow$ subordinada)

2.1 substituir "o que" por "isso"

Algoritmo B.3: Caso "o que" nas subordinadas adjetivas.

\section{B.1.2 Subordinada adverbial concessiva}

Caso para os marcadores "apesar de que", "apesar que", "conquanto", "embora", "mas", "posto que", "por muito que" e "se bem que".

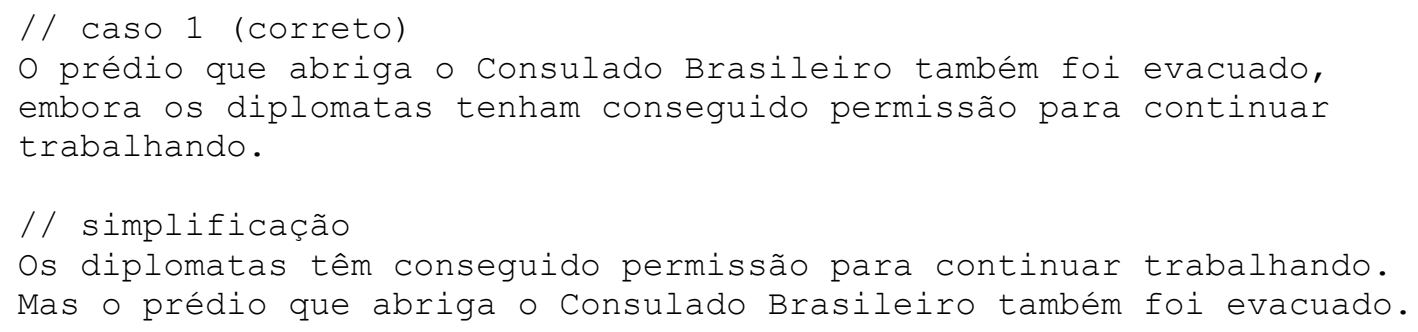

Exemplo B.5: Caso 1 para subordinadas adverbiais condicionais.

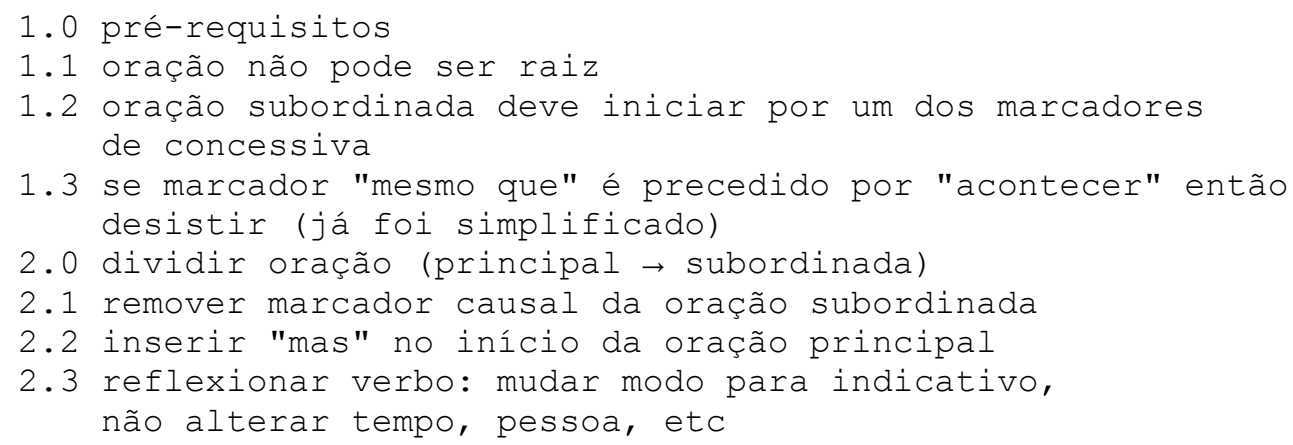

Algoritmo B.4: Caso 1 para subordinadas adverbiais condicionais.

Caso para os marcadores discursivos "ainda_que", "mesmo_que", "nem_que", "por_mais_que", documentados no Algoritmo B.5.

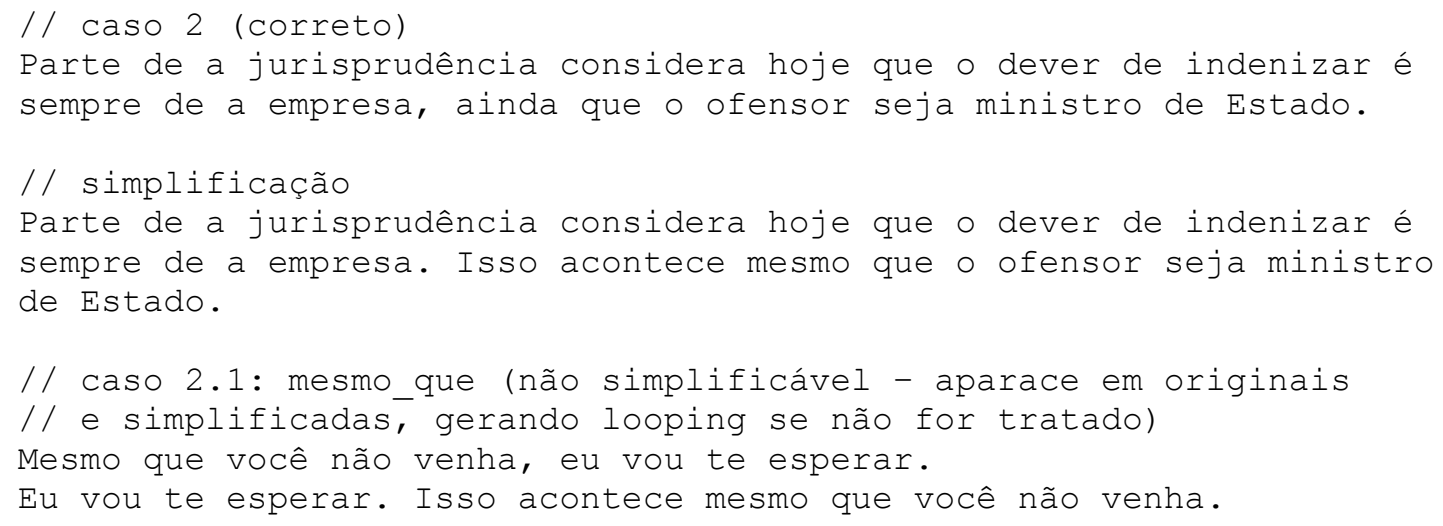

Exemplo B.6: Caso 2 para subordinadas adverbiais concessivas. 
1.0 pré-requisitos

1.1 oração não pode ser raiz

1.2 oração subordinada deve iniciar por um dos marcadores de concessiva

2.0 dividir oração (principal $\rightarrow$ subordinada)

2.1 remover marcador causal da oração subordinada

2.2 inserir "isso acontece mesmo que" no início da oração principal

Algoritmo B.5: Caso 2 para subordinadas adverbiais concessivas.

\section{B.1.3 Subordinada adverbial condicional}

Caso para "caso", "contanto_que”, e caso "se".

// caso para "caso", "contanto_que" (correto)

o lançamento de José é a ameaçā que João faz a o partido, caso os

dois partidos não cheguem a um amplo acordo

// simplificação

Se os dois partidos não chegarem a um amplo acordo, o lançamento de José é a ameaça que João faz a o partido.

// caso "se" (correto)

José disse que perderia sua linha de argumentação contra o projeto de lei, se aceitasse essa compensação.

// simplificação

Se aceitasse essa compensação, João disse que perderia sua linha de argumentação contra o projeto de lei.

Exemplo B.7: Grupo de casos 1 para subordinadas adverbiais condicionais.

1.0 pré-requisitos

1.1 oração não pode ser raiz

1.2 oração subordinada deve iniciar por um dos marcadores de condicional

1.3 se marcador for "se" e função for reflexivo, então desistir

1.4 se marcador for "se" e já estiver no início da oração, então desistir

2.0 mover marcador

2.1 se marcador não está no início da oração, desistir de mover

2.2 se marcador é precedido por vírgula ou traço, apagar predecessor

2.2 inserir marcador no início da oração sucedido por vírgula

3.0 se verbo finito está no presente do subjuntivo, então passar para futuro do subjuntivo

Algoritmo B.6: Grupo de casos 1 para subordinadas adverbiais condicionais.

Grupo de casos para "a menos que", "a não ser que", "exceto se", "salvo se".

// caso "a menos que", "a não ser que", "exceto se", "salvo se"

// (correto)

A menos que possa ficar em casa, te ligarei.

Se não puder ficar em casa, te ligarei.

// caso "negativa da negativa" (correto)

A menos que não possa ficar em casa, te ligarei. 
Se puder ficar em casa, te ligarei.

Exemplo B.8: Grupo de casos 2 para subordinadas adverbiais condicionais.

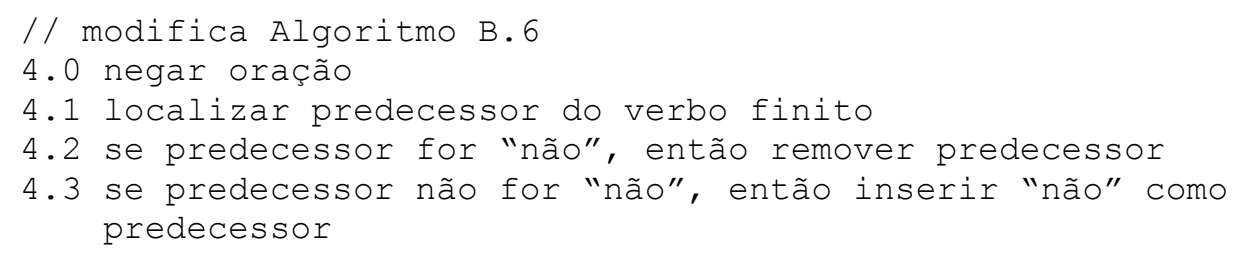

Algoritmo B.7: Grupo de casos 2 para subordinadas adverbiais condicionais.

Grupo de casos 3 para marcadores não tratados "antes que", "sem que", "desde que”.

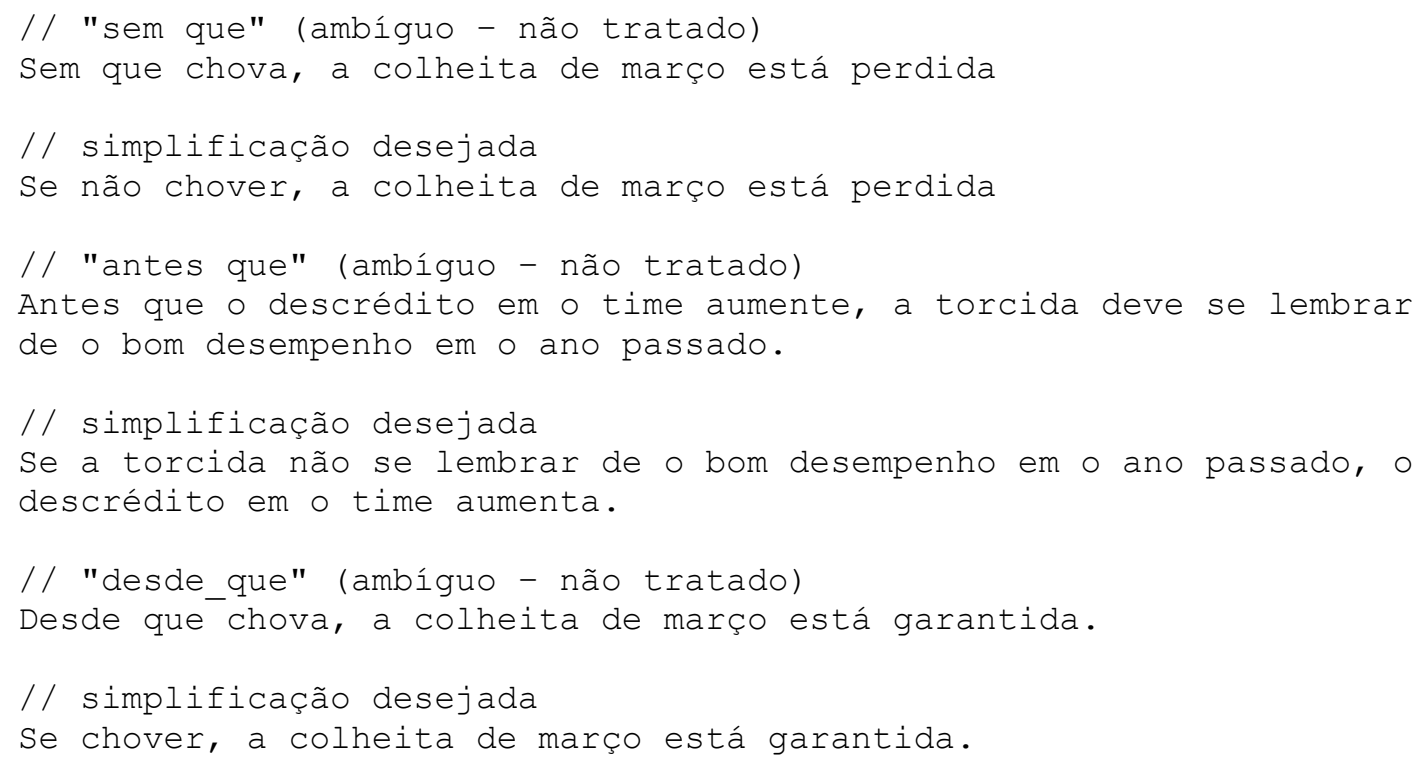

Exemplo B.9: Grupo de casos 3 para subordinadas adverbiais condicionais.

\section{B.1.4 Subordinada adverbial consecutiva}

Casos para "de forma que", "de modo que", "de sorte que", "tamanho que", "tal que"

// caso "de forma que", "de modo que", "de sorte que", "tamanho que", // "tal que" (correto)

Estamos dispostos a ajudar um parceiro muito importante, de forma que o processo seja benéfico.

// simplificação

Estamos dispostos a ajudar um parceiro muito importante. Por isso o processo é benéfico.

// "tamanho que": usar modificador "grande" (possível)

O livro sobre a Máfia que é um disparate tamanho que eu jamais

poderia esperar alguma coisa assim de um homem responsável.

// simplificação desejável

- livro sobre a Máfia que é um grande disparate. Por isso eu jamais poderia esperar alguma coisa assim de um homem responsável. 


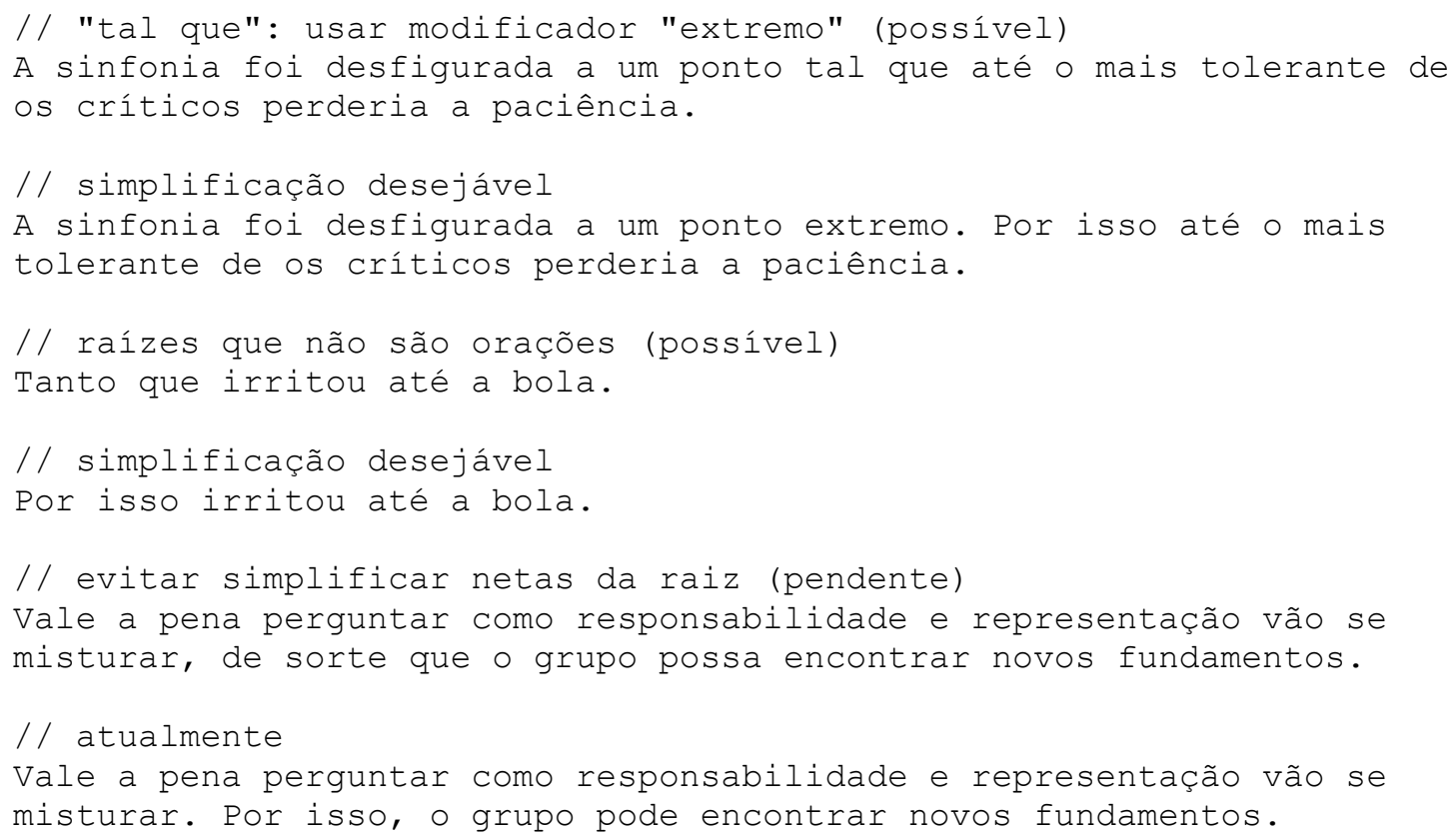

Exemplo B.10: Grupo de casos 1 para subordinadas adverbiais consecutivas.

1.0 pré-requisitos

1.1 oração não pode ser raiz

1.2 oração subordinada deve iniciar por um dos marcadores de consecutiva

2.0 dividir oração (principal $\rightarrow$ subordinada)

2.1 substituir marcador por "Por isso"

2.2 se verbo finito está no subjuntivo, então passar para indicativo

\section{Algoritmo B.8: Grupo de casos 1 para subordinadas adverbiais consecutivas.}

Casos para "tanto que".

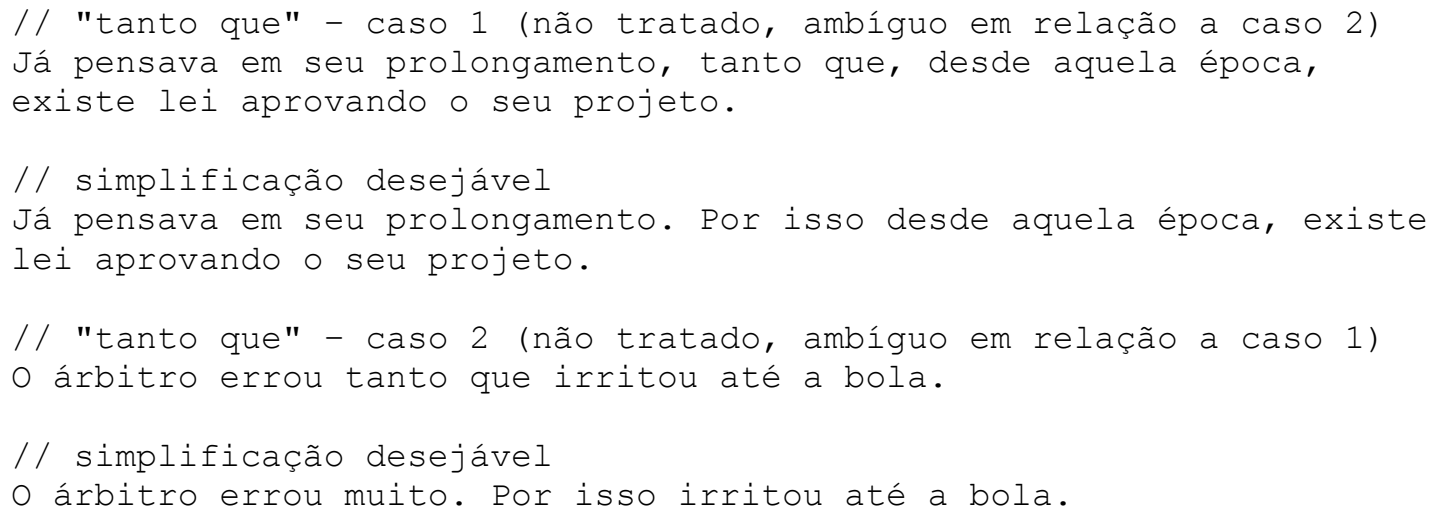

Exemplo B.11: Grupo de casos 2 para subordinadas adverbiais consecutivas.

Casos não implementados para "tão (...) que" , "tanto" (...) "que”, "tal (...) que", "tamanho (....) que".

// casos para "tão (...) que", "tanto" (...) "que", "tal (...) que", 
// "tamanho (...) que" (pendente)

O susto foi tão grande que ele caiu da cadeira.

seria: O susto foi muito grande. Por isso ele caiu da cadeira.

Exemplo B.12: Grupo de casos 3 para subordinadas adverbiais consecutivas.

\section{B.1.5 Subordinada adverbial conformativa}

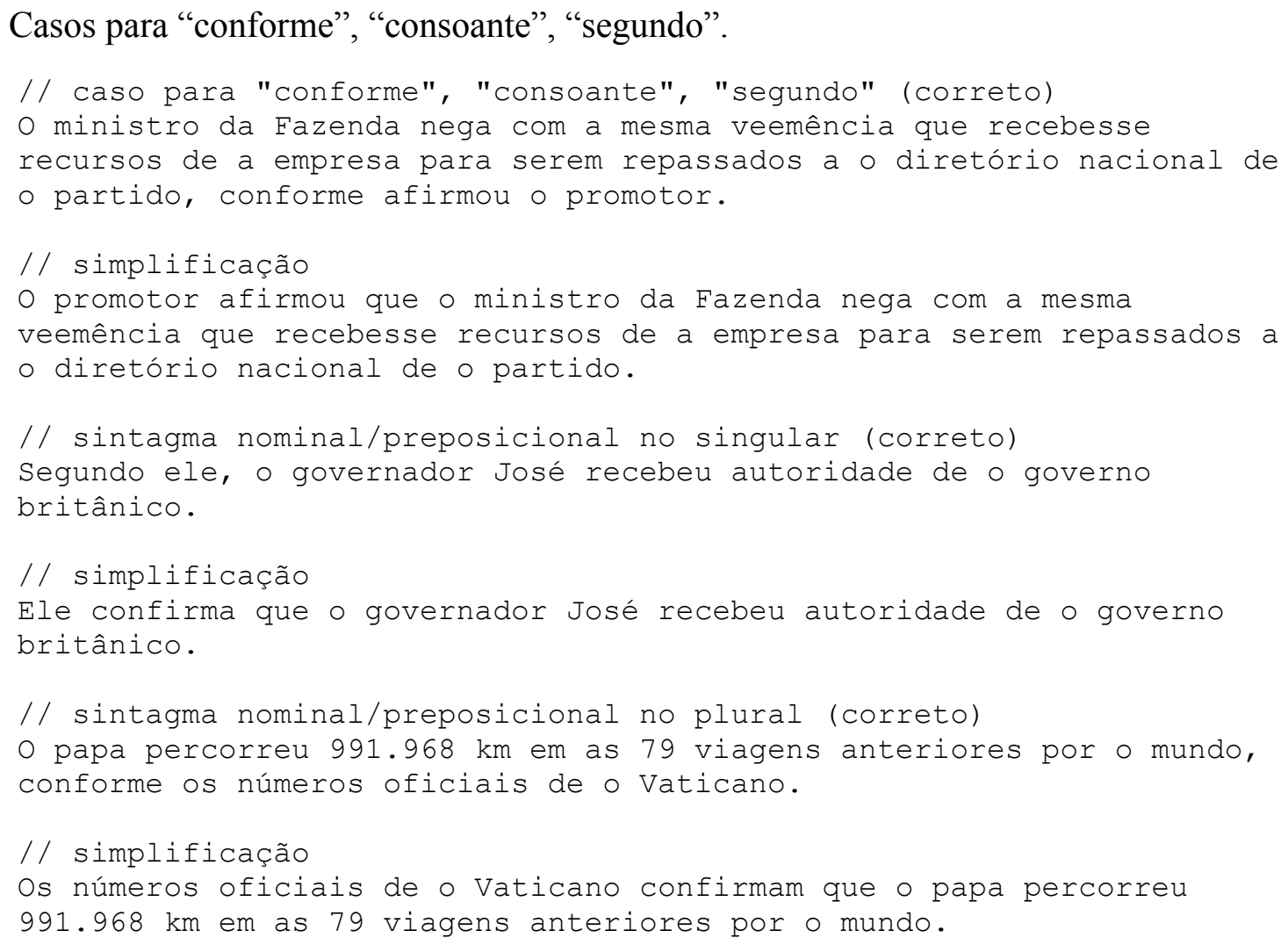

Exemplo B.13: Grupo de casos 1 para subordinadas adverbiais conformativas.

1.0 pré-requisitos

1.1 nó deve ser oração, sintagma nominal, ou sintagma preposicional

1.2 nó deve iniciar por um dos marcadores de conformativa

2.0 reordenar orações

2.1 se subordinada tem sujeito, mover sujeito para início da oração

2.2 se subordinada não tem sujeito, copiar da principal

2.3 subordinada passa a ser raiz; principal passa a ser subordinada no final da nova raíz

2.4 inserir "que" no início da nova subordinada

3.0 transformar nova principal em oração

3.1 se nova principal não for sintagma nominal ou preposicional, desistir de transformar

3.2 se nova principal é plural, inserir predicado "confirmam" antes da nova subordinada

3.3 se nova principal é singular, inserir predicado "confirma" antes da nova subordinada

Algoritmo B.9: Grupo de casos 1 para subordinadas adverbiais conformativas. 


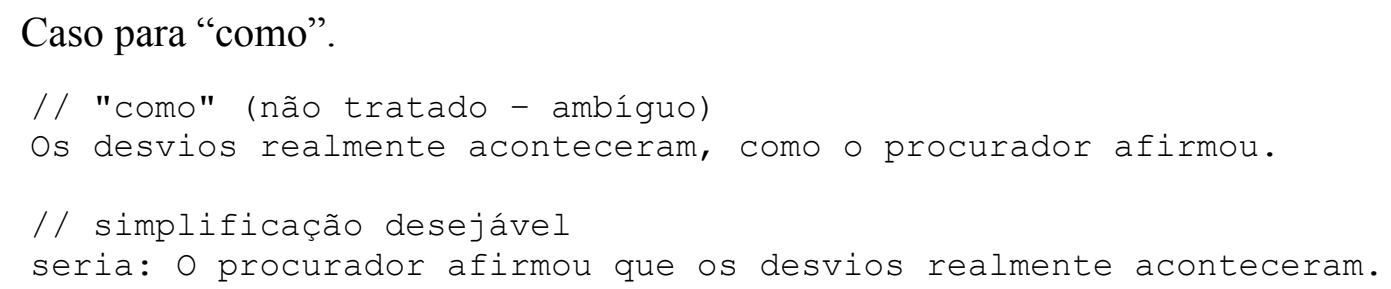

Exemplo B.14: Caso "como" para subordinadas adverbiais conformativas..

\section{B.1.6 Subordinada adverbial final}

Casos para "a fim de", "a fim de que", "para que".

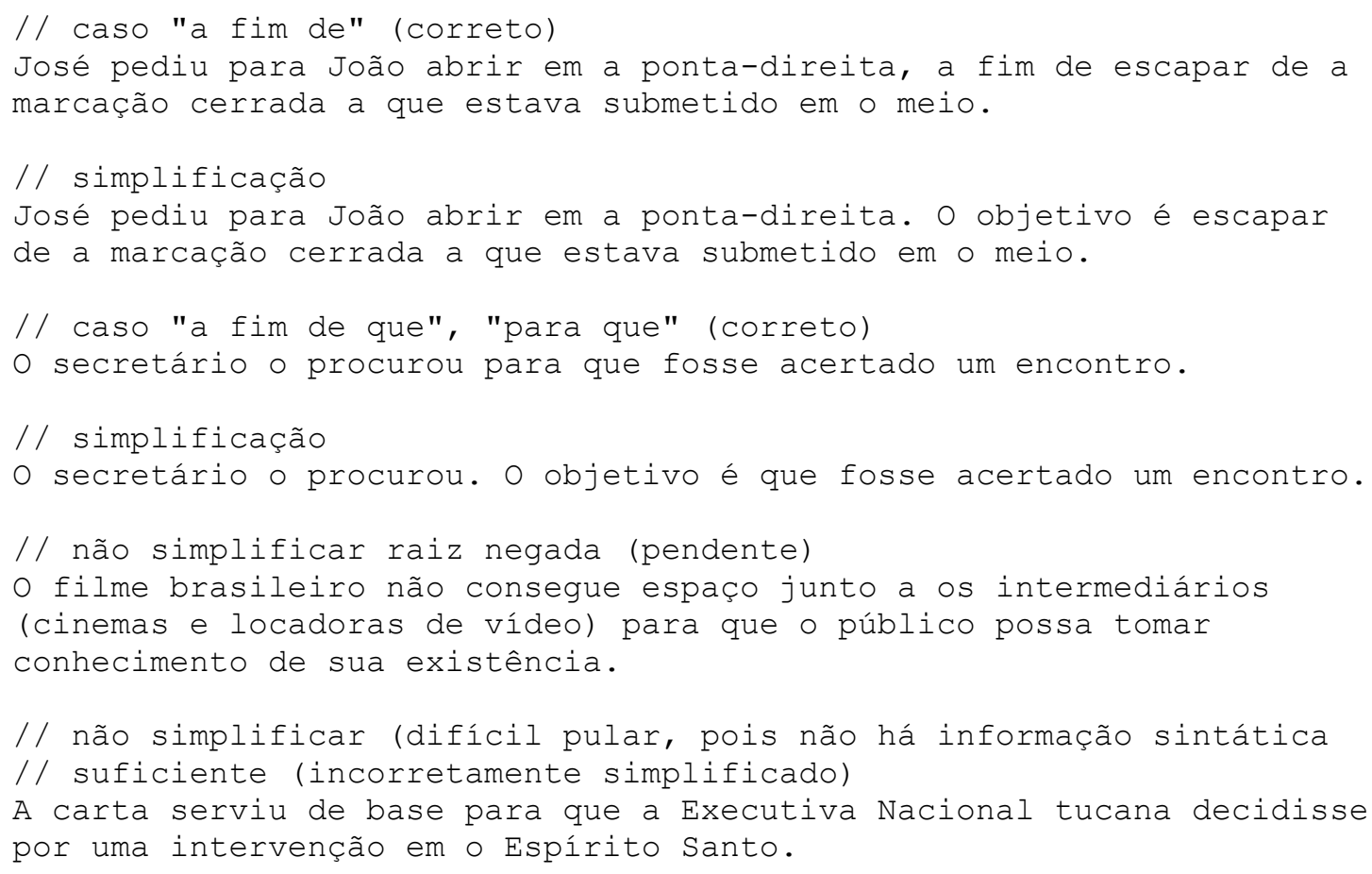

Exemplo B.15: Grupo de casos 1 para subordinadas adverbiais finais.

1.0 pré-requisitos

1.1 nó não pode ser raiz

1.2 nó deve ser oração ou clausula no infinitivo

1.3 nó deve iniciar por um dos marcadores de final

1.4 raiz da nó deve ser oração

2.0 dividir oração (principal $\rightarrow$ subordinada)

2.1 duplicar sujeito da oração principal se for o caso

2.2 se marcador contiver "que", substituir marcador por "que"

2.3 se marcador não contiver "que", remover marcador

2.4 inserir "o objetivo é" no início da oração subordinada

Algoritmo B.10: Grupo de casos 1 para subordinadas adverbiais finais.

O marcador "porque" não foi tratado por ser ambíguo e por falta de exemplos em córpus. 


\section{B.1.7 Subordinada adverbial temporal}

Casos para "assim que", "depois de", "depois que", "logo que".

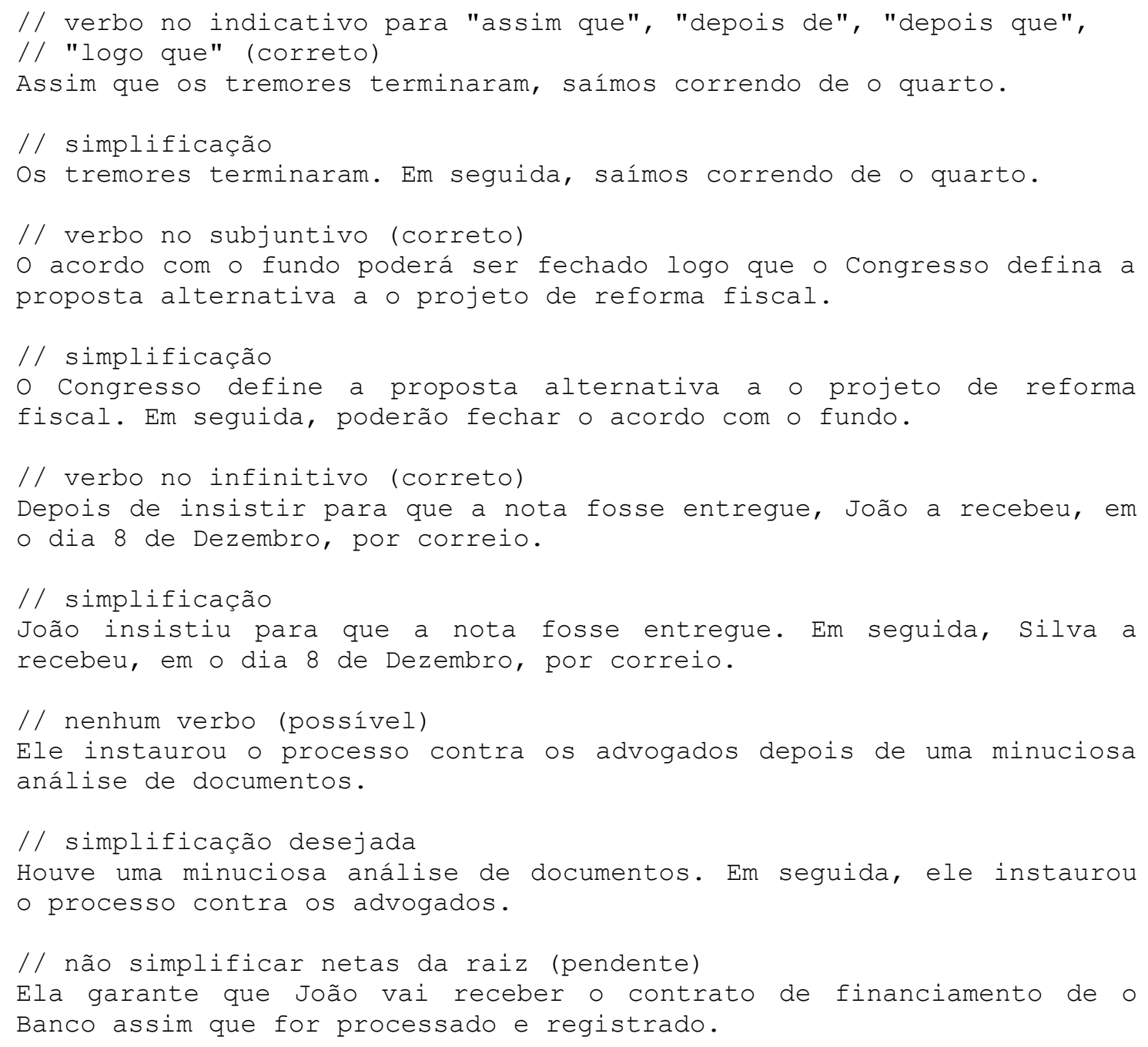

Exemplo B.16: Grupo de casos 1 para subordinadas adverbiais temporais.

1.0 pré-requisitos

1.1 frase não pode ser raiz

1.2 frase deve ser oração ou sintagma preposicional

1.3 frase deve iniciar por marcador de temporal

2.0 dividir oração (principal $\rightarrow$ frase)

2.1 duplicar sujeito da oração principal se for o caso

2.2 se frase é oração com verbo finito no subjuntivo, então passar para indicativo

2.3 se frase é cláusula com verbo no infinito, então passar para indicativo (tempo=tempo da principal)

2.4 se frase é sintagma preposicional, inserir predicado "houve"

2.5 remover marcador

2.6 inserir "em seguida," no início da oração subordinada

Algoritmo B.11: Grupo de casos 1 para subordinadas adverbiais temporais. 
// "antes que" (correto)

José foi expulso antes que João convertesse a cobrança.

// simplificação

José foi expulso. Em seguida, João convertia a cobrança.

Exemplo B.17: Caso "antes que" para subordinadas adverbiais temporais.

// modifica Algoritmo B.11

2.0 dividir oração (subordinada $\rightarrow$ principal)

2.3 inserir "em seguida," no início da oração principal

Algoritmo B.12: Caso "antes que” para subordinadas adverbiais temporais.

Casos não tratados para "apenas", "até que", "desde que"

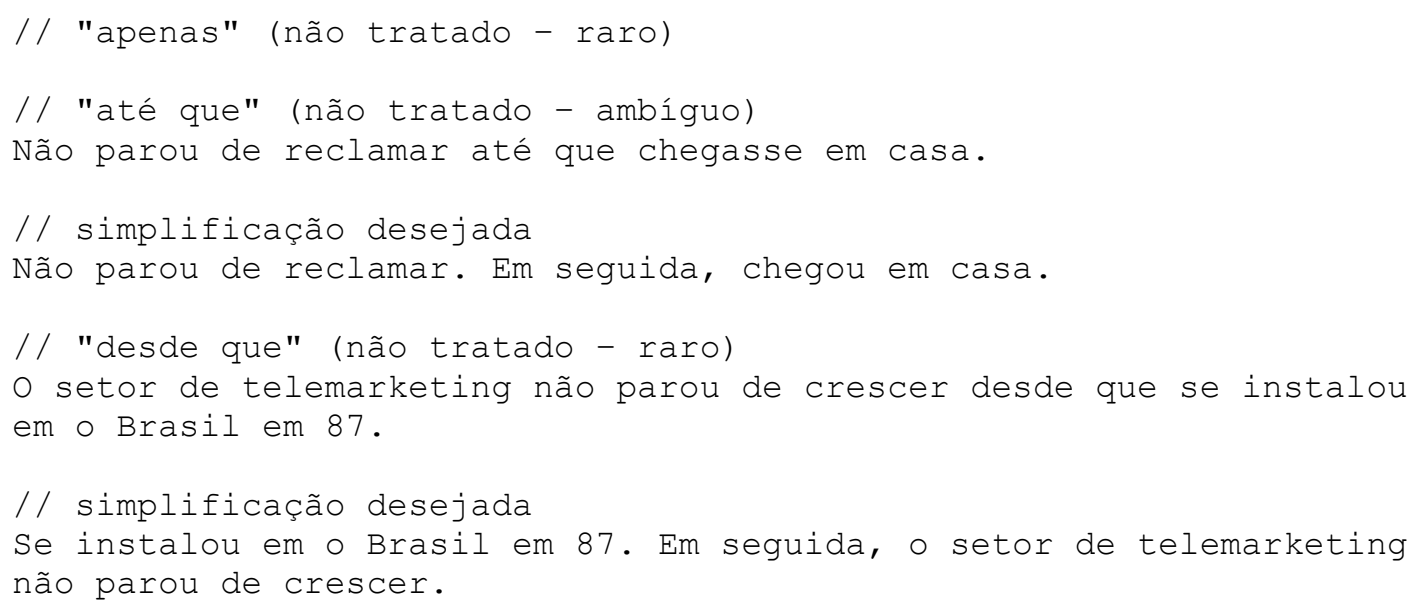

Exemplo B.18: Grupo de casos 2 para subordinadas adverbiais temporais.

Casos não tratados para “cada vez que”, “enquanto", "mal”, “quando”, “sempre que”.

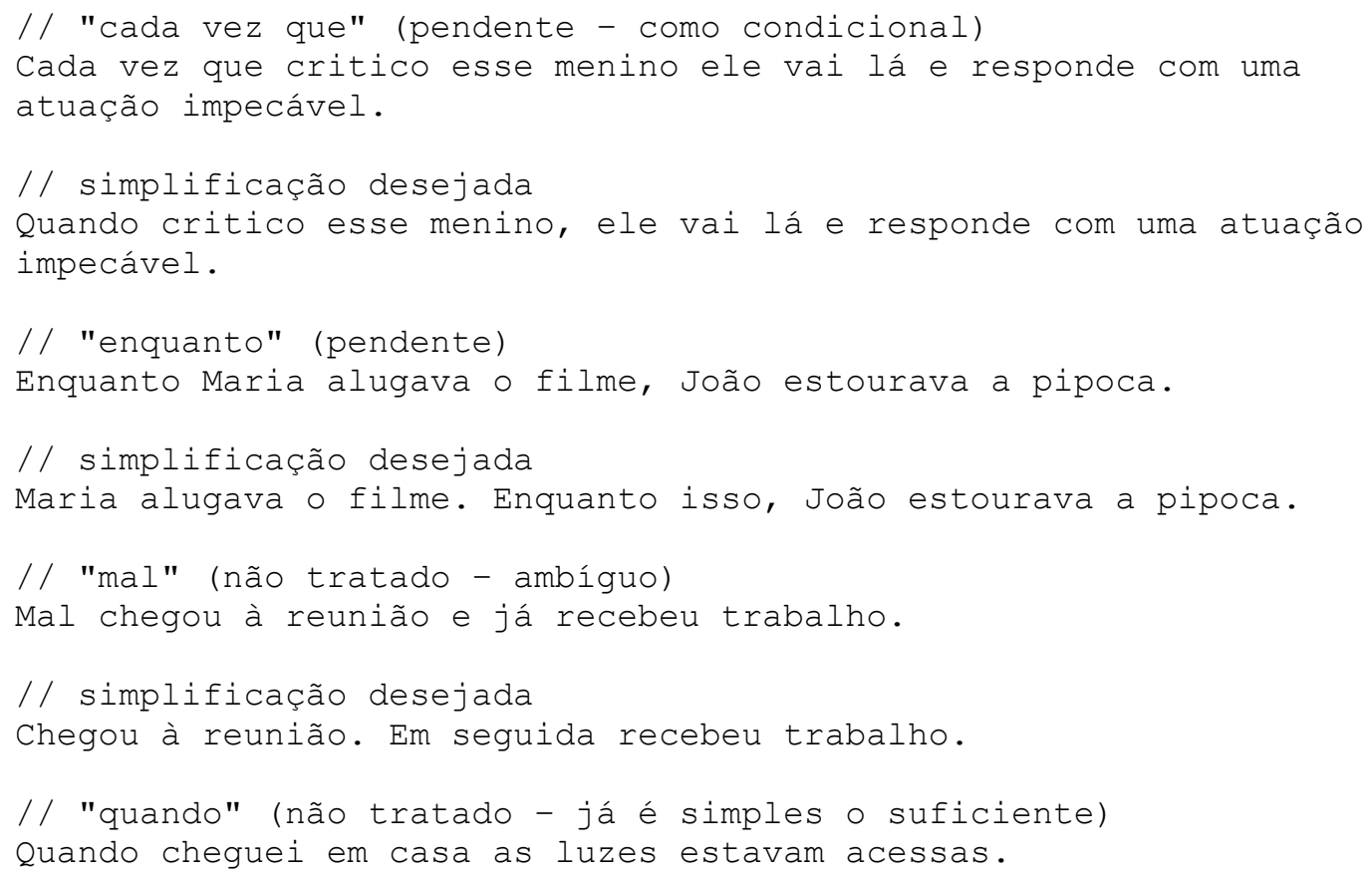




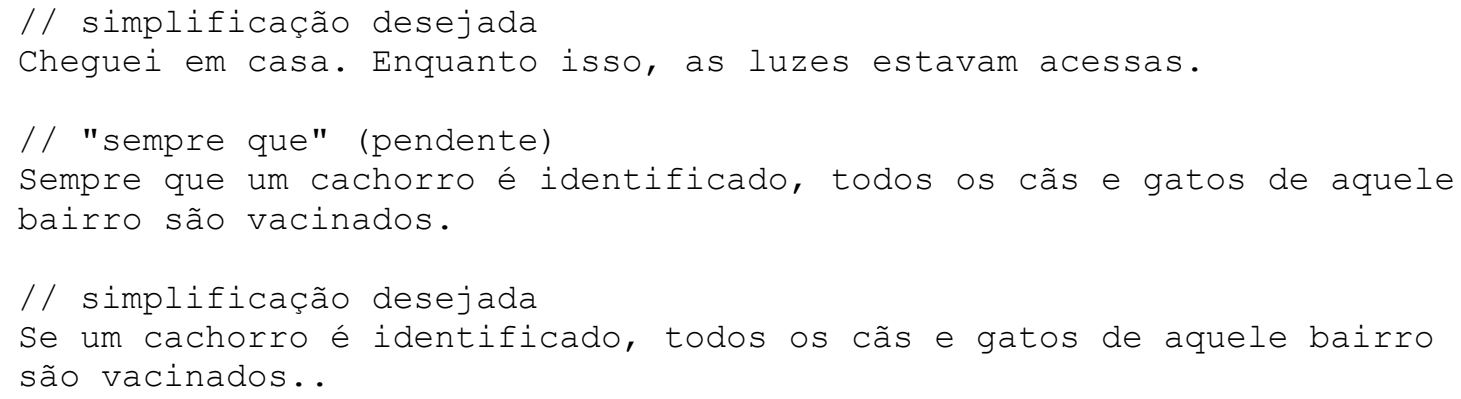

Exemplo B.19: Grupo de casos 3 para subordinadas adverbiais temporais.

\section{B.2 Marcadores discursivos}

Tabela B.1: Marcadores discursivos tratados e fenômenos associados.

\begin{tabular}{|c|c|c|c|}
\hline marcador & fenômenos & padrão & detalhes \\
\hline a fim de & 1 & 1 & \\
\hline a fim de que & 1 & 1 & \\
\hline a menos que & $\mathrm{i}$ & $\mathrm{i}$ & $\begin{array}{l}\text { Interferência de "a menos" + "que": o novo composto possui um átomo a } \\
\text { menos que o antigo }\end{array}$ \\
\hline a não ser que & $\mathrm{i}$ & $\mathrm{i}$ & $\begin{array}{l}\text { Interferência de "a não ser" + "que" ("exceto" + "que"): quase nada ficou } \\
\text { registrado, a não ser que gostava de música }\end{array}$ \\
\hline ainda que & $\mathrm{h}$ & $\mathrm{h}$ & \\
\hline antes que & $\mathrm{mi}$ & $\mathrm{m}$ & Interferência de "antes" + "que": você não disse antes que ia voltar cedo? \\
\hline apenas & $\mathrm{m}$ & - & \\
\hline apesar de que & $\mathrm{h}$ & $\mathrm{h}$ & \\
\hline apesar que & $\mathrm{h}$ & $\mathrm{h}$ & Interferência de "apesar" + "que” (erro de parsing) \\
\hline assim que & $\mathrm{im}$ & $\mathrm{m}$ & \\
\hline até que & $\mathrm{m}$ & - & \\
\hline cada vez que & $\mathrm{m}[\mathrm{i}]$ & - & \\
\hline caso & $\mathrm{i}$ & $\mathrm{i}$ & \\
\hline como & defk & - & \\
\hline conforme & $\mathrm{k}$ & $\mathrm{k}$ & \\
\hline conquanto & $\mathrm{h}$ & $\mathrm{h}$ & \\
\hline consoante & $\mathrm{k}$ & $\mathrm{k}$ & \\
\hline contanto que & $\mathrm{i}$ & $\mathrm{i}$ & \\
\hline cujo & de & de & \\
\hline de forma que & $\mathrm{j}$ & $\mathrm{j}$ & \\
\hline de modo que & $\mathrm{j}$ & $\mathrm{j}$ & \\
\hline de sorte que & $\mathrm{j}$ & - & $\begin{array}{l}\text { Interferência de "de sorte" + "que": quem seria o funcionário de sorte } \\
\text { que receberia o aumento? }\end{array}$ \\
\hline
\end{tabular}




\begin{tabular}{|c|c|c|c|}
\hline marcador & fenômenos & padrão & detalhes \\
\hline depois de & $\mathrm{m}$ & $\mathrm{m}$ & \\
\hline depois que & $\mathrm{m}$ & $\mathrm{m}$ & \\
\hline desde que & $\mathrm{im}$ & - & $\begin{array}{l}\text { Interferência de "desde" + "que": não te vejo desde que era uma criança. } \\
\text { Proposta para desambiguar: tempo presente e futuro para i; tempo } \\
\text { passado para m }\end{array}$ \\
\hline embora & $\mathrm{h}$ & $\mathrm{h}$ & \\
\hline enquanto & $\mathrm{m}$ & - & \\
\hline exceto se & $\mathrm{i}$ & $\mathrm{i}$ & \\
\hline já que & $\mathrm{f}$ & $\mathrm{f}$ & \\
\hline logo que & $\mathrm{m}$ & $\mathrm{m}$ & \\
\hline mal & $\mathrm{m}$ & - & $\begin{array}{l}\text { Interferência de "mal" no sentido de "ruim" } \\
\text { Proposta para desambiguar: "mal" seguido por verbo ("mal chegou") }\end{array}$ \\
\hline mas & $\mathrm{h}$ & - & Erro de parsing inviabiliza análise \\
\hline mesmo que & $\mathrm{h}$ & $\mathrm{h}$ & Erro de parsing "mesmo" + "que" \\
\hline nem_que & $\mathrm{h}$ & $\mathrm{h}$ & \\
\hline o qual & de & de & \\
\hline o que & de & de & Erro de parsing "o" + "que" \\
\hline onde & de & - & \\
\hline para que & 1 & 1 & \\
\hline pois que & $\mathrm{f}$ & - & $\begin{array}{l}\text { Interferência de "pois" + "que": pois que digam o que quiserem, não me } \\
\text { importo }\end{array}$ \\
\hline por mais que & $\mathrm{h}$ & $\mathrm{h}$ & \\
\hline por muito que & $\mathrm{h}$ & $\mathrm{h}$ & \\
\hline porquanto & $\mathrm{f}$ & $\mathrm{f}$ & \\
\hline porque & $\mathrm{fl}$ & - & \\
\hline posto que & fh & $\mathrm{h}$ & \\
\hline quando & dem & - & \\
\hline que & $\mathrm{de}$ & de & \\
\hline salvo se & $\mathrm{i}$ & $\mathrm{i}$ & \\
\hline se & $\mathrm{i}$ & $\mathrm{i}$ & \\
\hline se bem que & $\mathrm{h}$ & $\mathrm{h}$ & \\
\hline segundo & $\mathrm{k}$ & $\mathrm{k}$ & \\
\hline sem que & $\mathrm{i}$ & - & $\begin{array}{l}\text { Interferência de "sem" + "que": passou a primeira semana sem que } \\
\text { ninguém o chamasse ao trabalho. } \\
\text { Proposta para desambiguar por tempo e modo. }\end{array}$ \\
\hline sempre que & $\mathrm{m}[\mathrm{i}]$ & - & $\begin{array}{l}\text { Interferência de "sempre" + "que": lembre-se sempre que a vitória exige } \\
\text { esforço }\end{array}$ \\
\hline tal que & $\mathrm{j}$ & $\mathrm{j}$ & \\
\hline tamanho que & $\mathrm{j}$ & $\mathrm{j}$ & \\
\hline
\end{tabular}




\begin{tabular}{llll}
\hline marcador & fenômenos & padrão & detalhes \\
\hline tanto que & $\mathrm{j} 1 \mathrm{j} 2$ & - & \\
uma vez que & $\mathrm{f}$ & $\mathrm{f}$ & \\
visto como & $\mathrm{f}$ & - & Interferência de "visto" + "como": o amigo tem visto como joga o \\
visto que & $\mathrm{f}$ & $\mathrm{f}$ & \\
\hline
\end{tabular}

\section{B.3 Textos utilizados na avaliação}

Tabela B.2: Textos utilizados na avaliação.

\begin{tabular}{|c|c|c|}
\hline texto & domínio & amostrado \\
\hline Escultura etrusca & Arte & $\operatorname{sim}$ \\
\hline Palladianismo & Arte & $\operatorname{sim}$ \\
\hline Escultura do Gótico & Arte & $\operatorname{sim}$ \\
\hline Júpiter (planeta) & Arte & \\
\hline Dom Casmurro & Arte & \\
\hline Formatinho & Arte & \\
\hline Escultura do Renascimento italiano & Arte & \\
\hline Academicismo & Arte & \\
\hline Memórias Póstumas de Brás Cubas & Arte & \\
\hline Templo Expiatório da Sagrada Família & Arte & \\
\hline Friends & Arte & \\
\hline Escultura dos Sete Povos das Missões & Arte & \\
\hline Ferris Bueller's Day Off & Arte & \\
\hline Walking on Air & Arte & \\
\hline What the Hell & Arte & \\
\hline Alice (canção de Avril Lavigne) & Biografias & $\operatorname{sim}$ \\
\hline Fídias & Biografias & $\operatorname{sim}$ \\
\hline Antonio Canova & Biografias & $\operatorname{sim}$ \\
\hline Francisco de Assis & Biografias & \\
\hline Beyoncé Knowles & Biografias & \\
\hline Hildegard von Bingen & Biografias & \\
\hline Helena Blavatsky & Biografias & \\
\hline Emma Goldman & Biografias & \\
\hline Michelangelo & Biografias & \\
\hline Luís de Camões & Biografias & \\
\hline Cher & Biografias & \\
\hline Shawn Johnson & Biografias & \\
\hline Peyton Manning & Biografias & \\
\hline
\end{tabular}




\begin{tabular}{|c|c|c|}
\hline texto & domínio & amostrado \\
\hline Eminem & Biografias & \\
\hline Nastia Liukin & Biografias & \\
\hline Pedro Álvares Cabral & Biografias & \\
\hline Georg Friedrich Händel & Biografias & \\
\hline Nadia Comăneci & Biografias & \\
\hline Machado de Assis & Biografias & \\
\hline Shannon Miller & Biografias & \\
\hline Johan Cruijff & Biografias & \\
\hline Lisa Gherardini & Biografias & \\
\hline Gregório de Nazianzo & Biografias & \\
\hline 50 Cent & Biografias & \\
\hline Alfredo Di Stéfano & Biografias & \\
\hline Johann Sebastian Bach & Biografias & \\
\hline John Cena & Biografias & \\
\hline Pierre Le Gros, o Jovem & Biografias & \\
\hline Aleijadinho & Biografias & \\
\hline Honoré de Balzac & Biografias & \\
\hline Policleto & Biografias & \\
\hline Claudio Monteverdi & Biografias & \\
\hline Papa João XXIII & Biografias & \\
\hline Avril Lavigne & Biografias & \\
\hline Morte de Edgar Allan Poe & Biografias & \\
\hline Wolfgang Amadeus Mozart & Biografias & \\
\hline Svetlana Khorkina & Biografias & \\
\hline Emma Smith & Biografias & \\
\hline Máximo, o Confessor & Biografias & \\
\hline Diego Maradona & Biografias & \\
\hline Enzo Francescoli & Biografias & \\
\hline Joseph Fouché & Biografias & \\
\hline Fungi & Ciências da natureza & $\operatorname{sim}$ \\
\hline Ácido desoxirribonucleico & Ciências da natureza & $\operatorname{sim}$ \\
\hline Condor-da-califórnia & Ciências da natureza & $\operatorname{sim}$ \\
\hline Bacia do Paraná & Ciências da natureza & \\
\hline Gyromitra esculenta & Ciências da natureza & \\
\hline Melro-preto & Ciências da natureza & \\
\hline Agricultura no Brasil & Ciências da natureza & \\
\hline Gato & Ciências da natureza & \\
\hline Trachylepis atlantica & Ciências da natureza & \\
\hline
\end{tabular}




\begin{tabular}{|c|c|c|}
\hline texto & domínio & amostrado \\
\hline Eustrombus gigas & Ciências da natureza & \\
\hline Ragnarök & Ciências da natureza & \\
\hline Cão & Ciências da natureza & \\
\hline História do pensamento evolutivo & Ciências da natureza & \\
\hline Pinheiro-do-paraná & Ciências da natureza & \\
\hline Plutão & Ciências exatas & $\operatorname{sim}$ \\
\hline Sol & Ciências exatas & $\operatorname{sim}$ \\
\hline Mercúrio (planeta) & Ciências exatas & $\operatorname{sim}$ \\
\hline Vénus (planeta) & Ciências exatas & \\
\hline Atmosfera de Vênus & Ciências exatas & \\
\hline Calisto (satélite) & Ciências exatas & \\
\hline Atmosfera de Júpiter & Ciências exatas & \\
\hline Fração do Exército Vermelho & Ciências sociais & $\operatorname{sim}$ \\
\hline Homossexualidade & Cultura e sociedade & $\operatorname{sim}$ \\
\hline Bandeira do Japão & Cultura e sociedade & $\operatorname{sim}$ \\
\hline Jogos Olímpicos de Verão de 1996 & Desporto (esporte) & \\
\hline Eleição da cidade-sede dos Jogos Olímpicos de Verão de 2016 & Desporto (esporte) & $\operatorname{sim}$ \\
\hline Candidatura do Rio de Janeiro para os Jogos Olímpicos de Verão de 2016 & Desporto (esporte) & $\operatorname{sim}$ \\
\hline Eleição da cidade-sede dos Jogos Olímpicos de Verão de 2008 & Desporto (esporte) & $\operatorname{sim}$ \\
\hline Jogos Olímpicos & Desporto (esporte) & \\
\hline Jogos Pan-americanos de 2007 & Desporto (esporte) & \\
\hline Rei (xadrez) & Desporto (esporte) & \\
\hline Jogos Olímpicos de Verão de 1896 & Desporto (esporte) & \\
\hline Tabuleiro (xadrez) & Desporto (esporte) & \\
\hline Seleção de Ginástica Artística Feminina dos Estados Unidos & Desporto (esporte) & \\
\hline Ginástica & Desporto (esporte) & \\
\hline Vantagem do primeiro movimento no xadrez & Desporto (esporte) & \\
\hline Seleção Brasileira de Ginástica Artística Feminina & Desporto (esporte) & \\
\hline Federação Internacional de Ginástica & Desporto (esporte) & \\
\hline Curling & Desporto (esporte) & \\
\hline Seleção Russa de Ginástica Artística Feminina & Desporto (esporte) & \\
\hline Jogos Olímpicos de Inverno & Desporto (esporte) & \\
\hline Salto ornamental & Desporto (esporte) & \\
\hline Torre (xadrez) & Desporto (esporte) & \\
\hline Ginástica rítmica & Desporto (esporte) & \\
\hline Jogos Olímpicos de Inverno de 2010 & Desporto (esporte) & \\
\hline Cerimônia de abertura dos Jogos Pan-Americanos de 2007 & Desporto (esporte) & \\
\hline Don Geiss, America and Hope & Entretenimento & $\operatorname{sim}$ \\
\hline
\end{tabular}




\begin{tabular}{|c|c|c|}
\hline texto & domínio & amostrado \\
\hline Geografia de Coronel Fabriciano & Geografia & \\
\hline Fronteira interna alemã & Geografia & $\operatorname{sim}$ \\
\hline Alanya & Geografia & $\operatorname{sim}$ \\
\hline Canadá & Geografia & $\operatorname{sim}$ \\
\hline Tonga & Geografia & \\
\hline São José do Rio Preto & Geografia & \\
\hline Plasencia & Geografia & \\
\hline Porto Alegre & Geografia & \\
\hline Coronel Fabriciano & Geografia & \\
\hline Erechim & Geografia & \\
\hline Santana do Paraíso & Geografia & \\
\hline Torres (Rio Grande do Sul) & Geografia & \\
\hline Espírito Santo (estado) & Geografia & \\
\hline Juiz de Fora & Geografia & \\
\hline Ipatinga & Geografia & \\
\hline Caxias do Sul & Geografia & \\
\hline Goiana & Geografia & \\
\hline Brasil & Geografia & \\
\hline Estados Unidos & Geografia & \\
\hline Governador Valadares & Geografia & \\
\hline Andrelândia & Geografia & \\
\hline Águas de São Pedro & Geografia & \\
\hline Alemanha & Geografia & \\
\hline Coreia do Sul & Geografia & \\
\hline Timóteo & Geografia & \\
\hline Uberlândia & Geografia & \\
\hline Pau dos Ferros & Geografia & \\
\hline Japão & Geografia & \\
\hline Presidente Prudente & Geografia & \\
\hline Marabá & Geografia & \\
\hline Israel & Geografia & \\
\hline Itumbiara & Geografia & \\
\hline Austrália & Geografia & \\
\hline Santa Bárbara d'Oeste & Geografia & \\
\hline Belo Horizonte & Geografia & \\
\hline Ourinhos & Geografia & \\
\hline Batalha de Lipantitlán & História & $\operatorname{sim}$ \\
\hline Missões jesuíticas na América & História & $\operatorname{sim}$ \\
\hline
\end{tabular}




\begin{tabular}{|c|c|c|}
\hline texto & domínio & amostrado \\
\hline Perseguição de Diocleciano & História & $\operatorname{sim}$ \\
\hline História de Brasília & História & \\
\hline História de Andrelândia & História & \\
\hline Implantação da República Portuguesa & História & \\
\hline História de Coronel Fabriciano & História & \\
\hline Grande fome de 1845-1849 na Irlanda & História & \\
\hline Período regencial & História & \\
\hline Girlfriend (canção de Avril Lavigne) & Música & $\operatorname{sim}$ \\
\hline Love. Angel. Music. Baby. & Música & $\operatorname{sim}$ \\
\hline Under My Skin & Música & $\operatorname{sim}$ \\
\hline Ars nova & Música & \\
\hline Poemas sinfónicos (Liszt) & Música & \\
\hline Secos e Molhados (álbum de 1973) & Música & \\
\hline Alice do Reino Unido & Música & \\
\hline Ivete Sangalo no Madison Square Garden (Multishow ao Vivo) & Música & \\
\hline Dança hip hop & Música & \\
\hline Let Go & Música & \\
\hline Grunge & Música & \\
\hline In Utero & Música & \\
\hline Nightwish & Música & \\
\hline Nirvana (banda) & Música & \\
\hline A Igreja de Jesus Cristo dos Santos dos Últimos Dias & Religião & $\operatorname{sim}$ \\
\hline Doutrina da Igreja Católica & Religião & $\operatorname{sim}$ \\
\hline Apolo & Religião & $\operatorname{sim}$ \\
\hline Cardeal-sobrinho & Religião & \\
\hline Wicca & Religião & \\
\hline Hermes & Religião & \\
\hline Papa & Religião & \\
\hline Hades & Religião & \\
\hline Diocese de Macau & Religião & \\
\hline Atena & Religião & \\
\hline Mina-S & Tecnologia & sim \\
\hline
\end{tabular}




\section{Apêndice C - Código fonte codificado}

Este apêndice destina-se a leitores de versões digitais do presente documento. Ele traz o código fonte Java na integra do Miolin e da implementação Sinsim com fins à reprodutibilidade de experimentos. O processo de extração consiste em:

5. Copiar e colar a versão codificada do código fonte nesta e nas próximas páginas para um arquivo de texto, por exemplo "codigo.txt".

6. Em ambientes Unix, Windows com Cygwin ou equivalentes, executar: "cat codigo.txt | base64 -d | tar -xj".

O código fonte de ambas as ferramentas é distribuído pela licença LGPL (Lesser General Public License) 3 ou superior. A versão codificada não inclui os padrões utilizados no Molin, nem os casos de teste utilizados no Sinsim devido a restrições de espaço e de licença de redistribuição. É incluído:

- O código fonte Java de ambas as ferramentas.

- A documentação JavaDoc completa do Miolin.

- Os testes unitários utilizados no Miolin.

- O script responsável por executar os experimentos Miolin (necessita de importação dos recursos linguísticos utilizados no trabalho).

Versão codificada:

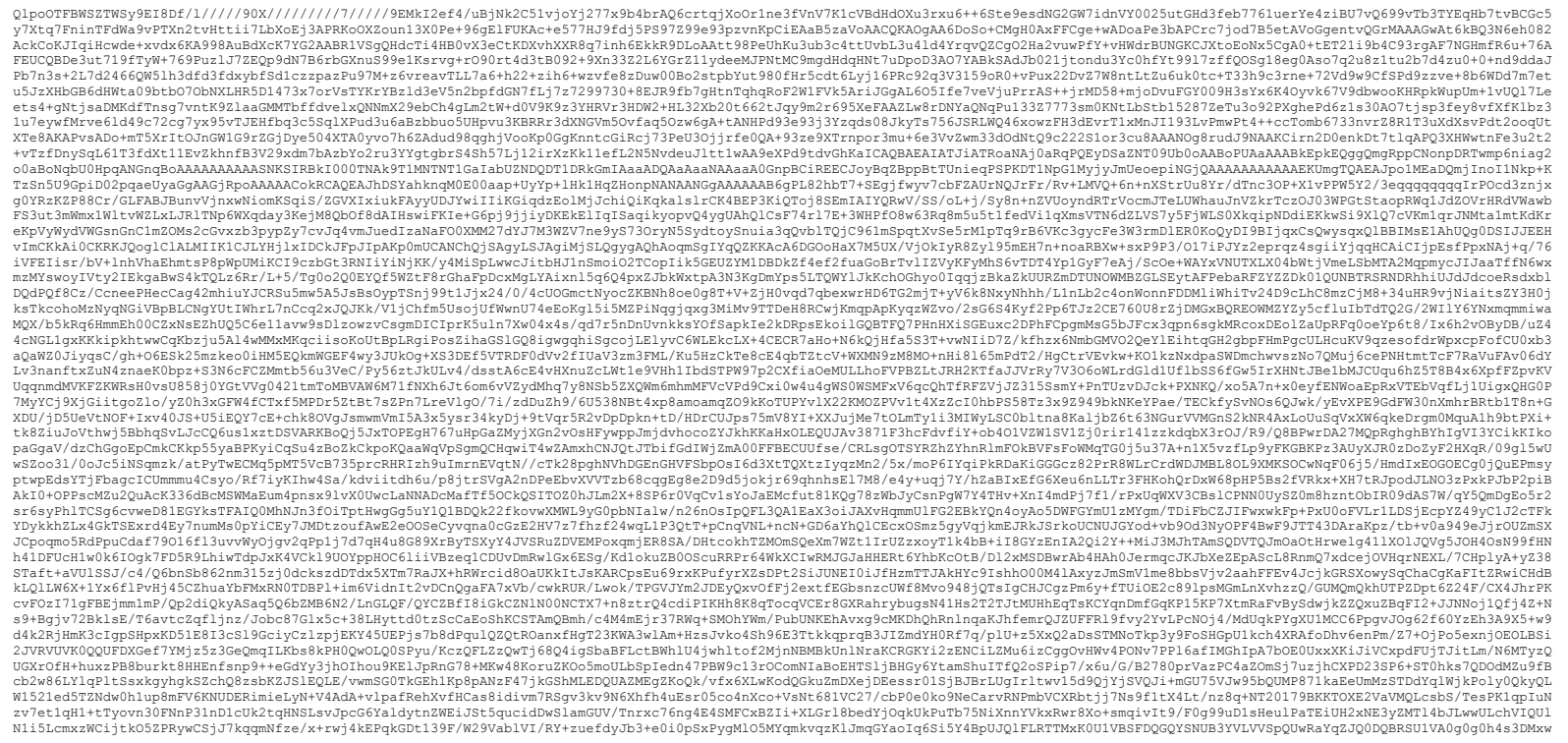




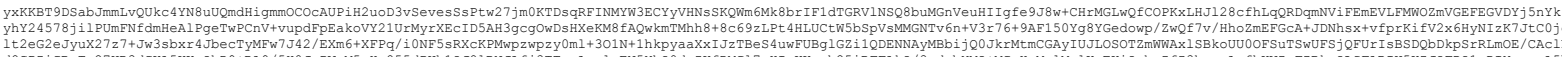

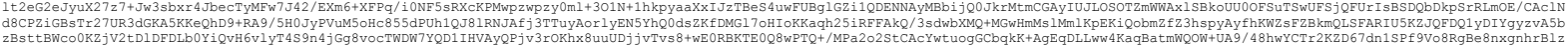

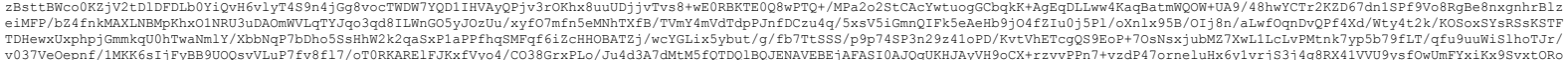

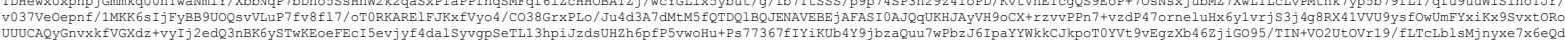

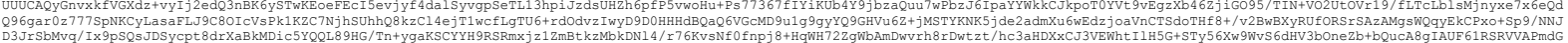

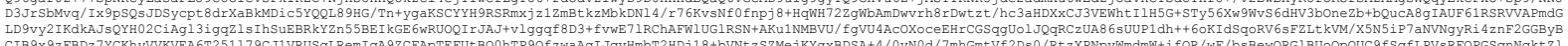

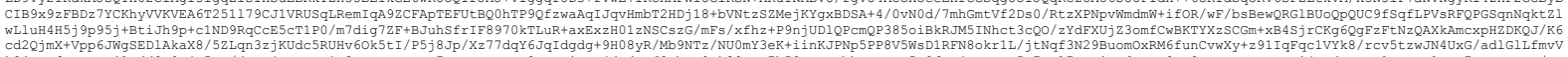

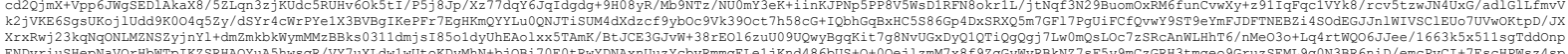

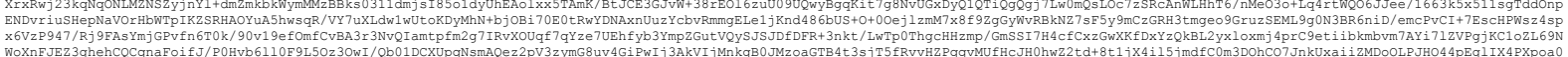

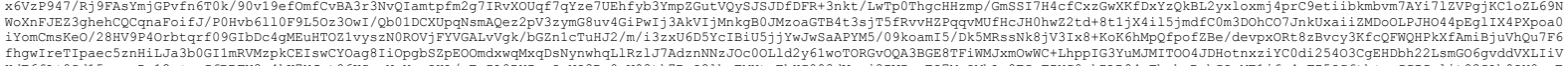

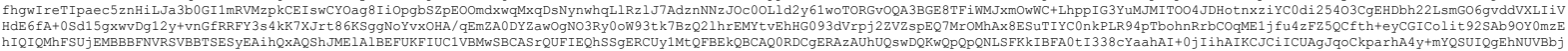

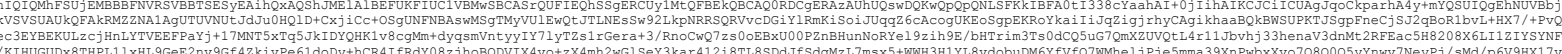

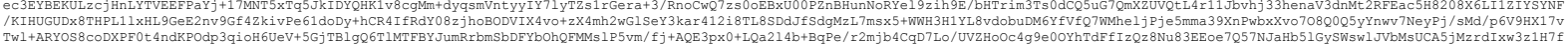

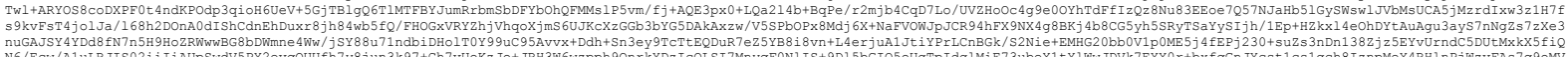

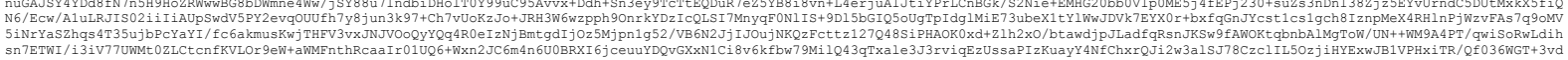

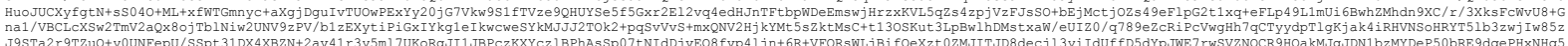

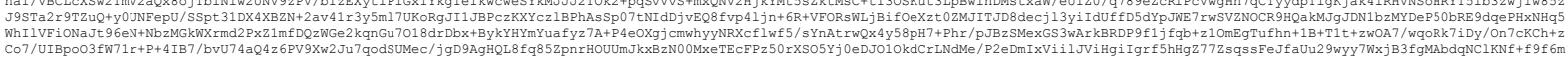

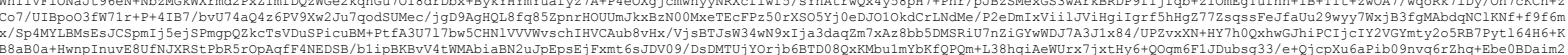

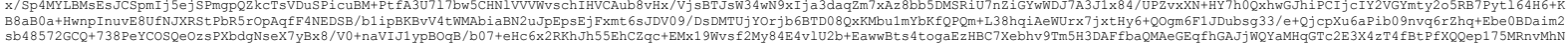

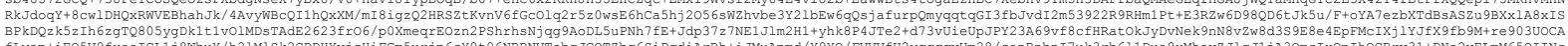

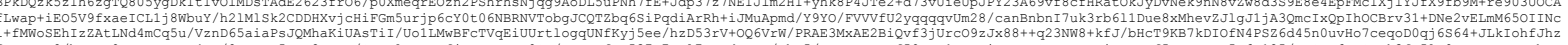

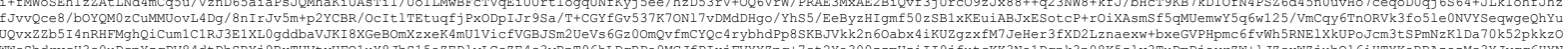

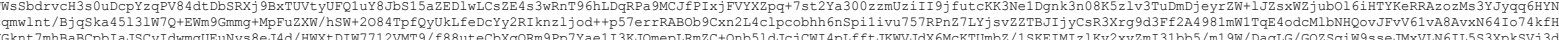

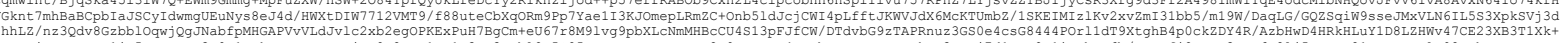

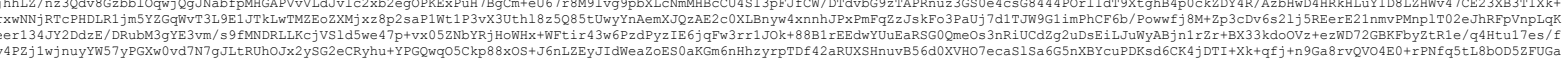

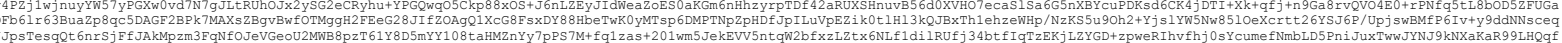

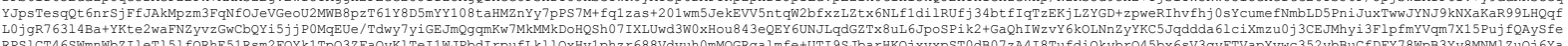

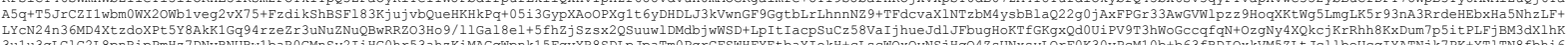

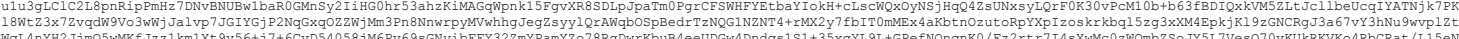

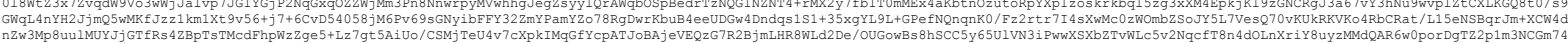

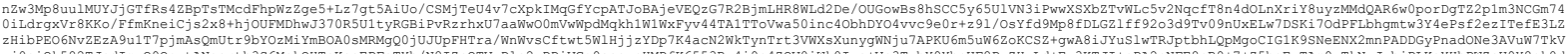

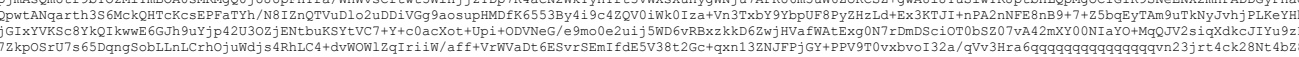

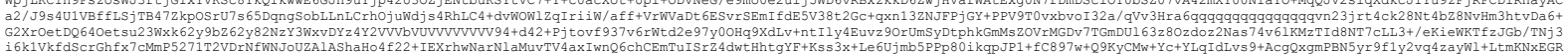

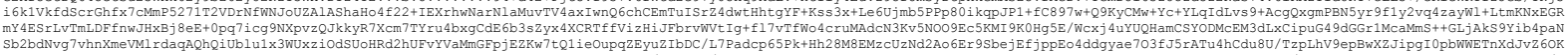

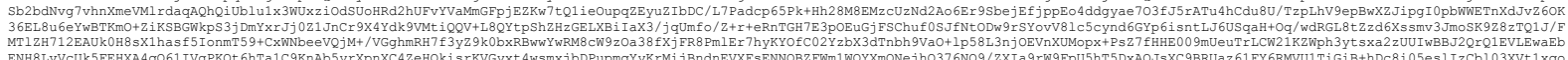

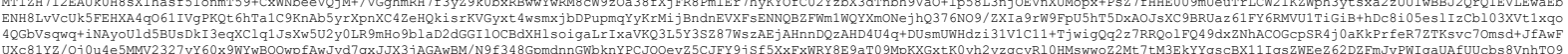

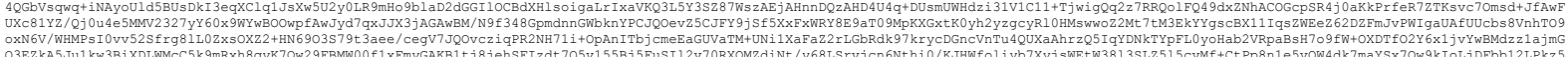

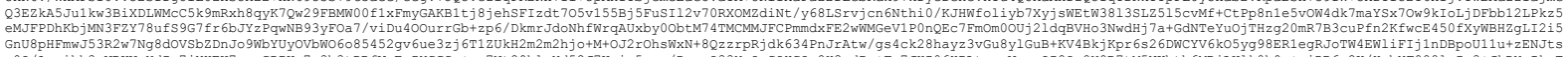

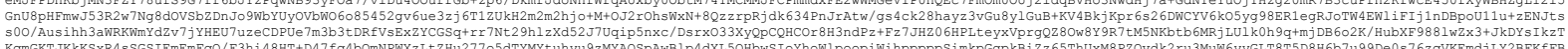

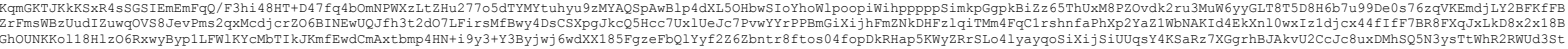

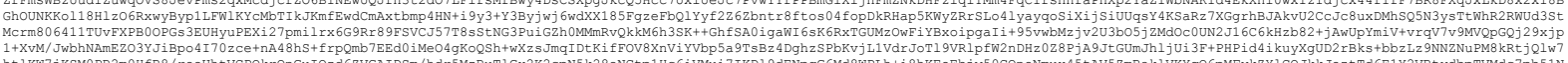

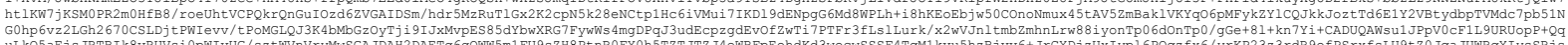

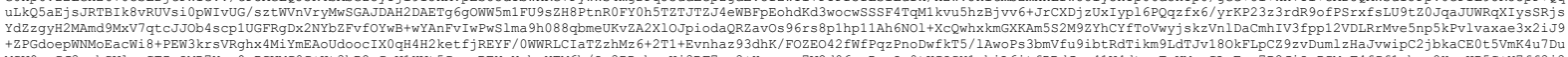

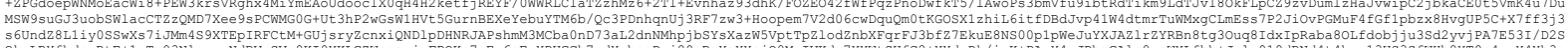

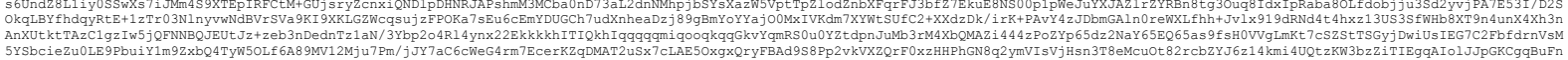

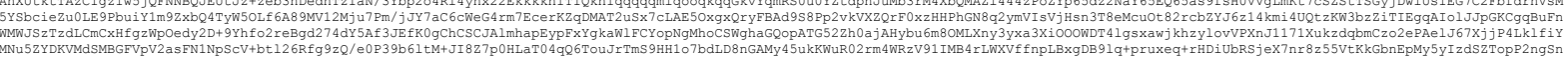

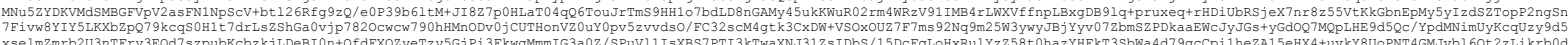

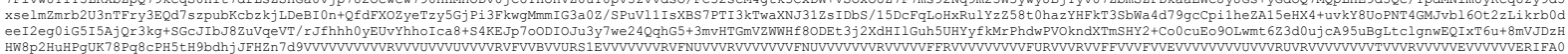

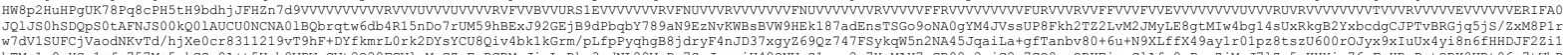

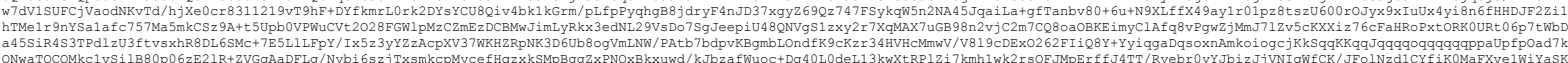

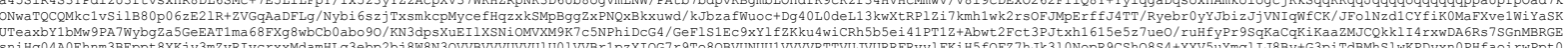

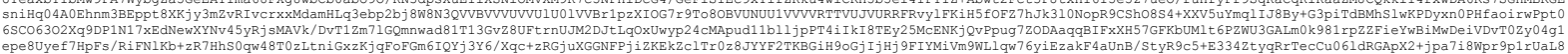

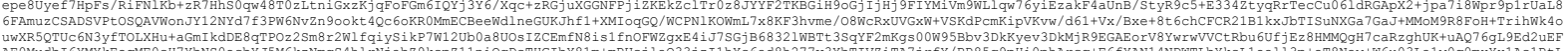

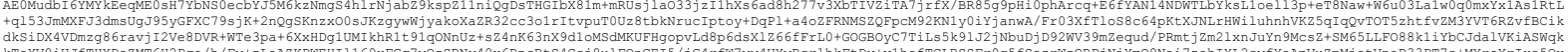

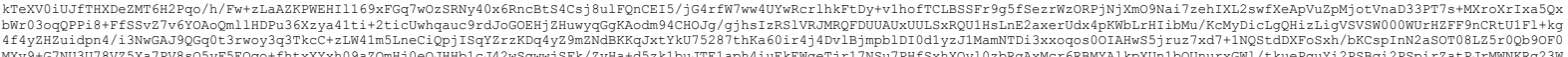

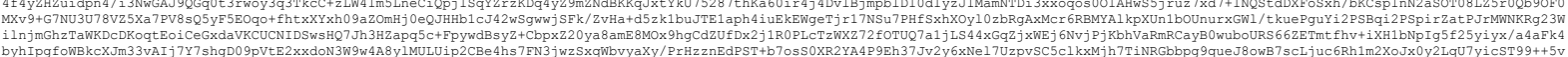

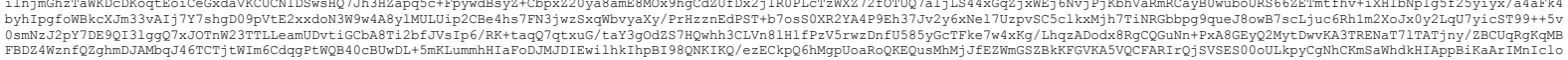

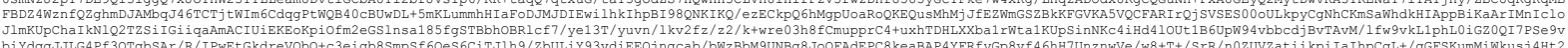

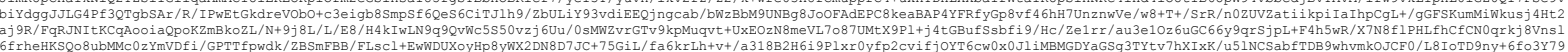

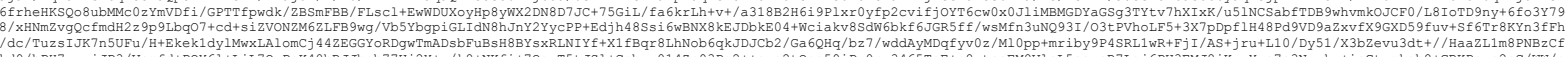

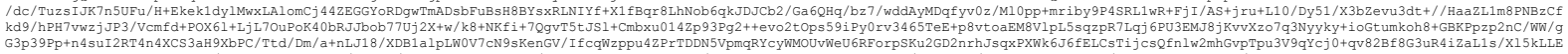

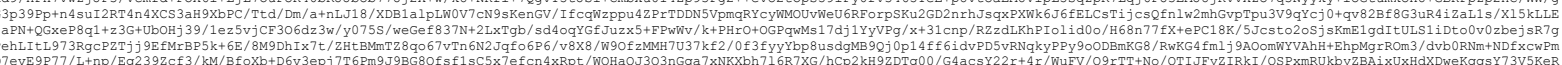

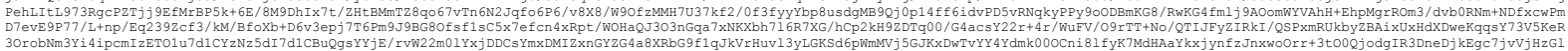

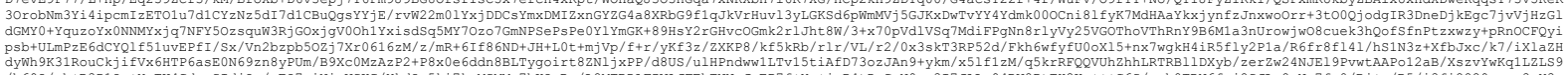

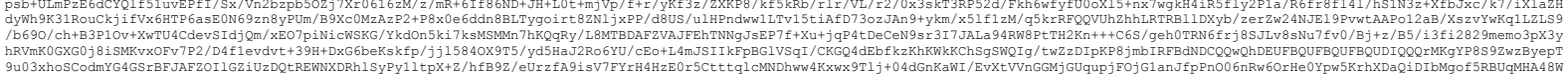

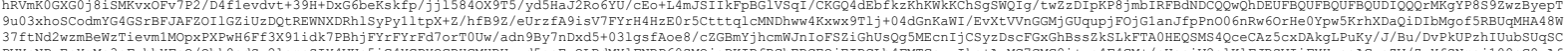

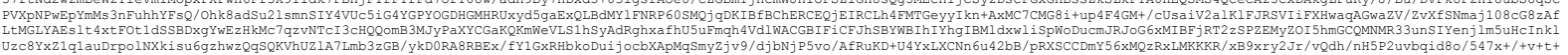




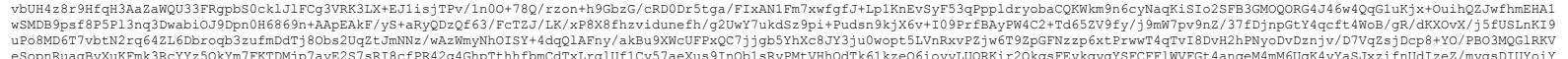

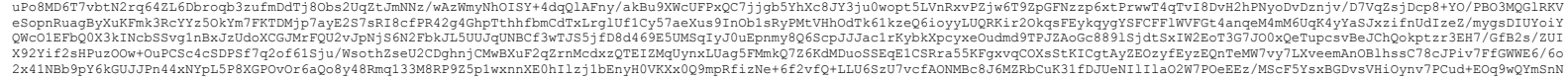

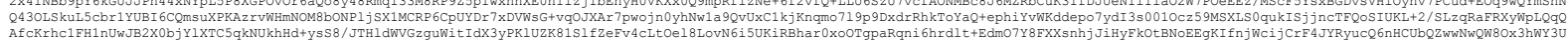

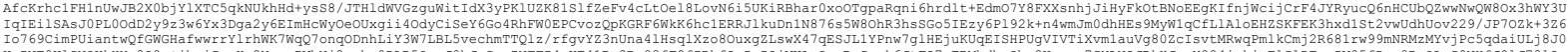

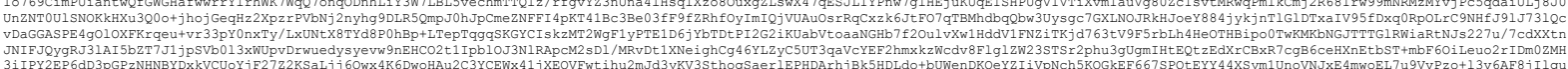

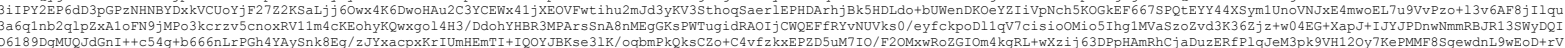

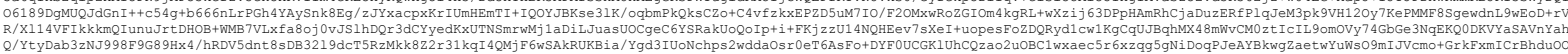

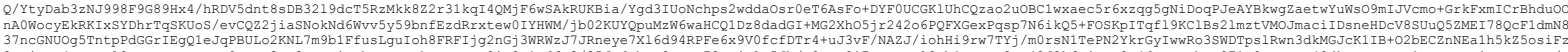

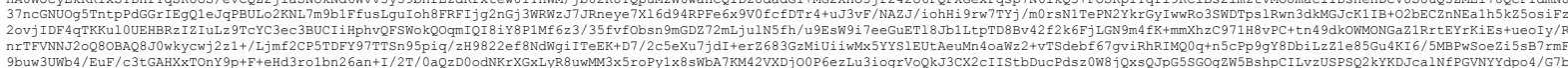

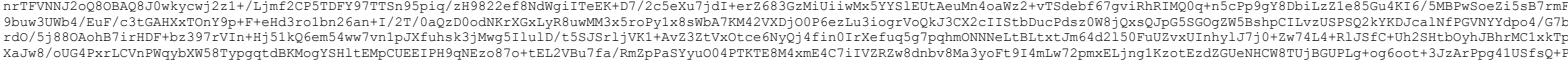

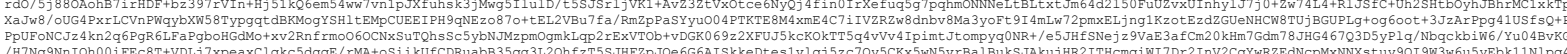

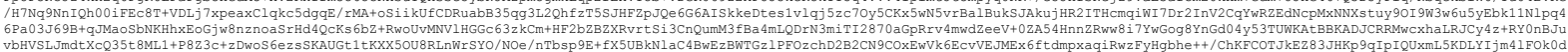

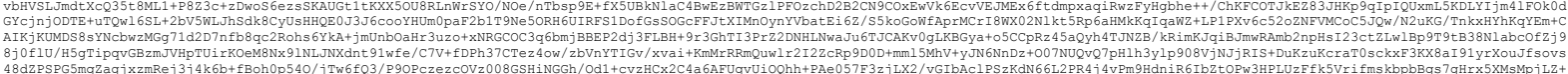

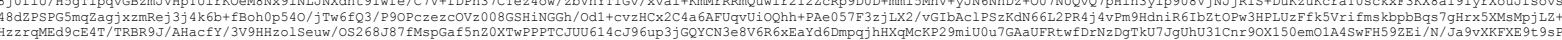

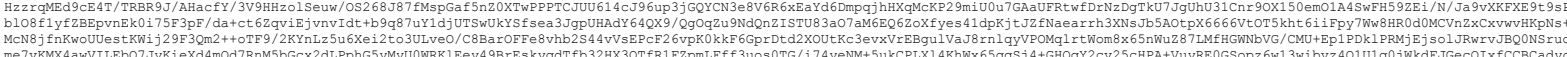

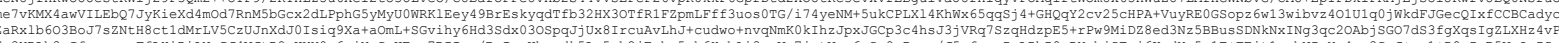

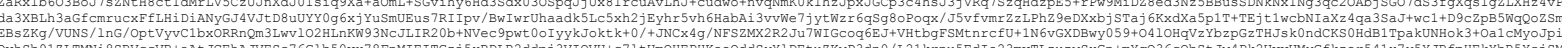

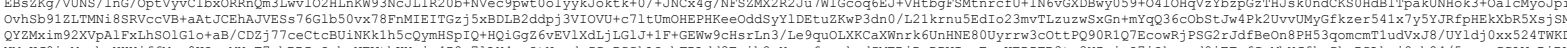

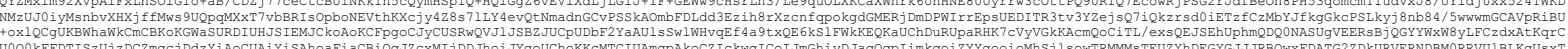

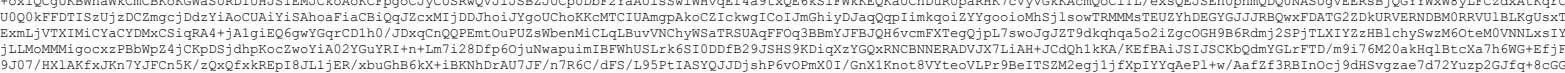

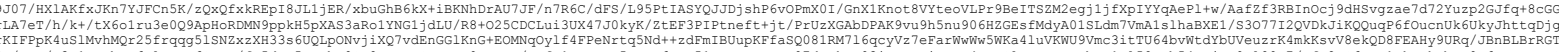

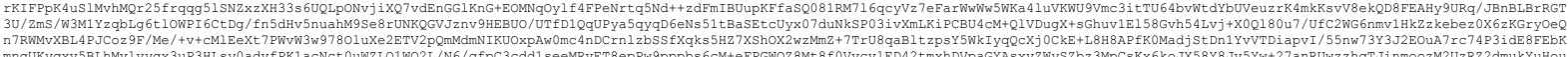

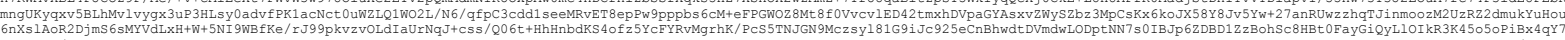

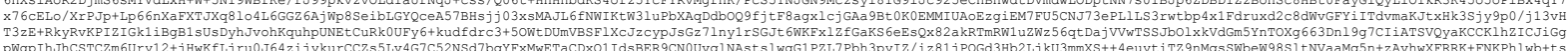

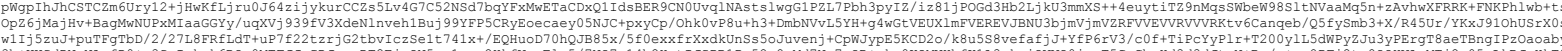

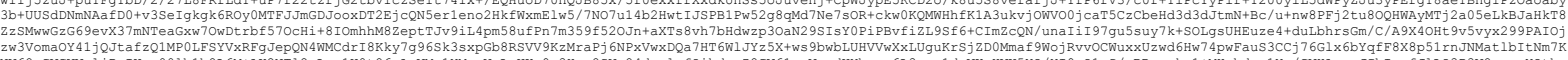

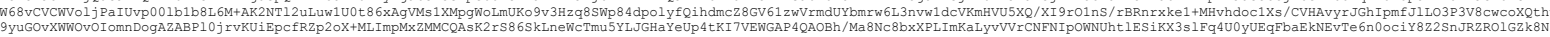

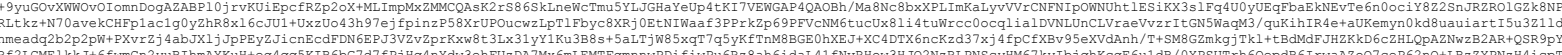

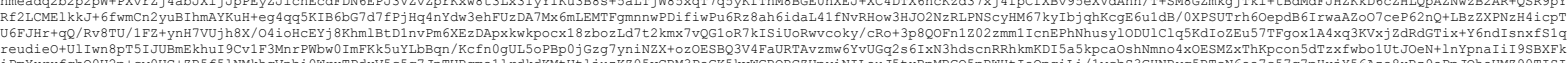

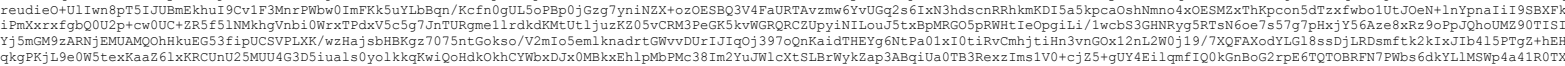

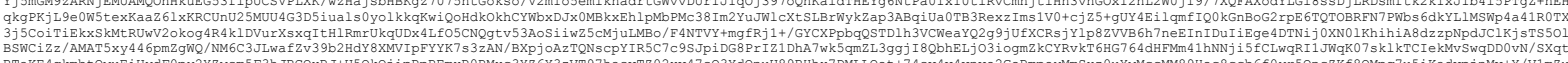

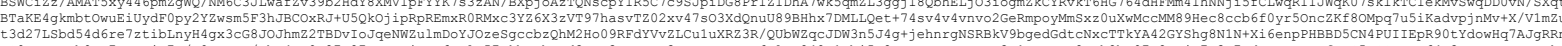

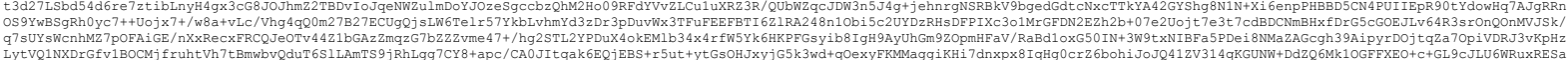

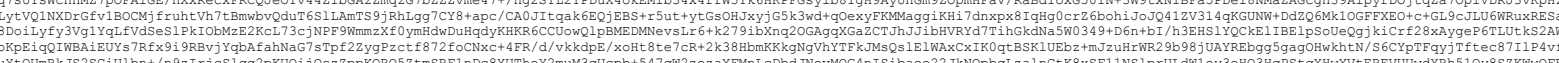

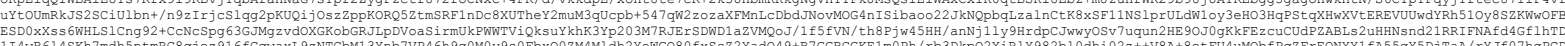

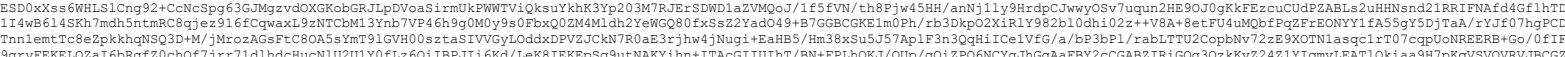

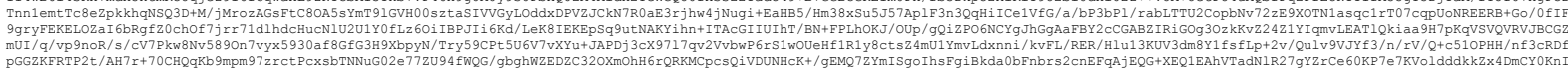

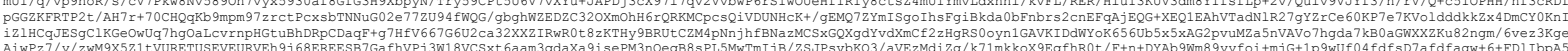

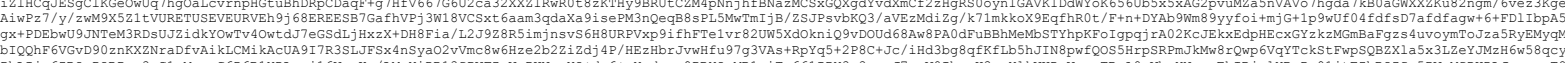

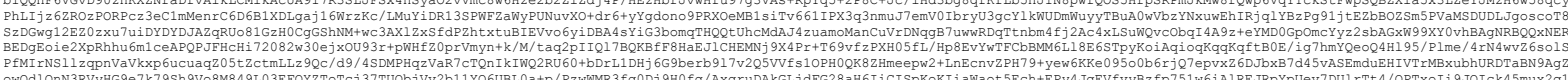

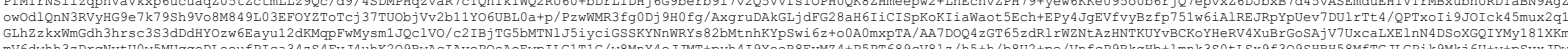

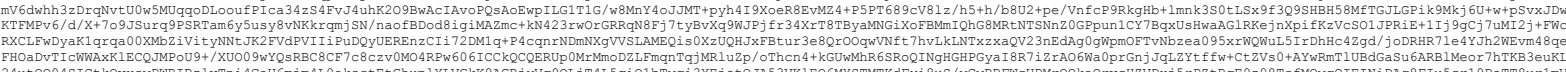

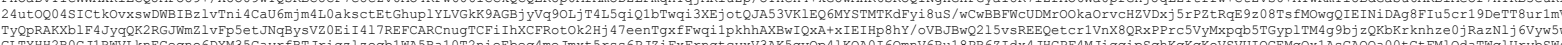

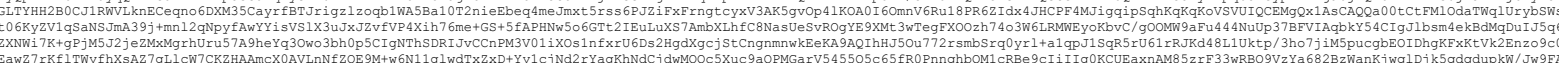

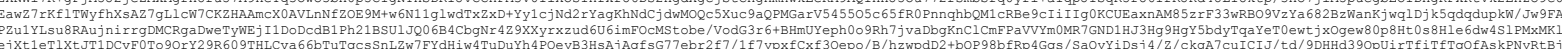

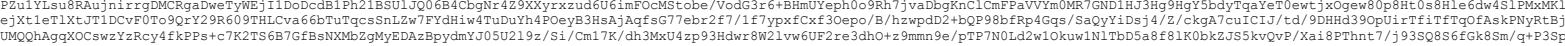

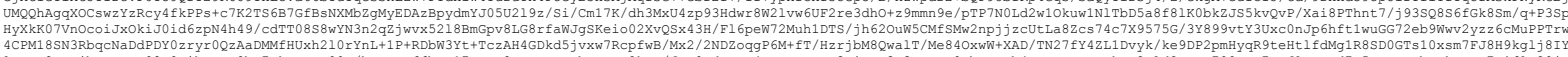

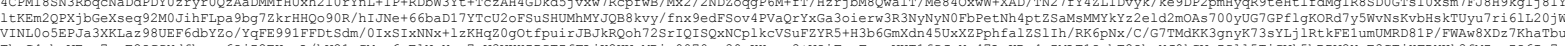

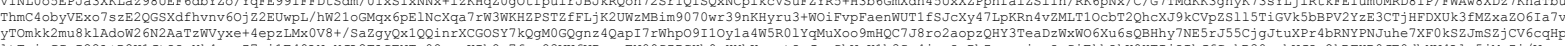

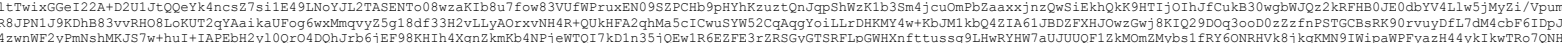

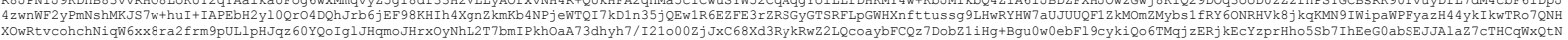

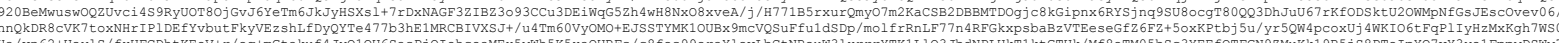

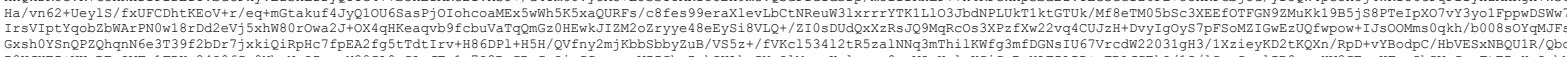

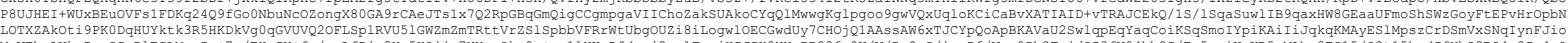

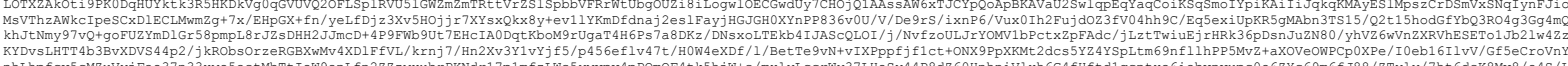

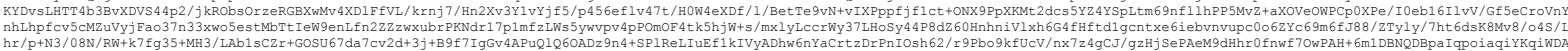
19GG

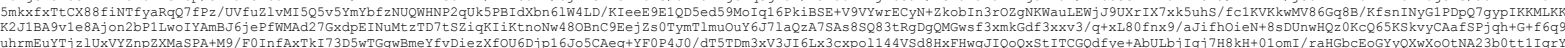

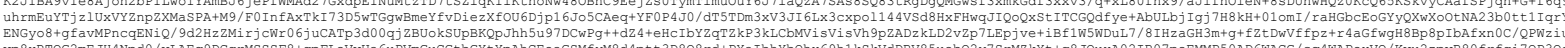

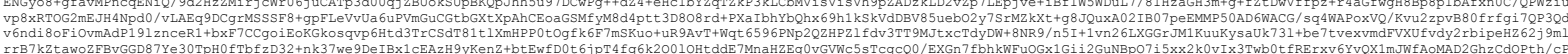

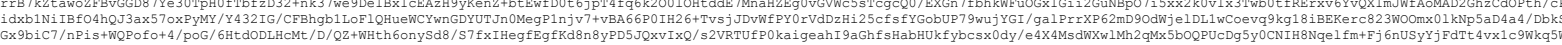

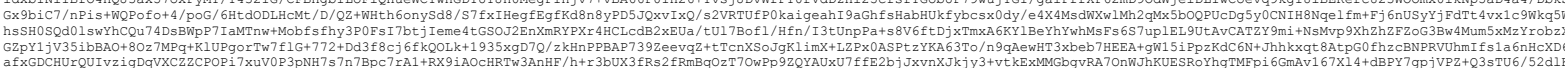

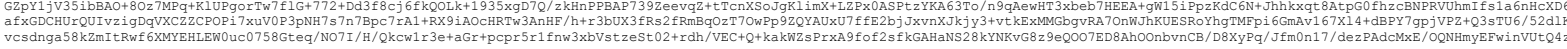




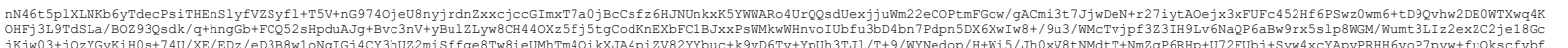

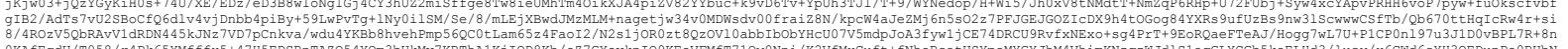

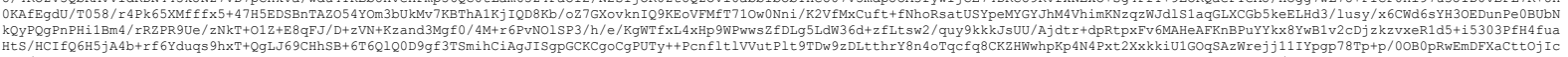

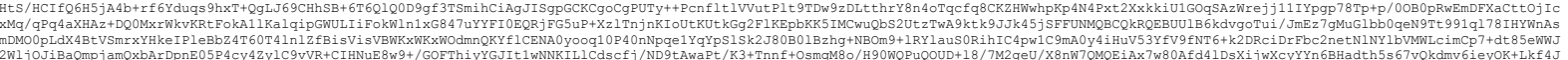

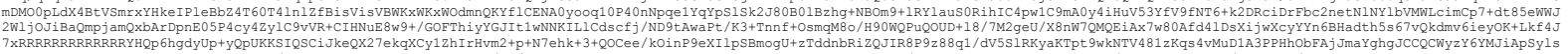

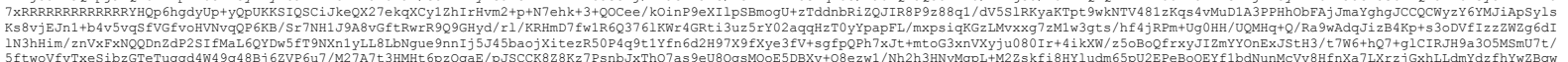

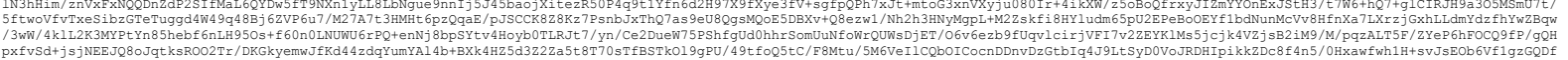

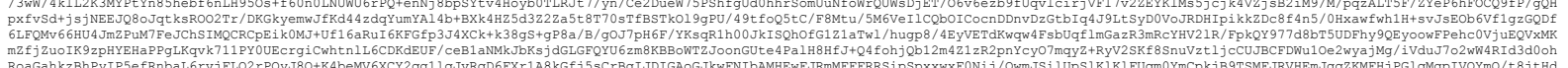

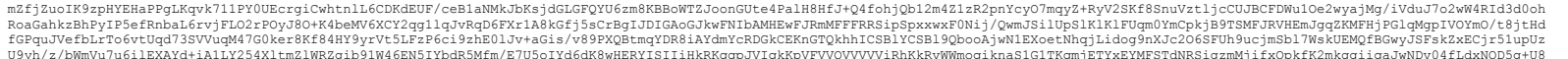

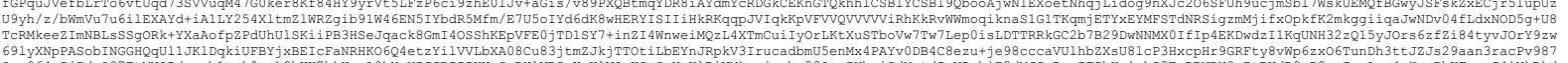

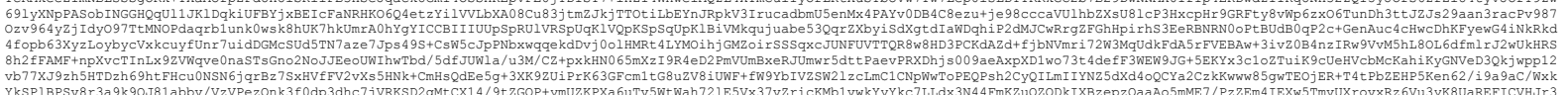

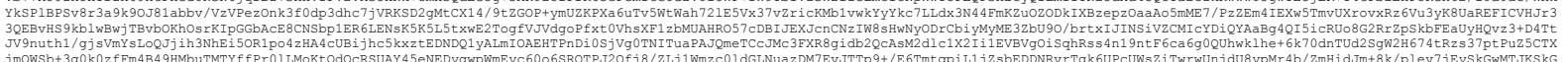

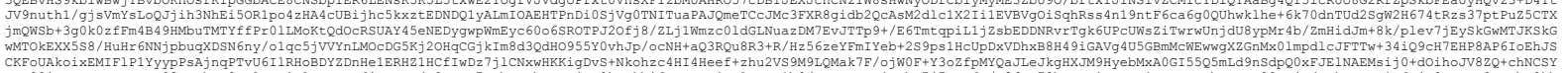

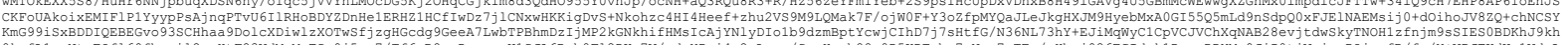

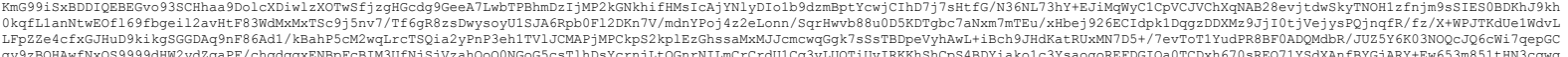

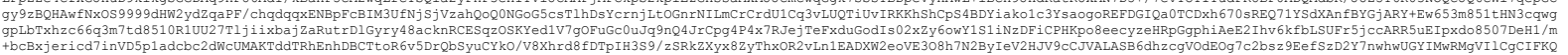

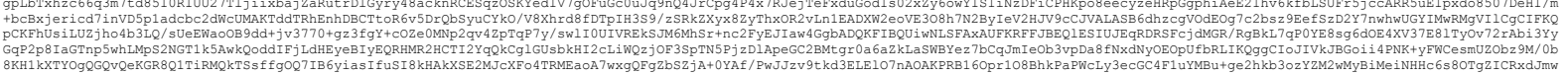

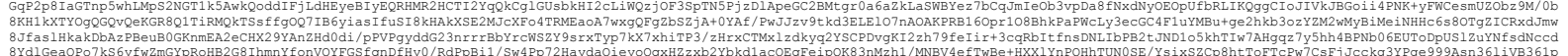

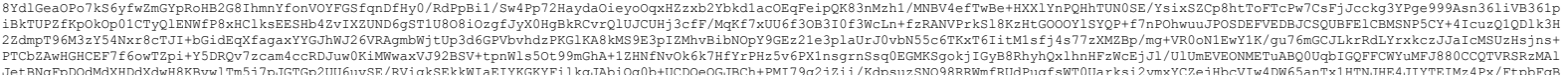

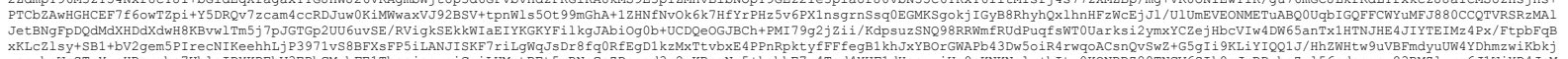

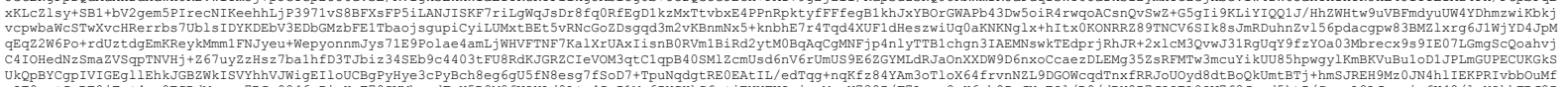

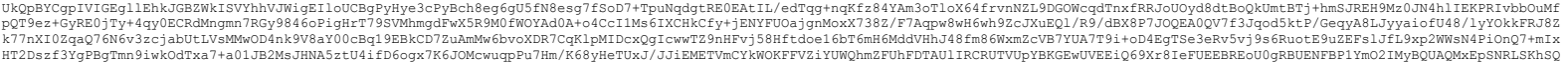

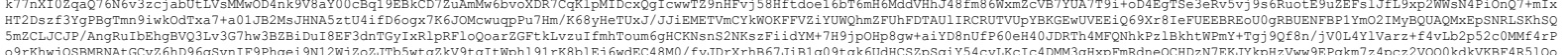

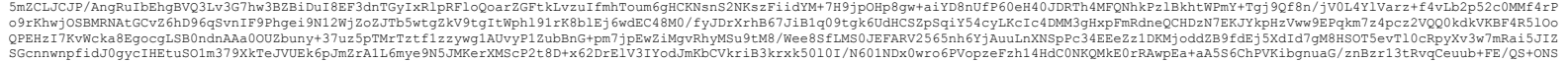

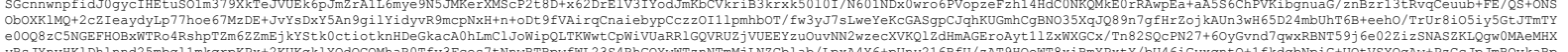

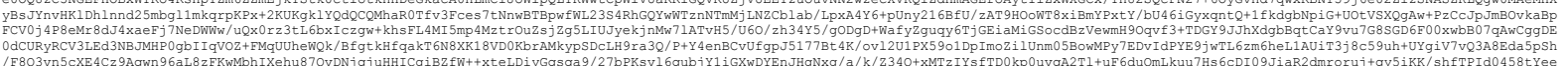

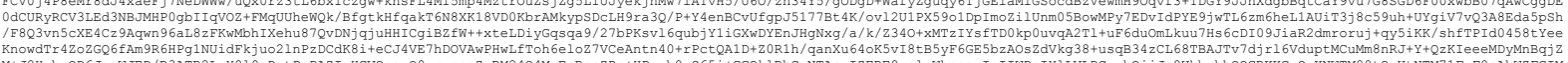

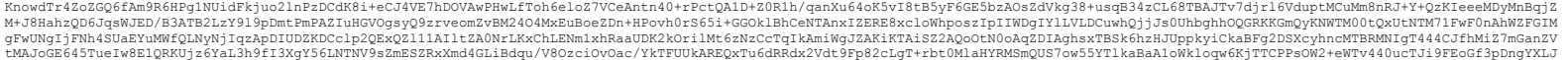

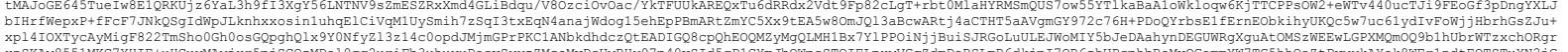

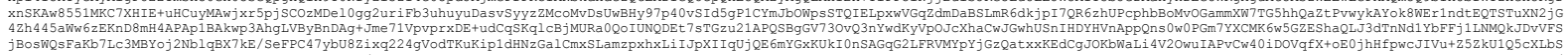

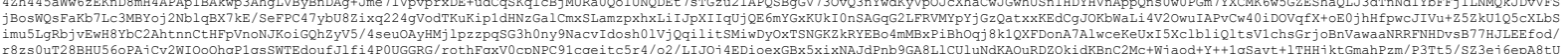

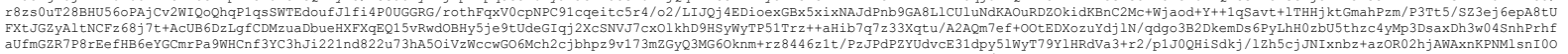

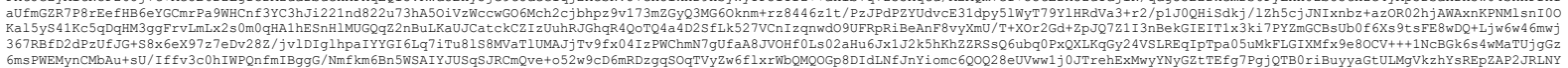

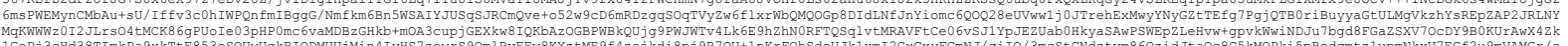

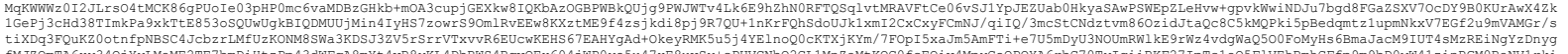

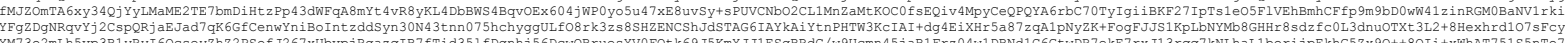

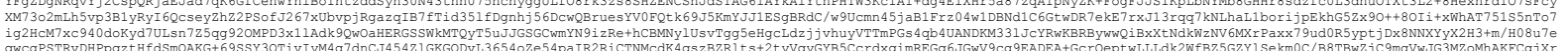

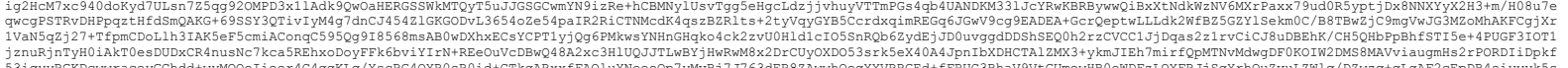

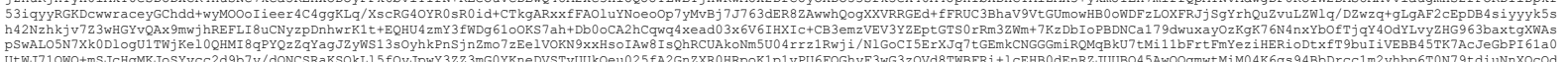

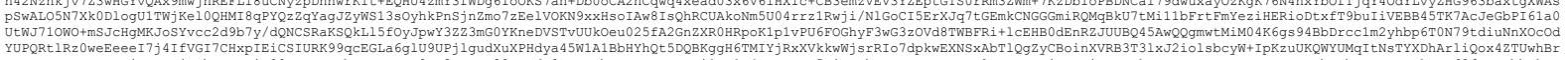

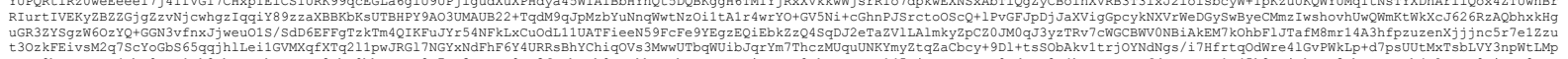

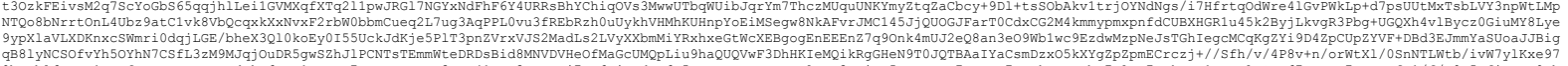

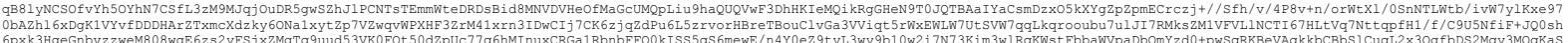

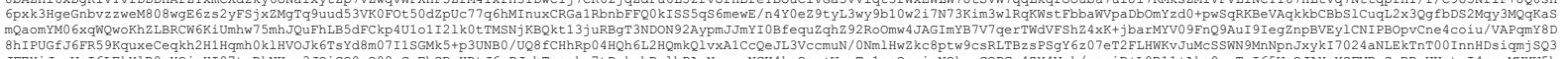

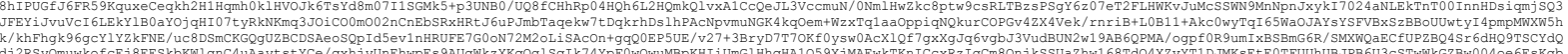

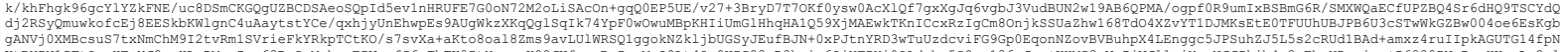

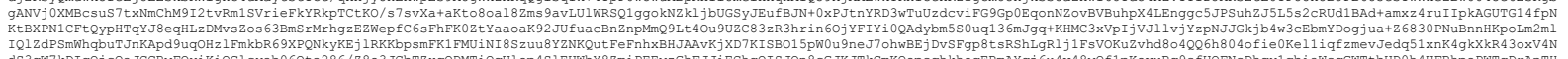

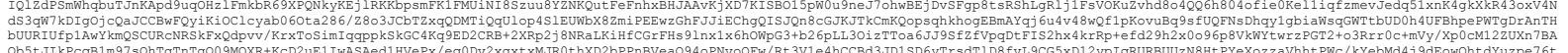

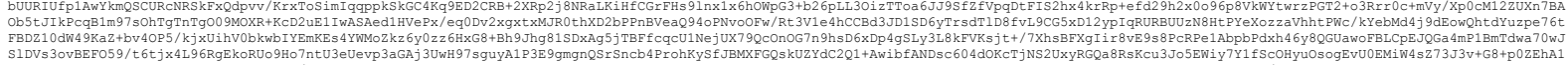

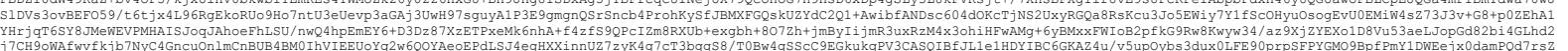

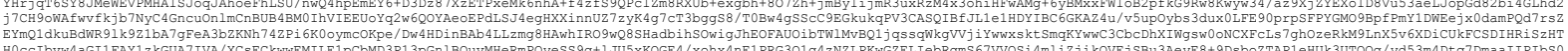

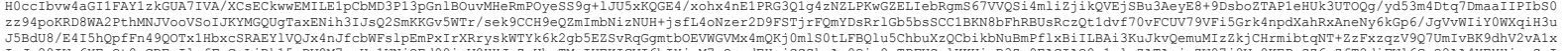

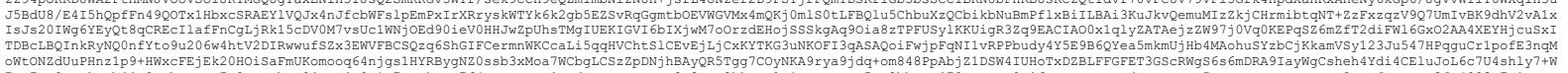

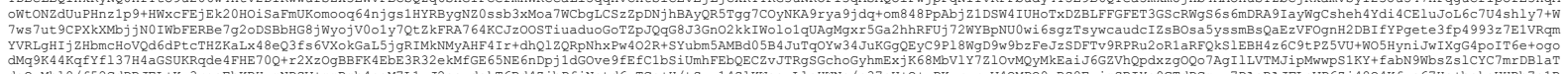

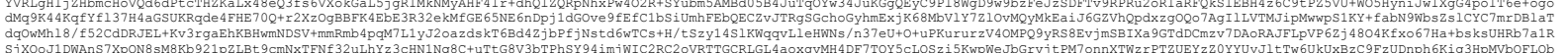

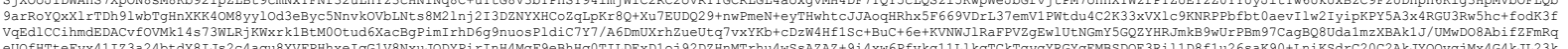

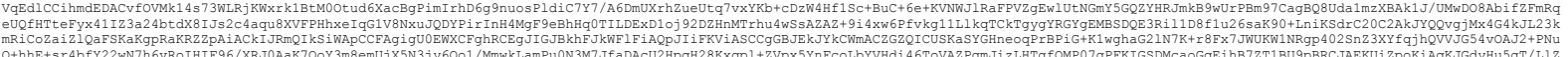

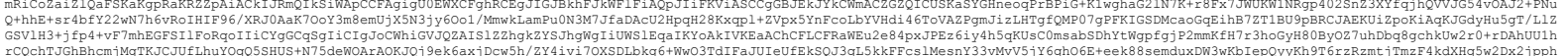

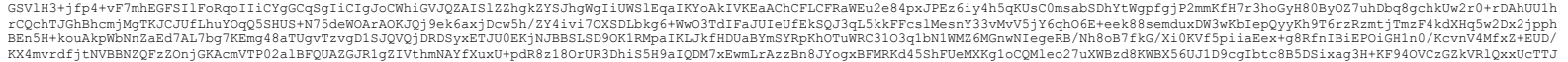

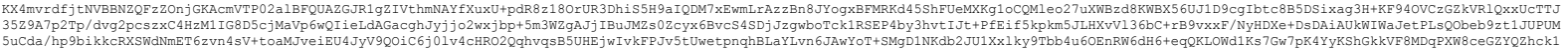

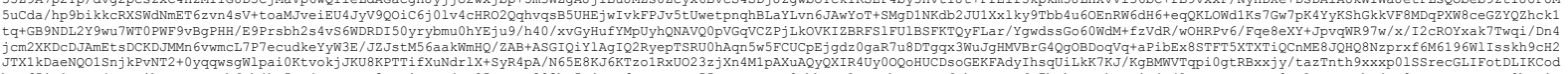




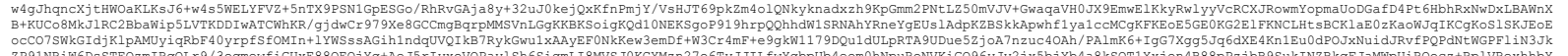

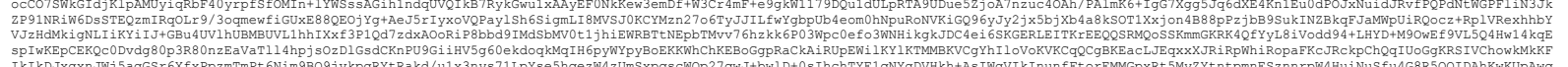

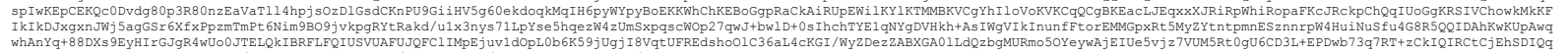

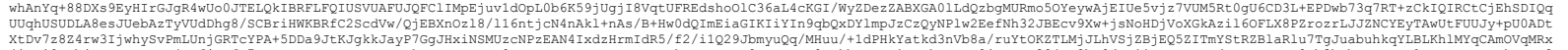

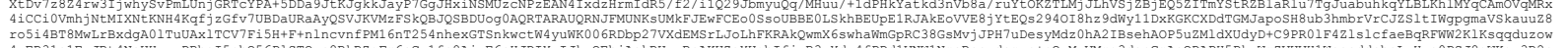

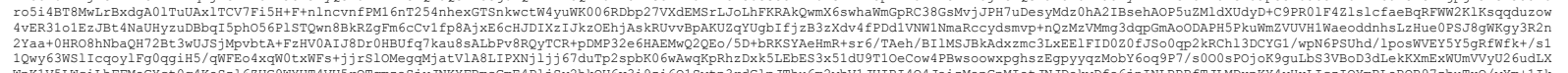

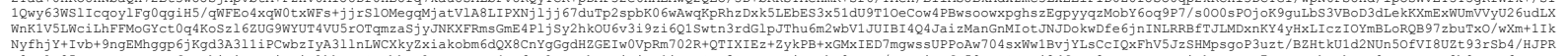

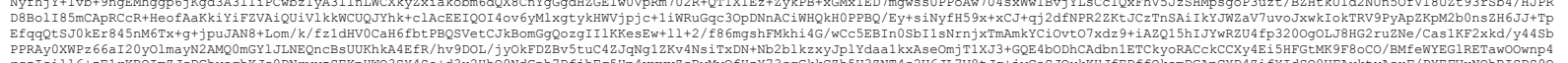

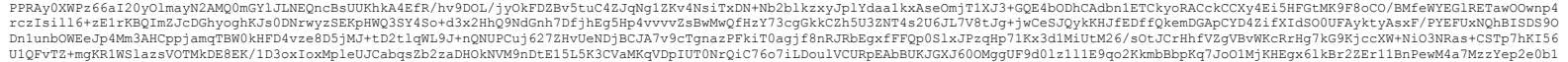

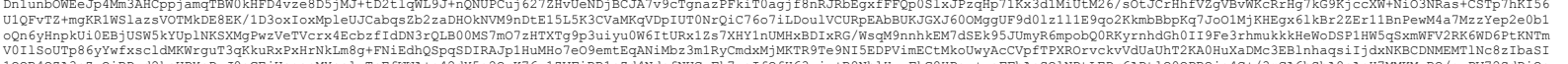

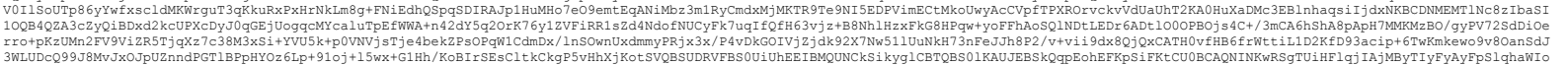

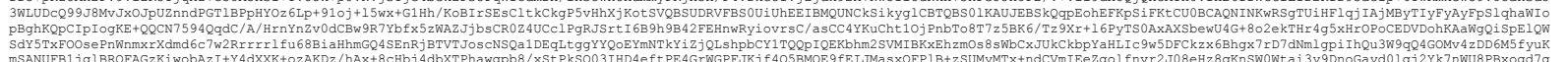

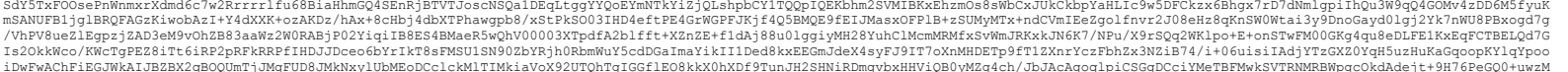

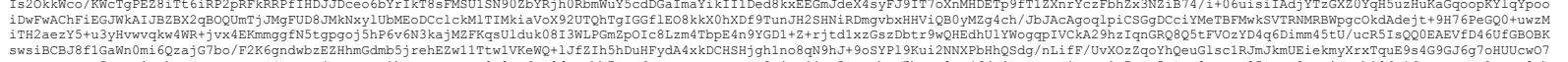

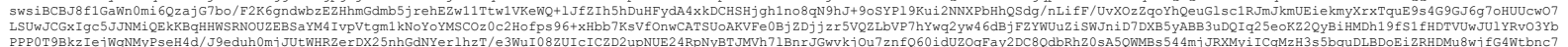

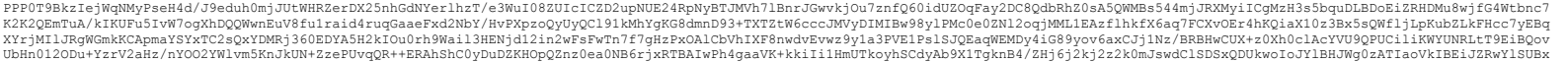

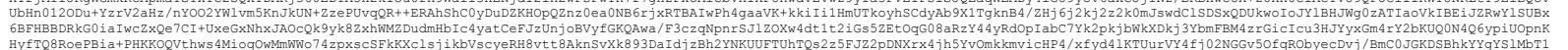

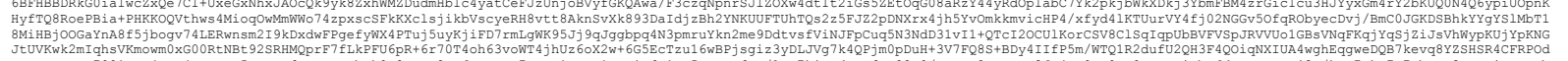

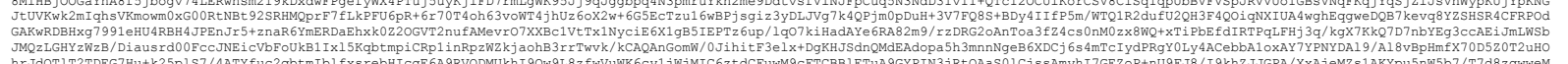

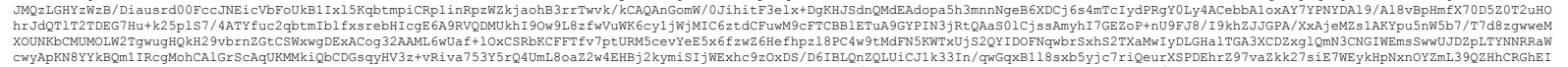

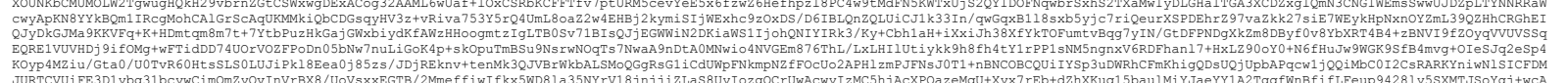

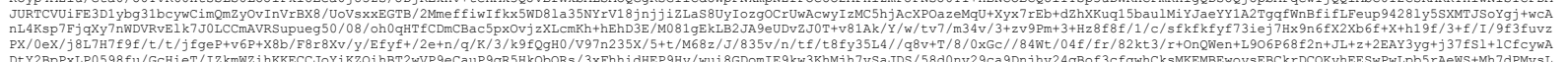

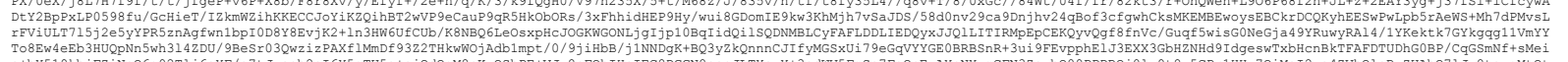

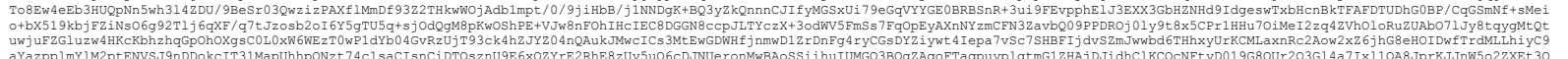

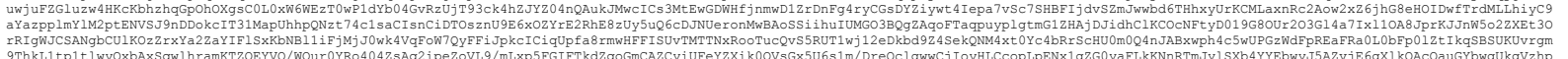

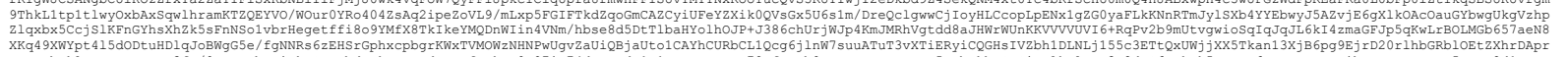

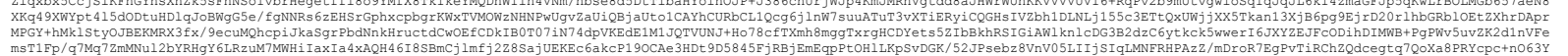

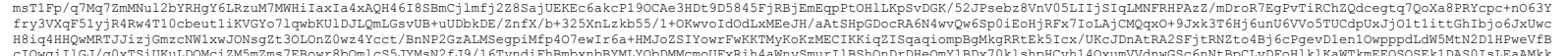

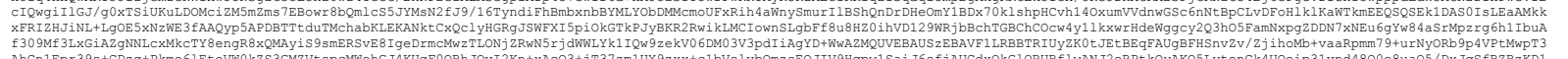

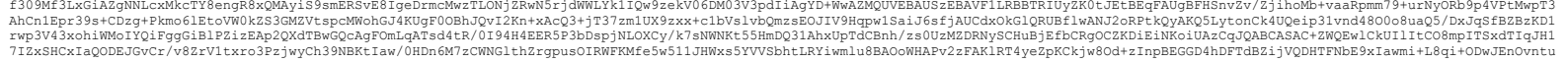

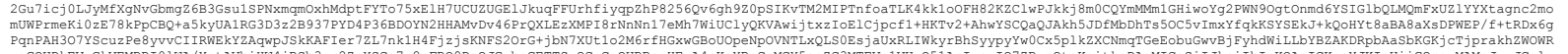

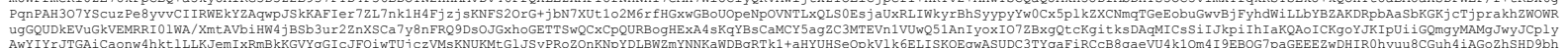

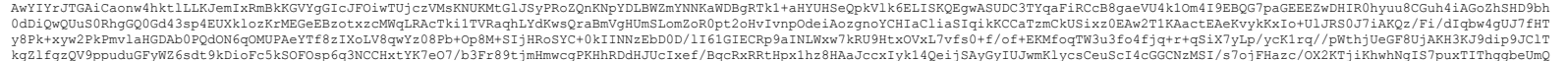

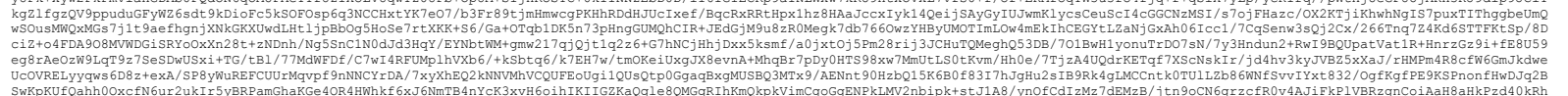

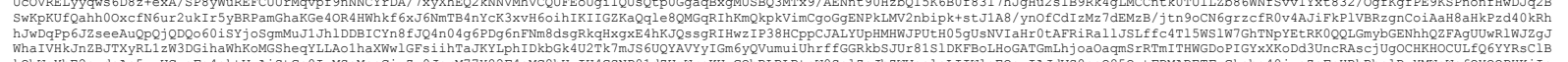

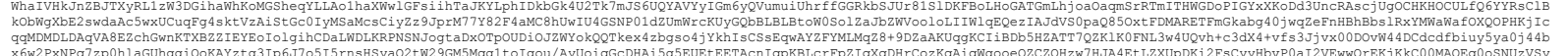

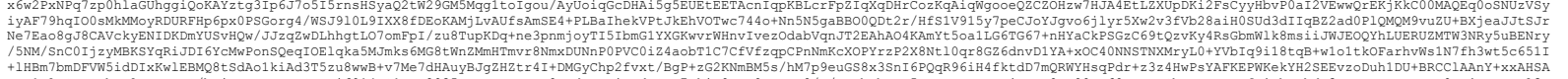

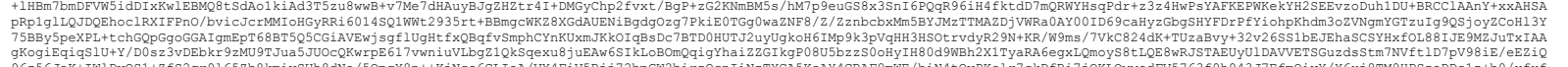

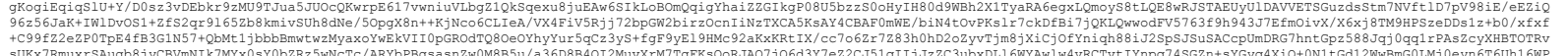

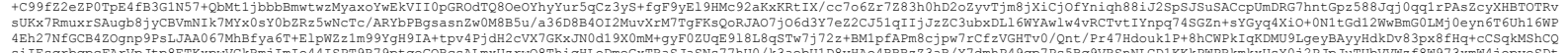

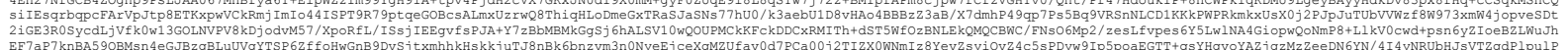

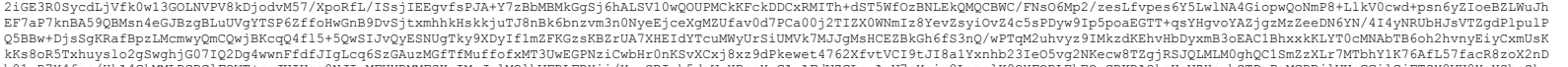

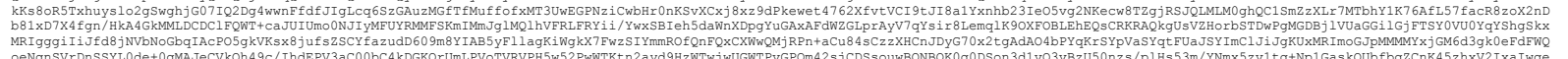

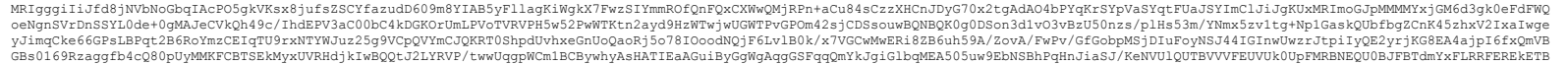

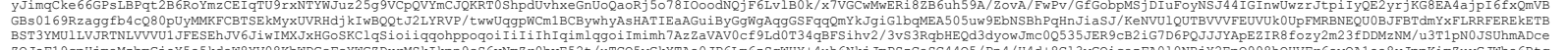

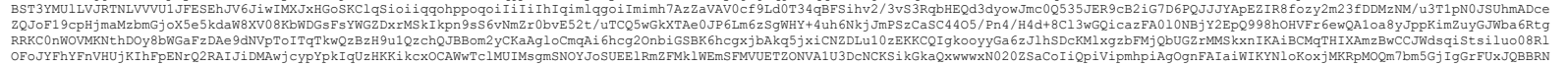

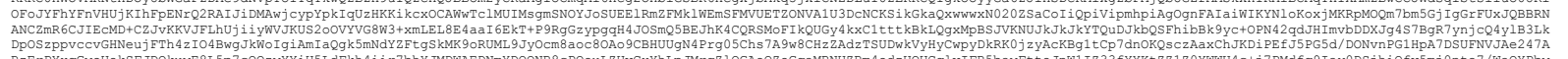

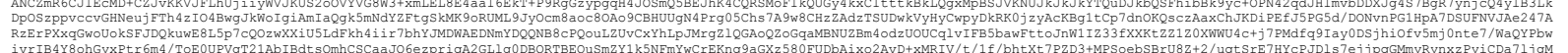

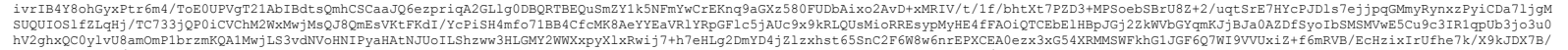

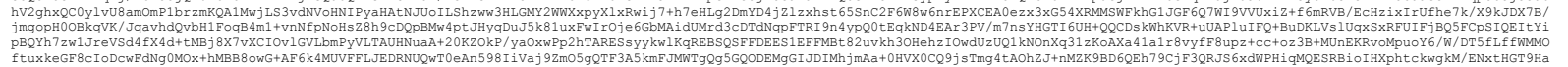

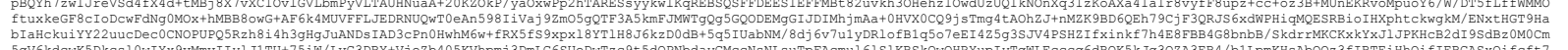

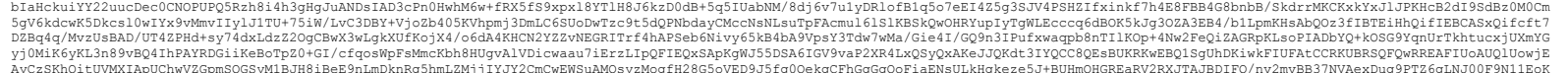

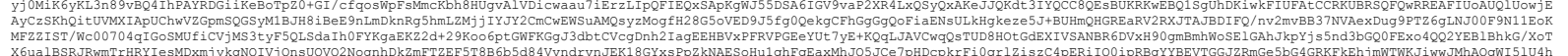

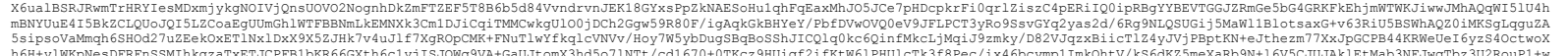

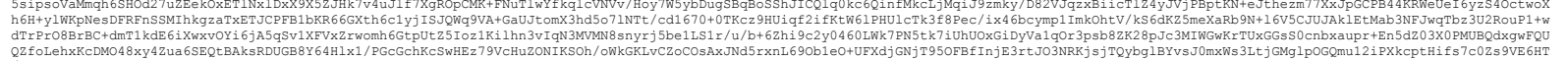

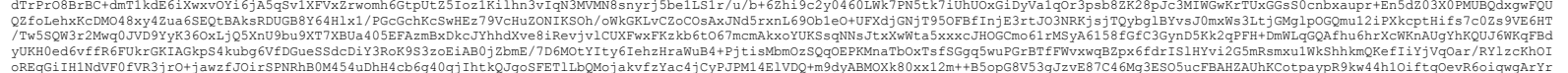

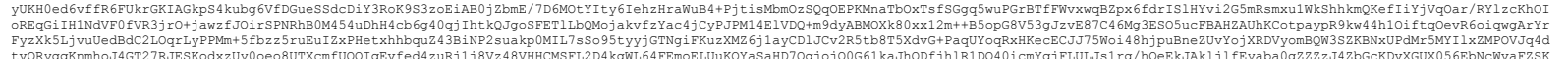

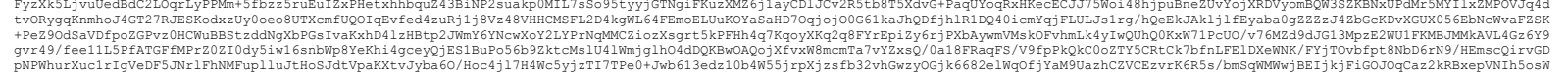




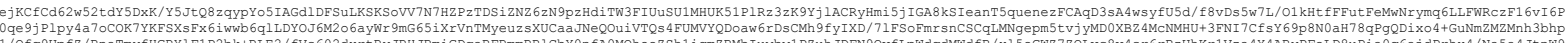

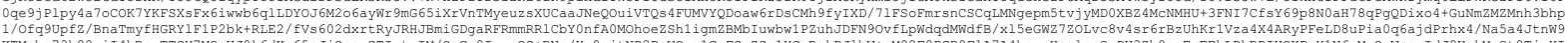

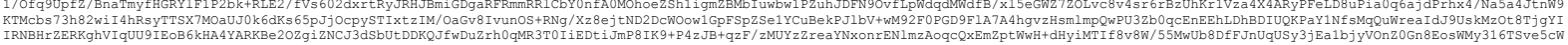

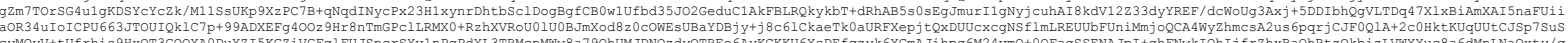

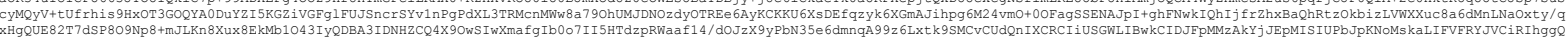

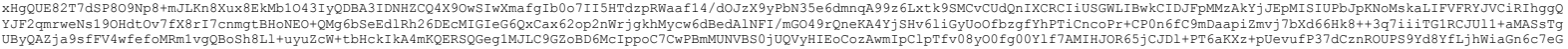

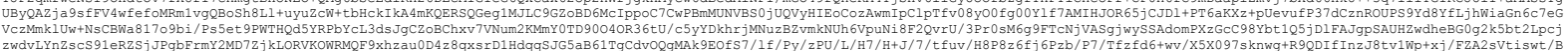

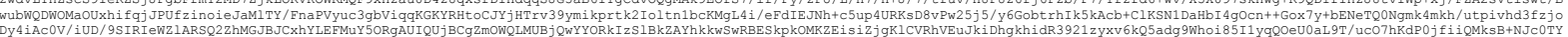

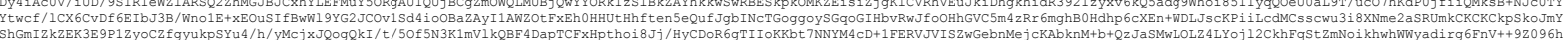

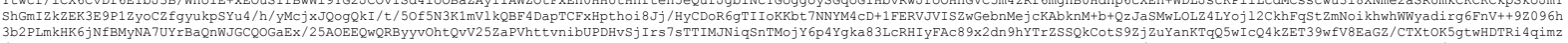

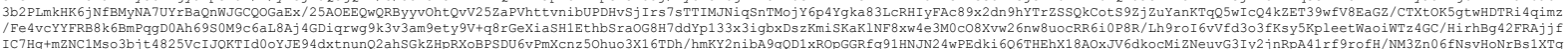

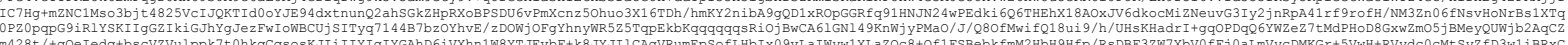

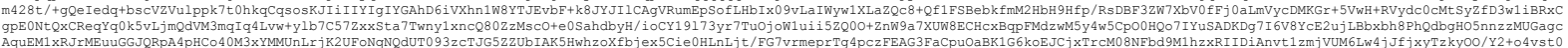

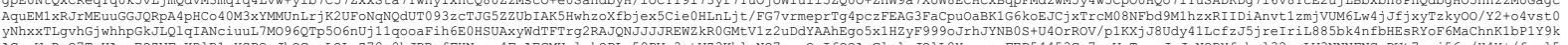

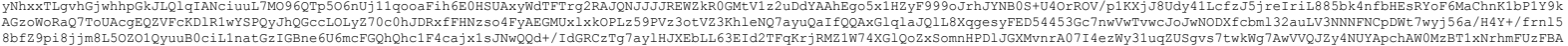

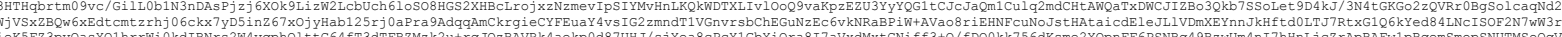

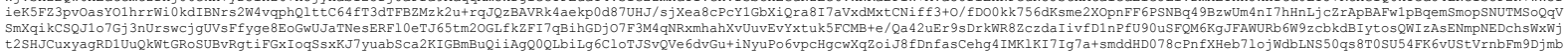

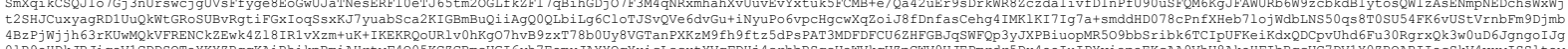

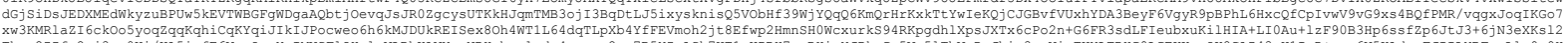

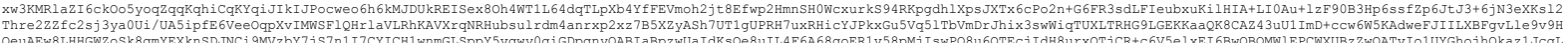

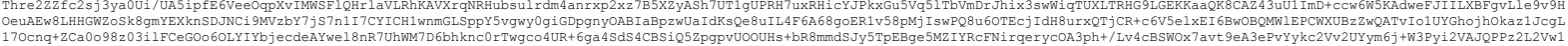

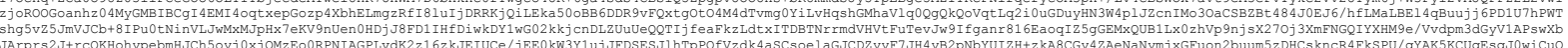

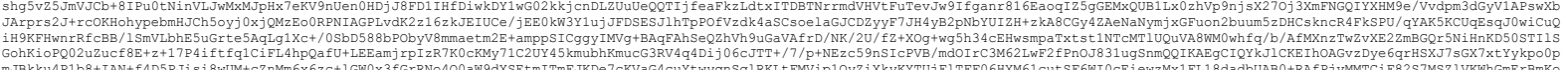

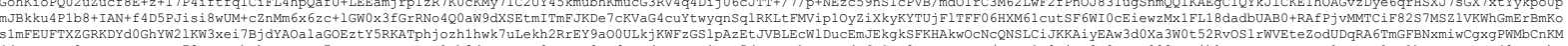

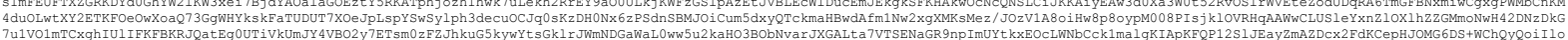

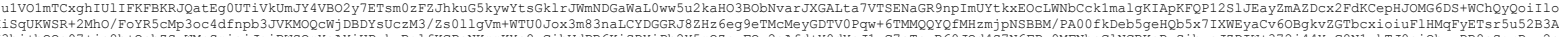
列

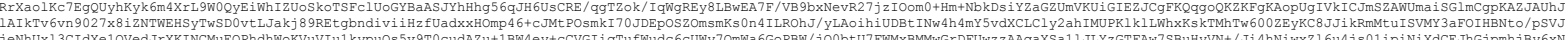

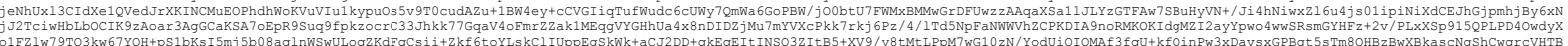

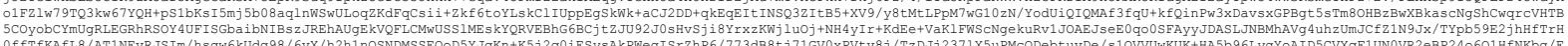

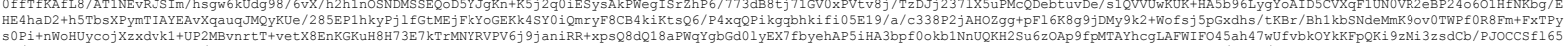

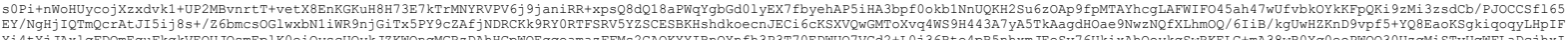

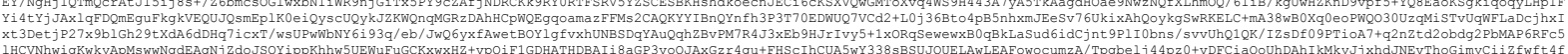

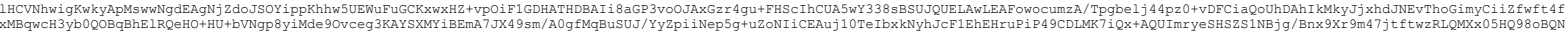

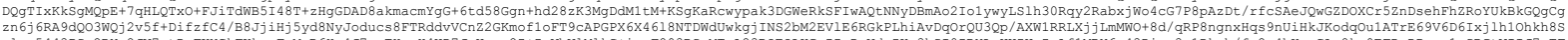

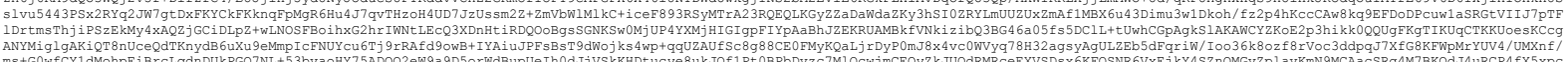

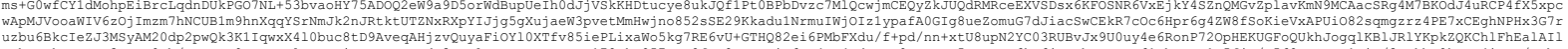

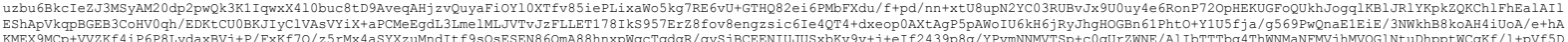

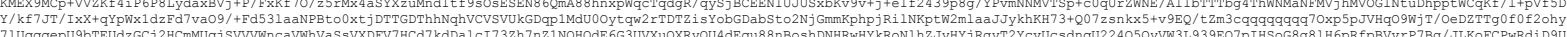

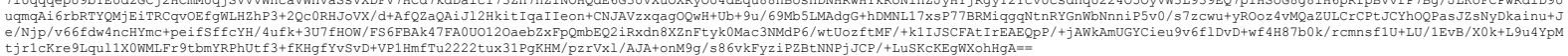

